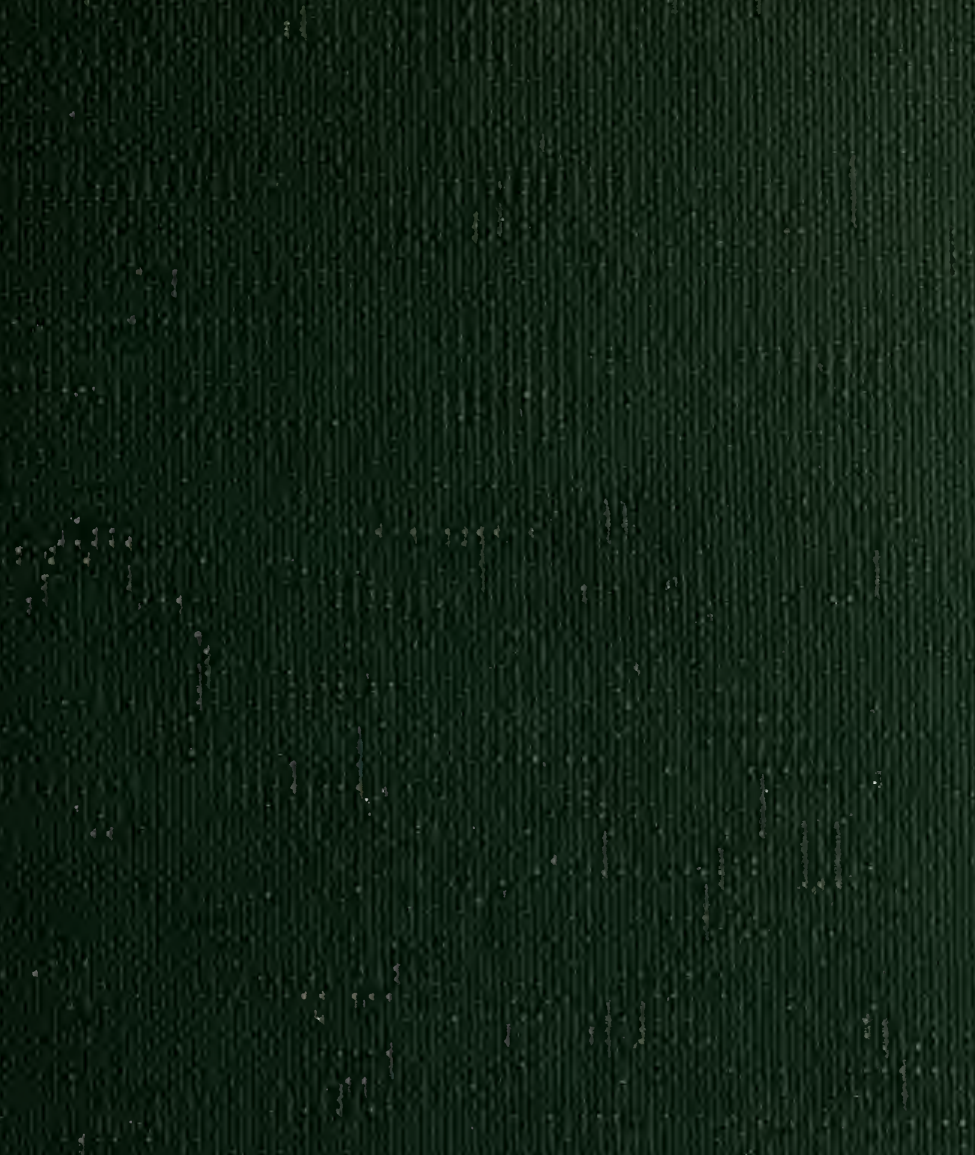




\begin{tabular}{|l|l|l|}
\hline CALL NO. & A.UTHOR OF BOOK (or Periodical Title, Vol. and Year) & CHARGED \\
\cline { 2 - 2 } & DUE \\
\hline TITLE, PLACE AND DATE OF BOOK (or Author, Tit le, \& Pages of Period. Article) \\
\hline REQUESTED BY (Name and Section) \\
RECEIVED BY (Name and Date) SITHSONIAN INSTITUTION LIBRARIES \\
ENTOMOLOGY BRANCH \\
SI-LIB-862b (Rev. 3-67) 20560
\end{tabular}





2100.

A. N. Caudill.

\section{NEW GENERA AND SPECIES}

$\mathrm{OF}$

\section{MELANOPLI}

FOUND WITHIN THE. UNITED STATES

(ORTHOPTERA; ACRIDIDAE)

by

Morgan Hebard

From the Transactions of the American Entomological Society, xliv, 141-169 Issued June 17, 1918

No. 777

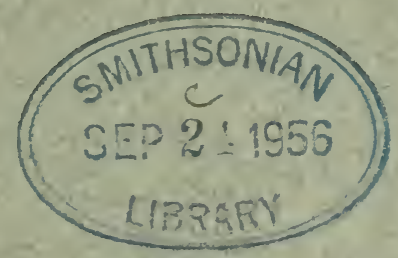





\title{
NEW GENERA AND SPECIES OF MELANOPLI FOUND WITHIN THE UNITED STATES (ORTHOPTERA; ACRIDIDAE)
}

\author{
BY MORGAN HEBARD
}

In the past few years the Melanopli from North America, north of the Mexican boundary, in the Philadelphia collections have been assembled, sorted to species and given a preliminary examination by the author. In addition, a large part of the historic material bearing on this group, in other American collections, has very kindly been loaned to us for comparison and study. The time for compilation of the manuscript of this study has arrived, the thousands of specimens being fully arranged and their relationships plotted, but active military service obliges the postponement of this work for an indefinite period. It appears advisable, however, to describe the new species, except those of the genus Melanoplus, which do not need further study to determine racial values, which species will later be more elaborately treated in the contemplated study.

The sequence of the species here described is according to the revised arrangement of the species from the preliminary studies already completed. ${ }^{1}$ The final study of the group will probably show some changes in this order, but we do not believe these will be at all drastic. It is clear that Scudder incorrectly grouped many forms.

Particular efforts have been made in all the field work by Rehn and Hebard to secure as large and representative series of the group as possible. This has shown that, though we are now in a far better position to treat the species with scientific accuracy, it is highly probable that intensive local field work, particularly at high elevations in the mountains of the West, will reveal additional undescribed forms.

In the present paper two new genera, ten new species and one new geographic racé are described. The series of these new

1 The same system of linear arrangement is followed in the author's "Notes on Mexican Melanopli," Proc. Acad. Nat. Sci. Phila., 1917, pp. 251 to 275, (1917).

TRANS. AM. ENT. SOC., XLIV. 
forms examined contains five hundred and sixty-six specimens, of which all but thirteen are in the Philadelphia collections.

\section{Gymnoscirtetes morsei ${ }^{2}$ new species '(Plate VIII, figs. 4, 5 and 6.)}

This species shows close relationship to $G$. pusillus Scudder (Plate VIII, figs. 1, 2 and 3), agreeing in form, coloration and color pattern. The genitalia of both sexes afford, however, striking and constant characters for specific distinction.

Type.- $\sigma^{x}$; De Funiak Springs, Walton County, Florida. August 30, 1915. (Rehn and Hebard.) [Hebard Collection, Type No. 215.]

Size larger than, form similar to, that of pusillus. Head with interocular space about as wide as first antennal joint ${ }^{3}$ (wider than normal in pusillus). Prosternal spine rather elongate, beyond base rather slender, cylindrical, scarcely tapering to the bluntly rounded apex (in this sex of pusillus, though individually slightly variable, this spine averages shorter and tapers distinctly to the less bluntly rounded apex). Supra-anal plate elongate shield-shaped, with surface longitudinally trisulcate, the lateral margins moderately reflexed and with two small, elongate, longitudinal convexities proximo-laterad of the small projecting apex (in pusillus much shorter, triangular, with lateral margins very feebly convex and apex blunt; contour similar but much less decided). Furcula as in pusillus. Cerci specialized, distinctive (see Plate VIII, fig. 5). Subgenital plate strongly elevated in a large, medio-dorsal projection, which is fully twice as long as broad, with apex blunt, directed dorso-cephalad (this is a similar but very much more decided development of the type found in pusillus).

\section{Allotype.—o ; same data as type. [Hebard Collection.]}

Size larger than male, larger than in pusillus. Agrees with male in ambisexual characters, except that the interocular space averages broader, the prosternal spine is heavier and shorter (this spine in females of pusillus shows the same relative difference, but not as conspicuously, as in the male sex of these species, in all exhibiting slight individual variation). Ovipositor valves elongate; the dorsal pair with disto-dorsal declivity brief to the blunted apical tooth (in pusillus the disto-dorsal declivity is much more elongate, with apical tooth acute); the ventral pair with disto-lateral and apical tooth blunted, the portion beyond the disto-lateral tooth very brief (in pusillus. with these teeth acute, the portion beyond the disto-lateral tooth elongate).

${ }^{2}$ In honor of Dr. Albert P. Morse, of Wellesley, Massachusetts, whose splendid studies in North American Orthoptera may be said to include among the first publications dealing with the subject in a thorøughly scientific manner.

${ }^{3}$ In the series at hand, however, this dimension shows some variation; it may be said to average wider in morsei than in pusillus. 


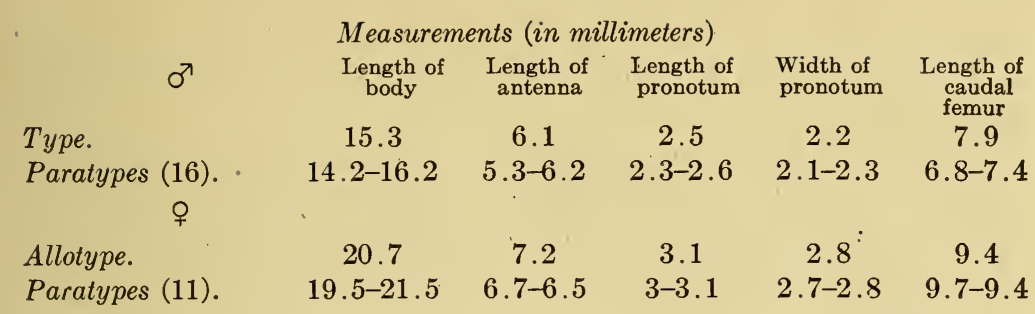

General coloration of dorsum ochraceous-tawny to clay color. Eyes chestnut brown, with a broad postocular band of shining blackish chestnut-brown extending caudad to distal third of abdomen. All portions below these bands and distal portion of male abdomen paler than dorsum, yellowish, sometimes with a greenish tinge. Caudal femora clay color, in occasional females strongly tinged with absinthe green. Caudal tibiae kildare green to absinthe green, spines white with distal half black. (In all features much as in pusillus.)

In addition to the type and allotype, a series of sixteen males and eleven females, all bearing the same data, are considered paratypes. This series was taken in a boggy area of wire-grass and bog plants, which was not over fifteen yards wide by forty yards long. No sign of the species was found elsewhere, even in areas of similar vegetation.

Phaulotettix eurycercus new species (Plate VIII, figs. 7 and 8.)

This insect is related to $P$. compressus Scudder. The major features of difference are the smaller size, distinctive cerci, pallium and subgenital plate of the male and the much smaller size and somewhat less robust form of the female. Unlike that species, ${ }^{4}$ strongly contrasting green and brown color phases do not appear to be developed in eurycercus. In the fifty-nine specimens before us all are brown, one female and a few males being tinged with greenish yellow; none show different types of caudal tibial coloration, the caudal tibiae being pink, individually varying in intensity.

While the distribution of compressus is known to extend in Mexico over the greater portion of Coahuila and over Tamaulipas to northern Vera Cruz, the material at hand shows its distribution in the United States to be coincident with, but much more

${ }^{4}$ See Hebard, Proc. Acad. Nat. Sci. Phila., 1917, p. 262, for synonymy and discussion of the striking color variations in compressus. It should be noted that the first description of adults of that species is by Rehn, for his synonymous Sinaloa brevispinis, Proc. Acad. Nat. Sci. Phila., 1904, p. 535.

TRANS. AM. ENT. SOC., XLIV. 
restricted than, that of eurycercus. The material before us of compressus is from Beeville, Cotulla, Sabinal, Uvalde and Del Rio, Texas.

Type.- $\sigma^{7}$; Laguna del Gato, three miles west of Sam Fordyce, Hidalgo County, Texas. Elevation 175 to 200 feet. August 6, 1912. (Rehn and Hebard.) [Hebard Collection, Type No. 218.]

Size smaller than compressus, form appreciably less robust, this the more pronounced in head, pronotum and caudal femora. Head and pronotum agreeing in contour with that species, the caudal margin of the pronotum similarly (normally) very feebly concave. Tegmina elliptical, (normally) smaller than in compressus, extending almost to caudal margin of metanotum (in series occasionally extending slightly beyond metanotum, as is normal for compressus). Prosternal spine blunt conical. Supra-anal plate and minute, linear, parallel furcula much as in compressus. Cerci distinctive, broad, tapering moderately in proximal two-thirds, distal third three-fifths as broad as base with margins parallel to transversely truncate apex, the dorsal angle of which is more broadly rounded than the ventral angle (compare Plate VIII, fig. 8 with fig. 9 of compressus). Pallium broad (twice as broad as in compressus), projecting dorsad, twice as broad as high, the convex dorsal surface forming nearly a semicircle with marginal convexity caudad. Subgenital plate rectangulato-convex, truncate (sub-conical convex in compressus).

\section{Allotype.- $q$; same data as type. [Hebard Collection.]}

Agrees with type in ambisexual characters, except the following. Size decidedly larger, form decidedly more robust; but not showing anything like the very great disparity between the sexes in these features found in compressus. Median carina of pronotum more distinct and percurrent, the pronotum (as in compressus) more inflated. Ovipositor valves as in compressus.

\begin{tabular}{|c|c|c|c|c|c|}
\hline \multicolumn{6}{|c|}{ Measurements (in millimeters) ${ }^{5}$} \\
\hline$\sigma^{7}$ & $\begin{array}{c}\text { Length of } \\
\text { body } \\
17\end{array}$ & $\begin{array}{c}\text { Length of } \\
\text { pronotum } \\
3.7\end{array}$ & $\begin{array}{c}\begin{array}{c}\text { Width of } \\
\text { pronotum }\end{array} \\
3.3\end{array}$ & $\begin{array}{c}\text { Exposed } \\
\text { length of } \\
\text { tegmen } \\
2.2\end{array}$ & $\begin{array}{c}\text { Length of } \\
\text { caudal } \\
\text { femur } \\
9.6\end{array}$ \\
\hline Paratypes. & $16-17.7$ & $3.7-3.8$ & $3.1-3.4$ & $2.2-2.8$ & $9-9.8$ \\
\hline Quitman Mou & & & & & \\
\hline Texas. & 13.2 & 3.2 & 2.8 & 2.2 & 8.2 \\
\hline $\begin{array}{c}\text { Del Rio, Texas. } \\
\text { o }\end{array}$ & 18 & 4.1 & 3.8 & 2.7 & 10.3 \\
\hline Allotype. & 23 & 5 . & 5 & 3. & 12.7 \\
\hline Paratype & $21-24.5$ & $4.6-5.6$ & $4.5-5.4$ & $3.1-2.9$ & $11.7-12.7$ \\
\hline Marathon, Texas & 27 & 5.8 & 5.7 & 3.4 & 13.4 \\
\hline
\end{tabular}

${ }^{5}$ In the present paper the measurements are given for the largest and smallest examples of both sexes in the series, where these are not represented in the extremes given for the typical series. 
Coloration.-Males. General coloration rather light brown, with a broad postocular band of dark brown on each side extending to the principal sulcus (or in other series to the caudal margin) of the pronotum, this often margined dorsad by a narrow band, which is paler than the general coloration. Abdomen with proximal dorsal segments maculate laterad with dark brown to varying degrees. Caudal femora very light brown, heavily twice banded with blackish brown and with genicular areas often as dark. Caudal tibiae pink.

Five males have the paler portions showing a greenish tinge, this most conspicuous on the limbs; in three of these the paler portions are pale yellowishgreen.

The females are usually paler, the general brown coloration more reddish. In all, the postocular band is subobsolete and in only the two or three darkest examples are the dark abdominal markings present. The two dark bands of the caudal femora are distinct, but as pronounced as in the male sex in but four specimens. The caudal tibiae are similar to those of the males, though in the paler examples the pink is more dilute.

Specimens Examined: 65 ; 32 males, 16 females, 9 immature males and 8 immature females.

Texas: Kerrville, Mission, Laguna del Gato, Uvalde, Del Rio, Sanderson, Marathon, Kent, Neville Spring in Brewster County, Cañon behind Pulliam Bluff in Chisos Mountains and Quitman Mountains.

The adults, with one exception, were taken from August 5 to September 13, 1912 by Rehn and Hebard.

One male from Mission and a series of nine males and ten females from Laguna del Gato, bearing the same data as the type, may be considered paratypes.

The type series was found occasional on small rounded hills covered with loose gravel and bearing scattered bunches of low bushy plants, in company with a slightly less abundant species of Rhabdotettix. The Melanopli were generally distributed through the clumps of plants, the present species found more numerous in a low green rhamnaceous shrub (probably Condalia obovata), in which Dichopetala castanea Rehn and Hebard was locally abundant. The species was found to be everywhere thamnophilous, and was taken up to an elevation of 5000 feet in the Quitman Mountains of extreme western Texas. It was twice found on a sensitive-leaved acacia, Acacia berlandieri, and twice singly on sotol, Dasylirion species.

TRANS. AM. ENT. SOC., XLIV. 


\section{CHLOROPLUS ${ }^{6}$ new genus}

This striking monotypic genus is nearest Campylacanıha, differing in the proportionately much larger head, larger eyes, shorter antennae, more inflated prozona, more delicate wing venation, less inflated cephalic and median femora, proportionately shorter and more robust caudal femora and longer caudal tarsi. The more inflated prozona, less decided pronotal sulci and more delicate venation of the tegmina give the insect a smoother general facies than any species of Campylacantha.

Only in the genus Phoetaliotes of the North American forms of the Melanopli is the head found to be similarly of disproportionately large size to that of the body. That genus, however, is clearly in no way closely related to Chloroplus.

Genotype.-Chloroplus cactocaetes new species.

Generic Characters. Head very large, longer than pronotum. Eyes large, longer than genae. Antennae short and delicate, only slightly longer than the depth of the head. Caudal margin of pronotum angulate-produced. Distal portion of male abdomen not enlarged, genitalia simple. Lateral margins of male subgenital plate straight. Prosternal spine conical. Caudal femora short and robust. Caudal tarsi nearly half as long as caudal tibiae.

Chloroplus cactocaetes ${ }^{7}$ new species (Plate VIII, fig. 10.)

This insect is one of the most delicately colored and beautiful of the North American Melanopli. It is apparently widely separated from any other known form.

Type.- $\sigma^{7}$; Corpus Christi, Nueces County, Texas. July 29, 1912. (Hebard:) [Hebard Collection, Type No. 475.]

Size medium, form medium, slightly less slender'than in Campylacantha lamprotata Rehn and Hebard. Head large, exceptionally large when compared with body bulk, length appreciably greater than that of pronotum. Vertex much as in Campylacantha, slightly produced and bluntly rounded, fastigium slightly broader and more concave than in C. lamprotata, frontal costa distinctly wider, widest with lateral margins decided between antennae, surface slightly depressed only at the median ocellus. Eyes very large and prominent, much longer than cheeks. Antennae slender and hardly longer than combined length of head and pronotum. Pronotum with dorsum and dorso-lateral portion of prozona somewhat inflated, smooth, with sulci weak;

- From $\chi \lambda \omega \rho o ́ s=$ pale green, and $\ddot{0} \pi \lambda o \nu=$ armor.

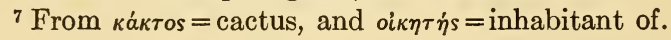


medio-longitudinal carina weak, particularly in caudal portion of prozona; metazona finely impresso-punctate; caudal margin produced, forming an angle of slightly over $90^{\circ}$ with apex rounded. Tegmina reaching to near base of supra-anal plate, venation very delicate. Wings reduced, reaching tegminal apices, incapable of sustained flight. Distal portion of abdomen evenly tapering, showing no enlargement. Furcula represented by two brief convexities, each projecting a distance of half its basal width. Supra-anal plate no longer than basal width, triangular with apex rounded, with a slender transverse carina mesad except at medio-longitudinal sulcus, which is deep in proximal half but obsolete distad. Cercus short, simple, broad at base, tapering to acute apex, length hardly one and one-half times basal width. Subgenital plate conical, produced to the dorso-distal blunt apex. Prosternal spine elongate, acute-conical. Interspace between mesosternal lobes over three times as long as wide. Cephalic and median femora moderately inflated. Caudal femora short, very robust, much more so than in any species of Campylacantha. Caudal tibiae with (10-11) spines. Caudal tarsus nearly half as long as caudal tibia.

\section{Allotype.—o ; same data as type. [Hebard Collection.]}

Agrees closely with male in coloration and relative proportions, except in the following characters. Size larger, form stouter and head even larger proportionately than in male. Vertex proportionately broader. Tegmina and wings extending to near apex of supra-anal plate. Genitalia normal, the ovipositor valves short with apices acute and rather strongly curved. Prosternal spine stouter than in male. Interspace between mesosternal lobes nearly twice as long as broad.

\section{Measurements (in millimeters)}

\begin{tabular}{|c|c|c|c|c|c|}
\hline Type. & $\begin{array}{c}\text { Length of } \\
\text { body } \\
21.7\end{array}$ & $\begin{array}{l}\text { Length of } \\
\text { pronotum } \\
4.8\end{array}$ & $\begin{array}{l}\text { Length of } \\
\text { tegmen } \\
11\end{array}$ & $\begin{array}{l}\text { Length of } \\
\text { caudal } \\
\text { femur } \\
11.8\end{array}$ & $\begin{array}{l}\text { Width of } \\
\text { caudal } \\
\text { femur } \\
3.3\end{array}$ \\
\hline Paratypes (7). & $18.5-21.8$ & $4.2-5.2$ & $10.2-12$ & $10.6-12.3$ & $3.2-3.8$ \\
\hline $\begin{array}{l}\text { Double Windmill, } \\
\text { Brewster County, }\end{array}$ & & & & & \\
\hline $\begin{array}{l}\text { Texas. } \\
\end{array}$ & 16.4 & 3.9 & 9.2 & 9.8 & 2.9 \\
\hline Allotyp & 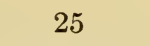 & & & 12. & 4 \\
\hline$P a r$ & $23-26$. & $5.7-6.2$ & $13.3-14$ & $13.5-14.3$ & $4.2-4$. \\
\hline Cotulla, Texas. & 28 & 6.4 & 14.3 & 14.8 & 4.4 \\
\hline
\end{tabular}

The size variation is shown by the series at hand to have no geographic significance whatever.

Coloration.-Little variation in general appearance is shown by the series, though considerable differences in shade are apparent on close examination. The material from Corpus Christi averages slightly darker than the other specimens. Those from San Antonio and Cotulla show the richest coloration.

Eyes buckthorn brown to chestnut brown. Antennae cinnamon-rufous, becoming paler and more yellowish proximad. Face light brownish olive,

TRANS. AM. ENT. SOC., XLIV. 
individually varying through mignonette green through chamois with a greenish tinge to tawny olive, becoming deeper dorsad and there shading evenly into the occipital color, which is jade green individually varying to buffy olive, always bordered on each side by a narrow suffusion of chamois. Genae same color as face, a postocular band of jade green between this area and the pale lateral margins of the occipital area. Occipital coloration extending caudad on dorsum of pronotum as a very broad band of equal width to principal sulcus, thence expanded to include the entire metazona which, however, in some specimens becomes paler ventro-laterad. Medio-dorsal very broad band of prozona broadly bordered on each side with chamois. Lateral lobes of pronotum with postocular band decidedly broadened, widest in caudal portion of prozona, jade green with sometimes a median fleck of chamois, individually varying to solid ivy green; below this the lateral lobes are chamois, often with ventral portion broadly suffused with the general coloration of the face (light brownish olive or mignonette green) or of the metazona (buffy olive). Tegmina immaculate, individually kildare green to cress green. Exposed remaining lateral portions of thorax green, with ventral portion of meta-epimerum and all but narrow proximal portion of meta-episternum strikingly chamois. Ventral portions and abdomen olivaceous or yellowish, the abdomen always tinged with olivaceous distad. Cephalic and median limbs ochraceous-buff, washed, often heavily, with mikado brown. Caudal femora mikado brown, often with external face narrowly paler. along the ventral margin and in proximal and distal portions, dorsal face individually. clay color or cinnamon, always showing two delicate, but distinct (though individually variable in extent and intensity) and broad, transverse bands of olive. Caudal tibiae lumiere blue (a rich blue, showing slightly more green than glaucous); spines pale lumiere blue or white, with black tips.

Specimens Examined: $35 ; 17$ males, 17 females and 1 immature female.

Texas: San Antonio, Cotulla, Robstown, Corpus Christi, Lake Lomalta in Cameron County, and in the Big Bend region, Double Windmill, camp two miles north of Bone Spring and Neville Spring.

One male from Robstown and a series of seven males and nine females from Corpus Christi, bearing the same data as the type, may be considered paratypes. The entire series was taken by Rehn and Hebard between July 29 and August 9, 1912.

This remarkable insect, though showing a fairly wide distribution, was found other than singly but once. It is very local, being almost entirely confined to joint-cactus, Opuntia species, of the Cylindropuntia group, in which heavily armed plant it lives. It was almost impossible to drive a specimen into the open unless the cactus was trampled down with heavy boots. In these plants the insects were found to be extremely alert and quick to dodge into the more sheltered recesses. When driven into the open they displayed unusual leaping powers, and the males were 
seen to increase the distance covered by their great leaps by the use of their reduced wings. Individuals made every effort to reach another joint-cactus when driven out and whenever this was accomplished they hid almost instantly. At Corpus Christi the species was found very locally, but in moderate numbers, in the cactus and surrounding low halophytic vegetation of the extensive sandy flats bordering the bay. At all other localities rare individuals were located always in clumps of joint-cactus in dry sandy areas.

\section{Paraidemona latifurcula new species (Plate VIII, fig. 11.)}

This insect, which in size averages smallest of the species of the present genus, is readily distinguished in the male sex by the very distinctive type of furcula. Females can be separated from those of $P$. fratercula, here described, only by the prosternal spine which is blunter in latifurcula. Both of these species average decidedly smaller than $P$. mimica Scudder, but in the Brownsville region of Texas a decided reduction in size is found to occur frequently in that insect.

In linear arrangement this species should be placed first in the genus, followed by fratercula.

Type.- $\sigma^{7}$; Brownsville, Cameron County, Texas. July 31 to August 5, 1912. (Hebard.) [Hebard Collection, Type No. 476.]

In all respects the type agrees with a paratypic male of mimica, ${ }^{8}$ except in the following features. Size very small (averaging smallest of genus); form moderately robust. Furcula a broad, transverse, briefly projecting plate, about three times as wide as long, with brief lateral margins straight and weakly convergent to the sharply but briefly produced, acute latero-caudal angles, caudal margin straight, transverse, between these. Supra-anal plate with lateral margins moderately convergent in proximal third, its surface showing a transverse ridge at this point; in distal two-thirds triangular, this portion about as long as its basal width,.the lateral margins moderately concave and more strongly convergent to the strongly acute-angulate rounded apex, surface of this portion showing a rather sharp medio-longitudinal sulcation. The supra-anal plate is decidedly more narrowly triangularly produced than in any other species of the genus. Cerci simple, slenderly acute conical, hardly two-thirds as long as supra-anal plate. Pallium very large and convexly protuberant, as in mimica. Subgenital plate very small, fitting into the deep and regular concavity of all but the proximal portion of the caudal margin of the preceding segment; free dorsal margin of subgenital plate rather

${ }^{8}$ We would note that in all the species of Paraidemona the caudal margin of the pronotum is weakly concave, and both tegmina and wings are absent.

TRANS. AM. ENT. SOC., XLIV. 
strongly obtuse-angulate with apex rounded. Prosternal spine conical with apex decidedly blunt, heavier with apex more blunted than in mimica. Interspace between mesosternal lobes hardly twice as long as broad.

\section{Allotype.- $\%$; same data as type. [Hebard Collection.]}

Agrees with male except in the following features. Size considerably larger, form much more robust. Ovipositor valves as normal for the genus, with distal teeth of dorsal pair not narrowing as much as is usual in allied genera, and with apex in consequence horizontally more broadly convex (in the present series the valves average proportionately slightly shorter than in the other species). Prosternal spine very heavy, heavier than in male, distinctly widest transversely. Interspace between mesosternal lobes quadrate. ${ }^{9}$

\begin{tabular}{|c|c|c|c|c|c|}
\hline \multicolumn{4}{|c|}{ Measurements (in millimeters) } & \multirow[b]{2}{*}{$\begin{array}{l}\text { Length of } \\
\text { caudal } \\
\text { femur } \\
6.9\end{array}$} & \multirow[b]{2}{*}{$\begin{array}{l}\text { Width of } \\
\text { caudal } \\
\text { femur } \\
2.2\end{array}$} \\
\hline$\sigma^{\pi}$ & $\begin{array}{l}\begin{array}{c}\text { Length of } \\
\text { body }\end{array} \\
10.8\end{array}$ & $\begin{array}{c}\text { Length of } \\
\text { pronotum } \\
2.7\end{array}$ & $\begin{array}{c}\text { Widt } \\
\text { pron } \\
2 .\end{array}$ & & \\
\hline $\begin{array}{l}\text { Type. } \\
\text { Paratypes }{ }^{10}(24) . \\
\text { ᄋ }\end{array}$ & $\begin{array}{c}10.8 \\
10-12.8\end{array}$ & $2.6-3.2$ & $\begin{array}{c}2.4 \\
2.4-3\end{array}$ & $\begin{array}{l}0.9 \\
6.7-8.7\end{array}$ & $2.1-2.8$ \\
\hline $\begin{array}{l}\text { Allotype. } \\
\text { Paratypes (8). }\end{array}$ & $\begin{array}{c}15.5 \\
15.2-17.8\end{array}$ & $\begin{array}{c}3.7 \\
3.2-3.8\end{array}$ & $\begin{array}{c}3.9 \\
3.4-4.1\end{array}$ & $\begin{array}{c}9.8 \\
9-10.2\end{array}$ & $\begin{array}{c}2.8 \\
2.7-3\end{array}$ \\
\hline
\end{tabular}

Coloration of male very similar to that of mimica, except that the buffy markings margining the dorsum of the pronotum laterad are decidedly narrower than is normal in that species, in a few specimens being obsolete. The males are brown, with pale markings buffy and darker markings dark brown. Minor differences in intensity of color pattern are frequent and occasional recessive specimens have the buffy portions yellow ish with a very weak tinge of green.

The femalee agree with the males in general type of color pattern, which is, however, usually much less strongly defined, the markings margining the dorsum of the pronotum laterad being reduced and confined to the prozona or entirely wanting, and the dorsal surface of the caudal femora shows the two dark transverse bands much less distinctly. Two color phases occur in this sex, one in which the general coloration is brown (warm sepia to mikado brown), the other with head, dorsal portions of thorax and caudal femora olive (yellowish olive to light yellowish olive) and abdomen brown. In all the species of Paraidemona the caudal tibiae are glaucous tinged with green (lumiere blue to turquoise green).

${ }^{9}$ This feature is not as valuable to separate females of this species from those of mimica (in which this interspace averages much longer than wide) as might be imagined. Individually a decided amount of variation occurs, which has convinced us that, though useful as a secondary diagnostic feature, this character has by no means the value we often find ascribed to it in the literature. In the series of $P$. mimica at hand the interspace between the mesosternal lobes varies from subquadrate to nearly three times as long as wide. We have found similar variation in this feature in species of Melanoplus.

${ }_{10}$ The average of the series is nearest the type, the maximum individual is decidedly larger than any of the others. 
Specimens Examined: 40; 26 males, 11 females, 1 immature male and 2 immature females.

Texas: Laguna del Gato in Hidalgo County, Brownsville and Piper Plantation in Cameron County.

In addition to the type and allotype, a series of twenty-four males and eight females bearing the same data are considered paratypes. The material was all taken, with the exception of three pairs, by Rehn and Hebard between July 31 and August 6, 1912. The others were taken at Brownsville April 30, 1895 (a pair in coitu) and May 23, 1913.

The insects were found common about Brownsville, in company with $P$. mimica Scudder, wherever grassy areas occurred, either in the open or in open spaces in the river plain jungle scrub. At the Piper Plantation, mimica was found to be much the more abundant species in such situations. The present insect probably enjoys a much wider distribution south of the Rio Grande than in the United States.

Paraidemona fratercula ${ }^{11}$ new species (Plate VIII, fig. 12.)

1897. Paraidemona punctata Scudder (not Pezotettix punctatus Stål, 1878),

Proc. U. S. Nat. Mus., XX, p. 42. (In part.) [o, Corpus Christi Bay, Texas.]

This insect is closely related to $P$. mimica Scudder, differing only in the average smaller size, slightly more robust form and in the male furcula and supra-anal plate.

The distribution of this species does not reach as far east, north or west in the United States as that of mimica. We would note that, from the material at hand, mimica is generally distributed over the entire known range of fratercula, everywhere averaging decidedly larger except in the Brownsville region of Texas, where a marked reduction in size is shown by the majority of specimens taken. As a result, we would have been unable to separate females of these species from that region without the large series now available.

Type.- $\sigma^{7}$; Lyford, Cameron County, Texas. August 6 and 7, 1912. (Rehn and Hebard.) [Hebard Collection, Type No. 477.]

${ }^{11}$ In allusion to the fact that this species is a diminutive form, showing close relationship to $P$. mimica Scudder.

TRANS. AM. ENT. SOC., XLIV. 
Agrees fully with a paratype of mimica before us except in the following features. Size small, (averaging) decidedly smaller than mimica, but appreciably larger than $P$. latifurcula, here described. Form moderately robust. ${ }^{12}$ Interspace between mesosternal lobes subquadrate. ${ }^{13}$ Furcula represented by twin, slightly swollen adjacent processes, which project beyond the margin of the segment less than (rarely in the series varying to fully) half the basal width of one of these. Supra-anal plate with lateral margins feebly convergent and rather strongly convex in proximal two-thirds and elevated, plate there decidedly (rarely in the series weakly) constricted, the distal third consequently small, triangular with lateral margins convergent and feebly convex to the acute apex, bearing in this portion a medio-longitudinal sulcus. Cerci simple, slender, acute conical, about two-thirds as long as supra-anal plate. Caudal margin of pronotum, pallium, subgenital plate and prosternal spine as in mimica.

\section{Allotype.—o ; same data as type. [Hebard Collection.]}

Similar in every way to females of mimica except for the (average) decidedly smaller size and (average) slightly more robust form, which causes the caudal femora to be shorter and slightly heavier. Prosternal spine moderately heavy with apex rather sharply rounded (in the series the apex is seen to vary somewhat in form and when more nearly acute is often slightly flexed cephalad). Interspace between the mesosternal lobes slightly longer than broad (varying in the series to distinctly longer than broad).

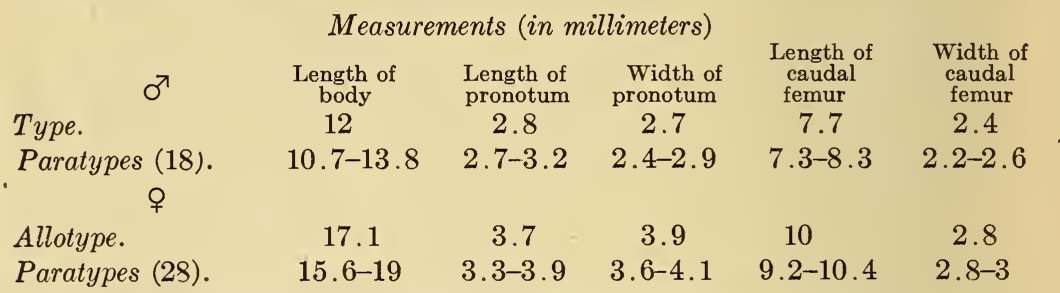

The variation shown by the Lyford series is not exceeded in any of the additional material at hand.

Coloration.-No noteworthy differences from mimica are apparent in coloration. As in that species, two color forms, green and brown, occur; in the present series in about equal numbers, while in the Laredo series a condition about intermediate, pale yellowish with a green tinge, is found. The intensification and recession of the color pattern is shown by the series to be considerable. Nearly all the brown females and a number of the green phase have the color pattern fully as marked as in the male sex, in this feature apparently differing from the usual condition found in latifurcula.

12 When the series at hand are placed beside each other, those of the present species appear slightly more robust than those of mimica and slightly less robust than those of latifurcula. The difference is, however, not sufficient to be of any value for individual comparisons.

${ }_{13}$ This feature varies in the present species. See page 150 , footnote 9 . 
Specimens Examined: 112; 49 males, 61 females and 2 immature males.

Texas: Beeville, Corpus Christi, Katherine, Lyford, Laguna del Gato in Hidalgo County, Piper Plantation in Cameron County, Lake Lomalta in Cameron County, Point Isabel, Benavides, Carrizo Springs, Cotulla and Laredo.

A series of eighteen males and twenty-eight females from Lyford, bearing the same data as the type, are here designated as paratypes. All but eight specimens of fratercula were taken by Rehn and Hebard, between July 28 and August 14, 1912. Two females at hand, from Corpus Christi Bay, were taken in December.

The species was found generally distributed in grassy areas, where at Lyford it was present in very large numbers. Its distribution in the United States is seen to be much wider than that of latifurcula, but by no means as extensive as that of mimica. The fourth species of the genus, punctata (Stål), shows the highest specialization of the male genitalia and is known to us only from Dallas, Texas. ${ }^{14}$

\section{Eotettix davisi ${ }^{15}$ new species (Plate VIII, fig. 13.)}

The two species of this genus here described differ widely from the three previously known species, in their brown general coloration and male cerci, which are in each differently specialized, not simple and acute conical. Their general coloration never shows greenish yellow or green in the adult and, though somewhat shining, has in life none of the pearly and distinctive luster which in the field so strikingly distinguishes the other species.

Both davisi and quercicola, here described, agree closely in general; the characters for separating them are given under the latter species. In general appearance these insects suggest rather strongly a very large and exceedingly smooth development of the Scudderi Group of the genus Melanoplus. The general structure, however, satisfies us that they must be assigned to Eotettix.

Type.- $\sigma^{\top} ;$ De Funiak Springs, Walton County, Florida. August 30, 1915. (Rehn and Hebard.) [Hebard Collection, Type No. 478.]

${ }^{14}$ Described from "Texas." Scudder has, in his revision, misidentified as punctata females of mimica from Goliad and Carrizo Springs and of fratercula from Corpus Christi Bay.

${ }^{15}$ In honor of our good friend Mr. William T. Davis, of Staten Island, New York, whose careful collecting trips in Florida and publications have helped greatly in the proper understanding of the Orthoptera of that state.

TRANS. AM. ENT. SOC., XLIV. 
Size large for the genus (averaging about as large as the maximum found in $E$. signatus Scudder); form medium, as in signatus. Surface well supplied with rather long microscopic hairs, as in signatus. Interocular space narrow, distinctly narrower than in signatus, palustris or pusillus. Fastigium moderately produced and shallowly concave mesad, not deeply so as in those species; frontal costa with lateral margins moderately pronounced, not as sharply carinate. Eye slightly longer than cheek. Antennae elongate, over twice as long as the elongate pronotum. Pronotum with medio-longitudinal carina moderately decided, cut only by principal sulcus, not as decided as in signatus, palustris or pusillus; caudal margin of pronotum very broadly obtuse-angulate produced. Tegmina very slightly overlapping, broadly oval, showing some truncation distad particularly in the distal marginal portion of the lateral field, as long as prozona and half the metazona; humeral angle distinct, the dorsal field being feebly but appreciably defined from the lateral field. Distal portion of abdomen not enlarged. Furcula consisting of two, nearly attingent, slight convexities, from each of which project beyond the segment a minute rounded projection, the length of which approximates, its width. Supra-anal plate moderately broad shield-shaped; lateral margins subsinuous, weakly convex to the rounded apex; surface rather decidedly concave laterad in proximal two-thirds, mesad raised, strongly sulcate in proximal third with lateral margins of this sulcation strongly carinate. Cercus a broad plate, slightly less than twice as long as its basal width, surface deplanate; margins feebly convergent to the rather broad, rounded apex, dorsal margin weakly concave, ventral margin weakly convex. Subgenital plate small, convex, tapering to the rather large and produced rounded apex, which is situated mesad on the dorsal free margin (in this respect differing from signatus, palustris and pusillus, in which the subgenital plate bears a distinctly subapical tubercle). Prosternal spine stout, moderately elongate, blunt. Interspace between mesosternal lobes considerably over twice as long as its least width. Caudal femora medium, slightly heavier than in signatus. Caudal tibiae with twelve spines (on each margin).

\section{Allotype.- - ; same data as type. [Hebard Collection.]}

Agrees with male except in the following features. Size much larger, form much more robust. Eye no longer than cheek. Tegmina with dorsal field more distinctly defined from lateral field. Ovipositor valves moderately elongate, not strongly curved distad to their acute apices. Prosternal spine heavier than in male. Interspace between mesosternal lobes about one and one-half times as long as least width.

\section{Measurements (in millimeters)}

\begin{tabular}{lcccccc}
\multicolumn{1}{c}{$\sigma^{7}$} & $\begin{array}{c}\text { Length of } \\
\text { body }\end{array}$ & $\begin{array}{c}\text { Length of } \\
\text { pronotum }\end{array}$ & $\begin{array}{c}\text { Length of } \\
\text { tegmen }\end{array}$ & $\begin{array}{c}\text { Width of } \\
\text { tegmen }\end{array}$ & $\begin{array}{c}\text { Length of } \\
\text { caudal } \\
\text { femur }\end{array}$ \\
$\begin{array}{l}\text { Type. } \\
\text { Paratypes (87). }\end{array}$ & $\begin{array}{c}21 \\
\text { 18.5-22 }\end{array}$ & $\begin{array}{l}4.8-5.2 \\
\text { क }\end{array}$ & & $4.1-5.1$ & $2.8-3.1$ & $11.7-12.9$ \\
$\begin{array}{l}\text { Allotype. } \\
\text { Paratypes (30). }\end{array}$ & 26.2 & 6.8 & 5.1 & 3.8 & 15.8 \\
& $25-27.2$ & $6.3-7$ & $4.2-5.7$ & $3.2-3.9$ & $14.8-15.7$
\end{tabular}


Considerable variation is shown by the size and length compared with breadth of the tegmina in this series, but in all the specimens these organs are distinctive from those of quercicola, as discussed under that species.

Coloration.-Male. Face varying from russet to yellowish. Eyes dark brown. Antennae ferruginous. Occiput, disk of prozona and entire metazona and dorsal field of tegmina sayal brown, individually varying to warm sepia. Lateral fields of tegmina slightly darker than dorsal field of the same. Head showing a broad postocular band of black, which is much broader on the pronotum, continued to the principal sulcus and occupying nearly the entire dorsal half of the lateral lobes; remaining portions of lateral lobes cephalad of principal sulcus clay color, rarely with a very weak olivaceous tinge. Abdomen clay color, other portions of ventral surface yellowish. Cephalic and median femora clay color, often with an olivaceous tinge (in some specimens isabella color). Caudal femora with external face sayal brown, individually varying to warm sepia, with a broad pregenicular yellowish annulus; ventral surface yellowish with a greenish tinge; dorsal surface buffy with two broad transverse bands of dark brown, which bands are very frequently individually citrine; genicular areas very dark, blackish brown except the distal portions of the genicular lobes which are paler. Caudal tibiae coral red, spines black.

Female (recessive). General coloration of dorsal surfaces ochraceous-tawny, paling to ochraceous-buff laterad and on the occiput. Head showing a narrow postocular black band, continued as a very narrow line along the dorsal margins of the lateral lobes of the pronotum to the principal sulcus. Eyes hazel. Tegmina appreciably bicolored, dorsal field ochraceous-tawny, lateral fields ochraceous-tawny washed with cinnamon-brown. Underparts yellowish. Caudal femora unicolorous, the genicular areas alone showing traces of black. Caudal tibiae coral red; spines black, except at bases which are pink. In the maximum intensive coloration females are almost as dark as males, the postocular bar very broad on the prozona, spreading over nearly half of the surface of the lateral lobes, with ventral margin frequently irregular and sometimes with a spot of the pale ground coloration showing through mesad, this bar continued more narrowly on the metazona to the caudal margin. Tegmina with dorsal field cinnamon-brown, lateral fields prouts brown. Caudal femora showing the bands of the dorsal surface, but not as pronounced'as in the male.

The series at hand shows that in the immature instars two distinct color phases occur, at least in females; in one the general coloration is yellowish green $^{16}(14)$, in the other brown $(18)^{\circ}$, the postocular dark bars in all variably well defined, except in a few of the yellowish green individuals.

Specimens Examined: 158; 93 males, 32 females, 1 immature male and 32 immature females.

Florida: De Funiak Springs and Pensacola.

A series of eighty-nine males and thirty-one females from De Funiak Springs, bearing the same data as the type, are here designated as paratypes. All of the material of this species was taken by Rehn and Hebard between August 28 and 30, 1915.

${ }^{16}$ Light green with a yellowish tinge in life.

TRANS. AM. ENT. SOC., XLIV. 
The species was found very rare in gallberry bushes, Ilex glabra, in low sandy long-leaf pine woods, Pinus palustris, at Pensacola. At De Funiak Springs in sandy long-leaf pine woods, with undergrowth of wire-grass and much oak shoots and dwarf oak, the insect was found in large numbers, locally wherever this type of country occurred, the oak undergrowth evidently being the food plant as was also found to be true for the allied quercicola. The species is truly thamnophilous, not rapid in its movements, but jumping with great power. When approached, individuals often hid on the underside of the oak leaves and when seized by a cautious approach and sudden grasp were found to cling tenaciously to their support.

Eotettix quercicola new species (Plate VIII, fig. 14.)

This species agrees closely with $E$. davisi, here described, in both general appearance, habits and actions. The present insect supplants davisi in Florida east of De Funiak Springs.

This species is readily distinguished from davisi in the male sex by the very different cerci and appreciably broader apex of the subgenital plate, and in both sexes by the tegmina, which show no distal truncation and have their surfaces even, showing no definition between the dorsal and lateral fields. The males of this species also average distinctly less attenuate, while the females show the postocular dark bars in their maximum intensification narrower than is normal in davisi, with coloration of the same solid and ventral margins not irregular.

Type.- $\sigma^{\top}$; Woodville, Leon County, Florida. September 1, 1915. (Rehn and Hebard.) [Hebard Collection, Type No. 479.]

Agrees in all respects with the type of davisi, except in the following features. Size moderately large (average somewhat smaller than in davisi); form medium, not as attenuate as in that species. Pronotum with medio-longitudinal carina not fully as decided as in davisi. Tegmina slightly overlapping, oval, the curvature of the margin greatest distad, surface showing no definition between dorsal and lateral fields. Supra-anal plate as in davisi except that a transverse carina runs for a brief distance laterad from the extremities of the carinae, bounding the proximal median sulcus. Cercus slightly over twice as long as proximal width, dorsal margin very feebly concave to apex, ventral margin feebly convex and converging toward dorsal margin in proximal three-quarters, the remaining narrow distal fourth of the cercus curved inward, with margins parallel to the rounded apex, this portion about one-third as wide as the basal width. Subgenital plate as in davisi except that it is somewhat more produced, 
with apex decidedly broader, over twice as wide as deep and feebly bilobate. Interspace between mesosternal lobes in length distinctly less than twice its least width. Caudal tibiae with (eleven and twelve) spines.

\section{Allotype.- $\%$; same data as type. [Hebard Collection.]}

Agrees with male except in the following features. Size much larger, form much more robust. Eyes slightly shorter than cheek. (Tegmina similar, this feature serving best to separate females of this species from davisi.) Ovipositor valves moderately elongate, not strongly curved distad to acute apices. Interspace between mesosternal lobes scarcely longer than broad.

\begin{tabular}{|c|c|c|c|c|c|}
\hline \multirow[b]{2}{*}{ ठ } & \multicolumn{4}{|c|}{ Measurements (in millimeters) } & \multirow[b]{2}{*}{$\begin{array}{c}\text { Length of } \\
\text { caudal } \\
\text { femur } \\
11.7\end{array}$} \\
\hline & $\begin{array}{c}\text { Length of } \\
\text { body } \\
19.7\end{array}$ & $\begin{array}{c}\text { Length of } \\
\text { pronotum } \\
4.7\end{array}$ & $\begin{array}{c}\text { Length of } \\
\text { tegmen } \\
4.2\end{array}$ & $\begin{array}{l}\text { Width of } \\
\text { tegmen } \\
2.3\end{array}$ & \\
\hline Paratypes (28). & $17.2-21$ & $4.7-5$ & $4-4.8$ & $2.7-2.8$ & $11.3-11.9$ \\
\hline Carrabelle, Florida. & 16.3 & 4.1 & 3.9 & 2.6 & 10.5 \\
\hline $\begin{array}{c}\text { Ocala, Florida. } \\
\qquad\end{array}$ & 20.8 & 5.2 & 4.7 & 3 & 12.3 \\
\hline Allotype. & 27.7 & 6.8 & 5.8 & 3.7 & 15.1 \\
\hline Paratypes (34). & $24.3-28.2$ & $6-7$ & $5-6.8$ & $3.6-4$ & $14.2-15.6$ \\
\hline Carrabelle, Florida. & 23.2 & 5.8 & 5.1 & 3.6 & 13.5 \\
\hline Ocala, Florida. & 30.5 & 7.2 & 5.9 & 4.2 & 16.5 \\
\hline
\end{tabular}

The size average is decidedly less for the Carrabelle material than for the series from Woodville, decidedly greater than that series for the Ocala specimens. Material from additional localities will be needed to determine whether the difference is attributable to geographic distribution or merely to different local environmental conditions.

The coloration is almost identical with that of davisi, the only noteworthy feature being the postocular dark bands in the female. This band averages narrower and is rarely continued beyond the principal sulcus in the females from Woodville and Carrabelle. In the eight females from Ocala it is decidedly broader, but shows no irregularities of its ventral margin or mesal pale marking, as it does when developed to this degree in davisi.

The three immature females at hand from Woodville are solidly greenish yellow, with face and disk of pronotum weakly suffused in two, but. showing no trace of postocular bars. These are from the series showing greater recessive coloration and immatures from Ocala would probably show the same features found in davisi.

Specimens Examined: 84; 36 males, 45 females and 3 immature females.

Florida: Woodville, Carrabelle and Ocala.

A series of twenty eight males and thirty four females from Woodville, bearing the same data as the type, are designated paratypes. The entire series was taken between September 1 and 19, 1915 and 1917, by Rehn and Hebard.

TRANS. AM. ENT. SOC., XLIV. 
The species was found common in sandy long-leaf pine, Pinus palustris, flatwoods among dwarf oaks and oak shoots at Woodville; very few in scrub oaks and oak shoots on flat sandy soil at Carrabelle, and few in oak clumps at from two to five feet from ground at Ocala, in an environment very similar to that of Woodville. The species, like davisi, is thamnophilous, not rapid in movements, but extremely powerful in leaping and unusually able in hiding in the oak undergrowth to which it is peculiar.

\section{HESPEROTETTIX Scudder}

The species of this genus are extremely difficult to define properly. The male genitalia, of such great diagnostic importance in so many species of the Melanopli, show no differences of value between many of the species. Moreover, features of coloration afford important factors in separating certain species, though in some a decided amount of color variation occurs. Virtually all the color variation within a species is attributable to intensification and recession of the color pattern, but it is clear that, with this in mind, great care must be exercised in attributing specific diagnostic values to features of coloration. Furthermore it is apparent that great reduction in the organs of flight constitute a valid reason for separating more than one species from a long-winged species showing very slight additional differences, though in other genera of the Melanopli (Melanoplus, Dendrotettix) species occur in which both these conditions are found, in some being ascribable to nothing more than individual variation.

We admit that the features used below are in some cases not as satisfactory as could be desired, but their sum total shows an insect widely different in general appearance from its nearest allies. We are confident that future studies in the chromosomes and internal anatomy of these species will prove them far more distinctive than might be supposed.

Hesperotettix gemmicula new species (Plate VIII, fig. 15.)

This, the smallest of the Eastern species of the genus, is in our opinion the handsomest of the known forms.

Nearest relationship is with $H$. osceola, here described, under which species a comparison is made. These species belong to the 
Pratensis Group, of which osceola is the only member having greatly reduced tegmina and wings.

Compared with $H$. brevipennis (Thomas) the present insect is seen to average smaller and more slender, the medio-longitudinal pronotal band is paler, usually paler mesad than laterad, the dark marking of the lateral lobes of the pronotum is very broadly bordered by white ventrad, the tegmina reach to the apex of the abdomen or slightly beyond and are green except for a longitudinal humeral band, the caudal femora show faintly two transverse bars on their dorsal surfaces and do not have their external faces washed with pink.

Type.- $-\sigma^{T}$; Carrabelle, Franklin County, Florida. September 2 to 3,1915 . (Rehn and Hebard.) [Hebard Collection, Type No. 481.]

Size small for the genus, form slender. Eyes very slightly more prominent and showing a less decided difference between length and width than in brevipennis. Medio-longitudinal dorsal band of pronotum not solidly pink, the median portion distinctly paler than the margins. Dark bar of prozonal portion of lateral lobes solid in coloration, the ventral border of this bar white and about equally broad (in a few specimens of the series narrower, this feature then showing no difference from brevipennis). Tegmina and wings fully developed, as in $H$. pratensis Scudder, extending nearly to apices of caudal femora (in the males at hand varying slightly, minimum extending to apex of abdomen, maximum to apices of caudal femora). Tegmina distinctively colored; dorsal and lateral fields green except for a broad longitudinal humeral band of pink (the dorsal portion of this band in the lateral field usually darkened). Genitalia of the same general type as found in pratensis and brevipennis, ${ }^{17}$ cerci alone differing in being narrow and of subequal width in distal half, moderately incurved in this portion, with apex sharply rounded. Prosternal spine shorter and stouter than in brevipennis, tapering more rapidly in distal portion to the sharply rounded apex. Antennae and broad annuli of cephalic and median femora similar to brevipennis, except that they are not as brilliantly colored. Caudal femora green, the pregenicular pinkish annulus distinct (but individually variable, and obsolete in a few specimens at hand); dorsal surface pale green with two weak but distinct broad transverse bands of darker green 18 and showing no trace of pink along the external margin as is characteristic of brevipennis; external surface green (never washed with pink as in brevipennis); dorsal half of lateral portions of genicular areas black as in brevipennis.

${ }^{17}$ In the present genus slight individual variation in the form of the subapical tubercle of the male subgenital plate occurs.

${ }_{18}$ These bands are exceedingly delicate and in poorly dried material might easily be obscured. No trace of such marking ever occurs in brevipennis.

TRANS. AM. ENT. SOC., XLIV. 


\section{Allotype.—o; same data as male. [Hebard Collection.]}

Agrees with type except in the following features. Size larger, form slightly more robust (averaging decidedly smaller and more slender than in females of brevipennis). Diagnostic features of coloration as given for male, except that the medio-longitudinal dorsal stripe of the pronotum is proportionately narrower (normally for the series, but in a few specimens proportionately fully as wide as in the male and unicolorous, not paler mesad than laterad), and longitudinal humeral band of the tegmina proportionately much narrower, so that more of the surface of the insect is green. Ovipositor valves normal for the genus.

\begin{tabular}{|c|c|c|c|c|c|}
\hline & Measure & ents (in $m$ & illimeters) & & \\
\hline Type. & $\begin{array}{c}\text { Length of } \\
\text { body } \\
15.2\end{array}$ & $\begin{array}{l}\begin{array}{c}\text { Length of } \\
\text { pronotum }\end{array} \\
3.9\end{array}$ & $\begin{array}{l}\text { Width of } \\
\text { pronotum } \\
2\end{array}$ & $\begin{array}{l}\text { Length of } \\
\text { tegmen } \\
10.8\end{array}$ & $\begin{array}{l}\text { Length of } \\
\text { caudal } \\
\text { femur } \\
9.5\end{array}$ \\
\hline Paratypes (4). & $14.5-15.3$ & $3.7-4$ & $1.9-2$ & $9.7-11.5$ & $9.2-10.2$ \\
\hline $\begin{array}{l}\text { ensacola, Florida } \\
\text { (4). }\end{array}$ & $14.5-15.5$ & $3.6-4.1$ & $1.9-2.2$ & $11.7-13$ & $8.8-10$ \\
\hline 우 & & & & & \\
\hline Allotype. & 17.9 & 4.8 & 2.7 & 11.9 & 11.7 \\
\hline Paratypes (6). & $16.8-20.8$ & $4.1-4.8$ & $2.3-2.7$ & $11.4-12.8$ & $10.2-12$ \\
\hline$(7)$ & $18.2-23.3$ & $4.8-5.7$ & $2.7-3.1$ & $14.6-15.5$ & $1.2-12$ \\
\hline
\end{tabular}

The Pensacola series shows no difference from that from Carrabelle, except in the slightly but distinctly longer tegmina and wings and in a greater size variation between the extremes. This species occurs in very dry environment and at Pensacola was taken at two widely separated situations, the optimum examples coming from the less extreme of these. The Carrabelle examples were all taken over an area showing the extreme condition of dryness and much more exposed to storms than at the points about Pensacola where the insect was collected. It would appear from the evidence that local environmental conditions explain all the size variation which occurs, while it is probable that the slight reduction in tegminal length is a response to the more exposed and wind-swept character of the coast at Carrabelle.

Head courge green, usually with a'very small black marking extending ventrad from the lower margin of the eye. Eyes metallic cinnamon brown. Antennae vinaceous-rufous. Pronotum courge green; with a medio-longitudinal band, which is flesh color with lateral margins heavily but narrowly suffused with cameo brown; lateral lobes with a broad blackish band, slightly ascendent cephalad, which extends caudad to the principal sulcus and is 
bordered ventrad by a band of white of about equal width. Other lateral portions of thorax courge green; the meso-episternum ventrad with a blotch of vinaceous-russet, deepening in color mesad; the meta-episternum occupied by a broad oblique white marking, margined above and below with black. Tegmina courge green with a broad longitudinal humeral band of congo pink, this much suffused with cameo brown toward the dorsal margin of the lateral field. Abdomen dull green yellow, the dorsal segments margined laterad with white. Cephalic and median limbs courge green, their femora almost completely occupied by very broad bands of salmon-orange to orange-rufous. Caudal femora (usually) showing a broad pregenicular annulus of orangerufous; dorsal surface courge green with two broad transverse bars of slightly darker shade; external face light hellebore green paling to courge green proximad with ventral margin of same color as ventral surface, bright chalcedony yellow; dorsal half of lateral portions of genicular areas black. Caudal tibiae lumiere blue. The variation in the series of the more important features of coloration is given with the original description.

Specimens Examined: 23; 9 males and 14 females.

Florida: Big Bayou near Pensacola, Pensacola and Carrabelle.

A series of four males and six females, in addition to the type and allotype, bearing the same data, are designated paratypes. The entire series was taken between August 28 and September 2, 1915 by Rehn and Hebard.

The species is peculiar to very sandy areas; at Big Bayou it was found occasional in a bushy low sand-loving plant, at Pensacola very scarce among the undergrowth of scant grasses and sand-loving plants in forest of long-leaf and small sand pines. At Carrabelle very few were taken through the low bushes of the sand dune areas, which are covered heavily with arenicolous shrubs and bushes and some scrubby pine and oaks. Only with particular effort was it possible to secure the series. Heavy beating was found to be the most productive method.

Hesperotettix osceola ${ }^{19}$ new species (Plate VIII, fig. 16.)

This species is closely related to H. gemmicula, here described, but is readily separated by the very abbreviate tegmina which in length average near that of the pronotum. Additional features of difference are: the normally narrower dark marking of the lateral lobes of the pronotum, with white marginal marking ventrad usually not reduced and the unicolorous dorsal surfaces of the caudal femora.

${ }^{19}$ War chief of the Seminole Indians in Florida.

TRANS. AM. ENT. SOC., XLIV. 
The similarity in general type of color pattern, particularly that of the tegmina, shows the affinity of these species and distinguishes them from the other species of the Pratensis Group.

Type.- $\sigma^{7}$; Ocala, Marion County, Florida. September 19, 1917. (Rehn.) [Hebard Collection, Type No. 482.]

Agrees with the type of gemmicula except in the following features. Size (averaging in series) larger; form slender, slightly"more robust than in gemmicula. Dark bar of prozonal portion of lateral lobes of pronotum narrow and solid in coloration, the ventral border of this bar white (as broad in the type, twice as broad or slightly more than twice as broad as the bar in the other specimens). Tegmina greatly reduced, appreciably shorter than pronotum (varying in series to very slightly longer than pronotum), slightly overlapping; form broad ovate, the dorsal field being distinctly defined from the lateral field. Tegmina distinctively colored, as in gemmicula; dorsal and lateral fields green except for a rather broad longitudinal humeral band of pink, the dorsal portion of this band in the lateral field darkened. Genitalia as in gemmicula, except that the cerci in the narrow distal portion have their margins feebly convex. ${ }^{20}$ Caudal femora green, the pregenicular pinkish annulus broad and distinct, no transverse bands occur on dorsal surface as in gemmicula, or pink suffusion on external face and external margin of dorsal surface as in $H$. brevipennis (Thomas).

\section{Allotype.- $\%$; taken in coitu with type. [Hebard Collection.]}

Agrees with type except in the following features. Size much larger, form more robust. Diagnostic features of coloration as given for the male, except that the medio-longitudinal dorsal stripe of the pronotum is decidedly broader, pale, with very dark margins and is continued on the abdomen to near its apex. Ovipositor valves normal for the genus.

\begin{tabular}{|c|c|c|c|c|c|c|c|}
\hline & & suremer & its (in mi & illimeters) & & & \\
\hline & $0^{\pi}$ & $\begin{array}{l}\text { Length } \\
\text { of } \\
\text { body }\end{array}$ & $\begin{array}{l}\text { Length } \\
\text { of } \\
\text { pronotum }\end{array}$ & $\begin{array}{l}\text { Width } \\
\text { of } \\
\text { pronotum }\end{array}$ & $\begin{array}{l}\text { Length } \\
\text { of } \\
\text { tegmen }\end{array}$ & $\begin{array}{l}\text { Width } \\
\text { of } \\
\text { tegmen }\end{array}$ & $\begin{array}{l}\text { Length } \\
\text { of caudal } \\
\text { femur }\end{array}$ \\
\hline Type. & & 18.5 & 4.7 & 2.4 & 4 & 2.3 & 11.7 \\
\hline Paratype. & & 16.1 & 4.2 & 2.2 & 3.8 & 2.3 & 11.7 \\
\hline & 우 & & & & & & \\
\hline Allotype. & & 24.5 & 5.7 & 3.3 & 4.7 & 3.1 & 14.3 \\
\hline Paratype. & & 24.2 & 5.7 & 3.3 & 5.8 & 3. & 15 \\
\hline De Leon $S_{p}$ & prings, Florida. & 21.4 & 5.1 & 3.1 & 4.8 & 2.9 & 13.2 \\
\hline
\end{tabular}

The coloration and color pattern of this insect shows no important differences from that of gemmicula. It is possible that this insect may eventually prove to be a geographic race of that

${ }^{20}$ In this genus, showing so little differentiation in the simple type of cerci, we believe that frequent slight individual variation will be found to occur and that such difference as here given may prove to be of very little diagnostic value. 
species, but we have no evidence of this as yet. We suggest this since a very similar condition in $H$. gillettei is clearly only of geographic racial value in that case, as treated below.

Specimens Examined: $6 ; 2$ males and 4 females.

FLORIDA: Ocala and De Leon Springs.

A male bearing the same data as the type and a female taken the following day by Hebard are designated paratypes. The series was taken between September 8 and 20, 1917 by Rehn and Hebard. The species was exceedingly scarce, very long search on-four days having been made to secure the six examples. It was evident that the date was very late for this species, as three of the specimens when taken had each lost one of the caudal limbs.

Like gemmicula the species was found peculiar to very sandy areas. At De Leon Springs one individual was beaten from a dwarf oak in a wide sand scrub area, the other from dwarf oaks, bay cedar and other bushes more than a mile distant in the sand scrub. At Ocala the four specimens were secured in sandy flatwoods by beating the undergrowth, which was composed of a leguminous plant and bunch grass.

Hesperotettix nevadensis termius ${ }^{21}$ new geographic race (Plate VIII, fig. 17.)

This geographic race is based on a condition showing greatly reduced tegmina and wings, developed over an apparently restricted area of the species' distribution. Comparable with this is Melanoplus occidentalis brevipennis Bruner. ${ }^{22}$ In both these species such a condition is constant over a certain area, elsewhere in their distribution never being found ${ }^{23}$; in the present species intermediates from the regions of intergradation with nevadensis gilletiei are at hand. ${ }^{24}$ It is possible that $H$. osceola, may prove to

${ }^{21}$ From $\tau^{\prime} \operatorname{\rho } \rho$ เos = last; as showing the highest specialization in this species.

${ }^{22}$ Described as flabellifer brevipennis. We find Melanoplus flabellifer Scudder to be an absolute synonym of Melanoplus occidentalis (Thomas).

${ }^{23}$ We would note that in the normally short-winged Melanoplus scudderi (Uhler) a long-winged condition is found,.though very rarely. In that species the structure of the tegmina shows that such a condition is wholly attributable to individual reversion to the primitive type, and should in no way receive nominal recognition.

${ }^{24}$ Without the large series at hand it would be impossible to determine the correct value of the features shown by the present material.

TRANS. AM. ENT. SOC., XLIV. 
be a similar race of $H$. gemmicula, both species here described, but we have no evidence as to this, and it is clear that $H$. floridensis Morse is similarly derived from a common stock with $H$. speciosus (Scudder), though still further specialized and no question of its specific validity now being possible.

The present species is a member of the Viridis Group, and $H$. gillettei Bruner represents another geographic race widely distributed over the central Rocky Mountain region.

We have discussed this question as to values of tegminal differentiation here, to show how absolutely essential it is to judge each case separately. Dogmatic treatment is utterly impossible.

Type.- $0^{7}$; Milford, Beaver County, Utah. Elevation 4900 feet. September 5, 1909. (Rehn and Hebard.) [Hebard Collection, Type No. 483.]

Agrees fully with the type of nevadensis gillettei except in the following characters. Size (averaging in series) smaller. Tegmina greatly reduced, slightly shorter than pronotum, slightly overlapping, somewhat truncate distad; tegminal form broad ovate, the dorsal field being distinctly defined from the lateral field.

The type is yellowish brown in general coloration, the color pattern is discussed below.

Allotype.- $\%$; same data as type. [Hebard Collection.]

This specimen agrees fully with the type except in the following features. Size larger. Tegmina broadly quadrato-ovate, due to the somewhat greater distal truncation; separated from each other by a brief interspace.

The allotype is brilliantly colored, with color pattern intensive as discussed below. General coloration dull green-yellow (a bright color).

Measurements (in millimeters)

\begin{tabular}{lccccc}
\multicolumn{1}{c}{$\sigma^{7}$} & $\begin{array}{c}\text { Length of } \\
\text { body }\end{array}$ & $\begin{array}{c}\text { Length of } \\
\text { pronotum }\end{array}$ & $\begin{array}{c}\text { Length of } \\
\text { tegmen }\end{array}$ & $\begin{array}{c}\text { Width of } \\
\text { tegmen }\end{array}$ & $\begin{array}{c}\text { Length of } \\
\text { caudal } \\
\text { femur }\end{array}$ \\
$\begin{array}{l}\text { Type. } \\
\text { Paratype. }\end{array}$ & 13.5 & 3.2 & 3.1 & 1.8 & 8.4 \\
$\begin{array}{l}\text { Caliente, Nevada } \\
\text { (4). }\end{array}$ & 13.8 & 3.6 & 3.1 & 1.8 & 8.2 \\
& $12.9-13$ & $3.1-3.2$ & $3.8-3$ & $1.5-1.7$ & $7.7-7.6$
\end{tabular}




\section{Measurements (in millimeters)-continued}

\begin{tabular}{|c|c|c|c|c|c|}
\hline 우 & $\begin{array}{l}\text { Length of } \\
\text { body }\end{array}$ & $\begin{array}{l}\text { Length of } \\
\text { pronotum }\end{array}$ & $\begin{array}{l}\text { Length of } \\
\text { tegmen }\end{array}$ & $\begin{array}{l}\text { Width of } \\
\text { tegmen }\end{array}$ & $\begin{array}{l}\text { Length of } \\
\text { caudal } \\
\text { femur }\end{array}$ \\
\hline Allotype. & 19.7 & 4.3 & 3.7 & 2.2 & 9.7 \\
\hline $\begin{array}{l}\text { Paratypes (5). } \\
\text { Crestline, Nevada }\end{array}$ & $17.1-20.4$ & $3.9-4.5$ & $3.1-4.5$ & $2-2.5$ & $9.4-10$ \\
\hline $\begin{array}{l}\text { (1). } \\
\text { aliente, Nevada }\end{array}$ & 19 & 4.1 & 3.3 & 2.1 & 9.8 \\
\hline (2) & 19.5 & $4.2-4.3$ & $5.4-5.9$ & 2.3 & $10.1-10.2$ \\
\hline
\end{tabular}

The Caliente series is atypical in having the tegmina lanceolate rather than truncate distad, these organs in the females being distinctly more elongate. This is clearly a slight divergence toward the condition of the typical race.

Several specimens of nevadensis gillectei from Tintic, Utah, on the other hand, show divergence toward the present race in having the tegmina reduced, decidedly variable in the series, proving that locality to be in the area of intergradation. ${ }^{25}$

Coloration.-A brilliant green and a yellowish brown phase of coloration are found in nevadensis termius. In the most vividly green individuals the color pattern shows its maximum intensification. The head has two postocular and one subocular whitish line on each side, the more dorsal of the postocular bars margining the eyes in the occipital region, which region also has a pale mediolongitudinal suffusion. The pale medio-longitudinal band of the pronotum is conspicuous, dark margined, and so continued to near the abdominal apex. The pronotal lateral lobes have a pale band above and below the dark marking. The tegmina are green, dark along the costal margin, with a weakly defined pale line above this and another near the sutural margin. The caudal femora have the pregenicular pink annulus decided, the dorsal surface pale and (normally) with two slightly darker transverse bands weakly defined, ${ }^{26}$ the external face rather dark green with a narrow pale ventral border of the same greenish yellow as the ventral surface.

In the remaining specimens this type of coloration is found, but the markings are variously less striking and blurred. Comparison with series of nevadensis gillette $i$ shows the coloration of that race to be very similar, specimens nearly identical with each individual here examined being obtainable. In that race, however, the large majority are of a rich brown color phase with color pattern intensive, and nearly all have the dorsal marginal band of the lateral lobes of the pronotum hroader and extending over the lateral portions of the pronotal disk.

${ }^{25}$ One specimen has fully caudate tegmina, a condition not shown in any other example of the considerable series of nevadensis before us.

${ }^{26}$ In nevadensis nevadensis these bands are normally strongly defined, in nevadensis gillettei they are normally obsolete.

TRANS. AM. ENT. SOC., XLIV. 
Specimens Examined: 15; 6 males and 9 females.

UтAн: Milford.

Nevada: Crestline and Caliente in Lincoln County (material from the latter locality somewhat atypical).

A series from Milford, of one male taken September 18, 1908, by J. C. Bradley and five females bearing the same data as the type and allotype, are designated paratypes. All but the specimen referred to above were taken by Rehn and Hebard between September 3 and 5, 1909.

The species was found very scarce in weedy areas of valley bottoms at Milford and Caliente, particularly in a yellow-flowered, feathery, green plant of the daisy family, growing solidly waisthigh over large areas. Every effort was made to secure a good representation, the material being obtained by long and continuous beating. Earlier in the season the insect is probably more numerous.

\section{ARGIACRIS ${ }^{27}$ new genus}

This monotypic genus is placed after Asemoplus and before Bradynotes in linear arrangement. In general appearance closest resemblance is found to Bradynotes, but from that genus it is readily separated by the pronotum which has the disk distinct from the lateral lobes, but showing no acute marginal carina on each side and the caudal margin obtuse-angulate produced, by the presence of very broadly lanceolate tegmina, and, in the female, by the fully exposed ovipositor valves. In this last feature it agrees rather with Asemoplus. Though the produced caudal margin of the pronotum distinguishes this genus from the genera following Melanoplus, viz.-Dendrotettix, Podisma, Asemoplus and Bradynotes, the general character of its robust structure, broad vertex, small eyes and general character of male genitalia show that it belongs with these genera and not with Melanoplus and allied genera.

Genotype--Argiacris rehni new species.

Generic Characters.-Form very stout. Head as in Bradynotes. Interocular space wide; vertex blunt; eyes small, very much shorter than cheeks. Pronotum with disk rounding rather broadly into lateral lobes, caudal margin obtuse-angulate produced. Abbreviate but broad tegmina present. Male genitalia

${ }^{27}$ From á $\rho \gamma$ เós =slow and ảkpis=grasshopper. 
of general type found in Bradynotes, small furcula present as in two of the species of that genus. Female ovipositor valves fully exposed.

Argiacris rehni ${ }^{28}$ new species (Plate VIII, fig. 18.)

This distinctive insect is obscurely colored, except for the brilliant pink of the internal faces of the caudal femora ventrad and of the caudal tibiae.

Type.- $0^{\top}$; Livingston, Park County, Montana. Elevation, 5000 feet. July 29, 1909. (Rehn and Hebard.) [Hebard Collection, Type No. 480.]

Size large, form very robust. Head with interocular space half as wide as length of one of the eyes; eye small, moderately protuberant, three-quarters as long as cheek. Pronotum with disk moderately convex; medio-longitudinal carina weakly defined only on metazona; transverse sulci not deep; caudal margin broadly obtuse-angulate produced with apex broadly rounded. Tegmina very broadly lanceolate, considerably shorter than pronotum, sutural margins attingent proximad (in the series varying from slightly overlapping to separated by a brief interval), apices acute and sharply rounded. Furcula represented by two minute rectangulate projections with angles rounded, separated by a space slightly wider than one of these projections. Supra-anal plate simple, triangularly shield-shaped, lateral margins convergent and feebly convex to the rather acute apex; surface concave each side of the mediolongitudinal sulcus, which is bounded by rather decided lateral carinae to near the apex of the plate. Cercus simple, about two and one-half times as long as basal width, tapering decidedly in proximal half, distal half showing a moderate flexure dorsad, widening very feebly then very slightly and gradually narrowing to the broad, rounded apex. Subgenital plate of the general type usual in Bradynotes, but with an acute-conical projection meso-dorsad on the free margin. Prosternal spine short, heavy, acute-conical. Interspace between mesosternal lobes distinctly longer than least (proximal) width. Limbs robust.

\section{Allotype.- $\%$; same data as type. [Hebard Collection.]}

Similar to male except in the following features. Size larger, form more robust. Interocular space with width about two-thirds length of eye. Eye about three-fifths as long as cheek. Tegmina separated by a brief interval (width of this interval individually moderately variable). Ovipositor valves fully exposed. Prosternal spine very short and heavy, with apex acute and sharply rounded. Interspace between mesosternal lobes with length contained about one and one-third times in least width.

${ }^{28} \mathrm{In}$ honor of our friend and fellow-worker, Mr. James A. G. Rehn, for whom both personally and scientifically we have the highest regard.

TRANS. AM. ENT. SOC., XLIV. 


\begin{tabular}{|c|c|c|c|c|c|c|}
\hline \multicolumn{7}{|c|}{ Measurements (in millimeters) } \\
\hline$\sigma^{x}$ & $\begin{array}{l}\text { Length of } \\
\text { body }\end{array}$ & $\begin{array}{l}\text { Length of } \\
\text { pronotum }\end{array}$ & $\begin{array}{c}\text { Width of } \\
\text { disk of } \\
\text { pronotum }\end{array}$ & $\begin{array}{l}\text { Length of } \\
\text { tegmen }\end{array}$ & $\begin{array}{l}\text { Width of } \\
\text { tegmen }\end{array}$ & $\begin{array}{l}\text { Length of } \\
\text { caudal } \\
\text { femur }\end{array}$ \\
\hline Type. & 22.3 & 5.5 & 3.4 & 4.9 & 3.3 & 11.9 \\
\hline Paratypes & & & & & & \\
\hline (6). & $16.9-21.8$ & $5.2-5.4$ & $3.3-3.4$ & $4.8-5.3$ & $3.1-3.3$ & $11.2-11.8$ \\
\hline $\begin{array}{l}\text { Allotype. } \\
\text { Paratypes }\end{array}$ & 27.4 & 6.3 & 4.6 & 5.4 & 4 & 12.3 \\
\hline (2). & $28.7-29.4$ & $6.3-6.2$ & $4.7-4.8$ & $6-5.8$ & $3.8-3.9$ & $12.1-12.2$ \\
\hline
\end{tabular}

General coloration snuff brown; paler on face, there buffy, darker on occiput and dorsum of pronotum, there tinged with sepia. Eyes verona brown. Antennae mikado brown. Underparts clay color. Caudal femora with two broad transverse blackish bands on dorsal surface, the first continued on the external face and running obliquely proximad half way across, the more distal crossing the external face vertically, there broader but more obscure. Caudal tibiae and ventral face of femora brilliant jasper red.

Little color variation is shown by the series, in the paler examples the general color is slightly lighter and the transverse dark bands of the dorsal surfaces of the caudal femora are not continued on the external faces.

In addition to the type and allotype, a series of six males and two females, bearing the same data, are designated paratypes.

This series was captured on the ridge of a slope of a bare hogback showing numerous cherty exposures. The ground there showed rather scant vegetation with tufts of a peculiar woolly plant all about. Careful and intensive collecting was necessary to secure the ten specimens, apparently members of a single colony, taken over a very restricted area. 


\section{Explanation of Plate VIII}

Fig. 1.-Gymnoscirtetes pusillus Scudder. Supra-anal plate of male (type) Jacksonville, Florida. $(\times 21)$

Fig. 2.-Gymnoscirtetes pusillus Scudder. Outline of cercus of male (type) Jacksonville, Florida. ( $\times 32)$

Fig. 3.-Gymnoscirtetes pusillus Scudder. Caudal view of subgenital plate of male (type). Jacksonville, Florida. $(\times 21)$

Fig. 4.-Gymnoscirtetes morsei new species. Supra-anal plate of male (typc). $(\times 21)$

Fig. 5.-Gymnoscirtetes morsei new species. Outline of cercus of male (type). $(\times 32)$

Fig. 6.-Gymnoscirtetes morsei new species. Caudal view of subgenital plate of male (type). (X21)

Fig. 7.-Phaulotettix eurycercus new species. Cercus of male (type). ( $\times 25)$

Fig. 8.-Phaulotettix eurycercus new species. Caudal view of subgenital plate of male (type). (X12)

Fig. 9.-Phaulotettix compressus Scudder. Outline of cercus of male. Uvalde, Texas. $(\times 25)$

Fig. 10.-Chloroplus cactocaetes new genus and species. Cercus of male (type). $(\times 22)$

Fig. 11.-Paraidemona latifurcula new species. Dorsal view of supra-anal plate and preceding segment of male (type). $(\times 15)$

Fig. 12.-Paraidemona fratercula new species. Dorsal view of supra-anal plate and preceding segment of male (type). ( $\times 15)$

Fig. 13.-Eotettix davisi new species. Outline of cercus of male (type). ( $(\times 25)$

Fig. 14.-Eotettix quercicola new species. Outline of cercus of male (type). $(\times 25)$

Fig. 15.-Hesperotettix gemmicula new species. Dorsal view of caudal femur of male (type). ( $\quad \times 3)$

Fig. 16.-Hesperotettix osceola new species. Dorsal view of tegmen, seen from directly above, in normal position. Paratype. $(\times 6)$

Fig. 17.-Hesperotettix nevadensis termius new race. Dorsal view of tegmen, seen from directly above, in normal position. Paratype. $(\times 6)$

Fig. 18.-Argiacris rehni new genus and species. Dorsal view of male (type). $\left(\times 2 \frac{1}{2}\right)$

TRANS. AM. ENT. SOC., XLIV. 

Trans. Am. Ent. Soc., Vol. XLIV.
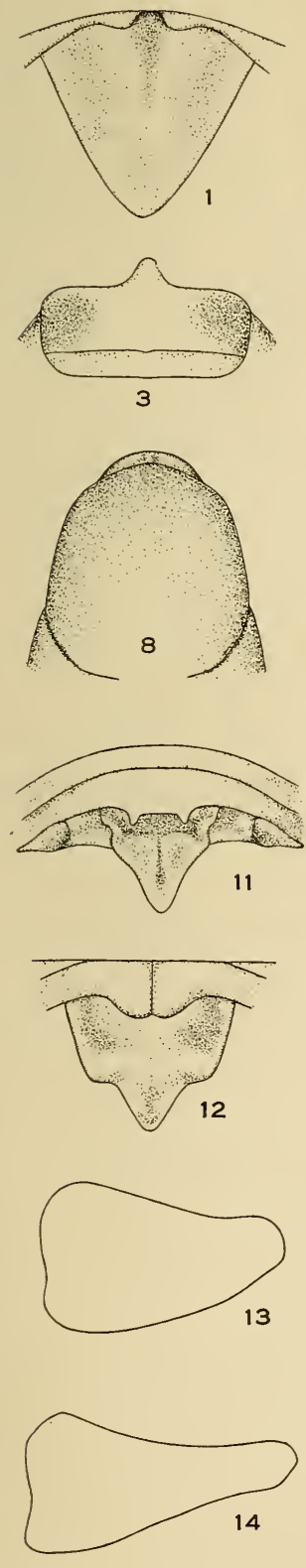

Pl. VIII
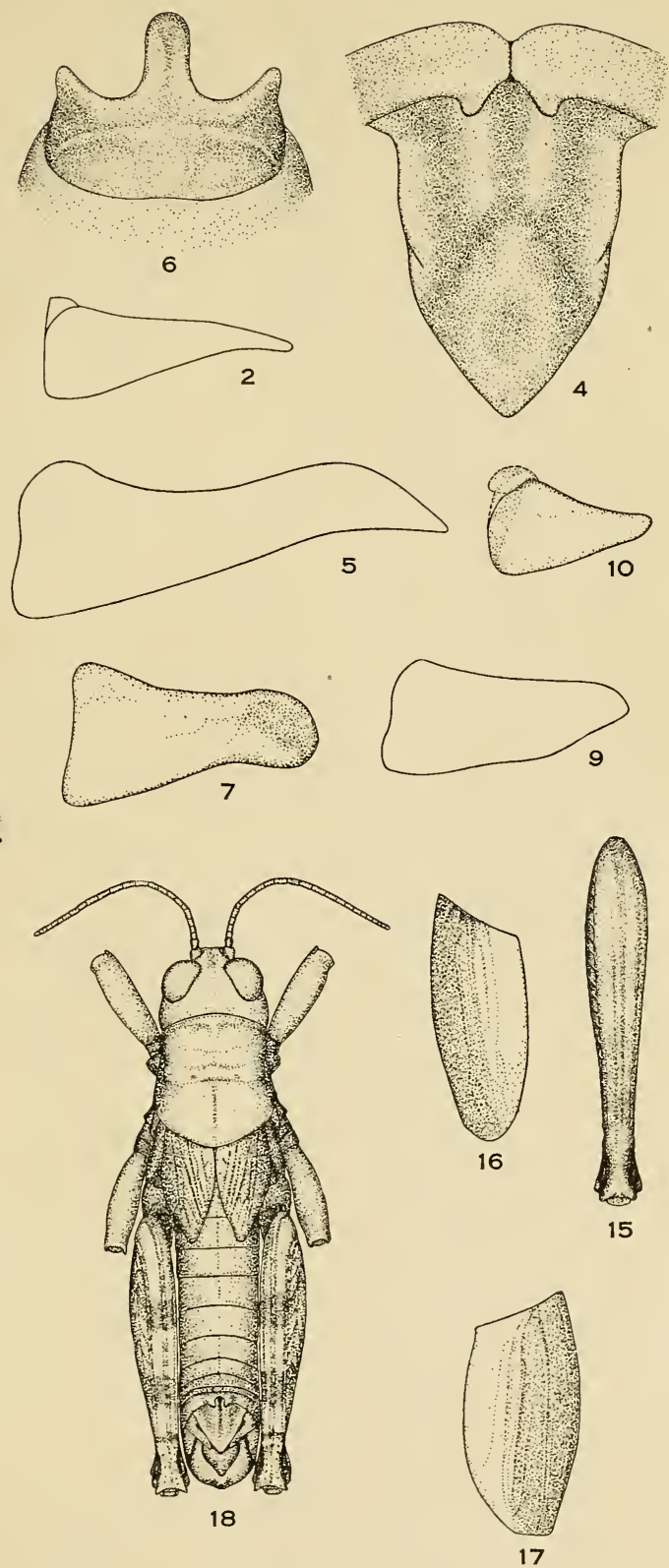

HEBARD—NEW NORTH AMERICAN MELANOPLI 





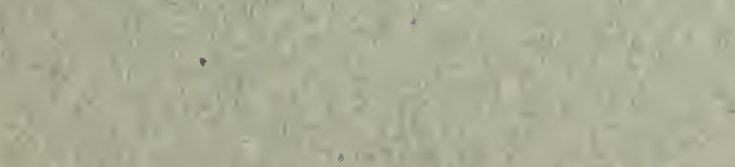







\section{NEW GENERA AND SPECIES}

$\mathrm{OF}$

\section{MELANOPLI}

FOUND WITHIN THE UNITED STATES

(ORTHOPTERA; ACRIDIDAE)

$$
\text { Part II }
$$

by

\section{Morgan Hebard}

From the Transactions of The American Entomological Society, xlv, 257-298

No. 792

\section{Issued SEP $25 \%$}

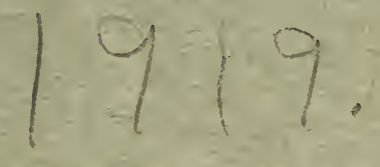





\title{
NEW GENERA AND SPECIES OF MELANOPLI FOUND WITHIN THE UNITED STATES (ORTHOPTERA; ACRIDIDAE)
}

\author{
BY MORGAN HEBARD
}

\section{Part II}

This is the second of a series of papers on undescribed Melanopli found in the United States. It was originally intended to include in the first paper, published in June, $1918,{ }^{1}$ all of the new forms found in the Philadelphia Collections, except those of the genus Melanoplus, but active duty in the Army prevented completion of the work to that point. Two new genera, ten new species and one new geographic race were there described. In the present paper twelve new species and one new geographic race are described, carrying this work through the first group of the genus Melanoplus with two eastern species in addition.

As in the first paper, the sequence of species described is in accordance with the revised arrangement of the species, from the preliminary studies already completed for the North American Melanopli. ${ }^{2}$ Scudder's grouping of many of the forms has been found incorrect, and, particularly in the genus Melanoplus, his "Series" are in so many cases composed of widely separated species, that we have been obliged to institute a very different arrangement and have decided to rearrange the species into units which we have given "Group" designation. It should, therefore, be borne in mind that our Groups do not in any way correspond to Scudder's "Series."

\footnotetext{
1 Trans. Am. Ent. Soc., xliv, pp. 141 to 169.

${ }^{2}$ We would note that our monotypic genus Argiacris, described in our first paper, comes between Asemoplus and Bradynotes. This genus was there described, in order to be able to make known one of the most distinctive units found among the undescribed forms at hand. One of our statements concerning this genus is, in part, incorrect. It is not distinguished from Podisma by the produced caudal margin of the pronotum, for in Podisma, as in Melanoplus, some of the groups are comprised of species which have the caudal margin of the pronotum angulate produced, while others have it weakly emarginate to different degrees. 
A detailed discussion of the problems found in the genus Melanoplus will be given at a later date. For the present we would remark only one vital error in Scudder's treatment. That author's efforts were concentrated in an attempt to find some valid character to separate Melanoplus from Podisma. He determined the fact that the typical species of Melanoplus had a narrow mesosternal and metasternal interspace, while in typical species of Podisma these intervals were wider. Further study showed that this was not universal, but he considered it the most satisfactory feature for the generic assignment of species, and separated Melanoplus from Podisma thereby in his key.

After careful study of the situation, we have found that the width of the mesosternal and metasternal interspaces is subject to such individual variation that it is frequently of no diagnostic value, even for specific separation. In addition, we note that the forms of the Melanopli developed in a temperate environment have in the great majority of cases the mesosternal and metasternal interspaces narrow, while those developed in an arctic or arctic alpine environment have these interspaces usually broad. As a result, we find that arctic or arctic alpine species of Melanoplus have the mesosternal and metasternal interspaces fully as broad as in the species of Podisma, the majority of the species of which genus are found in arctic or arctic alpine regions. We are unable to find a single diagnostic feature to separate these genera. That Melanoplus and Podisma represent two distinct units is clear. In each case the genus divides into numerous sections, many of which are readily separable from the others by distinctive features. In fact we again find a situation much resembling that which occurs in the Tettigoniid genera Conocephalus and Orchelimum, and of which Rehn and Hebard have said, "Material of the two genera is easily separated by a decidedly different general appearance, but when the characters of the two are compared, the variation in each genus leaves us unable to state a single absolute difference."

As a result of Scudder's misconception of the significance of the widening of the mesosternal and metasternal interspaces, that author assigned to Podisma the following species, all of which are clearly members of the genus Melanoplus: nubicola Scudder, stupefacta Scudder, dodgei (Thomas), ascensor Scudder, 
marshallii (Thomas), oregonensis (Thomas) and frigida (Boheman). Puschnig has more recently described still another European species of Melanoplus as a Podisma, this being prossenii from the Eisenhut in Carinthia.

We would remark that, as a result of the above assignments, all of the North American species remaining in the genus Podisma have the caudal margin of the pronotum concave and entirely lack organs of flight. To the genotype of Podisma, which is pedestris (Linnaeus), three North American species of Asemoplus, hispidus (Bruner), somesi here described and rainierensis Caudell, show a strong general similarity, but, in our opinion, represent a section of another valid unit. This unit, however, is almost as difficult to define as those discussed above.

In the preparation of the present paper we have met with most kind and hearty cooperation from many of our fellow workers. We are particularly indebted to Dr. E. M. Walker of the University of Toronto, Mr. Wm. T. Davis of New York and Mr. M. P. Somes, now of Kalispell, Montana. These gentlemen have furnished material which has increased the number of undescribed forms studied and has assisted in important comparative studies.

It must also be remembered that very large series are now assembled for a study of the North American Melanopli, and that these have proved invaluable in preparing the present series of preliminary papers. Without the opportunity to study these series, we would not be able to handle the problems involved with anything like the assurance we now consider ourselves justified in feeling. For the opportunity to study very important sections of these series we are deeply indebted to Mr. James A. G. Rehn of the Academy of Natural Sciences of Philadelphia, Dr. Samuel Henshaw of the Museum of Comparative Zoology and Mr. A. N. Caudell of the United States National Museum. In the present paper one thousand and forty-three specimens are recorded, one thousand and eleven of these belonging to the Philadelphia Collections.

TRANS. AM. ENT. SOC., XLV. 
Hesperotettix pacificus capillatus ${ }^{3}$ new geographic race (Plate XXIX, fig. 1.)

1897. Hesperotettix pacificus Scudder, Proc. U. S. Nat. Mus., xx, p. 61. (In part.) [\%; San Buenaventura, California. $]^{4}$

The present geographic race and pacificus pacificus Scudder, both show considerable size, tegminal and color variation. Considering the fact that, as is usual in the present genus, the male genitalia show no differential characters, the characterization of these races is difficult. The series at hand, however, offer such convincing proof that separation must be made, that we feel no hesitancy in describing the present race.

This race is clearly a depauperate condition of the species and will probably be found locally distributed along the Californian coast, from Monterey Bay southward to the Santa Barbara Channel. The size averages smaller, the surface is not as smooth and the hairy covering is generally more pronounced, the antennae average distinctly shorter and the caudal femora are slightly less enlarged proximad, than in pacificus pacificus.

Both races develop a green, pale brown and dark brown color form. In the green condition of the present race no broad reddish annuli of the cephalic and median femora and broad pregenicular reddish annulus of the caudal femora are found, which markings are usually met with in this phase of typical pacificus, and pacificus capillatus, further, is normally much less brilliantly colored. In both green and brown phases this race usually has the characteristic buffy markings less conspicuous and reduced to a greater extent than is usual in pacificus pacificus.

Type.- $\sigma^{T}$; Del Monte, Monterey County, California. September 9 and 10,1910. (Rehn and Hebard.) [Hebard Collection, Type no. 484.]

Size small for the genus, form slender, surface well supplied with minute pilose hairs, more thickly than is normal in pacificus pacificus. Eyes appreciably deeper than infra-ocular portion of the genae. Sulcation of the fastigium and frontal costa moderately decided, slightly more pronounced than in pacificus pacificus. Antennae short and stout for the genus, little longer than combined length of head and pronotum, shorter and stouter than in pacificus

${ }^{3}$ In allusion to the normally more hairy condition found in this race, when compared with the typical race of the species.

${ }^{4}$ An additional female from Scudder's series, in the Hebard Collection, labelled in pencil "Los Angeles, Cal. 1888," is referable to the present race. In this case, we believe the labelling to be incorrect, or inaccurate. 
pacificus. Caudal margin of disk of pronotum obtuse-angulate produced, with immediate angle rather sharply rounded. Tegmina small elongate-oval pads, costal margin curving distad more sharply than sutural margin, forming an acute point directed dorso-caudad. ${ }^{5}$ Genitalia showing no features of difference from pacificus pacificus. Caudal femora moderately enlarging proximad, appreciably less robust there than in pacificus pacificus.

\section{Allotype.- o ; same data as type. [Hebard Collection.]}

Differs from the type in the following features. Size larger, form moderately stout for the genus. Sulcation of the fastigium and frontal costa weaker and broader. Antennae even shorter, distinctly shorter than the combined length of the head and pronotum, distinctly shorter and stouter than in this sex of pacificus pacificus. Caudal margin of pronotum forming a more obtuse angulation. Genitalia as in this sex of pacificus pacificus.

\section{Measurements (in millimeters) of extremes only}

\begin{tabular}{|c|c|c|c|c|c|c|}
\hline$\sigma^{\pi}$ & $\begin{array}{l}\text { Length of } \\
\text { body }\end{array}$ & $\begin{array}{l}\text { Length of } \\
\text { antenna }\end{array}$ & $\begin{array}{l}\text { Length of } \\
\text { pronotum }\end{array}$ & $\begin{array}{l}\text { Length of } \\
\text { tegmen }\end{array}$ & $\begin{array}{l}\text { Width of } \\
\text { tegmen }\end{array}$ & $\begin{array}{l}\text { Length of } \\
\text { caudal femur }\end{array}$ \\
\hline ype & 15.3 & 6.4 & 4.1 & 2.9 & 1.8 & 9.4 \\
\hline $\begin{array}{c}\text { aratypes (53) } \\
\text { o }\end{array}$ & $13.5-1$ & $5.8-6.8$ & $3.5-4$ & $2.5-3.2$ & $1.2-1.7$ & $8.2-9.5$ \\
\hline . & 19 & & 5 & & 2 & 10 . \\
\hline aratypes ( & $18-20.3$ & $5.2-5.7$ & $4.4-5$ & $2.7-3.9$ & $1.7-2$ & $10-10.8$ \\
\hline
\end{tabular}

The female from San Buenaventura shows divergence toward pacificus pacificus only in having the caudal femora slightly heavier than is normal in the present race.

A single male of pacificus pacificus from Marcel, Kern County, California, shows some divergence toward the present race in the somewhat narrower tegmina and caudal femora, but in all other respects is typical.

Coloration.-Dark brown, lighter brown and yellowish green phases of coloration are found in pacificus capillatus. All of the males are brown and only a few show some recession in coloration; eleven of the nineteen females are brown, of the same shade as the paler males. In this phase the narrow buffy medio-longitudinal dorsal line and narrow bar or bars ${ }^{6}$ of the postocular portion of the genae and prozonal portion of the lateral lobes of the pronotum are distinct but not conspicuous. The external faces of the caudal femora are suffused proximad, mesad and in the pre-genicular area with dark brown, this sometimes greatly reduced, but in the majority distinct, the median and distal suffusions running across the dorsal surface as broad and distinct transverse bands.

${ }^{5}$ This feature varies individually in degree, but the entire series shows smaller and narrower tegmina, with apices less evenly rounded, than is shown in the considerable series of pacificus pacificus at hand.

${ }^{6}$ This is an individually variable feature. In the majority of specimens a narrow bar of buff is found below the broad dark bar of the prozonal portion of the lateral lobes of the pronotum. In others a trace of buff is shown also above the dark bar, and in some this is developed into a second bar of buff, as wide as or even wider than the ventral buff bar.

TRANS. AM. ENT. SOC., XLV. 
In the females the medio-longitudinal buffy line is broader, and in yellowishgreen individuals is often conspicuously margined with brown, which is most decided on the abdomen. In this phase the buffy lateral markings are sometimes greatly reduced or wholly obsolete, as is also the dark band of the prozonal portion of the lateral lobes. In the paler brown examples the caudal femora have the darker suffusions reduced, the dorsal surface unicolorous; in the yellowish green individuals these suffusions usually disappear, rarely being weakly indicated, the dorsal surface washed with pale brown. No trace of pink pre-genicular annuli is found in the present series.

The slightly rougher surface and more numerous hairs of the majority of examples of the present race, gives the series less of the smooth and shining facies of the series of pacificus pacificus at hand.

Specimens Examined: 74; 54 males and 20 females.

California: Del Monte and San Buenaventura.

With one exception, these specimens were taken at Del Monte by Hebard on August 20, 1909, and by Rehn and Hebard on September 9 and 10, 1910, and, excluding the type and allotype, are designated as paratypes. The female, recorded by Scudder from San Buenaventura, belongs to the United States National Museum.

At Del Monte this insect was found scarce on the shore side of the sand dunes, in low scattered grasses and bushes, where a low yellow-flowered "tar-weed" was conspicuous. In this situation more individuals were met with than elsewhere, particularly in the sand-loving Composite bush, Chrysoma ericoides (Less.). This race was also present, but scarce, in extensive open areas of short dry grass, where also much of the low yellow-flowered "tar-weed" was found. Orthoptera was present in great numbers in these areas, much the most abundant species being Melanoplus microtatus, here described, while Melanoplus devastator Scudder was very numerous and the species here described as Oedaleonotus phryneicus and fratercula were frequently encountered.

\section{AEOLOPLUS Scudder}

1897. Aeoloplus Scudder, Proc. Am. Acad. Arts and Sciences, xxxii, p. 199. 1897. Aeoloplus Scudder, Proc. U. S. Nat. Mus., xx, p. 68.

1916. Aeoloplides Caudell, Proc. U. S. Nat. Mus., xlix, p. 28.

The above synonymy is the result of Caudell's misinterpretation of the original type designation. The type of the genus is not "Caloptenus regalis by original designation," as stated by that author. Scudder gives Aeoloplus regalis as type, without 
further citation of author. This species is Aeoloplus regalis of Scudder and not Caloptenus regalis of Dodge. ${ }^{*}$ Scudder had a species of Aeoloplus, which he described and referred to regalis of Dodge, but with uncertainty, as his comments on page 73 show. Had Scudder given Aeoloplus regalis Dodge as genotype, Caudell's action would have been correct; but it is the species described by Scudder, not Dodge's species, which Scudder designated as genotype. It has been ascertained that Caloptenus regalis Dodge is a member of the genus Melanoplus; Aeoloplus regalis Scudder has been correctly renamed by Caudell, ${ }^{7}$ and now stands as Aeoloplus bruneri Caudell, type of the genus Aeoloplus.

Aeoloplus eremiaphila ${ }^{8}$ new species (Plate XXIX, figs. 2 and 3.)

The present species is the smallest known representative of the genus. The tegmina vary from ovate, but attingent, to a half fully-developed condition. The caudal femora do not have the margin of the ventral surface produced proximad in a shielding plate. In position we would place this insect after $A$. chenopodii (Bruner) and before $A$. turnbulli (Thomas), to the latter of which species it shows nearest relationship.

Comparing series including the types of chenopodii and eremiaphila, the former species is found to be larger and slightly heavier in structure, with vertex slightly broader, eye not as large in relative proportion, in length only slightly exceeding the genae, caudal margin of pronotum much more truncate, tegmina ovate and lateral, never attingent, subapical tubercle of male subgenital plate less acute, and coloration and color pattern distinctive.

Compared with a series of the more closely related turnbulli, that species is found to differ in its larger size, slightly more produced vertex, distinctly smaller eye in relative proportion, which in length is about equal to or slightly less than that of the genae, less definitely atrophied tegmina and wings even in the condition of maximum reduction, presence of a green as well as a brown color phase and coloration and color pattern distinctive.

Type.- $\sigma^{7}$; Foothills of Singatse Range at Mason, Lyon County, Nevada. Elevation, 4600 feet. September 6, 1910. (Rehn and Hebard.) [Hebard Collection, Type no. 485.]

Size very small for the genus; form moderately robust, medium for the genus. Fastigium of vertex very blunt, very slightly produced; eyes prominent, in

${ }^{7}$ Proc. Ent. Soc. Wash., viii, p. 134, (1907).

${ }^{8}$ From '́ $\rho \eta \mu i a$ and $\phi i \lambda \eta$, a lover of the desert.

TRANS. AM. ENT. SOC., XLV. 
length considerably greater than the genae. Pronotum with transverse sulci apparent but not pronounced, those cephalad feeble; medio-longitudinal carina of metazona distinct; caudal margin obtuse-angulate produced with apex rounded. Tegmina small, sub-ovate, attingent pads, about as long as pronotum, ${ }^{9}$ with apices rather sharply rounded. Cerci simple, moderately broad and compressed at base, tapering slightly and evenly in proximal half, the distal half very slender, nearly subequal in width to the rounded apex. Subapical tubercle of subgenital plate decided, its apex as slender and sharply rounded as the cercal apices. Cephalic and median femora almost straight and moderately heavy, not as much bowed or as heavy as in this sex of the majority of the species of Aeoloplus. ${ }^{10}$ Median tibiae scarcely at all curved. Caudal femora without margin of ventral surface produced proximad in a shielding plate.

\section{Allotype.- - ; same data as type. [Hebard Collection.]}

Agrees with the type in ambisexual features, differing in the following respects. Size slightly larger, ${ }^{11}$ form appreciably heavier. Fastigium of vertex broader. Ovipositor valves with apices moderately elongate and gently curved. Cephalic and median femora longer and more slender. Median tibiae straight.

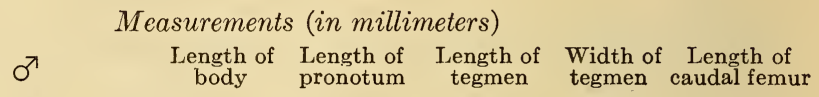

Singatse Range, Mason, Ne-

vada, type...............
Singatse Range, Mason, Nevada, paratype..........

Singatse Range, Mason, Nevada, paratype..........

운 12

$\begin{array}{lllll}12.1 & 3 & 3.6 & 2 & 6.8\end{array}$

$\begin{array}{lllll}12.4 & 3.3 & 4.7 & 2.1 & 7\end{array}$

Singatse Range, Mason, Nevada, allotype............

Singatse Range, Mason, Nevada, paratype.........

Mina, Nevada . . . . . . . . . 16.5 14.3 3.3 2 7.7

Mina, Nevada ........... . 15.5

\section{6}

3.3

2 7.8

Mina, Nevada........... 16.3

3.4

5.8

2.1

6

3.9

6.2

Pilot Mountains, Nevada . . 15

Pilot Mountains, Nevada . . . 16.2

3.6

5.9

2.2

2.3

3.5

5.6

2.2

2

5.9

2.2

6.9

Pilot Mountains, Nevada ...

16.5

3.8 8

${ }^{9}$ The tegmina vary in the present species from this type to a half fullydeveloped condition. Though clearly largely individual, geographic distribution may prove to have some effect on this feature. See table of measurements.

${ }^{10}$ Examination of the material at hand shows these to be secondary sexual features, as is the curvature of the median tibiae, differing in degree of development in the male sex of different species of the genus.

11 The majority of females at hand are distinctly larger than the type. 
In the examples having the longest tegmina, these organs are decidedly attenuate in their distal two-fifths, due to the fact that the costal and sutural margins show a very strong convergence in the third fifth of the tegmen.

In the condition of maximum tegminal reduction, the wings are minute and greatly atrophied. From this condition, they develop to fully as long as the tegmina in the condition of maximum tegminal development.

Coloration.-Type. Head cinnamon-buff, microscopically flecked with blackish brown; this increasing on the vertex and occiput, there forming an inconspicuous longitudinal band. Eyes clay color, microscopically marked with a network of blackish brown. Antennae pinkish cinnamon. Pronotum and tegmina sayal brown, with microscopic flecks and longitudinal streaks of bister; prozona showing an indistinct medio-longitudinal band of blackish brown, but with median carina sayal brown; lateral lobes with a longitudinal blackish suffusion dorsad before the principal sulcus. Cephalic limbs and underparts cinnamon-buff; median limbs of the same coloration but flecked with blackish brown. Caudal femora cinnamon-buff, with the three dark areas, characteristic of the species of the genus, heavy and blackish brown. Abdomen cinnamon-buff with proximal segments blackish brown proximad.

Little color variation is shown by the present series. A few individuals are somewhat recessive in coloration and in these the general coloration is clay color, with all darker markings reduced, the pronotal markings and those of the caudal femora weak and poorly defined. One such example from the Pilot Mountains has the caudal femoral markings obsolete.

Specimens Examined: 11; 3 males and 8 females.

Nevada: Foothills of Singatse Range at Mason, Mina and Pilot Mountains, three miles east of Mina.

The series examined, in addition to the type and allotype, are considered paratypes. All were taken by Rehn and Hebard.

The desert valley at Mina, 4800 to 5300 feet in elevation, with long and very gradual alluvial slopes running down into a large central playa, proved an area of scarce insect life. But, from the several species of dense and heavily thorned, leafless bushes on the slopes, three specimens of this species were secured after long and careful search. On the same day, three miles distant in the sterile and desert Pilot Mountains, three more specimens were taken. These were found in similar thorn bushes, scattered over the almost bare slopes at the foot of precipices and at the heads of cañons, at 5500 to 5700 feet. Great numbers of these bushes were examined, the only Orthoptera there found being the few specimens of the present species, Ligurotettix coquillettei McNeill in moderate numbers, and a single specimen of a Decticid which has as yet not been studied.

Two days later at Mason, in a generally similar area and from similar but heavier thorn bushes, five more individuals were.

TRANS. AM. ENT. SOC., XLV. 
secured, at elevations from 4500 to 5200 feet in the foothills of the Singatse Range. The most successful method of capturing these specimens was to tramp down the brittle thorn bushes, in which case individuals of Ligurotettix coquillettei McNeill would fly swiftly to other adjacent bushes, but those of the present species would appear confused and could be taken by exercising reasonable caution. When this method was not followed, these little insects were found to slip about in the dense twigs and thorns with great agility and would occasionally disappear, leaving the pursuer baffled, with hands usually well scratched.

\section{OEDALEONOTUS Scudder}

1897. Oedaleonotus Scudder, Proc. Am. Acad. Arts and Sciences, xxxii, p. 203. 1897. Oedaleonotus Scudder, Proc. U. S. Nat. Mus., xx, p. 390.

After careful consideration we find that the present genus, in addition to the species referred to it by Scudder, properly includes all the species which that author assigned to the Borckii Series of the genus Melanoplus, with the exception of Melanoplus scitulus Scudder.

The genus Oedaleonotus will be fully discussed at a later date. This rearrangement is noted here only in order to explain the generic assignment of the following new species.

Oedaleonotus phryneicus ${ }^{12}$ new species (Plate XXIX, figs. 5 and 6.) 1908. Melanoplus tenuipennis Caudell (not of Scudder, 1897), Proc. U. S. Nat. Mus., xxxiv, p. 78. [Guadalupe, California.]

Closely related to O. tenuipennis (Scudder), (see plate XXIX, fig. 7), which species differs from phryneicus in the average lighter build, particularly in the females, decidedly weaker and less irregular median and lateral carinae of the pronotum, less decidedly inflated prozona, less decided pronotal sulci and in particular the less decided channel of the first sulcus dorsad on the lateral lobes, where its termination occurs, less decided expansion of the pronotal disk caudad, this more decided in females, and less heavily pitted metazona and corresponding portion of the lateral lobes.

Type.- $\sigma^{T}$; Del Monte, Monterey County, California. August 20, 1909. (M. Hebard.) [Hebard Collection, Type no. 486.]

Size medium for the genus, form moderately robust. Head much as in tenuipennis. Pronotum with median and lateral carinae and sulci decided; lateral carinae feebly concave and feebly expanding on the prozona, more

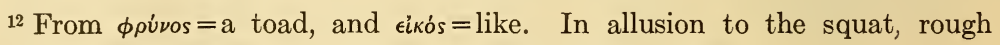
appearance, particularly of females of the present species. 
strongly expanding caudad on the metazona; channel of the first sulcus dorsad on the lateral lobes, where its termination occurs, brief but deep, margined caudad with a conspicuous fleck of pale coloration; prozona distinctly inflated; caudal margin of disk transverse, showing a feeble obtuse-angulate emargination mesad, the two halves thus formed feebly convex. Tegmina lateral oval pads, ${ }^{13}$ distinctly shorter than the pronotum, well separated. Genitalia as in tenuipennis. Longitudinal marginal carinae of the caudal femora pronounced.

\section{Allotype.- + ; same data as type. [Hebard Collection.]}

Similar to the male type except in the following features. Size decidedly larger, form very robust. All pronotal features intensified. The lateral carinae of the disk of the pronotum show microscopic pits, which give them an irregular roughened appearance; these carinae expand throughout their length, so that the caudal width of the pronotal disk is decidedly greater than the cephalic width, and very much more closely approximates the pronotal length than in this sex of tenuipennis. Tegmina ${ }^{14}$ separated by a greater interspace. Ovipositor valves as in tenuipennis.

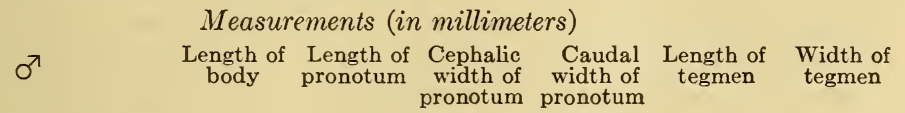

Del Monte, California,

type.............

Del Monte, California, paratype..........

Del Monte, California, paratype..........

Del Monte, California, paratype..........

Del Monte, California, paratype..........

우

$\begin{array}{llllll}16.5 & 4.1 & 2 & 3.1 & 2.8 & 1.8\end{array}$

$\begin{array}{llllll}15.5 & 3.9 & 1.9 & 3 & 3.2 & 1.8\end{array}$

$\begin{array}{lllllll}18.5 & 4.7 & 2.1 & 3.3 & 3.8 & 2\end{array}$

$\begin{array}{llllll}19.2 & 4.9 & 2 & 3.2 & 3.2 & 2.1\end{array}$

$\begin{array}{llllll}18 & 4.3 & 2 & 3.2 & 2.8 & 1.8\end{array}$

Del Monte, California, allotype..........

Del Monte, California, paratype $e^{15} \ldots \ldots \ldots$

Del Monte, California, paratype..........

Del Monte, California, paratype.........

Del Monte, California, paratype...........

Del Monte, California, $\begin{array}{lllllll}\text { paratype....... } 22.9 & 6.2 & 2.8 & 5.1 & 4 & 2.6\end{array}$

$\begin{array}{lllllll}\text { Monterey, California . } & 23 & 5.5 & 3.1 & 5.2 & 4 & 2.7\end{array}$

${ }^{13}$ Varying in the males from elongate oval to (rarely) broad oval. ${ }^{14}$ More variable in relative size and form than in males.

${ }^{15}$ In this specimen the pronotal proportions are as found in tenuipennis, but the individual is typical of phryneicus in all other respects.

TRANS. AM. ENT. SOC., XLV. 
The measurements give the extremes of the series. The specimen doubtfully recorded as tenuipennis by Scudder, from Monterey County, California, is an aberrant example of that species, showing no approach toward the present insect.

We would note that in this species, as well as in tenuipennis, the degree of expansion of the pronotum caudad is individually variable. The amount of expansion, however, in the present species averages very distinctly greater. The swelling of the cephalic portion of the pronotum also shows some individual variation, but the present species always shows this feature to some extent, and with its rugged structure and more strongly defined carinae is decidedly distinctive in appearance.

Coloration.-Type. Head ochraceous-tawny becoming darker, cinnamon brown, on the occiput, with a still darker, broad post-ocular bar of mummy brown on each side. Pronotum with disk appreciably darker than lateral lobes, cinnamon brown, with lateral carinae ochraceous-buff washed with tawny; lateral lobes ochraceous-buff washed with tawny, this heavier caudad, except on dorsal half of prozona which, not including the cephalic margin, is mummy brown with a conspicuous dorso-mesal fleck of ochraceous-buff where the channel of the first sulcus terminates. ${ }^{16}$ Tegmina and dorsal surface of abdomen cinnamon brown. Cephalic and median limbs internally pinkish buff, externally clay color with irregular flecks of blackish brown, these markings heaviest distad on cephalic femora and mesad on median femora. Caudal femora sayal brown; external face with a heavy proximal area of blackish brown, another mesad which is larger and very broadly V-shaped with apex mesocephalad, and another distad, the raised carinae bounding this face pale, clay color; dorsal surface sayal brown, its external half immaculate, the heavy median carina and internal half with three broad dark bands, which continue on the internal face, disappearing there mesad; ventral surface brilliant dragon's blood red, this color suffusing also the proximal portion of the internal face. Caudal tibiae deep bluish gray green, with a broad proximal annulus of cinnamon-buff; spines whitish, tipped with black. Ventral surface cinnamon-buff.

Only a moderate degree of intensification and recession is shown by the large series at hand, the general coloration ranging from bister, with paler portions sayal brown (intensive), to sayal brown, with paler portions clay color (recessive).

Specimens Examined: $187 ; 89$ males, 97 females, 1 gynandromorph. ${ }^{17}$

California: Del Monte, Monterey and Guadalupe.

${ }^{16}$ This fleck is a distinctive feature in the present species; with hardly any exceptions, being conspicuous in the large series before us. Hardly ever does this marking appear in tenuipennis, and when present is inconspicuous.

${ }^{17}$ This specimen is remarkable in having the entire sinistral portion from head to apex of abdomen male, the dextral portion female. As a result, due to the disparity of size in the sexes of this species, this specimen is asymmetrical throughout. This is the second gynandromorph examined by us, the first being a specimen of the Tettigoniid, Insara elegans consuetipes (Scudder) recorded by Rehn and Hebard, Trans. Am. Ent. Soc., xl, p. 81, (1914). 
A single male at hand, from the National Museum, was taken on sugar beets at Guadalupe, Santa Barbara County, on June 24, 1906, by A. N. Caudell. Excepting two males and four females from Monterey, captured by G. P. Englehardt on August 4, 1916, the remaining series was taken at Del Monte by Hebard on August 20, 1909, and by Rehn and Hebard on September 9 and 10, 1910; excepting the type and allotype, these are considered paratypes. On both occasions the species was found common, particularly in the extensive open areas of short dry grass, where a low yellow-flowered "tar-weed" was abundant..$^{18}$

Oedaleonotus fratercula new species (Plate XXIX, fig. 4)

This, the smallest species of the genus, is seen to be in some ways annectant between the other forms of the genus and the distinctive $O$. fuscipes (Scudder).

This insect agrees with fuscipes in general contour and appearance, and in the male sex in the absence of furcula and presence of an apical tubercle on the subgenital plate. It differs from that species in the smaller size, slightly less robust form, appreciable, though weak, lateral carinae of the pronotum and, in the male, in the supra-anal plate, which is unspecialized toward the cercal bases and the cerci, which are more slender distad.

Type.- $\sigma^{T}$; Del Monte, Monterey County, California. September 9 and 10, 1910. (Rehn and Hebard.) [Hebard Collection, Type no. 487.]

Size small, smallest of the genus; form medium, slender for the genus. Head very similar to that of fuscipes, eyes slightly longer than genae as in that species. Pronotum with lateral carinae weak; median carina well developed on metazona, moderately developed on proximal portion of prozona, subobsolete in intervening area; sulci moderately decided, the first the weakest; caudal margin of disk transverse, very feebly convex. Tegmina lateral, broadly oval pads, much shorter than pronotum, separated by a brief interspace. ${ }^{19}$ Furcula, absent. Supra-anal plate simple, elongate, triangular with margins gently convex and apex rounded, surface with a heavy and deep medio-longitudinal sulcation in proximal two-fifths, between the raised margins of this sulcation and the lateral margins it is broadly concave. Cerci proximad broad and moderately tumid, narrowing evenly in proximal three-fifths, distal two-fifths very narrow with apex rounded, ${ }^{20}$ this portion curving moderately inward. Subgenital plate with a large and moderately blunt apical tubercle.

\footnotetext{
${ }_{18}$ See notes under Hesperotettix pacificus capillatus on page 262.

${ }^{19}$ The tegmina are occasionally attingent in this sex.

${ }^{20}$ The width of the distal portion of the cerci is seen to be variable to a certain degree in the males of fratercula at hand.

TRANS. AM. ENT. SOC., XLV.
} 


\section{Allotype.- $\%$; same data as type. [Hebard Collection.]}

Similar to the male type except in the following features. Size decidedly larger; form robust, slenderest, however, for females of the species of Oedaleonotus. Pronotum similar, but with carinae and sulci all weaker. Tegmina very broad, sub-circular, ${ }^{21}$ separated by a very slightly greater interspace. Ovipositor valves normal for the genus.

\begin{tabular}{|c|c|c|c|c|c|c|}
\hline$\sigma^{\pi}$ & $\begin{array}{l}\text { Length of } \\
\text { body }\end{array}$ & $\begin{array}{l}\text { Length of } \\
\text { pronotum }\end{array}$ & $\begin{array}{c}\text { Caudal } \\
\text { width of } \\
\text { pronotum }\end{array}$ & $\begin{array}{l}\text { Length of } \\
\text { tegmen }\end{array}$ & $\begin{array}{c}\text { Width of } \\
\text { tegmen }\end{array}$ & $\begin{array}{l}\text { Length of } \\
\text { caudal } \\
\text { femur }\end{array}$ \\
\hline 9p........ & 11.5 & 2.8 & 1.8 & 1.9 & 1.7 & 7.8 \\
\hline $\begin{array}{c}\text { aratypes (64) } \\
\text { ㅇ }\end{array}$ & $10.8-13.7$ & $2.7-2.9$ & $1.8-1.9$ & $1.9-2.6$ & $1.7-1.8$ & $7.3-8$ \\
\hline otype. & 14.3 & 3.8 & 2.8 & 2.2 & 2 & 9 \\
\hline atypes & $13-14.8$ & $3.1-4$ & $2.3-3$ & $1.8-2.3$ & $1.6-2.1$ & $8.2-9.8$ \\
\hline
\end{tabular}

Though the series shows little variation in contour and pronotal expansion, the females exhibit decided variation in relative size of the tegmina.

Coloration.-Uniform pale avellaneous on face, genae (except for a broad post-ocular bar of clove brown and a subocular patch of the same color), ventral half of the lateral lobes of the pronotum (except a hair line of clove brown running down the second sulcus and curving cephalad in the mesal portion of this area), cephalic and median limbs (which, however, are flecked and washed with dark brown, particularly on their external faces) and underparts. Antennae avellaneous with a decided cinnamon tinge. Eyes tawny olive. Vertex and occiput, disk of pronotum (which, however, is paler toward the lateral carinae) and tegmina, saccardos umber. Dorsal half of lateral lobes of pronotum to principal sulcus occupied by a large, longitudinally rectangulate area of shining clove brown, separated from the cephalic margin by a narrow band of pale avellaneous; lateral lobes caudad of principal sulcus heavily washed with saccardos umber. Dorsal surface of abdomen avellaneous washed with saccardos umber, all but the distal segments heavily suffused laterad with blackish brown, each of which markings is invaded by an area of avellaneous meso-caudad; latero-proximal angles of subgenital plate heavily washed and flecked with blackish brown. Caudal femora clay color, external and dorsal faces crossed by three heavy, zig-zag bands of blackish brown, the two more distal of which also cross the internal face. Caudal tibiae pinkish buff washed and speckled with clay color, proximal spines blackish brown, distal (majority) spines blackish brown, buffy proximad on their convex dorsal faces. ${ }^{22}$

A usual amount of color variation is shown in the series, the intensive extremes having the dark patch of the lateral lobes of the pronotum and bands of the caudal femora very heavy and conspicuous. A few females are very pale, one in particular being clay color fading to cinnamon-buff on the abdomen, caudal femora and tibiae, the femoral bands very weak, sayal brown, showing only on the dorsal surface.

${ }^{21}$ In this sex rarely broad-ovate.

${ }_{22}$ This varies in the series to a condition in which the entire proximal portion of the majority of these spines is buffy. 
Another exceptional and striking variation, but one which is found to crop out in other species of the genus as well, is a condition in which the pronotum has a broad band of cinnamon-buff on each side dorsad on the lateral lobes along the lateral carinae of the disk, while the dorsal surfaces of the caudal femora are also cinnamon-buff except the genicular areas which are suffused with dark brown, only a trace of the dark bars remaining. Two males and eight females of the present series show this condition to varying degrees; it is very striking and as fully developed as described above in but three of these.

Specimens Examined: 136; 65 males and 71 females.

California: Del Monte.

The entire series of this interesting little insect was taken by Hebard on August 20, 1909, and by Rehn and Hebard on September 9 and 10, 1910. The species was found plentiful in the flat, open, sandy country, where much low grass and a low yellowflowered "tar-weed" was to be found. This species was also found moderately abundant on a yellow-flowered Composite bush, Chrysoma ericoides (Less.), growing about sand dunes near the shore. ${ }^{23}$

\section{Asemoplus somesi ${ }^{24}$ new species (Plate XXIX, figs. 8 and 9.)}

1904. Podisma polita Caudell (not of Scudder, 1899), Ent. News, xv, p. 63.

[ $\%$; Kitchener Glacier on Mt. Kokanee, British Columbia.]

1907. Asemoplus nudus Caudell (not of E. M. Walker, 189825), Proc. Ent.

Soc. Washington, viii, p. 134. [ $\sigma^{7}$, $\&$; Paradise Valley, Mt. Rainier, Washington.]

1910. Podisma nuda E. M. Walker (in part not Asemoplus nudus of E. M. Walker, 1898), Can. Ent. xlii, p. 333. [ [ $\sigma^{7}, ~ \circ$; Banff, Alberta, Canada, and referring Caudell's record of Podisma polita to this species.]

${ }^{23}$ See notes under Hesperotettix pacificus capillatus on page 262.

${ }^{24}$ We take pleasure in naming this species for Mr. M. P. Somes, who has done excellent work in Orthoptera in Minnesota, Iowa and Missouri, and who has frequently furnished us with material of great importance in our studies.

${ }^{25}$ Examination of the entire series of paratypes and the description and figures of Asemoplus nudus E. M. Walker and comparison with the type and allotype of Pezotettix hispidus Bruner, shows that nudus is an absolute synonym of the latter species. We have further learned from Dr. Walker that his original determination was hispidus, but that he wrote Scudder, sending material and asking if the specimens were not hispidus, to which a reply was received congratulating him on the discovery of a new species and making no allusion to hispidus whatever. Thus we find another synonym attributable largely to the carelessness of Scudder. Dr. Walker, a most careful and excellent student, was in this case the victim.

We would note that Scudder removed hispidus from Pezotettix to his new genus Bradynotes. This is unwarranted, the species being in no way a derivative from the Bradynotes stock and is best assigned to the genus Asemoplus as at present understood.

TRANS. AM. ENT. SOC., XḶv. 
In general appearance the present insect shows very close similarity to $A$. hispidus (Bruner); to these species $A$. rainierensis Caudell shows also close resemblance, though having small, elongate-ovate tegmina.

From both of the above species somesi differs in the male genitalia having relatively large furcula, which are longer than their basal width, the lateral portions of the supra-anal plate not thickened and raised in a separate small but distinct flange opposite the cerci ${ }^{26}$ and the cerci elongate and heavy proximad, very slender and scarcely tapering in the distal two-fifths. In hispidus the cerci are approximately as long, but taper gradually to the slightly heavier apex; in rainierensis the cerci are much as in hispidus, but proportionately shorter and frequently slightly heavier.

Females of rainierensis are readily distinguished by the presence of tegmina; those of somesi and hispidus show but little of differential value, this sex of somesi being, however, slightly heavier, with pronotal proportions slightly broader.

The three species compared above are much closer to each other than to the genotype, montanus, that species being readily distinguished by the more evenly convex pronotum, different coloration and color pattern and form of the male cerci, which show distinct deflection distad. Tegmina are present in montanus, of much the same type as found in rainierensis.

In linear order we would place the species as follows; montanus, somesi, hispidus and rainierensis.

Type.—o'; Upper Little St. Mary Valley, above Lake Ellen Wilson, Glacier National Park, Montana. Elevation, 6700 feet. August 9, 1918. (M. P. Somes.) [Hebard Collection, Type no. 500.]

Size medium for genus, form rather stout and heavily built, surface well supplied with minute but moderately elongate pilose hairs. Head much as in hispidus, full; vertex moderately tumid, interspace between eyes one and onequarter times as broad as first antennal joint, fastigium moderately depressed, frontal costa with margins feebly and broadly cingulate to below ocellus, nearly subequal in width throughout. Antennae shorter than caudal femora. ${ }^{27}$

${ }^{26}$ This feature is found to exhibit a certain amount of individual variation in some examples of A. montanus (Bruner), hispidus and rainierensis.

${ }^{27}$ We would note that in the series at hand of both hispidus and rainierensis, individuals from lower elevations have the antennae decidedly longer than those from higher levels. 
Eyes rather small, about as long as infra-ocular sulcus. Pronotum rather short, scarcely broader caudad than cephalad, with a medio-longitudinal carina weakly defined on prozona, well defined on metazona and dorsal abdominal segments; transverse sulci decided; dorsum rounding into the lateral lobes but with angulation indicated, not rounding evenly as in montanus, prozona quadrate, caudal margin of pronotum truncate, very feebly obtuse-angulate emarginate. Latero-caudal angle of lateral lobes sharply rounded, slightly greater than a right-angle. Tegmina and wings absent. Prosternal spine acute conical and moderately slender from its broad base. ${ }^{28}$ Interspace between metasternal lobes subquadrate. ${ }^{29}$ Furcula represented by a pair of parallel ${ }^{30}$ rounded projections, nearly one-fifth as long as supra-anal plate, decidedly larger than the maximum developed in either hispidus or rainierensis. Supraanal plate elongate shield-shaped, with latero-caudal angles weakly indicated; median channel broad, percurrent, moderately deep in proximal portion; lateral portions rather strongly concave, the lateral margins raised and showing a slight thickening opposite the cerci, but no lamellae as in hispidus and rainierensis. Cerci distinctly over twice as long as proximal width, heavy proximad, tapering to distal two-thirds, which portion is slender, straight, ${ }^{31}$ to the sharply rounded apex. Subgenital plate conical with margin toward apex scarcely elevated above lateral portions, apex notched and consequently binodose. ${ }^{32}$ Cephalic and median femora moderately inflated and slightly bowed.

\section{Allotype.— $\%$; same data as type. [Hebard Collection.]}

Very similar to this sex of hispidus, slightly heavier, with pronotum proportionately slightly broader. Larger and decidedly heavier than male, agreeing with that sex except in the following features. Eye about three-quarters as long as infra-ocular sulcus. Antennae distinctly shorter. Pronotum distinctly broader caudad than cephalad, with weak percurrent median carina cut by all the weak transverse sulci, caudal margin with obtuse-angulate emargination slightly stronger. Prosternal spine moderately blunt, conical from broad base. $^{33}$ Ovipositor valves as in hispidus. Cephalic and median femora not inflated, straight.

${ }^{28}$ See footnote 33.

${ }^{29}$ So great is the individual variation in the width of the interspace between the mesosternal and metasternal lobes in many species of the Melanopli that we have found these features of little or no value for diagnostic purposes.

${ }^{30}$ Divergent in one specimen from Banff, Alberta.

${ }^{31}$ In one specimen of the series showing a very feeble flexure ventrad.

32 This varies in the present species, as in hispidus, to a condition in which this feature is obsolete. In rainierensis it is obsolete, though occasionally faintly indicated.

${ }^{33}$ In the paratypic series slightly less blunt than in the Canadian series of hispidus at hand, distinctly blunter than in the allotype of hispidus from Washington. The form of the prosternal spine, as of the mesosternal and metasternal lobes, has been found by us to be extremely variable in certain species of the Melanopli, and consequently unreliable for specific diagnostic use.

TRANS. AM. ENT. SOC., XLV. 


\section{Measurements (in millimeters) of extremes only}

\section{$\sigma^{\pi}$}

Banff, Alberta

(2)

Upper St. Mary Valley, Glacier

Nat. Park, type. . . . . . . . . .

Upper St. Mary Valley, Glacier

Nat. Park, paratypes (11) .....

Mt. Rainier, Washington (7) .... 우

Lake Louise, British Columbia . . . Mt. Kokanee, British Columbia Upper St. Mary Valley, Glacier

Nat. Park, allotype...........

Upper St. Mary Valley, Glacier

Nat. Park, paratypes (18) .....

Mt. Rainier, Washington (11) ...
Length of Length of Width of Length of body pronotum pronotum ${ }^{34}$ caudal femur

$16.3-16.8 \quad 3.3-3.6 \quad 3.4-3.8 \quad 9.1-9.2$

4

10.1

$\begin{array}{llll}15^{35}-18.5 & 3.3-3.3 & 3.9-4 & 9.4-10.2\end{array}$

14.8-17 $3.1-3.4 \quad 3.6-3.9 \quad 9-9.7$

22

18.5

4

3.7

5

11

20.5

4.1

4.8

10.9

$19-23$

$3.9-4.1 \quad 5-5.2 \quad 11.2-12.3$

$18.9-26^{36}$

4.8-5 10.5-12.1

Coloration.-Male much as in hispidus; blackish olivaceous above, with a yellowish stripe on each side, interrupted at the first pronotal sulcus and sometimes at the intersections of the abdominal segments, running from the dorsocaudal portion of the eyes, along the dorsum of the pronotum just above the lateral lobes and along the abdomen to the last segments. The width and intensity of these bands shows some individual variation. Face and lower half of lateral lobes of pronotum yellowish. A blackish olivaceous band on each side starts from mesad on the caudal margin of the eye, occupies the dorsal half of the lateral lobes, expanding caudal on the metazonal portion, and is continued thence on the lateral portions of the abdomen, narrowing gradually distad. Underparts yellowish. Limbs reddish brown, the caudal femora showing three weakly defined, transverse suffusions of darker brown and a pregenicular pale area, which is weakly indicated on the caudal tibiae in the portion adjacent.

Female similar in general coloration, but much less brilliant. Reddish brown above, with paler bands represented only by a somewhat paler suffusion margining the dark lateral bands dorsad. Caudal limbs with markings even weaker.

Specimens Examined: 54; 20 males, 32 females and 2 immature females.

Alberta: Banff.

British Columbia: Lake Louise and Kitchener Glacier on Mount Kokanee.

Montana: Upper Little St. Mary Valley above Lake Ellen Wilson, Glacier National Park.

IDAно: Wallace.

Washington: Paradise Valley on Mt. Rainer.

${ }^{34}$ Including lateral lobes, which expand ventrad, particularly caudad.

${ }^{35}$ Specimen shrunken.

${ }^{36}$ Specimen abnormally distended. 
In addition to the type and allotype, a series of eleven males, eighteen females and two immature females bearing the same data, are designated paratypes. The specimens from Banff were taken by Sanson [Walker Cln.], that from Lake Louise by Mrs. Schaeffer on July 5 [A. N. S. P.], that from Mount Kokanee by Caudell, at 9000 feet, on August 10, 1903 [U. S. N. M.], and the male from Wallace on August 5, 1917 [Davis Cln.].

The species was found at the type locality to be very numerous on coarse herbage among the rocks. It was not, however, generally distributed but occurred in isolated spots of similar ecologic conditions.

Caudell found the species with rainierensis, in about equal numbers, in the alpine herbage of Paradise Valley on Mt. Rainier, in July, 1906. The series taken is before us, from the National Museum and Walker Collections. It is of interest to note that though rainierensis was found there in great numbers by Rehn and Hebard on August 23 and 24, 1910, the present species was not met with at all.

Bradynotes kaibab ${ }^{37}$ new species (Plate XXIX, fig. 12.)

The present species is closely related to $B$. compacta Morse (see plate XXIX, fig. 14), described from Ormsby County, Nevada, and to $B$. pinguis Scudder (see plate XXIX, fig. 11), the type of which is from "Reno," 38 Nevada. Nearest relationship is with pinguis, the present insect differing in the smaller size, slightly broader form and in the male sex in the much more slender cerci. The more elongate pronotum with much more conspicuous and continuous lateral carina in compacta, readily distinguishes that species, in males of which the supra-anal plate is more nearly elongate triangular, the cerci much as in the present species.

The female sex closely resembles a diminutive condition of that sex of pinguis. The carinae of the fastigium are, however, distinct between the eyes, obsolete or subobsolete above the foveolae, a condition not found in any other species of the genus.

In the present series two males and four females have the caudal tibiae nopal red, in the other five females the proximal portions of the caudal tibiae are, to different degrees, deep bluish

${ }^{37}$ Named for the tribe of Paiute Indians who inhabited this region. The tribal name derived from kaiba $=$ mountain.

${ }^{38}$ Probably from a high elevation in the mountains near Reno.

TRANS. AM. ENT. SOC., XLV. 
gray-green. This shows that the color of the caudal tibiae is of no diagnostic significance, at least in one sex of the present species. Type.- $0^{7}$; Duck Lake, Cedar Mountains, Iron County, Utah. Elevation, 9000 feet. July 14, 1917. (G. P. Englehardt.) [Hebard Collection, Type no. 501.]

Size small for the genus, not as small as in B. excelsa Rehn; form heavy, as in pinguis; surface very feebly pilose. Head broad and full, vertex gently tumid; fastigium shallowly concave, the lateral margins moderately prominent, rounded; frontal costa much as in pinguis, but very slightly narrower and moderately punctate, least width slightly greater than width of proximal antennal joint, shallowly sulcate, the lateral margins like those of the fastigium but slightly broader. Eye as long as infra-ocular sulcus. Pronotum as in pinguis, expanding moderately caudad, this stronger between first and second transverse sulci, with distinct lateral carinae on prozona not as decided as in compacta, median carina slightly ?ess well developed than in pinguis, weak but percurrent and cut only by the principal sulcus, continued on the three succeeding dorsal segments. Tegmina and wings absent, as in all species of Bradynotes. Interspace between mesosternal and metasternal lobes variable. ${ }^{39}$ Furcula absent. Supra-anal plate trigonal-produced ${ }^{40}$ with medio-longitudinal and lateral concavities decided proximad, the latter the more so. Cerci as long as supra-anal plate, tapering rather strongly in proximal half; distal half slender, more slender than in pinguis, tapering very slightly to the rounded apex, which is more sharply rounded ventrad than dorsad. Subgenital plate as in pinguis; conical, lateral margins very feebly convex, then as feebly concave to apex, which is small, slightly produced and feebly notched. Cephalic and median femora slightly inflated, very feebly bowed.

Allotype.- o ; same data as type, but taken July 17, 1917. [Hebard Collection.]

Larger and more robust than male. Lateral carinae of fastigium distinct proximad between eyes, obsolete ${ }^{41}$ above the foveolae; frontal costa $\cdot$ broader

${ }^{39}$ In the two males at hand, the mesosternal interspace is as wide as the lobes themselves in one, distinctly wider in the other; the metasternal interspace is quadrate in one, distinctly transverse in the other. These features are subject to individual variation in many species of the Melanopli and, in consequence, are of far less diagnostic value than has been supposed by Scudder and other authors.

${ }^{40}$ In the type this plate is narrow, with apex broadly rounded; in the paratype broader proximad, narrowing more strongly to the apex which is rather sharply rounded, forming an angle of slightly less than $90^{\circ}$. This much individual variability in the form of the male supra-anal plate is unusual. In the type of pinguis, the supra-anal plate is as long as its basal width, about intermediate in form between the present extremes, with concavities less decided.

${ }^{41}$ Varying to subobsolete in a few specimens of the series. 
and more shallowly sulcate than in male. Eye slightly shorter than infraocular sulcus. ${ }^{42}$ Pronotum much as in this sex of pinguis, but with very weak medio-longitudinal carina indicated throughout; pronotum considerably broadened caudad, with lateral carinae of prozona weakly defined. Succeeding segments to near apex of abdomen carinate medio-longitudinally. Ovipositor jaws much as in pinguis. Cephalic and median femora neither inflated or bowed.

\section{Measurements (in millimeters) of extremes}

\begin{tabular}{|c|c|c|c|c|c|}
\hline$\sigma^{7}$ & $\begin{array}{l}\text { Length of } \\
\text { body }\end{array}$ & $\begin{array}{l}\text { Length of } \\
\text { pronotum }\end{array}$ & $\begin{array}{l}\text { Width of } \\
\text { pronotal } \\
\text { disk } \\
\text { cephalad }\end{array}$ & $\begin{array}{l}\text { pronotal } \\
\text { disk at } \\
\text { principal } \\
\text { sulcus }\end{array}$ & $\begin{array}{l}\text { Length of } \\
\text { caudal } \\
\text { femur }\end{array}$ \\
\hline Type. & 18 & 3.8 & 2.2 & 3 & 10.1 \\
\hline 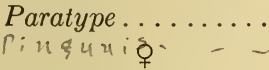 & $\begin{array}{l}16.2 \\
23\end{array}$ & $\begin{array}{l}3.3 \\
4.75\end{array}$ & 2.1 & 3 & $\begin{array}{r}9.7 \\
12.5\end{array}$ \\
\hline Allotype. & 23 & 4. & 3.2 & 4.7 & 11.8 \\
\hline Paratypes (8) & $18.7^{43}-25.8$ & $4.8-4.7$ & $3.1-3$ & $4.6-4.4$ & $11.6-12$ \\
\hline
\end{tabular}

Coloration.-General coloration of dorsal surface chestnut brown to mummy brown, becoming darker laterad on abdomen in males. Ventral surface antimony yellow in males, buffy in females, discolored in the majority of the present series. Head with occiput buffy, with a medio-longitudinal and two broader suffused bars of dark greenish brown, the lateral bars diverging caudad. Lateral carinae of fastigium individually jasper red to apricot orange proximad. Other portions of head ochraceous-buff with dark punctae, except for a suffused postocular bar of blackish brown. Pronotum with cephalic and caudal margins very narrowly jasper red, varying individually to apricot orange; smooth areas on lateral lobes beneath lateral carinae of disk buffy, as are the ventral portions of the lateral lobes in recessive examples. Cephalic and median limbs buffy. Caudal femora with pagina dark brown, irregularly buffy proximad; dorsoexternal and ventro-external surfaces ochraceous-buff; ventral portion of genicular lobes and narrow margin of dorsal surface scarlet to scarlet red; dorso-internal surface ochraceous-buff with two weak transverse bands of dark brown, these individually variable in intensity but more prominent in males than females; ventro-internal surface brazil red, deepening medio-longitudinally to claret brown or in some examples blackish. Caudal tibiae nopal red, the spines paler and black tipped; in three females the tibiae are deep bluish gray-green proximad, while in two the tibiae are deep delft blue, paler externally and shading to vandyke red in disto-internal half.

Specimens Examined: 12; 2 males, 9 females and 1 immature male.

Utah: Cedar Mountains and Duck Lake, Cedar Mountains, Iron County.

The present series, besides the type and allotype, are designated paratypes. All were taken by G. P. Englehardt, from July 11 to 17,1917 , in the same general region, at elevations from 8500

${ }^{42}$ Varying to as long as infraocular portion of genae in some specimens.

${ }^{43} \mathrm{~A}$ shrivelled specimen.

TRANS. AM. ENT. SOC., XLV. 
to 9000 feet. The species was found not uncommon and rather sluggish, most frequently along open parts of a trail, among sparse growth of grasses on dry, sandy soil.

Bradynotes deplanata new species (Plate XXIX, fig. 13; plate XXX, fig. 2.)

This species is closely allied to $B$. pinguis Scudder (see plate XXX, fig. 1), differing in the smaller size, broader form, deplanate disk of pronotum with lateral carinae decided and, in the male sex, in the slightly more slender cerci.

The insect agrees with $B$. compacta Morse in the well-developed lateral carinae of the pronotum. The pronotum differs in having the disk deplanate and broader caudad, due to the fact that the lateral carinae are strongly divergent caudad between the first and second transverse sulci, thence rather strongly divergent caudad, not almost evenly and weakly divergent caudad as in compacta. In the male sex the cerci are not as slender as in $B$. obesa (Thomas) (see plate XXIX, fig. 10), compacta or B. kaibab here described, of the same type but more slender than in pinguis.

Type.- $0^{7}$; Big Meadows of the Deschutes River, eighteen miles southwest of Bend, Crook County, Oregon. July, 1913. (C. H. Kennedy.) [Hebard Collection, Type no. 502.]

Size medium small for genus, slightly larger than in kaibab; form very heavy, heavier than in that species or in pinguis; surface moderately pilose. Head and eyes much as described for kaibab, except that the frontal costa is slightly less pinched at its juncture with the fastigium and is scantily punctate. Pronotum with disk strikingly deplanate, expanding rather strongly caudad, this greatest between the first and second transverse sulci, with lateral carinae well developed as in compacta and continued to near the caudal margin; mediolongitudinal carina as in kaibab, weak but percurrent and cut only by the principal sulcus, continued on the three succeeding dorsal segments. Tegmina and wings absent. Furcula absent. Supra-anal plate rather narrowly trigonal-produced, with apex broadly rounded, medio-longitudinal depression decided proximad, lateral concavities decided proximad. Cerci as long as supra-anal plate, of the same type as in pinguis, tapering to the slender apex, which is oblique truncate, the dorsal angle being obtuse-angulate but sharply rounded, the ventral angle acute-angulate but more broadly rounded, distal portion more slender than in pinguis, very slightly heavier than in kaibab. Subgenital plate conical, lateral margins almost straight to the very feebly elevated apex, which is small, slightly produced, entire. Cephalic and median femora slightly inflated, very feebly bowed. 


\section{Allotype.- $\%$; same data as type. [Hebard Collection.]}

Larger and more robust than male. Lateral carinae of fastigium percurrent, frontal costa as deeply sulcate as in male. Eye slightly shorter than infraocular sulcus. Pronotum considerably broadened caudad, with disk strikingly deplanate between the lateral carinae which are weaker than in male, but heavier than in females of pinguis, with a very weak medio-longitudinal carina indicated throughout. Succeeding segments to near apex of abdomen mediolongitudinally carinate. Ovipositor jaws apparently much as in pinguis. ${ }^{44}$ Cephalic and median femora neither inflated or bowed.

\begin{tabular}{|c|c|c|c|c|c|}
\hline \multicolumn{6}{|c|}{ Measurements (in millimeters) of extremes only } \\
\hline$\sigma^{x}$ & $\begin{array}{l}\text { Length of } \\
\text { body }\end{array}$ & $\begin{array}{l}\text { Length of } \\
\text { pronotum }\end{array}$ & $\begin{array}{l}\text { Width of } \\
\text { pronotal } \\
\text { disk } \\
\text { cephalad }\end{array}$ & $\begin{array}{l}\text { Width of } \\
\text { pronotal } \\
\text { disk at } \\
\text { principal } \\
\text { sulcus }\end{array}$ & $\begin{array}{l}\text { Length of } \\
\text { caudal } \\
\text { femur }\end{array}$ \\
\hline ype. & 19 & 3.9 & 2.6 & 3.6 & 10.4 \\
\hline $\begin{array}{c}\text { Paratypes (12) } \\
\circ\end{array}$ & $18-19.8$ & $3.5-4$ & $2.2-2.6$ & $3-3.7$ & $10-11.1$ \\
\hline llotype... & 23 & 4.7 & 3.1 & 4.6 & 12 \\
\hline aratypes (5) & $20.3-23$ & $4.5-4.9$ & $3.1-3$ & $4.4-4.8$ & $11.8-12$ \\
\hline
\end{tabular}

Coloration.-Male. Head light ochraceous-buff, occiput suffused triangularly with blackish, leaving the portions toward the eyes buff, lateral carinae of fastigium brazil red proximad, thence blackish with a claret tinge, as are the lateral carinae of the frontal costa; a vertical suffusion of this color from between antennal socket and eye to clypeal suture on each side and another oblique irregular suffusion across the genae, from an olivaceous postocular bar. Disk of pronotum snuff brown, the lateral carinae claret brown; lateral lobes of pronotum buffy ventrad, meso-proximad and in two smooth areas below lateral carinae of disk, remaining portions suffused with black. Mesonotum and metanotum suffused with black except for a medio-longitudinal line of buffy, and buffy in small areas dorso-laterad, from which tegmina and wings would spring if present. Abdomen suffused with black proximad, except for a medio-longitudinal line of buffy, the black areas continued half the distance to apex of abdomen on sides, and as a narrow weak suffusion dorso-laterad, to and including the supra-anal plate, remaining portions of abdomen buffy. Cephalic and median femora buffy, in type with dorsal surface washed with brick red and cephalic face heavily marked distad with black and brick red; in other individuals almost immaculate. Cephalic and median tibiae in type buffy, with cephalic face heavily lined longitudinally with black, this indicated only by a weak proximal suffusion in other examples. Caudal femora with pagina suffused with blackish, the reticulations buffy proximad and mesad; dorso-external and ventro-external surfaces ochraceous-buff, carinae tinged with reddish, ventral margin of genicular lobes and narrow dorso-distal margin garnet brown; dorso-internal surface ochraceous-buff with three heavy transverse blackish bands, the more proximal being basal in position; ventral surface

${ }^{44}$ In this specimen retracted, so that only the tips project beyond the supraanal plate.

TRANS. AM. ENT. SOC., XLV. 
with margins brazil red, the remaining portion black with a claret tinge. Caudal tibiae with dorso-proximal lobe strikingly salmon-orange; external face buffy except proximad, where it is deep bluish gray-green and narrowly dorsad bluish gray-green; ventral face buffy; dorsal face nopal red, except briefly suffused proximad with vandyke red;45 internal face similar but with intensity of coloration not as great. The allotypic female is similar but not as brilliant, while the dark areas are more extensive. The pronotal disk is mars brown, the dorsal surface of the abdomen mars brown, except for a narrow mediolongitudinal line and disto-laterad, where it is cinnamon brown.

Specimens Examined: $19 ; 13$ males and 6 females.

Oregon: Big Meadows of the Deschutes River, eighteen miles southwest of Bend.

This series was collected, in July, 1913, by C. H. Kennedy, probably in the eastern edge of the dry pine woods, covering the eastern edge of the Cascade Mountains, and given to W. T. Davis. Due to Mr. Davis' generosity, the series is now divided between the Davis and Hebard Collections and those of the Academy of Natural Sciences of Philadelphia and United States National Museum. The specimens, other than the type and allotype, are designated paratypes.

Melanoplus huporeus ${ }^{46}$ new species (Plate XXX, fig. 3; plate XXXI, fig. 2.)

The present species belongs to the Marginatus Group, and shows distinctly closer affinity to $M$. marginatus Scudder, than to $M$. gracilipes Scudder.

From the long-winged marginatus it differs in the slightly heavier form, blunter vertex and broad oval tegmina, which frequently have the immediate apex acute and sharply rounded, but are never produced distad, with apex acute, to the degree normal in the short-winged marginatus variety pauper Scudder. In addition, males are readily separated by the form of the cerci, which in marginatus (see plate XXXI, fig. 1) are shorter, with apex truncate and strikingly inflated. In coloration the two species are very similar.

${ }^{45}$ The extent of this purplish portion varies slightly in the series. In the type of pinguis the caudal tibiae are nopal red, slightly paler proximad on the external face; in the allotype similar, but with a blackish green annulus below the dorso-proximal lobe. In a very large series of that species from timber line on Mt. Shasta, California, however, the tibiae are all bicolored, dark purplish proximad and red distad. This indicates that the color of the caudal tibiae in pinguis, and probably in related species, can not be considered of specific diagnostic value, as supposed by Scudder and used in his key, Proc. U. S. Nat. Mus. $\mathrm{xx}$, p. 81 , (1897).

${ }^{46}$ From $\dot{v} \pi \dot{\omega} \rho \epsilon$ los $=$ living at the foot of the mountains. 
Type.- $\sigma^{\text {T }}$; Colfax, Placer County, California. Elevation, 2450 feet. August 28, 1910. (Rehn and Hebard.) [Hebard Collection, Type no. 503.]

Size small, form slender. Head much as in marginatus, but with area of fastigio-facial angle distinctly less produced, the angle itself more broadly rounded. Frontal costa shallowly concave. Eye large, about two and onehalf times as long as infra-ocular sulcus. Pronotum elongate, disk of equal width, with a slender but well defined and percurrent medio-longitudinal carina, lateral carinae very weakly defined, caudal margin nearly transverse, very broadly obtuse-angulate produced. Prosternal spine as in marginatus; small, bluntly elongate subconical. Tegmina slightly shorter than pronotum, broadly oval with immediate apex acute and sharply rounded. ${ }^{47}$ Furcula represented by a pair of minute, slender teeth, each about twice as long as wide, with apex bluntly rounded. Supra-anal plate simple, moderately elongate trigonal, the lateral margins showing very feeble convexity, surface with a moderately broad, proximal, medio-longitudinal sulcation. Cerci elongate, weakly curving inward, about three and one-half times as long as proximal width, tapering evenly in proximal two-fifths, median fifth slender with margins almost parallel, distal two-fifths enlarged, but not swollen or truncate as in marginatus, enlargement due to broad convexity of dorsal margin, with blunt apex at ventral margin; the ventral margin is almost straight, very feebly concave throughout, the dorsal margin more strongly concave to distal portion, where it is convex. Subgenital plate as in marginatus; median section of slightly greater depth laterad than mesad, with a small but distinct tubercle mesad, at the free margin. Limbs as in marginatus.

\section{Allotype.— o ; same data as type. [Hebard Collection.]}

Size larger, form heavier than in male. The heavier form and less produced fastigio-facial angle as strikingly in contrast with this sex of marginatus as between males of these species. Fastigium of vertex and frontal costa decidedly broader and less sulcate than in male. Eye about two and one-quarter times as long as infra-ocular sulcus. Pronotum with medio-longitudinal carina not as sharp as in male. Ovipositor and limbs as in marginatus.

\begin{tabular}{|c|c|c|c|c|c|c|}
\hline$\sigma^{7}$ & $\begin{array}{c}\text { Length of } \\
\text { body }\end{array}$ & $\begin{array}{l}\text { Length of } \\
\text { pronotum }\end{array}$ & $\begin{array}{l}\text { Caudal } \\
\text { width of } \\
\text { pronotal } \\
\text { disk }\end{array}$ & $\begin{array}{l}\text { Length of } \\
\text { tegmen }\end{array}$ & $\begin{array}{l}\text { Width of } \\
\text { tegmen }\end{array}$ & $\begin{array}{l}\text { Length of } \\
\text { caudal } \\
\text { femur }\end{array}$ \\
\hline $\begin{array}{c}\text { ratypes (28) } \\
\text { 우 }\end{array}$ & $\begin{array}{c}14.5 \\
14.8-16.8\end{array}$ & $\begin{array}{c}3.1 \\
3-3.9\end{array}$ & $\begin{array}{c}2 \\
2-2.1\end{array}$ & $\begin{array}{c}3 \\
3-3.9\end{array}$ & $\begin{array}{c}2 \\
1.9-2.2\end{array}$ & $\begin{array}{c}8.2 \\
7.9-9.8\end{array}$ \\
\hline atype...... & $\begin{array}{c}21 \\
18-22\end{array}$ & $\begin{array}{c}4 \\
3.6-4.8\end{array}$ & $\begin{array}{c}3 \\
2.6-2.9\end{array}$ & $\begin{array}{c}4.2 \\
3.3-4.9\end{array}$ & $\begin{array}{c}2.8 \\
2.1-3\end{array}$ & $\begin{array}{c}11 \\
9-11.3\end{array}$ \\
\hline
\end{tabular}

${ }^{47}$ In the majority of the series attingent, varying from subattingent to feebly overlapping.

TRANS. AM. ENT. SOC., XLY. 
Coloration.-The males range in general coloration from ochraceous-buff, with postocular band of buckthorn brown weakly indicated on prozonal portion of pronotal lateral lobes, and flecks of the same color on the sides of the abdomen proximad, to cinnamon brown with blackish postocular bar occupying the dorsal two-fifths of the prozonal portion of pronotal lateral lobes, and sides of abdomen heavily marked with blackish latero-proximad. In the darker examples the caudal femora have the dorso-internal surface showing weakly two dark flecks, while the face, ventral three-fifths of pronotal lateral lobes and ventral surface are ochraceous-buff, in striking contrast with the dorsal surface. In intensive examples the ventral face of the caudal femora is russet, shading to mars brown mesad; in recessive individuals ochraceous-buff tinged with ochraceous-orange. The caudal tibiae are buffy, tinged with glaucous.

Females are similarly colored, the intensive condition being less often encountered. In this sex also, buffy examples are often 'washed with greenish, this sometimes including the pronotal disk, but usually confined to the head, lateral portions of pronotum and body and exposed surface of the caudal femora.

Specimens Examined: $49 ; 29$ males, 20 females.

California: Colfax.

The series, in addition to the type and allotype, may be considered paratypes. These specimens were taken by Rehn and Hebard on August 27 and 28, 1910, at Colfax, California, at elevations from 2450 to 2800 feet. The series was found on hillsides, in open places overgrown with low plants and particularly where much poison oak occurred, intermingled with a low sweetsmelling bush. The hillsides were clothed generally with high manzanita and other bushes, with a scattering growth of pines and other trees. In the same environment $M$. lepidus Scudder was found, both species generally scarce, but lepidus common and the present species scarcer in one limited area only.

Melanoplus hesperus new species (Plate XXX, figs. 5 and 6; plate XXXI, fig. 3.)

The present species belongs to the Marginatus Group and to that section including the forms closely related to $M$. gracilipes Scudder.

Nearest relationship is with gracilipes (see plate XXX, fig. 4); males of the present insect differ in the slightly more elongate form, much more elongate furcula, more elongate supra-anal plate, more elongate cerci, with inbent distal portion twice as long 
as wide, instead of subquadrate, and even weaker blunt tuberculation of subgenital plate. Much the most important differences are found in the furcula and cerci. In size, form and general appearance this species agrees fully with $M$. ligneolus Scudder, another very closely related species. The present insect is particularly distinguished from all the forms closely related to gracilipes by the much more elongate furcula.

Females of these species are most difficult to separate. This sex of hesperus is a little more slender and elongate than females of gracilipes, in every way similar to females of ligneolus except in the very slightly more pronounced lateral carinae of the pronotum. ${ }^{48}$

Type.- $o^{7}$; San Luis Obispo, San Luis Obispo County, California. August 21, 1909. (M. Hebard.) [Hebard Collection, Type no. 504.]

Size small, but, with ligneolus, largest of the species closely related to gracilipes. Form slender, much as in gracilipes and in $M$. huporeus here described. Head much as in gracilipes, but with area of fastigio-facial angle slightly more produced, much as in huporeus, but with frontal costa appreciably wider, as in gracilipes, showing only very slight concavity toward median ocellus. Eye large, over two and one-half times as long as infra-ocular sulcus. Pronotum elongate, disk of almost equal width throughout, median carina well defined and percurrent, lateral carinae distinct though very weakly defined, not subobsolete as in gracilipes or fully as weak as in ligneolus, caudal margin of disk broadly obtuse-angulate produced, more produced than in gracilipes. Prosternal spine as in gracilipes; elongate, bluntly subconical. Tegmina shorter than pronotum, rather broadly oval, feebly overlapping, with apex bluntly rounded. Furcula represented by a pair of slender elongate processes, which diverge at an angle of sixty (to ninety in series) degrees, three and one-half times as long as greatest width, length contained in that of supra-anal plate slightly less than two and one-half times, width about the same in proximal two-thirds and there separated by an interval of nearly equal width, thence tapering to the acute apex. Supra-anal plate shield-shaped; surface with a deep medio-longitudinal sulcus, running through proximal two-thirds, the lateral carinae of this sulcus each with mere traces of a transverse carina externally, mesad on the plate; surface with lateral portions rather strongly concave in proximal two-thirds, beyond which two broad, longitudinal, parallel, short ridges run to the free margin just before the apex. Between the supraanal plate and the cerci, a portion of a basal plate is extruded, this causing the lateral margins of the plate to be somewhat elevated. Cerci moderately elongate, weakly curving inward, about two and one-fourth times as long as

${ }^{48}$ This feature is probably of little diagnostic value, as the degree of difference noted is easily within the limits of individual variation.

TRANS. AM. ENT. SOC., XLV. 
basal width, tapering slightly to distal third, which is twice as long as wide, with apex rounded and external face concave, this portion similar but rounded quadrate in gracilipes. Subgenital plate with median section of equal depth laterad and mesad, feebly blunt conical at free margin, this weaker than in gracilipes, not sufficiently developed to be termed a tuberculation. ${ }^{49}$ Limbs as in gracilipes.

\section{Allotype.- 9 ; same data as type. [Hebard Collection.]}

Size larger, form heavier than in male. Fastigium of vertex distinctly broader and less deeply sulcate than in male. Eye slightly more than twice as long as infra-ocular sulcus. Pronotum with lateral carinae even weaker than in male, but slightly more pronounced than in this sex of ligneolus. Ovipositor and limbs as in gracilipes.

\begin{tabular}{|c|c|c|c|c|c|c|}
\hline \multicolumn{7}{|c|}{ Measurements (in millimeters) } \\
\hline$\sigma^{x}$ & $\begin{array}{l}\text { Length of } \\
\text { body }\end{array}$ & $\begin{array}{l}\text { Length of } \\
\text { pronotum }\end{array}$ & $\begin{array}{c}\text { Caudal } \\
\text { width of } \\
\text { pronotal } \\
\text { disk }\end{array}$ & $\begin{array}{l}\text { Length of } \\
\text { tegmen }\end{array}$ & $\begin{array}{l}\text { Width of } \\
\text { tegmen }\end{array}$ & $\begin{array}{l}\text { Length } \\
\text { of caudal } \\
\text { femur }\end{array}$ \\
\hline Type. & 17.2 & . 3.8 & 2 & 3.7 & 2.2 & 9.7 \\
\hline $\begin{array}{c}\text { Paratypes (3) } \\
\text { ㅇ }\end{array}$ & $16.3-16.8$ & $.3 .7-3.8$ & $2-2.2$ & $3.3-3.9$ & $2.1-2.1$ & $9.3-10$ \\
\hline Allotype. & 19.2 & 4.1 & 2.9 & 4 & 2.8 & 11.9 \\
\hline
\end{tabular}

Coloration.-Head cinnamon, except occiput which is sayal brown and a broad and sharply defined postocular band of prout's brown. Eyes cinnamon brown. Dorsum of pronotum sayal brown, paling slightly toward lateral carinae, lateral lobes with a band of prout's brown occupying dorsal third of prozonal portion, corresponding portion of metazona suffused, sayal brown, lower portions of lateral lobes cinnamon. Tegmina sayal brown, darkening gradually to cinnamon brown latero-ventrad. Abdomen cinnamon-buff with large flecks of blackish laterad. on the four proximal segments. Underparts ochraceous-buff. Cephalic and median femora sayal brown. Caudal femora with pagina sayal brown, dorsal surfaces cinnamon with two proximal slightly darker areas on inner portion, remaining portions suffused cinnamon-buff. Caudal tibiae clay color.

The small series shows little color variation. The males of greater recessive coloration have the head, lower portions of the pronotal lateral lobes and dorsal surface of the caudal femora cinnamon-buff, the other portions paler to a like degree.

Specimens Examined: 5; 4 males and 1 female.

California: San Luis Obispo.

${ }^{49} \mathrm{~A}$ large series of this species will, however, be needed to determine the value of this character. In some species, the degree of tuberculation of the subgenital plate appears to be subject to but little variation. In the closely related $M$. nanus Scudder, however, great variation in this feature occurs. 
Other than the type, the three males are designated paratypes. The series was collected in a field of the sun-dried yellow grass which is characteristic of the Coast Ranges of California. The species was apparently numerous, the few specimens being secured during a brief train stop.

Melanoplus microtatus new species (Plate XXX, fics. 7 and 8.)

1909. Melanoplus sonomaensis Rehn and Hebard (not of Caudell, 1906),

Proc. Acad. Nat. Sci. Phila., 1909, p. 468. [ [ $\sigma^{\top}$, ㅇ ; Santa Cruz, California.]

This species belongs to the Marginatus Group and to that section including the forms very closely related to $M$. gracilipes Scudder.

Nearest relationship is with $M$. nanus Scudder, to which species close affinity is shown, though not to the degree found in $M$. sonomaensis Caudell. The insect differs from nanus in the average smaller size,,$^{50}$ the slightly but distinctly more slender form and, in the male sex, in the distinctive form of the cerci and the contour of the supra-anal plate.

Females of these species are almost inseparable. In the present very large series of microtatus, it is noted, however, that all are slightly but appreciably more slender, and that the large majority are of smaller size. The tegmina also average more approximate, but show so wide a range of variation in this feature, as well as in size and in length in proportion to width, that this can not be used safely as a character for individual determinations.

Type.- $\sigma^{x}$; Del Monte, Monterey County, California. August 20, 1909. (M. Hebard.) [Hebard Collection, Type no. 505.]

Size very small, smallest of the genus; form slender, slightly but appreciably more slender than in nanus. Head much as in nanus; fastigio-facial angle slightly more produced than in gracilipes, as in hesperus here described, nanus and sonomaensis; frontal costa as in nanus, no wider than in huporeus here described, but showing only slight concavity toward median ocellus, as in all the species here referred to except huporeus. Eye slightly over twice as long as infra-ocular sulcus. Pronotum elongate, disk of almost equal width throughout, median carina well defined and percurrent, lateral carinae distinct though weakly defined, much as in hesperus, caudal margin of disk broadly obtuseangulate produced, as in hesperus. Prosternal spine as in hesperus. Tegmina considerably shorter than pronotum, almost attingent,, ${ }^{51}$ with apex rather

${ }^{50}$ This is the smallest species of the genus Melanoplus known. The smallest known examples of $M$. puer (Scudder) show a lesser length, but have a considerably greater body bulk.

${ }^{51}$ Varying to slightly overlapping in the series of males.

TRANS. AM. ENT. SOC., XLV. 
broadly rounded. Furcula as in nanus; represented by a pair of minute, slender, tapering processes ${ }^{52}$ length contained in that of supra-anal plate over three and one-half times. Supra-anal plate moderately elongate, shieldshaped, median sulcus decided to slightly beyond median point, the lateral carinae of this sulcus at median point on plate connected with lateral margins by transverse carinae, lateral margins to intersection with these carinae raised and somewhat thickened, lateral concavities deep before and beyond the transverse carinae, laterad toward apex two low, short, parallel ridges are developed, which terminate in the lateral margins of the plate. ${ }^{53}$ As in nanus, between the supra-anal plate and the cerci, portion of a basal plate is extruded, this causing the elevation of the lateral margins of the supra-anal plate. Cerci decidedly shorter than in hesperus, somewhat shorter than in nanus, curving weakly inward with a trace of angulation at end of proximal two-thirds, slightly over twice as long as basal width, tapering strongly in proximal third, thence tapering weakly to the rounded apex, the shaft with a weak curvature dorsad, external surface of distal third deplanate, this portion about one and one-half times as long as its basal width. Subgenital plate with median section of equal depth laterad and mesad, tapering meso-distad to a well developed apical tubercle at the free margin. ${ }^{54}$ Limbs as in nanus, caudal femora very slightly more slender than in gracilipes or hesperus.

\section{Allotype: o ; same data as type. [Hebard Collection.]}

Size larger, form heavier than in male. Fastigium of vertex distinctly broader and less deeply sulcate than in male. Eye very slightly more than twice as long as infra-ocular sulcus. Pronotum with lateral carinae even weaker than in male. Tegmina separated by a very brief interval. ${ }^{55}$ Size smaller than in gracilipes, form more slender, and caudal femora proportionately smaller.

${ }_{52}$ Varying individually from parallel to rather strongly divergent.

${ }^{53}$ This is an intensification of the type found in nanus. Frequent slight individual variation is shown and in a few specimens, showing least decided contour of the supra-anal plate, little difference from nanus in this feature is found.

${ }^{54}$ Among the paratypes of nanus, as well as in a larger series of that species before us, the subgenital plate, though normally with a well developed apical tubercle, varies through a condition in which this tubercle is weak, to one in which the margin of the subgenital plate is rounded with no trace of a tubercle. As these species are very closely related, we might expect to find males of microtatus occasionally lacking an apical tubercle, but such is not the case in the very large series at hand, though some slight difference in degree is occasionally shown.

${ }^{55} \mathrm{In}$ females of the present series averaging about $.4 \mathrm{~mm}$.; in the series of females of nanus averaging about $.9 \mathrm{~mm}$. 


\begin{tabular}{|c|c|c|c|c|c|c|}
\hline$\sigma^{\pi}$ & $\begin{array}{c}\text { Measurem } \\
\text { Length of } \\
\text { body }\end{array}$ & $\begin{array}{l}\text { Length of } \\
\text { pronotum }\end{array}$ & $\begin{array}{l}\text { limeters) } \\
\text { Caudal } \\
\text { width of } \\
\text { pronotal } \\
\text { disk }\end{array}$ & $\begin{array}{l}\text { Length of } \\
\text { tegmen }\end{array}$ & $\begin{array}{c}\text { Width of } \\
\text { tegmen }\end{array}$ & $\begin{array}{l}\text { Length of } \\
\text { caudal } \\
\text { femur }\end{array}$ \\
\hline $\begin{array}{l}\text { Del Monte, Cal- } \\
\text { fornia, type . }\end{array}$ & 11.8 & 2.9 & 1.6 & 2 & 1.7 & 7.3 \\
\hline $\begin{array}{l}\text { Del Monte, Cal- } \\
\text { ifornia, para- } \\
\text { types (170) } \\
\\
\varnothing\end{array}$ & $11.7-14.7$ & $2.7-3.2$ & $1.5-1.8$ & $1.8-2.7$ & $1.3-1.8$ & $7-8.8$ \\
\hline $\begin{array}{l}\text { Del Monte, Cal- } \\
\text { ifornia, allo- } \\
\text { type....... }\end{array}$ & - & - $\quad 3.1$ & 2 & 2.3 & 1.8 & 8.8 \\
\hline $\begin{array}{l}\text { Del Monte, Cal- } \\
\text { ifornia, para- } \\
\text { types (152) .. }\end{array}$ & - $13-18.2$ & $2.9-3.9$ & $1.8-2.5$ & $2.2-3.7$ & $1.8-2.3$ & $8.1-10.7$ \\
\hline $\begin{array}{l}\text { Monterey, Cali- } \\
\text { fornia ....... }\end{array}$ & 17 & 3.9 & 2.5 & 3.2 & 2.2 & 10 \\
\hline
\end{tabular}

Coloration.-As described for hesperus on page 284, except that the type and a large proportion of the series are more intensive in coloration. In these the occiput, disk of pronotum and tegmina are blackish chestnut brown, the postocular bar and dorsal third of the prozonal portion of the pronotal lateral lobes shining black. The lateral dark markings of the abdomen are expanded and deepened into a suffused blackish band, which narrows distad, but is continued on the subgenital plate as a dark suffusion. The femora have the pagina very dark prout's brown, with an oblique line of light buff dorso-mesad and are bordered ventrad with warm buff, this widest proximad; the dark areas on the internal portion of the dorsal surface are prout's brown, while the internal face is suffused with prout's brown meso-distad and dorso-mesad. This intensive type of coloration is found in females, but not as frequently as in males.

Every gradation is shown by the series of females to a maximum recessive condition, in which the general coloration is clay color, the postocular band subobsolete on head and lateral lobes of pronotum, the dark lateral abdominal band indicated by three small suffusions of prout's brown on the proximal abdominal segments.

Specimens Examined: $327 ; 172$ males and 155 females.

California: Santa Cruz, Monterey and Del Monte.

The entire series, with the exception of three specimens, was taken at Del Monte on August 20, 1909, by Hebard and on September 9 and 10, 1910, by Rehn and Hebard. Excluding the type and allotype, these are designated as paratypes. The species was found in great numbers in extensive open areas of short, dry grass, where a low yellow-flowered "tar-weed" was

TRANS. AM. ENT. SOC., XLV. 
plentiful. It was, however, almost ubiquitous and in the heavy chaparral, where Orthoptera was not abundant, some of the darkest examples were secured.

One female was taken at Monterey on July 4, 1916, by G. P. Englehardt, while a pair was secured by Hebard at Santa Cruz, Santa Cruz County, on August 28, 1907. The male of this pair is somewhat atypical in having the cerci straighter and more slender distad than in any of the typical series.

Melanoplus aspasmus ${ }^{56}$ new species (Plate XXX, figs. 9 and 10; plate XXXI, fig. 4.)

This is a striking species of the Marginatus Group. It shows no close relationship to any of the other species. The fastigiofacial angle is as blunt as in $M$. gracilipes Scudder, the furcula resemble more closely those found in $M$. hesperus here described and the cerci to some degree suggest those of $M$. microtatus here described.

The insect is the most robust of the group and is distinctive in the form of the male genitalia, particularly that of the subgenital plate, which is rounded with free margin flaring outward evenly throughout.

Type.- $0^{7}$; Paso Robles, San Luis Obispo County, California. August 21, 1909. (M. Hebard.) [Hebard Collection, Type no. 506.]

Size small, slightly smaller than in gracilipes. Form moderately stout, distinctly the heaviest species of the Marginatus Group, many of the species of which are very slender. Surface moderately well supplied with long pile, this most noticeable on caudal limbs and subgenital plate. Head of the same type as in gracilipes, but not as deep, the fastigio-facial angle even blunter, the face distinctly less strongly retreating; the frontal costa wide, as wide as in gracilipes, showing only slight concavity toward the median ocellus..57 Eye large, distinctly broader than in gracilipes or the species closely related, about two and one-quarter times as long as infra-ocular sulcus. Pronotum moderately elongate, proportionately distinctly shorter than in gracilipes or the related species; lateral carinae subobsolete, as in gracilipes; caudal margin of disk obtuse-angulate produced, with angulation rather sharp, production greater than in gracilipes or any other species of the Marginatus Group, but of the same type found in $M$. marginatus Scudder. Prosternal spine bluntly conical, distinctly shorter than in gracilipes. Tegmina attingent, broad oval with

${ }^{56}$ From á $\sigma \pi a \sigma \mu \dot{o}^{\prime}=$ striking.

${ }^{57}$ In one paratypic male the lateral margins of the frontal costa are moderately carinate, the surface of the frontal costa resultantly shallowly concave, much as is normal in $M$. huporeus here described. 
apex rather broadly rounded, ${ }^{58}$ distinctly shorter than pronotum, attingent. Furcula represented by a pair of elongate processes, which diverge at an angle of about ninety degrees, tapering from their heavy and attingent bases to their slender and sharply rounded apices, nearly three times as long as basal width, length contained in that of supra-anal plate less than two and one-half times. Supra-anal plate trigonal shield-shaped, medio-longitudinal sulcus percurrent, but strongly defined only in proximal three-fifths, lateral portion deeply concave, the lateral margins strongly raised and thickened proximad, with a flexure at end of proximal third, thence gradually diminishing in height and weakly concave opposite apices of cerci at beginning of apical third; the apical portion beyond deplanate with a small node latero-proximad on each side. Between the supra-anal plate and the cerci a portion of a basal plate is conspicuously extruded, this causing the elevation of the lateral margins of the plate. Cerci suggesting those of $M$. microtatus here described, but distinctly more complex; about twice as long as proximal width, broad proximad, tapering strongly in proximal half, this due to the strong concavity of the dorsal margin, distal half relatively slender, of nearly subequal width, dorsal and ventral margins feebly convex to rounded apex, length about twice median (greatest) width, external surface longitudinally concave below median line. Subgenital plate with dorso-lateral angles at free margin rectangulate and rather sharply rounded, more sharply rounded and prominent than in any other species of the Marginatus Group; free margin of almost equal thickness and convexity throughout, somewhat more thickened mesad but showing no trace of tuberculation; median section of plate of almost equal depth laterad and mesad; surface flaring outward to free margin evenly throughout, this type distinctive and wholly unlike that developed in any other species of the Marginatus Group. Limbs much as in gracilipes, except that the caudal femora are distinctly shorter and heavier.

\section{Allotype.- o ; same data as type. [Hebard Collection.]}

Size larger, form heavier than in male, ${ }^{59}$ resultantly heavier than in any females of the Marginatus Group. Fastigium of vertex distinctly broader and less deeply sulcate than in male. Eye proportionately much as in male. Pronotum with lateral carinae subobsolete, obtuse angulation of caudal margin somewhat broader but similarly rather sharp. Tegmina attingent (to separated by a brief interval in the series), (normally) rather broadly rounded distad. Limbs with caudal femora as distinctly shorter than in the related species as in male.

Coloration.-Male (intensive). General coloration clay color tinged with cinnamon. Eyes russet. A postocular bar, continued on the prozonal portion of the lateral lobes and broadening caudad, is shining blackish mummy brown. Tegmina tinged with cinnamon brown, particularly laterad. Proximal segments of abdomen marked dorso-laterad with moderately large maculae

${ }^{58}$ Normally thus in males, apex occasionally rather sharply rounded; apex averaging more broadly rounded in females.

${ }^{59} \mathrm{It}$ is to be remembered that males of aspasmus are as heavy as females of microtatus.

TRANS. AM. ENT. SOC., XLV. 
of shining blackish mummy brown. Caudal femora with internal portion of dorsal surface showing two patches of dark brown, these continued on the internal face, and pagina tinged with dark brown dorsad in corresponding position. Caudal tibiae buffy, faintly tinged with glaucous.

The series shows variation to a recessive type (one male) in which the entire insect is ochraceous-buff, the postocular bar on head and pronotum obsolete, the markings of the caudal femora subobsolete, the caudal tibiae buffy. This recessive condition is in preponderance among females of the present series, fourteen being quite as immaculate, while but two of the remainder are strongly intensive.

This color pattern and similar intensification and recession is likewise found in other species of the Marginatus Group, but in none have we found as large a proportion of strongly recessive examples.

\begin{tabular}{|c|c|c|c|c|c|c|}
\hline & \multicolumn{6}{|c|}{ Measurements (in millimeters) of extremes only } \\
\hline & $\begin{array}{l}\text { Length of } \\
\text { body }\end{array}$ & $\begin{array}{l}\text { Length of } \\
\text { pronotum }\end{array}$ & $\begin{array}{l}\text { Caudal width of } \\
\text { pronotal disk }\end{array}$ & $\begin{array}{l}\text { Length of } \\
\text { tegmen }\end{array}$ & $\begin{array}{l}\text { Width of } \\
\text { tegmen }\end{array}$ & $\begin{array}{l}\text { Length of } \\
\text { caudal femur }\end{array}$ \\
\hline$\sigma^{\pi}$ & & & & & & \\
\hline Type. & 15.3 & 3.8 & 2 & 2.9 & 2.1 & 8.7 \\
\hline $\begin{array}{c}\text { Paratypes (7) } \\
\text { ㅇ }\end{array}$ & $.14-15.8$ & $3.2-3.7$ & $2-2.1$ & $2.6-3.7$ & $2-2.3$ & $8-8.8$ \\
\hline Allotype. & 16.2 & 3.8 & 2.5 & 3.2 & 2.4 & 8.9 \\
\hline Paratypes (19) & $15.2-18$ & $3.7-4$ & $2.7-2.9$ & $2.9-3.7$ & $2.2-2.6$ & $8.5-9.9$ \\
\hline
\end{tabular}

Specimens Examined: $28 ; 8$ males and 20 females.

California: Paso Robles.

The entire series, which in addition to the type and allotype may be considered paratypic, was taken at Paso Robles, California, on August 21, 1909, by the author. The species was found at elevations of from 750 to 900 feet in the low, dry, suncured, yellow grass, on hillsides dotted with oaks. Though not common, this was the most abundant species of Orthoptera encountered at this locality.

Melanoplus acidocercus ${ }^{60}$ new species (Plate XXXI, fig. 6.)

The present insect is a member of the Scudderi Group, showing nearest affinity to $M$. carnegiei Morse (see plate XXXI, fig. 5). Compared with that species it is found to be of average larger size, showing certain differences of color pattern, while the tegmina average broader. Males are, in addition, readily distinguished by the form of the cercus: in acidocercus the cercus is decidedly more elongate, averaging one and one-half times as long as basal width, tapering to the acute and slender apex; in carnegiei the cercus is short, averaging about as long as its basal

${ }^{60}$ From ákis=pointed (acute), and cercus. 
width, triangular, with apex acute, but not at all slenderly produced..$^{61}$

In general appearance the present insect is about intermediate between $M$. scudderi (Uhler) and Eotettix quercicola Hebard. It is evident that this species represents the type in the genus Melanoplus showing nearest approach to that section of the genus Eotettix which includes quercicola and davisi Hebard. The two latter species have a distinctive facies; in being more polished with coloration more brilliant, particularly in life, in showing distinctive features in color pattern and in having larger heads with antennae much more elongate.

The resemblance of the present species lies largely in the general, though not detailed, similarity of coloration, coupled with a very slightly greater smoothness than found in the allied species of Melanoplus.

Type.- $\sigma^{7}$; Bainbridge, Decatur County, Georgia. September 5 and 6, 1915. (Rehn and Hebard.) [Hebard Collection, Type no. 508.]

Size slightly larger, form slightly more elongate than in scudderi, much as in lowland series (Yemassee, South Carolina) of carnegici. Fastigium of vertex and frontal costa similar, but slightly more sulcate; sulcus weak but distinct throughout, well defined between the lateral ocelli. Antennae normal, about one and three-quarters times as long as pronotum, as in carnegiei. Eye slightly longer than cheek, about one and three-quarters times as long as infra-ocular sulcus. Pronotum much as in scudderi; the percurrent median carina, cut only by principal sulcus, very slightly heavier, about as well developed as in Eotettix davisi and quercicola; caudal margin of pronotum obtuse-angulate produced (at about $120^{\circ}$ ) with angulation broadly rounded, more produced than in Eotettix davisi or quercicola. Tegmina broad oval, overlapping.62 Distal portion of abdomen scarcely enlarged. Furcula as in carnegiei, represented by two minute projections, the areas from which they spring enlarged and separated by a subrectangulate emargination. Supra-anal plate as in carnegiei; shield-shaped, with a decided medio-longitudinal sulcus in proximal half, lateral portions broadly concave, distal portion nearly deplanate. Cercus slightly over one and one-half times as long as basal width, margins rather

${ }^{61}$ Some slight individual variation is shown by the series of that species at hand. One male, of two from Atlanta, Georgia, has the cercus approaching the condition found in acidocercus much more closely than in any other specimens. In this individual the cercus is nearly one and one-half times as long as its basal width, but much broader distad than in any specimen of acidocercus at hand. The other Atlanta male of carnogiei has perfectly typical cerci.

${ }^{62}$ Varying to attingent in a very few males of the series.

TRANS. AM. ENT. SOC., XLV. 
decidedly convergent in proximal half, thence less strongly convergent to the acute apex, dorsal margin broadly concave, ventral margin nearly straight. Subgenital plate as in carnegiei; short, tapering to the bluntly rounded apex. Limbs as in carnegiei.

\section{Allotype.- ㅇ ; same data as type. [Hebard Collection.]}

Size decidedly larger, form decidedly more robust than in male. Resembling females of Eotettix quercicola except that it is smaller, with head proportionately distinctly smaller, antennae shorter, disk of pronotum showing no gloss, caudal margin of pronotum less produced and caudal tibiae less heavy. Fastigium of vertex and frontal costa wider than in male, briefly deplanate in area between lateral ocelli and antennal sockets. Eye slightly longer than cheek, about one and one-half times as long as infra-ocular sulcus. Tegmina well overlapping. ${ }^{63}$ Ovipositor valves moderately elongate, moderately curved distad to their acute apices, much as in Eotettix quercicola, appreciably more curved than in carnegiei. Interspace between mesosternal lobes scarcely longer than broad. Limbs as in male but heavier, much as in females of Eotettix quercicola, but with caudal tibiae distinctly less strongly pilose.

\begin{tabular}{|c|c|c|c|c|c|c|}
\hline & & & 0 & $e$ & only & \\
\hline & $\begin{array}{l}\text { Length } \\
\text { of } \\
\text { body }\end{array}$ & $\begin{array}{c}\text { Length } \\
\text { of } \\
\text { pronotum }\end{array}$ & $\begin{array}{l}\text { Caudal width } \\
\text { of } \\
\text { pronotal disk }\end{array}$ & $\begin{array}{l}\text { Length } \\
\text { of } \\
\text { tegmen }\end{array}$ & $\begin{array}{c}\text { Width } \\
\text { of } \\
\text { tegmen }\end{array}$ & $\begin{array}{l}\text { Length of } \\
\text { caudal } \\
\text { femur }\end{array}$ \\
\hline$\sigma^{\pi}$ & & & & & & \\
\hline Type... & 18.7 & 5 & 3 & 3.7 & 2.9 & 11.1 \\
\hline aratypes & $18.5-20$ & $4.8-5.2$ & $2.9-3.1$ & $3.2-4.6$ & $2.8-3.2$ & $10.4-11.6$ \\
\hline 우 & & & & & & \\
\hline Allotype & 25 & 6.4 & 4.2 & 5. & 4 & 14.1 \\
\hline Paratypes & $.2-25.7$ & $5.8-6.7$ & $3.8-4.4$ & $4-6$ & $3.9-4.1$ & $12.8-14.4$ \\
\hline
\end{tabular}

Coloration.-Male. Almost identical with material of carnegiei from the lowland pine woods (Yemassee, South Carolina); more tawny and less grayish than highland material of that species. Face, underparts, cephalic and median limbs and lower portion of pronotal lataral lobes clay color. Antennae russet, becoming darker distad. Eyes deep chestnut. Occiput, pronotal disk and tegmina mars brown. A moderately broad, shining, black postocular band expands caudad on the prozonal portion of the pronotal lateral lobes, filling more than half that surface and continued on the metazonal portion, but there not shining. Metapleura without a pale bar. Abdomen sayal brown weakly suffused with mars brown proximad. Caudal femora sayal brown, the genicular areas and two weak transverse suffusions of the dorsal surfaces blackish. Caudal tibiae coral red, well supplied with whitish pile, spines entirely black.

In recessive males the occiput and disk of pronotum are often as pale as the caudal femora, while the transverse bands of the dorsal surfaces of the caudal femora become obsolete.

Female. Generally cinnamon; lateral lobes of pronotum and caudal femora slightly darker, mikado brown. Postocular bar subobsolete. Tegmina with veins cinnamon and interspaces verona brown. Caudal femora slightly paler

${ }^{63}$ To (rarely) subattingent in females before us. 
than general coloration, pinkish cinnamon, with genicular areas warm sepia and dorsal surfaces showing two broad transverse bands of mikado brown. Caudal tibiae as in male.

In females of maximum recessive coloration the entire insect is pinkish cinnamon, the postocular bar obsolete, the tegmina and dorsal surfaces of the caudal femora practically immaculate.

Specimens Examined: 84; 41 males, 37 females and 6 immature females.

Georgia: Bainbridge.

The entire series of adults, in addition to the type and allotype, may be considered paratypes. The series was taken by Rehn and Hebard on September 5 and 6, 1915. The species was found common in oak shoots in areas of sandy soil overgrown with oaks, and occasional among the scant grasses and plants growing on sandy soil, in the higher areas of the long-leaf pine woods near Bainbridge. Its habits much resembled those of scudderi.

Although this species was the sole member of the group found generally distributed in the oak and long-leaf pine woods at Bainbridge, it was absent from the undergrowth of the long-leaf pine woods growing in the narrow strip of flood-plain bordering the Flint River. In this latter locality, among scant plants, grasses and vines, scudderi, instead, was found.

Melanoplus pegasus new species (Plate XXXI, fig. 8.)

1916. Melanoplus furcatus Rehn and Hebard (not Melanoplus furcatus Scudder, 1897), Proc. Acad. Nat. Sci. Phila., 1916, p. 244. [Billy's Island, Jordan's on Billy's Island and Honey Island, all in Okeefenokee Swamp, Georgia.]

The present insect is closely selated to $M$. furcatus Scudder (see plate XXXI, fig. 7), and belongs to the Clypeatus Group. From furcatus it differs in the more solid coloration, in this respect closely resembling $M$. clypeatus (Scudder), and in the form of the male cerci, which show a further specialization of the type found in furcatus, the branches of the forked distal portion being more elongate and slender, and the ventral branch exceeding the dorsal branch in length.

With the unique male, type of furcatus, and a single male of the present species before them, Rehn and Hebard were, in 1916, unable to ascertain whether the differences found were specific

TRANS. AM. ENT. SOC., XLV. 
or due merely to individual variation. The series now at hand is constant in these differences, sufficient in our opinion for full specific separation.

Type.- $\sigma^{7}$; Billy's Island, Okeefenokee Swamp, Charlton County, Georgia. July 16 to 19, 1917. (M. Hebard.) [Hebard Collection, Type no. 515.]

Size large, form robust but graceful. Fastigium of vertex feebly sulcate, frontal costa subsulcate except at median ocellus; as in furcatus. Antennae elongate, nearly twice as long as pronotum. Eye large, longer than cheek, twice as long as infra-ocular sulcus. Pronotum as in furcatus; medio-longitudinal carina distinct but not well developed on prozona, well developed on metazona, cut by sulci; lateral margins of disk distinct, rounding into the almost vertical lateral lobes; caudal margin of disk obtuse-angulate produced with angle rounded but rather sharp. Tegmina and wings almost reaching apex of abdomen. ${ }^{64}$ Distal portion of abdomen enlarged. Furcula indicated as weak convexities on the segment from which these appendages spring when present, ${ }^{65}$ the segment between these broadly angulate emarginate. Supraanal plate as in clypeatus; very broadly shield-shaped and minutely triangularly produced meso-distad; medio-longitudinal carina deep and narrow in proximal two-thirds, thence weak, laterad of which sulcus the plate is broadly concave. Cercus moderately heavy, narrowing rather strongly to mesal portion, thence widening as strongly, strongly furcate; dorsal portion of furcation nearly twice as long as broad, with surface weakly concave, lateral margins feebly convex, subparallel and apex truncate with angles rounded; ventral portion of furcation distinctly longer than dorsal portion, broader at base, tapering evenly to the bluntly rounded apex, the dorsal portion of this margin, particularly distad, (frequently) sublamellate. Subgenital plate as in furcatus; moderately shallow, free margin briefly ascendant beyond cercal apices to the apex, which is slightly elevated in consequence, truncate, over twice as broad as high. Limbs as in furcatus.

\section{Allotype.- $\%$; same data as type. [Hebard Collection.]}

Size larger, form more robust than male, averaging not quite as heavy as in females of furcatus. Fastigium of vertex broader and scarcely concave. Tegmina and wings reaching base of supra-anal plate. ${ }^{66}$ Ovipositor valves much as in furcatus; dorsal valves moderately recurved, ventral valves very weakly decurved. Limbs proportionately as in males.

${ }^{64}$ In paratypic males from reaching to slightly beyond base of supra-anal plate, to reaching slightly beyond apex of abdomen.

${ }^{65}$ In paratypic males varying from practically obsolete (frequent) to having minute angulations caudad of the margin of the segment (one specimen).

${ }^{66}$ In paratypic females showing very little variation. Two with abdomen pressed out have the abdomen extending considerably beyond the tegminal apices for this reason solely. 
Measurements (in millimeters) of extremes only

\begin{tabular}{|c|c|c|c|c|c|}
\hline & $\begin{array}{l}\text { Length of } \\
\text { body }\end{array}$ & $\begin{array}{l}\text { Length of } \\
\text { pronotum }\end{array}$ & $\begin{array}{c}\text { Caudal } \\
\text { width of } \\
\text { pronotal disk }\end{array}$ & $\begin{array}{l}\text { Length of } \\
\text { wing }\end{array}$ & $\begin{array}{l}\text { Length of } \\
\text { caudal femur }\end{array}$ \\
\hline \multicolumn{6}{|c|}{ 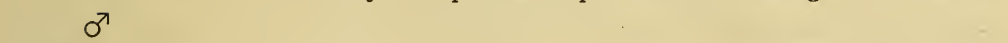 } \\
\hline rype... & 31.8 & 7.6 & 4.6 & 19.7 & 17.8 . \\
\hline $\begin{array}{l}\text { aratypes (23) } \\
\text { 우 }\end{array}$ & $29.9-$ & 7.2 & $4.1-4.7$ & $19.4-22.7$ & $17.9-18.9$ \\
\hline lllotype. & 37 & 8 & 5.3 & 21.3 & 21 \\
\hline aratypes & $.4-37.7$ & $8.2-9.2$ & $5-5.4$ & $19.3-22.2$ & $20-21.3$ \\
\hline
\end{tabular}

Coloration.-Head and pronotum chestnut brown, a narrow post-ocular bar of dark chestnut brown continued feebly along the dorsal margin of the prozonal portion of the pronotal lateral lobes. Antennae hazel, darker distad. Eyes blackish brown. Dorsal field of tegmina buffy, heavily suffused with chestnut brown, particularly proximad; lateral fields dark chestnut brown. Underparts and abdomen cinnamon brown, the latter slightly paler. Metapleura cinnamon brown, with an oblique bar of buffy. Cephalic and median femora hessian brown, a purplish-red tinge distinct. Caudal femora with pagina cinnamon brown, suffused with blackish brown at apex, ventral margin strikingly straw yellow, this bar slightly broader proximad than distad, there slightly invading the pagina itself. Ventral surface of caudal femora brick red, becoming dragon's-blood red in sulcate portion, margined externally at margin of straw yellow bar with a few black dots, which fuse into a black line proximad and distad, distad occurs a broad pregenicular annulus of light buff. Caudal femora with dorso-external surface immaculate cinnamon brown with a russet tinge; dorso-internal surface tawny, with three moderately well defined suffusions of blackish chestnut brown, one of which is proximad, the most distal the broadest. Internal surface of caudal femora proximad suffused with dragon's-blood red, shading into carnelian red dorsad, the second dorsal suffusion broader and darker in dorsal half only, the third blackish and much broader and crossing the entire internal surface, pregenicular annulus warm buff and nearly as broad, genicular area externally and internally blackish except for the lobes which are buffy. Caudal femora dragon's-blood red, except for a very narrow blackish suffusion proximad and the spines, which are wholly black.

The series of males varies in general coloration from prout's brown dorsad and tawny olive laterad, to a maximum intensive condition in which the head and pronotum are blackish chestnut brown, with a comparatively broad blackish postocular bar, while the lateral fields of the tegmina are darker than the pronotum.

The females are very similar in coloration. They are a trifle less brilliant and the markings are more suffused, while the dorsal field of the tegmina averages paler, weak ochraceous-tawny, usually with a few scattered and inconspicuous flecks of darker brown.

In the series of adults, the pale ventro-external bar of the caudal femora is a conspicuous feature, much more sharply defined than in furcatus, while in that

TRANS. AM. ENT. SOC., XLV. 
species the femoral dark areas are less solid and the median dark area extends on the pagina. The coloring of the lateral fields of the tegmina is also less solid in furcatus, in some specimens heavily flecked with darker brown.

Specimens Examined: 55; 24 males, 13 females, 3 immature males and 15 immature females.

Georgia: Billy's Island, Jordan's on Billy's Island and Honey Island, all in Okeefenokee Swamp.

In addition to the type and allotype, the adults are designated paratypes. The entire series, excepting those previously recorded, was taken by the author, on Billy's Island, from July 16 to $19,1917$.

This species was found in moderate numbers, the series being taken only after long and careful search through the proper areas. It was found in thick, rich, bushy undergrowth surrounding wet depressions filled with swamp-loving trees, these areas scattered through the long-leaf pine woods. Only in these thick margining zones of rich vegetation, growing about waist high, were specimens found. The males frequently flew short distances in a direct, plunging manner, the females were less likely to fly and were more difficult to locate.

In such environment we have found that all the species related to clypeatus occur. Thus all are extremely local in distribution and are easily overlooked. This probably accounts for the difficulty we had long experienced in securing series of any of these species. The present species probably reaches the maximum in number of adults about the beginning of August. The latest date we have for adults is September 1 to 5 . 


\section{EXPLANATION OF PLATES}

\section{Plate XXIX}

Fig. 1.-Hesperotettix pacificus capillatus new race. Lateral outline of male (type). $\left(\times 2 \frac{1}{2}\right)$

Fig. 2.-Aeoloplus eremiaphila new species. Lateral outline of male (type). $\left(\times 2 \frac{1}{2}\right)$

Fig. 3.-Aeoloplus eremiaphila new species. Lateral outline of tegmen of female, showing maximum tegminal development in series. Pilot Mountains, Nevada. $\left(\times 2 \frac{1}{2}\right)$

Fig. 4.-Oedaleonotus fratercula new species. Lateral outline of male (type). $\left(\times 2 \frac{1}{2}\right)$

Fig. 5.-Oedaleonotus phryneicus new species. Dorsal outline of pronotum of female (allotype). $\quad\left(\times 2 \frac{1}{2}\right)$

Fig. 6.-Oedaleonotus phryneicus new species. Lateral view of female (allotype). $\left(\times 2 \frac{1}{2}\right)$

Fig. 7.-Oedaleonotus tenuipennis (Scudder). Dorsal outline of pronotum of female. San Gabriel Mountains, California. $\left(\times 2 \frac{1}{2}\right)$

Fig. 8.-Asemoplus somesi new species. Furcula and supra-anal plate of male (type). (Greatly enlarged.)

Fig. 9.-Asemoplus somesi new species. Outline of cercus of male (type). (Greatly enlarged.)

Fig. 10.-Bradynotes obesa (Thomas). Outline of cercus of male. Helena, Montana. (Greatly enlarged.)

Fig. 11.-Bradynotes pinguis Scudder. Outline of cercus of male (type). (Same scale as fig. 10.)

Fig. 12.-Bradynotes kaibab new species. Outline of cercus of male (type). (Same scale as fig. 10.)

Fig. 13.-Bradynotes deplanata new species. Outline of cercus of male (type). (Same scale as fig. 10.)

Fig. 14.-Bradynotes compacta Morse. Outline of cercus of male (paratype). (Same scale as fig. 10.)

\section{Plate XXX}

Fig. 1.-Bradynotes pinguis Scudder. Dorsal view of pronotum of male

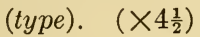

Fig. 2.-Bradynotes deplanata new species. Dorsal view of pronotum of male

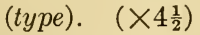

Fig. 3.-Melanoplus huporeus new species. Furcula and supra-anal plate of male (type). (Greatly enlarged.)

Fig. 4.-Melanoplus gracilipes Scudder. Cercus of male (type). (Greatly enlarged.)

Fig. 5.-Melanoplus hesperus new species. Furcula and supra-anal plate of male (type). (Greatly enlarged.)

TRANS. AM. ENT. SOC., LXV. 
Fig. 6.-Melanoplus hesperus new species. Cercus of male (type). (Same scale as fig. 4.)

Fig. 7.-Melanoplus microtatus new species. Furcula and supra-anal plate of male (type). (Same scale as fig. 5.)

Fig. 8.-Melanoplus microtatus new species. Cercus of male (type). (Same scale as fig. 4.)

Fig. 9.-Melanoplus aspasmus new species. Furcula and supra-anal plate of male (type). (Same scale as fig. 5.)

Fig. 10.-Melanoplus aspasmus new species. Cercus of male (type). (Same scale as fig. 4.)

\section{Plate XXXI}

Fig. 1.-Melanoplus marginatus Scudder. Cercus of male. Ahwahnee, California. (Greatly enlarged.)

Fig. 2.-Melanoplus huporeus new species. Cercus of male (type). (Same scale as fig. 1.)

Fig. 3.-Melanoplus hesperus new species. Caudal view of subgenital plate of male (type). (Greatly enlarged.)

Fig. 4.-Melanoplus aspasmus new species. Caudal view of subgenital plate of male (type). (Same scale as fig. 3.)

Fig. 5.-Melanoplus carnegiei Morse. Outline of cercus of male. Asheville, North Carolina. (Greatly enlarged.)

Fig. 6.-Melanoplus acidocercus new species. Outline of cercus of male (type). (Same scale as fig. 5.)

Fig. 7.-Melanoplus furcatus Scudder. Cercus of male (type): (Greatly enlarged.)

Fig. 8.-Melanoplus pegasus new species. Cercus of male (type). (Same scale as fig. 7.) 

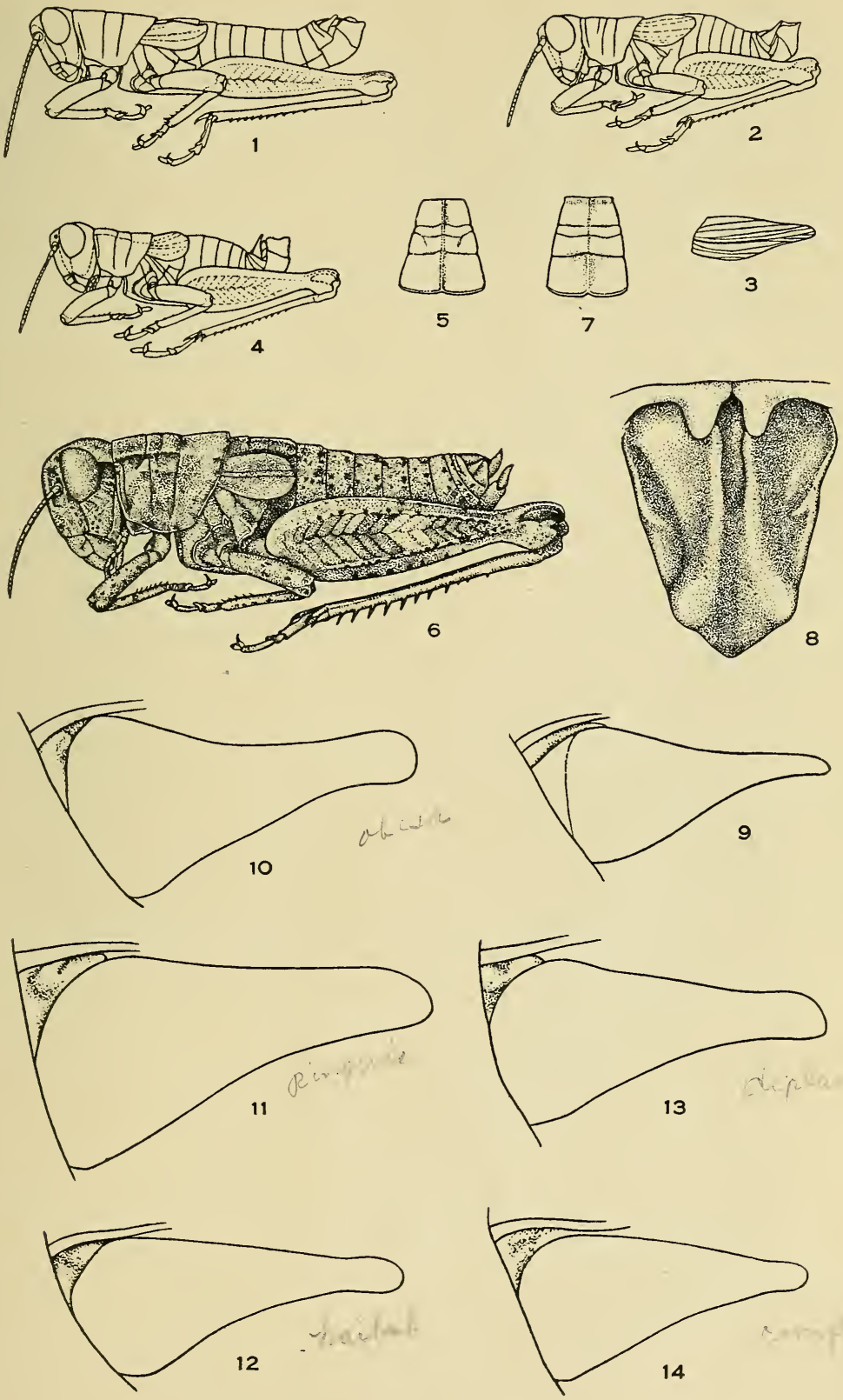

HEBARD-NEW NORTH AMERICAN MELANOPLI 

Trans. Am. Ent. Soc., Vol. XLV.

PI. XXX.
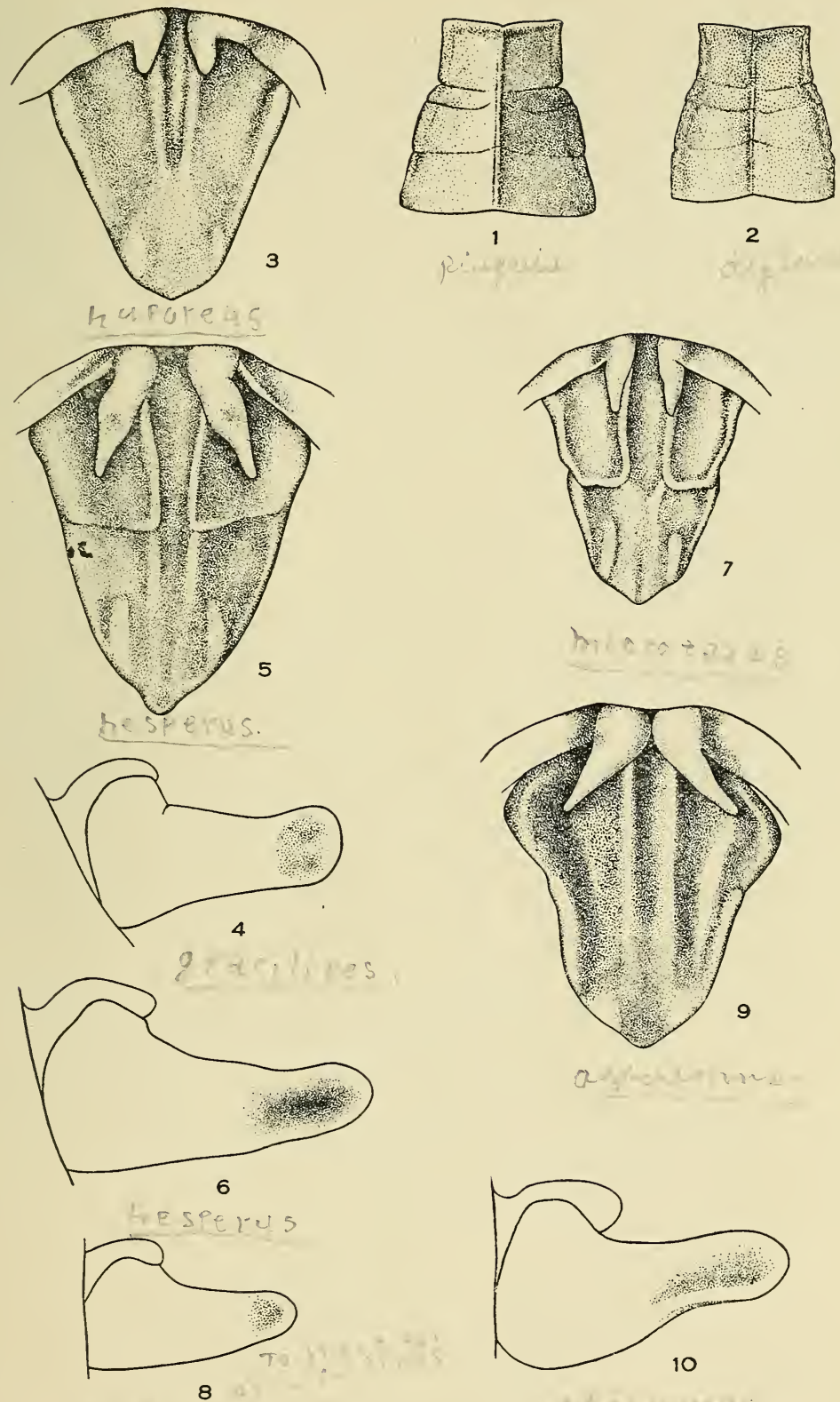

HEBARD-NEW NORTH AMERICAN MELANOPLI 

Trans. Am. Ent. Soc., Vol. XLV.

PI. XXXI.
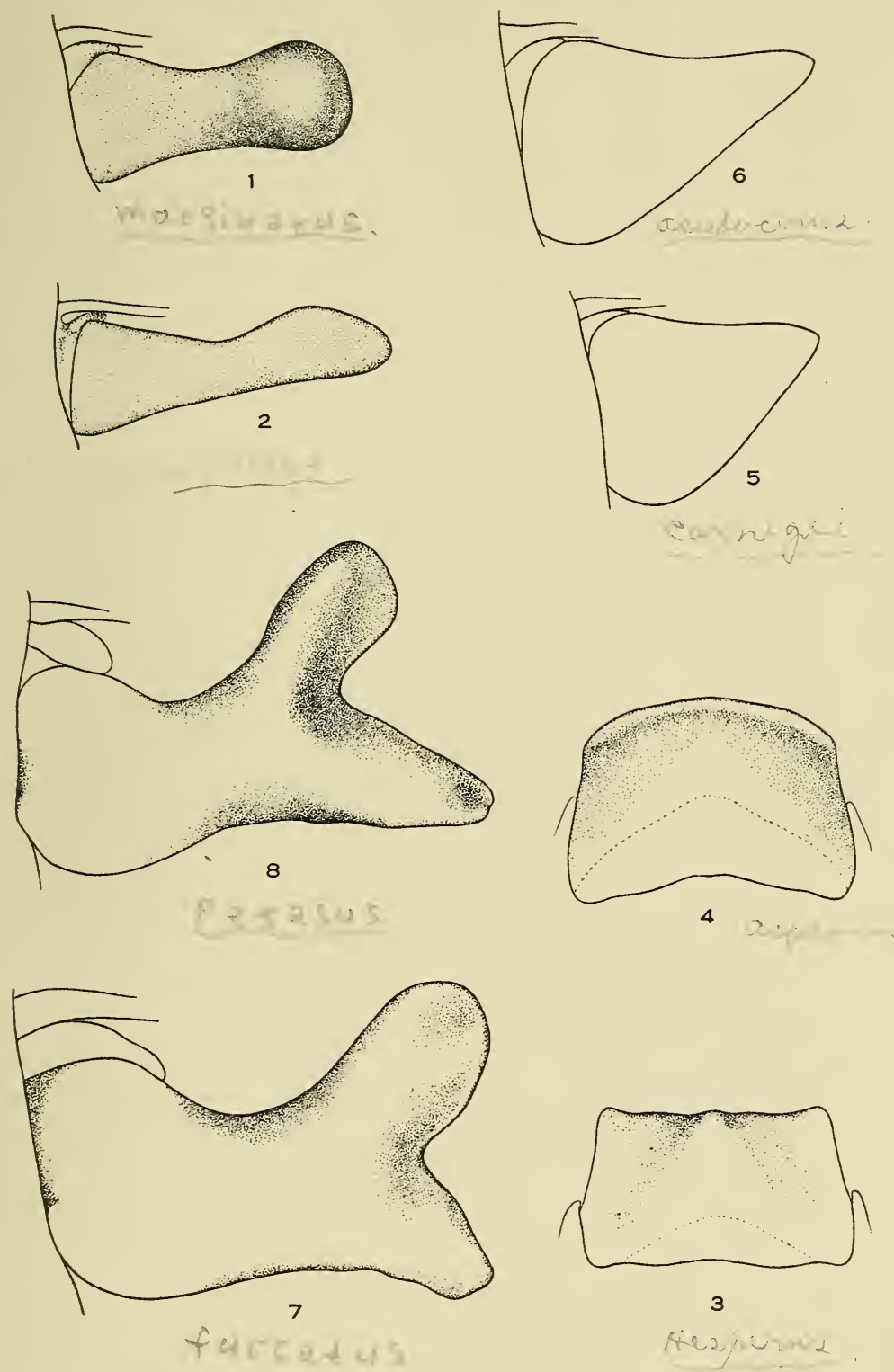

HEBARD-NEW NORTH AMERICAN MELANOPLI 




NEW GENERA AND SPECIES

$\mathrm{OF}$

MELANOPLI

' FOUND WITHIN THE UNITED STATES

(ORTHOPTERA; ACRIDIDAE)

$$
\text { Part III }
$$

by

\section{Morgan Hebard}

From the Transactions of The American Entomological Society, xlvi, 355-403 Issued

No. 808

LEC 14 '2U 



\title{
NEW GENERA AND SPECIES OF MELANOPLI FOUND WITHIN THE UNITED STATES \\ (ORTHOPTERA; ACRIDIDAE)
}

\author{
BY MORGAN HEBARD
}

\section{Part III}

For over five years preliminary work has now been progressing in preparation of the series of the Melanopli, in the Philadelphia Collections, for revisionary treatment of this group as found within the United States.

A large number of the species are found abundantly over extensive areas and the problem of handling series of very large size has proved difficult. In order to avoid original descriptions in the final work, which will in itself necessarily be very large, we have, in the sorting, put aside the material representing new species or races, and have followed the plan of publishing on all of these in advance of the comprehensive treatment.

The present paper is the third of the resultant publications, of which our "Notes on Mexican Melanopli" might be said to be the forerunner, as indicating the general arrangement, as understood by us, of the Melanopli known from that country. In our first paper, ${ }^{2}$ only species other than those of the genus Melanoplus were treated. In the second, ${ }^{3}$ a number of species of Melanoplus were described. Since that time the general affinities as indicated by us have required no readjustment, except that in the genus Melanoplus the order throughout has been reversed.

The present linear arrangement of the genus Melanoplus, which places the majority of the macropterous species first and the brachypterous species last, is used by Morse in his recent most excellent treatment of the New England species. ${ }^{4}$ The reason is that brachypterism in the Melanopli indicates specialization from a macropterous and more primitive type. In the

${ }^{1}$ Proc. Acad. Nat. Sci., Phila., 1917, pp. 251 to 275, (1917).

${ }^{2}$ Trans, Am. Ent. Soc., xuIv, pp. 141 to 169, (1918).

${ }^{3}$ Trans. Am. Ent. Soc., XLv, pp. 257 to 298, (1919).

${ }^{4} \mathrm{Manual}$ of the Orthoptera of New England. Proc. Boston Soc. Nat. Hist., xxxv, pp. 197 to 556, (1920).

TRANS. AM. ENT. SOC., XLVI. 
system of linear arrangement we strive to place the simplest forms first in a genus, grading up to the type of highest specialization.

The number of new species described in these preliminary papers is apparently large, but, considering the great size of the series now assembled for the study of the Melanopli, an even greater number of undescribed forms might easily have been expected. The number of species now appearing in the literature as valid is far in excess of the number recognized by Scudder. The series now before us, however, prove that very many recognized species, particularly among those described by that author, are mere synonyms. The completion of the studies of the Melanopli, found in North America south to the Mexican border, will consequently show that only a slightly greater number of known and valid species occur over this territory than were supposed to occur by Scudder in 1897.

The work of assembling sufficient material for a comprehensive study has been progressing steadily and the expedition during the summer of 1919, undertaken by Mr. Rehn and the author, was particularly successful. We believe that, for the region, practically all the widely and generally distributed forms are now known. In the western mountains, however, and partiularly in the more isolated high areas, we are confident that intensive search among the lesser known ranges will reveal the presence there of numerous new species and geographic races.

Under the new species and the new geographic race assigned to the Gracilis Group of the genus Melanoplus, we have occasion to criticise the recent work of Mr. Blatchley. ${ }^{5}$ We are compelled to do this, as that author appears to be unable to differentiate between the variation found in the genitalia of some more plastic species and the differences shown in varied degree by the more constant genitalic features of other less plastic, though often closely allied, species. The most serious situation lies, however, in that the author's apparent ignorance of what is meant by contemporary biologists when treating an entity such as is termed a geographic race. We are certain that the geographic race must be recognized. We feel that the day is past when the entomologist labelled and ticketed as species, without further

${ }^{5}$ Orthoptera of Northeastern America, pp. 1 to 784, (1920). 
comment, each specimen which had certain conspicuous features of difference. The geographic race is more subtle, and, to determine its validity, requires more thorough study and consideration of much more material than does the species. In the Melanopli the distinction between some species is far less striking than that between others, while the weighing of all evidence which can possibly be obtained is essential to determine the validity of certain geographic races.

As a result we find Morse's thorough, deliberate and conscientious work on the Melanopli almost universally correct. Blatchley is equally correct in considering most of the species distinguished by strikingly apparent features, but, with hardly an exception, he has failed to recognize the true values of the species or races wherever finesse or elaborate analysis was necessary. We regret that there is need to make so drastic an assertion as the above, but when we find an individual, after cursory examination of types and without time being given for study of the series available, attempting to relegate to oblivion numerous entities described by both Morse and ourselves, after years of study, incurring detailed and not hit or miss consideration, we feel obliged to speak.

It is a fundamental requirement in scientific work that no man synonymize or change the values of names appearing in the literature, without giving definite reasons for such action. Such reasons must be based on careful consideration and thorough analyses of all available evidence. Blatchley has not observed this requirement in his recent work.

In the present paper twelve new species and two new geographic races are described. The series of these new forms contain 939 specimens, of which all but 102 are in the Philadelphia Collections.

We take the present opportunity to thank for the loan of material, particularly important in determining the problems surrounding Melanoplus viridipes, Mr. J. R. Malloch of the Illinois State Laboratory of Natural History, Mr. Wm. T. Davis of New York, Mr. W. S. Blatchley of Indianapolis, Indiana, Professor A. P. Morse of Wellesley, Massachusetts, Mr. A. N. Caudell of the United States National Museum and Doctor Henry Fox of Macon, Georgia.

TRANS. AM. ENT. SOC., XLVI. 
Oedaleonotus borckii orientis new subspecies (Plate XVI, fig. 1.)

This geographic race is at present known only from the higher portions of southern and northeastern Nevada. Westward its limit of distribution certainly occurs before the Sierran uplift is reached, as in that region borckii pacificus (Scudder) is found. ${ }^{6}$

We find borckii orientis to be very close to typical borckii, though not as close as borckii pacificus. It differs in the average smaller size, more grayish general coloration, proportionately wider interval between the tegmina of both sexes and caudal femora with internal and ventral surfaces yellow, showing no tinge of orange.

Like typical borckii, the present race differs from borckii pacificus in having the lateral bands of the pronotum weak or subobsolete on the metazonal portion of the lateral lobes. Though variable in intensity in all the races of this species, these bands are normally percurrent and much the heaviest in borcki pacificus, this feature being indeed the best one to distinguish that very weakly defined race from typical borckii.

Type.- $\sigma^{7}$; Lee Canyon, Spring Mountains, Clark County, Nevada. Elevation, 7000 feet. August 19, 1919. (Rehn and Hebard.) [Hehard Collection, Type no. 552.]

Size medium small for the genus, averaging smaller than in typical borckii, though no smaller than the average- in borckii pacificus from the southern Sierras; form medium for the genus. Head and pronotum as in borckii borckii. Pronotum with medio-longitudinal carina well developed cephalad and caudad of the decided transverse sulci, subobsolete between these; lateral carinae weak, showing slight divergence caudad; caudal margin of disk very weakly obtuse-angulate produced. Tegmina elongate oval, separated by a marked interspace $(.9$ to $1.2 \mathrm{~mm}$. in the type and series of paratypic males ${ }^{7}$ ). Genitalia as in borckii borckii, the furcula very small, the cerci very slender and incurved distad. Prosternal spine short and sharply conical. Important features are noted in the color description.

${ }^{6}$ Study of the extensive series now at hand shows Scudder's Melanoplus pacificus to be a very weakly defined geographic race of Stål's Acridium (Podisma) borckii.

${ }^{7}$ This is subject to further variation, as the two Crestline and Ruby Range males before us have the tegmina broad oval and separated by an interspace $.5 \mathrm{~mm}$. in width. In males of the other races of borckii the tegmina usually slightly overlap or are attingent, in rare cases separated by an interspace, the maximum in the series before us being $.6 \mathrm{~mm}$. in width, in individuals of much larger size than those of borckii orientis. 


\section{Allotype.- 9 ; same data as type. : [Hebard Collection.]}

Similar to the male type except in the following features. Size decidedly larger, form robust. Pronotum similar (the series showing that the carinae and sulci are often weaker in this sex). Tegmina elongate ovate, slightly broader and separated by a wider interspace (1.4 to 1.9 in the allotype and paratypic females. ${ }^{8}$ )

\section{Measuremen's (in millimeters of extremes)}

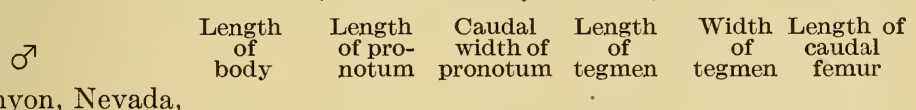

Lee Canyon, Nevada, type.............

Lee Canyon, Nevada,

$\begin{array}{ccccccc}\text { paratypes (13).... } & 14-16 & 3.3-3.8 & 2.3-2.6 & 2-2.9 & 1.6-2 & 8.2-9.3 \\ \text { Crestline, Nevada... } & 13.5 & 3.4 & 2.3 & 2.7 & 2 & 8.7 \\ \begin{array}{c}\text { Ruby Range, Nev- } \\ \text { ada............ }\end{array} & 15 & 3.8 & 2.6 & 2.6 & 2.1 & 9\end{array}$

Lee Canyon, Nevada, allotype..........

$3 \quad 4$

\section{$2.3 \quad 10.7$}

Lee Canyon, Nevada,

$\begin{array}{ccccccc}\text { paratypes (33).... } & 16.8-20 & 4-4.8 & 2.6-3.7 & 2.7-4 & 1.8-2.4 & 9-11.3 \\ \text { Crestline, Nevada (4) } & 16.2-18.7 & 4-4.4 & 2.7-3 & 2.3-3.4 & 2.2-2.7 & 9.6-9.9\end{array}$

The Spring Mountains series shows that, in the two thousand five hundred feet of vertical distribution through which this race was there found, the individual size remains unaffected.

Color pattern obscure. Type with head light pinkish cinnamon, occiput and cheeks minutely flecked with mummy brown, the former with a mediolongitudinal band of that color, which widens caudad, this band varying to weak or wholly obsolete in the series; a broad postocular band of mummy brown on each side, this varying to very weak in the series. Pronotum light pinkish cinnamon suffused and flecked with mummy brown, the post-ocular bar continued and occupying the dorsal half of the lateral lobes, but weakly defined, usually bister fading to snuff brown on the metazonal portions and frequently with a buffy fleck at the terminal portions of the principal sulcus. Tegmina light pinkish cinnamon suffused with bister, this least in dorsal portions and frequently deepening to blackish proximad near the costal margin. Abdomen light pinkish cinnamon, the proximal tergites heavily and extensively marked with black laterad. Antennae and cephalic and

${ }^{8}$ The females from Crestline have the pronotal carina and sulci more decided than in any from the typical series and the tegmina wider, broad oval, so that the interspace between these averages less (.3 to $1.1 \mathrm{~mm}$.). The Crestline material probably shows in these features incipient geographic racial differentiation, as yet not sufficiently advanced to warrant nominal recognition. The differences discussed show convergence toward borckii pacificus, but the examples in all other respects are typical of the present race.

TRANS. AMr. ENT. SOC., XLVI. 
median limbs suffused sayal brown, tinged with greenish distad. Caudal femora sayal brown in exposed portions, with two weakly defined bars of bister, which beginning on the dorsal portion of the internal face run across the dorsal face, being very weak on the external section and, with a more proximal suffusion, make up the usual color pattern of the pagina, as found more conspicuously developed in other forms of the genus; ventral and ventro-internal portions barium yellow. Caudal tibiae with external surface whitish, heavily overlaid with niagara green, other surfaces niagara green, except in brief proximal whitish portion; spines white in proximal portions, black distad.

The series shows little color variation from the type described. In some the coloration is more generally sayal brown, in others bister with pale areas of exposed surface of caudal femora contrastingly cinnamon. The Crestline series shows the weakest color pattern of all, the general coloration being tawny-olive.

Specimens Examined: 54; 16 males and 38 females.

Nevada: Lee Canyon, Spring Mountains, 6000 to 8500 feet, VIII, 18 to 21, 1919, (Rehn and Hebard), $14 \sigma^{7}, 34$ \%, type, allotype and paratypes. Crestline, Juniper Mountains, 6000 feet, IX, 4, 1909, (Rehn and Hebard), 1 ऊ', 4 ㅇ. Northern foothills of Ruby Range, Elko County, 5800 feet, IX, 18, 1919, (Hebard), 1 o?.

In the Spring Mountains this insect occurs through the zone of juniper and pinyon and well up into the zone of the bull pine (Pinus ponderosa douglasi). It reached its greatest numerical abundance, being moderately numerous and widely distributed, in the sparse grass and low green plants growing on pebbly soil at 7000 to 7200 feet, where the junipers and pinyons also reached their optimum development. At Crestline it was very scarce, the specimens being found singly and widely scattered, occurring in areas where a low yellow-flowered composite and sage brush grew among the scattered junipers and pinyons. The single individual taken at the foot of the Ruby Range was found under conditions similar to those at Crestline.

Bradynotes albida new species (Plate XVI, figs. 2 and 3.)

This interesting species shows nearest relationship to $B$. excelsa Rehn (plate XVI, fig. 4), differing in a number of color features and particularly in the more whitish general coloration, the subobsolete principal transverse sulcus of the pronotum, carinate abdomen and distinctive type of male cerci.

These two species are of broad form, but by no means as broad as the other species of Bradynotes. They inhabit the upper 
zones of the High Sierras, being found in a more rigorous environment than other species of the genus.

The cercal abbreviation in albida is exceeded only in B. satur Scudder, a very distinct species.

Type.- $\sigma^{7}$; Lone Pine Lake, Whitney Pass Trail, Sierra Nevada Mountains, Inyo County, California. Elevation, 10,000 to 10,100 feet. September 6, 1919. (Rehn and Hebard.) [Hebard Collection, Type no: 565 .]

Size small for the genus, form rather heavy. Surface subglabrous, well supplied with elongate though exceedingly fine hairs. Head broad and full; vertex gently tumid, fastigium very shallowly concave between eyes, the lateral margins not at all carinate; frontal costa deplanate, showing very slight depression at the median ocellus, there as wide as the interocular space, immediately below that portion suddenly narrowed by a fine but distinct and sharply curved sulcus on each side, completely obliterated below, where the face, above the clypeus, is evenly convex. Eye only slightly longer than wide, one and one-third times as long as the infra-ocular sulcus. Pronotum short, with disk rounding into the lateral lobes without carina, lateral lobes with prozonal section moderately inflated in dorsal portion, this cut vertically by the median transverse sulcus, which on the disk is weakly indicated mesad and obsolete meso-laterad, first transverse sulcus distinct only on disk, principal transverse sulcus subobsolete on disk; medio-longitudinal carina of disk weakly indicated near cephalic margin and on metazona, elsewhere obsolete; caudal margin of disk almost transverse, very broadly obtuse-angulate emarginate at the intersection of the nearly transverse though very broadly convex halves. Tegmina and wings absent. Abdomen with a fine but distinct medio-longitudinal carina. Furcula represented by two slightly produced convexities of the tergite at its median emargination. Supra-anal plate elongate shield-shaped, raised in a weak shoulder at lateral margins on each side at end of proximal two-thirds, lateral portions broadly and deeply concave, median portion raised, in proximal half with surface concave between heavy convergent lateral carinae, in distal half weakly convex except for a small sub-apical impression. Cerci small, not twice as long as proximal width, lateral margins very weakly concave, converging to near apex, there the dorsal margin curves obliquely downward to the sharply rounded apex. Subgenital plate roughly conical, tapering to the produced and bluntly rounded apex, with surface ventro-mesad showing a weak concavity, lateral margins almost straight to apex. Cephalic and median femora slightly inflated, very weakly bowed.

\section{Allotype.- o ; same data as type. [Hebard Collection.]}

Much larger and more robust than male. Head with interocular space wider and showing scarcely any concavity, frontal costa at median ocellus four-fifths as wide as the interocular space. Pronotum similar to that of

TRANS. AM. ENT. SOC., XLVI. 
male, except that the inflated portions of the lateral lobes are weaker. Ovipositor $^{9}$ valves showing very weak curvature to their rather blunt apices, with no median shoulders and having the margins of contact subcrenulate. Cephalic and median femora not inflated and scarcely bowed.

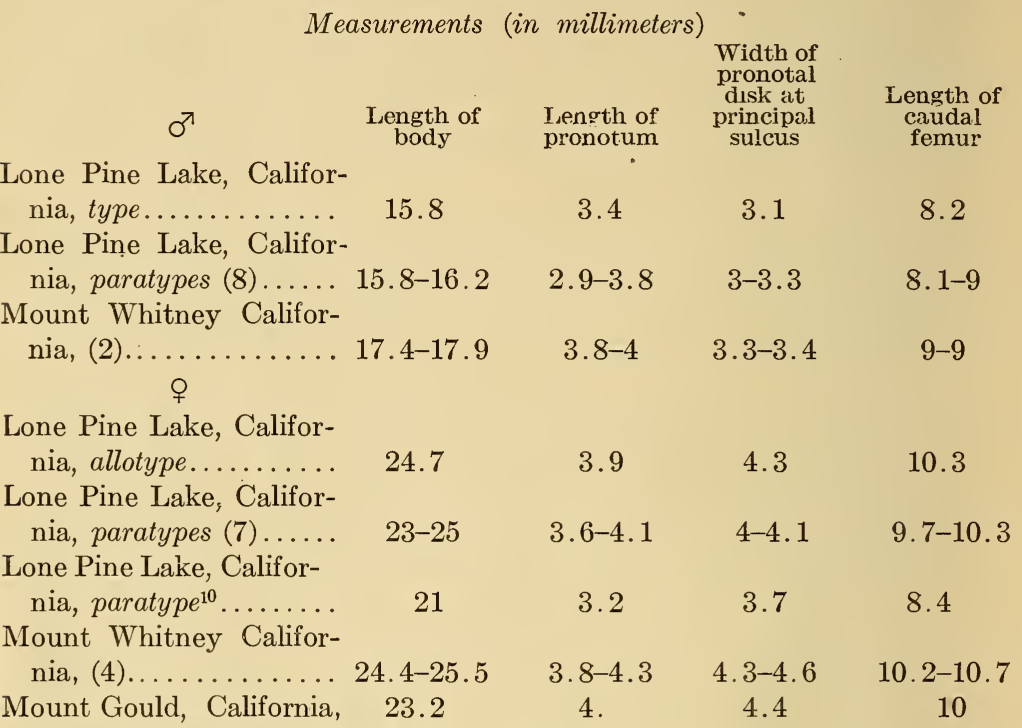

General coloration of head, prozonal portion of pronotal disk and exposed surfaces of femora cartridge buff, showing even more whitish in life than in dried specimens. Head with two postocular bars on each side of velvety black, the occiput flecked and suffused with velvety black, particularly caudad. Pronotum with prozonal portion of disk shading from cartridge buff to whitish laterad, metazonal portion of disk chamois; lateral lobes with a suffused metazonal band of velvety black dorsad, this individually extremely variable in width, remaining portions chamois. Mesonotum and metanotum suffused with black, the latter with a pale fleck on each side, which is usually conspicuous. Dorsal surface of abdomen honey yellow, the third and fourth tergites suffused with black. Ventral surface chamois, becoming ochraceous on caudal portion of sternum and on abdomen. Cephalic limbs cartridge buff marbled with a tinge of black, this more decided distad on the cephalic faces of the tibiae. Caudal femora cartridge buff, dorsal surface with a proximal fleck, a broad meso-proximal band, a weak medio-distal band and genicular areas black; the heavier band is continued to the median line on the external pagina, the weaker band invading that area only briefly, while

${ }^{9}$ In the species of this genus the ovipositor is carried with only the distal portion projecting. When in active use, however, it is probable that this organ can be fully extruded. Six specimens in the present series have been dried with the ovipositor in that position.

${ }^{10}$ This specimen, though having the ovipositor fully developed, appears to retain certain nymphal features. 
homologous markings occur on the ventral face, these reaching to the ventral margin of the external pagina. Caudal tibiae proximad dark, then with a broad annulus of cartridge buff; the remaining portions pinkish buff, suffused proximad and distad; tarsi pinkish buff; spines pinkish buff with immediate apices black, spurs pinkish buff with distal half black.

In some specimens the ground coloration varies toward vinaceous-cinnamon, in discolored examples approaching mikado brown. The degree of intensity and extent of the black suffusions and markings is variable.

The coloration of the sexes is similar and in no specimens is the general coloration dark or the ventral surfaces of the caudal femora richly colored as in excelsa.

Specimens Examined: 28; 11 males, 15 females and 2 immature individuals.

California: Mount Gould, Fresno County, 12,000 feet, VII, 9, 1910, (E. C. Van Dyke), 3 \%, [Cal. Acad. Sci. and Hebard Cln.]. Pinnacles of Mount Whitney, Sierra Nevada, Tulare County: 13,770 feet, IX, 7, 1919, (M. Hebard), 1 juv. $\&$. East foot of Whitney Pass, Sierra Nevada, Inyo County, 12,000 to 12,500 feet, IX, 7, 1919, (M. Hebard), $2 \sigma^{7}, 4$ ․ Lone Pine Lake, Whitney Pass Trail, Sierra Nevada, Inyo County, 10,000 to 10,100 feet, IX, 6, 1919, (Rehn and Hebard), 9 o', 8 \%, 1 juv.? \&, type, allotype and paratypes.

At the base of a two thousand foot north-facing precipice, just above Lone Pine Lake, a rather extensive detrital slope of gray decomposed granite was examined on September sixth. Scarcely any vegetation grew there, but a specimen of this species was found on the bare gravel between the boulders. Intensive search showed the insect to be widely distributed over this apparently barren area, though very scarce and difficult to see, due to its exceedingly protective coloration. Our notes say- "One male was watched. It would take two or three short toad-like leaps, then climb up on the nearest granite pebble with spider-like agility and, after weaving slightly from side to side once or twice, would come to rest. It then blended absolutely with its surroundings."

On the following day the author found an immature individual far above timber line, among the pinnacles of Mount Whitney, on bare granite sand. No vegetation wás noted anywhere near that elevation except lichens and one or two dandelions in a rock crevice. Below, at the head of Lone Pine Canyon and ascending Whitney Pass, six adults were taken. At the lower elevation there were a few arctic-alpine plants in the granite debris, at the upper elevation hardly any vegetation of any sort. 
Melanoplus splendidus new species (Plate XVI, figs. 5, 6 and 7.)

This handsome insect is a member of the Punctulatus Group, showing a close superficial resemblance to $M$. punctulatus arboreus (Scudder), but differing in features of coloration, in the very different and less highly specialized male cerci and the less produced male subgenital plate.

Type.- $\sigma^{7}$; Jemez Hot Springs, Jemez Mountains, New Mexico. Elevation, 7500 feet. August 18, 1913. (John Woodgate.) [Hebard Collection, Type no. 562.]

Size medium large for the genus, form moderately robust. Vertex rather decidedly depressed between the lateral carinae, which latter are continued on the frontal costa to below the median ocellus, frontal costa broader and shallowly depressed between the lateral carinae. Eye slightly over twice as long as the infraocular sulcus. Pronotum with medio-longitudinal carina very weak but percurrent on prozona though weakest in mesozonal section, well developed on metazona; transverse sulci distinct, the principal sulcus scarcely heavier than the others; disk with lateral margins slightly divergent between first and principal sulcus, in other portions subparallel, caudal margin rather broadly obtuse-angulate produced with apex rounded. Tegmina fully developed, extending beyond caudal femora and abdomen, the rather narrow apex broadly rounded. Prosternal spine elongate, cylindro conical with apex rather sharply rounded. Furcula indicated on the surface of the tergite as broad, weakly convex areas, their broadly convex caudal margins projecting slightly beyond the caudal margin of the tergite, between which the tergite is rather broadly cleft to near its base. Supra-anal plate shieldshaped, lateral margins convex proximad, then broadly convex and moderately convergent to apices of latero-caudal carinae where a slight emargination on each side occurs, the remaining distal portion with margins straight, decidedly convergent, forming a rectangle with apex sharply rounded; mediolongitudinal sulcus percurrent, decided in slightly less than proximal half, weak in slightly more than distal half, subobsolete and very delicate transverse carina indicated at the juncture of these portions, lateral portions of plate broadly concave to disto-lateral carinae, these represented by parallel rounded ridges, well developed and slightly over twice as long as broad. Cerci broad at base, narrowing strongly in proximal two-fifths, margins subparallel in median fifth, the width there three-fifths as great as that proximad, distal two-fifths moderately expanded, three-quarters as wide as basal width, with a moderate upward and inward curvature; ventral margin straight in proximal three-fifths, thence broadly convex to the rather broadly rounded apex, situated dorsad; dorsal margin strongly concave to distal portion where it is very feebly convex. ${ }^{11}$ Subgenital plate moderately broad, apically

11 This is seen to be a development from the same source as p. arboreus, but in splendidus the disto-ventral lamellate expansion, so strongly developed in that insect, does not occur, and as a result the general appearance of the cerci is very different and distinctive. 
abruptly elevated and thickened in a truncate projection, the apical production thus formed nearly four times as broad as thick and slightly broader than high. ${ }^{12}$

Allotype.- - ; same data as type, except that it was taken at 6400 feet on August 24, 1913. [Hebard Collection.]

Agrees with the type except in the following features. Size much larger, form decidedly more robust. Sulci and lateral carinae of the broader vertex and frontal costa much weaker, present on frontal costa only about region of median ocellus. Eye appreciably less than twice as long as infraocular sulcus. Medio-longitudinal carina of pronotum more conspicuous, particularly in metazonal portion. Tegmina and wings showing distinct reduction, extending slightly beyond caudal femora (failing to reach this point by a brief distance in the paratypic females), failing to reach the apex of the abdomen by a brief distance. Ovipositor valves with distal curvature decided particularly for the dorsal pair.

\begin{tabular}{|c|c|c|c|c|c|c|}
\hline \multicolumn{7}{|c|}{ Measurements (in millimeters) } \\
\hline$\sigma^{\pi}$ & $\begin{array}{c}\text { Length } \\
\text { of } \\
\text { body }\end{array}$ & $\begin{array}{l}\text { Length of } \\
\text { pronotum }\end{array}$ & $\begin{array}{l}\text { Greatest } \\
\text { width of } \\
\text { pronotal } \\
\text { disk }\end{array}$ & $\begin{array}{l}\text { Length of } \\
\text { tegmen }\end{array}$ & $\begin{array}{l}\text { Length of } \\
\text { caudal } \\
\text { femur }\end{array}$ & $\begin{array}{c}\text { Width } \\
\text { of } \\
\text { caudal } \\
\text { femur }\end{array}$ \\
\hline Type. . & 25.7 & 5.8 & 3.4 & 21 & 14 & 3.7 \\
\hline Paratype.. & 25.8 & 5.9 & 3.4 & 19.2 & 13.2 & 3.7 \\
\hline 우 & & & & & & \\
\hline Allotype... & 38.2 & 7.4 & 5 & 23.5 & 17.6 & 4.3 \\
\hline Paratypes (4) & $34-40$ & $6.8-7.5$ & $4.6-5$ & $18.7-23$ & $15.8-17.3$ & $4-4.8$ \\
\hline
\end{tabular}

Head grayish olive, maculate with dark grayish olive, on each side with a broad and shining postocular bar of blackish mummy brown. Pronotum with disk heavily overlaid, except rather broadly along lateral margins where the suffusion is weaker, with bone brown ${ }^{13}$; lateral lobes buffy, heavily flecked and suffused with bone brown, in the dorsal area the blackish mummy brown postocular bar is continued, much broadened but irregular with pale patches, so that the appearance is more that of a suffusion than of a bar. Tegmina hair brown, flecked with blackish, particularly along median line of costal fields. Wings transparent, hyaline, tinged with glass green proximad; veins black in all but caudal portion of axillary field, where they are glass green. Cephalic and median limbs hair brown, flecked and irregularly blotched, particularly on the external surfaces of the femora, with blackish

${ }^{12}$ This shows similarity in general structure to the type developed in $M$. punctulatus punctulatus and $p$. arboreus, the distal specialization being very much greater and normally more acute in those races and much the more decided in $p$. arboreus. Thus, in this respect only, $p$. punctulatus shows a condition about intermediate between that developed in splendidus and in $p$. arboreus.

${ }^{13}$ The suffusion is seen to be weak, with many darker flecks, under the microscope.

TRANS. AM. ENT. SOC., XLVI. 
mummy brown. Caudal femora drab externally, with proximal and genicular blotches and two intervening bars of darker brown very weakly defined; internal face dorsad with the corresponding darker areas more decided, blackish mummy brown, below and particularly in proximal portion bright ox blood red, often shading toward carmine. Caudal tibiae hair brown, shading to ox-blood red in distal half, this brilliant on flexor surface but merely tinging the extensor surface, external spines black, internal spines and all spurs buffy, black tipped.

In the series the general grayish coloration shows a more brownish tinge in individual specimens, the darker streaking and dotting showing little variation in intensity. The females have the dark and paler markings of the caudal femora averaging more decided than in the males. In these the pale areas are composed of an irregular proximal section, beyond this a marking like a short feathered shaft of an arrow meso-proximad, a large mesodistal section with margin produced proximad in a $\mathrm{V}$ and an irregular pregenicular band, these areas individually ranging from pinkish buff to clay color.

Specimens Examined: 8; 2 males and 6 females.

New Mexico: Jemez Hot Springs, Jemez Mountains, 7500 feet, VIII, 14 to 20, 1913, (John Woodgate), $2 \sigma^{\top}, 1$ \%, type and paratypes; 6400 feet, VIII 24 and IX, 17, 1913, (John Woodgate), 2 \%, allotype and paratype; no elevation given, VIII, 13, 1911 and VIII 25, 1914, (John Woodgate), 2 ㅇ, paratypes, [all Hebard Cln.]. Jemez Mountains, VIII, 1909, 1 \%, paratype, [Hebard Cln.].

Melanoplus eumera ${ }^{14}$ new species (Plate XVII, fig. 1; plate XVIII, fig.

1902. Melanoplus robustus Scudder and Cockerell (not Caloptenus robustus Scudder, 1875), Proc. Davenport Acad. Sci., Ix, p. 50. [Organ Mountains, New Mexico.]

This insect is a member of the Ponderosus Group, showing nearest relationship to ponderosus (Scudder) (plate XVIII, fig. 2) and supplanting that species westward of the Pecos River in Texas.

The major difference between these species is found in the male cerci, though a normal specimen of eumera appears to be very strikingly and differently marked and colored from a normal specimen of ponderosus. On closer examination, however, these latter differences are seen to be the result of an intensification and consolidation of the color pattern in eumera, showing less actually diagnostic differentiation than might at first be presumed, and the convergence of the color pattern between recessively

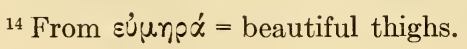


colored examples of eumera and intensively colored specimens of ponderosus is decided.

Both species are at their best in a semi-arid environment. Hence ponderosus is widely and generally distributed through the semi-arid belt of central Texas, while the distribution of eumera is more local, the species being largely confined to the semi-arid sections of the mountains of Trans-Pecos Texas and southeastern New Mexico, the surrounding desert country apparently being too dry for this insect.

Type.- $\sigma^{7}$; Lost Mine Peak, Chisos Mountains, Texas. Elevation, 5500 to 6500 feet. September 6, 1912. (Rehn and Hebard.) [Hebard Collection, Type no. 560.]

Size large, form robust (averaging smaller and less robust than ponderosus). Vertex distinctly narrower than in ponderosus, interocular space very slightly wider than proximal antennal joint, the vertex with surface weakly depressed to fastigio-facial angle, the frontal costa weakly depressed in vicinity of the median ocellus. Eye nearly twice as long as infra-ocular sulcus. Pronotum with medio-longitudinal carina well developed on metazona, subobsolete except briefly cephalad on prozona, principal sulcus deep, other transverse sulci weak; disk with lateral margins almost subparallel, very feebly diverging caudad, caudal margin obtuse-angulate produced with apex sharply rounded. Tegmina and wings fully developed (in series falling slightly short of apices of caudal femora to extending a brief distance beyond apex of abdomen). Prosternal spine as in ponderosus, rather elongate, subcylindrical, slightly larger mesad than proximad, tapering fairly suddenly at distal extremity to the rather sharply rounded apex. Furcula represented by two small, bluntly obtuse-angulate productions of the tergite. Supraanal plate as in ponderosus, broadly shield-shaped, the lateral margin briefly convergent and weakly convex, then subparallel, the distal margin strongly bracket-shaped; medio-longitudinal sulcus broad and deep proximad, narrower meso-distad, subobsolete distad, lateral portions broadly concave, the disto-lateral carinae indicated by small convexities which are slightly longer than broad. Cerci of same type as developed in ponderosus but smaller, with distal lobe less ample, its axis forming a more obtuse angulation with axis of shaft, its ventral margin not evenly convex. Cercus with margins of shaft in proximal two-fifths weakly convergent, the distal three-fifths formed by a lobe directed dorso-distad, not in bent, longer than broad, about one and one-quarter times as broad as the basal width of the cercus, its margins broadly convex, the ventral margin at its base forming a minute angulate production with the ventral margin of the shaft, which distad begins to curve ventrad. Subgenital plate full, broad, its dorsal free margins laterad broadly concave to the moderately broad, transverse, thickened and briefly elevated meso-distal portion.

TRANS. AM. ENT. SOC., XLVI. 
Allotype.- $\%$; same data as type. [Hebard Collection.]

Agrees with male except in the following respects Size larger, form more robust. Vertex broader, the vertex and frontal costa with depressed areas even weaker. Eye one and three-quarters times as long as infra-ocular sulcus. Tegmina (averaging) slightly shorter (in the series falling a brief distance short of the apices of the caudal femora to extending as far as the apex of the supra-anal plate). Ovipositor valves rather elongate, with distal curvature moderately decided.

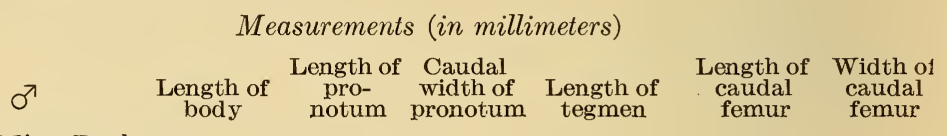

Lost Mine Peak,

$\begin{array}{lllllll}\text { Texas, type. } & 29.5 & 6.8 & 4 & 21.5 & 15.6 & 4.4\end{array}$

Lost Mine Peak,

Texas, para-

types $(18) \ldots$. $25.5-30$

$6-7 \quad 3.8-4.3 \quad 17$.

$17.4-22.7 \quad 13.8-16.8 \quad 3.8-4.7$

Chisos Mount-

ains, Texas ${ }^{15}$

(13) ........ 26.7

Sanderson, Tex-

as..........

$26.7-31.7$

$6.2-7 \quad 4-4.4$

$17-22.7$

$15-16.8 \quad 4.1-4.5$

Organ Mount-

ains, New

Mexico (2)....

$26.5-28.8$

$7.7 \quad 4.1$

24.2

18

4.9

우

Lost Mine Peak,

Texas, allo-

$\begin{array}{lllllll}\text { type........ } & 34^{16} & 7.3 & 4.8 & 20.7 & 17 & 4.6\end{array}$

Lost Mine Peak,

Texas, para-

types (8).... $30.7-39.7 \quad 7.3-8.4 \quad 4.7-5.7 \quad 19.8-22.8 \quad 16.2-19.2 \quad 4.2-5.2$

Chisos Mount-

ains, Texas ${ }^{15}$

$\begin{array}{lllllll}(12) \ldots \ldots \ldots & 36.4-40 & 8.6-9 & 5.6-5.7 & 23.1-26.4 & 19-19.8 & 5-5.3\end{array}$

Sanderson, Tex-

as..........

Organ Mount-

ains, New

Mexico (2)...

42

$9.2 \quad 5.9$

28

21.2

5.3

Florida Mount-

$37-35^{16} \quad 8-8.6 \quad 5-5.2 \quad 21.8-23$

$18.2-20 \quad 5-4.8$

ains, New

Mexico...... 36

$7.4 \quad 4.8$

19.2

17

4.1

${ }^{15}$ In canyon behind Pulliam Bluff.

${ }^{16}$ Length estimated, abdomen extended in specimen. 
Head pinkish cinnamon, dorsal surface darker, sayal brown, with broad post-ocular bar of shining bister on each side. Antennae ferruginous. Pronotum with disk sayal brown; lateral lobes with the broad postocular band dorsad of blackish bister, which is shining to the principal sulcus, on the metazonal portion represented by a narrower suffused line of bister, remaining portions of lateral lobes pinkish cinnamon deepening to cinnamon on metazonal portion. Tegmina with dorsal field verona brown; lateral field warm sepia, showing a few minute flecks of verona brown. Abdomen cinnamon buff, with a shining blackish brown patch on each side before the cercal bases. Distal portion of cerci and immediate apex of subgenital plate suffused with bister. Cephalic and median limbs pinkish buff, weakly washed laterad with walnut brown. Caudal femora cinnamon buff, dorsal surface with a proximal fleck, two broad transverse bars and entire genicular areas warm sepia, external pagina with a broad longitudinal maculation of warm sepia, which sends a ray to the proximo-dorsal fleck, a very broad band toward the first dorsal band and, before this, after narrowing strongly, it sends a broad band toward the second dorsal band; ventral surface orangecinnamon, with a row of black dots below the lower marginal carina of the external pagina. Caudal tibiae carnelian red, with a small proximal annulus of warm sepia, spines black, spurs buffy, black tipped.

Intensification and recession of color pattern causes the series to show decided diversity in superficial appearance.

In the maximum intensive condition (Florida Mountains), the head and pronotum, including the lateral lobes, are very dark, almost as dark as the very broad postocular bar, while that portion of the ventral surface of the caudal femora against which the tibiae fit is carnelian red.

In the maximum recessive condition (Sanderson), the general coloration is all much paler, the postocular bar very narrow and terminated at the principal sulcus, the caudal tibiae and ventral surface of the caudal femora primuline yellow, the sternum abdomen and remaining portions of the caudal femora amber yellow, except the dark areas of the external pagina of the caudal femora, which areas in the female are ribbed, this caused by the fact that the sutures of the imbrications are all pale.

This latter feature does not appear to occur in the male sex of the species, though it is shown to various weak degrees in all the paler females of the series. It is the normal condition in both sexes of ponderosus.

Specimens Examine1: 69 ; 37 males, 27 females and 5 immature individuals.

Texas: Sanderson, Terrell County, VIII, 25, 1912, (Rehn and Hebard), $10^{7}, 1$ ㅇ. Moss Well, Chisos Mountains, 4500 to 5000 feet, IX, 5 to 8 , 1912, (Rehn and Hebard), 2 ㅇ, 2 o $0^{7}, 1$ juv. $\sigma^{7}$, paratypes. Canyon behind Pulliam Bluff, Chisos Mountains, 4600 to 5000 feet, IX, 7, 1912, (Rehn and Hebard), $13 \sigma^{7}, 12$ ᄋ, 1 juv. $\sigma^{7}$, paratypes. Lost Mine Peak, Chisos Mountains, 5500 to 7500 feet, 8), IX, 6, 1912, (Rehn and Hebard), $19 \sigma^{7}$, 9 ᄋ, 1 juv. $ᄋ$, type, allotype, and paratypes. Livermore Peak, Davis Mountains, 8200 feet, VIII, 30, 1912, (Rehn and Hebard), 2 juv. $\sigma^{7}$.

TRANS. AM. ENT. SOC., XLVI. 
New Mexico: Dripping Spring, Organ Mountains, (J. Mendozas; T. D. Cockerell), $2 \sigma^{7}, 1$ \% , [Mus. Comp. Zool. and Hebard Cln.]. Filmore Canyon, Organ Mountains, 5700 feet, IX, 9, (C. H. T. Townsend), 1 ㅇ, [U. S. N. M.]. Florida Mountains, (H. A. Pilsbry), 1 o, [A. N. S. P.].

In the Chisos Mountains the species was found in moderate numbers wherever scrub brush occurred. The steep northern slope of Lost Mine Peak, at from 5500 to 6500 feet, was the only place where individuals were very abundant. Immature individuals were frequent, though it was early September and the season well advanced. In the Davis Mountains, a few days earlier, occasional immature examples alone were encountered, in heavy weeds on the upper edges of meadow areas reaching up to 8200 feet on Livermore Peak.

At Sanderson one specimen was secured in low grasses and plants in the dry bed of a stream, while another was taken on the adjacent slopes at 2900 feet. This was the nearest approach to desert conditions in which the species was found.

\section{Melanoplus tunicae ${ }^{17}$ new species (Plate XVIII, Figs. 3 and 4.)}

We place this species last in the Ponderosus Group, preceded by $M$. ponderosus viola (Thomas) ${ }^{18}$ (plate XVIII, fig. 5). From that insect it differs in its slightly more slender form, average longer tegmina, usually somewhat more solid coloration and distinctive male cerci.

The species is apparently widely distributed over the lower Mississippi Valley, south and east of the known distribution of p. viola. Both these insects, however, are apparently very local, being found only in the scant undergrowth of lofty deciduous forests and particularly those growing on low flat ground. This fact probably explains the reason why the present large species has until now remained unknown. In the obscurity of its favorite environment it is difficult to locate, and often, when apparently very scarce, close and exhaustive search over limited but selected areas resulted in securing a fairly large series.

${ }^{17}$ The Tunica, a tribe of friendly Indians, are prominent in early French history of the lower Mississippi, in which region the present insect is found.

${ }^{18 B l a t c h l e y ~(O r t h . ~ N . ~ E . ~ A m e r ., ~ p . ~ 406, ~ 1920) ~ h a s ~ c o n s i d e r e d ~ v i o l a ~ " t h e ~}$ short-winged form" of $M$. ponderosus Scudder. We find viola to be a geographic race of ponderosus, which is clearly defined over an extensive area of distribution. Various intermediate conditions between ponderosus ponderosus and ponderosus viola are found in all of Louisiana but the southeastes $n$ portion, and through the humid strip of eastern Texas. 
The greatest degree of convergence in the Ponderosus Group toward the Querneus Group is shown by tunicae.

Type.- $\sigma^{7}$; Strickton, Rankin County, Mississippi. September 12, 1915. (M. Hebard.) [Hebard Collection, Type no. 564.]

Size large; form moderately robust, much as in $M$. alabamae here described, appreciably less robust than in $M$. ponderosus viola. Vertex slightly but distinctly narrower than in $p$. viola, interocular space very slightly wider than proximal antennal joint, the vertex weakly depressed to fastigio-facial angle, the frontal costa weakly depressed in vicinity of the median ocellus. Eye twice as long as infra-ocular sulcus. Pronotum with medio-longitudinal carina moderately well developed on metazona, subobsolete except briefly cephalad on prozona, principal sulcus moderately deep, other transverse sulci weak; disk as in $M$. eumera here described, much as in $p$. viola, caudal margin similarly obtuse-angulate produced, with apex sharply rounded. Tegmina and wings somewhat reduced, failing to reach apex of supra-anal plate (in but one male of the series reaching the abdominal apex and in all showing reduction, though averaging longer than in $p$.viola). Prosternal spine rather elongate, subcylindrical, tapering rather suddenly distad to the rather sharply rounded apex. Furcula represented by two small, bluntly obtuseangulate productions of the tergite. Supra-anal plate much as in p. viola, broadly shield-shaped, the lateral margins briefly convergent and weakly convex, thence weakly convergent and broadly convex to the apical portion, which is briefly produced and rounded; medio-longitudinal sulcus rather broad and deep in proximal two-thirds, thence rapidly becoming obsolete, the disto-lateral carinae indicated by small convexities which are longer than broad. Cerci proportionately decidedly smaller than in $p$. viola, very much smaller than in $p$. ponderosus, with dorsal apex much more sharply rounded than in those races. Cercus with margins of shaft weakly convergent in proximal half, thence diverging without angulation, so that the margins are broadly concave to the enlarged distal portion; distal portion formed by a lobe, directed dorsad and very weakly distad and not in-bent, its axis nearly vertical, this lobe a third broader than long, approximately as long as the basal width of the cercus, its margins converging distad to the rounded apex which, though broadly rounded, is much less so than in $p$. viola and very much less so than in $p$. ponderosus, the distal and ventro-distal margins of this lobe almost straight, thus forming two weakly defined angulations. ${ }^{19}$ Subgenital plate rather broad, its dorsal free margins broadly concave laterad to the moderately broad, transverse, thickened and elevated meso-distal portion.

${ }^{19}$ In the series slight variation occurs, to a type in which these margins are broadly convex with the angulations obsolete. Occasional specimens have the dorsal apex of the cerci slightly narrower or broader than in the type, but none are comparable to the type developed in $p$. viola.

TRANS. AM. ENT. SOC., XLVI. 
Allotype.- $\%$; same data as type. [Hebard Collection.]

Agrees with male except as follows: Size larger; form more robust, though distinctly more slender than females of $p$. viola. Vertex broader, the vertex and frontal costa with depressed areas weaker. Eye nearly one and fourfifths as long as infra-ocular sulcus. Tegmina proportionately decidedly shorter, reaching to two-thirds of distance to apex of abdomen (normal condition in the series, rarely reaching three-quarters distance to apex of abdomen). Ovipositor valves moderately elongate, with distal curvature moderately decided (though apparently not as decided as in ponderosus).

\section{Measurements (in millimeters) of extremes}

\begin{tabular}{|c|c|c|c|c|c|c|}
\hline $0^{7}$ & $\begin{array}{l}\text { Length of } \\
\text { body }\end{array}$ & $\begin{array}{l}\text { Length } \\
\text { of pro- } \\
\text { notum }\end{array}$ & $\begin{array}{l}\text { Caudal } \\
\text { width of } \\
\text { pronotum }\end{array}$ & $\begin{array}{l}\text { Length of } \\
\text { tegmen }\end{array}$ & $\begin{array}{l}\text { Length of } \\
\text { caudal } \\
\text { femur }\end{array}$ & $\begin{array}{l}\text { Width of } \\
\text { caudal } \\
\text { femur }\end{array}$ \\
\hline $\begin{array}{l}\text { Iemphis, Tenn- } \\
\text { essee (2)..... }\end{array}$ & $24.9-27.2$ & $6.1-6$ & $3.6-3.8$ & $15.7-13.2$ & $15.7-16$ & $3.7-3.8$ \\
\hline $\begin{array}{l}\text { Hreenville, Miss- } \\
\text { issippi }(2) \ldots .\end{array}$ & $26.7-26.8$ & $6-6.3$ & $3.6-3.4$ & $16-15.6$ & $15.6-15.8$ & $4-3.9$ \\
\hline $\begin{array}{l}\text { trickton, Miss- } \\
\text { issippi, type. }\end{array}$ & 26.5 & 6.3 & 3.8 & 15.4 & 16.8 & 3.9 \\
\hline $\begin{array}{l}\text { trickton, Miss- } \\
\text { issippi, para- } \\
\text { types }(14) \ldots\end{array}$ & $26.5-29$ & $6.3-7.2$ & $3.7-4$ & $14.7-17.2$ & $15.8-17.7$ & $3.9-4.2$ \\
\hline $\begin{array}{l}\text { Lattiesburg, } \\
\text { Mississippi } \\
(10) \ldots \ldots \ldots\end{array}$ & $26.7-29.2$ & $6-6.8$ & $3.7-4$ & $14.7-17.7$ & $16-17.8$ & $3.8-4.3$ \\
\hline $\begin{array}{l}\text { Tatchez, Miss- } \\
\text { issippi (9). . } \\
\text { afavette, Lou- }\end{array}$ & $25.7-28.4$ & $6-6.7$ & $3.5-4$ & $14.2-16.1$ & $15.5-16.8$ & $4-4.1$ \\
\hline $\begin{array}{c}\text { isiana }(5) \ldots . \\
\text { ㅇ }\end{array}$ & $26.3-28.3$ & $6.2-6.9$ & $3.8-3.7$ & $14.6-15.8$ & $16.3-17.1$ & $3.9-4.1$ \\
\hline $\begin{array}{l}\text { Iemphis, Tenn- } \\
\text { essee (4).... }\end{array}$ & $34.8-36$ & $7.4-8$ & $4.8-5$ & $15.9-17.4$ & $18.7-20.6$ & $4.2-4.8$ \\
\hline $\begin{array}{l}\text { Greenville, Miss- } \\
\text { issippi....... }\end{array}$ & 36 & 8.3 & 5 & 19 & 20 & 4.8 \\
\hline $\begin{array}{l}\text { trickton, Miss- } \\
\text { issippi, allo- } \\
\text { type........ }\end{array}$ & 36 & 7.9 & 4. & 16.2 & 18.9 & 4.6 \\
\hline $\begin{array}{l}\text { trickton, Miss- } \\
\text { ississippi, } \\
\text { paratypes }\end{array}$ & $34.3-36$ & $7.1-7.8$ & $4.7-4.9$ & $15.9-16.9$ & $18.7-20.6$ & $4.7-4.8$ \\
\hline urg, & & & & & & \\
\hline Mississippi (11) & $32.5-37.2$ & $7.2-8.2$ & $4.7-5$ & $14-19.7$ & $18-20.3$ & $4.4-4.8$ \\
\hline $\begin{array}{l}\text { Natchez, Miss- } \\
\text { ississippi (8). }\end{array}$ & $32-36.2$ & $6.8-8.3$ & $4.6-4.8$ & $14.7-17.4$ & $18.3-20.2$ & $4-4.8$ \\
\hline $\begin{array}{l}\text { afayette, Lou- } \\
\text { isiana }(10) \ldots\end{array}$ & 34.5 & $7-8$ & $46-5$ & $158-18$ & $18.5-21$ & $4.1-4.9$ \\
\hline
\end{tabular}


It is clear that the size differences and degree of tegminal and wing reduction is a matter of individual variation in the present species, showing no geographic correlation.

Head cinnamon-buff with a faintly greenish tinge; dorsal surface darker, bister, with a'moderately broad postocular bar of shining blackish brown on each side, this bar narrowly margined dorsad with cinnamon-buff. Pronotum with disk bister, narrowly somewhat paler along lateral margins cephalad; lateral lobes dorsad with the broad postocular bar continued to the principal sulcus, paling in its ventral portion, with ventral margin irregular, remaining portions of lateral lobes tawny olive, paling ventrad. Tegmina with dorsal field pale, avellaneous; lateral field suffused with bone brown, with a number of darker solid flecks of bone brown. Ventral surface of thorax and all of abdomen olive-ocher, the abdomen with a very small suffusion of shining blackish brown, on each side before the cercal bases. Cerci and immediate apex of subgenital plate suffused with prout's brown. Cephalic and median limbs old gold, weakly suffused and obscurely flecked with brown. Caudal femora with dorsal surface cinnamon brown, with a proximal area, two bands and genicular areas of chestnut brown; external pagina with suffusions of dark chestnut brown on distal and median portions, these the continuation of the dorsal bands, the remaining areas buckthorn brown paling to antimony yellow along the ventral margin; ventro-external surface saccardo's olive, except for a pregenicular buffy area, with a series of blackish flecks bordering the carina forming the ventral boundary of the external pagina; ventrointernal surface and ventral portion of internal surface vinaceous-rufous, except for a pregenicular buffy area. Caudal tibiae brown proximad, with a small blackish area, followed by a broad buffy annulus, the remaining portions of the proximal half buffy, suffused with brown, this shading into carnelian red dorsad and internally and apricot buff externally in distal half; spines black, spurs buffy with black tips.

Intensification and recession of color is developed to a moderate degree. The palest specimens have the dark areas considerably weaker and more reduced, the postocular bar very weak on head and extremely narrow on lateral lobes of pronotum, the dorsal surface of the head, pronotum and tegmina tawny olive.

In the darkest specimens the pale and dark areas of the caudal femora are much more contrastingly colored and clearly defined. In the series at hand occasional specimens have the dorsal field of the tegmina supplied with a few dark flecks, but the species may be said to average more solidly colored, with less flecking and mottling, than $p$. viola.

Specimens Examined: 87; 43 males, 43 females and 1 immature individual.

Tennessee: Memphis, IX, 16, 1915, (Hebard), $2 \sigma^{7}, 4 \sigma^{7}$.

Mississippi: Greenville, IX, 14, 1915, (Hebard), $2 \sigma^{7}, 1 \sigma^{7}$. Strickton, IX, 12, 1915, (Hebard), 15 ơ , 9 ㅇ, type, allotype and paratypes. Hattiesburg, IX, 11, 1915, (Rehn and Hebard), $10 \sigma^{\nwarrow}, 11$ ๆ. Natchez, IX, 13 and 14, 1915, (Rehn), 9 o', 8 ㅇ.

Louisiana: Lafayette, VIII, 9, 1915, (Rehn and Hebard), $5 \sigma^{7}, 10 \%$, 1 juv. ㅇ.

TRANS. AM. ENT. SOC., XLVI. 
At Memphis the species was very scarce in patches of lush weedy plants in a heavy deciduous swamp forest, while two specimens were found after long search in the undergrowth of a heavy upland deciduous forest, which undergrowth was composed of many low shoots and a little coarse grass. At Greenville it was found in the undergrowth of a bayou forest. At Strickton it was generally distributed through a dense riverswamp deciduous forest, where the ground was generally bare but with few weedy plants and areas of coarse swamp grass, and it was even more frequently encountered in a short-leaf pine and oak forest on slightly higher ground, in undergrowth composed of ferns, grape and other vines, cane and a variety of plants. At Hattiesburg the series was taken in the deep shade of a high and heavy deciduous forest, where the scanty undergrowth was composed of partridge-berry and some grape and raspberry vines. ${ }^{20}$

At Natchez the species occurred in moderate numbers in a heavy deciduous forest, among tangles of raspberry and ground vines, at the base of the slopes of a ravine in the bluff formation. At Lafayette it was found in undergrowth composed of swamp grasses and low plants, weeds and vines of a tall open forest of tupelo, oaks and cypress near a bayou, and also in the rather scanty undergrowth of the heavy deciduous bayou forest.

Melanoplus alabamae new species (Plate XVIII figs. 6 and 7.)

This handsome grasshopper is a member of the Querneus Group and is very closely related to $M$. querneus Rehn and Hebard, ${ }^{21}$ differing apparently in the slightly smaller size and slightly more slender form, but strikingly in the shape of the male cerci.

${ }^{20} \mathrm{One}$ female contained ninety-three gordius worms, each about two inches long; another five such worms, each about three inches long. We believe the infestation of the first specimen to be the maximum recorded for an Orthopterous insect.

${ }^{21} \mathrm{At}$ the time querneus was described the species belonging to this group were referred to the "Fasciatus Group" by Rehn and Hebard (Proc. Acad. Nat. Sci., Phila., 1916, p. 231.). From our present knowledge of the species of Melanoplus we find that assignment to be incorrect, fasciatus (F. Walker) being a type more closely related to the phylum to which borealis (Fieber) belongs. 
The male cerci show some convergence toward the type developed in M. clypealus (Scudder), a species which belongs, however, to the distinct Clypeatus Group. These two groups include species showing many features of similarity; the members of the Clypeatus Group are, however, all decidedly larger and develop a distinctive color pattern of the caudal femora.

Type.- $\sigma^{7}$; Evergreen, Conecuh County, Alabama. August 4, 1915. (M. Hebard.) [Hebard Collection, Type no. 561.]

Size large, form moderately robust. Vertex and frontal costa below median ocellus shallowly depressed; interocular space narrow, slightly wider than proximal antennal joint. Eye slightly less than twice as long as infra-ocular sulcus. Pronotum with medio-longitudinal carina well developed on metazona, obsolete on mesozona, weak on prozona (varying in the series to percurrent, weak on prozona and mesozona and cut only by the principal sulcus), transverse sulci distinct; disk with lateral margins very feebly diverging caudad, almost subparallel, caudal margin broadly obtuse-angulate produced with apex rather broadly rounded. Tegmina semi-reduced, twice as long as median femur (varying to distinctly less than twice that length in the series), subacuminate, the apices narrowly rounded, sutural margins very weakly convex. Prosternal spine elongate cylindro-conical, with apex rather sharply rounded. Furcula merely the briefest of points projecting from the penultimate tergite, poorly indicated on the surface of the tergite as broad, feebly convex areas, between which the tergite is divided by a mediolongitudinal suture. Supra-anal plate broad shield-shaped, lateral portions longitudinally broadly concave, medio-longitudinal carina deep and narrow in proximal half (varying in one paratype to shallow and poorly defined), at end of which it is terminated by a low but sharp transverse carina which curves cephalad in its median section and caudad in its meso-lateral sections, in the distal half of the plate the disto-lateral carinae are distinct and parallel (in one paratype weakly convergent caudad) to proximal portion of this section. Cerci broad, the greatest distal width about three-quarters the length, very broad at base, narrowing very slightly to middle, the ventral margin moderately concave, the dorsal margin broadly angulato-concave with distal half straight, disto-ventral angle acute rectangulate, disto-dorsal section produced disto-dorsad, very broadly convex, this rounding weakly into the moderately oblique and almost straight distal margin; external surface of cercus showing a very feeble convexity, the axis of the cercus showing a weak inward curvature. Subgenital plate full, broad, proximolateral depth equal to median depth, free margin semi-elliptical in dorsal aspect; when seen from the side the lateral portions are broadly concave to the slightly produced blunted median section.22

${ }^{22}$ The degree of production of this extremity is seen to be slightly variable, as is also true of querneus in the series of that species now before us.

TRANS. AM. ENT. SOC., XLVI. 


\begin{tabular}{|c|c|c|c|c|c|c|}
\hline \multicolumn{7}{|c|}{ Measurements (in millimeters) } \\
\hline$\sigma^{\pi}$ & $\begin{array}{c}\text { Length } \\
\text { of } \\
\text { body }\end{array}$ & $\begin{array}{l}\text { Length } \\
\text { of pro- } \\
\text { notum }\end{array}$ & $\begin{array}{l}\text { Caudal } \\
\text { width } \\
\text { of nro- } \\
\text { notum }\end{array}$ & $\begin{array}{l}\text { Length } \\
\text { of } \\
\text { tegmen }\end{array}$ & $\begin{array}{l}\text { Length } \\
\text { of } \\
\text { caudal } \\
\text { femur }\end{array}$ & $\begin{array}{l}\text { Width } \\
\text { of } \\
\text { caudal } \\
\text { femur }\end{array}$ \\
\hline Evergreen, Alabama, type.. & 25.5 & 5.9 & 3.3 & 10.8 & 14.4 & 3.7 \\
\hline $\begin{array}{l}\text { Evergreen, Alabama, para- } \\
\quad \text { type.................. }\end{array}$ & 23 & 5.7 & 3.2 & 9.8 & 14 & 3.6 \\
\hline $\begin{array}{l}\text { Evergreen, Alabama, para- } \\
\text { type ................... }\end{array}$ & 25.3 & 6 & 3.4 & 10.3 & 15 & 3.8 \\
\hline $\begin{array}{l}\text { reenville, Alabama, para- } \\
\text { type................... }\end{array}$ & 25 & 6 & 3.3 & 12 & 14 & 3.6 \\
\hline
\end{tabular}

Head shining except dorsal portion, saccardo's umber becoming darker on genae, dorsal surface rich warm sepia, postocular bars blackish mummy brown, bordered dorsad by a very narrow buffy line. Antennae ochraceoustawny, deepening to russet distad. Pronotum with disk rich warm sepia, lateral lobes shining except on metazonal portion, snuff brown deepening dorsad to blackish mummy brown, the postocular bars weakly defined except as a marginal line which in the prozonal portion, as on the head, is bordered dorsad by a very narrow buffy line. Tegmina with dorsal field light pinkish cinnamon, lightly suffused proximad and with a few flecks along sutural margin of mummy brown, lateral field mummy brown flecked with blackish, fading to buffy in the apical portion. Abdomen dorsad warm sepia, ventrad yellow ocher. Cephalic and median limbs mottled saccardo's umber. Caudal femoral marking strikingly characteristic of the species of this group, the dark bands spreading over the external surface so that three pale areas are blocked off, the proximo-dorsal of these elongate oval and broken by the characteristic small dark suffusion of the dorsal surface, the proximoventral area broader and elongate oval, the third of these situated beyond the median point and forming a broad transverse band, these areas well defined, clay color paling ventrad, except the dorso-proximal which is sayal brown, the remaining portions of the dorsal and external surfaces mummy brown; internal surface ochraceous-buff with two brown suffusions dorsad; ventral surface apricot orange, shading to ochracecus-buff distad and narrowly in external section. Caudal tibiae carnelian red, deepening mesoproximad to a suff usion of liver brown before the proximal section, which is light ochraceous-salmon internally, suffused very weakly with liver brown externally; spines black, spurs buffy with tips black.

${ }^{23}$ In addition to this material, a female belonging to the present group, from Brookhaven, Mississippi, is before us. This specimen was taken by Rehn on September 15, 1915, in grass in a forest of second-growth oak and shortleaf pine. As we have no males of this group from west of the above localities, we are unable to determine this specimen at the present time, althougb it is unquestionably a representative of the present or a very closely related species. 
Specimens Examined: 13; 4 males and 9 immature individuals. ${ }^{23}$

Alabama: Greenville, Butler County, VIII, 3, 1915, (Hebard), 1 万", paratype, 2 juv. $\sigma^{7}, 6$ juv. $\odot$. Evergreen, Conecuh County, VIII, 4, 1915, (Hebard), $3 \sigma^{7}$, type and paratypes, 1 juv. $ᄋ$.

At Greenville the species was found, particularly about vine tangles, in the rather scanty undergrowth of a lofty forest composed chiefly of pine and sweet-gum. At Evergreen it was found to be very scarce in a heavy forest of magnolia, sweet gum and some holly and tulip trees, where the low ground was almost bare of vegetation but covered with leaf litter.

Iike querneus this species is doubtless local in distribution, but at the proper season should be found in fair sized colonies in the scanty undergrowth of the forests.

Melanoplus platycercus new species (Plate XVII, figs. 2, 3 and 4.)

This species is closely related to the variable $M$. rileyanus Scudder. In the male sex it may be readily separated by the much shorter and broader cerci, in which the length approximates the greatest width, as well as by the shorter subgenital plate, which has the free margin almost evenly semicircular in dorsal aspect. Females of platycercus average smaller and more slender, but can not be separated from a few of the specimens of the large series of rileyanus now before us.

Type.- $\sigma^{7}$; Lone Pine Canyon, Sierra Nevada Mountains, Inyo County, California. Elevation, 8000 to 8371 feet. September 5 and 8, 1919. (Rehn and Hebard). [Hebard Collection, Type no. 559.]

Size small, as small as the smallest examples of rileyanus before us; form medium. Vertex rather narrowly sulcate, frontal costa shallowly concave at and below the median ocellus, its lateral margins subcarinate,. Eye slightly over twice as long as infra-ocular sulcus. Pronotum moderately elongate, the disk widening very weakly caudad, medio-longitudinal carina distinct on metazona, weak elsewhere, sulci distinct but delicate, caudal margin of disk very weakly obtuse-angulate produced. Prosternal spine blunt conical (varying in the series to heavy, transverse, with apex very blunt). Tegmina considerably shorter than pronotum, ovate, rather broadly rounded distad, separated by a very brief interval. Furcula represented by a pair of slender, parallel, straight projections, which taper to their blunt apices, in total length equalling about one-quarter that of the supra-anal plate. Supra-anal plate slightly longer than wide, triangular, the lateral

TRANS. AM. ENT. SOC., XLVI. 
margins showing very faint convexity, medio-longitudinal sulcus deep in proximal third, weak beyond, lateral portions of plate with surface rather strongly but broadly concave, disto-lateral carinae stout, parallel, about twice as long as broad, their distal extremities causing the lateral margins to project slightly at the point of juncture on each side. Cerci very broad, greatest breadth almost equal to length, due to the production ventrad of the proximal section; dorsal margin straight to the rounded apex, ventral margin rather strongly convex, this becoming more decided toward end of proximal three-fifths, thence very feebly convex to the apex, in this way an obtuse-angulate emargination is formed at the end of the proximal threefifths; proximal portion of cercus with surface deplanate, vertical distal portion bent inward, with surface broadly and transversely concave (not longitudinally and deeply concave as in typical rileyanus). Subgenital plate with free margin in dorsal aspect of equal convexity throughout, showing sub obsolete bituberculation mesad (weak to obsolete in the series), on each side of which the margin shows feeble concavity for a brief distance.

Allotype.-o; same data as type. [Hebard Collection.]

Agrees with type except in the following respects. Size larger, form rather slender (for females of the majority of the species of the brachypterous Melanopli). Sulci of vertex and frontal costa weaker and broader. Eye about twice as long as infra-ocular sulcus. Pronotum with sulci and carina even less decided, the lateral margins of the disk showing no greater divergence caudad. Ovipositor valves with apices moderately curved.

\section{Measurements (in millimeters) of extremes}

\begin{tabular}{|c|c|c|c|c|c|c|}
\hline & $\begin{array}{l}\text { Length of } \\
\text { body }\end{array}$ & $\begin{array}{l}\text { Length of } \\
\text { pronotum }\end{array}$ & $\begin{array}{l}\text { Caudal } \\
\text { width of } \\
\text { pronotal } \\
\text { disk }\end{array}$ & $\begin{array}{l}\text { Length of } \\
\text { tegmen }\end{array}$ & $\begin{array}{l}\text { Width of } \\
\text { tegmen }\end{array}$ & $\begin{array}{l}\text { Length of } \\
\text { caudalal } \\
\text { femur }\end{array}$ \\
\hline ype & & & & & & 9 \\
\hline $\begin{array}{c}\text { aratypes }(13) . . \\
\text { 우 }\end{array}$ & $14.2-15.8$ & $3.3-3.6$ & $1.9-2$ & $.7-2.9$ & $1.8-2$ & $8.6-9.2$ \\
\hline me & & & & & & 10.1 \\
\hline atypes (15). & $.5-22$. & $3.8-4$ & $2.4-2.7$ & $3.1-3.4$ & $2-2.3$ & $9.8-11$ \\
\hline
\end{tabular}

Head avellaneous, dorsal surface suffused wood brown, with rather broad postocular bars of shining blackish brown on each side. Pronotum with disk suffused wood brown; lateral lobes with a rather broad dorsal band of shining blackish brown, which in the metazonal section is dull and paler, bone brown, remaining ventral portions of lateral lobes vinaceous-fawn. Tegmina with narrow dorsal section avellaneous, lateral section somewhat glossy bone brown. Abdomen dorsad cinnamon-buff, the proximal tergites marked heavily laterad with sharply defined areas of shining blackish brown. Ventral surface chamois, shading to cream buff distad on abdomen, slightly suffused with fawn color on sternum. Cephalic and median limbs fawn color, somewhat mottled. Caudal femora cinnamon-buff suffused with army brown, dorsal surface with a proximal area and two bands of bone brown, 
external surface with the characteristic Melanoplid picturing of this color weakly developed. . Caudal tibiae medici blue, fading to buffy proximad, with a small and weak proximal dark annulus; spines black and spurs buffy, black tipped.

The series shows little color variation. Some individuals are of a slightly more buffy general tone of coloration, others slightly more grayish.

Specimens Examined: 30; 14 males and 16 females.

California: Lone Pine Canyon, Sierra Nevada Mountains, Inyo County, 8000 to 8371 feet, IX, 5 and 8, 1919, (Rehn and Hebard), $14 \delta^{7}, 16$ ㅇ , type, allotype and paratypes.

This species was found in open areas of the pine forest, on bare soil of decomposed granite, where sage brush occurred in small quantities and scanty grasses were found. Difficult to locate and occurring in small colonies, the insect was found to be an active and powerful jumper. It was first seen, but not taken, in Lone Pine Canyon at an elevation of about 7500 feet.

Melanoplus rehni ${ }^{24}$ new species (Plate XVI, fig. 8; plate XVII, fig. 5.)

This handsome species is related to $M$. usitatus Scudder. Males differ in the much more extensive shining black area of the pronotal lateral lobes, the slightly greater production and angulation of the caudal margin of the pronotal disk and the more elongate supra-anal plate and cerci, which latter are furthermore not decidedly narrowed distad.

Both sexes differ in the proportionately slightly longer pronotum. The majority of the females have the lateral iobes of the pronotum with a broad dark band, this band solid and broadening caudad; a few, however, lack this marking. In usitatus females have traces of such a marking, but these are irregular in ventral outline and are narrower in the metazonal than in the prozonal portion.

The species of this group all have the head unusually large in proportion to the body bulk. This is particularly apparent in rehni.

Type.- $\sigma^{\text {7}}$; Glendale, Douglas County, Oregon. Elevation, 1500 to 1900 feet. August 12, 1909. (Rehn and Hebard.) [Hebard Collection, Type no. 558.]

Size large for the group, medium for the genus; form medium for the group. Vertex little produced, sulcation rather broad and not deep, though more decided than in usitatus, frontal costa shallowly concave from above

${ }^{24}$ In honor of our friend and co-worker Mr. James A. G. Rehn, the nigh standard of whose Orthopterological studies requires no comment.

TRANS. AM. ENT. SOC., XLVI. 
to below median ocellus; lateral carinae of vertex and frontal costa showing appreciable convergence at fastigio-facial angle. Eye about one and threefifths times as long as infra-ocular sulcus. Pronotum elongate, the disk showing feeble constriction in the prozonal portion, the lateral margins scarcely divergent on metazona; transverse sulci distinct, medio-longitudinal carina very weak except on metazona, not distinct on prozona as in usitatus, caudal margin of pronotal disk weakly obtuse-angulate produced, not weakly and broadly convex, subtruncate or feebly emarginate as in usitatus. Prosternal spine blunt conical. Tegmina shorter than pronotum, separated by a brief interval (slightly overlapping in the series from Siskiyou), ovate with apices rounded. Furcula represented by two minute points. Supra-anal plate slightly longer than wide (in the Siskiyou series averaging distinctly longer than wide, in usitatus frequently distinctly wider than long), surface weakly specialized, medio-longitudinal sulcus shallowly developed in proximal two-fifths, the lateral portions of the.plate rather strongly concave; the lateral margins showing a trace of thickening opposite the cerci, the distal surface raised in the portion between the subobsolete disto-lateral carinae. Cerci heavy, somewhat over twice as long as basal width, dorsal and ventral margins weakly convergent to distal two-fifths, where the distal portion is bent upward, the margins there subparallel until the curve into the broadly rounded apex is reached, external surface of this distal portion shallowly concave. Subgenital plate conical, tapering to a distinct meso-dorsal tubercle, which is very feebly raised above the other portions of the free margin.

\section{Allotype.--o ; same data as type. [Hebard Collection.]}

Agrees with type except in the following characters. Size much larger, form more robust. Sulci of vertex and frontal costa weaker and broader. Eye about one and one-third times as long as infra-ocular sulcus. Pronotum with sulci and carina weaker, lateral margins of disk more divergent caudad, but not as much so as is usual in this sex of usitatus. Ovipositor valves slightly longer than in usitatus, with apices similarly decidedly curved.

\begin{tabular}{|c|c|c|c|c|c|c|}
\hline \multicolumn{7}{|c|}{ Measurements (in millimeters) } \\
\hline$\sigma^{7}$ & $\begin{array}{l}\text { Length } \\
\text { of } \\
\text { body }\end{array}$ & $\begin{array}{l}\text { Length } \\
\text { of } \\
\text { pronotum }\end{array}$ & $\begin{array}{l}\text { Caudal } \\
\text { width of } \\
\text { pronotal } \\
\text { disk }\end{array}$ & $\begin{array}{l}\text { Length } \\
\text { of } \\
\text { tegmen }\end{array}$ & $\begin{array}{l}\text { Width } \\
\text { of } \\
\text { tegmen }\end{array}$ & $\begin{array}{l}\text { Length of } \\
\text { caudal } \\
\text { femur }\end{array}$ \\
\hline $\begin{array}{l}\text { lendale, Oregon, } \\
\text { type........... }\end{array}$ & 18.5 & 4.8 & 2.7 & 4.1 . & 2.5 & 10.8 \\
\hline $\begin{array}{l}\text { ylendale, Oregon, } \\
\text { paratypes (8)... }\end{array}$ & $18-19.5$ & $4.6-4.8$ & $2.7-2.8$ & $3.7-4.7$ & $2.5-2.7$ & $10.4-11$ \\
\hline $\begin{array}{c}\text { Siskiyou, Oregon, } \\
(7) \ldots \ldots \ldots \ldots \\
\text { q }\end{array}$ & $17.5-19.3$ & $4-4.7$ & $2.5-2.7$ & $4-4.3$ & $2.6-2.8$ & $10.7-11$ \\
\hline $\begin{array}{l}\text { lendale, Oregon, } \\
\text { allotype........ }\end{array}$ & 29.5 & 6 & 4.1 & 5.2 & 3.4 & 13.2 \\
\hline $\begin{array}{l}\text { tendale, Oregon, } \\
\text { paratypes (6)... }\end{array}$ & $26.5-28$ & $5.2-5.8$ & $3.7-4$ & $4.9-5.7$ & $3.2-3.3$ & $12.2-13.8$ \\
\hline (6)........ & $23.7-28$ & $5.2-5.7$ & $3.9-4$ & $5-5.8$ & $3.4-3.9$ & $12.8-13.7$ \\
\hline
\end{tabular}


Coloration.-Type. Head pinkish buff, with a very broad shining postocular band on each side,occiput bister paling to tawny-olive laterad andmesocephalad, Antennae clay color, becoming sayal brown distad. Pronotum with disk bister, paling narrowly to tawny-olive on each side of prozona; lateral lobes shining dark chestnut brown, narrowly margined ventro-cephalad and more broadly ventrad with cinnamon-buff, the dark marking paling slightly to warm sepia on caudal portion of metazonal section. Tegmina bister. Abdomen dorsad cinnamon-buff, with a broad and sharply defined band on each side of shining blackish chestnut brown, which narrows caudad, terminating at the cercal bases. Distal portion of cerci and lateral portions of subgenital plate of this color, running more narrowly around the free margin of the latter. Underparts warm buff. Cephalic and median limbs clay color. Caudal femora externally snuff brown, deepening to bister distad, the dorsal surface with two darker subobsolete transverse bands, ventral surface ochraceous-buff proximad, in remaining portions ochraceoussalmon, with a pregenicular annulus of warm buff. Caudal tibiae dark bluish glaucous, fading proximad to whitish with a weakly defined brown annulus; spines black.

The allotype is similarly but less contrastingly colored, except that the lateral lobes of the pronotum are differently marked, showing dorsad a band of shining bister which broadens caudad to the principal sulcus, there being about two-fifths as deep as the lateral lobe, the metazonal portion entirely verona brown. In the paratypic series little color variation is shown, some specimens being slightly more reddish than others and the intensity of the markings differing individually to a slight degree.

The Siskiyou series is much darker. In these the males have no pale margin of the lateral lobes of the pronotum, while the occiput, disk of pronotum and tegmina are solidly bister, the ventral surface of the caudal femora hay's russet and other portions correspondingly darkened. In the females of this series some have the occiput, disk and lateral lobes of pronotum and tegmina vandyke brown, with color pattern generally obscured. One specimen shows, however, a strongly recessive type, being generally ochraceoustawny, the pronotum entirely of this color, with only a trace of postocular darkening on the head. In this specimen the caudal tibiae are glass green, becoming buffy proximad.

Specimens Examined: 29; 16 males and 13 females.

Oregon: Glendale, Douglas County, 1500 to 1900 feet, VIII, 12, 1909, (Rehn and Hebard), 9 ऽ , 7 \% , type, allotype and paratypes. Siskiyou, Jackson County, 4100 to 5800 feet, VIII, 13, 1909, (Rehn and Hebard), 7 ऽ, 6 ㅇ․

At Glendale the species was found to be scarce and very active in small openings among the heavy growth of tall firs, in a valley of the Rogue River Mountains. At Siskiyou, on the steep forested slopes of the Siskiyou Mountains, it was found scarce in

TRANS. AM. ENT. SOC., XLVI. 
the forest undergrowth from 4200 to 5600 feet, two females being secured in the Canadian Zone forest up to 5000 feet, the others in the alpine undergrowth of a forest of scattered pine and alpine hemlock, where an interdigitating flora of the Canadian and Hudsonian Zónes occurred.

Melanoplus oreophilus new species (Plate XVII, figs. 6 and 7.)

This species is very closely related to $M$. montanus (Thomas) and $M$. washingtonianus (Bruner), showing nearer affinity to the latter.

Compared with these species, it is found to differ in both sexes in the average darker coloration, less sharply defined color pattern and deep pink coloration of the ventral and internal faces of the caudal femora. Occasional individuals of oreophilus, however, have the color pattern more intensive. The tegmina average narrower in washingtonianus and oreophilus than in montanus, in which latter species they are usually broad lanceolate.

The male genitalia are distinctive. In oreophilus the cerci are distinctly more slender and show a slight expansion distad, the margins there being weakly convex and giving to the apices of the cerci a weakly spatulate contour, not shown in either montanus or washingtonianus. The male subgenital plate is more drawn out, with apical tubercle slightly more sharply rounded than in washingtonianus. In montanus this tubercle is usually obsolete, rarely bluntly indicated.

Type.- $\sigma^{\text {T}}$; Cloud Cap Trail, Mount Hood, Oregon. Elevation, 6000 to 7000 feet. August 18 to 20, 1910. (Rehn and Hebard.) [Hebard Collection, Type no. 559.]

Size medium, form moderately robust. Vertex narrower than in washingtonianus, ${ }^{25}$ surface shallowly depressed between the distinct lateral carinae; frontal costa weakly depressed in vicinity of median ocellus. Eye about one and one-half times as long as infra-ocular sulcus. Pronotum much as in washingtonianus, medio-longitudinal carina weak on metazona, very weak on prozona (frequently obsolete between the sulci); transverse sulci weak, caudal margin of disk weakly obtuse-angulate produced with angle broadly rounded. Prosternal spine rather sharply conical (varying in the series to blunt conical). ${ }^{25}$ Tegmina as in washingtonianus, slightly longer than prono-

${ }^{25}$ This is an unreliable character, as the series shows variation in this feature to a condition in which it is as wide as in washingtonianus.

${ }^{26}$ In montanus we find the prosternal spine to vary from very blunt and distinctly transverse to blunt conical. It is clear that this process is subject to decided variation in the group to which these speci@s belong. 
tum, overlapping (varying from subattingent to strongly overlapping in the series), lanceolate pads. Furcula represented by two small stout processes, springing from convexities of the tergite, the projecting portions about twice as long as broad with apices rounded. Supra-anal plate shield-shaped, somewhat triangulate, surface little specialized, medio-longitudinal sulcus percurrent but deep only in proximal two-thirds, lateral portions of plate shallowly concave, disto-lateral carinae feebly indicated as nearly parallel, low ridges, about twice as long as broad. Cerci distinctly over three times as long as proximal width (varying in the series to three times as long as proximal width), slender, ventral margin almost straight to apical portion where a slight convexity occurs, dorsal margin broadly concave in proximal threefifths, broadly convex in distal two-fifths to the broadly convex distal margin, the apical portion of the cercus in consequence intermediate in width between the basal and median portions and subspatulate in outline (occasionally specimens show this distal spatulation reduced, the distal width being but very slightly greater than the median width; none show the cercus as broad, with apex as truncate as in washingtonianus). Subgenital plate appreciably, though only slightly, narrower than in washingtonianus, the sides converging to the rather sharply rounded apex, which projects dorso-caudad above the free disto-lateral margins of the plate.

Allotype.— $\%$; same data as type. [Hebard Collection.]

Agrees with type except in the following features. Size much larger, form much more robust. Vertex broader, similarly shallowly depressed but with lateral carinae weak. Eye one and one-third times as long as infraocular sulcus. Prosternal spine heavy, conical, with apex (normally) rather sharply rounded. Ovipositor valves moderately elongate, with distal curvature decided.

Measurements (in millimeters) of extremes

$\begin{array}{ccccccc}\sigma^{7} & \begin{array}{c}\text { Length } \\ \text { of } \\ \text { body }\end{array} & \begin{array}{c}\text { Length } \\ \text { of } \\ \text { pro- } \\ \text { notum }\end{array} & \begin{array}{c}\text { Caudal } \\ \text { width of } \\ \text { pronotal } \\ \text { disk }\end{array} & \begin{array}{c}\text { Length } \\ \text { of } \\ \text { tegmen }\end{array} & \begin{array}{c}\text { Width } \\ \text { of } \\ \text { tegmen }\end{array} & \begin{array}{c}\text { Length } \\ \text { of } \\ \text { caudal } \\ \text { femur }\end{array}\end{array}$

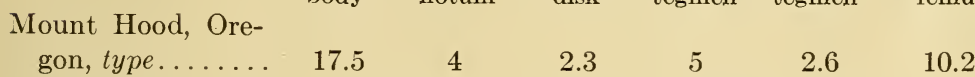

\section{Mount Hood, Ore-}

gon, paratypes,

(103)............

Oregon, (8) .....

$15.8-19-3.8$

$15.8-19$

$3.8-4.9$

10.2

Mount Hood, Ore-
gon, allotype..... $17.2-19$

$4-4.3 \quad 2.6-2.4$

$4.1-6$

$2-3$

$9.4-11.4$

Mount Hood, Ore-

$\begin{array}{llllll}25 & \cdot & 5.3 & 3.7 & 7.1 & 3.3\end{array}$

12.8

gon, paratypes

$(113) \ldots \ldots \ldots \ldots \quad 19.5-27 \quad 4.9-5.8 \quad 3-3.9 \quad 4.9-7.6 \quad 2.3-3.5 \quad 11.4-13.6$

Mount Hood, Oregon, $32 \varsigma 0$ feet...

26.8

5.4

3.6

$\begin{array}{ll}7.2 & 3.3\end{array}$

13.3

Blue Mountains,

Oregon, (5).... . 23.8-26

$4.8-5 \quad 3.3-3.5 \quad 5.3-6.5 \quad 2.9-3$

$11.8-12$

TRANS. AM. ENT. SOC., XLVI. 
The minimum extremes of size variation in the very large paratypic series before us, from the Hudsonian Zone on Mount Hood, are amplified by the presence of a few exceptionally small individuals, showing decided stunting, probably a result of the severe conditions under which their development had taken place.

Head deep olive buff, a broad postocular bar on each side of dark blackish olive, occiput and vertex olive brown. Antennae pecan brown, becoming darker distad. Pronotum with disk olive brown, shading to natal brown on metazona, lateral lobes with a shining band of bone brown dorsad which is narrow proximad, about two-fifths as wide as the lateral lobe at principal sulcus, caudad of this sulcus indicated by a dull suffusion of bone brown, remaining portions of lateral lobes deep olive buff showing a few flecks of brown. Tegmina bister with a few irregular blackish flecks, paling narrowly along the sutural margin and at apex to buff. Dorsal surface of abdomen tawny olive microscopically flecked with darker and with large irregular patches of blackish brown laterad on the proximal tergites. Ventral surface chamois. Cephalic and median limbs clay color washed with grayish and olivaceous. Caudal femora clay color with a grayish tinge, dorsal surface with two weakly defined irregular bars of brown, external face with the characteristic Melanoplid picturing defined in irregular areas of dark brown, the carinae margining the external pagina flecked with brown, these markings the more conspicuous on the ventral carina, which is of a paler buffy coloration; ventral surface and all but dorsal portion of internal surface jasper red, this sometimes confined to the internal half of the ventral surface. Caudal tibiae jasper red with a proximo-internal dark marking; spines black, spurs buffy, black tipped.

In females the tegmina and dorsal surface of the abdomen usually show numerous flecks of dark brown, while the latero-proximal dark areas on the latter are often much broken.

The general facies is distinctive, but plainly closer to that of washingtonianus than to that of montanus.

Specimens Examined: 232; 113 males, 118 females and 1 immature individual.

Oregon: Washington Gulch, foothills of Elkhorn Range, Blue Mountains, 3800 to 4300 feet, VIII, 14, 1910, (Rehn and Hebard), 8 o $^{7}, 3$ 우. Cloud Cap Turnaround, north slope of Mount Hood, 3290 feet, VIII, 20, 1910, (Hebard), 1 ㅇ. Cloud Cap Trail, Mount Hood, 6000 to 7000 feet, VIII, 18 to 20, 1910, (Rehn and Hebard), $104 \sigma^{\top}, 113$ 우, type, allotype and para- . types, 1 juv.; VIII, 18, 1916, (G. P. Englehardt), 1 ণ , 1 . paratypes, [Hebard Cln.].

In the Blue Mountains this insect was found scarce, one colony being located on the steep pine-clad hillsides among scant undergrowth, in which Spiraea petufolia was predominant.

On Mount Hood, in the Hudsonian Zone, the species was very abundant on the open slopes covered with rich green grasses 
above the fir forests and on the ridges. It was also found generally distributed but in small numbers at the foot of a glacier, in wet spots covered with green flowering plants and just above timber line on ground covered with volcanic ash in which scattered and thin dry grasses grew.

After dark individuals could be found in the dew-covered grasses, scarcely able to move, their bodies ice cold.

Melanoplus calapooyae ${ }^{27}$ new species (Plate XVII, fig. 8; plate XVIII, fig. 8.)

Scudder unfortunately included under his Melanoplus validus material referable to this species.

The present species is clearly the optimum development in the Saltator Group, both as to size and specialization. Nearest relationship is shown to $M$. validus Scudder, which species occurs in southern Oregon. This is shown by the male cerci, which are of a similar type, though having reached a higher degree of specialization.

From Scudder's species calapooyae further differs in the larger size, more robust form, male supra-anal plate with distal narrowing portion fully as long as the proximal portion and color of male caudal tibiae, which are yellowish with a pink tinge.

In the form of the male supra-anal plate nearest agreement is with the Shastan $M$. ascensus Scudder, this plate in the present species being only slightly more elongate, with disto-lateral sculpturing heavier.

Type.- $\sigma^{7}$; Divide, Calapooia Mountains, Lane County, Oregon. Elevation, 1400 to 1600 feet. August 11, 1909. (Rehn and Hebard.) [Hebard Collection, Type no. 557.]

Size large, form robust for the group. Vertex and frontal costa as in validus, much as here described for $M$. bernardinae. Eye slightly less than twice as long as infra-ocular sulcus. Pronotum with medio-longitudinal carina distinct on metazona, subobsolete on prozona (in the series varying from obsolete to weakly defined in this section); sulci distinct, the principal sulcus deep; caudal margin of disk weakly obtuse-angulate produced. Prosternal spine rather elongate, slender, tapering very weakly to the bluntly rounded apex. Tegmina very slightly longer than pronotum, moderately overlapping, broad lanceolate, with apices rather sharply rounded. Furcula

${ }^{27}$ The Calapooya Indians once inhabited the mountains which bear their name and from which the present species is known.

TRANS. AM. ENT. SOC., XlVI. 
subobsolete, represented by minute points on the margin of the penultimate tergite, which are not as long as broad. Supra-anal plate triangulate shieldshaped, the lateral margins straight, strongly raised and almost parallel in proximal half, straight and convergent to sharp apex in distal half; surface of plate showing a shallow percurrent medio-longitudinal sulcus, in proximal half bordered by low ridges which are flanked by deep concavities caused by the raised lateral margins, distal half with two decided marginal carinae, running from the lateral angles to the apex of the plate and broadly convex to the lateral margins, so that on each side the distal portions of the cerci fit into the intervening space. Cerci heavy, three times as long as basal width, curving inward distad so that the apices, extending beyond the apex of the supra-anal plate, fit in snugly beside the apices of the paired plates beneath the supra-anal plate; ventral margin broadly concave to the produced apex, dorsal margin more broadly concave to dorsal extremity, beyond which the distal margin of the cercus is rather gently oblique and almost straight to the produced apex, least width of shaft three-quarters proximal width, greatest width of distal portion distinctly greater than proximal width; distal portion with angles rounded and lamellate toward the distal margin. The cercus is heavier, with more decided distal expansion and lamellation and much greater production of the apex, which is situated ventrad, than in validus. Subgenital plate with a distinct median production of the free margin, this margin somewhat thickened latero-proximad and in the rather broadly transverse produced portion.

\section{Allotype-o ; same data as type. [Hebard Collection.]}

Agrees with type except in the following characters. Size larger, form more robust. Sulcation of vertex and frontal costa weaker and broader. Eye about one and two-thirds times as long as infra-ocular sulcus: Prosternal spine heavier. Ovipositor valves rather strongly curved.

Measurements (in millimeters)

\begin{tabular}{|c|c|c|c|c|c|}
\hline $\begin{array}{l}\text { Length } \\
\text { of } \\
\text { body }\end{array}$ & $\begin{array}{l}\text { Length } \\
\text { of } \\
\text { pronotum }\end{array}$ & $\begin{array}{l}\text { Caudal } \\
\text { width of } \\
\text { pronotal } \\
\text { disk }\end{array}$ & $\begin{array}{l}\text { Length } \\
\text { of } \\
\text { tegmen }\end{array}$ & $\begin{array}{l}\text { Width } \\
\text { of } \\
\text { tegmen }\end{array}$ & $\begin{array}{l}\text { Length of } \\
\text { caudall } \\
\text { femur }\end{array}$ \\
\hline
\end{tabular}

Divide, Oregon, type..........

Divide, Oregon, paratypes (76)

Drain, Oregon, (2) ...... 20.7-23 우

22.5

5

3.1

5.3

2.9

11.2

Divide, Oregon, allotype...... 
In this species the tegmina are found to overlap slightly in the majority of specimens, they are attingent in some and are separated by a slight to a moderate interspace (maximum $1.2 \mathrm{~mm}$.) in a few individuals, particularly among the females. The tegminal size is decidedly variable; in the great majority of specimens they are broadly lanceolate, in rare examples broadly oval.

The furcula are normally so little developed in this species that we are not surprised to find frequent males entirely lacking these processes.

Coloration.-Type. Head orange-cinnamon, vertex deep russet, postocular blackish bars not wide and narrowly margined dorsad with buffy. Pronotum with disk russet, deepening to mars brown laterad, lateral lobes buffy suffused with tawny, except for an irregular shining blackish brown bar dorsad which deepens caudad, terminated at the principal sulcus and there occupying two-fifths the depth of the lateral lobe; metazonal portion deepens to mars brown dorsad. Tegmina mars brown with a very few darker flecks. Abdomen ochraceous-tawny heavily suffused with blackish proximo-laterad, a small area before bases of cerci on eighth tergite and tips of cerci blackish. Cephalic and median limbs tawny, slightly suffused. Caudal femora tawny with the trivittate marking, characteristic of many of the Melanopli, showing in blackish brown, but much blurred; ventral surface tawny. Ventral surface of insect and caudal tibiae cinnamon-buff, the spines of the latter black tipped.

In the female sex the coloration is similar, usually of a somewhat less reddish tone, the markings of the caudal femora not as dark and the caudal tibiae coral pink.

In the maximum recessive coloration the insects are ochraceous-tawny, the tegmina slightly darker, the postocular bars and other darker markings obsolete.

It is of interest to note that males or females of at least some of the species of this group may show pink or bluish caudal tibiae.

Specimens Examined: 149; 79 males, 69 females and 1 immature individual.

Oregon: Divide, Calapooia Mountains, Lane County, 800 to 1600 feet, VIII, 10 and 11, 1909, (Rehn and Hebard), 76 o , 67 o 1 juv. 우, type, allotype and paratypes; IX, 12, 1897, (A. P. Morse), 1 으, paratype of $M$. validus Scudder, [Hebard Cln.]. Drain, Douglas County, 300 to 350 feet, VIII, 11, 1909, (Rehn and Hebard), 3 오, 1 우.

At Divide the species was generally distributed and very common both in the grassy valley and on hillsides covered with a scattering growth of scrub oaks. At an elevation of 800 feet, however, it was particularly plentiful in a brulé, among dead pine boughs and tops. At Drain it was rare on hillsides of short, dry, yellow grass.

TRANS. AM. ENT. SOC., XLVI. 
Melanoplus bernardinae new species (Plate XVII, figs 9 and 10)

This species is an aberrant member of the Saltator Group,and the smallest of the species there included. It shows no close relationships, and only a weakly defined development of the type of male supra-anal plate which is so distinctive a feature in males of the other species of the group.

The small size of the insect and brilliant coloration of its caudal limbs constitute striking features.

Type.- $\sigma^{7}$; Vivian Creek, San Bernardino Mountains, Riverside County, California. Elevation, 7200 feet. August 29, 1919. (Rehn and Hebard.) [Hebard Collection, Type no. 554.]

Size small for the genus, form slightly more slender than the other species of the Saltator Group. Vertex little produced, sulcation narrow and lateral carinae rather strongly developed, frontal costa with surface weakly concave from median ocellus ventrad, lateral margins slightly raised to fastigio-facial angle. Eye large, over twice as long as infra-ocular sulcus. Pronotum with medio-longitudinal carina distinct though not strongly developed, except between the principal and median sulci; sulci distinct, the principal sulcus deep; caudal margin of disk broadly obtuse-angulate produced. Prosternal spine longer than broad, moderately transverse, the sides showing little convergence to the bluntly rounded apex. Tegmina slightly shorter than pronotum (in the series varying to slightly longer than that dimension), slightly overlapping (varying to attingent in the series), broad oval, rounding distad but showing a slight angulation at the immediate apex. Furcula represented by two minute rounded projections no longer than broad. Supra-anal plate triangulate shield-shaped, the lateral margins moderately raised, straight and weakly convergent in proximal half, thence deplanate, straight and more strongly convergent to the sharply rounded apex; medio-longitudinal sulcus and margining carinae equally pronounced and occupying proximal three-fifths of plate, the lateral portions of the plate there moderately concave, disto-lateral carinae more lateral than usual in position, converging and blending distad with the lateral margins, thus rounded depressed areas beyond the raised portions of the lateral margins of the plate are formed, upon which rest the apices of the cerci. Cerci less than twice as long as basal width, bent weakly inward in distal third, with external surface weakly convex except along the ventral margin, where a weak linear depression occurs; ventral margin almost straight, dorsal margin weakly and broadly concave to apex which is truncate, with angles rounded and distal margin showing feeble convexity, the dorsal angle appreciably the more produced and sharply rounded, the marginal contour such that the distal portion of the cercus is very slightly wider than the narrowest portion of the shaft. Subgenital plate with a weak median production of the free margin, due to a weak lateral concavity of that margin, the free margin thickened lateroproximad and in the briefly transverse produced portion. 


\section{Allotype.— - ; same data as type. [Hebard Collection.]}

Agrees with type except in the following features. Size larger, form more robust. Sulcation of vertex and frontal costa weaker and broader. Eye twice as long as infra ocular sulcus, Pronotum with medio-longitudinal carina weaker on prozona. Tegmina similar (but showing more individual variation than in male sex, in the series very slightly overlapping to separated by a minute interval, individuals with the most elongate tegmina having these distinctly broad lanceolate in form). Prosternal spine blunter. Ovipositor valves short, with distal curvature decided.

\section{Measurements (in millimeters) of extremes}

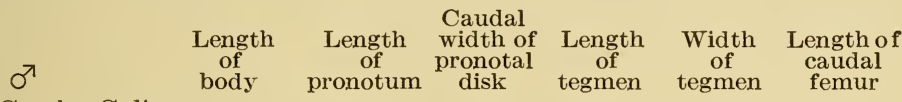

Vivian Creek, Cali-

fornia, type....

14

$3.2 \quad 2$

3

2

7.9

Vivian Creek, California, paratypes

(6) $\ldots \ldots \ldots \ldots$

$13.5-15$

\section{$3.1-3.7$}

$2-2.3$

$2.9-3.7 \quad 1.7-2.1$

$7.9-8.1$

High Creek, Cali-

fornia, (3).....

Santa Ana Canyon,

- California.......

San Jacinto Peak,

California (5) ...

$$
\text { 우 }
$$

Vivian Creek, California, allotype. .

Vivian Creek, California, paratypes

(34) ..........

fornia (13)......

South Fork of Santa

Ana River, Cali-

fornia.........

San Jacinto Peak,

California (4)...
3.5

2.1

3.7

2

8.3

$13.2-14.5$

$3.2-3.5$

$2-2.3$

$3-3.7$

$1.7-2$

7.7-8.4

17

3.9

2.7

3.9

2.1

9.8

$16.5-19.7$

$3.8-4.1 \quad 2.4-2.8$

$3.7-5$

$2.2-2.8$

9.3-10

$18.5-21.5$

$4.2-4.8$

$2.8-3.2 \quad 3.9-4.9$

2.2-3

10-11.6

16.5

4.7

2.9

4.9

2.9

11

It is of interest to note that, on the slopes of San Gorgonio Peak, the individuals taken at 7200 feet (Vivian Creek) average smaller than those taken at 9000 feet (High Creek). In the great majority of species of Orthoptera studied we have found size decreasing with an increase in altitude, if elevation showed any influence on the size of the individual.

Coloration. Head buckthorn brown, occiput very dark mummy brown, broad postocular bars shining blackish brown. Pronotum very dark mummy TRANS. AM. ENT. SOC., XLVI. 
brown, lateral lobes with dorsal half shining blackish brown to principal sulcus, below this prout's brown, shading dorsad in metazonal portion to mummy brown. Dorsal surface of abdomen cinnamon brown, very heavily and broadly suffused laterad on proximal tergites with shining blackish brown, small exposed portion of eighth tergite of this color and distal portions of cerci darkened. Cephalic and median limbs buckthorn brown, except the dorsal surfaces of the femora which are very dark mummy brown. Caudal femora cinnamon brown, with proximal median, distal and genicular areas of very dark mummy brown in the characteristic Melanoplid pattern, the darker areas very heavy; ventral surface dragons-blood red (brazil red in the most brilliant examples), paling to light coral red on the internal face dorsad, with a narrow pregenicular buffy annulus and the internal face with three large heavy suffusions of liver brown dorsad. Caudal tibiae gobelin blue, the spines black, the spurs buffy, black tipped, the tarsi buffy.

Slight recession from the described type is shown, except in the females from High Creek among which a strongly recessive type is developed. In these the general coloration is walnut brown and burnt umber, the postocular bar alone darker, the color pattern weaker. The caudal femora have the ventral surfaces bittersweet orange, while the caudal tibiae are glaucous blue.

Specimens Examined: 70; 16 males, 53 females and 1 immature individual.

California: Santa Ana Canyon, San Bernardino Mountains, 6500 feet, VII, 25, 1906, (J. Grinnell), 1 ㅇ , [A. N. S. P.]. South Fork of Santa Ana River, San Bernardino Mountains, 6200 feet, VII, 6, 1906, (J. Grinnell), 1 q, [A. N. S. P.]. High Creek, south flank of San Gorgonio Peak, San Bernardino Mountains, 9000 feet, VIII, 29, 1919, (Rehn and Hebard), $3 \sigma^{7}$, 13 ㅇ. Vivian Creek, south flank of San Gorgonio Peak, San Bernardino Mountains, 7200 feet, VIII, 29, 1919, (Rehn and Hebard), $7 \sigma^{7}, 35$ ㅇ , 1 juv., type, allotype and paratypes. San Jacinto Peak, San Jacinto Mountains, 7000 to 10,000 feet, VIII, 20, 1914, (J. C. Bradley), 5 ㄲ , 4 ㅇ , [Cornell Univ., A. N. S. P. and Hebard Clns.].

At Vivian Creek the species was found rather abundant in the thin, dry and rather scanty grassy ground-cover in a ravine forest of massive conifers. At High Creek it was less abundant in a more open meadowy ravine, heavily carpeted with richer grasses, surrounded by a conifer forest of smaller trees than at Vivian Creek, and immediately above which the forest of Lodgepole Pines began, extending upward to timber line. We do not believe that the distribution of the species extends into that forest, in which the undergrowth is very scanty and grasses practically absent. 
Melanoplus olamentke ${ }^{28}$ new species (Plate XVII, fig 11.).

This species is a member of the Lepidus Group, to which we refer Scudder's two Californian species, lepidus and ablutus. It is the least specialized of the three, showing nearest agreement with the Sierran lepidus.

Compared with males of that species, males of olamentke differ in the strength of the median carina of the pronotal disk which is heavy on the prozona, the more evenly rounded tegminal apices, the shorter and heavier caudal femora, the more simple male supra-anal plate, the narrower distal portion of the male cerci and in the male subgenital plate being much shorter and not produced meso-distad.

Type.- $\sigma^{7}$; Southern Sonoma County, California. December 4, 1910. (J. A. Kusche.) [Hebard Collection, Type no. 556.]

Size and form medium, as in lepidus. Head as in lepidus, vertex little produced, sulcus of vertex and frontal costa moderately deep, interrupted briefly between lateral ocelli. Eye as in lepidus, large, over twice as long as infra-ocular sulcus. Pronotum with medio-longitudinal carina strongly developed on metazona and on prozona to first transverse sulcus, transverse sulci weak, caudal margin of pronotal disk weakly obtuse-angulate produced. Prosternal spine as in lepidus, elongate conical with rounded apex. Tegmina shorter than pronotum, slightly overlapping, broad oval and differing from lepidus in having the apices more evenly rounded, showing no trace of the sublanceolate condition normal in that species. Furcula shorter than in lepidus, represented by a pair of minute rounded projections about as long as broad. Supra-anal plate shield-shaped, medio-longitudinal sulcus well developed with marginal carina on each side strongly defined in proximal two-thirds, disto-lateral carinae short, not strongly developed, not following the trend of the lateral margins, these latter simple, not specialized opposite cercal bases. Cerci slightly over twice as long as proximal width, ventral margin nearly straight, dorsal margin strongly though broadly concave mesad, thence strongly though broadly convex to the apex, which is situated ventrad at the juncture of this margin with the ventral margin, the cercus as a result with median portion slightly over half as wide as proximal portion and distal portion slightly wider than median portion. Subgenital plate less ample than in lepidus and not produced, median width equal to lateral width, free margin not raised mesad but showing a transverse thickening in that section.

${ }^{28}$ The division of the Moquelumnan Indians which once inhabited the region from which this species is knewn.

TRANS. AN. ENT. SOC., XLVI. 


\begin{tabular}{|c|c|c|c|c|c|c|}
\hline \multicolumn{7}{|c|}{ Mcasurements (in millimeters) } \\
\hline$\sigma^{\pi}$ & $\begin{array}{l}\text { Length } \\
\text { of } \\
\text { body }\end{array}$ & $\begin{array}{l}\text { Length } \\
\text { of } \\
\text { pro- } \\
\text { notum }\end{array}$ & $\begin{array}{l}\text { Caudal } \\
\text { width } \\
\text { of pro- } \\
\text { notal } \\
\text { disk }\end{array}$ & $\begin{array}{c}\text { Length } \\
\text { of } \\
\text { tegmen }\end{array}$ & $\begin{array}{l}\text { Width } \\
\text { of } \\
\text { tegmen }\end{array}$ & $\begin{array}{l}\text { Length } \\
\text { of } \\
\text { caudal } \\
\text { femur }\end{array}$ \\
\hline Туре & .. 16 & 4 & 2.3 & 3.8 & 2.1 & 9 \\
\hline Paratype... & .. 16.5 & 4 & 2.4 & 3.9 & 2.6 & 9.3 \\
\hline
\end{tabular}

Coloration similar to that of lepidus. Head light brownish olive, deepening to sepia on occiput, with a weak postocular dark bar on each side. Antennae warm sepia. Pronotum with disk bister, lateral lobes with a broad shining blackish brown band dorsad to principal sulcus, below this saccardo's umber shading into bister on the dorsal portion of the metazonal section. Tegmina bister. Abdomen above snuff brown, the proximal segments broadly suffused on each side with shining blackish brown; ventral surface cinnamon-buff, becoming pinkish cinnamon distad. Cephalic and median limbs externally bister, internally paler. Caudal femora with pattern characteristic of many Melanopli rather strongly defined in blackish brown and tawny-olive, ventral portion of internal surface and entire ventral surface hay's russet. Caudal tibiae deep bluish gray-green, the spines black except at bases.

In addition to the type, a single paratypic male is before us, bearing the same data, the property of the California Academy of Sciences.

Melanoplus viridipes eurycercus new subspecies (Plate XVI, figs. 9 and 10.)

1903. Melanoplus viridipes Blatchley, Orth. of Indiana, p. 305. [ $\left[\sigma^{\top}\right.$, 우; Marion County, Indiana. ${ }^{29}$

1906. Melanoplus viridipes Morse, Psyche, xiII, p. 135. [ [ $\sigma^{\top}$; North Adams, Massachusetts.]

1920. Melanoplus viridipes Morse, Manual Orth. New Eng., p. 522. (Except figures.)

1920. Melanoplus viridipes Blatchley, Orth. Northeastern Amer., p. 365. (In part.)

McNeill's record from Bloomington, Monroe County, Indiana, is apparently quoted by Blatchley in his studies of 1903 . A single female from McNeill from that locality is before us, and we are therefore unable to assign the record definitely. It is probable, however, that it applies to the present race, from what we know of its distribution.

${ }^{29}$ The cerci are missing in the only male before us from this locality. The record, as a result, cannot be assigned, except from the probability indicated by the geographic position. 
Of the other older records of viridipes and "virdulus," all apply to typical viridipes (plate XVI, figs. 11 and 12) except Lugger's state record for Minnesota, which was very possibly based upon an intermediate condition, such as we have from Wisconsin.

This geographic race agrees closely with typical viridipes, differing principally in the male cerci being heavier, shorter and taper distad, with apex bluntly rounded.

From over the wide range of this species eastward from Lake County, Indiana, not a single male before us shows a cercal development intermediate in character between the typical condition of $v$. eurycercus and that developed in $v$. viridipes, and we unhesitatingly describe this interesting geographic race. The race $v$. viridipes is similarly constant over a large portion of Illinois and some of the adjacent regions, as is demonstrated by very large series before us, in large part loaned by the Illinois State Laboratory of Natural History. ${ }^{30}$

${ }^{30} \mathrm{In}$ his "Orthoptera of Northeastern America" Blatchley has treated viridipes and its allies in a particularly superficial and unsatisfactory manner. Of the distinct though closely related species described by Morse, he has synonymized deceptus and similis under viridipes. The hasty examination of types and other historic material, without effort being made to secure additional evidence, has caused Blatchley's work to fall far below the standard requisite in contemporary studies, particularly in groups such as the present, where forms occur having differences between them which cannot be valued accurately without thorough investigation.

That author's failure to comprehend or recognize geographic races is difficult to understand, but when we consider that he published on the present problem without effort to study, let alone see or compare, the large Illinois and eastern seriess available, we are not surprised that the conclusions are incorrect. If time for compilation of so large a work, having "ever in mind the needs of the tyro and not those of the specialist," alone was available, it is much to be regretted that the author's desire for revision was not curbed. Many nomenclatorial changes were made, based on what may well be termed snap judgments, which sadly lack the substantial backing to be gained by thorough analyses and comparisons of a reasonable amount of material. We are well aware that little more than a cursory examination of the historic specimens involved was attempted, though the resultant findings often blandly contradict the published conclusions of others, which had been reached only after years of constant study, building little by little toward a substantial and scientific knowledge of the Orthoptera of North America.

TRANS. AM. ENT. SOC., XLVI. 
It is of interest to note that an intermediate condition occurs in material from Polk County, Wisconsin, showing nearer agreement with typical viridipes; while the males before us from Ann Arbor, Michigan, are also intermediates, referable to $v$. eurycercus, but showing distinct variation toward $v$. viridipes. In Indiana, however, the area of intergradation between the races is best demonstrated, as Blatchley has taken material of the species from a large number of localities. In the material before us from that state, males from Vigo and Tippecanoe Counties are typical v. viridipes; one from Fountain County and one from Vigo County are slightly atypical $v$. viridipes; intermediates are from Vigo and Lake Counties, while males from Fountain and Marion Counties are typical $v$. eurycercus.

It is apparent that the races intergrade in Indiana over the western section of the state, a certain amount of interdigitation occurring, $v$. viridipes sometimes pushing in from the west and $v$. eurycercus from the east.

Type.- $\sigma^{T}$; Derrick City, McKean County, Pennsylvania. June 6, 1915. (Wm. T. Davis.) [Hebard Collection, Type no. 563.]

Agrees closely with $v$. viridipes, differing only in the form of the cerci. ${ }^{31}$. Cerci moderately stout, curved inward distad, approximately twice as long as basal width, lateral margins almost straight and very feebly convergent to distal third, where the convergence becomes stronger to the broadly rounded apex; external surface of distal third showing a weak longitudinal depression.

Allotype.- o ; same data as type. [Hebard Collection.]

This sex can not be distinguished from females of $v$. viridipes. In the regions where the races interdigitate, males taken at the same time as the females are necessary for determination.

${ }^{31}$ As described by Scudder (Proc. U. S. Nat. Mus., xx, p. 256, (1897)). Blatchley's first description of the cercus of viridipes (Orth. of Indiana, p. $305,(1903))$ is apparently drawn from intermediate material which he had before him. 
Measurements (in millimeters) of extremes

Great Barrington,

\begin{tabular}{|c|c|c|c|c|c|}
\hline $\begin{array}{l}\text { Length of } \\
\text { body }\end{array}$ & $\begin{array}{l}\text { Length } \\
\text { of pro- } \\
\text { notum }\end{array}$ & $\begin{array}{l}\text { Caudal } \\
\text { width of } \\
\text { pronotum }\end{array}$ & $\begin{array}{l}\text { Length } \\
\text { of } \\
\text { tegmen }\end{array}$ & $\begin{array}{l}\text { Width } \\
\text { of } \\
\text { tegmen }\end{array}$ & $\begin{array}{l}\text { Length of } \\
\text { caudal } \\
\text { femur }\end{array}$ \\
\hline
\end{tabular}

Massachusetts

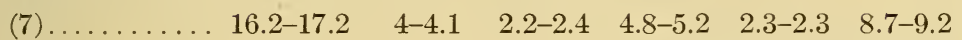

Derrick City,

Pennsylvania,

type..........

17

4.2

2.3

$5 \quad 2.4$

Derrick City,

Pennsylvania, paratypes (32).

$16.8-18.3$

$4-4.2$

$2.3-2.4$

$4.5-5 \quad 2.3-2.5$

9-9.3

Sounding Knob,

Virginia (2)... 16-17.5

$4-4.2$

$2.2-2.3$

$4.4-5.7 \quad 2-2.7 \quad 9.2-10$

Cincinnati, Ohio. .

$\begin{array}{llllll}18.8 & 4.8 & 2.7 & 6 & 2.7 & 10.2\end{array}$

Marion County,

Indiana (10)... 16.5-19.5 운

$4.2-4.6$

$2.4-2.8$

$4.9-6$

2.4-2.9

9.7-10.2

Great Barring-

ton, Massachu-

setts..........

21

4.7

3.2

$5.4 \quad 3$

10.2

Derrick City,

Pennsylvania,

allotype........

5

3.6

$5.1 \quad 3.3$

10.8

Derrick City,

Pennsylvania,

paratypes (33)...

19.4-22

$4.6-5$

$3.1-3.6 \quad 4.2-5.8$

2.4-3

9.4-11

Sounding Knob,

Virginia (2) ... 22.8-22 $\quad 4.6-4.9 \quad 3.6-3.2 \quad 5.3-5.4 \quad 3.1-2.8 \quad 10.8-10.9$

Marion County,

Indiana (10)... 22.2-24.3 $\quad 5-5.6 \quad 3.5-3.8 \quad 5.8-6.3 \quad 3.5-3.8 \quad 12-12.2$

Not only does the series from Marion County, Indiana average somewhat larger in individual size than any other, but the greatest recession in color pattern is also shown.

In the series of paratypes the cerci show the following variation, the general type, however, remaining distinctive. Length ranging from one and threequarters to two and one-quarter times proximal width. Apex ranging from very blunt to rather sharply rounded, median to meso-ventral in position. Ventral margin occasionally showing a very broad concave curvature distad. Depression of external surface distad subobsolete to rather strongly defined. The contour of the cercus often shows slight irregularities and in a single individual the cerci are rarely somewhat asymmetrical, one being slightly longer than the other or having the apex narrower.

In the eastern series a single specimen is before us, from North Adams, Massachusetts, the cerci of which may be considered atypical in character,

TRANS. AM. ENT. SOC., XLVI. 
though showing more strongly the $v$. eurycercus type. In this individual the length of these appendages is two and one-third times the basal width, the lateral margins showing weak convergence in the distal two-thirds to the rather broadly rounded distal portion, with apex meso-ventrad. The greatest cercal abbreviation is found in the two males from Sounding Knob, Virginia, in which the length of these appendages is but one and one-third times the basal width.

The apical tuberculation of the subgenital plate in males varies in degree of development, though usually prominent and sharply rounded. Rarely it is divided, giving to the subgenital plate of such individuals a bituberculate appearance.

In coloration full agreement with typical viridipes is shown, except that the caudal femora exhibit an average more intensive pattern. The two transverse bars are heavier, running from their origin in the dorsal portion of the internal surface across the dorsal surface and obliquely across the external surface, there fusing at the lower margin of the pagina. ${ }^{32}$ This is not a constant feature, some series showing a distinctly more intensive pattern than others. The Marion County, Indiana series shows extreme recession, the caudal femoral markings being subobsolete in some males and the majority of females. The specimens from Cincinnati, Ohio; White Sulphur Springs, West Virginia, and Sounding Knob, Virginia show the maximum of color intensification.

Specimens Examined: 121; 70 males, 40 females and 11 immature individuals.

Vermont: St. Albans, VI, 21, 1913, (C. W. Johnson), 3 ơ , 1 우, [Morse Cln.].

Massachusetts: Great Barrington, VI, 15 and 16, 1915, (C. W. Johnson), $7 \sigma^{7}, 1$ ㅇ , [Morse Cln.]. Cascade, North Adams, 1100 to 1400 feet, foothills of Mt. Greylock, VI, 14, 1915, (C. W. Johnson), 1 б , [U. S. N. M.]. One mile above Bashbish Falls, VI, 27, 1912, (C. W. Johnson), 1 व , [Davis Cln.].

New York: Groton, VI, 11, 1914, (E. A. Chapman), 1 주, 3 우, [Davis Cln.]. Mix Creek Valley, Cattaraugus County, VI, 11, 1915, (Davis and Bradley), $2 \sigma^{\urcorner}, 1$ 오 , [Davis Cln.]. Rock City, Cattaraugus County, VI, 6, 1915, (Davis and Bradley), 1 \& , [Davis Cln.]. Seneca Junction, VI, 7, 1915, (W. T. Davis), 2 ㅇ, [Davis Cln.]. Ithaca, 1 ㅇ ; [Hebard Cln.]. West Danby, V, 30, 1915, (W. T. Davis), 1 ơ $^{7}$, [Davis Cln.].

Pennsylvania: Derrick City, VI, 6, 1915, (W. T. Davis), 32 ㄱ, 22 우, type, allotype and paratypes, [Davis, Hebard and Fox Clns.]. Ligonier, Westmoreland County, V, 23, 1905, (G. Brugger), 1 ○ , 1 juv. $\sigma^{7}, 1$ juv. 우, [A. N. S. P.].

Maryland: Jennings, Garrett County, VI, 24, 1907, (B. Long), $1 \sigma^{7}$, 1 오 , [A. N. S. P.]. Near Jennings, Garrett County, 3000 feet, VI, 25, 1907, (B. Long), 2 우, [A. N. S. P.].

${ }^{32}$ In the series of eighty-seven specimens of typical viridipes before us, not a single case occurs of the fusing of these bars ventrad on the external face of the caudal femora. 
Virginia: Sounding Knob, Highland County, 3800 and 4200 feet, VIII, 21, 1916, (M. Hebard), $2 \sigma^{\top}, 2$ ㅇ, [Hebard Cln.]. Tazewell, Tazewell County, VI, 9, 1915, (L. O. Jackson), $10^{7}, 1$ 우, [U. S. N. M.].

West Virginia: White Sulphur Springs, VII, 2, 1919, (W. T. Davis), 2 ठ, [Davis Cln.].

Онго: Cincinnati, VI, 24, 1904, $1 \sigma^{7}$, [Blatchley Cln.].

INDIANa: Marion County, VI, 1 to 5, 1900, 1902 and 1904, (W. S. Blatchley), 10 ऽ , 10 ㅇ , [Blatchley, Morse and Hebard Clns., A. N. S. P. and U. S. N. M.]. Bloomington, Monroe County, VI, 11, 1886, (J. T. MeNeill), 1 o , ${ }^{33}$ ]Hebard Cln.]. Monroe County, (W. S. Blatchley), $1 \sigma^{7},{ }^{34}$ [Blatchley Cln.]. Vigo County, VII, 5, 1892, (W. S. Blatchley), 1 ช , [Blatchley Cln.].

\section{Atypical viridipes eurycercus.}

Specimens Examined: 11; 6 males, 4 females and 1 immature individual.

Indrana: Lake County, VI, 20, 1899, (W. S. Blatchley), $3 \sigma^{\top}, 1$ 우, [Blatchley and Univ. Minn. Clns.]. Vigo County, V, 16, 1904, (W. S. Blatchley), $1 \sigma^{\top}$, [Blatchley Cln.].

Michigan: Ann Arbor, V, 28, 1918, (T. H. Hubbell), $2 \sigma^{\nearrow}, 3$ ㅇ, 1 juv. 우 , [A. N. S. P.].

Wrsconsin: Polk County, VII, (C. F. Baker), ơ, [A. N. S. P.].

Intermediate between viridipes viridipes and viridipes eurycercus

Specimens Examined: 3; 3 males.

Indiana: Vigo County, V, 16, 1904, (W. S. Blatchley), $1 \sigma^{\top}$, [Blatchley Cln.]. Fountain County, 1907, (W. S. Blatchley), $1 \sigma^{\top}$, [Blatchley Cln.].

Wisconsın: Polk County, VII, (C. F. Baker), 1 б , [A. N. S. P.].

In the Appalachian Mountains this insect apparently frequents mountain meadows near the forests. In such an environment specimens, from their condition apparently the last of the season, were taken on Sounding Knob in Virginia.

We are told by Davis that he found the race very common at Derrick City, Pennsylvania. In life, as he states, the colors are bright and give individuals a most pleasing appearance. $\mathrm{He}$ found that "they climbed up on old stumps of trees and were running over the carpet of old leaves and the lesser woodland plants in every direction. They were moderately active, though it is true that the series was collected without much trouble."

From Blatchley's records, we learn that the series from Marion County, Indiana, was secured in upland woods.

${ }^{33}$ Without males from this locality we cannot definitely assign this specimen, except from the probability indicated by geographic position.

${ }^{34}$ The cerci are missing in this specimen, which as a result cannot be definitely assigned, except from the probability indicated by geographic position.

TRANS. AM. ENT. SOC., XLVI. 
The insect is local in distribution, being found in colonies, and is in consequence more liable to be overlooked by the collector than the more generally distributed forms. The fact that it is a spring form further explains why, though so widely distributed, the species is poorly represented in most collections. The number of localities represented, and large series of specimens in the Davis Collection, again gives excellent evidence of the thorough and specialized field methods of our able friend.

Melanoplus calloplus new species (Plate XVI, figs. 13 and 14.)

The present species is a member of the Gracilis Group, showing an annectant type between $M$. similis Morse and $M$. viridipes Scudder.

Compared with similis it is separated by the shorter tegmina, barred caudal femora ${ }^{35}$ and distinctive male cerci, which are bicolored, much less slender in distal half, widen there and are rather broadly truncate at the apex.

Like similis, this species has a slightly but appreciably smoother general facies than viridipes. In calloplus the pale and dark markings are usually somewhat more contrasted than is normal in viridipes, the markings of the caudal femora not as heavy or dark as is usual in that species, while the male cerci are of a distinct type.

Type.- $\sigma^{x}$; Collison Ridge, Bath County, Virginia. Elevation, 3200 feet. July 5, 1916. (M. Hebard.) [Hebard Collection, Type no. 553.]

Size, form and general structure as in viridipes. Fastigium of vertex and frontal costa similar but slightly more sulcate, the former with lateral margins weakly but distinctly rounded carinate. ${ }^{36}$ Antennae as in viridipes, fully twice as long as pronotum. Eye slightly longer than cheek $^{37}$ nearly twice as long as the infra-ocular sulcus. Pronotum much as in viridipes, the percurrent medio-longitudinal carina weak, cut only by the principal sulcus;38

${ }^{35}$ In occasional females of this species, as well as of viridipes, these usually conspicuous markings are subobsolete or wholly absent.

${ }^{36}$ In viridipes these margins are usually very weakly carinate, material from the Virginia Mountains of that species, however, showing variation toward the type described above.

${ }^{37}$ Averaging very slightly longer in viridipes.

${ }^{38}$ In viridipes the medio-longitudinal carina of the pronotum is sometimes cut by all three sulci or is sometimes subobsolete cephalad; it is normally cut by all but the first sulcus. Larger series of calloplus will probably show similar variation. 
caudal margin of disk very weakly obtuse-angulate produced. Tegmina overlapping as in viridipes, slightly longer than pronotum, ovate, with apex broadly rounded. Wings greatly atrophied, but retaining the characteristic folding of the radiate field. Prosternal spine small, blunt conical. Furcula as in viridipes, represented by two minute projections, the areas from which they spring perceptibly thickened and separated by a broad angulate emargination. Supra-anal plate as in viridipes, shield-shaped, slightly longer than basal width, with a decided medio-longitudinal sulcus in proximal half; lateral portions broadly concave, distal portion slightly raised and very weakly concave, bounded laterad by the rounded parallel disto-lateral carinae. Cerci slightly over twice as long as proximal width, tapering gradually in proximal half to narrowest point, where it is half as wide as the basal width, thence expanding slightly, the convexity of the dorsal margin slightly the greater, to the rounded distal angles; rather broadly truncate, weakly oblique at apex. ${ }^{39}$ Subgenital plate small, tapering to the distinct apical tubercle, which is twice as broad as thick. ${ }^{40}$

\section{Allotype.- $\%$; same data as type. [Hebard Collection.]}

Similar to females of viridipes, differing in the slightly more sulcate fastigium of vertex and frontal costa, with lateral margins slightly more distinct, as described for the male type of this species. Differing from the male in the larger size, more robust form and (usually ${ }^{4 !}$ ) more ample tegmina. Prosternal spine short and heavy, very blunt conical. Ovipositor valves as in viridipes, moderately elongate, the dorsal pair with distal curvature weak, the ventral pair with such curvature very weak.

\section{Measurements (in millimeters) of extremes}

\begin{tabular}{|c|c|c|c|c|c|}
\hline$\sigma^{7}$ & $\begin{array}{l}\text { Length of } \\
\text { body }\end{array}$ & $\begin{array}{l}\text { Length of } \\
\text { pronotum }\end{array}$ & $\begin{array}{l}\text { Caudal } \\
\text { width of } \\
\text { pronotal } \\
\text { disk }\end{array}$ & $\begin{array}{l}\text { Length of } \\
\text { tegmen }\end{array}$ & $\begin{array}{l}\text { Length of } \\
\text { caudal } \\
\text { femur }\end{array}$ \\
\hline$(3) \ldots \ldots \ldots \ldots \ldots$ & $17-17.5$ & $4-4.1$ & $2.3-2.4$ & $4.8-5.6$ & $9.6-9.7$ \\
\hline $\begin{array}{l}\text { ollison Ridge, Vir- } \\
\text { ginia, type......... }\end{array}$ & 17.5 & 4.6 & 2.7 & 5.1 & 9.7 \\
\hline $\begin{array}{l}\text { ollison Ridge, Vir- } \\
\text { ginia, paratypes, (5) } \\
\text { hite Sulphur Springs }\end{array}$ & $15.8-17.5$ & $4.2-4.3$ & $2.4-2.8$ & $4.8-5$ & $9.4-10$ \\
\hline West Virginia, (2). . & $16-16.8$ & $4-4.2$ & $2.4-2.6$ & $5-4.8$ & $6.2-9.6$ \\
\hline
\end{tabular}

${ }^{39}$ Slight variation in the length and degree of narrowing as well as in the arcuation of the margins of the cerci is shown by the males before us; the type, however, being readily recognizable.

${ }^{40} \mathrm{In}$ one paratype slight bituberculation is shown.

${ }^{41}$ Decided tegminal size variation is shown by the series before us.

TRANS. AM. ENT. SOC., XLVI. 


\begin{tabular}{|c|c|c|c|c|c|}
\hline 우 & $\begin{array}{l}\text { Length of } \\
\text { body }\end{array}$ & $\begin{array}{l}\text { Length of } \\
\text { pronotum }\end{array}$ & $\begin{array}{l}\text { Caudal } \\
\text { width of } \\
\text { pronotal } \\
\text { disk }\end{array}$ & $\begin{array}{l}\text { Length of } \\
\text { tegmen }\end{array}$ & $\begin{array}{l}\text { Length of } \\
\text { caudal } \\
\text { femur }\end{array}$ \\
\hline $\begin{array}{l}\text { West Point, New York } \\
(4) \ldots \ldots \ldots \ldots \ldots\end{array}$ & $23-24$ & $4.9-5$ & $3.3-3.3$ & $5.3-6.2$ & $10.2-11.3$ \\
\hline $\begin{array}{c}\text { Plainfield, New Jer- } \\
\text { sey............. }\end{array}$ & 22.7 & 4.9 & 3.2 & 5.7 & 11.2 \\
\hline $\begin{array}{l}\text { Collison Ridge, Vir- } \\
\text { ginia, allotype...... }\end{array}$ & 23.8 & 5.3 & 4.4 & 5.4 & 11.8 \\
\hline $\begin{array}{l}\text { Collison Ridge, Vir- } \\
\text { ginia, paratypes..... }\end{array}$ & & $5-5.3$ & $3.2-3.7$ & $4.8-5.8$ & $11-12$ \\
\hline $\begin{array}{l}\text { Snickers Gap, Vir- } \\
\text { ginia.............. }\end{array}$ & 24.5 & 5.2 & 3.9 & 6.4 & 11.9 \\
\hline $\begin{array}{l}\text { White Sulphur Springs, } \\
\text { West Virginia..... }\end{array}$ & 26.3 & 5.8 & 3.5 & 6.2 & 12.3 \\
\hline $\begin{array}{l}\text { Coloration similar to } \\
\text { from the usual in that } \\
\text { parison. } \\
\text { Male. Head reed yel } \\
\text { postocular bar on each si } \\
\text { with disk brownish olive, } \\
\text { est depth) shining black, } \\
\text { ulate brownish olive. } \\
\text { the penultimate sternite } \\
\text { plate shining black excep } \\
\text { cept for a quadrate dors } \\
\text { limbs olive-yellow, fading } \\
\text { femora olive-ocher, show } \\
\text { brown which, on the ex } \\
\text { line, entire genicular are } \\
\text { with green. Caudal tib } \\
\text { basal annulus; the spine } \\
\text { Female with less contr } \\
\text { to buff, tinged with taw } \\
\text { broad postocular bars sh } \\
\text { cinnamon brown. Pron } \\
\text { the dorsal portions of the } \\
\text { brown along the ventral } \\
\text { lobes buffy, weakly tinge } \\
\text { Abdomen ochraceous-tan } \\
\text { surface weak yellow och } \\
\text { femora with a greenish t } \\
\text { two broad transverse bar } \\
\text { to well defined), these se } \\
\text { nal face; genicular lobes, }\end{array}$ & $\begin{array}{l}\text { that occe } \\
\text { species as } \\
\text { llow, occip } \\
\text { ide, eyes a } \\
\text {, lateral lo } \\
\text {, remaining } \\
\text { Abdomen } \\
\text { e tipped } \\
\text { pt in subc } \\
\text { so-proxima } \\
\text { g on media } \\
\text { wing two } \\
\text { xternal fac } \\
\text { ea blackisl } \\
\text { oiae clear } \\
\text { es black, t } \\
\text { rasting but } \\
\text { ny on gen } \\
\text { hining blac } \\
\text { otum with } \\
\text { le lateral lo } \\
\text { l margin } \\
\text { ed with tar } \\
\text { wny dorsa } \\
\text { her. Ceph } \\
\text { tinge. Ca } \\
\text { rs of mars } \\
\text { carcely tra } \\
\text {, laterad o }\end{array}$ & $\begin{array}{l}\text { asionally } \\
\text { discussed } \\
\text { put browni } \\
\text { ind antenn } \\
\text { obes in dor } \\
\text { g portions } \\
\text { isabella c } \\
\text { with shinir } \\
\text { chitinous p } \\
\text { al area of } \\
\text { n femora p } \\
\text { broad trar } \\
\text { ce, run obl } \\
\text { h, the pale } \\
\text { light yello } \\
\text { the spurs b } \\
\text { t similar co } \\
\text { ae and da } \\
\text { ckish brow } \\
\text { h disk cinn } \\
\text { obes, that } \\
\text { and cepha } \\
\text { wny. Teg } \\
\text { d, suffused } \\
\text { halic and r } \\
\text { audal femor } \\
\text { s brown (ir } \\
\text { ceable on t } \\
\text { only, black }\end{array}$ & $\begin{array}{l}\text { developed } \\
\text { above in } \\
\text { ish olive, a } \\
\text { ae cinnamo } \\
\text { sal section } \\
\text { ivory yello } \\
\text { color dorsa } \\
\text { ng black, } \\
\text { ortion. C } \\
\text { chamois. } \\
\text { roximad to } \\
\text { nsverse do } \\
\text { liquely cep } \\
\text { er area bef } \\
\text { wish olive, } \\
\text { uffy with } \\
\text { oloration. } \\
\text { ark cinnam } \\
\text { n, eyes pre } \\
\text { amon brov } \\
\text { area freque } \\
\text { alad; lower } \\
\text { mina imms } \\
\text { a with cinn } \\
\text { median lim } \\
\text { ra dorsad } \\
\text { ndividually }\end{array}$ & $\begin{array}{l}\text { broad shi } \\
\text { on brown. } \\
\text { (three-fiftl } \\
\text { ow. Tegm } \\
\text { ad, chamoi } \\
\text { the entire } \\
\text { erci shinin } \\
\text { Cephalic a } \\
\text { olive-oche } \\
\text { orsal bands } \\
\text { halad to t } \\
\text { fore this o } \\
\text { with a s } \\
\text { black tips. } \\
\text { Head taw } \\
\text { on-brown } \\
\text { out's brown } \\
\text { wn, this co } \\
\text { ently shini } \\
\text { two-fifths } \\
\text { aculate pro } \\
\text { aamon-brov } \\
\text { nbs mars b } \\
\text { vinaceous-t } \\
\text { y varying }\end{array}$ & $\begin{array}{l}s \text {, differing } \\
\text { inary com- } \\
\text { ining black } \\
\text { Pronotum } \\
\text { hs of great- } \\
\text { ina immac- } \\
\text { is ventrad, } \\
\text { subgenital } \\
\text { g black ex- } \\
\text { nd median } \\
\text { r. Caudal } \\
\text { of prout's } \\
\text { he median } \\
\text { ften tinged } \\
\text { mall black } \\
\text { ny shading } \\
\text { on occiput, } \\
\text {, antennae } \\
\text { ntinued on } \\
\text { ng blackish } \\
\text { of lateral } \\
\text { ut's brown. } \\
\text { wn, ventral } \\
\text { rown, the } \\
\text { tawny with } \\
\text { from weak } \\
\text { rown exter- } \\
\text { eas brown. }\end{array}$ \\
\hline
\end{tabular}


Caudal tibiae dark olive buff becoming brownish buff proximad and distad, with a small black annulus near base.

Specimens Examined: 29; 13 males and 16 females.

New York: West Point, VI, 14, 1914, (W. T. Davis), $4 \sigma^{\nearrow}, 7$ 우, [Davis Cln.].

New Jersey: Plainfield, VIII, 4, 1907, (W. T. Davis; on ridge to west of town), 1 우, [Davis Cln.].

Virginia: Collison Ridge, Bath County, 3200 feet, VII, 5 and 8, 1916, (M. Hebard), $6 \sigma^{7}, 5$ ㅇ type, allotype and paratypes, [Hebard Cln.]. Snickers Gap near Bluemont, V, 28, 1914, (W. T. Davis), 1 ㅇ, [Davis Cln.].

West Virginia: White Sulphur Springs, VII, 2 and 3, 1919, (W. T. Davis), $20^{7}, 1$ 우, [Davis Cln.].

Tennessee: Mayland, Cumberland Plateau, Cumberland County, VI, 9, 1920, (S. Markovitch, in sylvan surroundings), $1 \sigma^{\nwarrow}, 1$ 우, [Hebard Cln.].

During the summer of 1916, the author collected constantly in the vicinity of Hot Springs, Virginia. The mountain ridges in this region are numerous and all but the highest are covered with heavy deciduous forests. On one of these, Collison Ridge. the typical series was taken at 3200 feet, just below the summit of the ridge, at its southwestern extremity, on the eastern slope, One small colony was found on July 5, when an intensive search was made. On July 8 this was repeated, four more individuals being secured in the original spot and close by in another similar area. For a month from this date we were constantly on the lookout for this species, no others being found at the original spot or elsewhere. The series was secured in the forest undergrowth of mountain laurel, huckleberry and other knee-high to waist-high bushes. The males were the more active, remaining up in the bushes and slipping through them rapidly, or springing from twig to leaf, but never to the ground.

We believe calloplus to be a thamnophilous sylvan species, occurring in widely scattered colonies. It may well be termed a late spring form, appearing adult probably earlier than the great majority of the Melanopli. 


\section{EXPLANATION OF FLATES}

\section{PLATE XVI}

Fig. 1.-Oedaleonotus borckii orientis new subspecies. Lateral view of male (type). (X3)

Fig. 2.-Bradynotes albida new species. Cercus of male (type). (Greatly enlarged.)

Fig. 3.-Bradynotes albida new species. Dorsal view of female (allotype). $(\times 3)$

Fig. 4.-Bradynotes excelsa Rehn. Cercus of male (type). Mount Tyndall, California, 12,000 feet. (Same scale as fig. 2.)

Fig. 5.-Melanoplus splendidus new species. Cercus of male (paratype). (Greatly enlarged.)

Fig. 6.-Melanoplus splendidus new species. Lateral outline of distal portion of abdomen of male (paratype). $(\times 8)$

Fig. 7.-Melanoplus splendidus new species. Lateral view of female (allotype). (X2)

Fig. 8.-Melanoplus rehni new species. Lateral view of pronotum of female (allotype). $(\times 3)$

Fig. 9.-Melanoplus viridipes eurycercus new subspecies. Lateral view of caudal femur of male (type). ( $\left.\times 3 \frac{1}{2}\right)$

Fig. 10.-Melanoplus viridipes eurycercus new subspecies. Cercus of male (type). (Greatly enlarged.)

Fig. 11.-Melanoplus viridipes viridipes Scudder. Lateral view of caudal femur of male. Muncie, Illinois. $\left(\times 3 \frac{1}{2}\right)$

Fig. 12.-Melanoplus viridipes viridipes Scudder. Cercus of male. Muncie, Illinois. (Same scale as fig. 10.)

Fig. 13.-Melanoplus calloplus new species. Lateral view of caudal femur of male (type). (X31/2)

Fig. 14.-Melanoplus calloplus new species. Cercus of male (type). (Same scale as fig. 10.)

\section{PLATE XVII}

Fig. 1.-Melanoplus eumera new species. Lateral view of female (allotype). $(\times 2)$

Fig. 2.-Melanoplus platycercus new species. Dorsal view of distal portion of abdomen of male (type). (About $\times 11$ )

Fig. 3.-Melanoplus platycercus new species. Cercus of male (type). (Greatly enlarged.)

Fig. 4.-Melanoplus platycercus new species. Dorsal view of female (allotype). (X3)

Fig. 5.-Melanoplus rehni new species. Cercus of male (type). (Greatly enlarged.)

Fig. 6.-Melanoplus oreophilus new species. Lateral outline of distal portion of abdomen of male (type). (X9)

Fig. 7.-Melanoplus oreophilus new species. Lateral view of female (allotype). ( $\times 3)$ 
Fig. 8.-Melanoplus calapooyae new species. Dorsal view of male supraanal plate (type). $(\times 13)$

Fig. 9.-Melanoplus bernardinae new species. Dorsal view of male supraanal plate (type). $(\times 17)$

Fig. 10.-Melanoplus bernardinae new species. Lateral outline of distal portion of abdomen of male (type). $(\times 10)$

Fig. 11.-Melanoplus olamentke new species. Lateral outline of distal portion of abdomen of male (type). $(\times 9)$

\section{PLATE XVIII}

Fig. 1.-Melanoplus eumera new species. Cercus of male (type). (About $\times 15)$

Fig. 2.-Melanoplus ponderosus ponderosus (Scudder). Cercus of male. Sweetwater, Texas. (Same scale as fig. 1.)

Fig. 3.-Melanoplus tunicae new species. Lateral outline of distal portion of abdomen of male (type). $(\times 8)$

Fig. 4.-Melanoplus tunicae new species. Cercus of male (type). (Same scale as fig. 1.)

Fig. 5.-Melanoplus ponderosus viola (Thomas). Cercus of male. St. Louis, Missouri. (Same scale as fig. 1.)

Fig. 6.-Melanoplus alabamae new species. Lateral outline of distal portion of abdomen of male (type). $(\times 8)$

Fig. 7.-Melanoplus alabamae new species. Cercus of male (type). (Same scale as fig. 1.)

Fig. 8.-Melanoplus . calapooyae new species. Cercus of male (type). (Greatly enlarged.) 


$$
\text { K- mase apion lite tisi }
$$



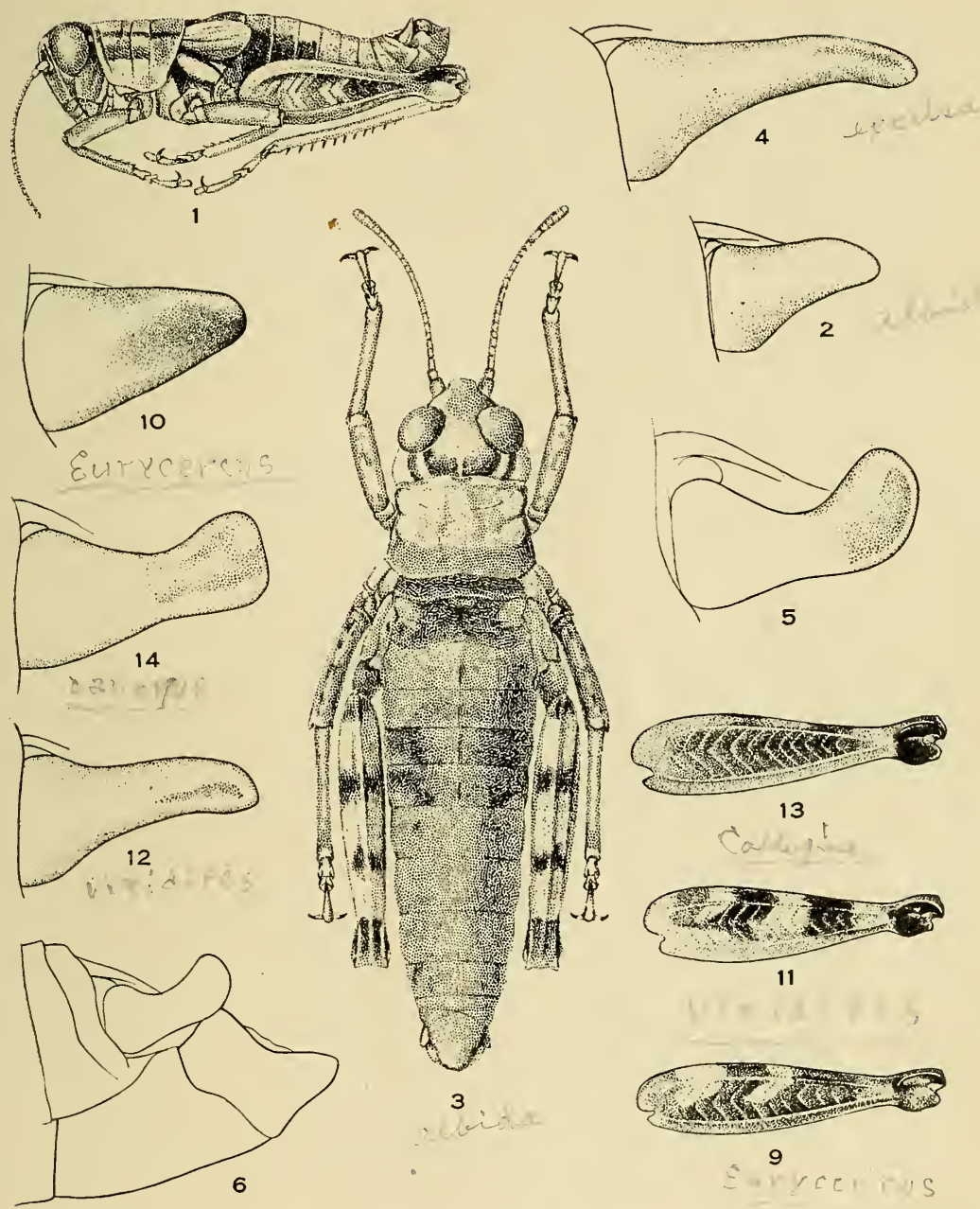

in
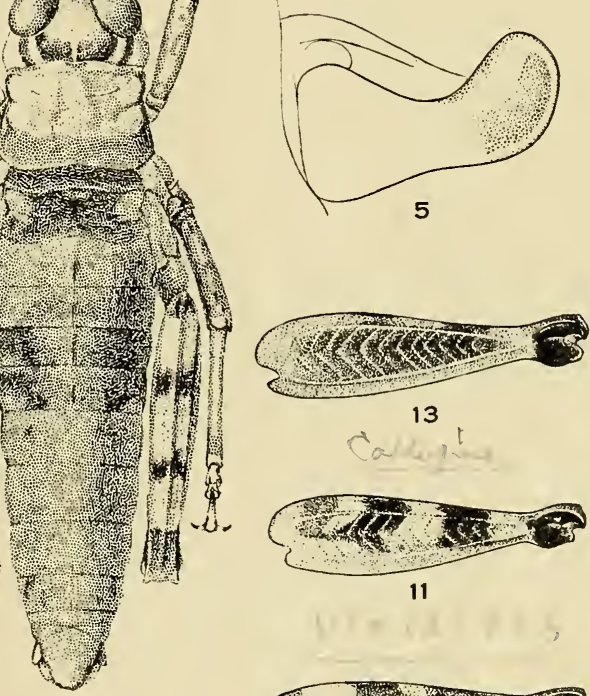

3

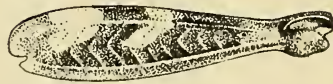

$\leqslant 9$

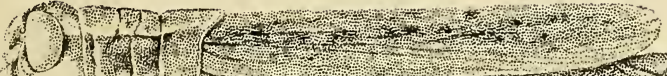

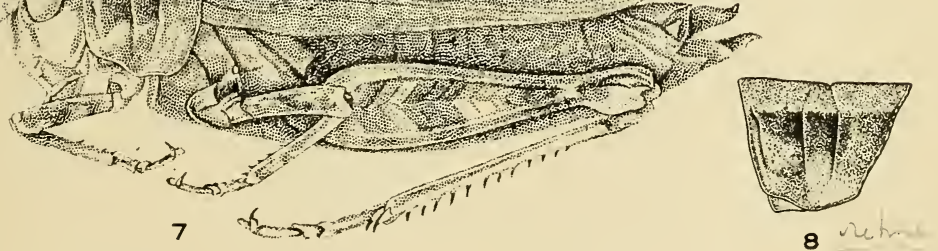

HEBARD-NEW NORTH AMERICAN MELANOPLI 



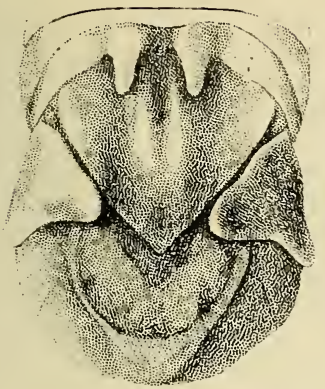

2

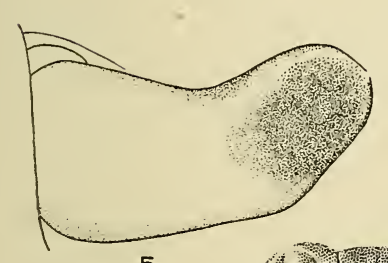

5
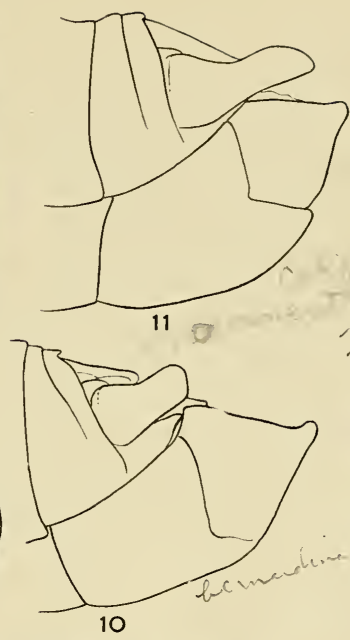

10
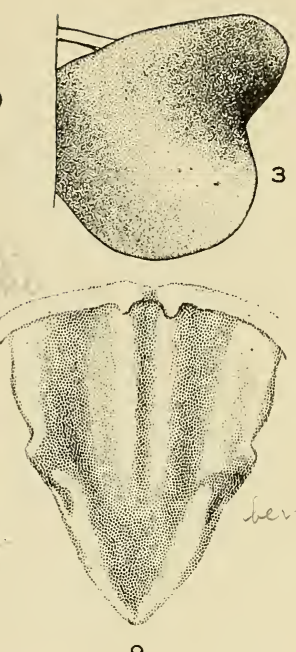
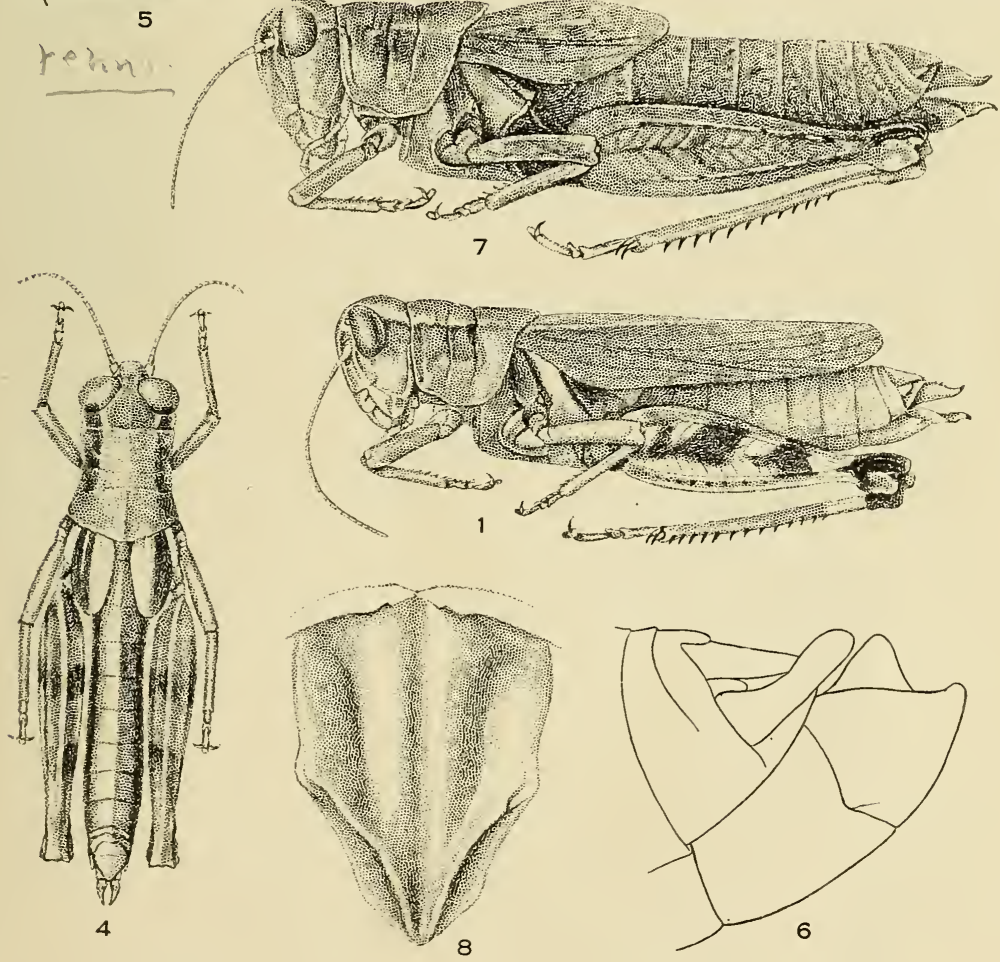

HEBARD-NEW NORTH AMERICAN MELANOPLI 


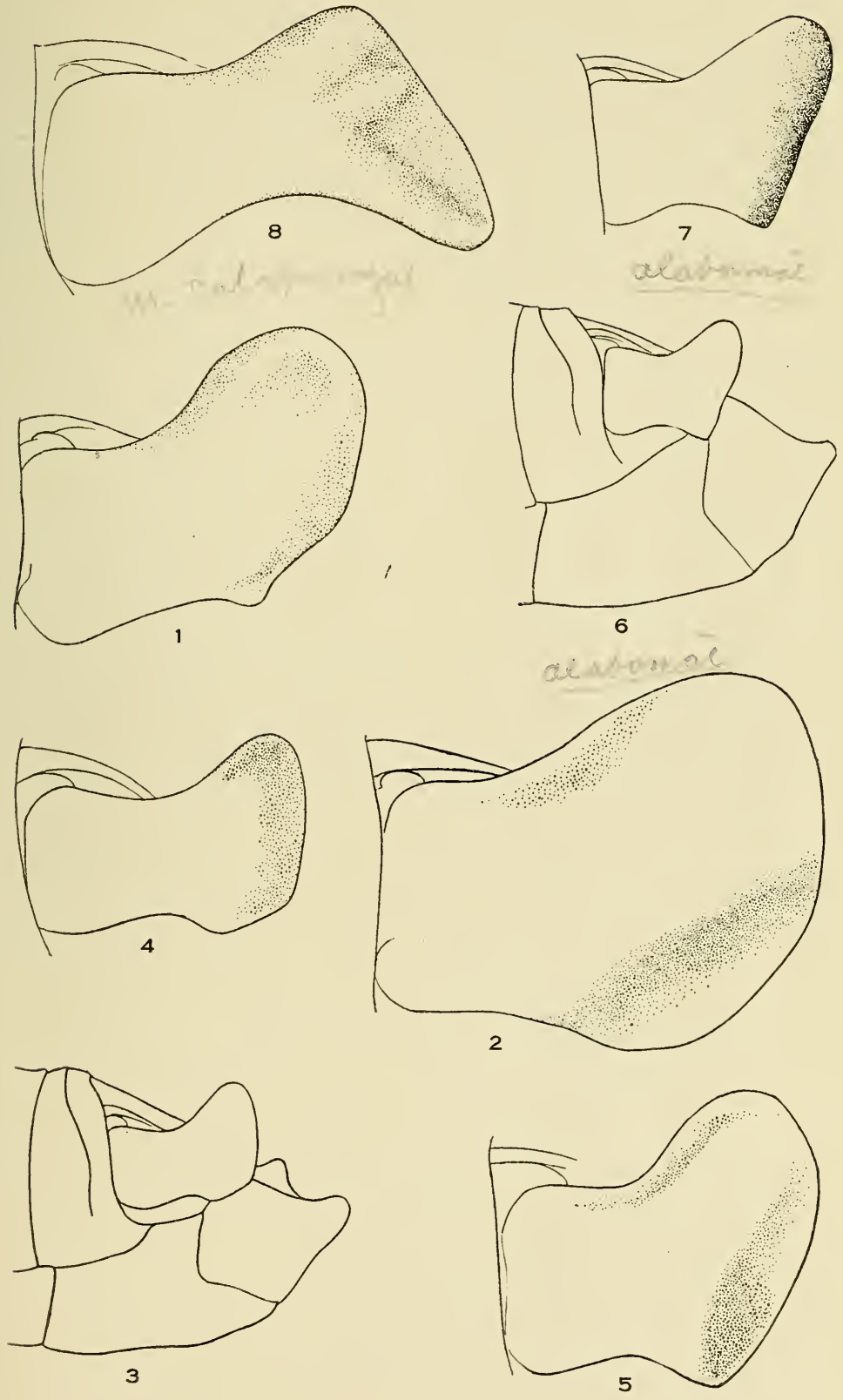

HEBARD-NEW NORTH AMERICAN MELANOPLI 





\title{
$-3566$. \\ N. Candell.
}

\section{NEW GENERA AND SPECIES}

\author{
$\mathrm{OF}$
}

\section{MELANOPLI}

\section{FOUND WITHIN THE UNITED STATES AND CANADA}

(ORTHOPTERA ; ACRIDIDAE)

\author{
Part IV \\ by \\ Morgan Hebard
}

From the Transactions of The American Entomological Society, xlviii, 49.66 



\title{
NEW GENERA AND SPECIES ON MELANOPLI FOUND WITHIN THE UNITED STATES AND CANADA (ORTHOPTERA; ACRIDIDAE)
}

\author{
BY MORGAN HEBARD
}

Part IV

Over a year ago, the third part of the present series of papers appeared. ${ }^{1}$ Since that time our study of the North American Melanopli has made some progress, the manuscript having been prepared as far as the genus Aeoloplus. Press of work on exotic material has prohibited a more rapid advance, however, and for this reason we believe it best to describe, at the present time, the four additional new species and two geographic races which have been encountered.

Among these the distinctive Bradynotes chilcotinae is of partic. ular interest. Added to the very large series of specimens available for study, the valuable information on this insect furnished by Mr. E. R. Buckell requires our very cordial thanks to that gentleman for such kind and thorough cooperation.

The discovery, by Dr. Witmer Stone, of another species of Melanoplus in the isolated Canadian Zone of the Chiricahua Mountains of Arizona, shows again the necessity for further careful work in such environment on all of the higher ranges of the Southwest.

A total of five hundred and seventy-three specimens are here recorded. In the present series of papers to date, a total of two genera, thirty-eight species and six geographic races have been described.

As is our custom, the location of all the material is indicated excepting that collected by Rehn and Hebard. This material is at present all in the Philadelphia Collections.

Agroecotettix modestus aristus new subspecies (Plate $\mathrm{H}$, figs. 1, 2 and 3.)

Compared with the female type of $A$. modestus modestus Bruner, described from Lerdo, Durango, Mexico, females

${ }^{1}$ Trans. Am. Ent. Soc., Xlvi, pp. 355 to 403, (1920).

TRANS. AM. ENT. SOC., XLVIII. 
assigned to the present geographic race are distinguishable by their more robust form, with pronotum presenting a slightly more swollen appearance and less definition between the disk and lateral lobes, much broader tegmina, which are attingent, and caudal tibial coloration, these members being bright red distad.

Males of the present race are similar to the females except as described below, the deeply forked cerci being distinctive. In general form they are more nearly comparable to males of Phaulotettix compressus (Scudder), than to those of the species of other North American genera of the Melanopli. From the latter they differ in the more flattened frontal costa, more inflated pronotum, with transverse sulci more decided and caudal margin feebly but distinctly convex, much broader and nearly attingent tegmina, small blunted and well separated furcula, much broader supra-anal plate, furcate cerci, prominent pallium, shallower and differently shaped subgenital plate and distinctive coloration.

Type.- $\sigma^{7}$; Uvalde, Uvalde County, Texas. Elevation, 1000 to 1100 feet. August 21, 1912. (Rehn and Hebard.) [Hebard Collection, Type no. 749.]

Size medium large; form robust, when compared with species of nearest affinity. Head large, eyes large and prominent, the greatest width across the eyes approximating the greatest pronotal breadth. Vertex much as in Phaulotettix, slightly produced and bluntly rounded, its dorsal surface moderately concave particularly between the eyes, where delicate convex lateral carinae are distinct and approximate. Frontal costa broad and flat, showing weak depression about the median ocellus, below that point gradually disappearing into the face.

Pronotum with dorsal and lateral portions of prozona smooth, but with a few impressed punctae laterad and somewhat inflated between the decided transverse sulci, which sever the medio-longitudinal carina, this carina distinct except between the transverse sulci, where it is very weak. ${ }^{2}$ Pronotal lateral carinae, which are subobsolete through the lateral margins of the disk, are apparent on the prozona, due to the color pattern; metazona impresso-punctulate, the caudal margin of the disk weakly but distinctly convex. Tegmina very broad oval, extending slightly beyond caudal margin of metanotum, separated by a very slight interval. Minute, very elongate oval, vestigial wings present, concealed by the tegmina. Large, open tympana covered by the tegmina.

${ }^{2}$ Apparently variable in this portion, as it is subobsolete to distinct in the large series before us of the Trans-Pecos Texan race (A. m. crypsidomus) of the species. 
Distal portion of abdomen distinctly, though not decidedly, enlarged. Furcula represented by two broad and well separated, very brief convexities, which extend very slightly beyond the margin of the tergite. Supra-anal plate with length about equal to width, broadly rotundato-triangular, lateral portions broadly and weakly concave, with a minute node mesad; median portion weakly elevated and rather broadly and weakly concave. Cercus over four times as long as its proximal width, bifurcate at end of proximal three-fifths, proximal portion narrowest at its median point (where it is about one-third as broad as long) due to the concavity of the dorsal margin, ventral margin straight throughout, except that feeble convexity is indicated proximad; internal section of distal portion produced in a straight, flattened finger, subequal in width, about three times as long as broad, with greatest thickness vertical and apex rounded, this finger directed meso-caudad; external section of distal portion produced in a straight slender spike, with apex very narrowly rounded, longer than internal section and directed caudad, so that the axes of these portions form an angle of something less than ninety degrees.

Subgenital plate with depth about one-half length of the free margin, that margin weakly concave laterad and feebly angulato-convex mesad. Prosternal spine rather sharply conical, showing a weak flexure cephalad. Interspace between mesosternal lobes nearly twice as long as wide. Cephalic and median femora heavy, inflated and bowed. Caudal femora rather short and very robust, though proportionately not as short and robust as in Phaulotctix compressus. Caudal tibiae with eight to ten spines. Caudal tarsus distinctly less than half as long as caudal tibia.

\section{Allotype.-o ; same data as type. [Hebard Collection.]}

Agrees closely with male in coloration and relative proportions; differing in the following features. Size larger, form moderately stouter. Vertex proportionately slightly broader. Tegmina proportionately broader, attingent. Genitalia normal, the ovipositor valves stout, with denticulations of dorsal margin of dorsal pair blunt, heavy and irregular and with the stout apices acute and well curved. Interspace between mesosternal lobes about one and onehalf times as long as broad.

\begin{tabular}{|c|c|c|c|c|c|}
\hline \multicolumn{6}{|c|}{ Measurements (in millimeters) } \\
\hline $\begin{array}{l}\text { Length } \\
\text { of } \\
\text { body }\end{array}$ & $\begin{array}{l}\text { Length } \\
\text { of } \\
\text { pro- } \\
\text { notum }\end{array}$ & $\begin{array}{l}\text { Width } \\
\text { of } \\
\text { pro- } \\
\text { notum }\end{array}$ & $\begin{array}{c}\text { Length } \\
\text { of } \\
\text { tegmen }\end{array}$ & $\begin{array}{c}\text { Width } \\
\text { of } \\
\text { tegmen }\end{array}$ & $\begin{array}{l}\text { Length } \\
\text { of } \\
\text { caudal } \\
\text { femur }\end{array}$ \\
\hline .21 .7 & 5.3 & 4.9 & 4 & 3 & 12.2 \\
\hline atypes . 21.7-23.3 & $5.6-5.8$ & $5.1-5.2$ & $3.8-4$ & $3-3.2$ & $12.8-13$ \\
\hline$\ldots .22 .3$ & 5.8 & 5.2 & 4 & 3.8 & 12.9 \\
\hline \multicolumn{6}{|l|}{ ㅇ } \\
\hline .31 & 7.8 & 7 & 4.8 & 4.6 & 16 \\
\hline & $7.3-7.3$ & $6.7-6.8$ & $5-4.3$ & $4.2-4.2$ & $15.8-15.3$ \\
\hline 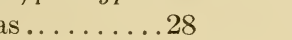 & 6.8 & 6 & 4.8 & 4.3 & 14.2 \\
\hline
\end{tabular}

Uvalde, Texas, allotype .31.2
Uvalde, Texas, paratypes.30.3-30

Laredo, Texas.........28

$\begin{array}{lll}7-7.3 & 6.7-6.8 & 5-4.3\end{array}$

TRANS. AM. ENT. SOC., XLVIII. 
In the present series the width of the caudal femur is; $\sigma^{7}, 4$ to 4.1 ; $9,4.8$ to $5 \mathrm{~mm}$. The tegmina slightly overlap in the Laredo male, in the others the interval between these organs is .25 to $.35 \mathrm{~mm}$.

Larger series are needed to determine whether the tegminal differences, which appear to aid in separating the races of this species, are constant in this race and modestus modestus.

General color ochraceous-buff (individually tinged with ochraceous-tawny, varying to yellow-ocher), with a conspicuous round spot of ochraceous-buff laterad near base of tegmina. Head marked with blackish as follows: mediolongitudinally on the dorsal surface in a band which is divided by a pale line caudad, with a postocular streak, flecks on the genae and with a transverse band on each side beneath the antennal sockets terminating at the margins of the frontal costa. Pronotum with medio-longitudinal band continued on prozona, there dividing and then converging and forming a very narrow oval, thence quickly becoming obsolete on the metazona; medio-longitudinal carina, sulci and prozonal portion of lateral lobes pictured with blackish, the sutures of the pleura and periphery of the pale spot also blackish. Tegmina with the multitude of minute veins ochraceous-tawny, the minute interstices mummy-brown. Abdomen with proximal tergites irregularly suffused with blackish meso-laterad. Ventral surface paler, usually tinged with yellowocher, sutures of abdominal sternites black, male subgenital plate with a median fleck of black. Cephalic and median limbs immaculate, of the general coloration. Caudal femora with two heavy transverse bands and a dorso-proximal suffusion of blackish, the first (median) band becoming oblique on the external pagina, ventral margin of external pagina with a few heavy black flecks, genicular areas black laterad except for entire area of genicular lobes which is yellow-ocher; internal face of caudal femora antimony yellow, tinged with coral-red ventro-proximad and crossed by the more distal of black bands. Caudal tibiae of general coloration proximad, with a blackish ring at end of swollen portion, and with flecks of blackish or suffused with that color at end of proximal third, remaining two-thirds bright coral-red, spines and spurs buffy tipped with black, except proximo-internal spines which are wholly black.

Specimens Examined: 8; 4 males and 4 females.

Texas: Uvalde, Uvalde County, 1000 to 1100 feet, VIII, 21, 1912, (R. and H.), $3 \sigma^{7}, 3$ \& , type, allotype, paratypes. Laredo, Webb County, 550 feet, VIII, 12, 1912, (R. and H.), $1 \sigma^{7}, 1$ ㅇ.

Like Rhabdotettix, this species is thamnophilous and usually found in thorn bushes, but it is also frequently encountered in other vegetation affording security. The comparative scarcity of the present race, in the small portion of the United States in which it occurs, causes us to believe that, in adjacent northern Mexico, modestus aristus will be found to have a very much wider distribution, occurring there much more abundantly. 
Agroecotettix modestus crypsidomus new subspecies ${ }^{3}$ (Plate II, figs. 4, 5 and 6.)

1917. Agroecotttix modestus Hebard, Proc. Acad. Nat. Sci. Phila., 1917, p. 263. [ ; Monclova, Coahuila, Mexico.]

The present geographic race is separated from $A$. modestus aristus, here described, by the average smaller size and less swollen pronotum. Males are further separated by the shorter cerci, the forks of which are much shorter, with the external arm shortel than the internal arm. Females are less readily distingished by the proportionately smaller tegmina, which are separated by a moderate interspace.

Compared with the type of $A$. modestus modestus Bruner, a female, individuals of that sex of the present race are distinguished by their smaller size and red coloration of the distal portions of the caudal tibiae. The slightly more swollen pro* notum and form and position of the tegmina show a development approximately intermediate between that of $m$. modestus and $m$. aristus.

The discovery of males of $m$. modestus will aid greatly in defining accurately the relative position of the races of the species.

Type.- $\sigma^{7}$ : Marathon, Brewster County, Texas. Elevation, 3940 to 4160 feet. September 12, 1912. (Rehn and Hebard.) [Hebard Collection, Type no. 750.]

Agrees fully with $m$. aristus, described on page 50, except in the following characters Size smaller, medium. Vertex distinctly narrower. Inflation of prozonal portion of pronotum less decided. Cercus about three times as long as its proximal width, proximal portion narrowest at its median point (where it is about one-third as broad as long), due to the concavity of the dorsal margin, ventral margin straight throughout, except that feeble convexity is indicated proximad; internal section of distal portion produced in a straight, flattened finger, subequal in width, about twice as long as broad, with internal surface moderately convex and exteınal surface flattened and moderately oblique, apex rounded, this finger directed meso-caudad; external section of dorsal portion produced in a straight, rapidly tapering spike, with apex very narrowly rounded, very slightly shorter than internal section and directed caudad, so that the axes of these parts form an angle of something less than ninety degrees.

In the large series at hand the extremities of the male cerci show som? variation in length and form. The external production is usually decidedly shorter than the internal production, rarely nearly as elongate.

${ }^{3}$ From крuџ́t-ठоouos $=$ dwelling in secret places.

TRANS. AM. ENT. SOC., XLVIII. 


\section{Allotype.- $\%$; same data as type. [Hebard Collection.]}

The female sex of the present race differs from males as described for the female of $m$. aristus on page 51 except that the tegmina are more similar and are always moderately well separated. ${ }^{4}$ Interval between the mesosternal lobes less than one and one-half times as broad as long. ${ }^{5}$

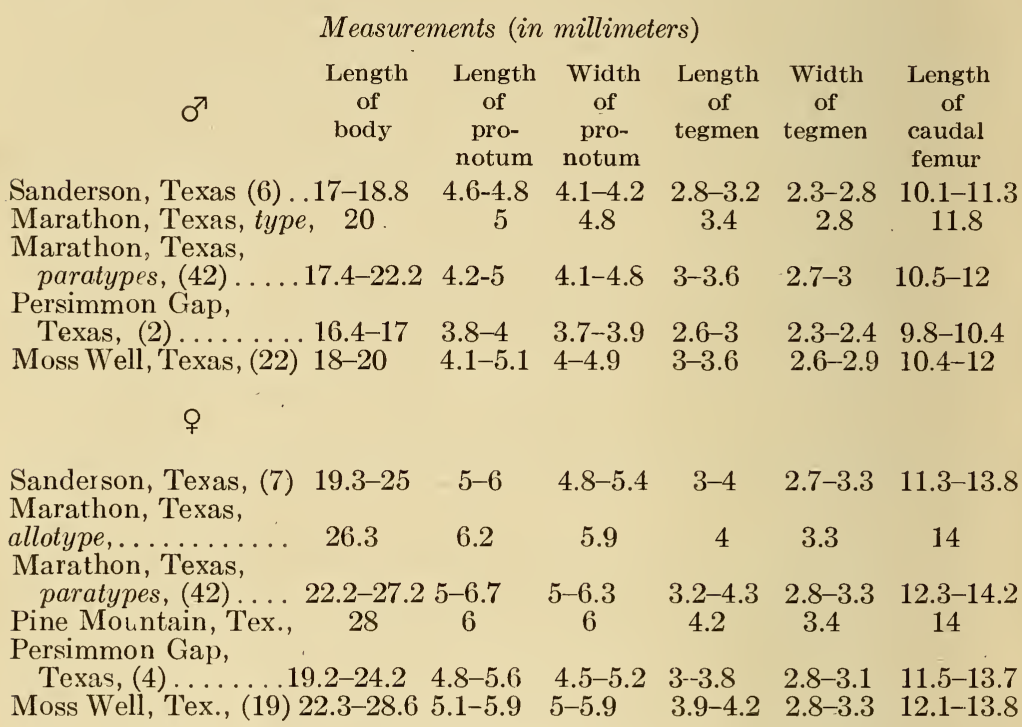

For convenience in comparing the measurements, we give the following for the type of modestus modestus Bruner, a female from Lerdo, Durango, Mexico. Length of body, 31.1; length of pronotum, 6.9 ; width of pronotum, 6.5 ; length of tegmen, 4.9; width of tegmen, 3.7; width between tegmina, 2.3 ; length of caudal femur, 15.8; width of caudal femur, $4.8 \mathrm{~mm}$.

The extremes of caudal femoral width are; $\sigma^{\nwarrow}, 3$ to 3.8 ; ㅇ, 3.1 to $4.4 \mathrm{~mm}$. The variation in width of the interval between the tegmina is; $\sigma^{7}, .1$ to .8 ; , .8 to $1.7 \mathrm{~mm}$.

In general coloration the present race agrees closely with modestus aristus, except that the majority of specimens have the general coloration darker, sayal brown, sometimes as deep as suffused bister. In consequence, the markings are less striking and the general appearance not as brilliant. The dark markings of the pronotal disk show decidedly less curvature, in the great majority of specimens being subparallel and in a few of maximum in-

${ }^{4}$ Varying in the large series at hand from .8 to $1.7 \mathrm{~mm}$.

${ }_{5}$ Varying in the series to very slightly broader than long, thus showing anew that this space is individually decidedly variable in the Melanopli, and can certainly not be used as of high generic or specific significance as was supposed by Scudder. 
tensive coloration fusing, so that in this region there is a dark medio-longitudinal band. In the darker specimens, the dark bars of the caudal femora are much less conspicuous and indeed are obsolete in a few of these.

The markings of the pronotal disk and darker general coloration show closer agreement with the type of modestus modestus. The present material, like that of modestus aristus, however, differs from that race in the red of the distal portions of the caudal tibiae and the ventro-proximal portion of the internal faces of the caudal femora.

Specimens Examined: 192; 88 males, 102 females and 2 immature individuals.

Texas: Sanderson, Terrell County, 2800 to 3150 feet, VIII, 25, 1912, (R. and H.), $6 \sigma^{7}, 7$ ㅇ. Marathon, Brewster County, 3900 to 4160 feet, VIII, 26 to IX, 13, 1912, (R. and H.), $43 \sigma^{7}, 43$ o , type, allotype, paratypes. Garden Spring, Brewster County, IX, 2, 1912, (R. and H.), $1 \sigma^{7}, 3$ ㅇ , 2 juv. Persimmon Gap, Brewster County, 3000 feet, IX, 10, 1912, (R. and H.), $20^{7}, 4$ ․ Avery Canyon, Grapevine Hills, Brewster County, 3000 feet, IX, 4, 1912, (R. and H.), 1 ơ 1 \&. Neville Spring, Brewster County, 3250 to 3300 feet, IX, 8, 1912, (R. and H.) ,1 $\sigma^{7}, 2$ ㅇ. Moss Well, Chisos Mountains, 4500 tc 5000 feet, IX, 5 to 8, 1912, (R. and H.), 22 o 19 ㅇ․ Lost Mine Peak, Chisos Mountains, 6000 feet, IX, 6, 1912, (R. and H.), 1 ㄱ, 1 ․ Canyon behind Pulliam Bluff, Chisos Mountains, 5000 feet, IX, 7, 1912, (R. and H.), $9 \mathrm{o}^{7}, 17$ ․ Pine Mountain, Davis Mountains, 6250 feet, VIII, 29, 1912, (R. and H.), 1 ㅇ․ Maguires Ranch, upper Limipa Canyon, Davis Mountains, 5600 feet, VIII, 29, 1912, (R. and H.), 1 ㅇ. Quitman Mountains, El Paso County, 4800 to 5400 feet, IX, 14, 1912, (Hebard), 2 o $^{\top}, 2$ ㅇ․ Zool.].

Mexico: Monclova, Coahuila, IX, 20, (E. Palmer), 1 , [Mus. Comp.

Not only was this insect often found abundant in the catclaw and other thorny shrubs, in the semi-desert areas of TransPecos Texas, but it was also seen frequently to seek shelter in the sotols (Dasylirion sp.). It was found at elevations from 2800 to 6250 feet, but was never met with in any numbers above the 5000 foot level in either the Chisos or Davis Mountains.

Conalcaea coyoterae ${ }^{6}$ new species (Plate III, figs. 1, 2 and 3.)

This insect is related to C. huachucana Rehn. It agrees closely in all features except that in most of the specimens before us the caudal femora are not conspicuously bicolored ${ }^{7}$, the

'The Coyotero Apaches, "Wolf-Men", inhabited the region from which the present species is known.

${ }^{7}$ In a single male, from Bill Williams Mountain, the coloration of the caudal femora is exactly as in huachucana. It would appear that no feature of coloration is of sufficient constancy, over the range of these species, to warrant its use as an unqualified diagnostic criterion.

TRANS. AM. ENT. SOC., XLVIII. 
male cerci are shorter with distal portion proportionately much broader and distal margin rounding strongly to the less produced ventro-caudal angle, while the male subgenital plate is shorter and not as sharply conical (for huachucana see plate III, figures 4 and 5).

In the coloration of the caudal femora, coyoterae agrees more closely with C. miguelitana (Scudder), in all other respects being, however, the opposite extreme of the forms of this stock, huachucana occupying an intermediate position in the form of the male cerci.

Type.- $\sigma^{7}$; Prescott, Arizona. Elevation, 5400 feet. July 21, 1917. (J. A. Kusche.) [Hebard Collection, Type no. 751.]

Size rather large compared with species of allied genera; form robust, subfusiform. Head as in huachucana ${ }^{8}$, small in proportion to the body bulk, distinctly narrower than greatest pronotal width, scutellum of the fastigium weakly concave between the very delicate but distinct lateral cari nae, frontal costa weakly concave toward the median ocellus, eye distinctly over one and one-half times as long as infra-ocular sulcus. Pronotum, tegmina and abdomen as in huachucana. Furcula represented by thickenings of the tergite, causing weak and well separated angulations of the margin. Supra-anal plate triangular with apex blunted, nearly as long as wide, modian sulcus broad and percurrent, deepest in proximal half, lateral portions weakly and broadly concave, with a minute conical projection near the lateral margins at twofifths the distance to the apex. ${ }^{9}$

Cercus narrowing in proximal third, thence widening greatly, due to expansion dorsad, the ventral margin being broadly and evenly convex throughout, the dorsal portion of the expanded section (which is nearly twice as wide as the proximal width and nearly half as wide as the cercal length) convex to the acute-angulate, briefly produced ventro-caudal angle (the apex). Subgenital plate conical, its apex blunt, shorter and blunter than in huachucana. Cephalic and median femora somewhat inflated and weakly bowed.

Allotype.- $\%$; Prescott, Arizona. Elevation, 5400 feet. July 31, 1917. (O. C. Poling.) [Hebard Collection.]

Very similar to females of huachucana, except that the caudal femora are not contrastingly colored, the external pagina of the general brown coloration, feebly and not solidly suffused with a darker shade.

Differs from the male in the following features. Size decidedly larger, form much more robust. Eye less than one and one-half times as long as infraocular sulcus. Even widening of the pronotal disk as regular but decidedly stronger. Ovipositor valves with stout apices moderately elongate and weakly curved, blunt teeth of dorso-external margin of dorsal valves large and irregular. Cephalic and median femora not inflated; the former nearly straight, the latter straight.

${ }^{8}$ Rehn's excellent description is best referred to; Proc. Acad. Nat. Sci. Phila., 1907, p. 48, (1907).

${ }^{9}$ Also found in huachucana. 
Measurements (in millimeters) of extremes

\begin{tabular}{|c|c|c|c|c|c|c|}
\hline$\sigma^{7}$ & $\begin{array}{c}\text { Length } \\
\text { of } \\
\text { body }\end{array}$ & $\begin{array}{c}\text { Length } \\
\text { of } \\
\text { pro- } \\
\text { notum }\end{array}$ & $\begin{array}{l}\text { Width } \\
\text { of } \\
\text { pro- } \\
\text { notum }\end{array}$ & $\begin{array}{l}\text { Length } \\
\text { of } \\
\text { tegmen }\end{array}$ & $\begin{array}{l}\text { Width } \\
\text { of } \\
\text { tegmen }\end{array}$ & $\begin{array}{l}\text { Length } \\
\text { of } \\
\text { caudal } \\
\text { femur }\end{array}$ \\
\hline Prescott, Arizona, type, & 18.5 & 4.2 & 4.2 & 4 & 1.9 & 11.2 \\
\hline $\begin{array}{l}\text { Prescott, Arizcna, } \\
\text { paratypes, (18)........ } \\
\text { Mount Union, Prescott, }\end{array}$ & $17-19.2$ & 4.2 .4 .4 & $3.9-4.2$ & $3.2-3.8$ & $1.9-1.7$ & $11-1$ \\
\hline $\begin{array}{l}\text { Arizona............ } \\
\text { Bill Williams Mountain, }\end{array}$ & 20 & 4.9 & 5 & 3.9 & 2 & 12.8 \\
\hline Arizona..... & 21 & 5 & 5 & 4.2 & 1.9 & 13 \\
\hline
\end{tabular}

\section{우}

Prescott Arizona, allotype, 26

Prescott, Arizona, paratypes, (42) $\ldots \ldots \ldots .21-30 \quad 5.1-6.3 \quad 5.4-7.2 \quad 4.7-5.4 \quad 1.9-2.5 \quad 12.7-15.7$

Mount Union, Prescott, Arizona, (3)......24.7-29.4 6.3-6.1 $\quad 6.7-6.8 \quad 4.8-4.6 \quad 2.1-2.1 \quad 15-15.4$

The width of the caudal femur in the series is: $\sigma^{7}, 3$ to 3.4 ; $9,3.4 .4-4.1 \mathrm{~mm}$.

Coloration very similar in the series, except that in the males the average is slightly more contrasting and brilliant. Occiput, disk of pronotum and dorsal surface of mesonotum and metanotum dull sayal brown (individually varying from cinnamon to warm sepia in the specimens of maximum recessive and intensive coloration). Cephalic and median limbs of this coloration, showing vague irregularities of shade. Dorsal surface of male abdomen, in proximal half shining blackish brown laterad, with a narrow medio-longitudinal band of pinkish cinnamon, remaining portions sayal brown; in females much more uniform, less shining, with latero-proximal portions only slightly darkened and medio-longitudinal band very weakly defined, in some individuals unicolorous. Remaining portions of head, lateral lobes of pronotum and underparts clay color, except for a weakly defined postocular bar on each side of the head (heavy in occasional specimens), which is continued on the dorsal portion of the pronotal lateral lobes as a broad, solidly colored, shining black band, in females often weak cephalad and caudad. On the sides, the meta-episternum and the meta-epimerum are shining black. Tegmina cinnamon-buff to clay-color in dorsal half, blackish brown to black and usually shining in ventral half. Caudal femora of the general coloration dorsad, paling to the ventral coloration ventrad, the external pagina vaguely and not solidly suffused with a darker shade, which in some females shows a faintly greenish tinge. Caudal tibiae varying from grenadine to peach red.

This type of caudal femoral coloration is strikingly different from the normal for huachucana, but a single male is before us agreeing fully in this respect with that sfecies. In that individual the external pagina is strikingly bicolored, the dorsal portion almost black, the ventral portion ochraceous-buff.

We would note that the usual difference from huachucana in the caudai femoral coloration is also shown in the immature stages, when dark markings:

TRANS. AM. ENT. SOC., XLVIII. 
are there present. In some of the juveniles the caudal femora are immaculate, the majority having, however, the entire external pagina black, except for invasions of the light general coloration. These invasions, when decided, break the black area into characteristic Melanoploid bands, which are continued across the dorsal surface of the femora.

Like the other species of this genus, the present is probably strictly geophilous, agreeing with huachucana in being an inhabitant of the Encinal, or Region of Oaks, in Arizona. The entire series was taken at elevations of from 5400 to 6500 feet.

Specimens Examined: 115; 20 males, 76 females and 19 immature individuals.

Arızona: Bill Williams Mountain, IX, 14, 1917, (O. C. Poling), 1 万", [Hebard Cln.]. Prescott, VII, 5 to VIII, 24, 1917, (Poling; Kusche), 19 व', $68 \sigma^{7}, 19$ juv., type, allotype, paratypes, [Hebard Cln.]. Granite Peak, Prescott, VIII, 17, 1917, (J. A. Kusche), 4 ㅇ , [Hebard Cln.]. Mount Union, Prescott, VIII, 15, 1917, (J. A. Kusche), $1 \sigma^{7}, 3$ \%, [Hebard Cln.]. Senator, Yavapai County, VIII, 12, 1917, (J. A. Kusche), 1 ㅇ, [Hebard Cln.].

Bradynotes chilcotinae new species (Plate III, figs. 6, 7 and 8.)

This species is readily separable from any of the previously known forms by the large triangular furcula of the male and other genitalic features in this sex.

In form it agrees best with $B$. caurus Scudder, the definition between the disk and lateral lobes of the pronotum being weakest in these species. In coloration it is dark, showing the greatest reduction of the brilliant colors found on the caudal limbs in the majority of the species of Bradynotes.

The caudal tibiae are buffy, as in B. albida Hebard, B. excelsa Rehn and $B$. satur Scudder, but these members are often strongly suffused in the present insect.

The male cerci often fail to reach as far distad as the apex of the supra-anal plate and are as slender at their apices as in B. compacta Morse ${ }^{10}$. The male supra-anal plate, though subject to considerable variation, is seen to be never of the simple, longer type developed in $B$. obesa (Thomas) and its closer allies, in which the lateral margins are weakly concave convergent to the broadly rounded apex.

Type.- $\sigma^{\text {r }}$; Riske Creek, Chilcotin, British Columbia. July 22, 1921. (E. R. Buckell.) [Canadian National Collection.]

Size medium large for the genus; form heavy, though not as heavy as in obesa and its closer allies; surface moderately pilose. Head broad and full, vertex gently tumid; fastigium shallowly concave, the lateral margins thick,

${ }^{10}$ Compare, Trans. Amer. Ent. Soc., xuv, pl. xxix, fig. 14, (1919). 
rounded and very weakly defined, the width at the ocelli decidedly oreater than between the eyes; frontal costa comparatively broad and shallowly concave, with lateral margins rounded and very weakly defined, surface rather decidedly impresso-punctate; least width distinctly greater than that of proximal antennal joint, greatest width between antennal bases. Eyes slightly longer than infra-ocular sulcus.

Pronotum much as in caurus, the weakly convex disk curving into the lobes, with the low and broadly rounded lateral carinae subobsolete; disk expanding very slightly caudad, medio-longitudinal carina obsolete, except very briefly cephalad on prozona and on metazona caudad of the principal sulcus, continued on abdomen but very weak and obsolete on proximal tergites. Tegmina and wings absent.

Furcula represented by a pair of large, triangular projections, which form mesad an obtuse-angulate emargination and have their external margins straight, longitudinal; these processes are broader than long, but in length from base of their tergite exceed one-fourth the length of the supra-anal plate. ${ }^{11}$ Supra-anal plate broad, its length equal to (varying in the series to slightly greater than) its basal width; lateral margins weakly convergent and very weakly convex to distal portion, where on each side a very strongly obtuseangulate emargination is indicated; (in the series at hand the apex of the plate varies from sharply triangular to very strongly rounded-triangular, the emargination laterad varying from obsolete to strongly defined,) surface deeply concave laterad, with a broad medio-longitudinal concavity, which is strong preximad, very weak mesad and shallow distad. ${ }^{12}$

Cerci shorter than (varying in the series to as long as) the supra-anal plate, tapering gradually from the broad base to the very slender, rounded apex. Subgenital plate full, conical, free lateral margins weakly convex to the very blunt apex, which is entire and is produced caudad but not elevated. Cephalic and median femora moderately inflated, very feebly bowed.

Allotype.- - ; same data as type, but taken June 24, 1921. [Canadian National Collection.]

Larger and more robust than male. Fastigium of vertex and frontc $]$ costa much broader and with surface much more weakly concave, the surface of the latter impresso-punctulate. Eye in length approximately that of infraocular sulcus. Pronotum moderately broadened caudad, its convexity very weakly interrupted by the subobsolete lateral carinae, which scarcely delimit the disk from the lateral lobes; medio-longitudinal carina subobsolete, obsolete on the three succeeding segments, but again weakly indicated on the abdominal tergites. Ovipositor valves much as in satur, the dorsal pair showing weaker curvature than in obesa. Cephalic and median femora neither inflated or bowed.

${ }^{11}$ Though somewhat variable in length and width, these projections are seen to be constant in general contour in the very large series under consideration.

${ }^{12}$ In no specimens could the type of this plate be confused with that of obesa and its closer allies.

TRANS. AM. ENT. SOC., XLVIII. 
Measurements (in millimeters) of extremes

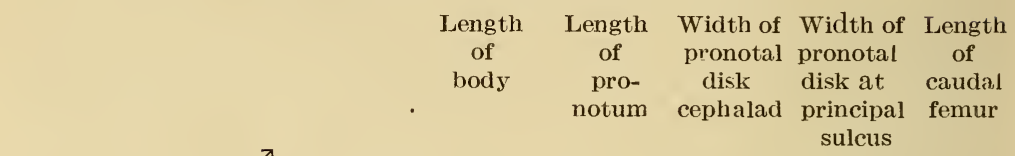

$\sigma^{x}$

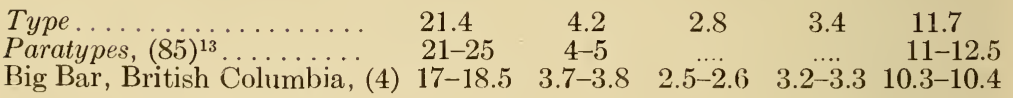

우

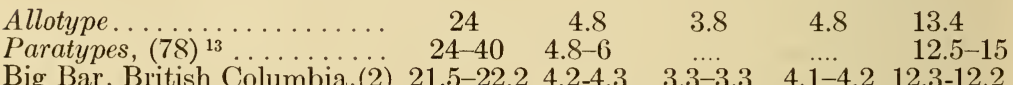

Big Bar, British Columbia,(2) 21.5

The size reduction shown by the Big Bar specimens is probably attributable to different local environmental conditions.

General coloration of dorsal surface of males chestnut-brown, deepening to shining blackish brown proximad on sides of abdomen, except ventrad toward margins of tergites, where narrow invasions of the buffy color of the ventral surface occur. Ventral surface light ochraceous-salmon, or antimony-yellow with a salmon tinge. Frontal costa, face, genae and ventro-lateral portions of pronotum and thorax buffy, darkened by very numerous dots and flecks of dark brown. Cephalic and median limbs similar, but not as much darkened. Pronotal lateral lobes with dorsal portion slightly darker and more shining than disk, this weakly defined band continued on the sides of the thorax.

Caudal fumora buffy, with minute flecks and dots of dark brown, dorsal and external faces with two broad bands of chestnut-brown, which are oblique on the external pagina, the genicular areas also darkened. In many specimens these portions are often greatly suffused, in some so dark that the bands have become almost obsolete. Internal surface of caudal femora proximar and ventro-internal surface distad vinaceous rufous or dragons blood red. Caudal tibiae buffy, frequently strongly washed with mummy brown; spines and spurs buff proximad, black distad.

The females vary in general coloration from chestnut-brown to prout's brown and are much more uniform, the darker bands of the body and caudal femora being subobsolete or absent. In this sex the ventral surface of the doby appears to be light brown, but is seen to be usually much discolored and darkened in dried specimens.

Mr. Buckell writes that this insect is "extremely common in semi-sylvan locations, especially in upland pastures beneath the aspens (Populus tremuloides). In some places it is the commonest grasshopper to be found." The species was found hatching

${ }_{13}$ These measurements were taken by Mr. Buckell, from the material before drying. 
as early as May 1st, while adults were numerous and freely pairing by July 20th. In early August it had become scarce, but about the middle of September many adults were again found, pairing freely, and the species was still common in October

These interesting notes by the energetic discoverer of this new species indicate that, in the Chilcotin, it is probably double brooded.

We are told that individuals are much sought after by the Indians for fish bait.

Specimens Examined: 245; 137 males and 108 females.

British Columbia: Riske Creek, Chilcotin, VI, 20, 1920, 3 o శ7 $^{7}$ q ; IX,

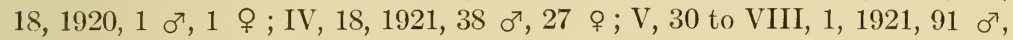
75 우, type, allotype and all others paratypes, (all taken by E. R. Buckell).14 Big Bar, 7400 feet, VII, 9, 1921, (E. R. Buckell), 4 ơ , 2 우.

Melanoplus chiricahuae new species (Plate III, figs. 9 and 10.)

This handsome insect agrees closely in size, coloration and general appearance with $M$..femur-nigrum Scudder, a species known from the northern portion of the Arizona Plateau.

In male cercal development nearest approach is found in $M$. calidus Scudder, which species occurs in the White and Sacramento Mountains of south-central New Mexico. The cerci of that species are, however, much broader and shorter, with broadened apical portion more conspicuously truncate. In other features wide differentiation between these two species occurs, chiricahuae being clearly much more closely related to femur-nigrum.

Type.- $\sigma^{\top}$; Ida's Peak, Chiricahua Mountains, Cochise County, Arizona. Elevation, 8000 feet. June 28, 1919. (Witmer Stone.) [Acad. Nat. Sci. Phila., Type no. 5381.]

Size and form medium for the group. Vertex and frontal costa as in femurnigrum. Eye large, nearly twice as long as infra-ocular sulcus. Pronotum as in femur-nigrum: medio-longitudinal carina weak on prozona, very weak between transverse sulci, moderately decided on remaining portion of metazona, sulci distinct but not deep; lateral margins of pronotal disk subparallel to principal sulcus, caudal margin of same broadly obtuse-angulate produced with apex rounded. Prosternal spine longer than broad, slightly transverse, cylindrical to distal portion which tapers off strongly to the rounded apex. Tegmina very slightly longer than pronotum. almost attingent, oval, with apex rounded, though not broadly so.

${ }^{14}$ The bulk of this series is in the Canadian National and Philadelphia Collections. Sets, however, will be sent to the other larger North American collections of Orthoptera.

TRANS. AM. ENT. SOC., XLVIII. 
Furcula represented by two minute projections, with bases weaky convex to base of their tergite, the projecting portions slightly longer than wide. Supra-anal plate shield-shaped, with lateral margins proximad straight and parallel for a short distance, then moderately raised, very weakly concave and convergent to the short, thick, weakly elevated disto-lateral carinae, the small apical portion triangular with apex bluntly rounded. Surface of supra-anal plate broadly concave laterad, with a broad medio-longitudinal sulcus in proximal half, which is very weak (absent in paratype) in distal half.

Cerci nearly two and one-half times as long as basal width, straight, narrowing gradually, then expanding, so that the distal third is slightly enlarged with dorsal margin slightly more convex than ventral margin, apical portion with external surface weakly concave, broadly rounded dorso-distad, but forming a moderately (sharply, in paratype) rounded rectangulate disto-ventral angle, the distal margin transverse. Subgenital plate produced meso-dorsad in a large, bluntly rounded tubercle, directed caudad, which tubercle is slightly more produced and less heavy than in femur-nigrum.

\section{Allotype.-o ; same data as type. [Acad. Nat. Sci. Phila.]}

Agrees with type except as follows. Size larger, form more robust. Sulcation of vertex and frontal costa weaker and broader. Eye about one and two-thirds times as long as infra-ocular sulcus. Pronotum with lateral margins of disk weakly divergent to principal sulcus. Prosternal spine heavier toward its base. Ovipositor valves moderately elongate, with distal curvature rather broad; the dorsal valves with dorsal surface and margins proximad rather well supplied with serrations.

\begin{tabular}{|c|c|c|c|c|c|c|}
\hline \multicolumn{7}{|c|}{ Measurements (in millimeters) } \\
\hline & $\begin{array}{l}\text { Length } \\
\text { of } \\
\text { body }\end{array}$ & $\begin{array}{l}\text { Length } \\
\text { of } \\
\text { pro- } \\
\text { notum }\end{array}$ & $\begin{array}{c}\text { Caudal } \\
\text { width of } \\
\text { pro- } \\
\text { notal } \\
\text { disk }\end{array}$ & $\begin{array}{l}\text { Length } \\
\text { of } \\
\text { tegmen }\end{array}$ & $\begin{array}{l}\text { Width } \\
\text { of } \\
\text { tegmen }\end{array}$ & $\begin{array}{c}\text { Length } \\
\text { of } \\
\text { caudal } \\
\text { femur }\end{array}$ \\
\hline $\begin{array}{l}\text { Type..... } \\
\text { Paratype. }\end{array}$ & $\begin{array}{l}20.2 \\
\ldots 19^{15}\end{array}$ & $\begin{array}{l}4.7 \\
4.6\end{array}$ & $\begin{array}{l}2.8 \\
2.7\end{array}$ & $\begin{array}{l}5 \\
4.9\end{array}$ & $\begin{array}{l}2.8 \\
2.6\end{array}$ & $\begin{array}{l}10.8 \\
10.7\end{array}$ \\
\hline \\
\hline Allotype.. & .24 & 5.3 & 3.9 & 5.9 & 3.4 & 12.7 \\
\hline
\end{tabular}

Dorsal surface of male blackish chestnut-brown; the lateral margins of the pronotal disk outlined in buffy to the principal sulcus in the paratype (a frequent color feature in species of this group). Other portions of head, ventral portions of pronotal lateral lobes, cephalic and median limbs and underparts clay color, often with an olivaceous tinge; the head with a broad shining postocular black bar, which broadens and is continued on the lateral lobes of the principal sulcus. Lateral portions of thorax blackish, with a striking, oblique bar of light buff. Sides of abdomen heavily overlaid with shining black, this narrowing strongly caudad.

${ }^{15}$ Estimated, the abdomen being curved upward in this specimen. 
Dorsal surface of caudal femora hazel, with all of genicular areas, two bars and a pioximal fleck of chestnut-brown, the first bar extending a brief distance on the internal surface, the second bar crossing the internal surface, which is elsewhere buff-yellow, becoming paler before the genicular area. External surface of caudal femora colored as is characteristic of the group; chestnutbrown, with the rather narrow ventral portion buff-yellow; ventral surface faintly tinged with orange. Caudal tibiae rich glaucous-blue, spines black, spurs white proximad and black distad.

The female is very similarly colored, the dor'sal surface being paler, chestnutbrown.

In addition to the type and allotype, a single paratypic male, hearing the same data, has been examined.

Melanoplus fultoni' ${ }^{6}$ new species (Plate III, figs. 11 and 12.)

This diminutive species is a member of the Marginatus Group, belonging to that section which includes the forms very closely allied to $M$. gracilipes Scudder.

It is nearest $M$. sonomaensis Caudell, differing in the male sex in the proportionately longer and more slender furcula, supra-anal plate with transverse inedian carina (subobsolete in sonomaensis) raised in a small but prominent rounded lamella on each side of the medio-longitudinal sulcus, and subgenital plate which rounds evenly to the blunt apex (where, in sonomaensis, there is a small but conspicuous subapical tubercle).

In the female sex these species are alinost inseparable. The females of fultoni before us differ from those of sonomaensis only in being slightly more robust, with fastigium of vertex a trflie less protuberant. The females of the other closely related species of this group are likewise almost indistinguishable. The difficulty in the present case is aggravated by the fact that we have sonomaensis, not only from north and south of Lagunitas, California, but from that locality as well.

Type.- $\sigma^{7}$; Lagunitas, Marin County, California. August 7, 1921. (B. B. Fulton.) [Hebard Collection, Type no. 832.]

Size small, form slender; agreeing closely with soromaensis. Head much as in that species. Eye distinctly more than twice as long as infra-ocular sulcus. Pronotum as in sonomaensis and other closely related species; elongate, disk of almost equal width throughout, median carina well defined and percurrent: caudal margin broadly obtuse-angulate produced. Prosternal spine conical with apex moderately blunt (varying from blunt to a condition in which the

${ }^{16}$ Named in honor of the collector of this insect, Mr. B. B. Fulton, whose masterly "Tree Crickets of New York" is one of the finest of recent entomological contributions.

TRANS. AII. ENT. SOC., XLVIII. 
spine is more slender with apex much more sharply rounded in the paratypes). Tegmina considerably shorter than pronotum, almost attingent, with apex broadly rounded.

Furcula represented by a pair of minute, slender processes, three times as long as broad, which do not taper to their rounded apices (varying to more slender and weakly tapering in the paratypes), are faintly divergent (varying to moderately divergent in the paratypes), with length contained in that of supra-anal plate nearly four times (varying to three and one-half times in the paratypes). Supra-anal plate moderately elongate, shield-shaped; median sulcus decided, with lateral margins distinctly carinate to slightly beyond median point; transverse carina there, toward the lateral margins of this sulcus, developed into a small but conspicuous lamella on each side, with margin rounded; lateral portions of plate rather strongly concave, disto-lateral carinae subobsolete.

Cerci faintly bent slightly beyond end of proximal two-thirds, approximately twice as long as basal width, tapering strongly proximad; dorsal margin broadly concave, ventral margin straight, becoming weakly convex distad; distal portion very slender to the rather sharply rounded apex, the external surface showing faint subapical concavity. Subgenital plate with median section of equal depth laterad and mesad, curving and tapering meso-distad to the blunt apex, which shows no trace of tuberculation. Limbs as in soromaensis.

\section{Allotype.- o ; same data as type. [Hebard Collection.]}

Size larger, form heavier, fastigium of vertex broader and less deeply sulcate than in male. Compared with females of sonomaensis above.

\begin{tabular}{|c|c|c|c|c|c|c|}
\hline \multicolumn{7}{|c|}{ Measurements (in millimeters) } \\
\hline$\sigma^{7}$ & $\begin{array}{l}\text { Length } \\
\text { of } \\
\text { body }\end{array}$ & $\begin{array}{l}\text { Length } \\
\text { of } \\
\text { pro- } \\
\text { notum }\end{array}$ & $\begin{array}{c}\text { Caudal } \\
\text { width } \\
\text { pro- } \\
\text { notum }\end{array}$ & $\begin{array}{l}\text { Length } \\
\quad \text { of } \\
\text { tegmen }\end{array}$ & $\begin{array}{l}\text { Width } \\
\text { of } \\
\text { tegmen }\end{array}$ & $\begin{array}{l}\text { Length } \\
\text { of } \\
\text { caudal } \\
\text { femur }\end{array}$ \\
\hline $\begin{array}{l}\text { Type........ } \\
\text { Paratypes, (6) }\end{array}$ & $\begin{array}{c}13 \\
13-14.7\end{array}$ & $\begin{array}{c}3.3 \\
3.3-3.4\end{array}$ & $\begin{array}{c}1.9 \\
1.9-2\end{array}$ & $\begin{array}{c}2.7 \\
2.1-3.2\end{array}$ & $\begin{array}{c}1.9 \\
1.3-2.2\end{array}$ & $\begin{array}{c}8 \\
7.9-8.5\end{array}$ \\
\hline 우 & & & & & & \\
\hline $\begin{array}{l}\text { Allotype..... } \\
\text { Paratypes, (2) }\end{array}$ & $\begin{array}{c}18.8 \\
17.7-18\end{array}$ & $\begin{array}{c}4 \\
4-3.9\end{array}$ & $\begin{array}{c}3.1 \\
3-2.9\end{array}$ & $\begin{array}{c}4 \\
3.6-4\end{array}$ & $\begin{array}{c}2.7 \\
2.7-2.7\end{array}$ & $\begin{array}{c}10.1 \\
10-10.1\end{array}$ \\
\hline
\end{tabular}

Head tawny-olive, except occiput which is verona brown and a broad, shining, sharply defined, postocular bar of blackish brown. Eyes cinnamonbrown tinged with tawny. Antennae tawny-olive proximad, russet in other portions. Pronotum with disk verona brown, lateral lobes with a band of shining blackish brown occupying dorsal two-fifths of prozonal portion, corresponding metazonal portion verona brown deepening to warm sepia in dorsal portion, lower portion of lateral lobes tawny-olive. Tegmina verona brown, somewhat darker ventrad. Abdomen cinnamon dorsad, cinnamonbuff ventrad, with a broad band of shining blackish brown on each side, which 
narrows and decreases into small flecks on the distal tergites. Other portions of ventral surface clay color. Cephalic and median limbs clay color, tinged with cinnamon. Caudal femora similar, but showing faintly the characteristic Melanoploid pattern in a slightly darker brown, ventral surface orange-cinnamon. Caudal tibiae weak grayish glaucous; external spines black, internal spines and all spurs whitish proximad, black distad.

In the intensive examples the markings of the caudal femora are more distinct, the ventral surfaces brick red. In one female the caudal tibiae are grayish, showing no trace of glaucous. Another female is pale greenish yellow, showing no darker markings.

In addition to the described pair, a paratypic series of six males and two females is before us, belonging to the Fulton and Hebard Collections.

\section{EXPLANATION OF PLATES}

\section{Plate II}

Fig. 1.-Agroccotettix modestus aristus new subspecies. Uvalde, Texas. Male (type). Lateral view. $\left(\times 2 \frac{1}{2}\right)$

Fig. 2.-Agroccolcttix modestus aristus new subspecies. Uvalde, Texas. Male (type). Lateral view of cercus. (Greatly enlarged.)

Fig. 3.-Agroccotettix modestus aristus new subspecies. Uvalde, Texas. Female (allotype). Lateral view. $(\times 23 \%)$

Fig. 4.-Agroecotettix modestus crypsidomus new subspecies. Marathon, Texas. Male (type). Lateral view. $\left(\times 2 \frac{1}{2}\right)$

Fig. 5.-Agroecotettix modestus crypsidomus new subspecies. Marathon, Texas. Male (iype). Lateral view of cercus. ${ }^{17}$ (Same scale as fig. 2.)

Fig. 6.-Agroecotettix modestus crypsidomus new subspecies. Marathon, Texas. Female, (allotype). Lateral view. $(\times 23 \%)$

\section{Plate III}

Fig. 1.-Conalcaea coyoterae new species. Prescott, Arizona. Male (type). Lateral view of cercus. (Greatly enlarged.)

Fig. 2.-Conalcaea coyoterae new species. Prescott, Arizona. Female (allotypє). Lateral view of caudal femur. $\left(\times 2 \frac{1}{4}\right)$

Fig. 3.-Conalcaea coyoterae new species. Prescott, Arizona. Female (allotype). Lateral view of dorsal ovipositor valve. (Greatly enlarged.)

${ }^{17}$ Due to the fact that the internal section of the distal portion of the cercus is of necessity foreshortened in this aspect, it appears as long as the external section, but is in reality very slightly shorter.

TRANS. AM. ENT. SOC., XLVIII. 
Fig. 4.-Conalcaea huachucana Rehn. Carr Canyon, Huachuca Mountains, Arizona. Male (type). Lateral view of cercus. (Same scale as fig. 1.)

Fig. 5.-Conalcaea huachucana Rehn. Carr Canyon, Huachuca Mountains, Arizona. Female (allotype). Lateral view of caudal femur. $\left(\times 2 \frac{1}{4}\right)$

Fig. 6.-Bradynotes chilcotinae new species. Riske Creek, Chilcotin, British Columbia. Male (type). Dorsal view of furcula and supraanal plate. (Greatly enlarged.)

Fig. 7.-Bradynotes chilcotinae new species. Riske Creek, Chilcotin, British Columbia. Male (paratype). Dorsal view of distal portion of supra-anal plate, showing variation in the species. (Same scale as fig. 6.)

Fig. 8.-Bradynotes chilcotinae new species. Riske Creek, Chilcotin, British Columbia. Male (type). Lateral view of cercus. (Greatly enlarged.)

Fig. 9.-Melanoplus chiricahuae new species. Ida's Peak, Chiricahua Mountains, Arizona. Male (type). Dorsal view of furcula and supra-anal plate. (Scale same as fig. 6.)

Fig. 10.-Melanoplus chiricahuae new species. Ida's Peak, Chiricahua Mountains, Arizona. Male (type). Lateral view of cercus. (Scale same as fig. 8.)

Fig. 11.-Melanoplus fultoni new species. Lagunitas, California. Male (type). Dorsal view of furcula and supra-anal plate. (Same scale as fig. 6.)

Fig. 12.-Melanoplus fultoni new species. Lagunitas, California. Male (type.) Lateral view of cercus. (Same scale as fig. 8.) 
Trans. Am. Ent. Soc.: Vol. XLVIII.

Pl. II.
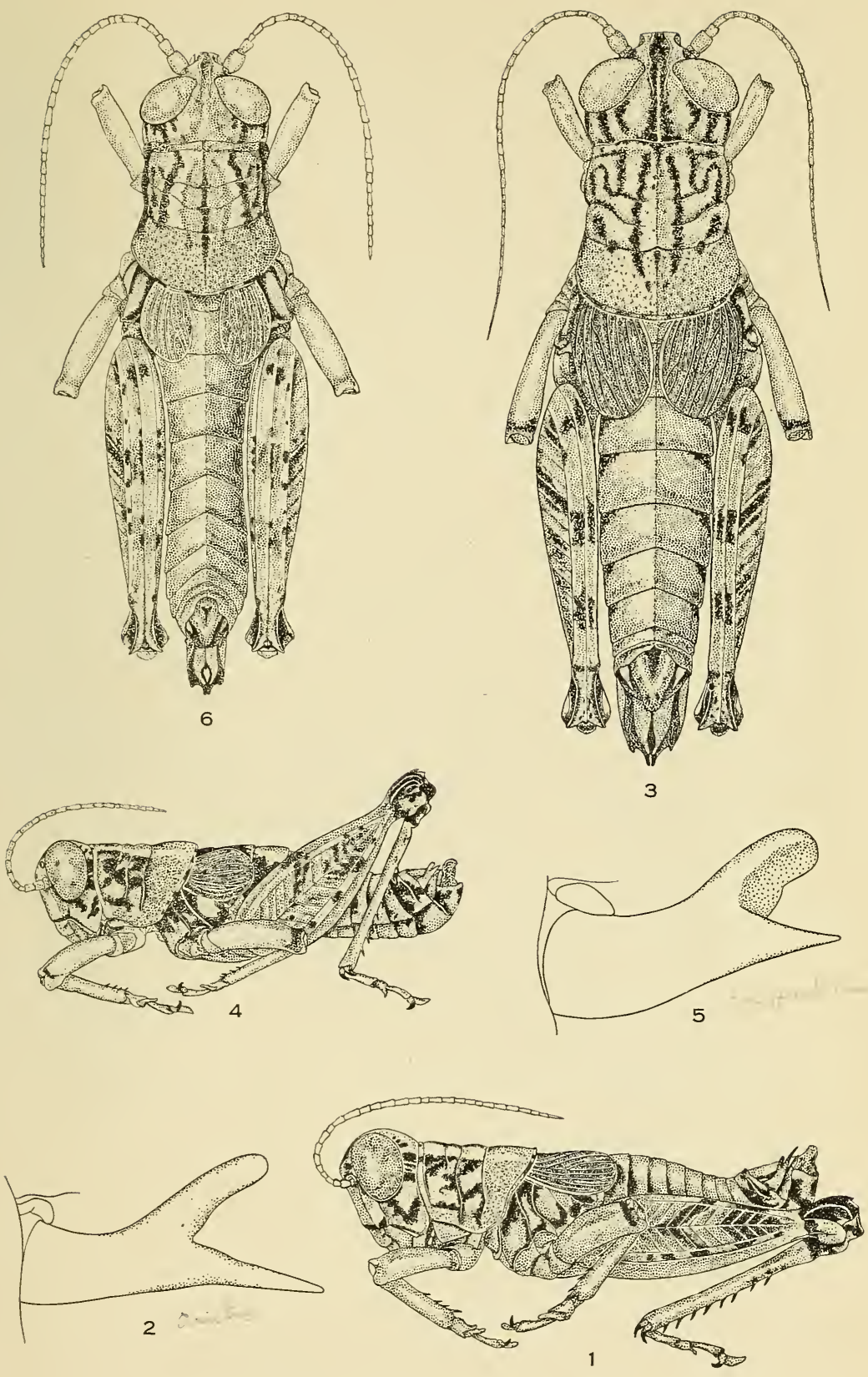

HEBARD—NEW NORTH AMERICAN MELANOPLI 

Trans. Am. Ent. Soc., Vol. XLVIII.

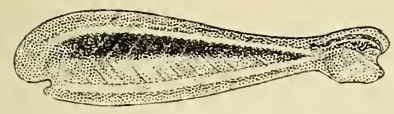

5
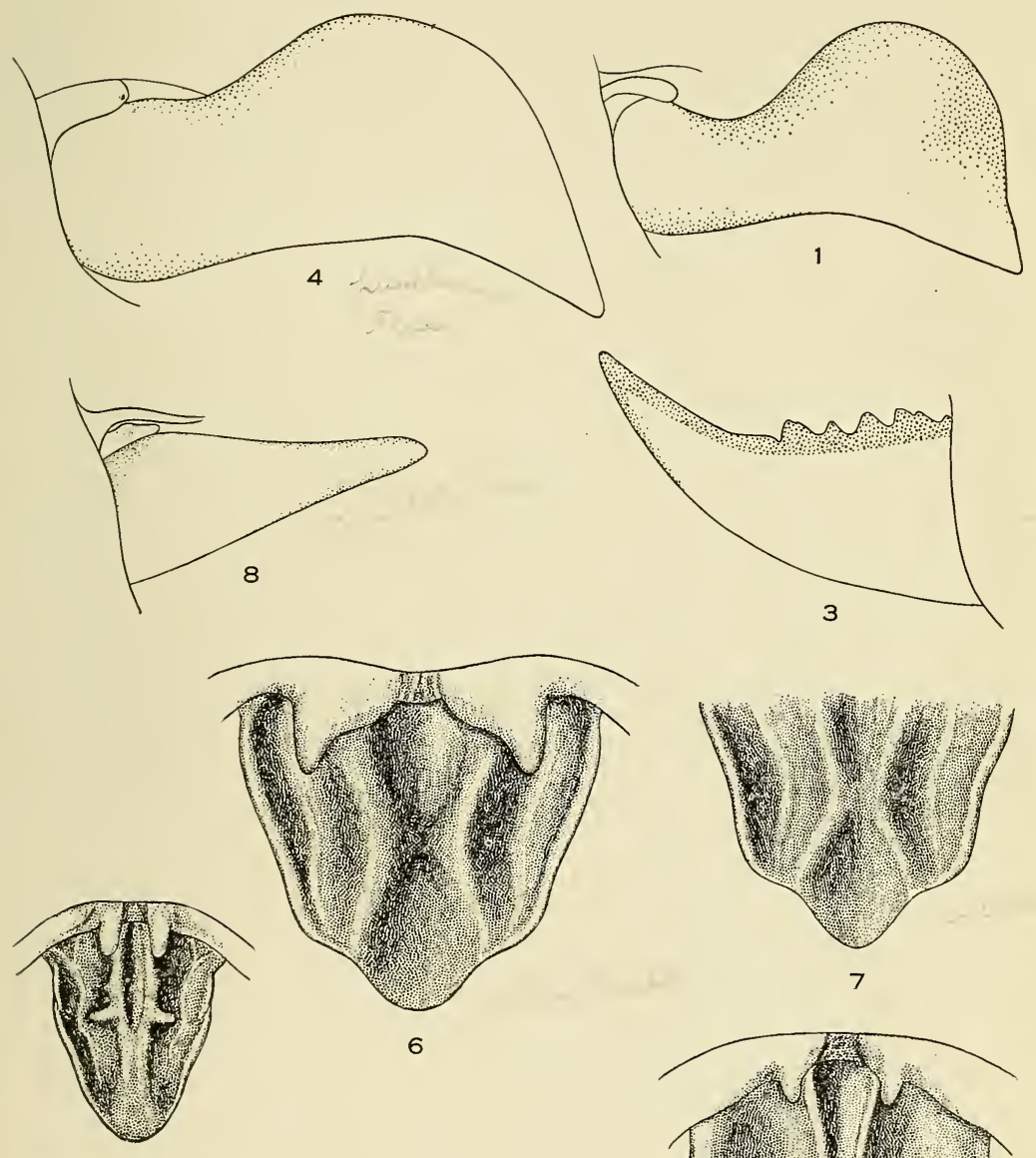

11

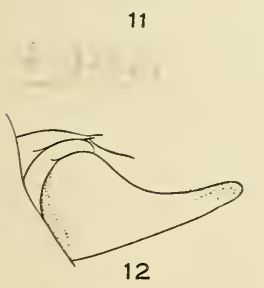

12
Pl. III.

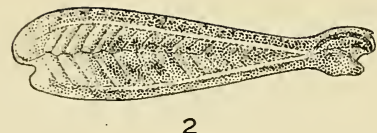

2
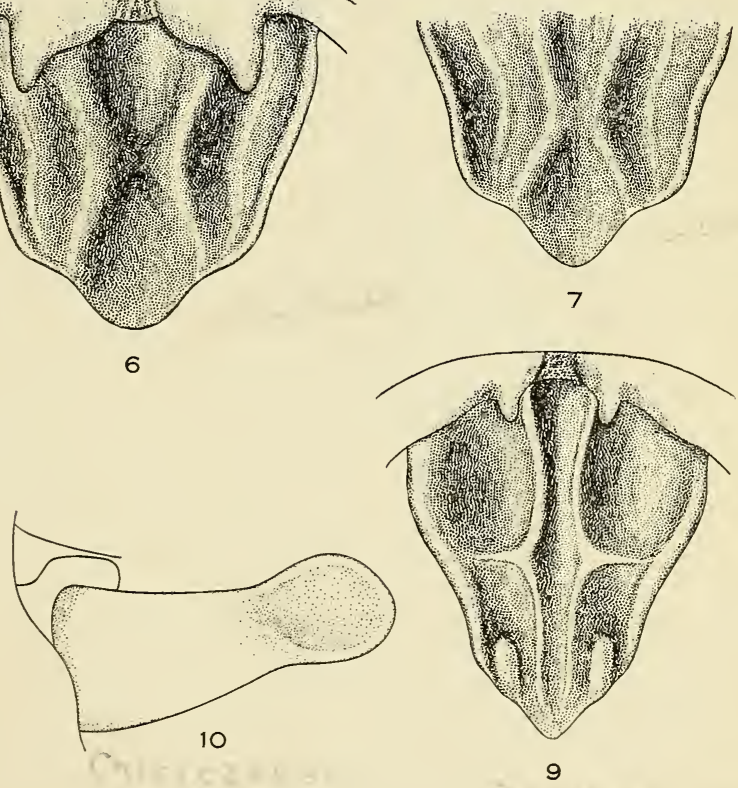

6

HEBARD—NEW NORTH AMERICAN MELANOPLI 






\title{
NEW GENERA AND SPECIES OF THE MELANOPLI FOUND WITHIN THE UNITED STATES AND CANADA
}

(ORTHOPTERA, ACRIDIDAE).

\author{
PARTS V AND VI
}

BY MORGAN HEBARD

(Plates XXII-XXVII)

Unless otherwise noted the material here studied is in the collection of the author, deposited at the Academy of Natural Sciences of Philadelphia. Duplicates of all series, however, collected jointly by Rehn and Hebard belong to that Institution.

\section{THE GRACILIS, VIRIDIPES AND TRIBULUS GROUPS}

Over twenty years ago the author decided upon specializing on the Group Melanopli as found in North America, and a number of papers dealing with this subject have already been published. ${ }^{1}$ It is now realized that years must elapse before sufficient material can be assembled and studied to make the treatment of certain groups as definite and final as is already possible for the majority. The literature on certain species is highly unsatisfactory and this is particularly true of Melanoplus viridipes and its nearest relatives. We therefore present at this time a study of the

\footnotetext{
1 1917. Notes on Mexican Melanopli. Proc. Acad. Nat. Sci. Phili., 1917, pp. 251-275.

1918. New Genera and Species of Melanopli found within the United States. Trans. Amer. Ent. Soc., XLIV, pp. 141-169.

1919. New Genera and Species of Melanopli found within the United States. Part II. Trans. Amer. Ent. Soc., xLv, pp. 257-298.

1920. New Genera and Species of Melanopli found within the United States. Part III. Trans. Amer. Ent. Soc., xLvi, pp. 355-403.

1922. New Genera and Species of Melanopli found within the United States and Canada. Part IV. Trans. Amer. Ent. Soc., xuviII, pp. 49-66.

1923. An Interesting New Species of the Genus Melanoplus from Central Georgia. Ent. News, xxxiv, pp. 260-262.
}

TRANS. AM. ENT. SOC., LX. 
Gracilis and Viridipes Groups and describe a new species of the Tribulus Group with a brief discussion of its relatives, based on far larger series than it has ever before been possible to assemble, (733 specimens in addition to several hundred previously correctly reported). For the loan of material, without which this work could not have been accomplished, we wish to thank most sincerely T. H. Hubbell of the University of Michigan, E. S. Thomas of the Ohio State Museum, A. N. Caudell of the United States National Museum, F. Sherman of Clemson College, N. Banks of the Museum of Comparative Zoology, W. T. Davis, B. B. Fulton, A. P. Morse and W. S. Blatchley.

During a visit to the Geneva Museum in 1927 we were able to study many of Saussure's types and his Pezotettix longicornis, unplaceable from the original description, is found to represent a species of the Viridipes Group, the essential characters of which are given in the present paper.

Although gracilis is nearer the species of the Viridipes Group than any others, we consider it the sole representative of a distinct group, distinguished by the following features.

A. Pronotum of both sexes with caudal margin transverse and usually feebly obtuse-angulate emarginate mesad. Tegmina of both sexes minute, elongate, apically rounded, widely separated, lateral pads. Meso-caudal projection of male subgenital plate greatest ventrad. Male penis an erect, stout tube terminating in two rounded triangular flaps which project horizontally and diverge latero-caudad; within the tube an extremely elongate slender flagellate paired process curves dorsad, then cephalad and tapers to an aciculate apex. Western Pennsylvania and Virginia to eastern Nebraska and Kansas; southern border of Great Lakes, southern Michigan and Minnesota to northern Alabama and Mississippi...Melanoplus gracilis (Bruner)

AA. Pronotum of both sexes with caudal margin weakly obtuseangulate produced. Tegmina of both sexes broad, rounded, subattingent to decidedly overlapping pads. Meso-caudal projection (tuberculation) of male subgenital plate, if present, dorsad. Male penis with large base bearing cephalad two slightly divergent, ear-like, erect flaps; before these and projecting from the tube are two erect, spike-like processes of less or only slightly greater length. Southwestern Vermont to southeastern Minnesota, Appalachian to Ozark Mountains as far south as northern Georgia and Arkansas.

Melanoplus viridipes and its allies. 
Further studies of the penis are proving more and more conclusively that this organ can not be disregarded when considering species of the genus Melanoplus. In fact it would otherwise have been impossible to determine safely as distinct species or races several of those here treated. We therefore give the following key based on the characters shown by the penis, as well as figures of this organ for all of the new forms we are describing. It must be remembered, however, that external characters often distinguish many species from all others quite as safely and we believe that when such is the case they should be given precedence over features which can not be determined for individual specimens without dissection. Indeed, among the species of the Viridipes Group, the structure of the penis is so similar in viridipes viridipes, viridipes eurycercus and longicornis that attempt to separate these insects on the basis of characters of the penis should not be made, but they are readily distinguished by features shown by the male cerci. In other cases in this group, knowledge of the distribution of the species is of distinct assistance in locating certain of them.

Penis with a stout base.

A. This base surmounted by a pair of horizontal triangular processes directed latero-caudad. A pair of very slender attingent median processes, very elongate and whip-like, are directed dorsad and curve cephalad, then ventrad.

gracilis Bruner

AA. This base with processes projecting vertically. The pair of median aciculate processes erect or sheathed by the pair of proximal processes.

B. The proximal processes with concave or flattened surfaces facing caudad. The median processes erect, aciculate.

C. Basal portion much less elevated caudad, so that the two pair of dorsal processes project much more conspicuously.

D. The proximal processes rounded triangular with caudal surfaces not conspicuously concave, less ear-like.

E. The proximal processes relatively small.

F. Male cercus broader, not or but feebly widened (in viridipes viridipes only) distad.

G. Male cercus larger, tapering but still broad distad with apex rounded. Caudal femora usually (but by no means always) heavily marked.

H. Male cercus short. New York to Michigan, south in Appalachians to North Carolina... viridipes eurycercus Hebard

TRANS. AM. ENT. SOC., LX. 
HH. Male cercus elongate. Indiana and Minnesota south through Illinois and Iowa....viridipes viridipes Scudder

GG. Male cercus small, strongly tapering, narrow distad with apex almost acute. Caudal femora never heavily marked. Ozark Mountains in Missouri and Arkansas.

sylvaticus McNeill

FF. Male cercus narrower, not strongly but distinctly widened distad. Caudal femora moderately to scarcely marked. Southern Appalachians........... longicornis (Saussure)

EE. The proximal processes relatively large. Eastern Kansas and northwestern Missouri............beameri Hebard

DD. The proximal processes with caudal surfaces conspicuously concave, ear-like.

E1. These processes short with margins more evenly convex, projecting scarcely further than the pair of aciculate median processes. Appalachians from southern New York and northern New Jersey to North Carolina and extending westward into eastern Ohio............. similis Morse

EE1. These processes more elongate, projecting considerably beyond the pair of aciculate median processes.

F1. These processes with dorsal margin convex. (Male cercus distinctive, its disto-ventral angle produced in a small sharp projection.) Appalachians from Virginia southward and extending westward through southern Indiana.

hubbelli new species

FF1. These processes with dorsal margin produced in a small sharply rounded median apex. (Male cercus distinctive, its disto-ventral apex rounded.)

G. Appalachians of North Carolina. (Male cercus elongate and slender.)...............acrophilus acrophilus new species

GG. Appalachians of Virginia. (Male cercus shorter and stout.) acrophilus pachycercus new subspecies

CC. Basal portion much more elevated caudad so that the two pair of dorsal processes surpass it very briefly. (The proximal processes more slender than in the preceding species.) Southern Appalachians........ deceptus Morse

BB. The proximal processes very slender and very elongate, directed dorsad and curving outward then inward like calipers, their outer surfaces convex, their inner surfaces concave. These processes act as sheaths to the median processes which are almost as elongate and are similarly curved. Appalachians of the Carolinas.

cherokee new species 


\section{The Gracilis Group}

Melanoplus gracilis (Bruner)

1876. Pezotettix gracilis Bruner, Canadian Ent., viII, p. 124. [0̛', ᄋ; Omaha, Nebraska.]

Specimens not previously recorded: $60 ; 31$ males and 29 females.

Oнго: Richmond Bog, Huron County, VII, 1 and 2, 1932, (E. S. and J. S. Thomas), $3 \sigma^{\top}, 2$ ․ Huron County, IX, 15, 1929, (J. S. Hine), $9 \sigma^{\top}, 7$ \%. Buckeye Lake, Licking County, VIII, 18, 1932, (Thomas and Walker), 1 \%; X, 18, 1931, (M. D. Neiswender), 1 б7. Fairfield County, VIII, 21, 1931, (R. Goslin), 1 or. Jackson, IX, 10, 1929, (J. S. Hine), 2 ․ Crissey, Lucas County, VII, 30, 1932, (R. Conant), 1 ㅇ. Logan County, XI, 12, 1931, (Thomas and Walker), 1 \%. Cedar Swamp, Champaign County, IX, 4, 1932, (Thomas and Walker), 3 ơ , 3 \% ; August 24, 1930, (J. S. Hine), 2 \%. Mud Lake, Williams County, VIII, 29, 1932, (Thomas and Walker), 1 \%. Williams County, IX, 8, 1930, (J. S. Hine), 1 o'. New Paris, Preble County, IX, 21, 1931, (E. S. Thomas), $1 \sigma^{7}, 1$ ․ [All from Ohio State Museum].

Michigan: Lakeside, Berrien County, VII, 1904, (J. L. Hancock), 1 ơ.

Indiana: Mineral Springs, VIII, 25, 1916, (B. B. Fulton; bog swamp), $5 \sigma^{7}, 1$ ㅇ, [Fulton Cln.]. Millers, X, 10, 1903, (J. L. Hancock), $1 \sigma^{7}$.

Alabama: Marion Junction, VII, 16, 1930, (P. W. Oman), $2 \sigma^{7}$, [Univ. of Kansas and Hebard Cln.].

MississipPI: Iuka, VII, 14, 1930, (P. W. Oman), 1 o', 1 ㅇ.

Iowa: Elmira, VIII, 17, 1910, (M. P. Somes), $1 \sigma^{7}$, [Somes Cln.]. Bedford, VIII, 4, 1909, (M. P. Somes), 1 \%, [Somes Cln.]. Mondamin, VIII, 14, 1925, (B. B. Fulton; on river bluffs), $1 \sigma^{7}$, [Fulton Cln.].

MissourI: Columbia, X, 19, 1904, $1 \sigma^{7}$. Willard, VIII, 1 to 8, 1919 and 1920, (A. E. Brower), 4 ㅇ.

Nebraska: Weeping Water, IX, 24, 1909, (L. Bruner), $2 \sigma^{\top}, 9$ \%

This species is known north to Bloomsburg, Pennsylvania; Richmond Bog in Huron County, Crissey and Mud Lake in Williams County, Ohio; Jackson and Berrien Counties, Michigan; Mahtomedi and Redwood Falls, Minnesota, and (probably) southeastern South Dakota: west to the latter; Omaha and Weeping Water, Nebraska; Leavenworth County, Kansas; Magazine Mountain, Arkansas, and Iuka, Mississippi: south to the latter; Marion Junction, Alabama, and southeast as far as Clarksville, Tennessee, and Monterey, Virginia. 


\section{The Viridipes Group}

The form of the male cerci is vastly the most important external feature in distinguishing the species of this group. Thickening of the apex of the male abdomen is weak in similis and our specimens of longicornis, very weak in sylvaticus, pronounced in all the other species. The male supra-anal plate averages definitely shorter in acrophilus, the races of cherokee and deceptus than in the other species. The apical tubercle of the male subgenital plate shows average differences in different species (weak or obsolete in hubbelli, our specimens of longicornis, acrophilus and deceptus) but individual variation is too great to give this feature much weight except in similis where this tubercle is distinctly transverse, broader than deep. Tegminal development is weakest in sylvaticus, the races of viridipes, similis and acrophilus pachycercus, but it is sometimes as weak in longicornis, the races of acrophilus, cherokee and deceptus. We have noted differences in coloration, but the general color pattern is similar throughout; great recession, however, distinguishes sylvaticus and great intensification is frequent in viridipes eurycercus and usual in the races of acrophilus, cherokee and deceptus.

Separation of females of these species and races without males is most difficult. The locality from which they come must first be considered to determine which species may occur there. Degree of tegminal development and depth of coloration alone remain as a clue toward their proper assignment.

Melanoplus sylvaticus McNeill

(Pl. XXII, fig. 1)

1899. Melanoplus sylvaticus McNeill, Psyche, viII, p. 345 . [0 , \&; Carroll, Boone and Newton Counties, Arkansas.]

This species was reported from along wooded cliffs and has not subsequently been recorded. It is probably widely distributed but local in the Ozark region.

Missourr: Mountain Grove, VI, 5, 1914 and VII, 1, 1915, (M. P. Somes), 1 ఠั, 1 ㅇ. Willard, VI, 29 to VII, 11, 1919, (A. E. Brower), 37 ơ 29 ․ ArKansas: Ozona, VI, 11, 1932, (R. H. Beamer), $6 \sigma^{7}, 5$ \%, [Univ. of Kansas]. 
1920. Melanoplus viridipes eurycercus Hebard, Trans. Amer. Ent. Soc., XLVI, p. 392 , pl. 16, figs. 9 and 10. [0', $\%$; type locality-Derrick City, Pennsylvania.]

This race has been repeatedly confused with typical viridipes in past literature.

In addition to the one hundred and thirty five specimens originally reported, the following material is now before us:

New York: Malioryville, Tompkins County, VI, 18 to 20, 1904, 1 ㅇ, [Cornell Univ.]. Freeville, VII, 4, 1904, $1 \sigma^{7}$. Caroline to Harford, VI, 15, 1904, $3 \sigma^{7}, 2$ ㅇ , [Cornell Univ. and Hebard Clns.]. Hopeoye Falls, VII, 1913, 1 ơ

Pennsyluania: Moosic Lake, VIII, 19, 1924, 1 우.

Virginia: One and a half miles north of spring on Elliott Knob, 4000 feet, VI, 30, 1933, (H. A. Allard), 2 o', [U. S. N. M.].

North CARolina: Bakersville, V, 1929, (D. A. Greene), 7 ơ , 9 \%, [U. S. N. M.].

Онго: Georgesville, V, 20, 1903, (C. S. Mead), $1 \sigma^{7}, 1$ ᄋ.2 Clifton, Green County, VI, 24, 1903, 2 б 2 ㅇ. Xenia, V, 30, 1903, (C. S. Mead), 1 \%. Michigan: Montmorency County, VII, 14, 1923, (T. H. Hubbell), 5 o', [Univ. of Michigan and Hebard Clns.]. ${ }^{3}$ Otsego County, VII, 11 to 14, 1923, (T. H. Hubbell), $7 \sigma^{\top}, 6$ \% , [Univ. of Michigan and Hebard Clns.]. ${ }^{3}$

\section{Atypical viridipes eurycercus}

Michigan: Lakeside, Berrien County, VI, 21 to VII, 13, 1903 and 1904, (J. L. Hancock), 3 or, 6 ㅇ.

The race viridipes eurycercus is known to occur typical north to St. Albans, Vermont; Slaterville, Groton and Cattaraugus County, New York; Kendall State Park in Summit County, Hanover Township in Ashland County and Salem Township in Champaign County, Ohio, 4 and Montmorency and Otsego Counties, Michigan: west to the latter and Marion County, Indiana: south to the latter; Cincinnati, Ohio, and Bakersville, North Carolina; east to the latter, Elliott Knob and Sounding Knob, Virginia; Moosic Lake, Pennsylvania; Great Barrington and North Adams, Massachusetts, and St. Albans, Vermont. Its distribution probably also includes nearly all of Kentucky.

${ }^{2}$ Reported as viridipes by Mead from Franklin and Highland Counties. Ohio Nat., IV, p. 110, (1904).

${ }^{3}$ It is surprising that these series are typical of viridipes eurycercus, as material from southern Michigan and most of Indiana is intermediate to varying degrees between this race and viridipes viridipes.

${ }^{4}$ These northern limits have been furnished us through the kindness of E. R. Thomas, who has assembled a large series of this race from Ohio. 
Melanoplus viridipes viridipes Scudder

(Pl. XXII, fig. 3)

1891. Pezotettix viridulus McNeill, Psyche, vi, p. 75. (Nomen nudum.) [Normal and Bloomington, Illinois.]

1897. Melanoplus viridipes Scudder, Proc. U. S. Nat. Mus., xx, p. 255, pl. 17, fig. 4. [ơ', ᄋ : Rock Island, Moline, Ogle County and Riviere de Parc, Illinois; Vigo County, Indiana..$^{5}$

1897. Melanoplus juvencus Scudder, Proc. U. S. Nat. Mus., xx, p. 266, pl. 18, fig. 1. (No locality for male type; see Rehn and Hebard, Proc. Acad. Nat. Sci. Phila., 1916, p. 212.)

The assignment by Blatchley in his "Orthoptera of NorthEastern America," p. 367, 1920, of deceptus and similis to synonymy under viridipes only shows how glaringly superficial was both his knowledge and treatment of the group. Had his field work been done in any but a casual manner he would certainly at least have recognized in Indiana the presence of two very distinct species.

Bruner reported viridipes in 1897 from along the Missouri River in Nebraska, but no such material is in the Bruner Collection, and we believe that, like several others, this name has no place on the Nebraska list.

In this species the male cerci vary from two and a third to three times as long as the proximal width. The distal half of the cercus is conspicuously narrower than in viridipes eurycercus, while the majority show to different degrees a weak distal broadening which is never developed in the eastern race.

As only a few measurements have been given for this race, the following have been taken.

${ }^{5}$ Material from this locality had been reported as viridulus and viridipes by Blatchley in 1892 and 1894. Examination of the series shows that it includes material of typical viridipes, atypical viridipes viridipes and also the species here described as hubbelli. Morse recognized the fact that a distinct species was represented in the series but referred that material to his deceptus at the time of original description, so that in the series of hubbelli from Vigo County, Indiana, there are specimens which are paratypes of both viridipes viridipes and deceptus. 


\begin{tabular}{|c|c|c|c|c|c|}
\hline$\sigma^{\pi}$ & $\begin{array}{l}\text { Length of } \\
\text { body }\end{array}$ & $\begin{array}{l}\text { Length of } \\
\text { pronotum }\end{array}$ & $\begin{array}{l}\text { Caudal } \\
\text { width of } \\
\text { pronotal } \\
\text { disk }\end{array}$ & $\begin{array}{l}\text { Length of } \\
\text { tegmen }\end{array}$ & $\begin{array}{l}\text { Length of } \\
\text { caudal } \\
\text { femur }\end{array}$ \\
\hline Lafayette, Indiana. & 18.5 & 4.1 & 2.3 & 5.7 & 10. \\
\hline St. Joseph, Illinois. & 17. & 3.8 & 2.3 & 5. & 9.3 \\
\hline Dubois, Illinois. & 17.5 & 4. & 2.4 & 5.6 & 9.7 \\
\hline Moline, Illinois. & $17.5-18$. & 4.- -4.2 & $2.4-2.5$ & $4.5-4.9$ & $9.3-9.6$ \\
\hline $\begin{array}{c}\text { Monticello, Iowa. } \\
\text { 우 }\end{array}$ & 17.5 & 4. & 2.3 & 5.1 & 9. \\
\hline Homer, Illinois. & 25. & 5. & 3.5 & 7. & 12.3 \\
\hline Dubois, Illinois. & 23.5 & 5. & 3.4 & 5. & 11.7 \\
\hline Muncie, Illinois. & $23 .-25.7$ & $4.8-5.1$ & $3.2-3.7$ & $5.4-7$. & $11.2-11.9$ \\
\hline Moline, Illinois. & 21.5 & 5.2 & 3.4 & 6.5 & 11.2 \\
\hline Normal, Illinois. & 21.5 & 5. & 3.4 & 5.6 & 11.8 \\
\hline
\end{tabular}

This race has the caudal femora averaging paler with bands narrower than in viridipes eurycercus. In no case do the two bands fuse on the ventral margin of the pagina of the caudal femora, as frequently occurs in the eastern race. In all the males the subgenital plate is shining black except for a narrow buffy crescent, the base of which is formed by the junction of this plate with the preceding sternite. That sternite is bordered with black proximad, laterad and distad, the internal margin of this marking along the distal margin convex so that the border is narrowest laterad. The two preceding sternites are suffused with black proximad.

We have recently studied large series of this race from Illinois, the data for which are appearing in a paper on the Orthoptera of that State.*

Specimens not previously recorded:

Wisconsin: Merrill, VII, 1 and 3, 1933, (Frison and Mohr), $2 \sigma^{7}$.

Minnesota: St. Anthony Park, VI, 1890, 1 우.

Indiana: Tremont, VI, 9, 1929, 1 万'.

This race is known to occur typical north to Merrill, Wisconsin, and Sunrise, Minnesota: west to St. Anthony Park, Minnesota, and Monticello, Iowa; south to the latter locality and Pulaski, Illinois: east to Vigo County and Lafayette, Indiana.

* Ill. Nat. Hist. Surv. Bull., xx, p. 192, (1934).

TRANS. AM. ENT. SOc., LX. 
Intergradation with viridipes eurycercus occurs in parts of southern Michigan, Wisconsin and most of Indiana. To varying degrees always atypical in central and northern Indiana and southern Michigan, it is surprising to find the species atypical in Polk County in northwestern Wisconsin and typical of the eastern race, viridipes eurycercus, in the northern portion of the Lower Peninsula of Michigan.

Melanoplus beameri Hebard

(Pl. XXII, figs. 4 and 5; pl. XXIII, fig. 4 ; pl. XXVII, fig. 1 )

1931. Melanoplus beameri Hebard, Proc. Acad. Nat. Sci. Phila., LxxxıII, p. 175, text figs. 1 and 2. [ [ $\sigma^{7}, \%$ : Leavenworth County, Kansas, and Kansas City, Missouri.]

This insect apparently supplants viridipes viridipes in western Missouri and eastern Kansas. No material from central or eastern Missouri is as yet available to enable us to decide whether or not it is a western race of that species. It may indeed prove to be a western race of similis, which insect typically has very different appearing male cerci, but in one male of similis from West Point, New York, a very definite approach toward the cercal type normal in beameri is shown. The cercal variation in similis is discussed under that species.

Melanoplus similis Morse (Pl. XXII, figs. 6, 7 and 8; pl. XXVII, fig. 2) 1904. Melanoplus similis Morse, Researches in North American Acrid., Carnegie Mus. Wash., Publ. 18, p. 47, text fig. 6. [07, ᄋ; Murphy, North Carolina.]

1920. Melanoplus calloplus Hebard, Trans. Amer. Ent. Soc., XLvi, p. 398, pl. 16, figs. 13 and 14. [ $\sigma^{\top}$, o ; type locality-Collison Ridge, Bath County, Virginia.]

At the time we described calloplus the original description and figure of similis alone were available. Examination of the original series of similis has subsequently shown that the latter is very inaccurate and that our material unquestionably represents the same species.

In frequent males the degree of convexity of the dorso-caudal angle of the cercus is variable, giving the apex a much less truncate appearance than usual when that convexity is greatest. Such is particularly prominent in one male from West Point, New York, where much closer than usual resemblance to the cercus of some 
specimens of the western beameri results; the latter species, however, having the cercus tapering in all but its distal third instead of tapering in only the proximal half or slightly less. Another male from Mount Sterling, North Carolina, has the distal portions of the cercus unusually narrow, but this we believe is also attributable wholly to individual variation. It is therefore evident that the male cerci are subject to some individual variation in the present species and the same we find to be true for the other species of the group. Although the form of the male cerci is the most important feature in distinguishing the species and although such variation occurs in probably all of the species, we are satisfied that, though the separation of the species and races is thereby made very difficult, sufficient series will always show whether individual variation, racial or specific status is actually indicated.

The apical tubercle of the male subgenital plate is slightly transverse, frequently dimpled, and in two specimens of the large series before us it is distinctly bituberculate. Such differences are wholly attributable to individual variation.

The caudal femora have the dark markings often rather broad in the males but never fusing ventrad. These markings individually vary from weak and diffused to almost obsolete in the females.

The male subgenital plate is blackish except in the narrow subchitinous basal portion, the preceding sternite being pale with distal portion alone blackish, which forms a very narrow transverse triangular marking.

In addition to the twenty nine specimens we originally recorded as calloplus, from West Point, New York; Plainfield, New Jersey; Collison Ridge and Snickers Gap, Virginia; White Sulphur Springs, West Virginia, and Mayland, Tennessee, the following material is now before us:

North Carolina: Mount Sterling, Haywood County, 3000 feet, VII, 31, 1924, (T. H. Hubbell), $1 \sigma^{\top}, 1$ \%. Crestmont, Haywood County, 2200 to 3000 feet, VII, 27 and 29, 1922, (T. H. Hubbell), $2 \sigma^{\top}, 3$ ᄋ. [All Univ. of Michigan Cln.].

Онго: Wills Township, Guernsey County, VI, 28, 1931, (C. F. Walker), 1 \&. Fallsburg, Licking County, VI, 18, 1932, (Walker and Handel), 1 \%. Greenfield Township, Fairfield County, VI, 18, 1931, (C. Goslin), 1 万. Lancaster, VII, 4, 1930, $2 \sigma^{7}$. Athens, VI, 8 to VII, 17, 1932, (Thomas and Stehr), $24 \sigma^{\top}, 14$ \% Harrison Township, Vinton County, VII, 11, 1931, (E. S. Thomas), $1 \sigma^{7}$. Jackson Township, Jackson County, VII, 11, 1931,

TRANS. AM. ENT. SOC., LX. 
(E. S. Thomas), $4 \sigma^{\top}, 3$ ㅇ. Washington Township, Jackson County, VII, 11, 1933, (C. F. Walker), 2 o', 3 우. Madison Township, Jackson County, VI, 25, 1932, (Thomas and Stehr), $11 \sigma^{\top}, 2$ ㅇ. Fort Hill, Highland County, VI, 26 and VII, 22, 1933, (E. S. Thomas), $3 \sigma^{\top}, 2$ ㅇ. J Jaybird, Adams County, VI, 18, 1933, (E. S. Thomas), 1 o'. [All Ohio State Mus.].

Tennessee: Allardt, Fentress County, 1600 feet, VI, 10 to VII, 19, 1924 and 1925, (T. H. Hubbell; only two females after June 11), $59 \sigma^{7}, 44$ 우, 2 juv. ㅇ. Clark Range, Fentress County, VII, 21, 1924, (T. H. Hubbell), $1 \sigma^{7}$. Grassy Cove, Cumberland County, 1700 to 2000 feet, VII, 8 to 12, 1922, (T. H. Hubbell), 4 б, 3 우. Clear Fork near Burrville, Morgan County, VI, 12, 1924, (T. H. Hubbell), 1 万'.

The range of this species is now known to extend east to West Point, New York; Plainfield, New Jersey; Collison Ridge and Snickers Gap, Virginia, and Crestmont and Murphy, North Carolina. In Ohio it is known only from the southeastern third of the State, not extending its range beyond the limits of glaciation, Guernsey County and Fallsburg being northern limits, the latter and Fort Hill western limits. Southward similis probably continues through the hills and mountains to the west of the main Appalachians to its present known southwestern limit, Cumberland County, Tennessee. It is therefore very evident that the insect inhabits very extensive areas in the mountains of Pennsylvania, West Virginia and Kentucky where it has not as yet been secured. Those regions have not yet been collected in nearly sufficiently; moreover the present species is not only alert and active but also local and sylvan, while adults appear in the late spring and early summer, largely if not wholly disappearing in the fall when the majority of grasshoppers are at their peak of seasonal abundance and most field work is done.

Melanoplus longicornis (Saussure)

(Pl. XXII, figs. 9 and 10)

1861. Pez[otettix] longicornis Saussure, Rev. et Mag. de Zool., xin, p. 159, [ $\sigma^{7} ;$ [South] Carolina.]

1916. Melanoplus similis Rehn and Hebard (not of Morse, 1904), (in part).

Proc. Acad. Nat. Sci. Philadelphia, 1916, p. 210. [ [ $\sigma^{7}$ only; Rabun Bald and Clayton, Georgia.]

The name longicornis long remained unidentifiable, due to the complete insufficiency of the original description. Examination of the type at the Geneva Museum by the author in 1927 showed it to represent a species of the Viridipes Group, nearest similis of 
the described forms. It occupies a position between that species and hubbelli here described.

Lack of sufficient material and the unsatisfactory character of the descriptions and figures of deceptus and similis brought about our incorrect determinations of 1916 and the author's description in 1920 of calloplus (a synonym of similis).

Saussure's type is dried from immersion in alcohol. The caudal femora have the genicular areas dark, a short dorsal dark suffusion preceding them, this preceded by another smaller suffusion continued narrowly and obliquely on the external pagina and terminating mesad near its base. The tegmina are attingent, rather sharply rounded distad and slightly shorter than the pronotum. The male cerci are more slender and decidedly less truncate than in the type of similis as the dorso-distal angle rounds very broadly, with apical portion more elongate. The tubercle of the subgenital plate is very blunt. All but the base of the subgenital plate is dark and all of the preceding sternite is dark except for a large transverse rectangular area.

The two other males which we believe are referable to longicornis differ from the type in having the tegmina longer than the pronotum and fully as elongate as is normal in hubbelli, while in these the subgenital plate shows no tuberculation. We hardly believe that racial status is indicated, but more material must be secured before the significance of such differences can be satisfactorily determined.

The male cerci in longicornis are very much more attenuate than is normal in any other eastern species of the group, with distal portion scarcely broadened and disto-dorsal angle showing the broadest convexity.

\begin{tabular}{|c|c|c|c|c|c|}
\hline$\sigma^{\top}$ & $\begin{array}{l}\text { Length of } \\
\text { body }\end{array}$ & $\begin{array}{l}\text { Length of } \\
\text { pronotum }\end{array}$ & $\begin{array}{l}\text { Caudal } \\
\text { width of } \\
\text { pronotal } \\
\text { disk }\end{array}$ & $\begin{array}{l}\text { Length of } \\
\text { tegmen }\end{array}$ & $\begin{array}{l}\text { Length of } \\
\text { caudal } \\
\text { femur }\end{array}$ \\
\hline ald & 17.8 & 4.6 & 2.6 & 5.9 & 9.8 \\
\hline Clayton, Georgia. & 18. & 4.3 & 2.4 & 6. & 9.8 \\
\hline
\end{tabular}

The only fresh material we refer here is the following.

Georgia: Rabun Bald, VII, 1910, (W. T. Davis), $1 \sigma^{x}$, [Davis Cln.]. Clayton, 2000 to 3700 feet, (W. T. Davis), 1 ơ , [Hebard Cln.]. 
Melanoplus hubbelli new species

(Pl. XXII, fig. 11; pl. XXVII, fig. 3)

1897. Melanoplus viridipes Scudder (in part), Proc. U. S. Nat. Mus., xx, p. 255. [0 $\sigma^{\top}$, ᄋ ; Vigo County, Indiana.]

1903. Melanoplus viridipes Blatchley (in part not of Scudder, 1897), Orth. of Indiana, p. $305 . \quad$ [ $\sigma^{7}, \%$; Vigo County, Indiana.]

1904. Melanoplus deceptus Morse (in part), Psyche, XI, p. 9. [o ; Indiana and Vigo County, Indiana; Jasper, Georgia at 2600 feet.]

1916. (probably) Melanoplus similis Rehn and Hebard (not of Morse, 1904), Proc. Acad. Nat. Sci. Philadelphia, 1916, p. 211. [o only: Bluemont, Virginia; Clayton and Tuckoluge Creek, Georgia.]

1916. Melanoplus deceptus Rehn and Hebard (in part not of Morse, 1904), Proc. Acad. Nat. Sci. Philadelphia, 1916, p. 212. [ [o ; Clayton, Georgia.] 1920. Melanoplus viridipes Blatchley (in part not of Scudder, 1897), Orth. of North-Eastern America, p. 365. [ [0'; Vigo County, Indiana; Jasper, Georgia.]

Morse recognized that Scudder and Blatchley had confused two species in their material from Vigo County, Indiana, but insufficiency of material prevented his realizing that his male specimen from Jasper, Georgia, represented one of those species and not deceptus which he was describing from Jones' Peak, Balsam Mountains, North Carolina.

Blatchley's attempt to place all of these species as synonyms of viridipes in 1920 indicates wholly unjustified undervaluation of male cercal characters, such possibly due to the fact that his series of viridipes showed decided variation in the male cerci as all of it came from Indiana in the area of intergradation between viridipes viridipes and viridipes eurycercus. ${ }^{6}$

This species is nearer deceptus than any of those already treated. The tegmina are proportionately larger and more ample (excepting in longicornis) and the male cerci are distinctive, with disto-dorsal portion roundly elevated and the disto-ventral angle produced as a small tooth. The male subgenital plate either entirely lacks an apical tubercle or has a very low bluntly rounded apex.

Type.-- ơ $^{7}$ Red Hills, Franklin County, Ohio. July 14, 1931. (E. S. Thomas). [Hebard Collection, Type no. 1258].

Size medium, form graceful for the brachypterous Melanopli. Fastigium of vertex and frontal costa shallowly but definitely

\footnotetext{
${ }^{6}$ See Hebard, Trans. Amer. Ent. Soc., xLvi, p. 392, (1920).
} 
sulcate. Antennae elongate, as long as the caudal femur. Eye prominent, very slightly longer than cheek. Pronotum with medio-longitudinal carina distinct on metanotum (elsewhere obsolete in type, very feeble in occasional individuals), caudal margin of disk very weakly rounded obtuse-angulate produced. Tegmina ample, overlapping, definitely longer than pronotum, apices broadly rounded, dorsal and lateral fields weakly defined but distinguishable. Prosternal spine small, blunt conical. Furcula represented by two small blunt projections. Supra-anal plate distinctly longer than broad, triangularly shield-shaped, a pair of heavy medio-longitudinal carinae present proximad, followed by the distal slightly raised area, the lateral margins of which are formed by much weaker and more rounded short longitudinal carinae, often with a short longitudinal carina inside the lateral margins opposite the cercal bases. Cercus almost two and one-fifth times as long as proximal width, curving gently inward, tapering strongly in proximal half due to the declivity and slight concavity of the dorsal margin; shaft mesad slender, less than half as wide as proximad; slightly over distal third enlarged, moderately flattened, its dorsal margin convex produced, the disto-ventral angle produced in a minute acute tooth; ventral margin of cercus nearly straight. Subgenital plate small, apex rounded (often slightly elevated, rarely definitely forming a low blunt tubercle).

\section{Allotype.— $\%$; same data as type. [Hebard Collection].}

Much larger and more robust than male with eyes less prominent. Sulcation of vertex and frontal costa much weaker than in that sex. Amplitude of tegmina (usually) even more conspicuous than in male. Prosternal spine shorter and heavier. Ovipositor valves moderately elongate, curvature at apices moderate.

Coloration generally brown, a broad shining blackish postocular band extending to abdomen. Ventral portions of pronotal lateral lobes brownish buff, ventral portions of face slightly darker. Cephalic and median limbs light brownish, in life possibly always yellow green, this richer in males than in females. Caudal femora with characteristic dark markings of group often diffused and extensive, never intensive, but often running together ventrad in males; these markings weaker, often obsolete in dried females. The male subgenital plate is blackish except for the narrow subchitinous proximal buffy area, the preceding sternite blackish except for a very large transverse rectangular buffy area. 


\begin{tabular}{|c|c|c|c|c|c|}
\hline$\sigma^{\pi}$ & $\begin{array}{l}\text { Length of } \\
\text { body }\end{array}$ & $\begin{array}{l}\text { Length of } \\
\text { pronotum }\end{array}$ & $\begin{array}{l}\text { Caudal } \\
\text { width of } \\
\text { pronotal } \\
\text { disk }\end{array}$ & $\begin{array}{l}\text { Length of } \\
\text { tegmen }\end{array}$ & $\begin{array}{l}\text { Length } \\
\text { of } \\
\text { caudal } \\
\text { femur }\end{array}$ \\
\hline d Hills, Ohio. & $18.6-19.7$ & $4.3-4.6$ & $2.6-2.8$ & $5.3-5.7$ & 10. -10.8 \\
\hline Vigo County, Indiana. & $15.7-18.2$ & $4.2-4.9$ & $2.7-2.8$ & $5.3-6.7$ & $9.3-10.7$ \\
\hline Allardt, Tennessee. & $17.7-20$ & $4.8-4.9$ & $2.7-2.9$ & $6.1-7$ & $10.8-10.9$ \\
\hline ayton, Georgia. & 20.7 & 5. & 2.9 & 6.6 & 10.8 \\
\hline sper, Georgia. & 19.8 & 5.2 & 3.1 & 6.7 & 11.1 \\
\hline \multicolumn{6}{|l|}{ 우 } \\
\hline uemont, Virginia. & 24. & 5.7 & 3.8 & 7.3 & 12.2 \\
\hline ed Hills, Ohio. & $22.2-25$. & $5.2-5.7$ & $3.7-3.9$ & $5.9-6.9$ & $10.8-12.3$ \\
\hline Hocking County, Ohio. & 21. & 5.8 & 3.9 & 6.7 & 11.8 \\
\hline go County, Indiana. & $20.8-23.7$ & $5.8-5.7$ & $3.8-3.8$ & $5.8-6.3$ & $10.8-11.4$ \\
\hline lardt, Tennessee. & $22.3-24$ & $5.6-5.8$ & $3.7-3.9$ & 6. -6.8 & $11.3-12.6$ \\
\hline $\begin{array}{l}\text { ckoluge Creek, } \\
\text { Georgia. }\end{array}$ & & & & & \\
\hline layton, Georgia. & 26. & 5.5 & 3.6 & 7.5 & 11.8 \\
\hline
\end{tabular}

Southern specimens of this species are larger and more graceful than any others.

Though yet known from few localities, this local, sylvan species is seen to have a wide distribution and will certainly be found over very extensive areas in southwestern Pennsylvania and most of West Virginia, Kentucky and Tennessee. It is known north to the Catoctin Mountains, Maryland; the Red Hills in Franklin County, Ohio, and Vigo County, Indiana; east to Bluemont, Virginia; Rocky Bottom, South Carolina, and Clayton, Georgia; south to Jasper, Georgia. Southwestern limits can not be defined.

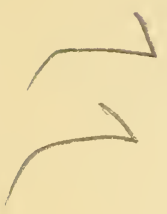

Specimens Examined: 86; 41 males and 45 females.

Maryland: Catoctin Mountains near Thurmont, VII, 4, 1933, (H. A. Allard), 1 ơ, 2 \%, [U. S. N. M. and Hebard Cln.].

Virginia: Bluemont, VII, 1, 1914, (J. D. Hood), 1 ㅇ, [Hebard Cln.].

South Carolina: Rocky Bottom, Pickens County, V, 31 to VII, 4, 1932 and 1933, (F. Sherman), $6 \sigma^{\top}, 13$ \%, [Sherman and Hebard Clns.]. Jocassee, VII, 4, 1931, (J. A. Berly), 1 우.

Онго: Red Hills, Blendon Township, Franklin County, VI, 13 to VII, 17, 1931 to 1933, (Thomas and Walker; in rather open second growth woodland with a xeric south exposure on hills, undergrowth of Aster, Anychia, Phlox, Pennyroyal, Nabalus; much more sluggish and easy to capture than the very alert similis), $22 \sigma^{7}, 17$ \%, type, allotype and paratypes. Good Hope Township, Hocking County, V, 30 to VI, 9, 1932 and 1934, (Thomas and Walker; in second growth oak and chestnut woodland with an extremely xeric south 
exposure), $2 \sigma^{\top}, 4$ ९. Cedar Falls, Hocking County, VII, 4, 1932, (Thomas and Walker; one specimen only found in a mixed mesophytic forest), $1 \sigma^{\text {T}}$. [All from Ohio State Museum].

Tennessee: Allardt, Fentress County, 1600 feet, VI, 10 to 13, 1924 and 1925, (T. H. Hubbell), $40^{7}, 2$ \%, [Univ. of Michigan]. La Follette, Cumberland Mountain, Campbell County, VI, 10, 1934, (R. G. Goslin), 3 ơ, [Ohio State Mus.].

Georgra: Tuckoluge Creek, Rabun County, VI, 1909, (W. T. Davis), 2 , [Davis and Hebard Clns.]. Clayton, VI, 1909, (W. T. Davis), $10^{7}, 1$ \%, [Hebard Cln.]. Jasper, 2600 feet, VII, 26, 1903, (A. P. Morse), $1 \sigma^{7}$, [Mus. Comp. Zool.].

INDIANA: Vigo County, part VI, 8, 1893, (W. S. Blatchley), $6 \sigma^{7}, 2$, [Blatchley, Mus. Comp. Zool. and Hebard Clns.].

Melanoplus acrophilus acrophilus new species

(Pl. XXII, fig. 12;

pl. XXIII, fig. 5 ; pl. XXVII, fig. 4)

1916. Melanoplus deceptus Rehn and Hebard (in part, not of Morse, 1904),

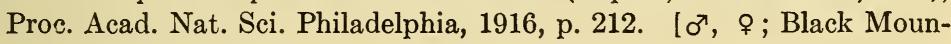
tain, North Carolina.]

This is an extremely interesting species as it approaches deceptus closely in general appearance and has cerci approaching those of that insect more nearly than those of any of the preceding forms, though they are decidedly less highly specialized, but the penis is very distinct, of the general type found in the preceding species and nearest that of hubbelli here described.

Comparison with cherokee here described shows that, without examination of the penis, these species are apparently indistinguishable, although the specialization of that organ in cherokee is remarkably distinctive and wholly unlike that of any other species of the Viridipes Group.

Type.- $\sigma^{T}$; Black Mountain, North Carolina. June, 1912. (Wm. Beutenmüller). [Hebard Collection, Type no. 1257].

Generally very similar to viridipes. Tegmina slightly longer than pronotum. Tergite preceding supra-anal plate not (rarely moderately) swollen at point where furcula (present in rare specimens and then very minute) would be. Supra-anal plate shorter than in viridipes, as in deceptus, no longer than broad, the lateral margins very faintly convex, contour much as here described for hubbelli. Cercus about two and one-half times proximal width, curved decidedly inward, tapering in proximal third (to two-fifths in paratypes) due to the declivity and slight concavity there of the dorsal margin, shaft mesad over half proximal width, distal half (to very slightly more in paratypes)

TRANS. AM. ENT. SOC., LX. 
moderately (weakly to moderately decidedly in series) enlarged, the dorsal margin there convex and rounding to the subrectangulate and sharply rounded disto-ventral angle, the ventral margin very broadly and very feebly concave, almost straight. Apical enlarged portion of cercus conspicuously longer and narrower than in hubbelli. From the stout base of the penis spring two pairs of erect ear-like lobes, each of which is longer than broad with caudal surface concave, the dorso-external portion of the caudal pair with a small projection curling caudad; at the inner bases of these are two small adjacent erect aciculate projections which are considerably shorter than the lobes (see plate B, figure 5). Subgenital plate small, rounded, with a stout, moderately blunt, apical tubercle.

Allotype.-o ; same data as type. [Hebard Collection].

Indistinguishable from females of cherokee and deceptus. Tegmina slightly longer than pronotum, but their exposed portions appear no longer. Ovipositor valves as here described for hubbelli.

\begin{tabular}{|c|c|c|c|c|c|}
\hline $0^{7}$ & $\begin{array}{l}\text { Length of } \\
\text { body }\end{array}$ & $\begin{array}{l}\text { Length of } \\
\text { pronotum }\end{array}$ & $\begin{array}{l}\text { Caudal } \\
\text { width of } \\
\text { pronotal } \\
\text { disk }\end{array}$ & $\begin{array}{l}\text { Length of } \\
\text { tegmen }\end{array}$ & $\begin{array}{l}\text { Length } \\
\text { of } \\
\text { caudal } \\
\text { femur }\end{array}$ \\
\hline $\begin{array}{l}\text { Black Mountain, } \\
\text { North Carolina. }\end{array}$ & 18. -19 . & $4.3-4.7$ & $2.7-2.7$ & 5. -5.8 & $10.1-10.3$ \\
\hline $\begin{array}{l}\text { North Carolina. } \\
\text { Mount Graybeard, }\end{array}$ & $15.7-16.7$ & $3.7-3.9$ & $2.1-2.3$ & $4.8-4.7$ & $8.7-8.7$ \\
\hline $\begin{array}{l}\text { North Carolina. } \\
\text { Grandfather Mountain, }\end{array}$ & 16.7 & 4.6 & 2.7 & 5. & 9.4 \\
\hline $\begin{array}{c}\text { North Carolina. } \\
\qquad \leftarrow\end{array}$ & 18.1 & 4.4 & 2.7 & 5.2 & 10. \\
\hline $\begin{array}{l}\text { Black Mountain, } \\
\text { North Carolina. } \\
\text { Mount Graybeard, }\end{array}$ & $21.7-24$ & $5 .-5.4$ & $3.3-3.6$ & $5.4-6.7$ & $10.8-11.8$ \\
\hline $\begin{array}{l}\text { North Carolina. } \\
\text { Grandfather Mountain }\end{array}$ & $19.6-21.2$ & $5 .-5.2$ & $3.2-3.3$ & $5.6-5.3$ & $10.3-10.5$ \\
\hline North Carolina. & $22 .-22.7$ & $5.2-5.3$ & $3.4-3.7$ & $5.2-5.8$ & $10.8-11.1$ \\
\hline
\end{tabular}

General coloration as characteristic for the group but rich and very intensive. Post-ocular band shining black, very broad, not paling caudad on pronotum. Pronotum with ventral portions of lateral lobes buffy, the post-ocular dark band sometimes margined narrowly dorsad with dull buffy. Cephalic and median limbs light brown, often with the femora weakly, the tibiae strongly 
tinged with green. Caudal femora so intensively colored that they are black, with two bands (oblique and extending only over dorsal half of external pagina), a pre-genicular annulus and a ventro-external line in proximal half of buffy, the ventral surface buffy often suffused with greenish glaucous externally and mesodistad. Caudal tibiae greenish glaucous with a post-proximal buff annulus, before (strongly) and after (weakly) suffused with brown. All of the greenish coloration is apparently lost when specimens of this group become discolored and in the females which were not eviscerated the color pattern of the caudal femora is often partly or wholly lost.

Specimens Examined: $21 ; 13$ males and 8 females.

North Carolina: Hawkshill Mountain, Burke County, 3600 feet, V, 24, 1934, (F. Harper), $1 \sigma^{7}$, [A. N. S. P.]. Black Mountain, VI and VII, 1912, (W. Beutenmüller), $2 \sigma^{\pi}, 3$ \% type, allotype and paratypes, [Davis and Hebard Clns.]. Mount Mitchell, above 5000 feet, V, 20, 1928, (F. Sherman), $6 \sigma^{7}$, [Sherman, Hebard and U. S. N. M. Clns.]. Mount Graybeard, V, 1923, (N. Banks), $3 \sigma^{7}, 2$ \%, [Mus. Comp. Zool. and Hebard Clns.]. Grandfather Mountain, VII, 8, 1928, (B. B. Fulton; in shrubby spot on southeast slope between Blowing Rock and Linville at about 4000 feet), $1 \sigma^{7}, 3$ \%, [Fulton and Hebard Clns.].

Melanoplus acrophilus pachycercus new subspecies (Pl. XXII, fig. 13)

Serious discoloration has occurred in the series before us, but the insect is very similar to typical acrophilus in general appearance, differing only in being very slightly stockier and in having distinctive male cerci.

It is probably similarly an inhabitant of mountain forest undergrowth and very local in distribution. Material from the mountains between the type locality, which is the northernmost point known for the species, and southwestern North Carolina, will, we believe, show intergradation and prove the present to be a northern geographic race.

Type.- $\sigma^{7}$; Mountain Lake, Giles County, Virginia. Elevation about 4000 feet. July 18, 1915. (P. P. Calvert). [Acad. Nat. Sci. Phila., Type no. 5537].

Generally very similar to the type of typical acrophilus. Tergite preceding supra-anal plate swollen at bases of the very minute, triangular furcula. Supra-anal plate as here described for cherokee but all carinae coarse and very weak. Cercus slightly more than twice as long as proximal width, curved decidedly inward, tapering moderately in proximal half due to the declivity

TRANS. AM. ENT. SOC., LX. 
of the dorsal margin, shaft mesad thick and over half proximal width, distal half moderately enlarged, the dorsal margin there broadly convex to the sub-rectangulate and rather blunt distoventral angle, ventral margin of cercus broadly concave. Compared with that of cherokee the cercus is seen to be shorter and broader with apical enlarged portion proportionately more extensive and disto-dorsad with its margin more oblique-declivent to the disto-ventral apex. Subgenital plate small, with a stout blunt apical tubercle.

\section{Allotype.—o; same data as type. [Acad. Nat. Sci. Phila.].}

Indistinguishable from females of typical acrophilus (except that the tegmina in the series average shorter). The shorter tegmina make females almost impossible to distinguish from this sex of viridipes eurycercus.

The extremes in the present series measure as follows. Length of body $\sigma^{7} 17$. and 17.2, 919.5 and 22.3; length of pronotum $\sigma^{7} 4.7$ and 4.4, 4.7 and 4.8; caudal width of pronotal disk $\sigma^{7} 2.7$ and 2.7 , 93.4 and 3.3 ; length of tegmen $\sigma^{7} 4.7$ and 4.8 , 4.6 and 5.2; length of caudal femur $\sigma^{7} 8.7$ and 8.9, +9.7 and $10.8 \mathrm{~mm}$.

In addition to the type and allotype, two male and three female paratypes and a male in the instar preceding maturity, bear the same data except that they were taken from the 17 th to the 26 th of July.

\section{Melanoplus deceptus Morse}

(Pl. XXII, fig. 14; pl. XXIII, fig. 6)

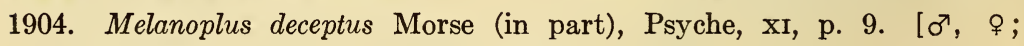
Jones' Peak, Balsam Mountains, North Carolina.]

1910. Melanoplus deceptus Rehn and Hebard, Proc. Acad. Nat. Sci. Phila., 1910, p. 633. [ठॅ, Tennessee.]

Morse originally included in his original series of deceptus specimens from Vigo County, Indiana and Jasper, Georgia, which represent a distinct species, here described as hubbelli. In addition, the figure of the cercus which Morse published later in 1904 is very badly drawn and foreshortened to such a degree that recognition of typical deceptus has been almost impossible. This situation led to the assignment to deceptus of material of cherokee here described from Black Mountain, North Carolina, and of hubbelli here described from Clayton, Georgia, by Rehn and Hebard in 1916.

The size, form and coloration of deceptus agree fully with cherokee as here described. 
Close agreement with the type is shown by all of the males of deceptus in the distinctive form of the cercus. It is about two and one-half times as long as its proximal width, curved decidedly (moderately in one paratype only) inward, tapering decidedly in proximal two-fifths due to the strong declivity and concavity of the dorsal margin, the shaft mesad over one-half its proximal width, then strongly enlarging in the distal three-fifths, its dorsal margin mesad deeply concave in consequence, thence broadly convex declivent to the decidedly subrectangulate (sharply rounded to acute) disto-ventral angle, ventral margin of cercus nearly straight (sometimes very feebly convex to distal portion, in Siler's Bald and "Tennessee" males feebly concave in distal portion only). Subgenital plate with a prominent apical tubercle in all but one paratype, in which that tubercle is stouter and blunt.

\begin{tabular}{|c|c|c|c|c|c|}
\hline  & $\begin{array}{c}\text { Length } \\
\text { of } \\
\text { body }\end{array}$ & $\begin{array}{l}\text { Length } \\
\text { of } \\
\text { pronotur }\end{array}$ & $\begin{array}{l}\text { Caudal } \\
\text { width of } \\
\text { pronotal } \\
n \text { disk }\end{array}$ & $\begin{array}{l}\text { Length } \\
\text { of } \\
\text { tegmen }\end{array}$ & $\begin{array}{l}\text { Length } \\
\text { of } \\
\text { caudal } \\
\text { femur }\end{array}$ \\
\hline rth Carolina. & 17.7 & 4.2 & 2.4 & 5.4 & 10. \\
\hline orth Carolina. & $15.5-16.2$ & $4.5-4$ & $2.6-2.7$ & $5.2-4.8$ & $8.8-8.9$ \\
\hline rolina. & 18.5 & 4.7 & 2.7 & 6.1 & 10.2 \\
\hline essee. & 15 & 3.9 & 2.4 & 5. & 9. \\
\hline & 18.3 & 4. & 2.6 & 5.7 & - \\
\hline
\end{tabular}

웅

Jones' Peak, North Carolina. $\quad 21.8-23 . \quad 5 .-5 . \quad 3.8-3.7 \quad 6.4-6 . \quad 11.1-10.8$

The following 23 males and 12 females have not been previously correctly reported.

South Carolina: River Falls, VI, 7, 1932, (M. B. Stevenson), $1 \sigma^{7}$, [Brimley Cln.]. Caesar's Head, VI, 29, 1926 and V, 3, 1928, (J. A. Berly and F. Sherman), $2 o^{7}, 1$ \%, [Hebard Cln. and U. S. N. M.]. Sassafras Mountain, Pickens County, V, 31, 1933, (O. L. Cartwright), 1 ơ. Rocky Bottom, Pickens County, VIII, 16, 1929, (F. Sherman), $1 \sigma^{7}$.

North Carolina: Crestmont, Great Smoky Mountains, 4000 feet, VII, 29, 1922, (T. H. Hubbell), 1 o', [Univ. of Michigan]. Sunburst, Haywood County, late V, 4 o $^{7}, 3$ \& ; 3500 to 5000 feet, VI, 14, 1924, (all C. S. Brimley), 12 ơ $^{7}, 7$ \% , [North Carolina State and Hebard Clns.].

Tennessee: Siler's Bald, Great Smoky Mountains, 5700 feet, VII, 31, 1910, $1 \sigma^{3}$.

Georgia: Rabun Bald, VI, 16, 1924, (H. Fox), $1 \% .{ }^{7}$

${ }^{7}$ Without males we can not deterinine whether this female should ba referred to the present species or to cherokee.

TRANS. AM. ENT. SOC., LX. 
Melanoplus cherokee new species

(Pl. XXII, fig. 15; pl. XXIII, fig. 7)

This species, like the races of acrophilus here described, could easily be mistaken for a race of deceptus were the penis not examined, which in the present case is very widely different from that of any of the other members of the Viridipes Group.

In appearance and structure, even of the male genitalia, close resemblance is shown to acrophilus and the student is warned that mistakes in identification are certain to occur if the pallium is not removed from above the penis in males so that the latter can be examined. We have not been able to find anything by which females of these species can be distinguished.

Like acrophilus and deceptus the insect is unquestionably sylvan, local and restricted in distribution to the southern Appalachian Mountains.

Type.-Crestmont; Great Smoky Mountains, North Carolina. Elevation 3200 feet. July 21, 1922. (T. H. Hubbell). [Univ. of Michigan].

Closely similar to acrophilus here described, agreeing in all features here given except the penis. This in the present insect has the lobes greatly narrowed, erect, curving evenly outward and then inward so that they almost meet at their extremities, the more caudal pair chitinized and with their caudal surfaces transversely convex so that they conceal and act as outer sheaths for the more cephalic pair.

The following much less significant differences from the type of acrophilus are shown by the present type. Cercus about two and three-quarters times proximal width, tapering in proximal third, distal three-fifths weakly enlarged. Apical enlarged portion of cercus much longer than in hubbelli. Subgenital plate with a stout blunt apical tubercle (which is less blunt in two paratypes).

$0^{x}$

Rocky Bottom, South Carolina.

Mt. Sterling, North Carolina. $5100 \mathrm{ft}$.

Crestmont, North Carolina. $3200 \mathrm{ft}$.

Crestmont, North Carolina. $1800 \mathrm{ft}$.

\begin{tabular}{|c|c|c|c|c|}
\hline \multicolumn{5}{|c|}{$\begin{array}{l}\text { Caudal } \\
\text { width }\end{array}$} \\
\hline $\begin{array}{l}\text { Length } \\
\text { of } \\
\text { body }\end{array}$ & $\begin{array}{l}\text { Length } \\
\text { of } \\
\text { pro- } \\
\text { notum }\end{array}$ & $\begin{array}{l}\text { of } \\
\text { pro- } \\
\text { notal } \\
\text { disk }\end{array}$ & $\begin{array}{l}\text { Length } \\
\text { of } \\
\text { tegmen }\end{array}$ & $\begin{array}{l}\text { Length } \\
\text { of } \\
\text { caudal } \\
\text { femur }\end{array}$ \\
\hline 19.2 & 4.9 & 2.7 & 5.7 & 10.7 \\
\hline 16. & 4.1 & 2.3 & 6.2 & 9.7 \\
\hline 17.3 & 4.2 & 2.6 & 5.7 & 9.7 \\
\hline 17.8 & 4.3 & 2.7 & 5.8 & 10.2 \\
\hline
\end{tabular}


ㅇ

$\begin{array}{llllll}\text { Rocky Bottom, South Carolina. } & 25.3 & 5.3 & 3.3 & 6.2 & 12.2\end{array}$

$\begin{array}{lllllll}\text { Crestmont, North Carolina. } & 3200 \mathrm{ft} . & 22.4 & 4.9 & 3.6 & 5.8 & 10.8\end{array}$

$\begin{array}{lllllll}\text { Crestmont, North Carolina. } & 3000 \mathrm{ft} . & 21.3 & 4.8 & 3.6 & 5.9 & 12 .\end{array}$

Specimens Examined: 9; 6 males and 3 females.

South Carolina: Rocky Bottom, Pickens County, 3500 feet, VI, 1, 1933, $1 \sigma^{7}$; VI, 21, 1933 and VI, 22, 1932, $1 \sigma^{x}, 1$ ㅇ, (all F. Sherman), [Sherman Cln.].

North Carolina: Mount Sterling, Great Smoky Mountains, 5100 feet, VIII, 2, 1924, (T. H. Hubbell), $1 \sigma^{\top}$, paratype, [Univ. of Mich.]. Crestmont, Great Smoky Mountains, 1800 to 4200 feet, VII, 18 to 29, 1922 and 1924, (T. H. Hubbell), $4 \sigma^{7}, 2$ \& type, allotype and paratypes, [Univ. of Mich. and Hebard Clns.].

\section{The Tribulus Group.}

We have recently decided that obovatipennis (Blatchley) is nothing more than a race of rusticus (Stål). Examination of topotypes of tribulus Morse and a paratype of devius Morse in the author's collection now show that the latter is a synonym of the former, but that the species which has usually been recorded in the literature as tribulus is actually a distinct undescribed species here named delaware. In addition, a paratype of tribuloides Morse in the author's collection is found to have a very different penis from that of tribulus or delaware and is not a race of trubulus as was indicated by Blatchley in 1920 .

The species belonging to the present group we arrange in the following sequence: tepidus Morse, morsei Blatchley, rusticus obovatipennis (Blatchley, rusticus rusticus (Stål), delaware here described, tribuloides Morse, tribulus Morse and decoratus Morse.

Melanoplus delaware new species

(Pl. XXII, fig. 16; pl. XXIII,

figs. 1 and 8)

This species has been recorded as tribulus from Clove Valley, Reeds Valley, Graniteville, Lambert's Lane, Watchogue and Richmond, New York (Davis); Ramapo Mountains, Ramsey, Barnegat, Reega, Belleplain, Sea Isle Junction, Dennisville, Dias Creek (Fox) and Stafford's Forge (Rehn and Hebard), New Jersey; Pink Hill, Pennsylvania (Rehn and Hebard); Beltsville and Plummer's Island, Maryland (Rehn and Hebard); Pohick (Rehn and Hebard) and Wingina (Davis) Virginia; Weldon,

TRANS. AM. ENT. SOC., LX. 
North Carolina (Rehn and Hebard); Clayton, Rabun County and Lost Mountain, Georgia (Rehn and Hebard). ${ }^{8}$

The following features are shared by delaware and its nearest allies. Pronotum with a fine percurrent medio-longitudinal carina. Tegmina pad-like, rounded, separated by a slight to decided interval, conspicuously shorter than the pronotum. Male subgenital plate with a small but decided blunt subapical tubercle, the dorsal surface of which is darkened. Limbs showing no trace of green.

These species may be distinguished as follows:

A. Male furcula very small, scarcely longer than proximal width. Penis with four large erect lamellate plates cephalad and curling cephalad like flower petals, yoke of shaft slightly produced and bluntly rounded dorso-caudad, leaving a meso-caudal interspace (Pl. XXIII, fig. 8). (Female normal. Vertex less projecting. Pronotal lateral lobes and ovipositor jaws less deep. Broad postocular dark bar sharply outlined on pronotal lateral lobes. The insect appears adult earlier than tribulus in the regions where the distribution of the two coincide.) Extreme southern New York and northern New Jersey to mountains of extreme northeastern Georgia............. delaware new species

AA. Male furcula small, but considerably longer than proximal width (Pl. XXIII, figs. 2 and 3). Penis lacking large lamellate plates.

B. Penis with four small lamellate plates directed cephalad at apex, yoke of shaft with caudal margins rounding broadly ventrad, leaving a meso-caudal interspace (Pl. XXIII, fig. 9). Female as in delaware but with pronotum deeper. Mountains of northeastern Alabama...tribuloides Morse

BB. Penis terminating in a flat knob, with four very small projections caudad, yoke of shaft with caudal margins attingent, produced dorsad as small rounded projections (Pl. XXIII, fig. 10). Female heavier with more projecting vertex, pronotal lateral lobes and ovipositor jaws deeper and broad postocular dark bar (usually) less sharply outlined on pronotal lateral lobes. (Appears adult late in season.) Collison Ridge in mountains of central-

8 The records from Toccoa, Dalton, Jasper, Sharp Mountain, Buckhead and near Stone Mountain were, however, correctly referred to tribulus. We now realize that delaware extends its distribution into the lowlands only in the northern portion of its distribution, while tribulus does this only in the southern portion of its range. In addition the former species appears much earlier in the season than the latter. 
western Virginia south to Spartanburg, South Carolina and Atlanta and Dalton, Georgia.........tribulus Morse

Type.- $\sigma^{T}$; Flag Rock Pass, Warm Springs Mountain, Bath County, Virginia. Elevation 2900 feet. July 6, 1916. (M. Hebard). [Hebard Collection Type no. 1263].

Size slightly below medium, form graceful. Vertex narrow, concave between the distinct lateral carinae; frontal costa depressed only around median ocellus. Pronotum with a very fine percurrent medio-longitudinal carina, principal sulcus alone distinct on dorsum, caudal margin convex on each side leaving a very small median angulate emargination. Prosternal spine rather slenderly conical and sharply rounded at apex. Tegmina ovate, shorter than pronotum, separated by a distinct interval. Apex of abdomen definitely thickened. Furcula very small, springing from thickened areas on tergite, very slightly longer than basal width with rounded apices. Supra-anal plate shieldshaped, medio-longitudinal sulcus percurrent, lateral portions concave, paired distal carinae short prominent and divergent cephalad. Cercus elongate, shaft slender, apical portion as broad as base with disto-dorsal margin broadly rounded and disto-ventral portion moderately produced disto-ventrad and bluntly rounded acute-angulate. Penis as given in above key. Subgenital plate with a small but sharply defined blunt subapical tubercle.

\section{Allotype.- $\%$; same data as type. [Hebard Collection].}

Larger and more robust than male, but the contrast between the sexes is decidedly less than in tribulus. Vertex broader. Prosternal spine heavier but with apex as sharply rounded. Tegmina even shorter in proportion to pronotal length. Ovipositor jaws medium, with moderate distal curvature, dorso-external margins of dorsal valves toothed.

\begin{tabular}{|c|c|c|c|c|c|}
\hline$\sigma^{\pi}$ & $\begin{array}{c}\text { Length } \\
\text { of } \\
\text { body }\end{array}$ & $\begin{array}{l}\text { Length } \\
\text { of } \\
\text { pronotum }\end{array}$ & $\begin{array}{l}\text { Caudal } \\
\text { width of } \\
\text { pronotal } \\
\text { disk }\end{array}$ & $\begin{array}{l}\text { Length } \\
\text { of } \\
\text { tegmen }\end{array}$ & $\begin{array}{l}\text { Length } \\
\text { of } \\
\text { caudal } \\
\text { femur }\end{array}$ \\
\hline , New Jersey. & 19. & 4.7 & 2.9 & 4.2 & 10.8 \\
\hline re, New Jersey. & 17.8 & 4.3 & 2.7 & 3.2 & 9.8 \\
\hline rginia. & 17. -18 . & $4.3-4.4$ & $2.6-2.7$ & $2.9-3.2$ & $9.8-10.2$ \\
\hline $\begin{array}{l}\text { ty, Georgia. } \\
\text { 우 }\end{array}$ & 18.8 & 4.4 & 2.7 & 3.4 & 10. \\
\hline Connecticut. & 23.3 & 5. & 3.7 & 3.7 & 11.3 \\
\hline ge, New Jersey. & 23.7 & 5.3 & 3.8 & 4. & 11.7 \\
\hline land, Maryland & 25.8 & 5.8 & 4.6 & 4.8 & 12.2 \\
\hline Virginia. & $19.8-23.3$ & $4.8-5.3$ & $3.7-4$ & $4 .-4.7$ & $10.7-11.7$ \\
\hline ity, Georgia. & 22.7 & 5.1 & 3.8 & 4. & 11.3 \\
\hline
\end{tabular}

TRANS. AM. ENT. SOC., LX. 
Generally dark brown, a broad postocular shining black band present which is sharply defined and widens caudad on the pronotal lateral lobes. Face, genae and ventral portions of pronotal lateral lobes brownish buff, often clear buff. Limbs brown. Caudal femora with dorsal surface often showing weakly a suffused transverse median band and distal suffusion, the paler portions in some series often tawn; ventral surface buff with a yellowish tinge. Sides of abdomen with blackish patches decreasing and weakening in intensity caudad. Ventral surface buff.

This is the only short-winged woodland species of Melanoplus known from New Jersey and eastern Pennsylvania. It is extremely local, widely distributed through the hilly woodlands of northern New Jersey and in favorable spots in the Pine Barrens. In eastern Pennsylvania it occurs much less frequently. At Pink Hill the few specimens secured were found among scanty grasses and plants growing on the poor soil of a serpentine outcrop near the edge of a deciduous forest. Only at the type locality have we found the species sufficiently abundant so that a series could be taken without long and intensive search, even after a colony had been located.

The following previously unreported 81 males, 92 females and 9 immature individuals are before us.

ConNecticut: Woodbridge, VIII, 20 and 30, 1896, 2 q.

New JERSEY: Stafford's Forge, VII, 21 and 29, 1915, (M. Hebard; in undergrowth of pine barrens where small oaks were present; very local, long

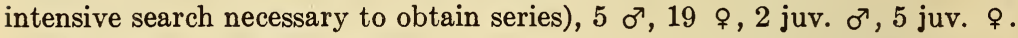

MARYLAND: Plummer's Island, X, 13, 1918, (M. Hebard; undergrowth of deciduous forest), 1 o , (unusually large).

Virginia: Round Hill, VII, 14, 1916, (J. D. Hood), 1 ơ, 1 \%. Rest, VIII, 25, 1906, (M. Hebard; occasional in open deciduous forest), $2 \sigma^{7}, 1$. Two miles east of Covington, 1000 to 1300 feet, VIII, 16, 1906, (M. Hebard; in weeds and short grasses on hillside), $2 \sigma^{7}, 4$ \&. Flag Rock Pass, Warm Springs Mountain, 2900 to 3000 feet, VII, 4 to VIII, 2, 1906, (M. Hebard; locally in very large colonies in short herbage of open area on mountain), $63 \mathrm{o}^{7}, 56$ \% , type, allotype, paratypes, 2 juv. ㅇ (VII, 4). Hot Springs, 1800 feet, VII, 6, 1916, (M. Hebard; on shaly hillside in huckleberry and other bushes), $2 \sigma^{7}$. Deer Lick Mountain, Little Mountain Ridge, 2800 feet, VII, 10, 1916, (M. Hebard; very few in undergrowth of deciduous forest), $1 \sigma^{7}, 4$ 웅. Dunn's Gap, VIII, 20, 1916, (M. Hebard; in low dry forest undergrowth), 1 ㅇ.

South Carolina: Pickens, VI, 24, 1932, (F. Sherman), 1 o $\sigma^{7}, 1$ \%. Rocky Bottom, VI, 26, 1934, (F. Sherman), 1 \%

Georaia: Mountain City, ${ }^{9}$ VI, 14 to 17, 1924, (H. Fox), $4 \sigma^{7}, 1$ \% .

9 The specimen from Wilson Gap near this locality, recorded as devius by Rehn and Hebard in 1916, actually represents delaware. 


\section{THE LEPIDUS, FEMUR-NIGRUM, ARTEMISIAE AND MONTANUS GROUPS}

The above western groups of Melanoplus were known to us to include species which had not been described. Six new species are treated in the present paper.

The penis had not been studied for any of the species and has been found to furnish characters of the greater importance. This is particularly true for the species of the Montanus Group, where it was possible to state definitely that washingtonius, repetinus and oreophilus were distinct species and not races only after each was known to have a strikingly distinctive penis. ${ }^{10}$

\section{The Lepidus Group}

To this group we now refer olamentke Hebard, solitudinis here described, lepidus Scudder and ablutus Scudder. Of these olamentke and solitudinis are clearly nearly related but quite widely distinct from the other two species, which are themselves widely distinct in certain characters but show agreement to different degrees in many features.

Following this group is the Saltator Group in which we have placed first the very aberrant bernardinae Hebard. Below we show that in two features of male genitalia solitudinis agrees more closely with that insect than with any of the other species of either of these groups.

The first two species of the succeeding group, the Femurnigrum Group, are femur-nigrum Scudder and snowii Scudder, and these again have certain features in common with some of the species of the Lepidus Group and the Saltator Group.

Melanoplus olamentke Hebard

(Pl. XXIV, figs. 1 and 2)

1897. Melanoplus olamentke Hebard, Trans. Amer. Ent. Soc., XLvi, p. 391,

pl. 17, fig. 11. [ [ $\sigma^{7}$; southern portion of Sonoma County, California.]

This interesting insect is still known only from the two originally described males. We here figure the penis.

${ }^{10}$ The importance of the concealed male genitalia must in many cases, however, not be overemphasized. Thus all of the species of the Femur-nigrum Group are readily separable by external characters quite as striking as the great differences of the penis which each also shows.

It is further noteworthy that the structure of the penis would often be actually misleading in associating species, as in some species of unquestionably close relationship a wholly differently developed penis is found to exist.

TRANS. AM. ENT. SOC., LX. 
Melanoplus solitudinis new species

(Pl. XXIV, figs. 3,4 and 5)

This distinctive insect inhabits the undergrowth of the conifer forests of the Markagunt and Paunsagunt Plateaus in southern Utah.

Compared with olamentke Hebard, males of this species are found to agree closely in general structure, coloration and color pattern, differing in the very weak or absent medio-longitudinal carina of the pronotal disk, slightly longer and less tapering furcula, supra-anal plate with more convex lateral margins which show a marked thickened elevation just before the cercal apices (in this feature and the inbent cercal apices somewhat recalling the otherwise very distinct bernardinae Hebard), cerci with apical portions shorter, broader, inbent and with external surfaces more strongly impressed and penis with proximal processes not nearly as tubular and others more acute.

Type.- $\sigma^{x}$; Bryce, Paunsagunt Plateau, Utah. Elevation 8200 feet. August 30, 1926. (Rehn and Hebard). [Hebard Collection, Type no. 1264].

Size and form medium (size varying considerably in response to conditions of immediate environment but not to altitude). Vertex narrow, concave between the distinct lateral carinae; frontal costa showing very weak blunt lateral carinae and extensive but weak impression about the median ocellus. Pronotal disk with fine medio-longitudinal carina present on metazona but absent on prozona, sulci distinct but fine on dorsum, caudal margin of disk obtuse-angulate produced with apex rounded. Prosternal spine moderately elongate, distad rather slender with apex bluntly rounded. Tegmina broad lanceolate with apices sharply rounded, narrowly overlapping, length distinctly less than that of pronotum (but individually variable to slightly longer than that dimension). Apex of abdomen conspicuously thickened. Furcula a minute pair of rounded projections springing from moderately thickened areas of the tergite, slightly longer than basal width. Supra-anal plate rather broadly shield-shaped but longer than broad, medio-longitudinal sulcus very broad and strong to median point, much weaker in distal portion, lateral portions strongly concave, lateral margins showing rounded thickening just before cercal apices, a trace of a very short transverse carina opposite these at extremity of the deeper portion of the medio-longitudinal sulcus; paired short disto-lateral carinae prominent, parallel. Cercus short, shaft stout, proximal half narrowing moderately due to the concave declivity of the dorsal margin; distal half enlarging to become almost as broad as the 
base, its dorsal margin concave ascendant then rounding without angulation and becoming convex to the disto-ventral angle, which is rounded subrectangulate; ventral margin almost straight, showing some concavity above dorso-proximal angle of subgenital plate (or broadly and shallowly concave); distal portion (which is sometimes slightly less than half of cercus) definitely bent inward with external surface prominently impressed. Penis with lateral margins of stout shaft meeting dorso-caudad without projections to form a narrow cleft, proximal processes erect and tubularly enfolding the first pair of central projections which project briefly beyond them and have their subchitinous apices with external margins curving to the sharp dorso-internal subrectangulate apex, the second pair of central projections protecting the basal portions of these as erect elongate flat shafts with rounded apices reaching dorsad as far as the lateral enfolding sections. Subgenital plate broad, terminating at dorso-distal margin mesad in a transverse rounded and slightly projecting apex (this individually varying from almost sharply conical and not transverse to a pair of low rounded projections).

\section{Allotype.- $\%$; same data as type. [Hebard Collection].}

Considerably larger and more robust than male. Vertex broader with carinae and impressions of it and frontal costa weaker. Prosternal spine considerably stouter with blunt apex. Tegmina shorter in proportion to pronotal length (but individually also varying to slightly longer than pronotum and occasionally attingent or subattingent only at widest point), dorsal and lateral fields weakly defined. Ovipositor apices rather short and stout, dorsal pair strongly curved, with dorso-external margins bluntly toothed and two transverse rows of blunt teeth on dorsal surface, ventral apices less strongly curved.

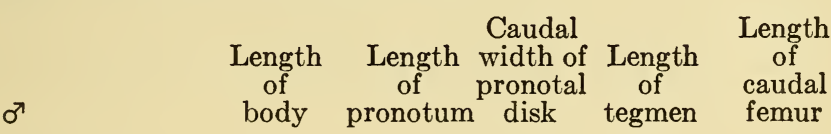

$\begin{array}{lllllll}\text { Red Canyon. } 6700 \text { feet. } & 18 . & 4.1 & 2.7 & 4 . & 9.8\end{array}$

Bryce. 8200 feet.

$16.8-18.8 \quad 4.2-4.6 \quad 2.3-2.7 \quad 2.9-5.3 \quad 9 .-10$.

$\begin{array}{llllll}\text { Near Midway. } 9700 \text { feet. } \quad 18 .-20.3 & 5 .-5.2 & 2.8-3 . & 5 .-5.8 & 10.3-10.4\end{array}$

$\begin{array}{lllllll}\text { Duck Creek. } 9900 \text { feet. } & 17.3 & 4.9 & 2.8 & 5.7 & 10.3\end{array}$

Cedar Breaks. 10400 feet. $\quad 17.3-20.8 \quad 4.3-5.2 \quad 2.6-3.3 \quad 4.8-6.7 \quad 9.5-11.7$

Red Canyon. 6700 feet.

Bryce. 8200 feet.

$\begin{array}{lllll}19 . & 4.8 & 3.1 & 5.3 & 10.8\end{array}$

Near Midway. 9700 feet.

Duck Creek. 9900 feet.

$\begin{array}{lllll}17.7-20.3 & 4 .-4.8 & 2.7-3.2 & 4.9-6 . & 9.8-10.7\end{array}$

$\begin{array}{lllll}19.7-27.3 & 4.8-6 . & 3 .-4.3 & 5.8-7.3 & 10.8-12.8\end{array}$

20.-23.7 $\quad 4.8-5.4 \quad 3 .-3.8 \quad 5.3-6.8 \quad 10.7-11.5$

Cedar Breaks. 10400 feet. $20.6-22$. $\quad 5 .-5.2 \quad 3 .-3.4 \quad 5.3-5.8 \quad 9.9-11.3$ 
Though it is true that the size average optimum is reached in this species at from 9000 to 10400 feet and that series from lower elevations all average smaller, it is clear that conditions of immediate environment often produce very great individual size differences.

Generally dark brown, in pale brown individuals often with markings all recessive. A very dark postocular bar present but extending caudad only to principal sulcus on pronotal lateral lobes, this frequently flanked with buffy dorsad on occiput and proximal portion of prozona, very rarely interrupted by an oblique buffy fleck on the cephalic portion of the pronotal lateral lobes. Occiput and pronotal disk sometimes weakly tinged with reddish, sometimes with olivaceous. Tegmina the same, or occasionally paler dorsad, or occasionally darker laterad and then sometimes with flecks of paler there. Dorsal surface of abdomen buffy or light reddish brown, the sides with dark areas which decrease in size caudad. Cerci weakly and subgenital plate narrowly suffused with brown at apices, this rarely extending to the lateral margins of the latter and dorsal margins of the preceding sternite in intensive individuals. Underparts buffy. Limbs individually brown, reddish buff or buff; caudal femora with two broad oblique bands and apices dark brown, the first band forming a $\mathrm{V}$ on the external pagina and often fusing ventrad with the second band, ventro-external margin and ventral surface buff or yellowish tinged with dragons blood red internally (usual in series from Paunsagunt Plateau) or dragons blood red with intervening sulcus and basal and apical annulus yellowish or buff (in series from Markagunt Plateau). Caudal tibiae usually rich glaucous, rarely pale glaucous, but pink in pair from Red Canyon, seven males and seven females from Bryce and two males and one female from Cedar Breaks. Such dimorphism in the brachypterous species of the genus is found only in some of the species of a few groups. ${ }^{11}$

The present species is known from the following series of seventy-seven specimens.

Utaн: Bryce, Paunsagunt Plateau, 8200 feet, VIII, 29 and 30, 1926, (Rehn, Hebard and Farrar; series taken only after long search in Black Sage and Antelope Brush, Purshia tridentata, on flat surface of plateau under Western Yellow Pines, Pinus ponderosa), 16 o 15 ㅇ. type, allotype, paratypes. Red Canyon near western base of Paunsagunt Plateau, 6700 feet, VIII, 30,

${ }^{11}$ It will be probably found in olamentke Hebard of the present group and is known in saltator Scudder and ascensus Scudder of the Saltator Group, while dichromatism of a different character in the caudal tibiae occurs in a number of species of the Femur-nigrum Group. 
1926, (Rehn and Hebard; very scarce under Western Yellow Pines and at foot of rock slides where neither Black Sage or Antelope Brush was present), $1 \sigma^{7}, 1$ o. Markagunt Plateau, 8300 feet, VIII, 30, 1926, (M. Hebard; in Western Yellow Pine forest), $1 \sigma^{\top}$. Duck Creek, Markagunt Plateau, 9000 feet, VIII, 30, 1926, (Rehn and Hebard; one on flat of short grass with no other Orthoptera, others on edge of conifer forest), $3 \sigma^{x}, 5$ \%, 1 juv. $q$. Five miles east of Midway, Markagunt Plateau, 9700 feet, VIII, 31, 1926, (Rehn and Hebard; Hudsonian Zone, moderately common in high dry grass under clumps of thickly growing pines), $9 \sigma^{\top}, 14$. Cedar Breaks, Markagunt Plateau, 10400 feet, VIII, 31, 1926, (Rehn and Hebard; not common in a single glade of Hudsonian Zone herbage, the majority in one small area of a species of dandelion), $7 \sigma^{7}, 4$ ㅇ.

\section{Melanoplus lepidus Scudder}

1897. Melanoplus rileyanus Scudder (in part), Proc. U. S. Nat. Mus., xx, p. 152. [ 9 ; Yuba County and mountains near Lake Tahoe, California.] 1897. Melanoplus lepidus Scudder, Proc. U. S. Nat. Mus., xx, p. 321, pl. 21, fig. 9. $\left[\sigma^{7}\right.$, o ; Humboldt River, Nevada; mountains near Lake Tahoe and Truckee (type locality), California.]

Four paratypes are in the author's collection. The following material shows the range of the species to extend far northward.

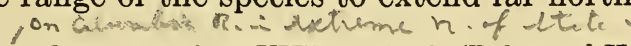

Oregon: Hood River, 200 to 500 feet, VIII, 18, 1910, (Rehn and Hebard), 1 \%; IX, 21, 1897, (A. P. Morse), 5 ơ , 3 우, [Mus. Comp. Zool. and Hebard Clns.].

$$
\text { modoc CD. }
$$

California: Sugar Hill, Goose Lake, 5300 feet, VIII, 24, 1922, (Rehn and Hebard; locally in moderate numbers in chaparral and mats of ground chinquapin under Western Yellow Pines, Pinus ponderosa), $12 \sigma^{7}, 13$ ․ Tahoe, 6300 to 7000 feet, VIII, 30, 1910, (Rehn and Hebard; scarce in conifer forest with chaparral and areas of a mullen-like plant, Rhamnus tomentella), 2 ơ, 4 \% ; 7500 feet, VIII, 8, 1930, (E. R. Tinkham), 1 o7. Blue Canyon, Placer County, 4700 to 5000 feet, VIII, 29, 1910, (Rehn and Hebard; few on open hillsides covered with clumps of high green bushes), $3 \sigma^{7}, 4$ ㅇ, 1 juv. + . Colfax, 2450 to 2800 feet, VIII, 27, 1910, (Rehn and Hebard; common on hillsides with scattered trees and much poison oak and chaparral, particularly in Chamaebatia foliosa), 24 o', 20 , 1 juv. $\%$.

In color individuals range from very dark with sharply defined color pattern to pale buffy brown with color pattern almost obliterated.

\section{Melanoplus ablutus Scudder}

1899. Melanoplus ablutus Scudder, Proc. Davenport Acad. Nat. Sci., vIII, p. 185, pl. 8, fig. 3. [ơ, \% ; Wawona, California.]

1909. Melanoplus ablutus Rehn and Hebard, Proc. Acad. Nat. Sci. Phila.,

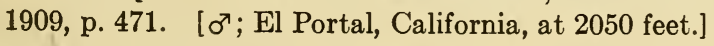

TRANS. AM. ENT. SOC., LX. 
The pair of small but striking tubercles or short transverse high lamellae mesad on the male supra-anal plate constitute a feature distinguishing this species and lepidus Scudder from their allies.

The male cerci are much more extensively spatulate distad in ablutus, and the two erect proximal processes of the penis are ear-like and no higher than wide, whereas in lepidus they are elongate and slenderly spindle-shaped.

\section{The Femur-nigrum Group}

To this group we refer, in the following sequence, calidus Scudder, chiricahuae Hebard, femur-nigurm Scudder, snowii Scudder, magdalenae here described and truncatus Scudder.

Striking differentiation is shown by all; chiricahuae, femurnigrum and snowii are clearly nearer each other and the same is true of magdalenae and truncatus.

All have the external pagina of the caudal femora dark (except in the palest examples of quadratus and truncatus) and uniformly colored with a very conspicuous pale longitudinal ventral marginal band. The pronotum is very bluntly rounded obtuseangulate produced except in magdalenae and truncatus. The tegmina are rather broad lanceolate pads with bluntly rounded apices. The apex of the male abdomen is enlarged, often very strongly so, with furcula very small, supra-anal plate moderately broad and subgenital plate with dorso-distal margin distinctly convex produced but not showing any tendency toward tuberculation except in magdalenae. The penis is of very dissimilar character in quadratus, femur-nigrum and its nearest allies, magdalenae and truncatus.

Melanoplus calidus Scudder

(Pl. XXIV, fig. 6)

1899. Melanoplus calidus Scudder, Proc. Davenport Acad. Nat. Sci., vir, p. 203. [ $\sigma^{\top}$, $\% ;^{12}$ Gilman's Ranch, Eagle Creek, White Mountains, New Mexico, at 7000 feet.]

1902. Melanoplus quadratus Scudder, Proc. Davenport Acad. Nat. Sci., IX, p. 49. [ $\sigma^{\top}$, o ; South Fork of Eagle Creek, White Mountains, New Mexico, at 8100 feet.]

1909. Melanoplus calidus Rehn and Hebard, Proc. Acad. Nat. Sci. Phila., 1909 , p. 165, text figs. 15 and 16. [ $\sigma^{7}$, $ᄋ$; Cloudcroft, [Sacramento Mountains], New Mexico, at 8600 to 8700 feet.]

12 These and specimens from the South Fork of Eagle Creek were recorded by Scudder and Cockerell as calidus in 1902 . 
Comparison of the original series with the material now available shows quadratus to be an absolute synonym of calidus. We had at first thought that the large series from Cloudcroft might represent a geographic race, due to the brown general coloration and small size of the specimens when compared with the strikingly olivaceous (except in much discolored individuals) and large size of the specimens in the series from the White Mountains. In all diagnostic characters, however, including the penis (here figured), such close agreement is shown that we are strongly of the opinion that the differences noted are wholly attributable to conditions of local environment. Material from other localities in this practically continuous mountain uplift will alone enable us to tell whether any geographic significance is indicated.

The size variation in the Sierra Blanca series taken at 10500 feet is as great as in the entire series secured from 8000 to 10800 feet. The decided majority of that series is about intermediate between its extremes given below.

\begin{tabular}{|c|c|c|c|c|c|}
\hline & $\begin{array}{r}\text { Leng } \\
\text { bo }\end{array}$ & $\begin{array}{l}\text { Length of } \\
\text { pronotum }\end{array}$ & $\begin{array}{l}\text { Caudal } \\
\text { width of } \\
\text { pronotal } \\
\text { disk }\end{array}$ & $\begin{array}{l}\text { Length of } \\
\text { tegmen }\end{array}$ & $\begin{array}{l}\text { Length } \\
\text { of } \\
\text { caudal } \\
\text { femur }\end{array}$ \\
\hline & & & $\begin{array}{l}2.8-3.2 \\
2 .-2.3\end{array}$ & & \\
\hline
\end{tabular}

\section{우}

Sierra Blanca, N. M. $\quad 22.3-27.8 \quad 5.5-6.8 \quad 3.2-4.6 \quad 6.7-8.2 \quad 12.9-14.3$ Cloudcroft, N. M. $\quad 18.2-23.3 \quad 5 .-5.2 \quad 3 .-3.3 \quad 5.2-6.1 \quad 11.3-12.2$

The caudal femora are always a clear rich pink, as are the ventro-internal portions of the caudal femora.

The following seventy six specimens have not been previously reported.

New Mexico: Sierra Blanca, White Mountains, 9300 to 10800 feet, VII, 20, 1930, (E. R. Tinkham; the insect was not found from above timber line to the summit), $33 \sigma^{7}, 18$ ㅇ. South Fork of Eagle Creek, White Mountains, 8000 to 8300 feet, VIII, 19 and 20, (C. H. T. Townsend), $1 \sigma^{\top}, 5$ \%, taken with types of quadratus, [U. S. N. M. and Hebard Cln.]. Cloudcroft, Sacramento Mountains, VI, 28, 1932, (R. H. Beamer), 7 ๙ 12 \% , [Univ. of Kansas].

1922. Melanoplus chiricahuae Hebard, Trans. Amer. Ent. Soc., XLviII, p. 61, pl. 3, figs. 9 and 10. [o', 우 Ida's Peak, Chiricahua Mountains, Arizona, at 8000 feet.]

TRANS. AM. ENT. SOC., LX. 
A series of twenty six males and nineteen females was taken at 8500 feet in the Chiricahua Mountains on September 15, 1931, by E. R. Tinkham for the author and seventeen males and six females on July 8, 1932, by R. H. Beamer for the University of Kansas. In all the caudal tibiae are glaucous. The penis is here figured.

Melanoplus femur-nigrum Scudder

(Pl. XXIV, figs. 7, 8 and 9)

1899. Melanoplus femur-nigrum Scudder, Proc. Davenport Acad. Nat. Sci., viI, p. 165, pl. 7, fig. 4. [o', \& ; San Francisco Mountains, Arizona.]

1908. Melanoplus femur-nigrum Rehn and Hebard, Proc. Acad. Nat. Sci. Phila., 1908, p. 397. [ơ, ๑ ; Bright Angel [trail, Coconino Plateau], Arizona..$^{13}$ ]

This species is widely distinct from $M$. indigens Scudder and Scudder was certainly incorrect in erecting an "Indigens Series" as that species is a member of the distinctive Oregonensis Group.

Normally deep glaucous, the caudal tibiae are pink, usually of a deep shade, in only sixteen females from the San Francisco Mountains. Such dichromatism confined to the female sex is known elsewhere only in snowii Scudder, saltator Scudder and ascensus Scudder.

Arizona: Ten miles east of Flagstaff, Coconino Plateau, VII, 20, 1930, (E. R. Tinkham; undergrowth in Western Yellow Pine forest, Pinus ponderosa), $1 \sigma^{7}, 2$ \%. San Francisco Mountains, VII, 10, 1913, (A. K. Fisher), $1 \sigma^{\top}$, [U. S. N. M.]; 8500 to 9200 feet, VII, 28, 1930, (E. R. Tinkham; under pines), 4 ơ 6 \%; VII, 30, 1897, (J. L. Hancock), $10 \sigma^{7}$ paratypes, 14 \&, allotype and topotypes; 9200 to 10000 feet, VII, 31, 1919, (Rehn and Hebard; few in lower forest and meadow, very common above in meadow to near its upper limit where it was replaced by $M$. truncatus Scudder), $84 \sigma^{\top}, 100 \%, 1$ juv. $\sigma^{\top}$, 2 juv. $\$$; 9000 feet, VII, 31, 1919, (Rehn and Hebard; few in scant grasses and plants in upper margin of Western Yellow Pine forest), $2 \sigma^{7}, 1$ \%, 1 juv. ; 8000 feet, VII, 31, 1919, (Rehn and Hebard; very scarce in scant grasses and plants in Western Yellow Pine forest on lower slopes), $3 \sigma^{7}, 1$ juv. $\%$; IX, 8, 1932, (E. D. Ball), 2 ఠ", 3 \&, [Univ. of Arizona]. Flagstaff, Coconino Plateau, VIII, 1 and 5, 1933, (R. H. and J. D. Beamer), $1 \sigma^{7}, 2$ \%, pair in coitu, [Univ. of Kansas]; (C. N. Ainslie), 2 ค, [U. S. N. M.] Williams, Coconino Plateau, VI, 30, 1932, (E. D. Ball), $1 \sigma^{\top}, 1$ \%. Bill Williams Mountain, IX, 14 to 30, 1917, (O. C. Poling), $10 \sigma^{7}, 20$ \%. Oak Creek Canyon, VII, 30, 1930, (E. R. Tinkham), 2 ণ 1 \% ; VIII, 9, 1932, (R. H. Beamer), $11 \sigma^{7}, 8$ \% , [Univ. of Kansas]. Dewey, IX, 9, 1917, (O. C. Poling),

${ }^{13} \mathrm{We}$ are now certain that a female then recorded was incorrectly labelled "Albuquerque, N. Mex.". The species does not occur east of the Coconino Plateau in Arizona, and is replaced by snowii Scudder in the White Mountains of this state. 
$1 \sigma^{7}$. Senator, VIII, 12, 1917, (J. A. Kusche), 1 ㅇ. Mount Union, VIII, 15, 1917, (J. A. Kusche), $2 \sigma^{7}$.

Melanoplus snowii Scudder

(Pl. XXIV, fig. 10; pl. XXV, fig. 1)

1897. Melanoplus snowii Scudder, Proc. U. S. Nat. Mus., xx, p. 274, pl. 18, fig. 7. [o', \% ; Magdalena [Mountains], New Mexico.]

Dr. R. H. Beamer has aided greatly in our studies in having obtained permission to send us the type and allotype of this species for examination, which specimens belong to the University of Kansas.

The penis is here figured for the first time. The species is much more closely related to femur-nigrum than to any of the others of the present group.

Though the caudal tibiae are rich glaucous in all of the males they are pink or glaucous in the females, as follows: Magdalena Mountains, New Mexico, 6 pink, none glaucous; Alpine, Arizona, 2 pink, 5 glaucous; White Mountains, Arizona, 11 pink, 7 glaucous. Such dichromatism peculiar to the female sex is here discussed under femur-nigrum Scudder.

New Mexico: Magdalena Mountains, 9600 to 9900 feet, VII, 23, 1933, (E. R. Tinkham; on eastern slopes among scrub oaks and grasses), 12 ๆ 10 ㅇ.

Arizona: MeNary, VIII, 29, 1932, (E. D. Ball), $1 \sigma^{7}$. Alpine, VI, 24, 1932, (E. D. Ball), $4 \sigma^{7}, 7$ ᄋ, [Univ. of Arizona and Hebard Clns.]. White Mountains eight miles west of Springerville, 9300 feet, VII, 25, 1930, (E. R. Tinkham; four in meadows, twenty one on pine forest floor), $11 \sigma^{7}, 16$. White Mountains twenty five miles west of Springerville, 10000 feet, VII, 25, 1930, (E. R. Tinkham; in mountain meadows), $4 \sigma^{7}, 2$ ㅇ.

Melanoplus magdalenae new specics

(Pl. XXV, figs. 2, 3, 4 and 5)

This insect supplants $M$. snowii Scudder at higher elevations in the Magdalena Mountains, just as truncatus Scudder supplants femur-nigrum Scudder in the San Francisco Mountains.

It is clearly nearest truncatus, the general coloration and color pattern being very similar, the male furcula and cerci being nearest those of that species but showing distinctive features. The insect is distinctly less robust, the male with apex of abdomen less enlarged, supra-anal plate much shorter, cerci tapering more conspicuously in distal portion, penis with processes very differently shaped and subgenital plate with apical tubercle considerably more prominent.

TRANS. AM. ENT. SOC., LX. 
In both of these species the caudal tibiae are normally rich pink, but larger series may show rare individuals of both sexes to have the caudal tibiae buffy weakly tinged proximad and distad with brown as is the case in truncatus.

The structure of truncatus gives to it a suggestion of the general appearance of a small species of Conalcaea; this is shared to some extent by the present species.

Type.- $\sigma^{7}$; Magdalena Mountains, New Mexico. Elevation 9900 feet. July 23, 1930 . (E. R. Tinkham). [Hebard Collection, Type no. 1265].

Size medium, form more robust than average. Vertex and frontal costa as in truncatus, slightly broader than in femurnigrum; the former concave between the distinct lateral carinae, the latter lacking lateral carinae, broadening appreciably to opposite median ocellus and distinctly impressed about it. Pronotum with medio-longitudinal carina percurrent but strongest on metazona, sulci distinct on dorsum, caudal margin of dorsum almost transverse and showing extremely faint convexity. Prosternal spine moderately elongate, rounding distad to the rather strongly rounded apex, not as slender as in femur-nigrum or truncatus. Tegmina ovate pads separated by an interval (very narrow to rather decided in series), considerably shorter than pronotum. Apex of abdomen very conspicuously thickened though not as much enlarged as in truncatus. Furcula represented by small stout tapering spikes, each less than twice as long as its basal width, shorter than in truncatus. Supra-anal plate decidedly shorter and more simple than in that species, slightly longer than proximal width, shield-shaped, lateral margins convex, lateral portions longitudinally broadly concave with intervening median sulcus coarse proximad, then followed by a low flattened carina which is impressed distad, short disto-lateral carinae very vaguely suggested. Cercus of same general type as in truncatus but not showing flattening of external surface and with apical portion narrower; very short, broad proximad, tapering distad to a broadly rounded apex which is directed dorso-distad, dorsal margin broadly and evenly concave, ventral margin broadly convex, then very faintly concave and becoming almost straight in distal portion. Penis broad, erect, shaft with margins meeting caudad to form a V-emargination, proximal processes large, erect, in caudal aspect with apices pointed but in lateral aspect these are seen to be produced in delicate rounded rectangular flanges directed cephalad, succeeding processes prominent, erect and fairly broad lamellate plates with almost attingent sharply 
rounded apices reaching as far as the bases of the apices of the proximal processes opposite the termination of the incurled lateral portions of those processes. Subgenital plate convex with a prominent apical tubercle.

\section{Allotype.- ; ; same data as type. [Hebard Collection].}

Considerably larger and more robust than male. Pronotum with medio-longitudinal carina (usually) almost as decided on prozona as on metazona. Prosternal spine broader proximad but with sharply rounded apex. Tegmina broader (sometimes almost circular), separated by a decided (to very decided) interval. Ovipositor valves moderately elongate, apices well curved, dorsal pair with dorso-external margins irregularly and not decidedly toothed but dorsal surfaces in proximal portion with a number of very irregular and broken rows of teeth.

The extremes in the series measure as follows: length of body o 16 . to 17.5 , क 20. to 21.; length of pronotum $\sigma^{7} 4.2$ to 5.1 , \% 5.3 to 5.8 ; caudal width of pronotal disk or 2.7 to 3 ., ㅇ 3.9 to 4.1 ; length of tegmen $\sigma^{7} 3.2$ to 4 , ᄋ 2.4 to 4.1 ; length of caudal femur ơ 10.1 to 11.1 , क 11.1 to $11.6 \mathrm{~mm}$.

The apex of the abdomen is curled upward in males and the length here given is taken with this in normal position, not straightened out.

Generally dark chocolate brown, postocular bar very broad, percurrent on pronotal lateral lobes, rarely flanked dorsad narrowly with dull buffy. Face, genae and ventral portions of lateral lobes buffy washed with reddish brown or dull olivaceous. Oblique streak on pleura very conspicuous, clear buff. Dorsum of abdomen often paler and more reddish brown than elsewhere. Cephalic and median limbs buffy, often heavily suffused with dull olivaceous. Caudal femora dorsad usually suffused and dark, sometimes buffy with two weakly indicated transverse bands on inner portions only, external pagina solid shining deep chocolate very narrowly margined dorsad (this widest proximad) with buffy and with a broad, very conspicuous, longitudinal ventral marginal band of cream color; ventral surfaces vandyke red with base and a pre-genicular annulus of buffy, genicular areas very dark brown paling only on the lobes. Caudal tibiae deep pink, paler on sides, with a post-proximal brown fleck.

A series of twelve male and five female paratypes was taken with the type from 9800 to 9900 feet on the north slopes of the Magdalena Mountains in grass under Aspen, Poplus tremuloides, saplings.

TRANS. AM. ENT. SOC., LX. 
1899. Melanoplus truncatus Scudder, Proc. Davenport Acad. Nat. Sci., vir, p. 177, pl. 7, fig. 8. [ [0', $\$$; San Francisco Mountains, Arizona.]

This insect is compared with magdalenae under the description of that species. It is clearly a more highly specialized insect. The distinctive penis is here figured.

Normally rich pink, the caudal tibiae externally suffused with brown on the sides proximad and distad in five males and buffy with a very faint glaucous tinge in three females of the very large series from the San Francisco Mountains. Such dichromatism of the caudal tibiae is distinct from that found in femur-nigrum and snowii.

A moderate number of females are very dull light olivaceous yellow in general coloration with dark postocular bar reduced to different degrees and dark area of external pagina of caudal femora usually obsolete, rarely weakly indicated.

The following one hundred and fifty three specimens have been studied.

Arizona: White Mountains, 9300 feet, VII, 24, 1930, (E. R. Tinkham; on floor of pine forest), $3 \sigma^{7}, 1$. San Francisco Mountains, VII, 28, 1930, 9400 to 9600 feet, (E. R. Tinkham; north slope in grass under Aspen, Poplus tremuloides), $1 \sigma^{\top}, 1$ \% ; VII, 30, 1897, (J. L. Hancock), $3 \sigma^{\top}$, paratypes; 9700 to 10000 feet, VII, 31, 1919, (Rehn and Hebard; moderately common in upper mountain meadow especially in areas of Sieversia ciliata (Pursh.), a few above in heavy stands of balsam and Aspen thickets, these very intensive in coloration), $50 \sigma^{\nwarrow}, 72$ \% , 4 juv. $\sigma^{7}, 6$ juv. ; ; VIII, 5, 1933, (R. H. Beamer), $1 \sigma^{\nearrow,} 6$ \% , [Univ. of Kansas]; VIII, 10 and IX, 8, 1932, (E. D. Ball), 2 ơ, 2 \%, [Univ. of Arizona]. Bill Williams Mountain, IX, 15 to 30, 1917, (O. C. Poling), 1 ㅇ.

\section{The Artemisiae Group}

This group is erected to include artemisiae Scudder and a closely related species lemhiensis here described. They are separable only by the male genitalia, which differ as follows:

A. Furcula very small, slender. Cercus with disto-ventral angle no more or very slightly more broadly rounded than the disto-dorsal angle, the dorsal and ventral margins of the distal portion parallel. Generally similarly specialized penis much narrower. Salmon River Mountains, Idaho, from 4000 to 6650 feet............. artemisiae Scudder 
AA. Furcula very small, moderately stout. Cercus with distoventral angle decidedly more broadly rounded than the disto-dorsal angle, the dorsal and ventral margins of the distal portion convergent due to definite obliquity of the latter. Generally similarly specialized penis much heavier and broader. Cow Creek, Lemhi Mountains, Idaho, from 4300 to 4400 feet.............. lemhiensis new species

Both species are grayish brown with darker markings not conspicuous, in general appearance closely resembling salmonis here described except that the caudal tibiae are pale glaucous. Relationship, however, is not close either to that species or the similarly grayish mottled but submacropterous kennicotti Scudder. Both of those species have very different male genitalic specialization.

Other features characterizing the group are the pad-like ovate tegmina with blunt lanceolation suggested, the male with small cerci which have the distal portion bent both inward and upward and its external surface conspicuously impressed and concave and male subgenital plate with a submarginal apical tubercle.

Melanoplus artemisiae Scudder

(Pl. XXVI, figs. 1 and 2)

1897. Melanoplus artemisiae Scudder, Proc. U. S. Nat. Mus., xx, p. 217, pl. 11, fig. 8. [ [0', 우 ; Salmon City, Idaho.]

The original series was secured by L. Bruner, probably in the foothills of the Salmon River Mountains west of the town, as it was there that Rehn and Hebard first secured specimens, though close search for the species at a number of localities nearer Salmon City proved fruitless.

Four males and two females of the original series, a pair being paratypes, are in the author's collection, but the figured male was selected as type by Rehn and Hebard in 1912, which specimen was not returned to Bruner by Scudder and is consequently now at the Museum of Comparative Zoology.

The following additional material is before us:

IDAно: Foothills of Salmon River Mountains just west of Salmon City, 4000 feet, VIII, 14, 1928, (Rehn and Hebard; very rare in area thickly covered with sage brush and a few composites), $2 \sigma^{\top}, 1$ \% . Upper Canyon, Morgan Creek, Salmon River Mountains, 6650 feet, VIII, 15, 1928, (M. Hebard; small numbers in sage brush on hillsides, difficult to capture as the sage brush was very large and thick), $1 \sigma^{\top}, 1$ ㅇ.

TRANS. AM. ENT. SOC., LX. 
This insect is generally very similar to artemisiae, differing as noted above. These species and salmonis here described have the dark postocular band often solid in males, broken by a small pale fleck in females; never as broad or as sharply defined as in montanus (Thomas).

Type.- $\sigma^{\top}$; Cow Creek, Lemhi Range, near Salmon River, Idaho. Elevation 4300 to 4400 feet. August 13, 1928. (Rehn and Hebard). [Hebard Collection, Type no. 1260].

Agrees very closely with salmonis here described in size, form, pronotum, general coloration and color pattern. Vertex slightly narrower. Frontal costa showing impression only in immediate vicinity of median ocellus. Eye deeper than in salmonis, about one and four-fifths times length of infra-ocular sulcus. Tegmina very short, considerably shorter than pronotum, feebly overlapping, distad rounding to a (normally) weak emargination at juncture of dorsal and lateral fields, ${ }^{14}$ the apex in dorsal field rounded angulate produced. Furcula represented by two very small processes springing from the tergite without convexities preceding them, the projecting portion blunt triangular (varying to rounded quadrate) and very slightly (to distinctly) longer than its basal width. Supra-anal plate triangularly shield-shaped, longer than proximal width, surface moderately specialized, medio-longitudinal sulcus deep in proximal three-fifths (thence varying from weak to obsolete). Cercus small, about twice as long as proximal width, proximal portion (slightly less than half of cercus) scarcely narrowing, subquadrate, slightly deeper than long; distal portion flattened, bent inward and upward, its outer surfaces weakly concave, its dorsal and ventral margins very weakly convergent and very weakly convex, the disto-dorsal angle broadly rounded, the disto-ventral angle very broadly rounded; apices approaching each other and briefly separated just before apex of supra-anal plate. Subgenital plate with a small blunt subapical tubercle. Penis much broader but of same general type as that of artemisiae (see plate XXVI, figure 4).

\section{Allotype.- $\%$; same data as type. [Hebard Collection].}

Agrees with type except as follows. Size much larger, form much more robust though not as robust as in this sex of salmonis.

${ }^{14} \mathrm{This}$ is rarely very weakly indicated in artemisiae. It is a condition which never occurs in the great majority of the brachypterous species of Melanoplus. 
Eye one and one-quarter times as long as infra-ocular sulcus. Prosternal spine conical, sharply rounded at apex. Tegmina almost attingent (varying in series from attingent to narrowly separated), with shallow emargination at juncture of distal margins of dorsal and lateral fields distinct (rarely very weak in series). Ovipositor valves of medium length with distal curvature decided (as in artemisiae, stronger than in salmonis).

Seven male and ten female paratypes bear the same data as the type. The extremes measure: length of body $\sigma^{7} 17.5$ to 18.7 , $\%$ 22.3 to 24 ; length of pronotum $\sigma^{7} 4.2$ to 4.6 ; ㅇ 5 . to 5.7 ; caudal width of pronotal disk o 2.2 to 2.4 ; 93 . to 3.3 ; length of tegmen $\sigma^{7} 3.2$ to 4.2 , 93.8 to 4.9 ; width of tegmen $\sigma^{7} 2$. to 2.2 ; 92.1 to 2.8 ; length of caudal femur $\sigma^{7} 9.1$ to 9.3 , $\% 10.7$ to $11.8 \mathrm{~mm}$.

Color as described for salmonis except as follows. Occiput and disk of pronotum light brownish, this continued on dorsal fields of tegmina, but in frequent specimens the lateral fields of the tegmina are definitely darker. Such individuals show a tegminal bicoloration usual in the species of the Rileyanus Group, which group is, however, not at all closely related. Caudal femoral dark bars very weak. Caudal tibiae very pale dull glaucous.

This interesting series was secured on steep slopes of rock fragments thickly overgrown with sage brush. The species was common only on the steepest upper slopes where there were many tufts of a fine dry yellow grass. The insect is a powerful though slow leaper, suggesting in its actions Oedaleonotum borckii orientis Hebard (another inhabitant of the sage brush in the Great Basin), but instead of immediately jumping into another bush individuals usually leaped about in the open and were consequently much easier to capture. Limited time alone prevented assembling a large series and the spot would have been revisited had we realized that the insect would not be found anywhere else in the hills along the Salmon River. North of that river in this region lemhiensis is apparently supplanted by artemisiae.

\section{The Montanus Group}

We would have separated montanus and idaho here described in a group distinguished from washingtonius and its allies by the more contrasting coloration with postocular bar unbroken and in sharper contrast, pronotum with definitely weaker demarkation 
of disk from lateral lobes and cerci with broader and more definitely truncate apices, were it not for salmonis here described, a species which is clearly nearer the former but has the pronotal contour and as little contrast in coloration as the latter species, while the shorter and more tapering cerci are distinct from either.

The species included in this group have pad-like tegmina, simple male cerci which are neither bent inward nor have the external surfaces of their apices concave, male subgenital plate with tubercle very weak to rather well developed and pink caudal tibiae.

Melanoplus montanus (Thomas)

(Pl. XXVII, fig. 7)

1873. Pl[atyphyma] montana Thomas, Rept. U. S. Geol. Surv. Terr., v, p. 155. [0์, क; Montana.]

Until the penis of this species and its allies was studied, decided uncertainty existed as to whether or not races instead of species were represented. Large series now before us representing all the known as well as a number of undescribed forms show that each must be given full specific status.

The following material, in addition to large series already reported, ${ }^{15}$ is now before us:

Alberta: Cold Lake, VI, 12, 1930, (E. R. Tinkham), $1 \sigma^{\nearrow 7}$ (showing extreme depauperation).

Montana: Avalanche Lake, Glacier National Park, 4400 feet, VIII, 17, 1930, (E. R. Tinkham), 2 ఠ’, 1 ㅇ․ Haugan, VIII, 9, 1931, (R. H. Beamer), 18 ๙7, 21 우, [Univ. of Kansas].

Wroming: Big Horn Mountains, (L. Bruner), $2 \sigma^{7}$. Mount Washburn, Yellowstone National Park, western slope at 9300 feet, VIII, 13, 1922, (M. Hebard; in scant vegetation on edge of conifer forest), $2 \sigma^{\top} ; 8600$ feet, VIII, 18, 1930, (E. R. Tinkham; in long grass on south slope), 1 o7, 1 우.

British Colombia: Crows Nest, VIII, 31, 1930, (E. R. Buckell), 1 ㅇ.

The distribution of this species is now known to extend north to Cold Lake, Alberta: east as far as that locality and the Waterton Lakes, Alberta; Avalanche and Upper Little St. Mary Valley in the Glacier National Park, Helena and Bozeman Mountain,

${ }^{15}$ Glover; Illustr. N. A. Ent., Orth., pl. 18, fig. 11, (1874). Scudder, Proc. U. S. Nat. Mus., xx, p. 232, pl. 15, fig. 8, (o', o ; Montana), (1897). Rehn and Hebard, Proc. Acad. Nat. Sci. Phila., 1906, p. 409, (Wyoming records). Hebard, Proc. Acad. Nat. Sci. Phila., Lxxx, p: 272, (Montana records), (1928). Hebard, Proc. Acad. Nat. Sci. Phila., LxxxIr, p. 393, (Alberta records), (1931). 
Montana; Crescent Hill in the Yellowstone National Park and the Big Horn Mountains of Wyoming: west to Banff, Alberta; the Swan Range, Beaver Creek and West Yellowstone, Montana: south to the latter, Norris Pass in the Yellowstone National Park and the Big Horn Mountains, Wyoming.

In its distribution southward it becomes paler, more contrastingly marked and larger, males measuring as follows:

$0^{7}$

Cold Lake, Alberta.

Banff, Alberta.

Waterton, Alberta.

Bozeman Mountain, Montana.

Mammoth Hot Springs, Wyoming.

\begin{tabular}{|c|c|c|c|c|}
\hline & & & & \\
\hline $\begin{array}{c}\text { Length } \\
\text { of } \\
\text { body }\end{array}$ & $\begin{array}{l}\text { Length } \\
\text { of } \\
\text { pro- } \\
\text { notum }\end{array}$ & $\begin{array}{c}\text { of } \\
\text { pro- } \\
\text { notal } \\
\text { disk }\end{array}$ & $\begin{array}{l}\text { Length } \\
\text { of } \\
\text { tegmen }\end{array}$ & $\begin{array}{l}\text { Length } \\
\text { of } \\
\text { caudal } \\
\text { femur }\end{array}$ \\
\hline 11.1 & 2.7 & 1.4 & 2.8 & 6.9 \\
\hline 16.8 & 3.8 & 2.3 & 3.8 & 7.9 \\
\hline 18.3 & 4.7 & 2.7 & 4.1 & 9.8 \\
\hline 19.8 & 4.8 & 2.9 & 5. & 10.2 \\
\hline 20. & 4.7 & 2.9 & 4.8 & 10.3 \\
\hline
\end{tabular}

Melanoplus idaho new species (Pl. XXVI, fig.6; pl. XXVII, figs.6 and 8)

This striking species is very closely related to montanus (Thomas). In coloration it shows as great contrasts as the maximum developed in that species. The male cerci are mesad definitely bent upward but the penis shows decidedly the most distinctive development.

Type.- $\sigma^{7}$; Cow Creek, Lemhi Range at Salmon River, Idaho. Elevation 4350 feet. August 13, 1918. (M. Hebard). [Hebard Collection, Type no. 1261].

Size larger and form more robust than in salmonis here described, much as in males of montanus from southern Montana. Vertex beyond eyes strongly declivant with impression narrow, frontal costa feebly impressed only about median ocellus. Pronotum with lateral carinae obsolete on prozona and very weak on metazona so that the disk merges into the lateral lobes more gradually than in montanus and much more gradually than in salmonis, medio-longitudinal carina weak on metazona, very weak on prozona and obsolete there between the decided transverse sulci; caudal margin of disk very weakly obtuse-angulate produced. Prosternal spine rounded conical. Tegmina short, shorter than pronotum, separated by a narrow interval, ovate pads with apices sharply rounded. Furcula represented by two small stout truncate processes springing from weak convexities

TRANS. AM. ENT. SOC., LX.

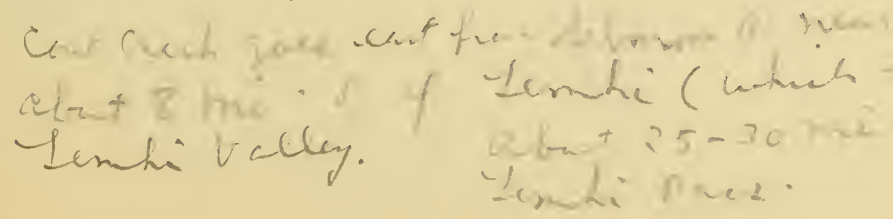


of the tergite, the projecting portion feebly widening proximad and twice as long as broad. Supra-anal plate shield-shaped, distinctly longer than proximal width, medio-longitudinal sulcus deep in slightly over proximal half, a short coarse carina on each side of apical portion. Cercus of only moderate size, proximal half slightly narrowing, shaft there bent dorso-distad and showing extremely slight widening to the truncate apex which has the disto-dorsal angle more strongly rounded and more produced than the disto-ventral angle. Penis very broad and heavy, with two broad erect convoluted plates cephalad before which are two nearly adjacent erect aciculate processes, each of which proximad has a very delicate rounded flange on its outer margin. Subgenital plate with a very low blunt apical tubercle feebly suggested.

Length of body 19., length of pronotum 4.7, caudal width of pronotal disk 3.7, length of tegmen 3., length of caudal femur $9.2 \mathrm{~mm}$.

General coloration light ochraceous buff, occiput and dorsal surface of pronotum sayal brown (a light brown), tegmina slightly darker. A very broad unbroken postocular bar, all but ventral portions of pleura, large areas laterad on abdominal tergites (which decrease in size on each tergite and are extremely small on the distal tergites) and apices of cerci blackish brown. Eyes warm sepia. Antennae mikado brown (more reddish). Caudal femora with two bars of dark brown dorsad of which the second is heaviest, these extend on the external pagina as broad oblique suffusions reaching only slightly below the median line, apices mikado brown, ventral and internal surfaces light ochraceous buff. Caudal tibiae light ochraceous buff tinged with pink.

This specimen was on a steep slope where, when disturbed, it had jumped out of an area thickly covered with sage brush onto a slide of bare rock fragments. A single female only was seen in addition, but most of our time was occupied at this locality in collection a series of lemhiensis here described, as we did not then recognize the present insect to be undescribed.

Melanoplus salmonis new species

(Pl. XXVI, figs. 7 and 8)

This remarkable species in general appearance and marking shows close resemblance to artemisiae Scudder, in which species and the allied lemhiensis here described, however, the caudal tibiae are pale glaucous; in the present species yellow buff tinged with pink distad; in the other species of the Montanus Group richer pink. 
The male genitalia are distinctive. The cerci are not inbent distad, the tubercle of the subgenital plate is subapical, these features and the general structure of the penis indicating that the insect is a member of the Montanus Group and not of the Artemisiae Group. The distal tapering of the cerci is distinctive, these appendages otherwise suggesting those of montanus (Thomas) and idaho here described more closely than those of the succeeding species.

Type.- $\sigma^{T}$; upper Morgan Creek, Salmon River Mountains, Idaho. Elevation 7080 feet. August 15, 1928. (Rehn and Hebard). [Hebard Collection, Type no. 1273.]

Size and form medium. Vertex as in oreophilus Hebard, surface shallowly concave between the distinct lateral carinae, frontal costa weakly depressed particularly in the vicinity of the median ocellus. Pronotum similar; medio-longitudinal carina weak on metazona, very weak on prozona and obsolete between the transverse sulci; caudal margin of disk weakly obtuse-angulate produced with angle broadly rounded. Prosternal spine very blunt conical. Tegmina short, shorter than pronotum, feebly overlapping (to narrowly separated in other male paratypes) ovate pads, slightly more sharply rounded (to broadly rounded in one male paratype) at apices (not lanceolate as in the other species of this group). Furcula represented by two very small stout processes springing from weak convexities of the tergite, the projecting portion no longer than broad. Supra-anal plate triangularly shield-shaped, no longer than proximal width and definitely shorter than in oreophilus; surface little specialized, medio-longitudinal sulcus percurrent but deep only in proximal two-fifths. Cercus small and simple, about three times as long as proximal width, dorsal margin concave and ventral margin convex particularly proximad, these margins gradually convergent to the rounded apex; the apical two-fifths of the cercus with external surface very feebly and irregularly impressed. Subgenital plate with a small blunt subapical tubercle.

Allotype.- $\%$; same data as type. [Hebard Collection].

Agrees with type except as follows. Size much larger, form much more robust. Vertex broader. Eye one and one-third times as long as infra-ocular sulcus. Prosternal spine shorter. Tegmina separated by a narrow interspace (and similar in the four paratypic females), sublanceolate (individually variable, in two female paratypes with apices broadly rounded). Ovipositor valves moderately elongate, with distal curvature moderately decided.

TRANS. AM. ENT. SOC., LX. 
Three male and four female paratypes, bearing the same data as the type, are before us. The extremes measure: length of body $\sigma^{7} 14.2$ to 17.8 , ㅇ 22.2 to 23.3 ; length of pronotum ot 3.2 to 3.9 , 5 . to 5.2 ; caudal width of pronotal disk $\sigma^{7} 2.2$ to 2.4 , ㅇ 3.5 to 3.6 ; length of tegmen $\sigma^{7} 2.8$ to 3.7 , o 4.7 to 5.1 ; width of tegmen $0^{7} 1.8$ to 2.2 , o 2.8 to 2.8 ; length of caudal femur $o^{7} 7.7$ to 9.7 , ㅇ 10.8 to $11 . \mathrm{mm}$.

General coloration grayish brown. Head and pronotum mottled brown, postocular bar only slightly darker and often including a buffy dot. Tegmina appearing more grayish. Abdomen buffy, in dorsal portions very thickly mottled with brown. Caudal femora light brown with two broad but only moderately darker bars, apices darker brown, ventral surface buff faintly tinged with yellow. Caudal tibiae buff faintly tinged with yellow proximad, becoming pale pink in other portions.

The small series was taken only after considerable effort, on an open hillside surrounded by forest with low cover largely of alpine plants and some sage brush. The species was there local and usually near the latter bushes.

Melanoplus washingtonius (Bruner)

(Pl. XXVI, fig. 9)

1885. Pezotettix washingtonius Bruner, Canadian Ent., xvII, p. $14 . \quad$ [0, \% ; Loon Lake, Colville Valley, Washington.]

1897. Melanoplus washingtonianus Scudder, Proc. U. S. Nat. Mus., xx, p. 233, pl. 15, fig. 9 .

This species was recorded in $1906^{16}$ as M. validus from Nelson, British Columbia, which error was corrected by Walker in Buckell in $1922 .{ }^{17}$

We had been long doubtful as to the validity of washingtonius, but examination of the penis of the species of this group shows that of the type of this species to be very different from that of its nearest allies, repetinus here described and oreophilus Hebard. The penis in these species is distinctive in each, shows very slight individual variation and none toward any of the others. Except that the male cerci are not subspatulate distad and are more definitely truncate at their apices, however, we can find no ex-

${ }^{16}$ Material from Lake Agnes and Fairview, Alberta, recorded as washingtonianus by Caudell in 1906, has since been correctly assigned to montanus.

${ }^{17}$ Proc. Ent. Soc. British Columbia, No. 20, p. 33. 
ternal features sufficiently constant to enable certain identifcation. ${ }^{18}$

In addition to the type, allotype and a paratypic male the following material is in the author's collection.

British Columbia: :19 Cranbrook, VIII, 20, 1925, (E. R. Buckell), $1 \sigma^{\top}, 1$ 오. Revelstoke Mountain, VIII, 12, 1923, (P. N. Vroom), 1 o , 1 \%. Rockcreek, VI, 9 to 25, 1922 and 1923, $3 \sigma^{7}$; VIII, 21, 1922, 1 ㅇ, (all E. R. Buckell). Aspen Grove, VII, 13 and 14, 1922, (E. R. Buckell), 6 o', 5 우. Merritt, VIII, 3, 1931, (R. H. Beamer); 1 ㅇ, [Univ. of Kansas].

IDAHO: Wallace, VIII, 19, 1917, 1 ㅇ.

Melanoplus repetinus new species

(Pl. XXVI, fig. 10)

1920. Melanoplus oreophilus Hebard (in part), Trans. Amer. Ent. Soc.,

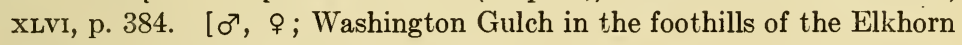
Range of the Blue Mountains, Oregon.]

In 1920 the male penis was not known to show striking diagnostic characters in many species of the Melanopli. In this organ repetinus differs very widely from oreophilus, but in coloration, color pattern and external structure it agrees so closely that we can find no other feature by which individuals may be distinguished with any certainty. Such a situation has recently been found by us in species we have described, cherokee and acrophilus of the Viridipes Group of Melanoplus. The value of the penis in distinguishing certain species of Melanoplus was discovered some years ago by T. H. Hubbell, who at that time found that packardii and foedus foedus had been generally confused, but that the very different penis would at once show to which species any male belonged.

In large series of both repetinus and oreophilus before us the structure of the penis is strikingly constant and in no individual is convergence between the two shown.

Type.- $\sigma^{7}$; Middle Onion Patch, Strawberry Peak, Oregon. Elevation 8250 feet. August 21, 1928. (Rehn and Hebard). [Hebard Cln., Type no. 1262].

18 Variation in degree of development of a subapical tubercle on the subgenital plate excludes this feature as a character of value, though when we described oreophilus we believed it had diagnostic importance.

${ }^{19} \mathrm{E}$. R. Buckell has kindly sent us the additional information that he has also examined material of washingtonius from Premier, Wasa, Nelson, Grand Forks, Nicola and Canyon House, British Columbia.

TRANS. AM. ENT. SOC., LX. 
Size and form medium. Vertex slightly narrower than in oreophilus, surface shallowly depressed between the distinct lateral carinae; frontal costa weakly depressed in vicinity of median ocellus. Eye proportionately slightly smaller than in oreophilus, nearly one and one-half times as long as infra-ocular sulcus. Pronotum much as in that species and washingtonius, disk more clearly separable from lateral lobes than in montanus particularly caudad; medio-longitudinal carina weak on metazona, weak on prozona and obsolete between the sulci there; transverse sulci weak; caudal margin of disk weakly obtuse-angulate produced with angle broadly rounded. Prosternal spine rather sharply conical. Tegmina as in oreophilus and washingtonius, slightly longer than pronotum, subattingent (but slightly overlapping in great majority of series), lanceolate pads. Furcula represented by two small stout processes springing from convexities of the tergite, the projecting portions about twice as long as broad with apices rounded. Supra-anal plate triangularly shield-shaped, medio-longitudinal sulcus deep only in proximal two-fifths, disto-lateral short carinae very feeble and parallel. Cercus distinctly over three times as long as proximal width, simple, slightly curved dorsad, distad subspatulate with slight and irregular impression indicated on external surface of that area. Penis distinctive as figured, the outer processes curving almost to meet dorso-mesad but not at all hooding the inner processes as is the case in oreophilus (see plate XXVI, figure 10), the inner processes with minute apices curled inward and caudad of these two slender erect straight sharp processes reach almost as far dorsad as the inner processes. Subgenital plate apically rather sharply rounded, so that it might be said to terminate in a tubercle, this not elevated above the lateral margins (and in some males distinctly transverse).

Allotype.—o ; same data as type. [Hebard Collection].

Agrees with type except as follows. Size much larger, form much more robust. Vertex broader. Eye deeper. Prosternal spine heavier conical, with apex sharply rounded. Ovipositor valves moderately elongate, with distal curvature decided.

Generally dull brown; face, genae and lateral lobes of pronotum paler, brownish buff. Postocular bar moderately wide, not very strikingly defined, dark brown, with a fleck or short oblique bar of brownish-buff dorso-cephalad on pronotal lateral lobes (this is normally obsolete in washingtonius, usually weakly indicated in oreophilus), this more conspicuous in females. Occiput, disk of pronotum and tegmina brown, the latter sometimes slightly mottled with darker brown, occasionally with lateral portions 
slightly darker than dorsal portions. Lateral portions of abdomen often very dark, particularly in males. Cephalic and median limbs buffy brown often suffused with darker. Caudal femora dorsad with genicular area and two bands weakly darker brown, external pagina with characteristic marking of this and the allied species; a broad V-shaped dark suffusion followed by a very broad suffused vertical band, the intervening areas often decidedly paler; internal surface with dorsal bands accentuated and intervening areas pale, the pre-genicular area often buff, below and ventral surface jasper red, the latter surface sometimes paling to yellowish medio-longitudinally particularly proximad. Caudal tibiae jasper red with a small proximal dark suffusion; spines black, spurs buffy, black tipped.

The similarity of color pattern to that of washingtonius and oreophilus and of color as well in specimens from similar environment (the original series of washingtonius is recessive and pale, probably due to aridity at the type locality) is remarkable, when the very decided differences in the penis are noted.

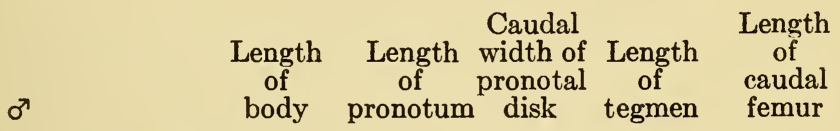

Washington Gulch, Oregon. $17.2-19 . \quad 4 .-4.3 \quad 2.4-2.6 \quad 4.7-6 . \quad 10 .-10.3$

Strawberry Peak, Oregon, 8900 feet.

15.8

$3.7 \quad 2$

4.6

8.8

Middle Onion Patch, Oregon, 8250 feet.

Strawberry Creek, Oregon, 4450 feet.

$15.6-17.3 \quad 3.8-4.3 \quad 2.2-2.5 \quad 3.6-5.8 \quad 9.2-10$.

$\begin{array}{lllll}18.8 & 4.4 & 2.7 & 5 . & 10.7\end{array}$

우

Washington Gulch, Oregon. $23.8-26 . \quad 4.8-5 . \quad 3.3-3.5 \quad 5.3-6.5 \quad 11.8-12$.

$\begin{array}{lllllll}\text { Strawberry Peak, Oregon. } & 23 . & 4.8 & 3.3 & 5 . & 10.8\end{array}$

Middle Onion Patch, Oregon.

$\begin{array}{lllll}18.7-23.7 & 4.3-4.9 & 3.2-3.3 & 4.9-6.7 & 10.8-12.1\end{array}$

A very gradual and slight decrease in size with increase in elevation is shown by the different series taken from the base to the summit of Strawberry Peak. The species was there everywhere scarce or very scarce except in extremely restricted spots in a hudsonian mountain meadow surrounded by a very close stand of Lodgepole Pines (the type locality). Its distribution 
there shows that it occurs from the conifer forests composed largely of Western Yellow Pine upward to timber line conditions among stunted stands of the White-bark Pine.

The following eighty eight specimens have been studied:

Oregon: Haines, VII, 10, 1931, (R. H. Beamer), $6 \sigma^{7}, 5$ ค, [Univ. of Kansas]. Washington Gulch, foothills of Elkhorn Range, Blue Mountains, 3800 to 4300 feet, VIII, 14, 1910, (Rehn and Hebard; one colony on steep pine-clad hillsides, among scant undergrowth in which Spiraea petufolia was predominant), $8 \sigma^{\top}, 3$ \% . Four miles east of Summit, Whitman National Forest, Blue Mountains, 4600 feet, VIII, 19, 1928, (M. Hebard; very rare in undergrowth of Western Yellow Pine, Western Larch, fir and spruce forest), $2 \sigma^{\pi}, 1$ o . Summit, Baker-Grant County line, Whitman National Forest, Blue Mountains, 5095 feet, VIII, 20, 1928, (Rehn and Hebard; very scarce in undergrowth of heavy conifer forest), $4 \sigma^{\top}, 8$ ㅇ. Strawberry Peak, Blue Mountains, 8900 feet, VIII, 21, 1928, (Rehn and Hebard; extremely scarce on gravel and rock fragments with small mountain plants among stunted White-bark Pines, Pinus albicaulis, no other Orthoptera there or up to 9640 feet at summit), $1 \sigma^{\top}, 1$ \%, paratypes: 8400 feet, (Hebard; in Lodgepole Pine forest, Pinus contorta), 1 \&, paratype. Middle Onion Patch, Strawberry Peak, Blue Mountains, 8250 feet, VIII, 21, 1928, (Rehn and Hebard); very scarce except locally in hudsonian mountain meadow surrounded by heavy stand of Lodgepole Pine), $19 \sigma^{\top}, 16$ \%, type, allotype, paratypes, 1 juv. + . Strawberry Peak trail, Blue Mountains, 7100 feet, VIII, 21, 1928, (Rehn and Hebard; few in scanty patches of undergrowth in Western Yellow Pine forest, Pinus ponderosa), $10 \sigma^{\top}, 1$ \%, paratypes. Strawberry Creek, Blue Mountains, 4450 feet, VIII, 20, 1928, (J. A. G. Rehn; one only seen in undergrowth of conifer forest composed largely of Western Yellow Pine), $1 \sigma^{\top}$.

Usually very scarce and always local, the large series was assembled only after many hours of close search through favorable areas, made in an effort to secure all the species of shortwinged Melanopli present. Only at Washington Gulch was $M$. indigens Scudder found in addition.

\section{Melanoplus oreophilus Hebard}

1920. Melanoplus oreophilus Hebard, Trans. Amer. Ent. Soc., xLvI, p. 382. $\left[\sigma^{7}\right.$, $\%$; northern slopes of Mount Hood, Oregon, ${ }^{20}$ from 3290 to 7000 feet (above the latter solid snows).]

The following corrections to our original comments must be made. The species is much more closely related to washingtonius than to montanus, but the penis is very distinct and shows far

${ }^{20}$ Incorrectly referred to this species, the series from Washington Gulch in the Blue Mountains of eastern Oregon is here properly placed as the closely related but previously unrecognized repetinus. 
higher specialization than that of those species. Definitely closer affinity to repetinus, here described, is shown.

The coloration of material of washingtonius from British Columbia, unlike the original series of that species, agrees with that of oreophilus in being darker with color pattern less sharply defined and has the ventro-internal and ventral surfaces of the caudal femora deep pink. These features are probably due to conditions of immediate environment and have no diagnostic significance.

The only material which has been subsequently secured is the following:

Oregon: Hood River, VII, 17, 1931, (R. H. Beamer), 1 ot, [Univ. of Kansas]. Santiam National Forest, Cascade Mountains, (W. J. Chamberlin), 1 \&, [U. S. N. M.]. South rim of Crater Lake, Cascade Mountains, 7050 feet, VIII, 26, 1928, (Hebard and Farrar; female in fine dry grass on slope of volcanic ash, males on very small ridge of volcanic boulders in open thickly clothed with alpine plants particularly Erigonum umbellatum Torr.; long search failed to disclose other specimens; those taken were very sluggish) $2 \sigma^{\top}, 1$ \%

\section{Explanation of Plates}

\section{Plate XXII}

(Lateral view of male cercus. Greatly enlarged.)

Fig. 1.-Melanoplus sylvaticus McNeill. Willard, Missouri.

Fig. 2.-Melanoplus viridipes eurycercus Hebard. Type. Derrick City, Pennsylvania.

Fig. 3.-Melanoplus viridipes viridipes Scudder. Paratype. Ogle County, Illinois.

Fig. 4.-Melanoplus beameri Hebard. Type. Leavenworth County, Kansas.

Fig. 5.-Melanoplus beameri Hebard. Paratype. Leavenworth County, Kansas. (Showing extreme of variation in cercal form in original series.)

Fig. 6.-Melanoplus similis Morse. Paratype. Murphy, North Carolina.

Fig. 7.-Melanoplus similis Morse. (Paratype of the synonym calloplus, showing variation in form of cercus.) Collison Ridge, Bath County, Virginia.

Fig. 8.-Melanoplus similis Morse. Mount Sterling, Haywood County, North Carolina. (Showing variation in form of male cercus very unusual in this species.)

Fig. 9.-Melanoplus longicornis (Saussure). Clayton, Georgia.

Fig. 10.-Melanoplus longicornis (Saussure). Type. North Carolina. (From outline sketched in note book by the author.)

Fig. 11.-Melanoplus hubbelli new species. Type. Red Hills, Franklin County, Ohio. 
Fig. 12.-Melanoplus acrophilus acrophilus new species. Type. Black Mountain, North Carolina.

Fig. 13.-Melanoplus acrophilus pachycercus new subspecies. Type. Mountain Lake, Giles County, Virginia.

Fig. 14.-Melanoplus deceptus Morse. Type. Balsam, North Carolina.

Fig. 15.-Melanoplus cherokee new species. Type. Crestmont, Haywood County, North Carolina.

Fig. 16.-Melanoplus delaware new species. Type. Flag Rock Pass, Bath County, Virginia.

\section{Plate XXIII}

(Dorsal view of male supra-anal plate. Figures greatly enlarged.)

Fig. 1.-Melanoplus delaware new species. Type. Flag Rock Pass, Bath County, Virginia.

Fig. 2.-Melanoplus tribuloides Morse. Paratype. Cheah Mountain, Alabama.

Fig. 3.-Melanoplus tribulus Morse. Topotype. Sharp Mountain, Pickens County, Georgia.

(Caudal view of penis.)

Fig. 4.-Melanoplus beameri Hebard. Type. Leavenworth County, Kansas.

Fig. 5.-Melanoplus acrophilus acrophilus Hebard. Type. Black Mountain, North Carolina.

Fig. 6.-Melanoplus deceptus Morse. Type. Balsam, North Carolina.

Fig. 7.-Melanoplus cherokee new species. Type. Crestmont, Haywood County, North Carolina.

Fig. 8.-Melanoplus delaware new species. Type. Flag Rock Pass, Bath County, Virginia.

Fig. 9.-Melanoplus tribuloides Morse. Paratype. Cheah Mountain, Alabama.

Fig. 10.-Melanoplus tribulus Morse. Topotype. Sharp Mountain, Pickens County, Georgia.

\section{Plate XXIV}

(Figures greatly enlarged.)

Fig. 1.-Melanoplus olamentke Hebard. Paratype. Male. Lateral outline of cercus. Southern Sonoma County, California.

Fig. 2.-Melanoplus olamentke Hebard. Paratype. Male. Caudal view of penis. Southern Sonoma County, California.

Fig. 3.-Melanoplus solitudinis new species. Type. Male. Dorsal view of supra-anal plate. Bryce, Paunsagunt Plateau, Utah.

Fig. 4.-Melanoplus solitudinis new species. Type. Male. Lateral view of cercus. Bryce, Paunsagunt Plateau, Utah.

Fig. 5.-Melanoplus solitudinis new species. Type. Male. Caudal view of penis. Bryce, Paunsagunt Plateau, Utah.

Fig. 6.-Melanoplus calidus Scudder. Male. Caudal view of penis. Sierra Blanca, White Mountains, New Mexico, at 10000 feet. 
Fig. 7.-Melanoplus femur-nigrum Scudder. Male. Paratype. Caudal view of penis. San Francisco Mountains, Arizona.

Fig. 8.-Melanoplus femur-nigrum Scudder. Male. Ten miles east of Flagstaff, Coconino Plateau, Arizona. (Showing individual variation in length of processes of the penis.)

Fig. 9.-Melanoplus femur-nigrum Scudder. Male. Lateral view of distal portions of penis, (showing apical specialization which can not be seen in caudal aspect.)

Fig. 10.-Melanoplus snowii Scudder. Male. Topotype. Caudal view of penis. Magdalena Mountains, New Mexico, at 9900 feet.

\section{Plate XXV}

(Figures greatly enlarged.)

Fig. 1.-Melanoplus snowii Scudder. Male. Topotype. Lateral view of cercus. Magdalena Mountains, New Mexico, at 9900 feet.

Fig. 2.-Melanoplus magdalenae new species. Male. Type. Dorsal view of supra-anal plate. Magdalena Mountains, New Mexico, at 9900 feet.

Fig. 3.-Melanoplus magdalenae new species. Male. Type. Lateral outline of cercus. Magdalena Mountains, New Mexico, at 9900 feet.

Fig. 4.-Melanoplus magdalenae new species. Male. Type. Caudal view of penis. Magdalena Mountains, New Mexico, at 9900 feet.

Fig. 5.-Melanoplus magdalenae new species. Male. Paratype. Lateral view of distal portion of abdomen. Magdalena Mountains, New Mexico, at 9900 feet.

Fig. 6.-Melanoplus truncatus Scudder. Male. Paratype. Lateral view of distal portion of abdomen. San Francisco Mountains, Arizona.

Fig. 7.-Melanoplus truncatus Scudder. Male. Topotype. Dorsal view of supra-anal plate. San Francisco Mountains, Arizona.

Fig. 8.-Melanoplus truncatus Scudder. Male. Topotype. Lateral outline of cercus. San Francisco Mountains, Arizona.

Fig. 9.-Melanoplus truncatus Scudder. Male. Caudal view of penis. San Francisco Mountains, Arizona.

\section{Plate XXVI}

(Figures greatly enlarged.)

Fig. 1.-Melanoplus artemisiae Scudder. Male. Topotype. Lateral view of cercus. Salmon River Mountains near Salmon City, at 4000 feet.

Fig. 2.-Melanoplus artemisiae Scudder. Male. Paratype. Caudal view of penis. Salmon City, Idaho.

Fig. 3.-Melanoplus lemhiensis new species. Male. Type. Lateral view of cercus. Cow Creek, Lemhi Range, Idaho.

Fig. 4.-Melanoplus lemhiensis new species. Male. Type. Caudal view of penis. Cow Creek, Lemhi Range, Idaho.

Fig. 5.-Melanoplus lemhiensis new species. Male. Type. Lateral view of distal portion of penis, (to show specialization not visible from caudal aspect).

TRANS. AM. ENT. SOC., LX. 
Fig. 6.-Melanoplus idaho new species. Male. Type. Caudal view of penis. Cow Creek, Lemhi Range, Idaho.

Fig. 7.-Melanoplus salmonis new species. Male. Type. Lateral outline of cercus. Upper Morgan Creek, Salmon River Mountains, Idaho, at 7080 feet.

Fig. 8.-Melanoplus salmonis new species. Male. Type. Caudal view of penis. Upper Morgan Creek, Salmon River Mountains, Idaho, at 7080 feet.

Fig. 9.-Melanoplus washingtonius (Bruner). Male. Type. Caudal view of penis. Loon Lake, Colville Valley, Washington.

Fig. 10.-Melanoplus repetinus new species. Male. Type. Caudal view of penis. Middle Onion Patch, Strawberry Peak, Oregon, at 8250 feet.

\section{Plate XXVII}

(Lateral views magnified approximately $21 / 2$ times.)

Fig. 1.-Melanoplus beameri Hebard. Male. Type. Lateral view. Leavenworth County, Kansas.

Fig. 2.-Melanoplus similis Hebard. Male. (Paratype of synonym calloplus.) Lateral view. Collison Ridge, Bath County, Virginia.

Fig. 3.-Melanoplus hubbelli new species. Male. Paratype. Lateral view. Red Hills, Franklin County, Ohio.

Fig. 4.-Melanoplus acrophilus acrophilus new species. Male. Type. Lateral view. Black Mountain, North Carolina.

Fig. 5.-Melanoplus lemhiensis new species. Male. Type. Cow Creek, Lemhi Range, Idaho.

Fig. 6.-Melanoplus idaho new species. Male. Type. Cow Creek, Lemhi Range, Idaho.

Fig. 7.-Melanoplus montanus (Thomas). Male. Summit of Bozeman Mountain, Montana, at 7600 feet. Lateral outline of cercus. (Greatly enlarged.)

Fig. 8.-Melanoplus idaho new species. Male. Type. Cow Creek, Lemhi Range, Idaho. Lateral outline of cercus. (Greatly enlarged.)

Fig. 9.-Melanoplus chiricahuae Hebard. Male. Topotype. Chiricahua Mountains, Arizona. Caudal view of penis. 
Trans. Am. Ent. Soc., Vol. LX.

Pl. XXII.
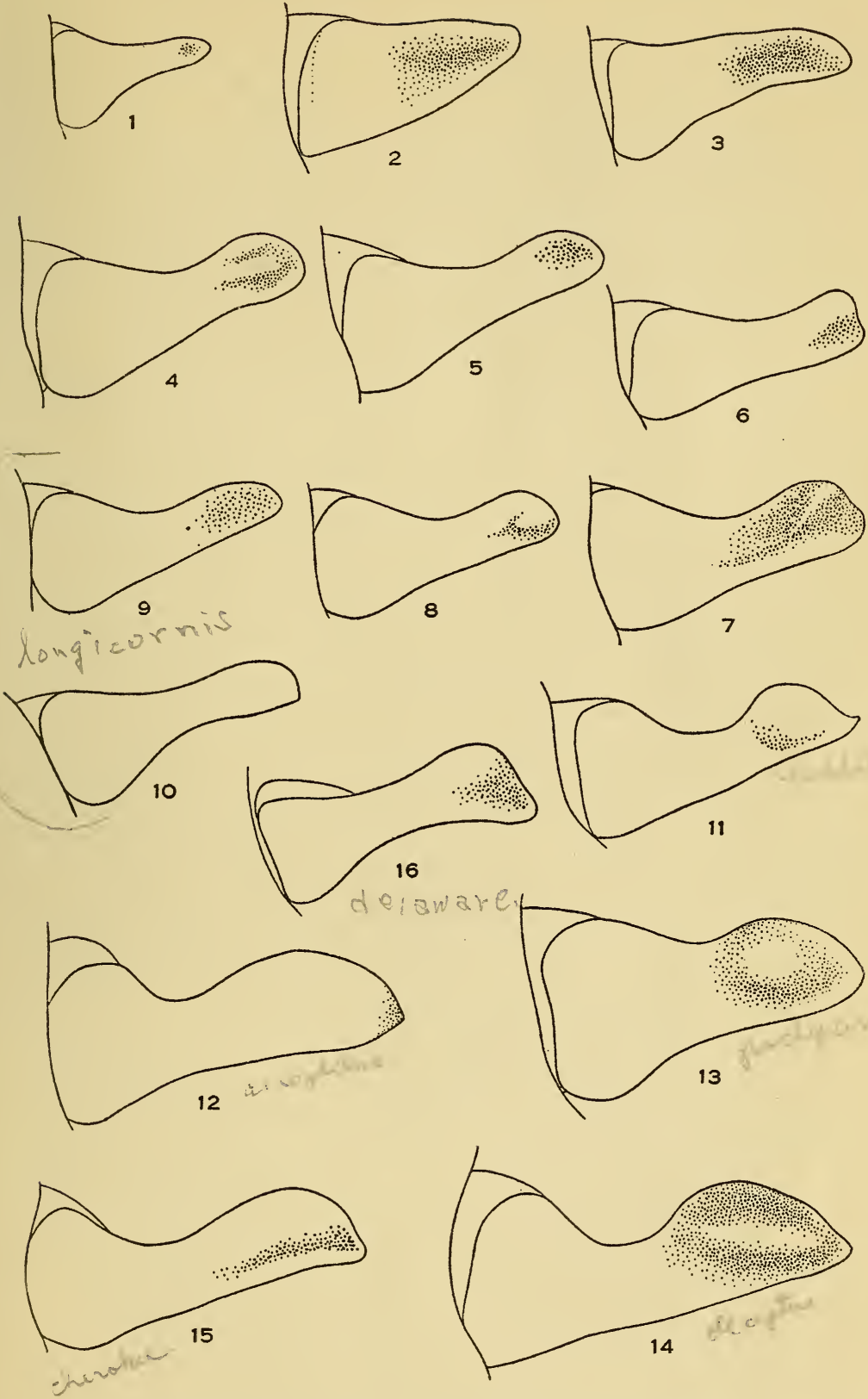

HEBARD-NORTH AMERICAN MELANOPLI 

Trans. Am. Ent. Soc., Vol. LX.

Pl. XXIII.
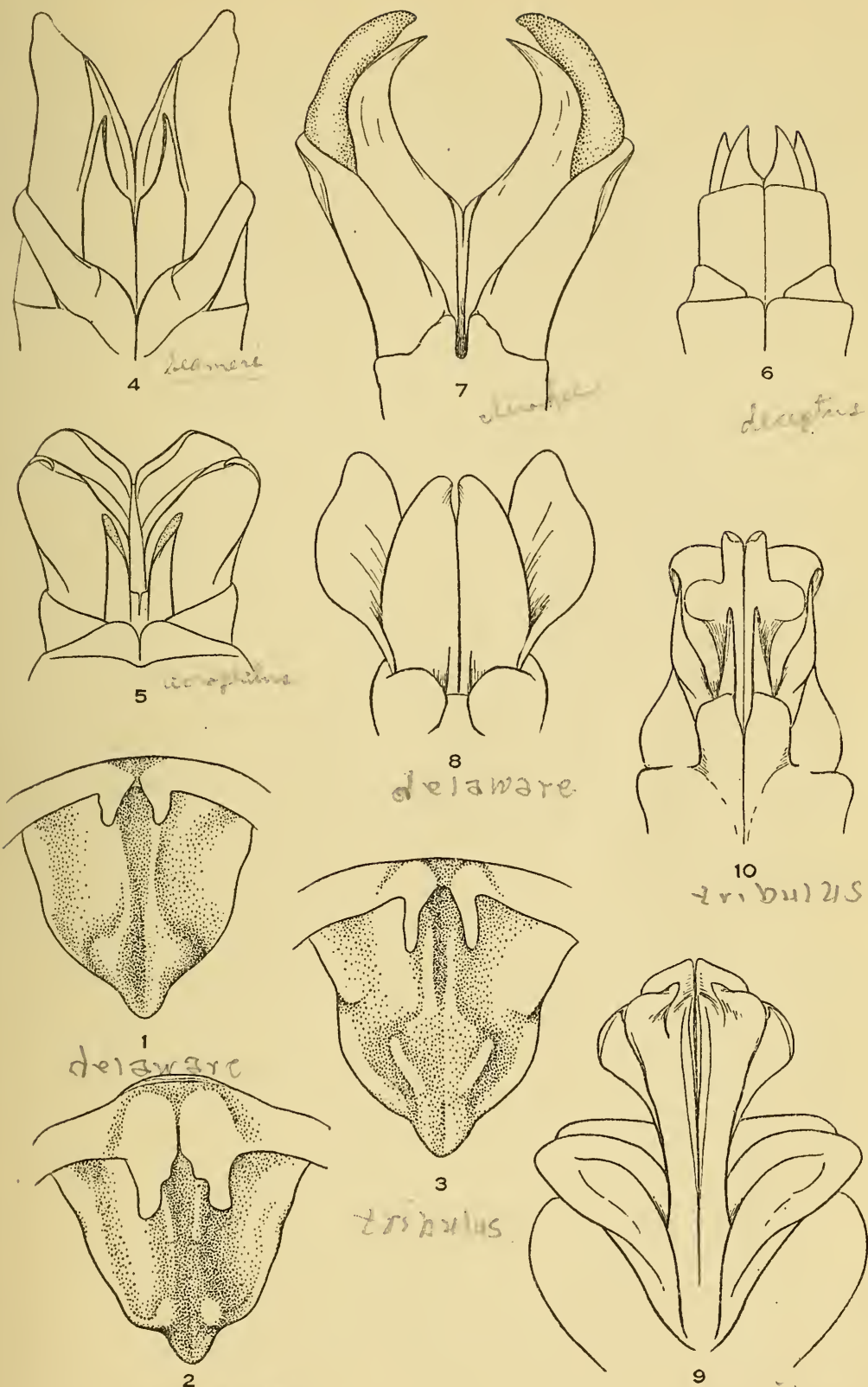

2.) HEBARD-NORTH AMERICAN MELANOPL 

Trans. Am. Ent. Soc., Vol. LX.

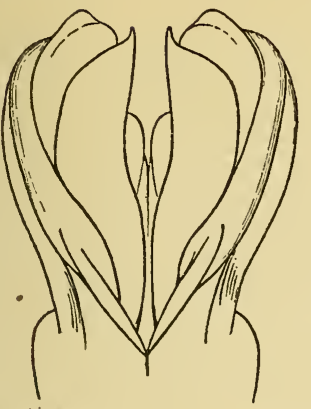

olzmentic 2



6

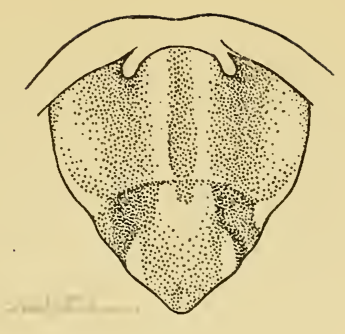

3

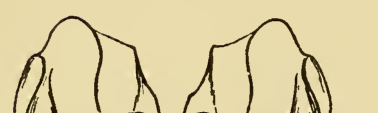

112
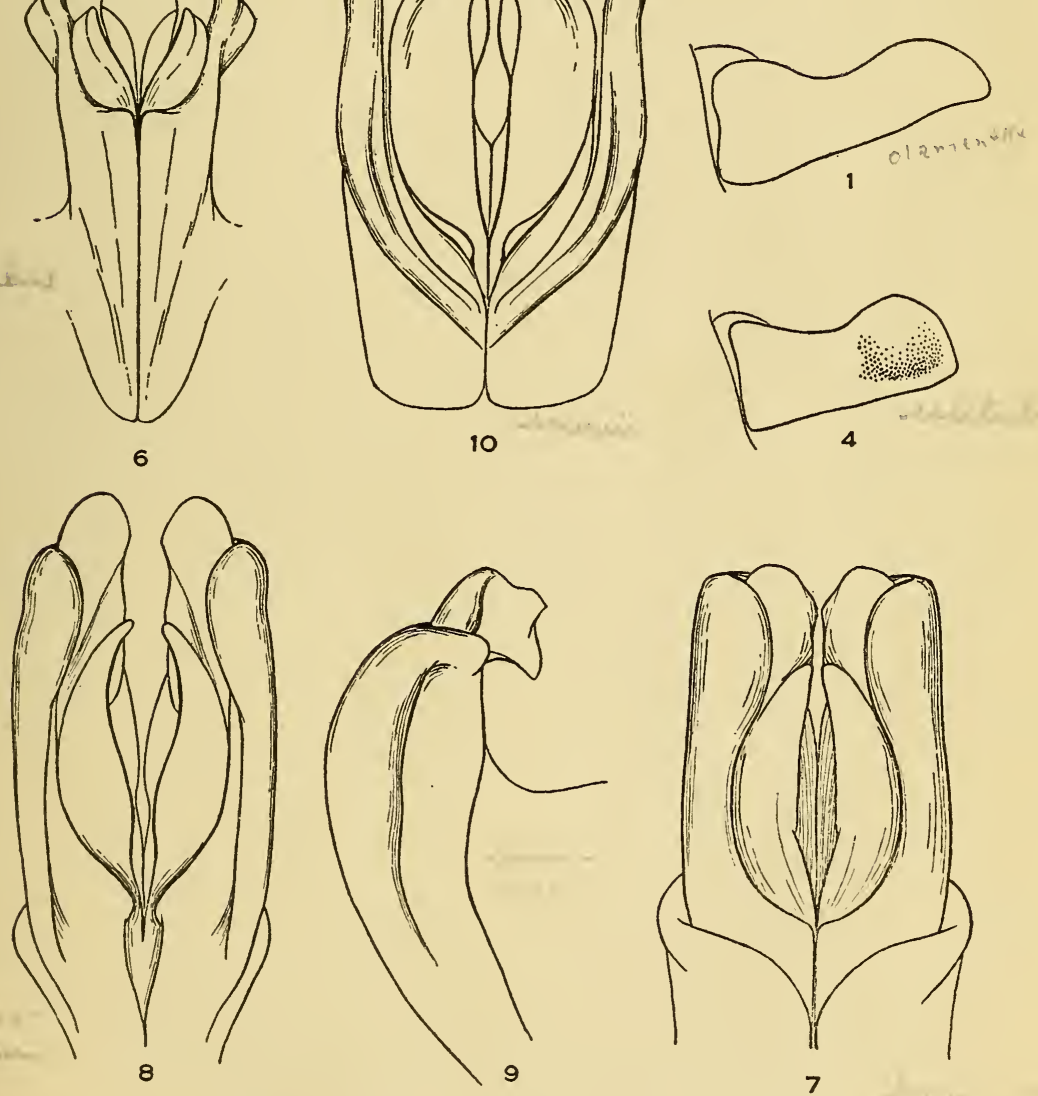

HEBARD-NORTH AMERICAN MELANOPLI
Pl. XXIV.
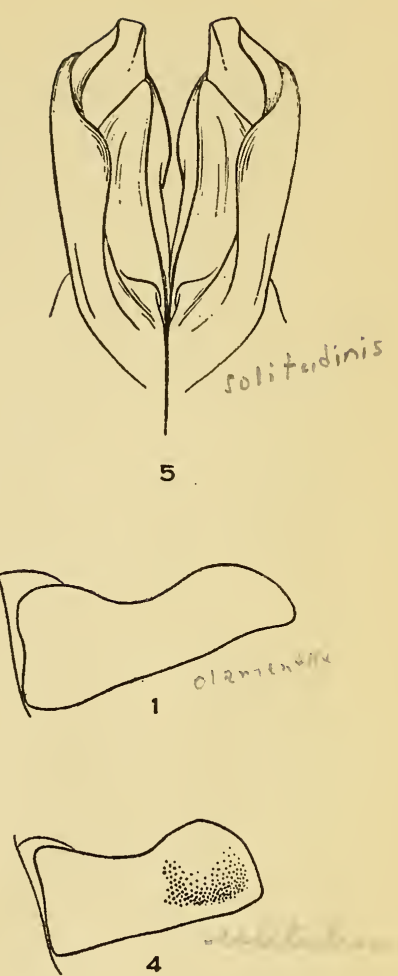


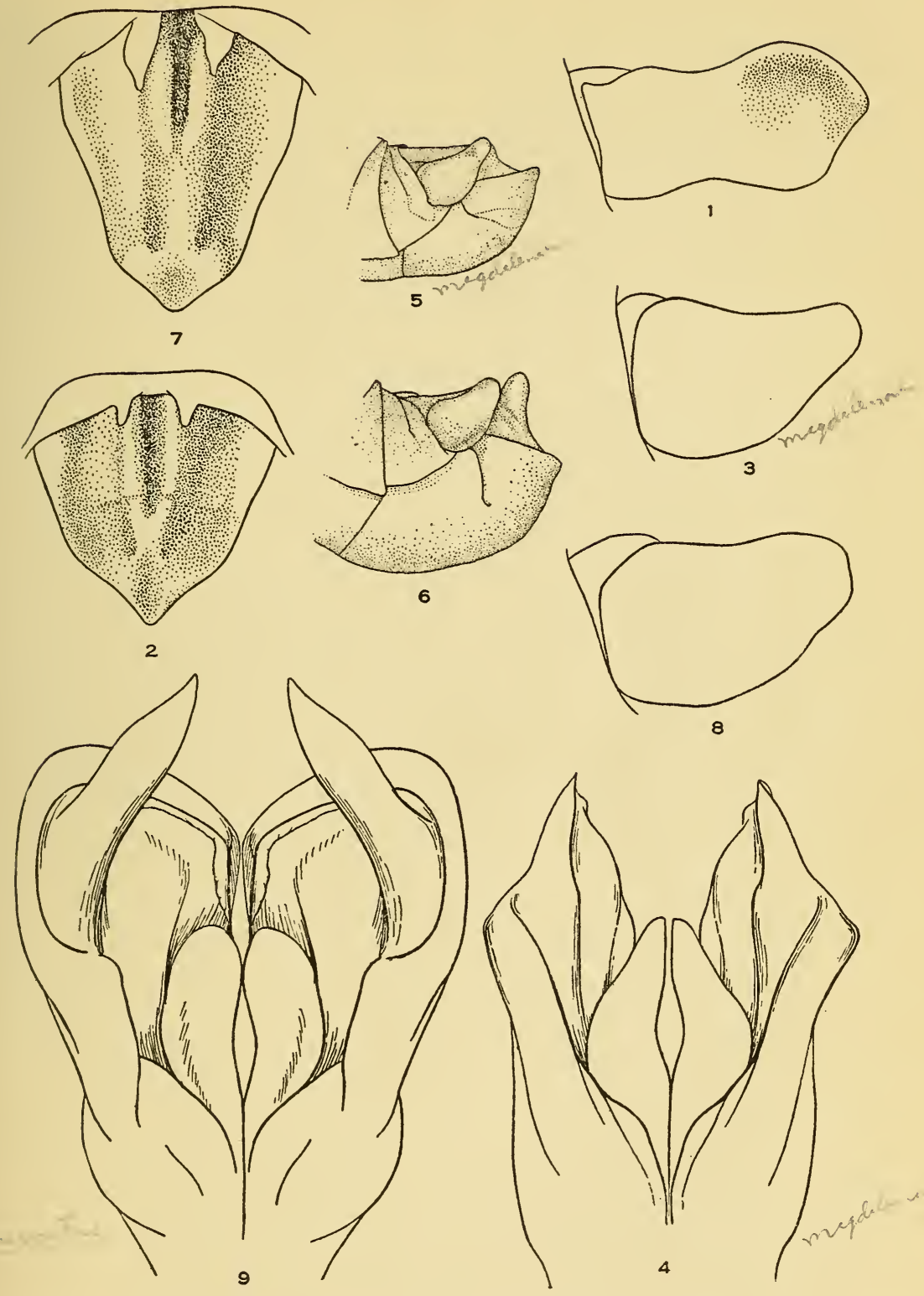

HEBARD-NORTH AMERICAN MELANOPLI 

Trans. Am. Ent. Soc., Vol. LX.

Pl. XXVI.
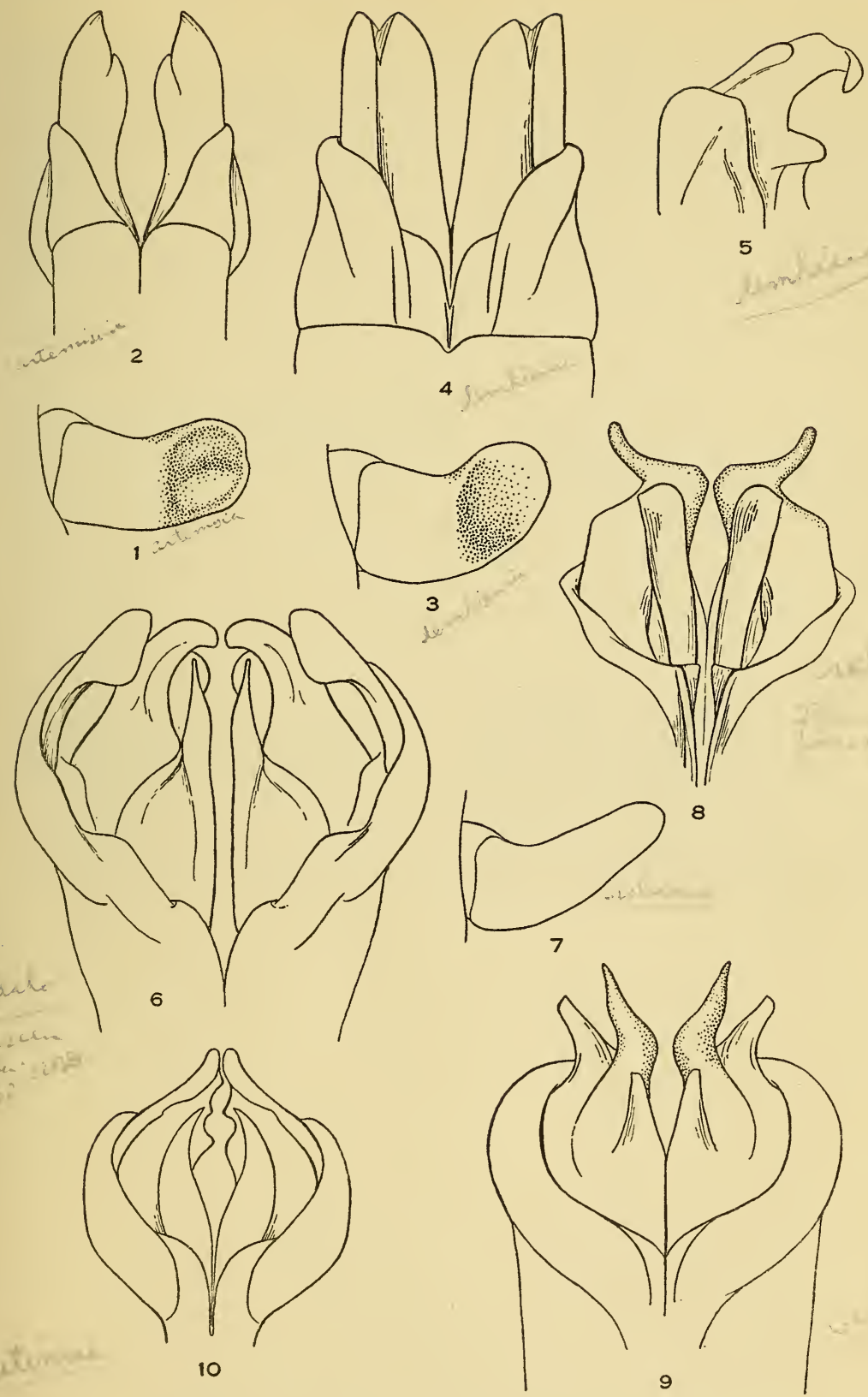

HEBARD-NORTH AMERICAN MELANOPLI 



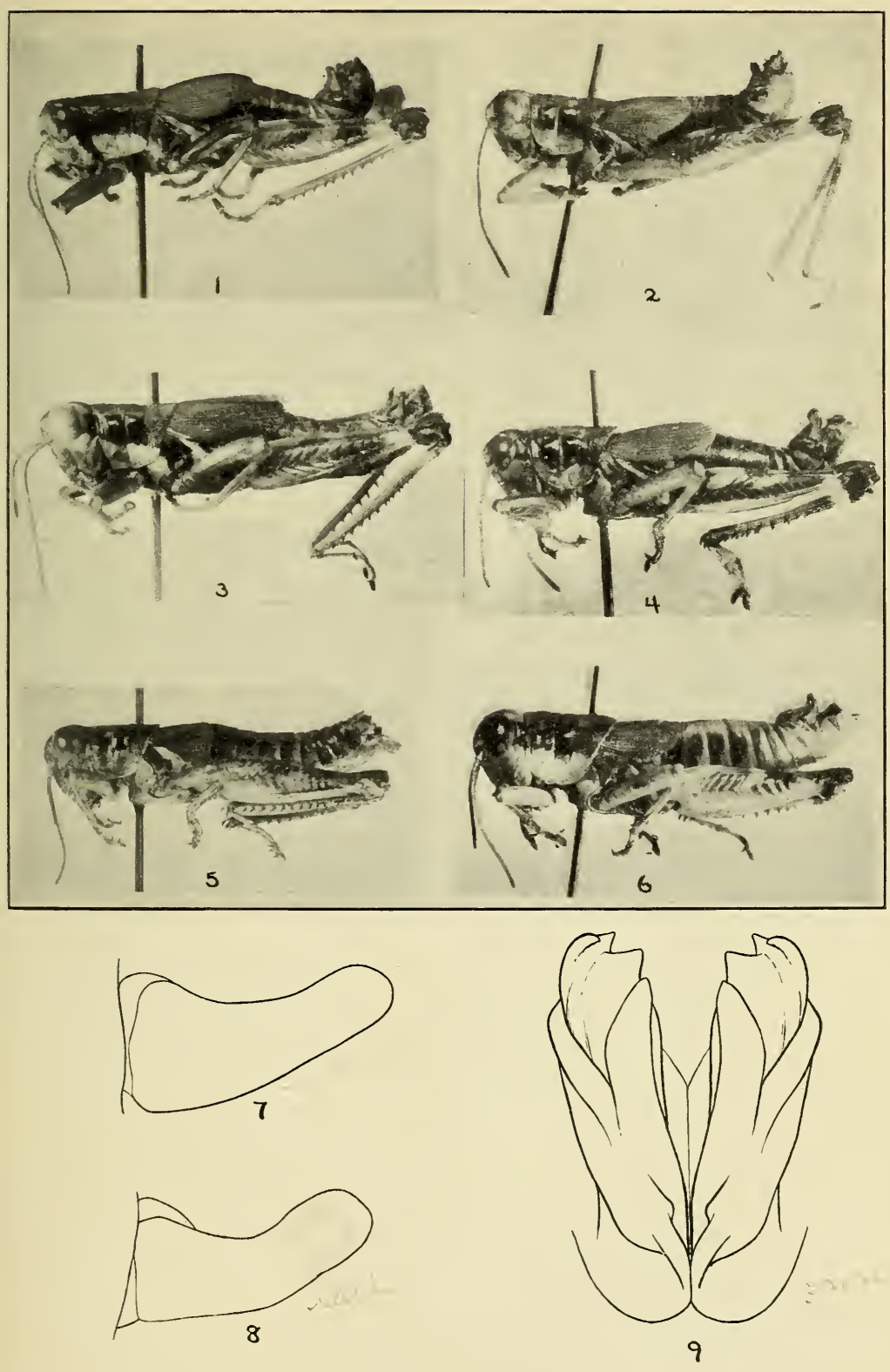

HEBARD—NORTH AMERICAN MELANOPLI 



\section{PUBLICATIONS}

\section{$\mathrm{OF}$}

\section{THE AMERICAN ENTOMOLOGICAL SOCIETY}

Procendings of The Entomological Society of Philadelphia

This series contains most of the important papers on American structural and systematic entomology.

Volumes I to VI, 1861-1867 (Out of print and cannot be supplied).

Transactions of The American Entomological Societr

A quarterly containing important papers on structural and systematic entomology.

Volumes I to IV, 1867-1873 (Out of print and cannot be supplied).

Volume $\mathrm{V}$ to present (in sets only, but most volumes are available separately) not ineluding Supplement to volume XIV. Price on application.

Subscription price per annual volume, $\$ 5.00$.

\section{Memoirs of The American Entomological Society}

An irregular serial, containing monographic papers by students of authority in their respective subjects.

No. 1. The Cresson Types of Hymenoptera. By Ezra T. Cresson. 1916. 141 pp. Price $\$ 2.00$.

No. 2. The Blattidae of North America, North of the Mexican Boundary. By Morgan Hebard. 1917. $284 \mathrm{pp}$., 10 pls. Price $\$ 4.50$.

No. 3. A Venational Study of the Suborder Zygoptera. (Odonata), with Keys for the Identification of Genera. By Philip A. Munz. 1919. $78 \mathrm{pp}$, 20 pls. Price $\$ 1.50$.

No. 4. The Blattidae of Panama. By Morgan Hebard. 1920. 148 pp., 60 pls. Price $\$ 2.50$.

No. 5. The Types of Hymenoptera in the Academy of Natural Sciences of Philadelphia other than those of Ezra T. Cresson. By Ezra T. Cresson. 1928. 90 pp. Price $\$ 2.00$.

No. 6. Revision of the Rhipiphoridae of North and Central America (Coleoptera). By Ezekiel Rivnay. 1929. 68 pp., 4 pls. Price $\$ 2.00$.

No. 7. A Revision of the Dipterous Family Rhagionidae (Leptidae) in the United States and Canada. By Mortimer D. Leonard. 1930. $182 \mathrm{pp}$., 3 pls. Price $\$ 4.50$.

No. 8. The Eumastacinae of southern Mexico and Central America. By James A. G. Rehn and John W. H. Rehn. 1934. 84 pp., 6 pls. Price $\$ 2.50$.

\section{Practical Entomologist}

A journal established in $\mathbf{1 8 6 5}$ for distribution among the farmers and agriculturists. This was the first journal of economic entomology published in America. Volumes I and II, 1865-1867, all published. Price $\$ 4.00$ per set.

\section{Entomological News}

A monthly, introduced in 1890 , containing the scientific proceedings of the meetings of the Society, a list of current American entomological literature, and articles of interest to all entomologists. Annual subseription, domestic $\$ 3.00$, foreign $\$ 3.25$.

Separates of papers published in the Proceedings and Transactions, if in stock, can be supplied at prices given in our price lists, which may be secured upon application, stating order or orders desired. The Society has also inaugurated a system of subscription to papers published by it on individual orders; which arrangement is of material benefit to the student who desires promptly the literature on any special group, but who does not desire to subscribe to entire volumes of the Transactions. Detailed information supplied upon application.

In sending subscriptions or in making inquiries relative to publications, address:

THE AMERICAN ENTOMOLOGICAL SOCIETY, Academy of Natural Sciences, Philadelphia, Pa.

On the date of issue the present publication was mailed to the following institutions with the request that it be placed in their libraries for reference:

Société Entomologique de France

Deutsche Entomologische Gesellschaft

Società Entomologica Italiana

Entomological Society of London

Entomological Society of Ontario
American Museum of Natural History

Boston Society of Natural History

California Academy of Sciences

Field Museum of Natural History

Smithsonian Institution 


\title{
NEW GENERA AND SPECIES
}

\author{
$\mathrm{OF}$ \\ MELANOPLI
}

FOUND WITHIN THE UNITED STATES AND CANADA

(ORTHOPTERA; ACRIDIDAE)

Parts VII,-IX

BY

Morgan Hebard

From the Transactions of The American Entomological Society, LXII, 167-222

Issued

SEP $8-1936$

No. 1017

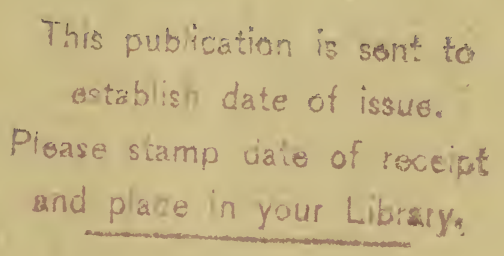

This is a separatum from the TRANSACTIONS and is not a reprint. It bears the original pagination and plate numbers, and was placed on sale at the price quoted and library copies mailed at Philadelphia on the above date of issue. 



\title{
NEW GENERA AND SPECIES OF THE MELANOPLI FOUND WITHIN THE UNITED STATES AND CANADA
}

\author{
(ORTHOPTERA: ACRIDIDAE)
}

\section{PARTS VII, VIII AND IX}

\author{
BY MORGAN HEBARD
}

(Plates XII-XVII)

Unless otherwise noted the material here recorded is in the author's collection, except the series collected by Rehn and Hebard, which latter has been shared with the Academy of Natural Sciences of Philadelphia.

The author's publications on the North American Melanopli began in 1917 with a study of the Mexican Melanopli, published in the proceedings of the Academy of Natural Sciences. The first of the present series was published in 1918 and the last in 1935, ${ }^{*}$ all in the Transactions of the American Entomological Society except the description of a single new species of Melanoplus, published in the Entomological News in 1923.**

In the last two parts it was found advisable to consider all of the species of the seven Groups concerned, and this method has been followed in parts VII and IX of the present study. Assistance of the utmost value has been given through the kindness of R. H. Beamer of the University of Kansas, F. B. Isely of Trinity College, Nathan Banks of the Museum of Comparative Zoology and the authorities of the United States National Museum.

\footnotetext{
* Trans. Am. Ent. Soc., Lx, pp. 337-390.
}

** Ent. News, xxxiv, p. 260. 


\section{PART VII. THE INDIGENS GROUP OF THE GENUS MELANOPLUS}

So similar are the species of this group in many features and so much individual variation is shown in several of the limited number of characters by which the species and races are distinguishable that their proper association has always been most difficult. It was for this reason that we have postponed a final report on them until we have gone over all the species of the short-winged Melanopli, examining the penis of each with a view to finding out just how much help the characters of that organ might afford. Nowhere in these studies has the structure of the penis proved more valuable in placing the actual number of species and races represented.

We find that in past literature the confusion has been very great, and though all existing synonymy was correctly established by us in $1928,{ }^{1}$ we at that time not only made many errors in referring to indigens and oregonensis triangularis specimens which were actually otherwise referable, but we also recognized four races of oregonensis, whereas that species has but a single northern race, oregonensis triangularis, while marshalli represents a distinct though very closely related species of which ascensor is a weakly defined but apparently separable western race. Although it is evident that we made a series of serious errors we can state definitely that, without recourse to the characters of the penis, little better could ever be expected. Thus in the material referred incorrectly to indigens all other features except those of the penis showed only differences which might easily and were then believed to indicate mere individual variation and the individual variation in the shape of the supra-anal plate is so unusually great that at that time we referred incorrectly to oregonensis triangularis those specimens in which the supra-anal plate is very much shorter than is normal for indigens. With the differences of the penis as a guide, however, it is now evident that the richness of coloration of the ventral surfaces of the caudal femora in those specimens is a safe index in distinguishing them from oregonensis triangularis, which dif-

\footnotetext{
1 Proc. Acad. Nat. Sci. Phila., Lxxx, pp. 266 to 271.
} 
ference is however well known to be usually an utterly unsafe feature except in conjunction with other more stable characters and we consequently repudiated it at that time.

In associating the forms nearer oregonensis even more misleading were the few (and well known to be unsatisfactory) external features by which marshallii could be separated from oregonensis. The average slightly narrower male supra-anal plate and average smaller size of the former were the strongest reasons we had for giving that insect even racial recognition, and the Wyoming series which were smaller than is usual for oregonensis appeared to indicate intergradation. As a matter of fact large series from Colorado and Utah are now found to have a penis sufficiently differently constructed to warrant specific separation and our Wyoming material (all from the northern portions of that State) is as clearly representative of oregonensis. Though we have no males from central or southern Wyoming, our knowledge of the distribution of other species in that State enables us to predict that oregonensis will probably be found in the mountains at sufficient elevation south to central eastern and southwestern Wyoming, while that species is as probably supplanted by marshallii in similar environment throughout southeastern Wyoming. The distribution westward and intergradation between typical marshallii and marshallii ascensor can only be definitely charted when material of the species from a number of stations in the Uinta Mountains has been secured, though we believe that intergradation will be found in the mountains in the vicinity of the Green River in extreme northwestern Colorado and northeastern Utah.

It is particularly interesting to note that the ventral surfaces of the caudal femora are dull buff, tinged with orange only in intensive specimens of some series, in all of the species of this group except in indigens. These areas are rich reddish or orange in all well preserved specimens of the races of that species except in decidedly recessive or badly discolored specimens. ${ }^{2}$

\footnotetext{
${ }^{2}$ Such unfortunately is the case in the type of indigens indigens, which though dark in general coloration, has the ventral surfaces of the caudal femora dirty buff, this plainly the result of very poor preservation.
} 
1. Male subgenital plate with apex produced, coarsely transversely nodose or weakly binodose. Penis with very different development of dorsal lobes. Tegmina averaging narrower and so often more separated in both sexes. ........................................

Male subgenital plate with apex scarcely produced, feebly binodose. Penis with dorsal lobes very greatly produced as very large, horizontally spread, erect processes which in caudal aspect show an exceptionally great expanse (Pl. XII, fig. 10). Male cerci proportionately smaller, (not spatulate distad. Male furcula small and very strongly divergent. Tegmina averaging broader and so less separated in both sexes than is usual in the related species. Ventral surfaces of caudal femora dull yellowish buff.) Mountains of central western Idaho and adjacent Washington, in Canadian Zone........payettei new species

2. Male cerci not widened distad and there narrowing to the broad rounded apex; distal spatulation consequently not indicated. .............

Male cerci widened distad, the distal portion definitely (though rarely strongly) elongate spatulate. (Ventral surface of caudal femora, at least in external portion, richly colored (rich orange to deep red)

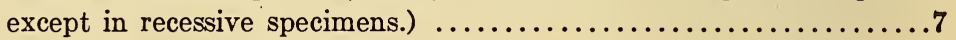

3. Ventral surface of caudal femora dull yellowish buff, tinged with orange

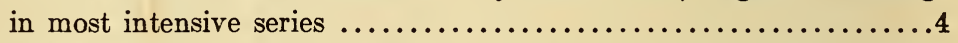

Ventral surface of caudal femora, at least in external portion, richly colored (rich orange to deep red), except in recessive specimens. Male furcula not heavy, less than one-third as long as the shield-shaped supra-anal plate. Penis with projecting portions of dorsal lobes very small and short, rounded (Pl. XIII, figs. 1 and 2). Missoula, (in western), Montana............. indigens missoulae new subspecies

4. Male supra-anal plate much longer than broad. ...............

Male supra-anal plate only slightly longer than broad, triangularly shield-shaped. Furcula and penis as in oregonensis oregonensis. Rocky Mountains in southern Alberta and northern Montana.

oregonensis triangularis Hebard

5. Male penis with dorsal lobes vertical, their apices not produced cephalad. ${ }^{3}$ (Male supra-anal plate shield-shaped to linguliform. Male furcula long and heavy, less than half as long as supra-anal plate, rarely divergent.) Rocky Mountains from northern Montana to (probably central eastern and) southwestern Wyoming and extreme southeastern Idaho, in Canadian Zone.

oregonensis oregonensis (Thomas)

Male penis with dorsal lobes projecting cephalad. ..............6

${ }^{3}$ Showing nearest approach to the type developed in indigens missoulae, see plate XIII, figs. 1 and 2. 
6. Male penis with dorso-proximal apices of dorsal lobes produced cephalad (Pl. XII, fig. 2). Male supra-anal plate shield-shaped to linguliform. (Male furcula variable.) Mountains of Colorado (and probably southeastern Wyoming) at high elevations, (probably in Canadian) and in Hudsonian Zone. .............marshalli marshalli (Thomas)

Male penis with dorsal lobes produced cephalad in dorsal portion but with a delicate integument the cephalic margin of which is vertical which joins this production to the basal portions (Pl. XII, fig. 5). Male supra-anal plate narrowly linguliform. (Male furcula long and heavy, less than half as long as supra-anal plate, rarely divergent.) Uinta and Wasatch Mountains of Utah in Canadian and Hudsonian Zones. .........................marshalli ascensor (Scudder)

7. Male penis with dorsal lobes broader and erect, with lateral surfaces flattened, dorsal outline rounded angulate in lateral aspect and apices not meeting above the parameres. (PI. XIII, fig. 3). Mountains of extreme western Montana (possibly only in southern portion) and throughout south-central Idaho. ........... indigens indigens Scudder

Male penis with dorsal lobes narrower, slanting inward, with moderately convex lateral surfaces and apices evenly rounded and meeting above the parameres. Mountains of extreme northwestern Montana (probably north-central Idaho) to northeastern Oregon.

indigens digitifer new subspecies

A key to the forms of as difficult a group as the present should be used as an aid, but not as the sole means to distinguish undetermined material. Additional series are badly needed from extreme western Montana, southern Wyoming, northeastern Utah, central and northern Idaho and eastern Washington, and without material from these regions the group can not be analyzed with finality. Thus portions of the limits of distribution of several races now remain far from definite, the peculiar condition of indigens occurring in the Payette Lake region of Idaho is assigned to the typical race only tentatively and the condition, known from only a female, which is present in eastern Washington, may well represent a distinctive and undescribed race or species.

Melanoplus marshalli marshalli (Thomas)

(P1. XII, figs. 1 to 3.$)$

1875. Pezotettix marshalli Thomas, Rept. Expl. and Surv. West of 100th

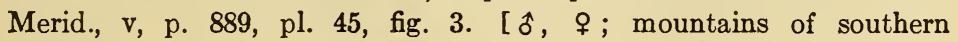
Colorado.]

1897. Podisma marshalli Scudder, Proc. U.S. Nat. Mus., xx, p. 108, pl. 7, fig. 9. [ $\hat{o}$, ㅇ; ; Mount Lincoln, Colorado, at 11000 to 13000 feet.]

TRANS. AM. ENT. SOC., LXII. 
I was correct in placing gillettei Scudder as a synonym in 1928 , but the insect is the typical race of a closely related species and not a race of oregonensis (Thomas) as I then supposed, as is now shown by study of the penis. The individuals which were then considered atypical representatives of "oregonensis marshalli", from the type of that organ, are seen to be referable to oregonensis oregonensis.

The present race is represented in the author's collection by material from many localities in the Rocky Mountains of Colorado, those with altitude given being from 10000 feet or over in the Hudsonian Zone. ${ }^{4}$ As already noted here, this race almost certainly occurs also in the mountains of southeastern Wyoming in similar environment. Mount Lincoln is a southern known limit. Extensive collecting in the San Juan Rockies of southwestern Colorado indicates that it is not present there, nor has it been found anywhere much west of the continental divide, though it is probably present in the mountains of northwestern Colorado.

The only material at hand which has not been previously correctly reported is the following.

Colorado: Trail Ridge Road in Rocky Mountain National Park, 10500 feet, VIII, 25, 1933, (G. Alexander), $1 \hat{\delta}, 1$ ㅇ․ North Park, VIII, 25, 1926, (B. B. Fulton), $2 \hat{\delta}, 2$. Summit of Gore Mountain near Toponas, VII, 10, 1927, (J. C. Bradley), $1 \hat{o}, 1$ ㅇ․

Melanoplus marshalli ascensor (Scudder)

(P1. XII, figs. 4 and 5.)

1897. Podisma ascensor Scudder, Proc. U.S. Nat. Mus., xx, p. 107, pl. 7,

fig. 8. [ $\hat{\jmath},+$; American Fork Canyon, [Wasatch Mountains,] Utah.]

As I have noted in $1928,{ }^{5}$ the type of this insect is an abnormal specimen in which, though adult, the form of the genitalia of the instar preceding maturity has persisted. This condition is very rare and is apparently developed only in species which, living in exceptionally rigorous environment, are forced in growth at an unusual rate, during the brief period in which the temperature is sufficiently high for them to move about and feed normally.

\footnotetext{
${ }^{4}$ See Hebard, Proc. Acad. Nat. Sci. Phila., Lxxxi, p. 375 (1929), for five Colorado records.

5 Proc. Acad. Nat. Sci. Phila., Lxxx, p. 269.
} 
At that time ascensor was also placed as a race of oregonensis, but study of the penis shows it to be a race of the closely related marshalli (Thomas).

The present insect is known only from the Bear River Mountains and the Wasatch Mountains of Utah, where it occurs in the Canadian and Hudsonian Zones at elevations from 6400 up to 10000 feet. It is apparently very scarce at the latter elevation and reaches its maximum abundance at distinctly lower elevations than does marshalli marshalli. It is now known from Logan Canyon south to American Fork Canyon. The Uinta Mountains of northeastern Utah, which extend east and west for a great distance, may carry this insect far east of its known range. The area of intergradation with typical marshalli can, however, not be determined until material from the mountains of northeastern Utah and northwestern Colorado has been secured.

The caudal tibiae are very dull weak glaucous, the "pale red" noted by Scudder being attributable to discoloration.

Only the following material, additional to the described pair, is known.

UTAH: Red Banks in Logan Canyon, Bear River Mountains, 6400 feet, VIII, 10, 1928, (Rehn and Hebard; very few in areas of "Cow Cabbage" (Wyethia amplexicaulis Nutt.), where Melanoplus utahensis Sc. was abundant and also in mountain herbage in open), 1o, 4ㅇ. Lake Catharine in Wasatch Mountains, 10000 feet, VIII, 19, 1924, (J. A. G. Rehn; granite slopes with firs and patches of Hudsonian Zone vegetation, only specimen seen), 1 ㅇ. Lake Martha in Wasatch Mountains, 9200 to 9700 feet, VIII, 19, 1924, (Rehn and Hebard; scarce in lush Hudsonian Zone herbage with much fir about), $4 \hat{\delta}, 8$. . Big Cottonwood Canyon in Wasatch Mountains, 7400 feet, VIII, 18, 1924, (Rehn and Hebard; Canadian Zone, like Melanoplus utahensis present in moderate numbers in lush herbage near stream on flat with much Aspen and spruce), $2 \hat{\delta}, 6$ ㅇ.

Melanoplus oregonensis oregonensis (Thomas)

1875. Pezotettix oregonensis Thomas, Wheeler's Rept. Expl. and Surv. West of 100th Merid., v, p. 888. [ $\delta$; northwestern United States. ${ }^{6}$ ]

1897. Podisma oregonensis Scudder, Proc. U.S. Nat. Mus., xx, p. 110, pl.

7, fig. 10. [ $\widehat{o}$, ㅇ : Yellowstone, Montana; Henry Lake, Idaho.]

${ }^{6}$ The original labelling "Oregon" was due to the inexact or inaccurate method often shown on natural history specimens secured on the early government expeditions to the Northwest.

TRANS. AM. ENT. SOC., LXIr. 
The type is lost but the original description of the male furcula and cerci give convincing evidence that Scudder correctly recognized the species in 1897. His material then recorded from Fort McLeod, Alberta, represents oregonensis triangularis Hebard. In 1932 the author reported a series from Logan Pass in Glacier Park, Montana, of which fifteen males were typical of oregonensis oregonensis or nearly so, one male representing oregonensis triangularis. The area of intergradation between these races evidently lies in northern Montana. West of the Bridger Range and the Continental Divide in southwestern Montana and southeastern Idaho, the present species is supplanted by the races of indigens Scudder and the related payettei here described.

The following unreported material is in the author's collection.

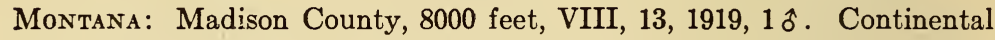
Divide in Beaverhead County, VIII, 18, 1925, 1 ㅇ.

Wyoming: Mount Washburn in Yellowstone Park, 9800 feet, VIII, 18, 1930, (E. R. Tinkham; on bare grassy ridge), $7 \hat{\delta}, 7 \stackrel{9}{9} 9300$ feet, VIII, 13 , 1922, (M. Hebard; moderately common on grassy north slopes), $3 \hat{o}, 1$; ; 8600 feet, VIII, 18, 1930, (E. R. Tinkham), $4 \hat{b}, 4$. . Dunraven Pass in Yellowstone Park, VIII, 31, 1924, (N. Criddle), $1 \hat{\delta}$. Grand Canyon of the Yellowstone River, 7900 feet, VIII, 12, 1922, (M. Hebard; in lush herbage), $3 \hat{\delta}, 3$ \% ; VII, 26, 1923, (B. B. Fulton), $2 \hat{\delta}, 2$ ․ Sheep Mountain in Gros Ventre Range, 10000 to 10500 feet, VIII, 4, 1922, (M. Hebard; few at 8000 feet, moderate numbers but local up to 10200 feet, a very few at 10500 feet, no Orthoptera whatever above that elevation, in Hudsonian Zone herbage above timber line), $15 \hat{\delta}, 11$ \%. Menor's Ferry in Jackson's Hole, 6500 feet, VII, 5 to 12 , 1922, (M. Hebard; local, moderate numbers in lush grasses and mountain plants in Aspen thickets in valley), $9 \hat{\sigma}, 6 \%$. Peak north of Death Canyon in Teton Range, 10000 to 11300 feet, VIII, 8, 1922, (M. Hebard; moderately common in Hudsonian Zone herbage, few in ArcticAlpine Zone grasses and plants), $13 \hat{\jmath}, 8 \%, 2$ juvs. Death Canyon in Teton Range, 8600 feet, VIII, 7, 1922, (M. Hebard; very few in mountain meadow of lush vegetation), 3 q .

IDAHO: Henry Lake, VII, 28, 1930, $2 \hat{o}$; VIII, 1883, (L. Bruner), $4 \hat{o}, 5$ ㅇ. Georgetown Canyon in Aspen Range, 6650 to 6800 feet, (Rehn and Hebard; few in Canadian Zone undergrowth in Aspen thickets.

Melanoplus oregonensis triangularis Hebard

1928. Melanoplus oregonensis triangularis Hebard, Proc. Acad. Nat. Sci. Phila., Lxxx, p. 269, pl. 25, fig. 5. [ $\hat{\jmath}$, $\$$; Middle Fork of Old Man's River (near Fort McLeod) in Livingston Range (type locality) and Waterton, Alberta; Swan Range and Flathead Lake, Montana.] 
A male in a series in which the majority represent oregonensis oregonensis (Thomas) from Glacier Park, Montana, was recorded by the author in 1932 .

The material originally recorded as this race from Idaho is now known, from study of the penis, to represent indigens Scudder.

Melanoplus indigens missoulae new subspecies

(P1. XII, fig. 6; pl. XIII, figs. 1 and 2.)

1928. Melanoplus indigens Hebard, Proc. Acad. Nat. Sci. Phila., Lxxx, p. 267. [Only the series of eight males and eleven females from Missoula, Montana.]

Hitherto I had supposed that a single variable species, indigens, nearest in relationship to oregonensis, existed. Study of larger series now show that there are actually two species, one of which divides into three geographic races. The characters shown by the penis are by far the most important in distinguishing these.

The present race resembles typical indigens closely and in external characters can be distinguished only by the male cerci which do not widen distad. The dorsal lobes of the penis, however, are distinctive, their apices represented by very small rounded projections.

Realizing that the cerci agree with those of oregonensis and that the penis is of very similar type, it is evident that missoulae represents a condition diverging from indigens toward oregonensis. I do not, however, feel justified in placing either indigens or missoulae as a race of that species.

Type.-ô ; Missoula, Montana. August 2, 1904. [Hebard Collection, Type No. 1268].

Indistinguishable from typical indigens in all external characters except the cercus. Size and form medium. Vertex moderately broad with distinct lateral carinae, its dorsal surface concave. Frontal costa with weak blunt lateral carinae, moderately impressed at median ocellus. Pronotal disk with a fine medio-longitudinal carina on metazona, absent (or rarely very weakly indicated, this more frequent in females) on prozona. Prosternal spine moderately elongate, rather slender, with apex well rounded. Tegmina elongate ovate (with apices varying from broadly to rather sharply rounded, the normal condition intermediate), separated by a brief interval, length very definitely less than that of pronotum. Apex of abdomen moderately thickened. Furcula represented by a pair of small, slender, moderately

TRANS. AM. ENT. SOC., LXII. 
divergent (varying in paratypes to very feebly divergent) projections, over twice as long (shorter in one paratype) as the width of one of them just beyond the thickened areas from which they spring. Supra-anal plate shield-shaped, median and lateral processes longitudinally concave, the former with concavity broader and weaker distad, transverse carinae absent; lateral margins moderately thickened (this stronger in one paratype) for some distance opposite cercal bases. Cercus with length approximately twice proximal width, curved feebly dorsad; dorsal and ventral margins weakly convergent proximad, nearly parallel mesad, converging and rounding into the truncate distal margin, external surface definitely (to not at all) impressed distad. ${ }^{7}$ Penis with ventral lobes ${ }^{8}$ prominent, their caudal margins moderately oblique convergent, then vertical to base and briefly separated; parameres acute, projecting over half distance to apices of dorsal lobes; the latter with portions projecting dorsad very small and rounded. 9 Subgenital plate produced in a broad blunt rounded apex which occasionally shows a small median impression.

\section{Allotype.- $\%$; same data as type. [Hebard Collection].}

Very similar to male but larger and more robust. Vertex broader with impression weaker. Tegmina broader but separated by a greater interspace. Prosternal spine shorter, broader and decidedly heavier. Ovipositor apices of medium length and moderately curved, dorsal surface of dorsal valves weakly nodose proximad, the lateral margins acute, the external subcrenulate but very feebly and bluntly toothed proximad.

The measurements of the extremes are given in a series of eight male and fourteen female paratypes bearing the same data as the type and one female paratype from the same locality taken August 11, 1931, by M. W. Sanderson, belonging to the University of Kansas. Length of body $\hat{\delta} 18$. to 19.3 , $q 22$. to 23.7 ; length of pronotum 0 i 4.7 to 4.9 , o 5 . to 5.6 ; caudal width of pronotal disk $\hat{\delta} 2.8$ to 2.9 , $q 3.5$ to 3.8 ; length of tegmen $\hat{\delta} 3.7$ to 4.2 , 94.5 to 4.8 , length of caudal femur $\delta 9.8$ to 10 , $q 11.1$ to $12 . \mathrm{mm}$.

Generally dark brown, the paler brown recessive individuals with color pattern weaker. A broad darker postocular band extends to the principal sulcus on the pronotal lateral lobes. Face, ventral portion of pronotal

7 In indigens indigens the male cercus is spatulate distad, definitely broader than the median section, the ventral margin rounding more sharply into the distal than does the dorsal margin, the external surface more generally flattened.

8 In the last paper of this series, Trans. Amer. Ent. Soc., Lx, p. 339, (1935), the ventral lobes were termed "the base of the penis and the lateral margins of the shaft", the dorsal lobes "the surmounting pair of processes or the dorsal processes" and the parameres "the median processes" or the dorsal lobes and parameres "the two pair of dorsal processes".

${ }^{9}$ In indigens indigens the dorsal lobes of the penis are decidedly larger, with lateral surfaces flattened and dorsal outline rounded-angulate in lateral aspect, see plate XIII, figure 3 . 
lateral lobes, dorsum of abdomen, three markings on caudal femora and ventral surface buffy or grayish, often very finely tessellate with brown except ventrad. Tegmina unicolorous brown. Caudal femora ventrointernally and ventrad yellowish buff, orange only in a few intensive males, ventro-external portion dull scarlet red, paler in some specimens and yellow buff in the two most recessive females. Caudal tibiae buffy, suffused with brown in the most intensive females, spines black.

Melanoplus indigens indigens Scudder

(P1. XII figs. 7 and 8; p1. XIII, fig. 3.)

1897. Melanoplus indigens Scudder, Proc. U.S. Nat. Mus., xx, p. 211, pl. 14, fig. 4. [ ô ; Salmon City, Idaho.]

When recording the series here described as indigens missoulae in 1928, the material of payettei here described from the Payette Lake region in Idaho and the Blue Mountains of Oregon was incorrectly referred to indigens, while in the series then described as oregonensis triangularis, material of the present insect from Soldier, McCall and Evergreen, Idaho, was also incorrectly referred to that race. These mistakes were mainly due to the fact that, at that time, the (normally concealed) penis was not known to possess characters of the highest value in distinguishing the species and races of the present group.

Under indigens missoulae and indigens digitifer here described, comparisons are made with indigens indigens. The species is plastic and the few external differences which distinguish its races could easily be attributed to individual variation if not associated with the differences shown by the penis. ${ }^{10}$

Specimens Examined. $-56 ; 22$ males and 34 females.

Montana: Rocky Mountain Divide, IX, 29, 1907, $1 \hat{o}$.

IDAH0: Salmon City, VIII, 1883, (L. Bruner), $1 \hat{\delta}$, type, [Hebard Cln. Type No. 102]. Morgan Creek in Salmon River Range, VIII, 15, 1928, (Rehn and Hebard): summit of pass, 7575 feet, (Very small colonies in scanty Canadian Zone undergrowth of Lodge-Pole Pine and fir forest), $2 \hat{o}$, 4 ; ; upper creek, 7300 feet, (same environment but more undergrowth), $1 \hat{o}, 1 \%$; hillside at 7080 feet, (occasional on open hillside covered with low mountain plants and some sage brush), $3 \hat{o}, 10$ \% ; upper canyon, 6650 feet, (locally in sage brush particularly near Aspen thickets), $5 \hat{\delta}, 12$. Galena Summit, Sawtooth Range, 8750 to 9225 feet, VIII, 17, 1935, (M. Hebard; decidedly scarce on slopes at summit with fine grasses and some sage brush,

${ }^{10}$ As the dorsal lobes of the penis show the greatest amount of differentiation, but in life are somewhat fleshy, it must be remembered that distortion in drying may occur. Such is, however, fortunately a rare occurrence.

TRANS. AM. ENT. SOC., LXII. 
in grasses and among Hudsonian Zone plants near Fox-Tail Pines and firs), $3 \hat{o}, 4$. Mountains north of Soldier, (L. Bruner), $4 \hat{o}, 113 \%$. McCall, Big Payette Lake, 5000 feet, VIII, 11, 1910, (Rehn and Hebard; pair only found after long search in heavy conifer forest where only undergrowth was a few grasses and wild strawberry plants), $1 \hat{\delta}, 1$ \% (atypic). Evergreen in Washington County, 3600 feet, VIII, 12, 1910, (Rehn and Hebard; only specimens found after long search in or near thickets of wild rose and Spiraea betulifolia in conifer forest on lower edge of Canadian Zone, with more Western Yellow Pine than higher up), $1 \hat{\delta}, 2$ ㅇ (atypic).

The richly colored males from McCall and Evergreen are atypical and may indicate the presence in central western Idaho of an undescribed geographic race. The supra-anal plate and cerci are decidedly shorter than normal while the dorsal lobes of the penis show distinct livergence toward the type developed in indigens digitifer. The specimens from Evergreen are, in addition, unusually small.

It is noteworthy that the species was not found below 6000 feet in either the Salmon River or the Sawtooth Ranges.

Melanoplus indigens digitifer new subspecies

(P1. XII, fig. 9; pl. XIII, figs. 4 and 5.)

1897. Melanoplus saltator Scudder (in part), Proc. U.S. Nat. Mus., xx,

p. 262. [ 9 ; Loon Lake in Colville Valley, Washington.12]

1928. Melanoplus indigens Hebard (in part), Proc. Acad. Nat. Sci. Phila., Lxxx, p. 268. [Bear Mountain, Idaho.]

This race in external characters is apparently indistinguishable from indigens indigens except in average differences in the male cercus, which appendage in the present species shows more individual variation than is usual in the genus. The races of indigens can indeed be said to be safely distinguished only by the characters shown by the penis and differences from the normal in that organ are here noted for three males recorded as atypical indigens indigens.

Typical material of indigens digitifer differs from indigens indigens in having the dorsal lobes of the penis more elongate,

11 One male in form of the penis shows divergence toward indigens digitifer.

12 This female quite closely resembles the females from Haines, Oregon, except that it is larger than the largest, with tegmina broader and frontal costa with lateral carinae more prominent. Though quite possibly representing the present race, this assignment can not be made with any certainty until males from that region have been secured. 
more lateral in position, slanting to their attingent apices, widening gradually distad with lateral surfaces definitely convex (instead of vertical and flattened) and distad finely shagreenous and evenly rounded (without indication of angulation).

In the Montana and Idaho males some tendency toward indigens indigens is shown in the dorsal lobes of the penis having their lateral surfaces less convex and the lateral outline of their apices with weak but appreciable rounded angulation indicated in rare specimens of the Haugan series. More material from other localities in the mountains of Idaho and extreme western Montana is needed to decide the geographic significance of the present insect. It is surprising to find it at the more eastern localities noted, there being apparently little geographic or zonal significance when these are considered in conjunction with the localities from which indigens indigens is known.

Type.-ô ; Haines, Oregon. July 10, 1931. (R. H. Beamer). [Hebard Collection, Type No. 1269].

Generally as here described for type of indigens missoulae, except as follows. Pronotal disk (usually) with medio-longitudinal carina very weakly indicated on prozona (but varying to obsolete there); transverse sulci sometimes (but not always) slightly more distinct. Furcula very feebly divergent (varying in paratypes to moderately divergent). Supra-anal plate with lateral margins showing a moderately decided thickening opposite cercal bases. Cerci with margins more convex in distal portion and resultantly more spatulate, which portion includes over half the cercus and has its outer surfaces impressed, more evenly rounded at apex with ventral margins rounding dorsad distinctly more definitely than in indigens indigens. ${ }^{13}$ Subgenital plate produced in a heavily binodose apex (the apex in paratypes varying from this condition to transverse and dimpled or broad and bluntly transverse). Dorsal lobes of penis distinctive, as described above.

\section{Allotype.- + ; same data as type. [Heband Collection].}

Differs from male as does this sex of indigens missoulae. Females of the races of indigens are apparently indistinguishable.

The measurements of the extremes in the nine males and ten females from Haines, Oregon, are: Length of body of 17. to 20.5 , $q 18.5$ to 21.8 ; length of pronotum $\hat{o} 4.8$ to 5 ., $\$$ 5. to 5.3 ; caudal width of pronotal disk is 2.7 to 2.9 , $q 3.3$ to 3.4 ; length of tegmen $\delta 2.7$ to 3.8 , o 3.4 to 4.4 ; length of caudal femur of 10 . to 10.9 , o 11.8 to $12.3 \mathrm{~mm}$.

\footnotetext{
13 Only in a few of the males from Haugan, Montana, is distal truncation of the cercus shown.
}

TRANS. AM. ENT. SOC., LXII. 
The coloration of the series from Haines, Oregon, is much as in indigens missoulae except that the buffy areas show a very weak dull olivaceous tinge, while the caudal femora are dark brown on the external pagina and distad, dull brick red elsewhere externally, but brighter red internally and ventrad in males and in some rich ox-blood red there. Usually richly colored the series show decided variability and the most recessive females from Haugan, Montana, lack all red coloration and are as pale as the most recessive females of indigens missoulae discussed under that race.

Specimens Examined.-19 males and 22 females.

Montana: Haugan, VIII, 9, 1931, (Beamer, Anderson, Nottingham and Peters), $17 \hat{\delta}, 18 q$, [Univ. of Kansas and Hebard Clns.]. Taft, VII, 1929, (E. R. Buckell), 1 ô, 1 \% , [Can. Nat. Cln.].

IDAHo: LoLo Trail on Bear Mountain, 6000 feet, VIII, 1902, (C. V. Piper), 2 $\delta, 3$ ㅇ, [U.S.N.M. and Hebard Cln.].

Washington: Loon Lake in Colville Valley, VII, 23, 1882, (S. Henshaw), $19,{ }^{14}$ paratype of Melanoplus saltator Scudder, [Mus. Comp. Zool.].

Oregon: Haines, VII, 10, 1931, (R. H. Beamer), $9 \hat{o}, 10$ 으, type, allotype, paratypes, [Hebard and Univ. of Kansas Clns.].

Melanoplus payettei new species (P1. XII, fig. 9; pl. XIII, fig. 6.) 1908. Melanoplus indigens Hebard, (in part not of Scudder, 1897), Proc. Acad. Nat. Sci. Phila., Ixxx, p. 268. [ $\hat{o}$, + : Payette Lake Region, Idaho; Blue Mountains, Oregon.]

The discovery of an exceptionally distinctive penis in males of the present insect has come as a great surprise. Generally the resemblance to indigens is very close, but now that a distinct species is known to be represented, the following inconspicuous but definite external differences are noted: tegmina averaging broader in both sexes (with consequently narrower interspace) and tapering more definitely in distal half to the apex; male cerci proportionately smaller, not widened distad (the latter a feature, however, which distinguishes indigens missoulae as well), and subgenital plate with apex very briefly (instead of prominently) produced.

In the entire series of payettei the ventral surfaces of the caudal femora are buffy, very faintly tinged with orange only in males, whereas in the few males of indigens from the Payette Lake region those areas are deep or bright nopal red. This feature is, however, known to be often unreliable and in indigens

14 See footnote 12 . 
a few of the specimens from other parts of its range are colored the same as in payettei.

Type.-ô; McCall, Big Payette Lake, Idaho. Elevation 5000 feet. August 11, 1910. (M. Hebard). [Hebard Collection, Type No. 1266].

Generally similar to large individuals of indigens except as noted above. Vertex very slightly more produced than is normal in that species, it and the frontal costa as here described for indigens missoulae. Pronotal disk with fine medio-longitudinal carina on metazona, still finer but distinct on prozona. Prosternal spine moderately elongate, rather slender, tapering evenly to the rather sharply rounded apex. Tegmina ovate, lateral margins in distal half convergent to the rounded apices, separated by a very narrow interspace, length very definitely less than that of pronotum. Apex of ablomen moderately thickened. Furcula a pair of small, slender, very strongly divergent projections, over twice as long as width from beyond the thickened areas from which they spring. Supra-anal plate shieldshaped, median and lateral portions longitudinally concave, transverse carina absent (but indicated in one paratype), lateral margins thickened in proximal portion but only slightly more so (or not at all) opposite cercal bases. Cercus proportionately distinctly smaller than in indigens, length slightly over twice proximal width, nearly straight but directed slightly dorsad of caudad; dorsal margin declivent proximad, then subparallel to ventral margin, distad rounding into the convex apex slightly more broadly than does the ventral margin; distal portion as broad as the median, its entire surface feebly impressed. Penis with dorsal lobes developed into two very large, erect, transverse, adjacent, fleshy plates (see plate XII, figure 10 ), one minute aciculate pair of parameres visible meso-proximad. Subgenital plate with apex scarcely produced, very weakly and bluntly binodose.

\section{Allotype. - $\%$; same data as type. [Hebard Collection].}

Differs from male as does this sex of indigens missoulae, described on page —. Tegmina similar to those of male (but in some paratypes proportionately smaller, more nearly oval and slightly more widely separated).

The measurements for the extremes in the series (all from McCall except the smallest female, from Evergreen) are: length of body $\hat{o} 20$. to 21., ㅇ 23.8 to 27.2 ; length of pronotum ô 4.7 to 4.9 , o 5.4 to 6 .; caudal width of pronotal disk $\hat{o} 2.6$ to 2.7 , ㅇ 3.7 to 3.8 ; length of tegmen $\hat{o} 4.4$ to 3.8 , o 4.7 to 5.4 ; length of caudal femur $\hat{o} 11$. to 11.5 , o 13.8 to $14.2 \mathrm{~mm}$.

Coloration much as in indigens missoulae as described on page 175, except as follows. In the present small series little intensification and no recession is shown. Caudal femora sometimes appearing gray brown with darker oblique suffusions (instead of dark with paler areas as is sometimes

TRANS. AM. ENT. SOC., IXII. 
the case in indigens), internally and ventrad buffy, the ventro-external section with a very faint trace of orange in the majority of the males. Caudal tibiae buffy, usually with a mere trace of a glaucous tinge.

Specimens Examined.-14; 6 males and 8 females.

IDAнo: McCall on Big Payette Lake, 5000 to 5050 feet, VIII, 11, 1910, (Rehn and Hebard; though not numerous the most abundant grasshopper in the dry grasses, wild rose and other bushes in the Western Yellow Pine, Douglas Fir and Western Tamarack forest of the Canadian Zone), $5 \hat{\text { o }, 6}$ 우, type, allotype, paratypes. Evergreen, 3600 feet, VIII, 12, 1910, (Rehn and Hebard; in rather similar but less boreal environment on lower edge of Canadian Zone), 1 \% , paratype.

Oregon: Foothills of Elkhorn Range in Blue Mountains, 3800 to 4300 feet, VIII, 14, 1910, (Rehn and Hebard; in undergrowth, particularly Spiraea betulifolia, of steep pineclad hillsides), $1 \hat{\sigma}, 1 \%$, paratypes.

\section{PART VIII. DESCRIPTIONS OF A NEW RACE AND TWO NEW SPECIES}

This part includes the descriptions of a new race of Melanoplus foedus, which was studied in the work on the Orthoptera of Texas, now in course of preparation by the author, and the description of two unusually interesting new species of the Melanopli, one from the Cascade Mountains in Oregon, the other from the northern Sierra Nevada Mountains of California.

Melanoplus foedus iselyi 15 new subspecies (P1. XVII, figs. 1 and 2.) 1907. Melanoplus foedus Morse, Carnegie Inst. of Wash., Publ. 68, p. 48.

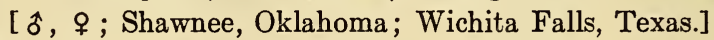

1926. Melanoplus packardii Rehn in Hubbell, (not of Scudder, 1878),

Proc. Oklahoma Acad. Sci., vi, p. 175. [ $\hat{o}, q$; Fort Sill, Oklahoma.]

1931. Melanoplus foedus fuviatilis Hebard (in part,16 not of Bruner, 1897),

Proc. Acad. Nat. Sci. Phila., LxxxıI, p. 187. [Cowley and Barber Counties, Kansas.]

1935. Melanoplus foedus fluviatilis Isely, Ent. News XıvI, p. 74. [Western

Parker County, Worth Ranck in Palo Pinto County and Hill County, Texas.]

Though in Kansas and Arkansas this race grades into foedus fluviatilis, series now before us from Oklahoma and northeastern Texas show such differences in average size and structure, colora-

${ }^{15}$ Named in honor of Professor F. B. Isely, who has aided the author greatly in his studies on the Orthoptera of Texas, now being prepared.

${ }^{16}$ Four specimens then suggested as possibly racially distinct. 
tion and marking that its racial validity is evident. The more yellow Texas individuals, though the resemblance is purely superficial, look indeed much like the yellowish specimens of Melanoplus differentialis (Thomas) which are also present there.

From typical foedus fluviatilis it is distinguished by the average larger size and more robust form, the buffy or yellow caudal tibiae and the postocular bar which is rarely solid, usually decidedly broken and sometimes subobsolete.

Like in the other races of foedus and in the related packardii Scudder, the variation in coloration and intensity of the dark markings is often great.

A large series of foedus fluviatilis from Kansas averages large for that race, the postocular bar is much more solid and prominent, the caudal femora ventrad and internally are rich orange in most of the dark individuals and buffy as in foedus iselyi only in recessive specimens, while the caudal tibiae are glaucous or pink, very rarely buff ${ }^{17}$ and never yellow buff as is always the case in richly colored typical examples of the present race. A single female from Barber County, Kansas, is here listed as atypical foedus iselyi, being in every way typical of it except that the caudal femora are rich pink.

Type. - ô; Weatherford, Texas. July 31, 1934. (F. B. Isely). [Hebard Collection, Type No. 1291].

Size large for the genus, form graceful but fairly robust. Vertex with surface concave between the prominent lateral carinae, frontal costa at and below the median ocellus similarly concave. Eye less than one and onehalf times as long as infra-ocular sulcus. Pronotum with medio-longitudinal carina prominent on metazona, obsolete elsewhere; transverse sulci distinct, averaging slightly more prominent than in foedus fluviatilis; caudal margin of disk obtuse angulate produced with apex broadly rounded. Organs of flight fully developed, well surpassing apices of caudal femora. Prosternal spine erect, elongate cylindro-conical, with apex sharply rounded. Furcula represented by small, strongly (rarely varying to moderately) divergent, slender, tapering fingers, each several times as long as its width beyond the thickened base. Supra-anal plate rather broadly shield-shaped; its lateral margins moderately elevated to opposite the cercal bases, thence straight convergent to the moderately acute apex; medio-longitudinal concavity bounded by carinae which extend to near apex, lateral portions concave. Cerci comparatively small, over twice as long as broad, tapering

\footnotetext{
${ }_{17}$ The few specimens known with caudal tibiae buff are all probably teneral or discolored.
} 
moderately in slightly over proximal half, remainder spatulate, expansion moderate with dorsal and ventral margins rounding into the truncate distal margin, the external surface in that section impressed. Penis as characteristic of the species; tubular section with a wide meso-caudal cleft, the dorsal margins forming two heavy dorsal (apical) lobes (the dorsal lobes) which do not surpass the lateral margins; from within project for some distance two fleshy, divergent fingers (the proximal pair of parameres), each having a delicate vertical lamella on its caudal surface which terminates abruptly proximad above the erect, usually concealed, elongate, vertical, plate-like pair of parameres, the apex of each being chitinous and concave. Subgenital plate ample, produced mesad to a sharply rounded apex.

\section{Allotype. - $\%$; same data as type. [Hebard Collection].}

Longer and more robust than male. Organs of flight fully as caudate. Ovipositor apices short, the dorsal pair strongly recurved, dorsal surface with distal portion concave, its lateral margins sharply raised and a similar cutting transverse ridge joining them and separating the distal from the flattened proximal dorsal portion.

General coloration primuline yellow (a buffy yellow) in Weatherford series, all but one from Palo Pinto County and specimen from Hill County, Texas. Head and cephalic limbs immaculate except for mere traces of a postocular suffusion and a disto-external fleck of dark brown on median femora. Pronotum with lateral lobes showing a dorsal line and two sulci for some distance brown (this the remaining traces of a broad postocular bar). Caudal femora with dorsal carinae and ventro-external carina distad with scattered dark brown dots, internal portion of dorsal surface with three dark brown suffused areas (the remnants of broad transverse bands) and distal arch and base of genicular areas dark brown. Tegmina pale and vitreous distad. Caudal femora internally and ventrad more richly colored, light orange yellow.

The male from Kingfisher County, Oklahoma, and the female from Colorado County, Texas, are decidedly less yellow, a dull buffy yellow, with broad but broken postocular bar on pronotal lateral lobes and transverse bars on dorsal surface of caudal femora incomplete but suggested throughout.

A male from Palo Pinto County, Texas, is similar but dirty buff in general coloration.

All of the other specimens (including Morse's series from Wichita Falls) are more like the latter, or generally buff tinged with tawny or wood brown, the postocular bar varying from faintly suggested to nearly solid but never as conspicuous as in typical foedus fluviatilis, the dorsal transverse bars of caudal 
femora crossing that surface or limited to its inner portion. The caudal tibiae range from primuline yellow to buffy.

Though ranging in general coloration from light yellow to brown, a distinctive and similar general facies is shown, widely different from that of the other races of foedus.

While foedus foedus Scudder is particularly apt to be found in restricted sand areas but often occurs as well on sandy plains or river bottoms to the west, both foedus fluviatilis and foedus iselyi are decidedly more local in distribution and are probably largely confined to sandy areas along rivers, streams and lakes, in the regions in which they occur. It is evident that the former is a northeastern and the latter a southeastern race.

\begin{tabular}{|c|c|c|c|c|c|}
\hline$\hat{\jmath}$ & 5 & 可兘 & 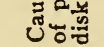 & 焉 & 远 \\
\hline Cowley County, Kansas. ..... & 29. & 6.8 & 3.7 & 23.5 & 15.7 \\
\hline Foss, Oklahoma. ............ & 31.5 & 7.2 & 3.8 & 25.1 & 17. \\
\hline Fort Sill, Oklahoma. (2) ..... & 25. -31.5 & $5.7-7.2$ & $3.1-3.9$ & $20.7-26.6$ & $13.8-16.7$ \\
\hline Weatherford, Texas. Type.... & 31. & 7.7 & 4. & 27. & 16.8 \\
\hline Palo Pinto County, Texas. (6) & $29.5-32.8$ & $6.9-7.8$ & $3.8-4$. & $25.6-27.1$ & $15.5-17.2$ \\
\hline $\begin{array}{c}\text { Hill County, Texas. ........... } \\
\wp\end{array}$ & 27.4 & 6.8 & 3.5 & 22.7 & 16.7 \\
\hline 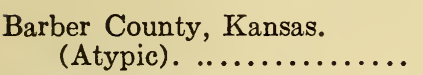 & 35.7 & 7.7 & 4.5 & 26.8 & 19.4 \\
\hline Foss, Oklahoma. ............ & 30.7 & 7.4 & 4.3 & 24.5 & 17.2 \\
\hline Chickasha, Oklahoma. ....... & 35.7 & 7.7 & 4.4 & 26.7 & 19.8 \\
\hline Weatherford, Texas. Allotype. & 34.8 & 7.9 & 4.7 & 28.5 & 18.7 \\
\hline Vernon, Texas. ............. & 31.8 & 7.2 & 4.2 & 25.7 & 18.2 \\
\hline Colorado County, Texas. .... & 32.7 & 7.3 & 3.9 & 26.8 & 16.8 \\
\hline
\end{tabular}

Specimens Examined.-58; 31 males, 26 females and 1 immature individual.

Kansas: Cowley County, 1114 feet, 1916, (R. H. Beamer), $3 \hat{o}$. Barber County, 1468 feet, (R. H. Beamer), 1 \%, (atypic).

Okгaнoma: Kingfisher County, VI, 1925, (T. O. Stringer), $1 \hat{\delta}$, Shawnee, 1000 feet, VIII, 26, 1905, (A. P. Morse), 10 o , 1812 ㅇ , [Mus. Comp. Zool.].

${ }^{18}$ Typical except that one male has pink, two females deep and eight females pale glaucous caudal tibiae.

TRANS. AM. ENT. SOC., LXII. 
Foss, VII, 1916, 1ㅅ, 1ㅇ. Chickasha, IX to X, 1928, (M. J. Brown), $1 \hat{\delta}$, 3 ㅇ, 1 juv. + , [Hebard and Brown Clns.]. Fort Sill, X, 22 to XI, 10, 1918, (T. H. Hubbell), 2 ô , 2 \% , [Acad. Nat. Sci. Phila. and Hebard Clns.].

Texas: Weatherford, VII, 31, 1934, (F. B. Isely; low lying weedy field, fifteen miles west of), $3 \hat{\delta}, 1$, type, allotype, paratypes. Worth Ranch, Palo Pinto County, VIII, 1, 1934, (F. B. Isely; on Brazos River), $6 \hat{\delta}$, paratypes, [Hebard and Isely Clns.]. Hill County, XI, 30, 1933, (F. B. Isely; on Brazos River), $1 \hat{o}$, paratype. Wichita Falls, Texas, 950 feet, VIII, 15 and 16, 1905, (A. P. Morse), $3 \hat{o}, 4$ ㅇ, [Mus. Comp. Zool.]. Vernon, VIII, 31, 1932, (F. B. Isely), $1 \hat{\delta}, 1$. Colorado County, IX, 5, 1927, (J. C. Bradley), 1 ㅇ.

\section{Dendrotettix hesperus new species}

(P1. XIII, figs. 7 to 9 ; pl. XVII, fig. 3.)

Examination by the author of a very dense conifer forest, largely of spruce, on the western ridges of the Cascade Mountains in central Oregon at approximately a thousand feet below and just west of McKenzie Pass, revealed the presence there of a single brachypterous Melanoplid and a female of Trimerotropis suffusa Scudder.

The former insect was seen to represent an unusual type, and vigorous efforts were made to find a male in the bushy undergrowth (with practically no grasses or plants) of the forest twilight where the first specimen had been located. Close general search, of necessity local due to lack of sufficient time, failed completely. It can only be assumed that the individual secured, now found to be representative of a striking new species of the genus Dendrotettix, was a stray into an unfavorable environment from some nearby colony and that other colonies might have been located, but only after very long search, probably in brushy areas (for there is every reason to believe that the insect is thamnophilous) on the borders of or in openings in the very dense forests.

Recent revision of the genus and its close allies by Rehn and Rehn ${ }^{19}$ enables me not only to place the present female with certainty as to genus, but also to describe the species satisfactorily from that sex alone; it is indeed the female sex which affords the most valuable generic diagnostic features as well as showing excellent specific characters in both the present species and its allies.

19 Trans. Amer. Ent. Soc., LXII, pp. 6 and 22, with 11 figures, (1936). 
The presence of a species of Dendrotettix in the Cascade Mountains of the Northwest comes as a great surprise, the genus not having been found previously west of southeastern Kansas and east-central Texas, or north of the former and northeastern Illinois. Nearest known related form in the Northwest is an isolated species of Zubovskya Dovnar-Zapolskij, present in the mountains of central-western Oregon.

Generally strongly suggesting Dendrotettix zimmermanni (Saussure), the present insect is easily separated by the less enlarged head with eyes less prominent and vertex slightly more produced, tegmina (though very similar in other respects) with humeral vein irregularly and poorly indicated proximad and not close to the prominent discoidal vein but the mediastine vein very conspicuous, the cross-veinlets heavier and more numerous, distal margin of ultimate tergite acute, coloration more uniformly dark with paler markings much more obscured, deep pink ventral surface of the caudal femora and yellow buff caudal tibiae.

The presence of a prominent and percurrent mediastine vein on the tegmina and rich coloration of the ventral portions of the caudal femora suggest instead the otherwise very much more widely separated Dendrotettix quercus (Packard).

The insect differs from Appalachia hebardi Rehn and Rehn much as it does from zimmermanni, but it differs still further in having the pronotal lateral lobes deeper, the tegmina broader with their disto-dorsal margin not regularly curved and the ovipositor valves much deeper with dorsal margins of dorsal pair much more strongly sigmoid. The caudal tibiae are, however, much the same color in these species and the ultimate sternite is acute-produced distad (this eliminating that character as of value in distinguishing Appalachia from Dendrottetix).

Type. $-q$; Alder Springs below and west of McKenzie Pass, Cascade Mountains, Lane County, Oregon. Elevation 3700 feet. August 24, 1928. (M. Hebard). [Hebard Collection, Type No. $1300]$.

Size medium, form robust. Head not proportionately as large nor eyes as protruding as is normal in this genus, more nearly normal for the Melanopli as in the genus Zubovskya but with interocular space broader. Interocular space broad, equalling the greatest dorsal ocular width,

TRANS. AM. ENT. SOC., IXII. 
fastigium very slightly broader than wide, deplanate declivent; frontal costa very slightly narrower at dorsal extremity than just below, lateral carinae fine but distinct, frontal costa narrowed and decidedly impressed at and just below median ocellus, then rapidly subsiding into face. Eyes normal, not conspicuously protuberant. Antennae moderately elongate. Pronotum truncate cephalad and caudad, the latter margin showing the barest trace of bilobation; disk feebly convex and smooth on prozona and mesozona, with medio-longitudinal carina briefly indicated only cephalad, very feebly subtectate on metazona to the decided medio-longitudinal percurrent carina with surface thickly and regularly impressopunctate; transverse sulci prominent but not as deep as in quercus; lateral lobes with dorsal length approximately one and one-quarter times greatest depth. Prosternal spine with large base, then strongly constricted and produced in a short slender apical portion with tip rounded. Tegmina represented by small oval lateral pads, margin more convex ventro-distad and distad than dorso-distad; longitudinal veins fairly regular with mediastine and discoidal the most prominent and humeral not decided or nearer the latter than those above it, transverse veinlets numerous, prominent and quite regular. Wings the merest rudiments, concealed by the tegmina. Tympana large, broad, also covered by the tegmina. Ovipositor valves of more normal type than in Appalachia Rehn and Rehn; dorsal pair broad, with dorsal margins strongly sigmoid and dorsal surface proximad deplanate and not abruptly cut off from the concave distal portion. Limbs delicate and not robust. Caudal tibiae with ten or eleven spines, both externally and internally.

Tegmina and limbs burnt umber (dark brown), the body still darker; caudal femora with merest traces of two very slightly paler chevron-shaped transverse bands. Ventral surface of body brownish buff. Caudal femora with ventral surface acajou red, paling internally. Caudal tibiae yellow buff, with spines and spurs black tipped.

Length of body 27.7, length of pronotum 5.8, greatest width of pronotal disk (caudad) 4.8, length of tegmen 4., greatest tegminal width 1.9, least (meso-proximal) distance between tegmina 3.2, length of caudal femur 11.9, width of caudal femur $2.65 \mathrm{~mm}$.

\section{Asemoplus sierranus new species}

(P1. XVI, figs. 3 to 5.)

This species is closely related to Asemoplus montanus (Bruner) (Pl. XVI, figs. 1 and 2), in general appearance being decidedly more similar to that species than to any other of the genus. It differs in the normal and consequently less enlarged head and pronotum, the much less broadly blunt apex of the fastigium and much narrower frontal costa which extends well below the median ocellus and is there moderately sulcate, the absence of extensive strikingly pale pronotal markings and medio- 
longitudinal dorsal abdominal stripe, longer cerci which are decidedly narrower proximad and broader distad, somewhat differently proportioned penis and differently shaped subgenital plate.

Females are smaller than that sex of montanus, differing quite as decidedly as the opposite sex in proportions of head and pronotum, narrower fastigium and frontal costa and coloration.

Type. - ô ; Harkness Peak, Plumas County, California. Elevation 8000 to 9200 feet. August 20, 1922. (M. Hebard). [Hebard Collection, Type No. 1301].

Size rather small, form rather slender, averaging smaller and less robust than montanus. Head and pronotum normal, not enlarged out of proportion to size of body. Interocular space very slightly less than one-half dorsal width of the large but not unusually protruding eyes. Fastigium weakly impressed, transverse but decidedly smaller and slightly more produced than in montanus. Frontal costa different as noted above. Pronotum with dorsum curving into lateral lobes with definition between these parts little indicated; medio-longitudinal carina very feeble cephalad, subobsolete mesad, distinct across metazona; transverse sulci distinct but decided only on lateral lobes; caudal margin of disk transverse, showing the faintest trace of bilobation; lateral lobes distinctly more elongate than in montanus, depth equal to length of prozona and mesozona. Prosternal spine moderately slender, tapering to the rounded apex. Tegmina represented by small narrowly oval pads which reach the caudal margin of the large tympana. Furcula represented by very slight projection of the weak thickenings of the tergite. Supra-anal plate shield-shaped, mesoproximal and lateral concavity pronounced, a small but prominent node present laterad opposite cercal bases. Cerci elongate, gradually narrowing to distal fourth, there moderately falcate and also curved moderately inward, apex very slightly widened with dorso-distal margin curving down to the sharply acute-angulate ventro-distal angle. Penis similar to that of montanus but exposed portions narrower and longer and dorso-lateral margins of dorsal lobes less flaring. Subgenital plate shorter than in that species, deeper lateral but only slightly more produced mesad and there terminated in a very weak, low, blunt tubercle.

\section{Allotype. - $\%$; same data as type. [Hebard Collection].}

Larger and decidedly more robust than male, differing from females of montanus as noted above. Agrees with male except as follows. Pronotal sulci even weaker dorsad. Caudal margin of pronotal disk feebly subbilobate. Prosternal spine shorter, stouter and blunter. Ovipositor normal.

General coloration of male dull dark brown. Pronotal lateral lobes sometimes slightly (rarely distinctly) paler, buffy brown ventrad below two large

TRANS. AM. ENT. SOC., LXII. 
shining blackish brown areas and often with a buff fleck dorso-cephalad of these. Tegmina unicolorous or sometimes with veins slightly paler than the ground coloration. Abdomen often definitely paler, more buffy, but never showing a medio-longitudinal dorsal pale band. Cephalic and median limbs buffy brown, caudal femora externally similar or somewhat paler but with genicular areas and margins of external pagina (this usually weaker on ventral margin of that area) blackish brown. Internal and ventral surfaces of caudal femora, ventral surface of body and caudal tibiae yellow buff (probably usually clear light yellow in life in the two latter areas), spines and spurs black.

Females are even more uniform in coloration and usually darker, with a short dorso-cephalic oblique buffy line on pronotal lateral lobes alone more conspicuously developed, the other paler brown areas usually generally darkened.

Length of body $\hat{o} 16.6$ to 18.4 , $q 20.1$ to 23.7 ; length of pronotum $\hat{o} 3.7$ to 4 ., 94.4 to 4.7 ; caudal width of pronotal disk $\hat{o} 2.3$ to 2.7 , ㅇ 3.8 to 4.3 ; length of tegmen $\hat{\delta} \mathbf{2 . 7}$ to 2.8 , $q 3.1$ to 3.8 ; length of caudal femur $\hat{o} 8.3$ to 9.2 , o 10.2 to $10.8 \mathrm{~mm}$.

A series of twenty-nine males and eleven females, paratypes, bear the same data as the described pair. These were found in the open forest of Sugar Pine, in chaparral mainly composed of Manzanita and Purshia tridentata (Pursh) but particularly in areas carpeted with a low chinquapin; very scarce on the south slopes but common on the summit of Harkness Peak, which is an extinct volcanic cone not distant from Mount Lassen. Males were found to leap quite vigorously but rarely attempted hiding down in the bushes and so were easier to capture than such thamnophilous insects as Aeoloplus, which are adepts at hiding as well as at leaping. The females were more difficult to locate, but were very sluggish and clumsy and consequently easy to capture when once seen.

\section{PART IX. A REVISION OF THE GENUS APTENOPEDES}

\section{APTENOPEDES Scudder}

1877. Aptenopedes Scudder, Proc. Boston Soc. Nat. Hist., xIx, p. 83. [Genotype, selected by Scudder in 1897.-Aptenopedes sphenarioides Scudder.]

This genus is peculiar to the lowlands of Georgia, extreme southeastern Alabama and Florida. Some of the species are widespread through the undergrowth of the pine forests in par- 
ticular, but also in the open in many types of natural undergrowth, over the Saw Palmetto flats and in the beach vegetation on the upper levels of the sea beaches. Still other species are now known which are much more local in distribution, limited to xeric areas of sandy scrub.

Three species were originally described, sphenarioides, rufovittata and aptera, of which the second was made a synonym of the first by Rehn and Hebard in 1916. ${ }^{20}$ In 1902 Rehn described clara, which was placed as a geographic race of sphenarioides by the present author in 1915 .

In 1920 the capture of remarkably large specimens on the rare Silver Palm, Coccothrinax argentea Lodd, in tropical Florida led the author to believe that a distinct race or species from the one found generally in the pine woods of that region might be represented. Laboratory examination, however, showed them to be identical except for size.

In 1930 and 1934 receipt of material found to include three new species led to further investigation, particularly as examination of the series which had been recorded as aptera by Rehn and the author, substantiated information which T. H. Hubbell had written me to the effect that that species divided into several races. Not until the present time has it been possible to examine the very large series of sphenarioides which has been assembled by Rehn and Hebard, and that is now found to include an undescribed race as well as series from certain areas which indicate definite progress toward the development of still other geographic races, the differentiation in which has not, in my opinion, as yet reached a degree sufficient to warrant nominal recognition.

The presence of so many species and races peculiar to so small an area shows that an unusual amount of plasticity once existed in the stock, which resulted in many changes and that a number of these have since become fixed. Of the species, only sphenarioides and aptera extended their distribution over much the greater part of the region occupied by the genus. These are not corresponding conditions occupying the same niche in the biota of the region, as both are often present at the same

\footnotetext{
20 By selection of the described (immature) female as type, the four males originally described as rufovittata actually representing aptera.
}

TRANS. AM. ENT. SOC., LXII. 
place even in the same environment; sphenarioides is, however, much more generally distributed, aptera apparently preferring slightly more xeric conditions and particularly associated with oak shoots and dwarf oaks in the undergrowth where it occurs. Only in central western and southwestern peninsular Florida is aptera supplanted by a similar appearing species, hubbelli, in which the penis plainly shows that higher than racial status exists. In addition, the particularly xeric areas of sandy scrub in peninsular Florida are, in different limited areas of quite similar environment, inhabited by three additional strikingly distinctive species.

Throughout the Sabalian Zone ${ }^{21}$ Aptenopedes is known except in the lowlands of South Carolina and southeastern North Carolina (but briefly invading the Lower Austral Zone in central eastern Georgia). Numerous assemblages of species and races peculiar to that Zone are likewise encountered in the Puer Group of the genus Melanoplus ${ }^{22}$ and in the genus Belocephalus. ${ }^{23}$

Contrary to Scudder's statement, none of the species of $A p$ tenopedes are actually apterous, all having minute, vestigial, scale-like tegmina, except sphenarioides and robusta, in which the tegmina are very small and very narrow, but extend to or across the face of the large tympanum.

The male subgenital plate (more accurately termed the genital lobe of the ninth sternite) is reduced externally to a narrow collar beyond the distal margin of the very large ninth sternite, revealing dorsad a large pallium. When the pallium is drawn back and the subgenital plate is deflexed, however, the latter is found to be developed internally in a very unusual manner. Large fleshy lobes are attached to it dorso-laterad, hinged to it so that they can swing upward and outward. This hinging is accompanied by intricate folding in sphenarioides, but is much more simple in the other species.

\footnotetext{
21 Proposed by Rehn and Hebard, Proc. Acad. Nat. Sci. Phila., 1916, p. 102.

22 Hubbell, Univ. of Michigan, Mus. Zool. Misc. Publ. 23, pp. 1 to 64, (1932).

23 Hebard, Trans. Amer. Ent. Soc., LII, pp. 147 to 186, (1926).
} 
The natural sequence and range of the species and races is as follows: ${ }^{24}$

aptera simplex new subspecies. Northeast coast of Florida.

aptera borealis new subspecies. Lowlands of eastern and southwestern

Georgia and northern Florida (except narrow northeast coastal areas), as far west as Carrabelle.

aptera aptera Scudder. Central peninsular Florida (except southwestern area).

aptera saturiba new subspecies. Xeric sandy areas in northeastern central peninsular Florida.

aptera coquinae new subspecies. Southwestern peninsular Florida (and probably Big Pine Key).

hubbelli new species. Western peninsular Florida (except northeastern area).

nigropicta new species. Xeric sandy areas northwest of Lake Okeechobee in peninsular Florida.

robusta new species. Xeric sandy areas near coast east of Lake Okeechobee in penisular Florida.

sphenarioides apalachee new subspecies. Southwestern Georgia, extreme southeastern Alabama and adjacent Florida to Gulf Coast, (atypic in lowlands of southeastern Georgia and northeastern Florida).

sphenarioides sphenarioides Scudder. Central peninsular Florida.

sphenarioides clara Rehn. Southern peninsular Florida and Florida Keys.

\section{Key to the Species of the Genus Aptenopedes}

1. Form comparatively robust, female cylindrical but blunt cephalad. Male subgenital plate broader, without proximo-lateral sulcus on each side. Male with inner flaps of subgenital plate folding in a less complex manner and no conspicuous inner caudal marginal tissue developed. (Male cerci simple, not showing striking differentiation.

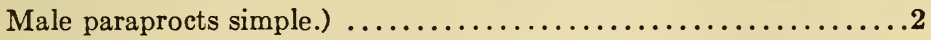

Form definitely more slender, female more slenderly cylindrical and not nearly as blunt cephalad. Male subgenital plate very narrow, with a nearly vertical proximal sulcus on each side. Male with inner flaps of subgenital plate folding in a complex manner and a conspicuous inner triangular caudal marginal tissue also present on that plate. (Both sexes with small, narrow, lateral, pad-like tegmina. Both sexes with postocular bands margining pronotal disk and continued on tegmina. Male cerci showing striking racial differentiation. Male paraprocts simple or bearing a tubercle. Penis simple, with four minute adjacent erect apices of parameres projecting. Caudal tibiae pale; glaucous, greenish or pink, sometimes light pink proximad and light glaucous distad.) ................Races of sphenarioides 9

24 See also map on plate XVII.

TRANS. AM. ENT. SOC., LXII. 
2. Both sexes with microscopic minute scale-like vestigial tegmina. ....3 Both sexes with small, narrow, lateral, pad-like tegmina. (Form decidedly robust. Both sexes with caudal tibiae pink. Female lacking pale lateral marginal bands on pronotal disk. Penis very distinctive (Pl. XVI, figs. 6 and 7).) Local; on east coast of peninsular Florida opposite Lake Okeechobee. ................ robusta new species

3. Male without blackish brown markings on pronotum. (Form moderately robust. Caudal tibiae glaucous, in females changing to purplish or pink dorsad (the latter condition rare in the north, usual in the

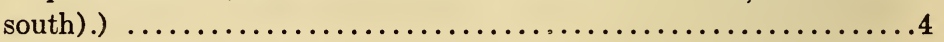

Male with the transverse and short lateral sulci of the pronotum strikingly blackish brown. (Form decidedly robust. Caudal tibiae of males deep glaucous, of females dull glaucous becoming purplish pink dorsad. Female lacking pale lateral marginal bands on pronotal disk. Penis distinctive (Pl. XV, figs. 9 and 10).) Local; in central peninsular Florida northwest of Lake Okeechobee.

nigropicta new species

4. Female lacking pale lateral marginal bands on pronotal disk. Penis very different from type developed in sphenarioides. ..........5

Female with pale lateral marginal bands on pronotal disk. Penis distinctive (Pl. XV, figs. 7 and 8), showing much closer agreement with the type developed in sphenarioides than in the otherwise more generally similar species, (the dorsal lobes, however, developed into small specialized horizontal lobes and the dorsal pair of parameres lamellate). All but northern portion of western peninsular Florida.

hubbelli new species

5. Lateral pronotal and medio-longitudinal abdominal bands whitish (varying to yellowish buff only in occasional specimens of aptera

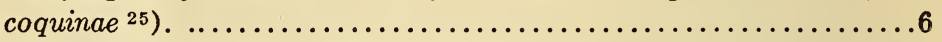

Lateral pronotal and medio-longitudinal abdominal bands orange (sometimes varying individually to buffy). Penis distinctive (Pl. $\mathrm{XV}$, fig. 1). Central peninsular Florida. .......aptera aptera Scudder

6. Dorsal lobes of penis not strikingly bilobate. ................

Dorsal lobes of penis strikingly bilobate (Pl. XIV, figs. 4 and 5). Lowlands of eastern and southwestern Georgia and northern Florida (except east coastal strip) west as far as Carrabelle.

aptera borealis new subspecies

7. Dorsal lobes of penis less chitinous, without prominently projecting processes (Pl. XIV, figs. 1 to 3). Northeast coast of Florida.

aptera simplex new subspecies

Dorsal lobes of penis more chitinous and darkened, with prominently

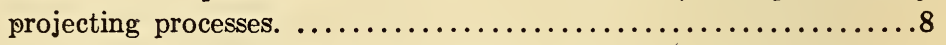

${ }^{25}$ Note that in hubbelli these markings vary individually from light yellow buff to rich orange. 
8. Dorsal lobes of penis with a prominent dorsal finger and no corresponding ventral projection (Pl. XV, fig. 3). Dorsal pair of parameres not enlarged distad (Pl. XV, fig. 2). Northeastern portion of central peninsular Florida (probably local). .. aptera saturiba new subspecies

Dorsal lobes of penis with a ventral as well as a dorsal projection or finger (Pl. XV, fig. 5). Dorsal pair of parameres decidedly enlarged distad (Pl. XV, figs. 4 and 6). Southeastern penisular Florida.

aptera coquinae new subspecies

9. Male pseudosternite armed with a single spine mesad on each side (Pl. XVI, fig. 10; atypic "C", fig. 11). (Male cerci short, with apices blunt (Pl. XVI, fig. 8; atypic " A", fig. 9). Paraprocts armed with a tubercle in typical and atypic "A" conditions.) Lowlands of eastern and southwestern Georgia, extreme southeastern Alabama and northern Florida west to DeFuniak Springs.

sphenarioides apalachee new subspecies

Male pseudosternite armed with a lamella or with irregular lobes mesad on each side. ......................................10

10. Male cerci simple, moderately falcate distad (Pl. XVI, fig. 12). Male pseudosternite with its lateral productions distinctive (Pl. XVI, fig. 13; atypic "E", fig. 14). Central peninsular Florida.

sphenarioides sphenarioides Scudder

Male cerci sigmoid, with over distal half strikingly falcate (Pl. XVI, fig. 15). Male pseudosternite with distinctive, irregular, trilobate lateral productions (PI. XVI, fig. 16). Southern peninsular Florida. sphenarioides clara Rehn

The majority of species and races of Aptenopedes may be recognized without examination of the normally concealed male genitalia. Moreover, once the characters of the penis are known, the type represented in a specimen may often be recognized merely by observation of the manner in which the pallium is elevated over the tip of that organ. I had, indeed, hoped that the structure of the portions of the penis, exposed when that organ is extruded, would alone require study, these being easily exposed by relaxing a specimen, deflexing the subgenital plate and at the same time working the pallium back and then down. The discovery that a very different pseudosternite distinguishes certain of the races of sphenarioides has necessitated a much more elaborate operation.

When the specimen is relaxed, the subgenital plate deflexed and the pallium worked back, the penis is free. A dissecting needle may then be inserted just before the penis to force it 
out, or just under it (from behind) to work it upward, thus stretching the membranes at the base of the penis to their full extent. The chitinous pseudosternite lies across the anal chamber proximad and is then sometimes visible, but to see both its dorsal and ventral processes the dissecting needle must be driven down behind it and then forward under it. By working this needle carefully so that it pushes against the pseudosternite from below, that organ may be slowly forced upward and slightly caudad, when it will rotate suddenly dorsad, exposing both its dorsal and ventral processes. It may then be left resting across the top of the large proximal portion of the ninth sternite, just beyond the apices of the epiprocts and supra-anal plate. Though these normally concealed organs are thus left in an unnatural position, I prefer this method to dissecting them out entirely. Such very small parts, if mounted on a slip with the specimen or separately, are easily lost or misplaced.

These parts of the male genitalia are mainly named in conformity with R. E. Snodgrass, ${ }^{26}$ but I have used "penis" instead of "aedeagus" and "pseudosternite" in place of "epiphallus" in conformity with the first important study of these structures by E. M. Walker ${ }^{27}$ and Hubbell's Revision of the Puer Group of the genus Melanoplus and recent Monograph of the Ceuthophili.

\section{Aptenopedes aptera simplex new subspecies}

(Pl. XIV, figs. 1 to 3.)

This race is as yet known only from near the Atlantic Coast just south of the St. Johns river in northeastern Florida, the present series having been reported as aptera by Rehn and Hebard in 1907 and 1916. No adult males have been secured in extreme southeastern Georgia, so that although Rehn and Hebard reported the species from St. Marys and Cumberland Island, the race represented can not yet be determined.

The development of the dorsal lobe of the penis affords much the most striking character to distinguish the present race.

Type. - ô; Pablo Beach, Florida. August 11, 1905. (Rehn and Hebard). [Hebard Collection, Type No. 1292].

${ }^{26}$ Smithsonian Misc. Coll., cxrv, No. 6, (1935).

27 Ann. Ent. Soc. Amer., XI, pp. 1-76, (1922). 
Generally similar to aptera aptera Scudder. Size small, form moderately robust for the species. Head moderately large in proportion to size of body, vertex very small, frontal costa in dorsal aspect very broad and almost transverse in outline, frontal costa strongly sulcate throughout. Eyes large, deep and prominent. Pronotum dorsad and laterad, pleura, mesonotum and metanotum thickly and shallowly impresso-punctate. Tegmina vestigial, represented by minute inconspicuous scales, which project only as far as mesad on mesonotum. Tympana large. Prosternal spine elongate cylindro-conical with apex rounded. Furcula represented by a pair of minute divergent fingers, each scarcely longer (individually varying to no longer) than wide. Cercus simple, slightly over twice as long as broad, tapering to the acute apex, distad with dorsal margin feebly convex and ventral margin almost straight, very faintly concave. Supraanal plate shield-shaped (in some paratypes rather narrow, with lateral margins weakly convergent, then rounding sharply into the only slightly produced distal portion), these margins not at all (to slightly in paratypes) thickened proximad, medio-longitudinal sulcus present only in proximal half but deep, lateral portions concave. Paraprocts large, simple. Eighth sternite very large. Subgenital plate represented by a narrow chitinous ring bounding that sternite caudad, which is only a little broader mesad than laterad, bearing within dorso-proximad on each side a large fleshy rounded flap which normally rests over the base of the penis, but springs upward and outward when that organ is extruded. Pseudosternite with dorsal lobes each having a stout short inner finger and an outer ridge which projects less. Penis with very large base, each of dorsal lobes shagreenous, their lateral margins converging moderately dorsad then nearly straight so that very weak marginal concavity is shown. These lobes are flattened and not at all bulbously bilobate as is the case in aptera borealis; dorsal pair of parameres greatly enlarged and specialized, in dorsal aspect appearing as adjacent, shagreenous, rounded, wedge-shaped surfaces much as in aptera borealis but narrower (decidedly broader in males from San Pablo).

\section{Allotype. — $\%$; same data as type. [Hebard Collection].}

Much larger and decidedly more robust than male. Distinguishable from immatures by the perfectly developed ovipositor valves and (from all immatures except the last instars) by the minute, scale-like tegmina. Prosternal spine heavier. Ovipositor valves with apices moderately elongate, the dorsal pair recurved, their external margins irregularly dentate, coarsely so distad, a transverse dorsal flange delimiting distal portion at base, the surface of which portion is strongly concave proximad.

General coloration delicate green in life, usually fading to yellow-brown or brown in drying, but a brown color phase also occurs. Males with lateral margins of pronotal disk and abdomen medio-longitudinally dorsad

TRANS. AM. ENT. SOC., IXII. 
with moderately broad bands of white or pinkish white, the former suffused ventrad narrowly, the latter margined with a suffusion of blackish brown. Females with these markings always absent on pronotum, often weakly indicated on abdomen. Mouthparts, supra-anal plate of male (entirely or medio-longitudinally only) and genicular areas of caudal femora pinkish brown, genicular arches of latter blackish brown. Caudal tibiae deep glaucous, caudal tarsi rich pink.

The extremes shown by the series (all from paratypes) measure: length of body $\delta 16.2$ to 18.7 , 922.8 to 25.7 ; length of pronotum $\delta 3.5$ to 4.3 , q 5.2 to 5.4 ; caudal width of pronotal disk $\delta 2.7$ to 2.9 , o 3.9 to 4.7 , length of caudal femur ô 8.8 to 10 , ㅇ 11.3 to $12.2 \mathrm{~mm}$.

Specimens Examined. - 58; 33 males, 22 females and 3 immature individuals.

Florida: Atlantic Beach, VIII, 24 and 25, 1911, (Rehn and Hebard), $3 \hat{\jmath}$, 49 , paratypes. Pablo Beach, VIII, 11 to 13, 1905, (Rehn and Hebard; particularly in sandy Saw Palmetto scrub, associated with Aptenopedes sphenarioides appalachee here described, atypic "B"), $28 \hat{o}, 15$ \% , type, allotype, paratypes, 1 juv. $\delta$, 2 juv. + . San Pablo, VIII, 13, 1905, (Rehn and Hebard; in undergrowth of pine woods) $2 \hat{\jmath}, 3 q$.

Aptenopedes aptera borealis new subspecies (P1. XIV, figs. 4 to 9.)

The present race has been recorded as aptera from numerous localities in Georgia and northern Florida (except the narrow coastal section inhabited by aptera simplex here described). It inhabits the lowlands of Georgia north to Groveland, Jesup, Homerville and Bainbridge; west to the latter, Woodville and Carrabelle, Florida, and in peninsular Florida south to Pomona (apparently, as females only were taken there), Ocala and Cedar Key. A series from Kissimmee suggests discontinuous distribution, as the present race is not present at a number of localities to the north where material has been secured.

Type. - ô; Bainbridge, Georgia. September 5 and 6, 1915. (Rehn and Hebard). [Hebard Collection, Type No. 1293].

Generally similar to aptera simplex here described, differing signally in having each of the dorsal lobes of the penis very strongly bilobate. Size averaging larger and form very slightly more robust than in aptera simplex (but marked difference in the average size is shown by different series, apparently irrespective of geographic distribution. The material from Jacksonville, Gainesville, Archer, Newberry and Ocala averages very large; a large series from Kissimmee small, no larger than the average for aptera simplex. Moreover the larger specimens appear to average slightly more 
robust, the smaller more slender). Pronotum, tegmina, tympana, prosternal spine, cercus, supra-anal plate (except that a thickening or tooth is often present proximad on the lateral margins), paraprocts, subgenital plate and pseudosternite as described for aptera simplex. Furcula very similar, but projecting portions no longer than wide. Penis of similar type but with dorsal lobes each strikingly developed into two large, shagreenous, approximate, bulbous lobes of which the ventral is the larger, while the dorsal pair of parameres have their dorsal surfaces broader.

\section{Allotype. - $\%$; same data as type. [Hebard Collection].}

Indistinguishable from this sex of aptera simplex, (but averaging larger and slightly more robust).

Coloration much as described for aptera simplex, the males apparently more often with margins of medio-longitudinal abdominal stripe pinkish brown and entire apex of abdomen pink. The males from Ocala have the brown suffusions more extensive, while the pronotum usually has a mediolongitudinal brown line, rarely the pale medio-longitudinal abdominal band with its lateral suffusions continued to near the cephalic margin of this tergite. In the present race the caudal tibiae are usually deep glaucous, sometimes paler and sometimes have the dorsal surface purplish or pinkish.

The following extremes in measurements are shown by the series.

$\hat{o}$

Bainbridge, Georgia. Type...

Ocala, Florida.

Kissimmee, Florida.

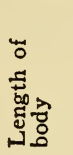

20.8

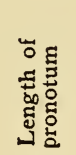

4.6

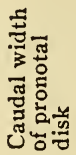

3.2

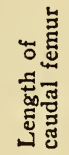

11.7

12.2 to 12.3

\section{우}

Bainbridge, Georgia. Paratype. 26.2 to $28.8 \quad 6$. to 6.1 5. to $5.3 \quad 13.3$ to 13.7

Ocala, Florida.

30. to $31.5 \quad 6.3$ to $6.6 \quad 5.6$ to $5.9 \quad 15$. to 15.2

Kissimmee, Florida.

20.7 to $25.5 \quad 4.4$ to 5 . $\quad 3.7$ to $4.4 \quad 10.2$ to 11.2

Specimens Examined.-137, 54 males, 48 females and 35 immature individuals.

Georgia: Groveland, ${ }^{28}$ IX, 21, 1917, (Rehn and Hebard; very few in undergrowth of pine forest on Cannoche river plain), $1 \hat{\delta}, 2 \%$. Chesser

28 This locality is probably well to the north of the northern line of fairly general distribution of the species. It was not seen by Fox at nearby localities or elsewhere in the region by Rehn and Hebard.

TRANS. AM. ENT. SOC., LXII. 
Island, Okefenokee Swamp, VII, 30 and VIII, 3, 1934, (J. D. and R. H.


Clns.]. Bainbridge, IX, 5 and 6, 1915, (Rehn and Hebard; not abundant on oak shoots in sandy oak forest), $8 \hat{\sigma}, 13$, type, allotype, paratypes, 6 large juv. + .

FLORIDA: Hilliard, VIII, 19, 1930, (R. H. and J. D. Beamer; Tuthill; Nottingham; McKinstry), 5 $\hat{\delta}, 3$ \% [Univ. of Kansas and Hebard Clns.]. Pomona, IX, 7 and 8, 1917, (Rehn and Hebard; in areas of oak shoots in pine woods), 5 o , 2 small juv. $\hat{o}$. Gainesville, VIII, 15 to 17, 1905, (Rehn and Hebard; in undergrowth of pine woods and Saw Palmetto scrub), $1 \hat{\delta}$, 2 medium juv. ô, 2 medium juv. $\&$. Ocala, ${ }^{29}$ IX, 19 and 20, 1917, (Rehn and Hebard; moderately common in areas of oak shoots in sandy pine flatwoods), $13 \hat{\jmath}, 9$ ㅇ, 1 large juv. $\hat{\delta}, 2$ medium juv. + . Kissimee, IX, 9, 1917, (Rehn and Hebard; very few on sandy flats with wire grass and Saw Palmetto), 3 of, 2 ㅇ. Woodville, IX, 1, 1915, (Rehn and Hebard; in oak shoots in undergrowth of Long-Leaf Pine flatwoods), $3 \hat{\delta}, 2$ \%, 2 large juv. o, 6 large to medium small juv. $q$. Carrabelle, IX, 2 and 3, 1915, (Rehn and Hebard; moderate numbers everywhere in scrub on sandy flats), $18 \hat{\sigma}$, 10 ㅇ, 3 medium large to medium juv. $\hat{\sigma}, 8$ medium large to medium juv. ㅇ. .

Aptenopedes aptera aptera Scudder

(P1. XV, fig. 1.)

1877. Aptenopedes rufovittata Scudder ( $\hat{\sigma}$, not [juv.] ${ }^{\circ}{ }^{30}$ ), Proc. Boston Soc. Nat. Hist., xIx, p. 85. [ $\hat{o}$; Fort Reed, Florida.]

1877. Aptenopedes aptera Scudder, Proc. Boston Soc. Nat. Hist., xIx, p.

86. [\%; Fort Reed, Florida.]

This insect in size and appearance shows an average close agreement with the large individuals of aptera borealis here described which are found in the region immediately to the north (from Ocala to Gainesville). It differs in the males having the lateral pronotal and medio-longitudinal abdominal bands unusually wide and usually orange (zinc orange in the most intensive specimens), but sometimes these bands are buffy, such individuals being very similar in general appearance to those of the other races of the species. The male penis, however, has the

29 It should be noted that aptera aptera and hubbelli also occur at this locality. Females of aptera borealis and aptera aptera from Ocala appear to be virtually indistinguishable and immatures of these races and of hubbelli from there can not be separated at present with any degree of assurance.

30 The immature female was selected as single type of rufovittata by Rehn and Hebard in 1916, thus placing rufovittata as a synonym of sphenarioides. 
dorsal pair of parameres more enlarged, broader, particularly distad, and not at all wedge-shaped in dorsal aspect.

Females are virtually indistinguishable from large females of aptera borealis.

One of the topotypic males, originally recorded as rufovittata, has been loaned for examination through the kindness of the Museum of Comparative Zoology. It is slightly smaller than the average in our series, agrees closely in all features here considered diagnostic for the race, and is intensive in coloration, with pronotal and medio-longitudinal abdominal bands broad and zine orange.

Specimens Examined. - 70; 23 males, 37 females and 10 immature individuals.

Florida: Ocala, IX, 19 and 20, 1917, (Rehn and Hebard; moderately common in areas of oak shoots in sandy pine flatwoods), $3 \delta, 3$. Dunnellon, IX, 18 and 19, 1917, (Rehn and Hebard; moderately common in rolling deforested country with thick undergrowth of Saw Palmetto, Bayberry and oak shoots but very few grasses), $10 \hat{o}, 18 \%, 3$ large to moderately large juv. $ᄋ$. Gotha, X, 1901, (H. Nehrling), $1 \hat{o}$ (recorded as aptera), [A.N.S.P.]. Fort Reed, IV, 10 to 21, (J. H. Comstock), paratype of rufovittata, [Mus. Comp. Zool.]. Trilby, IX, 16, 1917, (Rehn and Hebard; moderately numerous particularly in Saw Palmetto thickets and other dense undergrowth in open), $5 \hat{\delta}, 3 \uparrow, 1$ small juv. $\hat{\delta}, 1$ large and 1 medium small juv. + . Lakeland, IX, 11, 1917, (Rehn and Hebard), $3 \hat{o}$, 3 , 1 large juv. ô, 3 medium juv. $q$.

Where both aptera aptera and aptera borealis occur, intergradation is to be expected. Females may be indistinguishable, but in the present race they more often show the dorsal surface of the caudal tibiae purplish or pink.

It is probable that aptera aptera is limited in distribution to a comparatively small portion of central peninsular Florida.

Aptenopedes aptera saturiba ${ }^{31}$ new subspecies ( $\mathrm{Pl}$. XV, figs. 2 and 3.)

This race is described from a series secured in a sandy oak scrub area at DeLeon Springs, to the east of the St. Johns River, in the northeastern portion of central peninsular Florida. With it were found Hesperotettix osceola Hebard (also recorded from Ocala) and Melanoplus adelogyrus Hubbell (also known and

31 Aboriginal inhabitants of the region in which this race occurs. 
originally reported from similar environment near Emporia and Enterprise Junction). Like the latter species it is probably very locally distributed and is supplanted in the surrounding more extensive areas of different ecology by related races or species.

It is superficially quite similar to aptera simplex here described, but the dorsal lobes of the penis are definitely more chitinous, produced in a blunt decurved finger dorsad and a smaller and much shorter finger ventrad, with intervening lateral margin broadly concave. This is much like the type developed in aptera coquinae here described except that in that southeastern race the dorsal finger is much shorter and heavier. The dorsal pair of parameres rather suggest those of aptera aptera but are definitely narrower and more produced.

It is probable that this race will be found only locally, in central eastern Florida. Intergradation with aptera coquina may appear in material from along the northern portion of the Indian River.

Type. - ô; DeLeon Springs, Florida. September 9, 1917. (Rehn and Hebard). [Hebard Collection, Type No. 1294].

Generally similar in external structure to aptera simplex here described, differing as noted above. Size and form similar, averaging smaller and less robust than the other races. Penis with basal portion very large, dorsal lobes dark, more strongly chitinous than in the preceding races (but agreeing with aptera coquinae) of distinctive form as described above; dorsal pair of parameres rather suggesting those of aptera aptera but more produced, very much less produced than in aptera coquinae, in dorsal aspect otherwise similar to those of aptera aptera but not as much expanded..$^{32}$

Allotype. - $q$; same data as type. [Hebard Collection].

Indistinguishable from females of aptera simplex.

Coloration as described for aptera simplex. Lateral pronotal lines and medio-longitudinal dorsal band of abdomen of males usually whitish, sometimes faintly tinged with pinkish. Females with the abdominal band only, this narrower, not continued on the pronotum in either sex.

Specimens Examined.-16; 8 males and 8 females.

Florida: DeLeon Springs, IX, 8 and 9, 1917, (Rehn and Hebard; not scarce in dwarf oaks throughout extensive sandy scrub area), $8 \hat{0}, 8$, type, allotype, paratypes.

32 Atypical material of aptera coquina more strongly indicates that aptera saturiba is definitely more closely related to it than to aptera aptera. 
Aptenopedes aptera coquinae ${ }^{33}$ new subspecies (P1. XV, figs. 4 to 6.)

This handsome southeastern race is quite similar in general appearance to large examples of aptera borealis here described. The females show, however, pale lines margining the disk of the pronotum laterad, in this sex also present only in hubbelli here described of the other almost apterous species, but much more prominently developed in all of the races of sphenarioides Scudder.

The great size of the specimens found on Silver Palms suggests that this feature is more influenced by food plant or immediate environment than by geographic distribution. This factor probably explains the decided size difference from the normal shown by certain series of a number of the forms of Aptenopedes.

Type. - $\hat{o}$; Miami, Florida. March 3, 1916. (M. Hebard). [Hebard Collection, Type No. 1295].

Size medium, form moderately robust for the species (the normal for this race, which varies in different series from small to extremely large). Generally similar to aptera saturiba here described. Dorsal lobes of penis similarly dark and chitinous, shagreenous, with dorsal finger shorter than in that race, straight and rounded at apex and ventral finger very similar to it (individually varying from heavier to definitely smaller and less produced than the dorsal finger). Dorsal pair of parameres of same type but produced, curved to become horizontal, narrow and elongate but enlarged distad.

\section{Allotype. - $\%$; same data as type. [Hebard Collection].}

Differs from all the other races of aptera in having narrow pale marginal bands delimiting the pronotal disk from the lateral lobes (but similar to those found in females of hubbelli). Much larger and decidedly more robust than male.

General coloration very similar to aptera simplex as here described. The lateral pronotal and medio-longitudinal abdominal bands broad in the males, usually whitish, rarely weakly yellowish buff; in females less heavy, apparenty more often tinged with yellowish buff or brownish. Caudal tibiae glaucous to deep glacous, in females with dorsal surfaces often purplish.

The great size variation occurring over a comparatively small area is demonstrated by the following specimens.

${ }^{33}$ In reference to the coquina rock underlying the pine woods (Pinus caraibea) which cover much the greater portion of the range of this race.

TRANS. AM. ENT. SOC., IXII. 


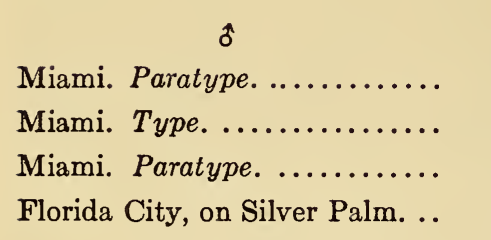

ㅇ

Miami. Allotype. ............

Miami. Paratype. ...........

Florida City, on Silver Palm. ..

Royal Palm Key. ...........

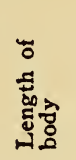

17.7

20.2

22.1

23.7

27.3

31.8

48.

45.5



3.1

4.7

4.9

5.1

5.8

4.9

5.8

6.3

7.8

7.7
13.

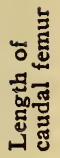

9.3

11.1

11.9

13.2

15.5

17.3

17.1

In the vicinity of Miami, however, a series taken at the same place and in the same environment almost always shows very little size variation.

Of the Florida Keys, only Big Pine Key has an extensive growth of pine flatwoods, Pinus caribaea, and unfortunately only immatures were secured there. The race represented is probably aptera coquinae, but adult males must be secured before this can be definitely stated.

Specimens Examined, (almost all of which have been previously recorded as aptera).-58; 26 males, 14 females and 18 immature individuals.

FlorIDA: Vero, VIII, 23, 1933, (E. R. Helwig), $3 \hat{\delta}$, [A.N.S.P. and Hebard Clns.]. Likely, VII, 24, 1934, (R. H. Beamer; Griffith), $4 \hat{\delta}, 4$ ㅇ, [Univ. of Kansas and Hebard Clns.]. Boca Raton, III, 1, 1916, (M. Hebard; very scarce on dwarf oaks in sand area with scrub pines), $1 \hat{\delta}, 1 \%$. Deerfield, III, 1, 1916, (M. Hebard; same as at last locality), $2 \hat{\delta}$. Miami, I, 17, 1899, (S. N. Rhoads), $1 \hat{\delta}$, paratype, [A.N.S.P.] ; II, 7, 1904, (M. Hebard; in wire grass in pine woods, Pinus caribaea, to north of town), $3 \hat{\delta}$, paratypes, 1 large juv. $\delta$; III, 3, 1916, (M. Hebard; in Saw Palmetto, Sofkee and wire grass of pine woods, Pinus caribaea), $7 \hat{\delta}, 2 \%$, type, allotype, paratypes; Southside, III, 6 and 16, 1915, (M. Hebard; same), 3 \%, paratypes, 2 small juv. $\hat{o}, 1$ medium juv. + ; Southside, III, 27, 1910, (M. Hebard; same), $2 \hat{o}$, $1 \%$, paratypes, 1 large juv. + . Cocoanut Grove, VIII, 9, 1930, (L. D. Tuthill), 1 very large juv. $\$$, [Univ. of Kansas]. Florida City (Homestead), III, 13, 1920, (M. Hebard; on Silver Palms, Coccothrinax argentea, found very scarce while searching for Belocephalus sleighti simplex 
Hebard, ${ }^{34}$ in pine flatwoods, Pinus caribaea), $2 \hat{\delta}, 2$ \& III, 17 to 19,1910 , (M. Hebard; in undergrowth of pine flatwoods, Pinus caribaea), 1 teneral $\hat{\delta}$; VII, 10 to 12, 1912, (Rehn and Hebard; same), 3 juv. $\delta, 7$ juv. $q$ (large to small). Detroit, VII, 12, 1912, (Rehn and Hebard; same), 2 medium juv. $q^{35}$ Royal Palm Key, (F. M. Jones), 1q, [A.N.S.P.]. ? Big Pine Key, VII, 6, 1912, (Rehn and Hebard; same), 1 small juv. $\hat{o}$, 3 small juv. $q$.

Aptenopedes hubbelli 36 new species

(P1. XV, figs. 7 and 8; pl. XVI, fig. 5.)

1914. Aptenopedes aptera Rehn and Hebard, (not of Scudder, 1877), Jour.


Marco, Florida.]

1916. Aptenopedes aptera Hebard, (not of Scudder, 1877), Ent. News,

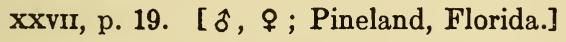

This insect in external appearance strongly resembles aptera aptera Scudder. Its range includes the greater portion of western peninsular Florida except the northern section, and throughout this extensive area it apparently completely supplants aptera except that the ranges of the two evidently overlap in a narrow northeastern strip.

In spite of the great general similarity, however, both sexes may be easily distinguished from that race without dissection, the males by the usually narrow pronotal bands (which are usually, but not always, tinged with orange) and the scarcely enlarged apex of the abdomen combined with the much sharper and less extensive elevation of the pallium (caused by the very differently shaped penis), the females by the presence of pale lateral pronotal bands (also developed in aptera coquinae here described, alone of the races of that species).

The penis, though of wholly different type from that of any of the more closely allied species, shows close similarity to the type developed in sphenarioides Scudder, except for the greater

${ }^{34}$ At the time I thought an unknown race or species might be present, peculiar to the Silver Palm. Laboratory examination, however, immediately showed that nothing of the sort occurs in either case.

35 Contrary to our original comments on these immatures, the present species shows microscopic rudimentary tegminal scales not only in adults but also in the later instars of immaturity in both sexes.

36 Named in honor of T. H. Hubbell, whose masterly studies in the Orthoptera and constant coöperation have been of the utmost value to the author. 
development of the dorsal lobes and the lamellation of the dorsal pair of parameres.

Type.- ô ; Fort Myers, Florida. September 13 to 15, 1917. (Rehn and Hebard). [Hebard Collection, Type No. 1296].

Size medium large and form robust for the genus. Head, pronotum, mesonotum, metanotum, pleura, microscopic tegminal scales, tympana, prosternal spine, furcula, supra-anal plate (except that the lateral margins are developed proximad in a usually prominent proximal node or tooth), cerci, paraprocts, pseudosternite and subgenital plate as here described for aptera simplex. Penis with a large base, dorsal lobes greatly reduced when compared with those of aptera, produced latero-cephalad (on each side of the erect, adjacent, sharp, slender projecting tips of the four parameres) as much smaller but similarly shagreenous, rounded (very often somewhat irregular) flaps; exposed distal portions of parameres distinctive, all adjacent, straight, attingent, erect and slender, the dorsal pair lamellate, in lateral aspect tapering evenly to their acute apices and projecting the same distance as the ventral pair, the latter aciculate.

\section{Allotype. - $\%$; same data as type. [Hebard Collection].}

As described for aptera simplex except for the distinctive lateral pale pronotal bands discussed above. Apparently indistinguishable from females of aptera coquinae except through distributional data.

The extremes of the series are included in the following measurementes. $\hat{o}$

Ocala, Florida.

Lake Jovita, Florida. ........ 14.6 to 16.2

Fort Myers, Florida. Paratypes. 18.3 to 20.5

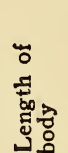

8.7 to 20.8
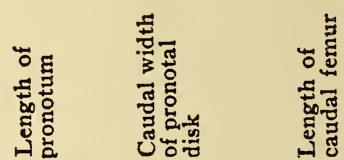

4. to 4.52 .9 to $3.2 \quad 10.3$ to 11.8

3.5 to $3.8 \quad 2.1$ to $2.7 \quad 8.8$ to 9 .

3.8 to $4.3 \quad 2.8$ to $3.2 \quad 9.8$ to 11.3

?

Yankeetown, Florida. 27.8 to 39.4

5.9 to 6.2

5. to 5.6

13.8 to 14.1

Lake Jovita, Florida.

23.

4.7

3.8

11.2

Fort Myers, Florida. Paratypes. 27.5 to $32.6 \quad 5.5$ to $6.3 \quad 5$. to $5.7 \quad 13.2$ to 15 .

Size in the present species is again clearly influenced largely by conditions of immediate environment and is little affected by geographic distribution. 
Coloration and color pattern very similar to aptera aptera, the males with lateral marginal bands of pronotal disk usually light orange, rarely whitish, the females with these bands likewise present but narrower, varying from light yellow buff through light yellow orange (usual) to rich orange (rare). Caudal tibiae glaucous with dorsal surface purplish, this latter usually more strongly indicated in females and occasionally rich pink, caudal tarsi rich pink. Cephalic and median limbs of the general green coloration except in males of some series in which all or the majority have these members rich orange brown. Pinkish coloration of apex of male abdomen, so often shown in aptera, obsolete or weakly indicated.

That this is a distinct species and not a race of aptera is clearly shown by the penis, convergence and intergradation between the two types now being impossible. In hubbelli the form of the penis further shows no variation worthy of note in the large series at hand. Though aptera and sphenarioides are quite generally present over a great area of coincident distribution, hubbelli (apparently wholly) supplants the former over a region where its distribution is similarly coincident with that of sphenarioides. The other species of the genus are less extensively distributed and where found are local, limited to xeric sand scrub-oak areas.

Specimens Examined.-107; 62 males, 33 females and 12 immature individuals.

Frorma: Ocala, IX, 19 to 20, 1917, (Rehn and Hebard; with aptera borealis and aptera aptera in areas of oak shoots in sandy pine flatwoods), 11 ô, 2 \%. Yankeetown, VII, 17, 1934, (R. H. and J. D. Beamer; Griffith; McKinstry), $11 \hat{\delta}, 6 q, 1$ medium juv. $\&$, [Univ. of Kansas and Hebard Cln.]. Trilby, IX, 16, 1917, (Rehn and Hebard; lowland pine woods, undergrowth of Saw Palmetto, Gallberry and Kalmia), 1ô, 6q. Lake Jovita, VII, 20, 1934, (R. H. Beamer, Jr.), $3 \hat{\delta}, 1$ ㅇ, [Univ. of Kansas and Hebard Cln.]. Anona, IX, 17, 1917, (Rehn and Hebard; occasional in sandy scrub of low oaks), 3 q, 1 medium small juv. $\hat{\delta}, 1$ medium small and 1 small juv. $\$$. Arcadia, IX, 12, 1917, (Rehn and Hebard; in Long Leaf Pine woods undergrowth, a few in Myrica cerifera), 5 ô, 2 9 . Fort Myers, IX, 13 to 15, 1917, (Rehn and Hebard; throughout undergrowth of pine woods, particularly in Saw Palmetto clumps), 28 $\hat{\delta}, 11 q$, type, allotype, paratypes, 4 large to medium juv. $\&$. Iona, IX, 13, 1917, (Rehn and Hebard; same), $2 \hat{\delta}, 1$ large juv. $\hat{\delta}, 1$ medium juv. $\$$. Pineland on Pine Island in Charlotte Harbor, V, 18 and 20, 1915, (M. Hebard; only two adults seen, immatures numerous in undergrowth of Saw Palmetto and wire grass of Pinus caribaea flatwoods), $2 \hat{o}$. Marco, IV, 19, 1912, (W. T. Davis), 1\%, [Hebard Cln.]. Estero, VII, 21, 1934, (R. H. and J. D. Beamer; Griffith), 1 \&, 2 medium juv. $\$$, [Univ. of Kansas and Hebard Clns.].

TRANS. AM. ENT. SOC., LXII. 
Aptenopedes nigropicta new species

(P1. XV, figs. 9 and 10.)

This remarkable species is strikingly differentiated by its coloration, marking and development of the penis. It is a species of medium small size but is slightly more robust than any of the races of aptera Scudder, to which species nearest relationship is indicated. It is probably an insect of very discontinuous distribution, occurring in xeric sandy areas and may be limited to the central ridge of Florida northwest of Lake Okechobee.

Type. - ô ; Childs, DeSoto County, Florida. August 6, 1930. (R. H. Beamer). [Hebard Collection, Type No. 1297].

Size medium small, form decidedly robust for the genus, in this latter chapter approaching robusta here described. Head much as in aptera aptera Scudder, but it and the eyes slightly less deep. Pronotum proportionately shorter, its sulci more pronounced, but this accentuation more from coloration than contour. Tegmina, furcula, cerci, supra-anal plate, paraprocts, and subgenital plate much as in aptera aptera. Penis distinctive though of the same general type as in that insect; dorsal lobes each developed into two bilobate shagreenous chitinous proximo-lateral processes much as in aptera aptera, dorsal pair of parameres produced in two large, adjacent, rounded-subquadrate lobes with a decided concavity caudad, the ventral pair of parameres situated ventro-proximad, adjacent, directed distad and curving dorsad to their acute apices.

\section{Allotype. - $\%$; same data as type. [Hebard Collection].}

Larger and more robust than male. More robust but otherwise very similar to the smaller of the females of aptera aptera, the general coloration in life being, however, probably quite different. Curved apices of dorsal valves of ovipositor relatively elongate.

General coloration of males (apparently somewhat discolored) light brownish buff. Pronotum with all transverse as well as latero-longitudinal short sulci more or less strikingly defined in blackish brown, this weakest dorso-mesad. Pleura and proximal abdominal tergites laterad suffused and with sulci also blackish brown. Sides of face in one male washed with olivaceous. Cephalic and median limbs and caudal femora yellowish olive, the latter yellowish buff internally and ventrad, the genicular arches blackish brown with other portions dull whitish. Caudal tibiae deep glaucous; base, spines and apices of spurs black. Caudal tarsi dull pink. Female (somewhat discolored) dull yellowish olive, immaculate. Caudal tibiae dull glaucous, purplish pink dorsad. Caudal tarsi pink.

Three males and one female, paratypes, bearing the same data as the described pair, show little size variation. Length of body $\hat{o} 17.8$, ㅇ 24.; length of pronotum $\hat{o} 3.8$, $q 5$.; caudal width of pronotal disk $\hat{o} 3.2$, ㅇ 4.7; length of caudal femur ô 9.7 , ㅇ $12.2 \mathrm{~mm}$. 


\section{Aptenopedes robusta new species}

(P1. XVI, figs. 6 and 7 ; pl. XVII, fig. 5.)

This insect may well be considered the most anomalous of the genus. The penis is of entirely different type from that of any other species. It is the most robust species of Aptenopedes but agrees with the slenderest and most widely separated species, sphenarioides Scudder, in having very small but extremely narrow tegmina which reach to (female) or across (male) the large tympanum. The rich pink tibiae in both sexes afford another striking character.

Undoubtedly another restricted type, the insect should be sought in xeric sand areas along the east coast of Florida in the Indian River region opposite Lake Okeechobee.

Type. - ڤ̂; Likely, Palm Beach County, Florida. July 24, 1934. (J. D. Beamer). [Hebard Collection, Type No. 1298].

Size moderately large and form very robust for the genus, the general form showing greatest similarity to that of nigropicta here described. Head in dorsal aspect similarly very blunt, but eyes much deeper and general contour of head and pronotum otherwise more as in aptera coquinae here described. Pronotum with definition between dorsum and lateral lobes very feeble though suggested, sulci not conspicuous. Tegmina represented by very narrow pads which expand feebly to their rounded apices, the latter slightly surpassing the large tympana but the latter wider than their vertical width. Furcula represented by two moderately stout, irregular, very faintly divergent fingers, deeply inset due to the sudden and decided emargination mesad of the tergite from which they spring, each twice as long as broad beyond its basal weakly thickened portion. Supra-anal plate rather narrowly shield-shaped, proximad medio-longitudinally concave and weakly so laterad, a very small blunt tooth on each lateral margin opposite cercal bases. Cerci narrowing strongly proximad, with remaining portion very slender to the acute apex, directed dorso-caudad and failing to reach as far caudad as the apex of the supra-anal plate. Paraprocts simple. Penis remarkably distinctive; dorsal lobes produced, adjacent along their inner margins, erect, curving caudad narrowly at apices where the distal margin is broadly concave on each side, widened also distad so that a sort of partial hood is formed; dorsal pair of parameres broad but not as broad as the dorsal lobes, similarly produced dorsad and distad curving caudad to project caudad narrowly beyond them with distal margin convex on each side (thus this margin of each dorsal lobe is concave and of each dorsal paramere convex), so that with the dorsal lobes they form a hood above the broad, attingent, erect ventral pair of parameres, the latter 
adjacent, their lateral margins curving obliquely to the adjacent acuteangulate meso-distal apices, their caudal faces moderately concave.

Allotype. - ; ; same data as type, but taken by M. R. Griffith. [Hebard Collection].

Decidedly larger and more robust than male, but proportionate difference between the sexes slightly less than in the other species excepting nigropicta. Form and coloration definitely different from that of this sex of any other known species of the genus. Tegmina similar to those of male but slightly less well developed, slightly narrower in proportions and reaching only to median point on tympana. Curved apices of dorsal valves of ovipositor relatively short.

Male generally olivaceous, a moderately broad post-ocular band of whitish margins the pronotal disk laterad and is continued to include the dorsal portion of the tegmina, a brownish suffusion narrowly margining this on lateral lobes and ventral portions of tegmina of that color. Furcula and medio-longitudinal portion of supra-anal plate light pink, this more weakly suggested medio-longitudinally dorsad on abdomen and in genicular areas of caudal femora, the bases of the genicular areas marked with a small black area on each side. Caudal tibiae pink, blackish very briefly proximad and suffused and darkened (individually to different degrees) internally for some distance distad, spines and apices of spurs black. Caudal tarsi pink.

Female rich green except for dorsal portions of tegmina which are paler, similar inconspicuous blackish markings on caudal limbs except the pink caudal tibiae lack the disto-internal suffusion.

The extremes in measurements are as follows: length of body $\hat{\sigma} 19.5$ to 20.1 , ㅇ 27.7 to 28.8 ; length of pronotum ô 4.7 to 4.8 , 우 6.2 to 6.3 ; caudal width of pronotal disk $\hat{\delta} 3.7$ to 3.7 , o 5.9 to 6 ; length of tegmen $\hat{o} 4.2$ to 4.2 , o 4.8 to 4.9 ; length of caudal femur $\hat{o} 10.7$ to 10.9 , o 13 . to $13.6 \mathrm{~mm}$.

Two male and three female paratypes bear the same data as the described pair except that one female was secured by J. D. Beamer.

\section{Aptenopedes sphenarioides and its races}

The present species, more slenderly cylindrical than any of the others belonging to the genus Aptenopedes and possessing narrow pad-like tegmina, developed elsewhere only in robusta here described, is found to be definitely even more complex in its geographic differentiation than is aptera Scudder. 
Whereas aptera divides naturally into five geographic races, ${ }^{37}$ showing as a rule decided uniformity in these races where they occur, sphenarioides has apparently reached a less advanced stage in its development. Subject to even greater geographic differentiation, the recognition of not more than three races appears to be advisable; a northern, a central peninsular and a southern peninsular. Each of these is subject to decided differentiation, in more than one case fixed over a portion of its range. Thus the northern race can be separated readily into a western and an eastern type, while a change from the eastern again occurs to the south. Difference in a single feature in some cases and sometimes marked instability leads me to believe that only the three races mentioned above should be recognized and that the other conditions should be treated as atypic of these, indicating in some cases formative geographic races which are as yet insufficiently differentiated to warrant nominal recognition.

Nowhere in the Orthoptera have I encountered a species so clearly divided into geographic races showing in themselves from strong to weak evidence of further racial evolution.

In sphenarioides a much more complicated subgenital plate is developed than in any other species of Aptenopedes. In it the subgenital plate forms only a comparatively narrow distal rim of the very large proximal portion of the eighth sternite; this shows upon external examination to have a nearly vertical sulcus close to the proximal margin which converges to meet that margin dorsad. When the subgenital plate is deflexed this sulcus as well as the proximal margin are found to expand dorsad and have there an intricately attached area of soft tissue which is produced in a very large fleshy flap. When in normal position this flap covers the side and caudal portions of the bulbous base of the penis, but becomes erect and then assumes a lateroexternal position when the penis is extruded. In addition the internal margin of the subgenital plate bears a broad median triangular integument which protects the base of the penis from the rear but springs into an erect position when that organ is extruded.

37 With indices that in certain areas other races may be present but should not be described without more adequate evidence, obtainable only from more and larger series than are now available.

TRANS. AM. ENT. SOC., LXII. 


\section{Aptenopedes sphenarioides appalachee new subspecies}

(P1. XVI, figs. 8 to 11.)

1904. Aptenopedes sphenarioides Morse, Carnegie Inst. Washington, Publ. No. 18, p. 55. [Juvs.; Waycross, Georgia; Live Oak (?), Tallahassee, Carrabelle and DeFuniak Springs, Florida.]

1905. Aptenopedes sphenarioides Rehn and Hebard, Proc. Acad. Nat. Sci. Phila., 1904, p. 793. [256 specimens, $\hat{\delta}$, $q$ : Thomasville, Georgia; Leon County, Florida. ${ }^{38}$ ]

1907. Aptenopedes sphenarioides Rehn and Hebard (the present race in part), Proc. Acad. Nat. Sci. Phila., 1907, p. 299. [Atypic "B": 29 ô, 11 ㅇ, 24 immatures; Pablo Beach, Florida.]

1916. Aptenopedes sphenarioides sphenarioides Rehn and Hebard (the present race in part), Proc. Acad. Nat. Sci. Phila., 1916, p. 252. [Atypic "A"; Jesup and Brunswick, Georgia. Atypic "B": St. Simons Island and Cumberland Island, Georgia; Atlantic Beach, Pablo Beach and Daytona, Florida. Atypic “AB"; Jacksonville, Florida. Typical: Suwanee Creek (= Hopkins), Billys Island and Jordans in Okefenokee Swamp, Homerville, Albany and Bainbridge, Georgia; (?) Live Oak, Florida.]

1920. Aptenopedes sphenarioides Blatchley (the present race in part), Orth. of Northeastern America, p. 345. [Atypic "B"; Ormond, Florida.]

From sphenarioides sphenarioides Scudder typical material of this race is distinguished by characters of the male cerci, paraprocts and pseudosternite. Its distribution extends across southern Georgia to extreme southwestern Georgia, into extreme southeastern Alabama, in adjacent eastern Florida and as far west as DeFuniak Springs.

Four divisions are present in sphenarioides apalachee which are here considered "typical", "atypic A", "atypic B" and "atypic C".

Type. - ô; Thomasville, Florida. November 30, 1903. (M. Hebard). [Hebard Collection, Type No. 1299].

Very similar to sphenarioides sphenarioides in all except male genitalic characters. Size medium, form slender for the genus. Face strongly retreating. Pronotum elongate with percurrent medio-longitudinal carina. Tegmina very small, slender, elongate pads with apices rounded, extending across the large tympanum. Furcula represented by stout parallel fingers, longer than broad beyond the thickened areas from which they spring. Supra-anal plate narrowly linguliform, proximad broadly sulcate medio-

${ }^{38}$ Color phases, habitat and habits discussed. 
longitudinally, laterad concave. Cerci short, stout, simple, truncate distad with dorso-distal angle broadly rounded and ventro-distal angle nearly as much so. Paraprocts large, each armed beneath the cercus with a stout elongate tubercle. Penis with proximal portion briefly tubular produced, from which project the four minute, straight, adjacent, elongate, erect parameres of which the first pair are very delicate with truncate apices, the second pair shorter, narrower and with convex apices. ${ }^{39}$ Pseudosternite armed mesad on each side with a slender thorn-like curved spine, its apex acute, its base simple.

\section{Allotype. - 9 ; same data as type but taken December 26,} 1903. [Hebard Collection].

Decidedly larger and more robust than male and more cylindrical. Fastigium somewhat more produced than in the other species of the genus, from females of which it may be distinguished by the presence of very small but readily visible tegmina, except those of robusta in which species similar tegmina are developed.

\section{ô}

Thomasville, Ga. (41)

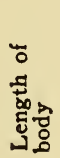

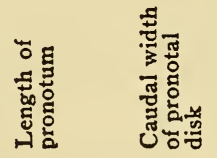
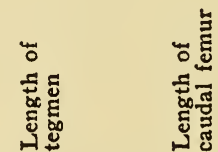

Tallahassee, Fla. ....

19.8

4.2

3.2 to 3.8

8.7 to 9.2

\section{우}

Thomasville, Ga. (38)

22. to 25.5

4.2 to 5 .

3.8 to $4.2 \quad 3.2$ to $4.4 \quad 10.8$ to 12.2

Tallahassee, Fla. ....

28.6

5.7

4.9

4.8

13.9

The green and brown color phases were discussed fully by Rehn and Hebard in 1904. The post-ocular pale line is very straight, defining the pronotal disk from the lateral lobes and including the dorsal half of the tegmina; it is buffy or faintly pinkish and is margined below with a narrow brown line (naturally least conspicuous in dark brown individuals). A striking feature is the pale (in dark specimens) or blackish (in pale specimens) dot caudad on each side of the abdominal tergites; in the males longitudinal but slightly oblique dark streaks are often present crossing the tergite to these dots, the intervening median area often suffused, while in

39 The penis is similar in all the races of sphenarioides. That of hubbelli is much nearer this type than any other species of the genus. 
pale females the dots may have a minute whitish area on each side. The most beautiful of the color phases is one in which the entire dorsal area is rich purplish pink, this being most striking in otherwise green females. The caudal tibiae are light glaucous, often with a pale greenish tinge, or light pink, sometimes the latter proximad and the former distad.

Typical Specimens Examined, in addition to $44 \hat{\delta}, 45 \%$ and 12 immatures previously recorded, of which the $41 \hat{\sigma}$ and $38 \%$ now at hand are designated paratypes.-95; 24 males, 13 females and 58 immature individuals.

Georgia: Bainbridge, IX, 5, 1915, (Rehn and Hebard; in undergrowth of Long-Leaf Pine woods near "branch"), $5 \hat{\jmath}, 2$ $\uparrow, 5$ medium juv. $\hat{o}, 10$ medium juv. + .

Alabama: Dothan, IX, 6, 1915, (Rehn and Hebard; adults rare, immatures in moderate numbers in undergrowth of Long-Leaf Pine woods), $2 \hat{o}, 1$ large juv. $\hat{o}, 2$ medium juv. $\hat{\delta}, 1$ large juv. $q, 7$ medium juv. $q$.

Florida: Tallahassee, IX, 2, 1915, (Rehn and Hebard; moderately abundant in luxuriant weeds in fields and woodland near pond, few in waste field), $4 \hat{\delta}, 6 q, 6$ juv. $q$, from small to medium large. Woodville, IX, 1, 1915, (Rehn and Hebard; few in pine woods undergrowth, common in richer vegetation about a sink-hole), $6 \hat{\delta}, 2$ ㅇ, 2 medium juv. $\hat{\delta}, 2$ medium juv. ㅇ. Quincy, X, 27, 1905, (W. A. Hooker), 1 ㅇ, [U.S.N.M.]. Sopchoppy, IX, 4, 1915, (M. Hebard; undergrowth in Long-Leaf Pine forest), $1 \hat{\delta}$. Carrabelle, IX, 2 and 3, 1915, (Rehn and Hebard; few in moisture loving grasses and plants on the edge of swampy areas), $3 \hat{\delta}, 10 \%$, 3 juv. $\hat{o}, 2$ juv. + , from small to very large. River Junction, VIII, 31, 1915, (Rehn and Hebard; moderately abundant in lush vegetation in stream bottom), $3 \hat{\jmath}, 2 \uparrow, 2$ medium juv. $\hat{o}, 11$ medium to small juv. $\$$. De Funiak Springs, VIII, 30, 1915, (M. Hebard; very scarce in gallberry bushes and also in moisture loving plants in Long-Leaf Pine woods), 4 medium to small juv. $\$$.

Atypic "A". (Pl. XVI, figs. 9 and 10.) This condition differs from the typical only in having the disto-ventral angle of the male cerci to different degrees more angulate and produced, thus showing the first step in the transition toward sphenarioides sphenarioides. It occurs in eastern Georgia north of the range of typical sphenarioides apalachee as far as Pembroke, Groveland, Collins, Vidalia and Dublin, and westward also as far as McRae.

Atypic "A" Specimens Examined, in addition to $10 \hat{0}, 6 q$ and 2 juvs. previously recorded. -145 ; 79 males, 42 females and 24 immature individuals. 
Georgia: Pembroke, IX, 23, 1913, (H. Fox), $2 \hat{\delta}, 1$ small juv. $q$. Groveland, IX, 21, 1917, (Rehn and Hebard; in gallberry bushes bordering swampy area), $15 \hat{\delta}, 5 q, 2$ medium juv. $\delta, 5$ medium juv. $q$. Cannoche River near Groveland, IX, 21, 1917, (Rehn and Hebard; in heavy undergrowth of gallberry and other bushes in river plain pine forest), 1 . Claxton, IX, 22, 1923, (H. Fox), $2 \hat{\jmath}, 2$, 1 small juv. $\widehat{o}$. Collins, IX, 21, 1923, (H. Fox), 14 ô, $9 q, 1$ medium juv. $\delta, 2$ medium juv. + . Vidalia, IX, 20 to 23, 1923, (H. Fox), $2 \hat{\delta}$. Hazelhurst, IX, 29, 1923, (H. Fox), $20 \hat{\delta}, 7 \uparrow, 4$ small juv. $\hat{\delta}$. Dublin, IX, 20, 1923, (H. Fox), $2 \hat{\delta}$. McRae,

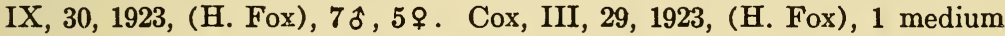
juv. . Folkston, VIII, 2, 1934, (J. D. and R. H. Beamer, Jr.), 5 \%, [Univ. of Kansas and Hebard Clns.]. Chesser Island, Okefenokee Swamp, VII, 30 and VIII, 3, 1934, (Beamer and McKinstry), $2 \delta, 1 q$, [Univ. of Kansas and Hebard Cln.].

FLORIDA: Hilliard, VII, 28, 1934 and VIII, 19 and 31, 1930, (Beamer; Nottingham; Oman; Lee), $11 \hat{\delta}, 7 q, 7$ juv. + , [Univ. of Kansas and Hebard Cns.].

Atypic " A" toward "B," in addition to $8 \hat{\sigma}$ and $8 \%$ previously recorded from Jacksonville; moreover the female originally recorded from the locality by Scudder is probably the same.

FloriaA: Magnolia Springs, V, 22, 1916, (M. Hebard; in boggy undergrowth of pine woods), $1 \hat{\delta}$.

Atypic "B". This condition differs further from typical sphenarioides apalachee in the males having shorter furcula, a more falcate apex of the cercus with ventro-caudal angle more acute and the paraprocts not tuberculate.

This is a strictly coastal condition of which 43 males, 18 females and 13 immatures have been recorded from Cumberland Island, Georgia; Atlantic Beach, Pablo Beach, Ormond and Daytona, Florida.

Atypic "C". (Pl. XVI, fig. 11.) This condition is much like atypic "B", but the thorn-like process on each side of the pseudosternite is shorter, more curved and blunter.

Atypic "C" Specimens Examined, in addition to $3 \hat{\delta}$ previously recorded from Gainesville.- 39; 17 males, 21 females and 1 immature individual.

Florida: Pomona, IX, 7 and 8, 1917, (Rehn and Hebard; common in marsh grasses, occasional in pine woods undergrowth), $11 \hat{\delta}, 15 q, 1$ large juv. $\$$. Waldo, VIII, 18, 1930, (Beamer and Nottingham), $6 \hat{\delta}, 8$, [Univ. of Kansas]. 


\section{Aptenopedes sphenarioides sphenarioides Scudder}

(P1. XVI, figs. 12 to 14.)

1877. Aptenopedes sphenarioides Scudder, Proc. Boston Soc. Nat. Hist., XIX, p. 84. [ $\delta, 40$ \% ; Fort Reed, Florida.]

1877. Aptenopedes rufovittata Scudder (in part), Proc. Boston Soc. Nat. Hist., XIX, p. 85. [Juv. $\$$;11 Fort Reed, Florida.]

Important features for this race are as follows. Average size small for the species, close to that of our Thomasville, Georgia series of sphenarioides apalachee here described. Male. Furcula heavy, almost parallel and even more elongate than in typical sphenarioides apalachee, being over twice as long as broad. Supra-anal plate narrow, with a decided proximo-lateral tooth. Paraprocts simple, unarmed. Cerci with apical portion not elongate but definitely falcate. Pseudosternite with a lamellate rounded process, the dorso-external portion of which is slightly produced dorsad and curved inward to its sharply rounded apex.

Specimens Examined.-26; 16 males, 9 females and 1 immature individual.

Florma: Gotha, X, 1901, (H. Nehrling), 1 ઈิ, 2 q, [A.N.S.P.] Kissimmee, IX, 9 and 10, 1917, (Rehn and Hebard; very few in undergrowth of cypress bays, moderate numbers about their edges on wet prairie), $15 \delta, 7 q, 1$ large juv. + .

Atypic "D". Compared with sphenarioides sphenarioides this condition differs as follows. Size large to very large. Male. Furcula decidedly smaller, divergent. Supra-anal plate broad. Cerci and paraprocts similar, the latter, however, showing a slight rounded elevation beneath the cerci. Pseudosternite showing a large irregularly knobbed process, evidently a development from the typical for this race but much more thickened and irregular.

Atypic “D" Specimens Examined.-139; 79 males, 56 females and 4 immature individuals.

${ }^{40}$ The male from Fort Reed, Florida, figured by Scudder in 1897 (Proc. U. S. Nat. Mus., xx, pl. 26, fig. 10) and at the Museum of Comparative Zoology, is here selected single type. The female from Jacksonville, Florida, then recorded, is probably representative of sphenarioides apalachee, atypic " $\mathrm{A}$ " toward " $\mathrm{B}$ ", here discussed under that race.

41 This specimen was selected as type by Rehn and Hebard in 1916, rufovittata consequently falling as a synonym. The males described as rufovittata, however, are representative of aptera aptera Scudder. 
Florids: Ocala, VIII, 17, 1930, (R. H. Beamer), 1 \%, [Univ. of Kansas] ; IX, 19 and 20, 1917, (Rehn and Hebard; moderately common in undergrowth, but especially so about fennel and grassy spots), 21 of, 15\%, 1 medium juv. ô. Dunnellon, IX, 19, 1917, (Rehn and Hebard; locally moderately numerous on sand flats with Saw Palmetto, Bayberry and scanty grasses), $4 \hat{\delta}, 7$. Trilby, IX, 16, 1917, (Rehn and Hebard; common in gallberry bushes in undergrowth of cypress bays and other undergrowth of Long Leaf Pine forest), 11 ô, 16 \%. Anona, IX, 17, 1917, (Rehn and Hebard), $1 \hat{\delta}$. Indian Beach on Sand Key, IX, 17, 1917, (Rehn and Hebard; moderate numbers in tall weeds and grasses on inner marshy edge of Key, few in beach vegetation), $9 \hat{\delta}, 5 \hat{q}, 1$ medium juv. $\hat{\delta}$. Tampa (recorded as clara by Rehn and Hebard in 1905), $4 \hat{\delta}, 2 \%$ (small but otherwise similar). St. Petersburg, VIII, 18 to 26, 1931, (Bradley and Knorr), $1 \hat{\delta}$. Mulberry, VIII, 27, 1931, (Bradley and Knorr), $1 \hat{\delta}$, (slight cercal divergence toward sphenarioides clara). Arcadia, IX, 12, 1917, (Rehn and Hebard; few in Heliotropium polyphyllum on sand bars of Peace

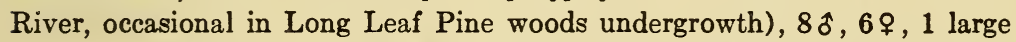
juv. $\hat{\delta}, 1$ medium juv. $q$, (with stronger cercal divergence toward sphenarioides clara). Vero, VIII, 23, 1933, (E. R. Helwig), 9ô, 2ㅇ, (same), [A.N.S.P. and Hebard Cln.]. Kelsey City, VIII, 23, 1933, (E. R. Helwig), $10 \hat{o}, 2$ \% , (same), [A.N.S.P. and Hebard Cln.].

Atypic "E". (PI. XVI, fig. 14.) Size below to above median. Male. Pseudosternite with mesal projection on each side having a blunt curved outer spine (much like the blunt spine developed in atypic "C" of sphenarioides apalachee but an inner rounded projection indicating closer resemblance to sphenarioides sphenarioides. In other respects much like the latter, but furcula scarcely longer than broad and supra-anal plate broader, more as in atypical "D".

Atypic "E" Specimens Examined.-51; 29 males and 22 females.

FLorida: Lakeland, (G. O. Ainslie), 1 ô, 1 \% , [U.S.N.M.]; IX, 11, 1917, (Rehn and Hebard), $22 \hat{\delta}, 17 \%$, (and $6 \hat{\delta}, 4 \uparrow$ previously recorded as clara by Rehn and Hebard).

\section{Aptenopedes sphenarioides clara Rehn}

(P1. XVI, figs. 15 and 16 ; pl. XVII, fig. 4.)

1902. Aptenopedes clara Rehn, Ent. News, xıI, p. 14. [ $ڤ$; Miami, Florida.]

1917. Aptenopedes sphenarioides clara Hebard, Ent. News, xxvi, p. 407. (Great size variation, due to local environmental conditions, noted and measurements given for three series.)

Rehn and Hebard recorded this insect as clara until 1915, when the author placed it as a race of sphenarioides. 
Specimens Examined.-204; 102 males, 77 females and 25 immature individuals.

Of these $70 \hat{\delta}, 52 \%$ and 20 immatures, previously recorded, are at hand from Miami Beach, Virginia Key, Cape Florida, Miami, Homestead (Florida City), Detroit, Long Key, Boot Key, Key Vaca, Big Pine Key, Key West, Pineland on Pine Island and Useppa Island, Florida.

FLoRIDA: Royal Palm Key, III, 3, 1917, (M. Hebard; in undergrowth of tropical hammock land in Everglades), $1 \hat{\delta}, 1$ medium juv. $\hat{\sigma}$. Key Largo, VIII, 9, 1930, (R. H. Beamer), 4 ô, 1 ㅇ , [Univ. of Kansas] ; VIII, 21, 1931, (Bradley and Knorr), 1 large juv. $\$$. Lower Matecumbe Key, IX, 4, 1931, (Bradley and Knorr), 2\%. Thirty miles west of east border of Everglades on Tamiami Trail, VIII, 30, 1931, (Bradley and Knorr), 19. Fort Myers, VIII, 11, 1930, (R. H. Beamer), $2 \hat{\delta}$, [Univ. of Kansas] ; IX, 13 to 15, 1917, (Rehn and Hebard; generally distributed in wire-grass, Saw Palmetto, Bayberry undergrowth of Pinus caribaea forest on edge of cypress swamps), $23 \hat{o}, 20$ q , 2 medium juv. $\hat{\jmath}, 1$ medium juv. + . Iona, IX, 13, 1917, (J. A. G. Rehn; in undergrowth of pine woods), $1 \hat{\delta}, 1 \%$. Useppa Island in Charlotte Harbor, V, 19, 1919, (M. Hebard), $1 \hat{\delta}$.

The extremes in size are found in material from the immediate vicinity of Biscayne Bay. These are: length of body ô 20.3 to 27.4 , ᄋ 26 . to $34.9 \mathrm{~mm}$.

\section{Explanation of Plates}

\section{Plate XII}

(Figures of male genitalia)

Fig. 1.-Melanoplus marshalli marshalli (Thomas). Marshall Pass, Colorado. ${ }^{42}$ Dorsal view of furcula and supra-anal plate. (Much enlarged.)

Fig. 2.-Melanoplus marshalli marshalli (Thomas). Marshall Pass, Colorado. Lateral view of apices of dorsal lobes of penis. (Greatly enlarged.)

Fig. 3.-Melanoplus marshalli marshalli (Thomas). Gothic, Colorado. Caudal view of penis. (Much enlarged.)

Fig. 4.-Melanoplus marshalli ascensor (Scudder). Lake Martha, Wasatch Mountains, Utah. Dorsal view of furcula and supra-anal plate. (Same scale as Fig. 1.)

Fig. 5.-Melanoplus marshalli ascensor (Scudder). Lake Martha, Wasatch Mountains, Utah. Lateral view of apices of dorsal lobes of penis. (Greatly enlarged.)

42 This specimen is figured as it came probably from near the type locality. The majority of our specimens of the race, however, have the furcula longer to different degrees and the supra-anal plate variously narrower. In none however are the furcula as long or the supra-anal plate as narrow as in marshalli ascensor, shown in figure 4. 
Fig. 6.-Melanoplus oregonensis missoulae new subspecies. Paratype. Missoula, Montana. Lateral view of cercus. (Much enlarged.)

Fig. 7.-Melanoplus indigens indigens Scudder. Upper Morgan Creek, Salmon River Range, Idaho. Lateral view of cercus. (Same scale as Fig. 6.)

Fig. 8.-Melanoplus indigens indigens Scudder, atypic. Evergreen, Idaho. Lateral view of cercus. (Same scale as Fig. 6.)

Fig. 9.-Melanoplus indigens digitifer new subspecies. Type. Haines, Oregon. Lateral view of cercus. (Same scale as Fig. 6.)

Fig. 10.-Melanoplus payettei new species. Paratype. McCall, Big Payette Lake, Idaho. Caudal view of penis. (Much enlarged.)

\section{Plate XIII}

Fig. 1.-Melanoplus oregonensis missoulae new subspecies. Paratype. Missoula, Montana. Lateral view of distal portion of penis. (Much enlarged.)

Fig. 2.-Melanoplus oregonensis missoulae new subspecies. Paratype. Missoula, Montana. Caudal view of penis. (Same scale as Fig. 1.)

Fig. 3.-Melanoplus indigens indigens Scudder. Type. Salmon City, Idaho. Lateral view of penis. (Same scale as Fig. 1.)

Fig. 4.-Melanoplus indigens digitifer new subspecies. Type. Haines, Oregon. Lateral view of penis. (Same scale as Fig. 1.)

Fig. 5.-Melanoplus indigens digitifer new subspecies. Type. Haines, Oregon. Caudal view of penis. (Same scale as Fig. 1.)

Fig. 6.-Melanoplus payettei new species. Paratype. McCall, Big Payette Lake, Idaho. Lateral view of cercus. (Same scale as Pl. XII, Fig. 6.)

Fig. 7.-Dendrotettix hesperus new species. Type. Alder Springs, Cascade Mountains, Oregon. Dorsal outline of ovipositor valves. (Much enlarged.)

Fig. 8.-Dendrotettix hesperus new species. Type. Alder Springs, Cascade Mountains, Oregon. Lateral outline of ovipositor valves. (Same scale as Fig. 7.)

Fig. 9.-Dendrotettix hesperus new species. Type. Alder Springs, Cascade Mountains, Oregon. Ventral outline of subgenital plate and bases of ovipositor valves. (Same scale as Fig. 7.)

\section{Plate XIV}

(Greatly enlarged figures of male penis. All on same scale)

Fig. 1.-Aptenopedes aptera simplex new subspecies. Paratype. Pablo Beach, Florida. Caudal view.

Fig. 2.-Aptenopedes aptera simplex new subspecies. Atypic in having dorsal pair of parameres very broad. San Pablo, Florida. Caudal view.

TRANS. AM. ENT. SOC., IXII. 
Fig. 3.-Aptenopedes aptera simplex new subspecies. Atypic in having dorsal pair of parameres very broad. San Pablo, Florida. Dorsal view.

Fig. 4.-Aptenopedes aptera borealis new subspecies. Paratype. Bainbridge, Georgia. Dorsal view.

Fig. 5.-Aptenopedes aptera borealis new subspecies. Paratype. Bainbridge, Georgia. Ventro-caudal view.

Fig. 6.-Aptenopedes aptera borealis new subspecies. Atypic depauperate condition. Kissimmee, Florida. Dorsal view.

Fig. 7.-Aptenopedes aptera borealis new subspecies. Atypic depauperate condition. Kissimmee, Florida. Ventro-caudal view.

Fig. 8.-Aptenopedes aptera borealis new subspecies. Showing narrowed dorsal pair of parameres, possibly due to crushing. ${ }^{43}$ Cedar Key, Florida. Dorsal view.

Fig. 9.-Aptenopedes aptera borealis new subspecies. Showing narrowed dorsal pair of parameres, possibly due to crushing. Cedar Key, Florida. Ventro-caudal view.

\section{Plate XV}

(Greatly enlarged figures of male penis. All on same scale)

Fig. 1.-Aptenopedes aptera aptera Scudder. Gotha, Florida. Dorsal view.

Fig. 2.-Aptenopedes aptera saturiba new subspecies. Paratype. DeLeon Springs, Florida. Dorsal view.

Fig. 3.-Aptenopedes aptera saturiba new subspecies. Paratype. DeLeon Springs, Florida. Caudal view.

Fig. 4.-Aptenopedes aptera coquinae new subspecies. Paratype. Miami, Florida. Dorsal view.

Fig.5.-Aptenopedes aptera coquinae new subspecies. Paratype. Miami, Florida. Caudal view.

Fig. 6.-Aptenopedes aptera coquinae new subspecies. Atypic. Vero, Florida. Dorsal view.

Fig. 7.-Aptenopedes hubbelli new species. Yankeetown, Florida. Lateral view.

Fig. 8.-Aptenopedes hubbelli new species. Yankeetown, Florida. Dorsal view.

Fig. 9.-Aptenopedes nigropicta new species. Type. Childs, Florida. Dorsal view.

Fig. 10.-Aptenopedes nigropicta new species. Type. Childs, Florida. Lateral view.

43 The dorsal pair of parameres being inflated very feebly chitinized lobes dorsad, care must be taken not to mistake distortion for an atypic condition. In rare cases before me such distortion might have been mistaken for even a feature of racial significance had this not been realized. 


\section{Plate XVI}

Fig. 1.-Asemoplus montanus (Bruner). Paratype. From near Helena, Montana. Lateral outline of male cercus. (Much enlarged.)

Fig. 2.-Asemoplus montanus (Bruner). Paratype. From near Helena, Montana. Caudal view of penis. (Greatly enlarged.)

Fig. 3.-Asemoplus sierranus new species. Paratype. Harkness Peak, California. Dorsal view of furcula and supra-anal plate. (Much enlarged.)

Fig. 4.-Asemoplus sierranus new species. Type. Harkness Peak, California. Lateral outline of male cercus. (Same scale as Fig. 1.)

Fig. 5.-Asemoplus sierranus new species. Type. Harkness Peak, California. Caudal view of penis. (Same scale as Fig. 2.)

Fig. 6.-Aptenopedes robusta new species. Paratype. Likely, Florida. Dorsal view of penis. (Same scale as Plate XIV, figure 3.)

Fig. 7.-Aptenopedes robusta new species. Paratype. Likely, Florida. Caudal view of penis. (Same scale as Fig. 6.)

Fig. 8.-Aptenopedes sphenarioides apalachee new subspecies. Paratype. Thomasville, Georgia. Lateral view of male cercus. (Much enlarged.)

Fig. 9.-Aptenopedes sphenarioides apalachee new subspecies, atypic "A". Hilliard, Florida. Lateral view of male cercus, showing deviation toward sphenarioides sphenarioides. (Same scale as Fig. 8.)

Fig. 10.-Aptenopedes sphenarioides apalachee new subspecies, atypic " A". Hillard, Florida. Latero-median spine of pseudosternite (as developed in the typical, atypic " $A$ " and atypic " $B$ " conditions of the present race). (Greatly enlarged.)

Fig. 11.-Aptenopedes sphenarioides apalachee new subspecies, atypic "C". Pomona, Florida. Production of pseudosternite, showing first deviation from the normal in this race (Fig. 10) in this feature. (Same scale as Fig. 10.)

Fig. 12.-Aptenopedes sphenarioides sphenarioides Scudder. Paratype. Fort Reed, Florida. Lateral view of male cercus. (Same scale as Fig. 8.)

Fig.13.-Aptenopedes sphenarioides sphenarioides Scudder. Paratype. Fort Reed, Florida. Production of pseudosternite. (Same scale as Fig. 10.)

Fig. 14.-Aptenopedes sphenarioides sphenarioides Scudder atypic "E". Lakeland, Florida. Production of pseudosternite, showing nearest approach to sphenarioides apalachee atypic " $\mathrm{C}$ ". (Same scale as Fig. 10.) 
Fig.15.-Aptenopedes sphenarioides clara Rehn. Topotype. Miami, Florida. Lateral view of male cercus. (Same scale as Fig. 8.)

Fig. 16-Aptenopedes sphenarioides clara Rehn. Topotype. Miami, Florida. Production of pseudosternite, showing intricate and irregular lobation characteristic of this race. (Same scale as Fig. 10.)

\section{Plate XVII}

Fig. 1.-Melanoplus foedus iselyi new subspecies. Type. Male. Weatherford, Texas. (X 1 1/4)

Fig. 2.-Melanoplus foedus iselyi new subspecies. Allotype. Female. Weatherford, Texas. (X 1 1/4)

Fig. 3.-Dendrotettix hesperus new species. Type. Female. Alder Springs, Cascade Mountains, Oregon. (X 1 1/4)

Fig. 4.-Aptenopedes sphenarioides clara Rehn. Female. Miami Beach, Florida. (X 1 1/4)

Fig. 5.-Aptenopedes robusta new species. Allotype. Female. Likely, Florida. (X 1 1/4)

Map showing the distribution of the races of Aptenopedes aptera and the new species here described.

1. aptera simplex. Limited to near coast. 5. aptera coquinae. (Dots.)

2. aptera borealis. (Dots.)

6. hubbelli. (Triangles.)

(Note single isolated record.)

7. nigropicta. (Circle.)

3. aptera aptera. (Crosses.)

8. robusta. (Circle.)

4. aptera saturiba. (Dot.) 
Trans. Am. Ent. Soc., Vol. LXII.

PI. XII.
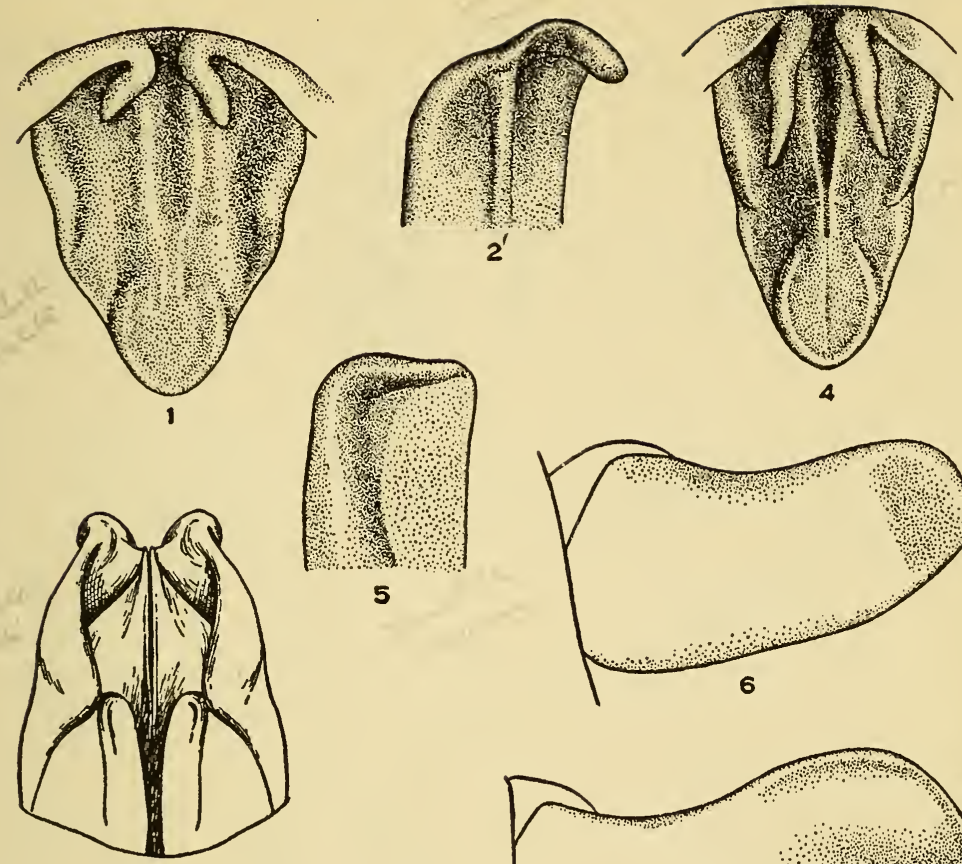

5
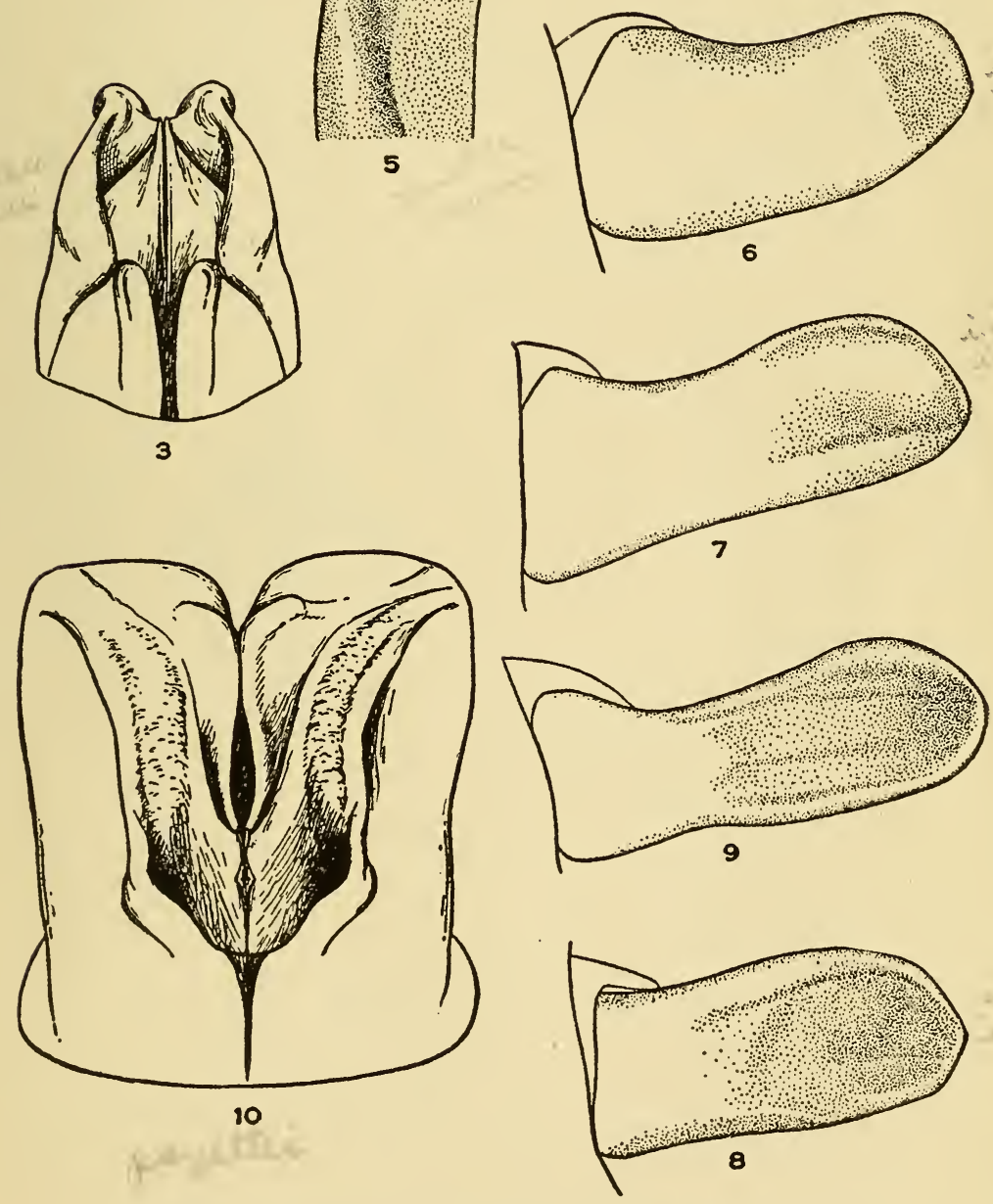

HEBARD-NORTH AMERICAN MELANOPLI 

Trans. Am. Ent. Soc., Vol. LXII.
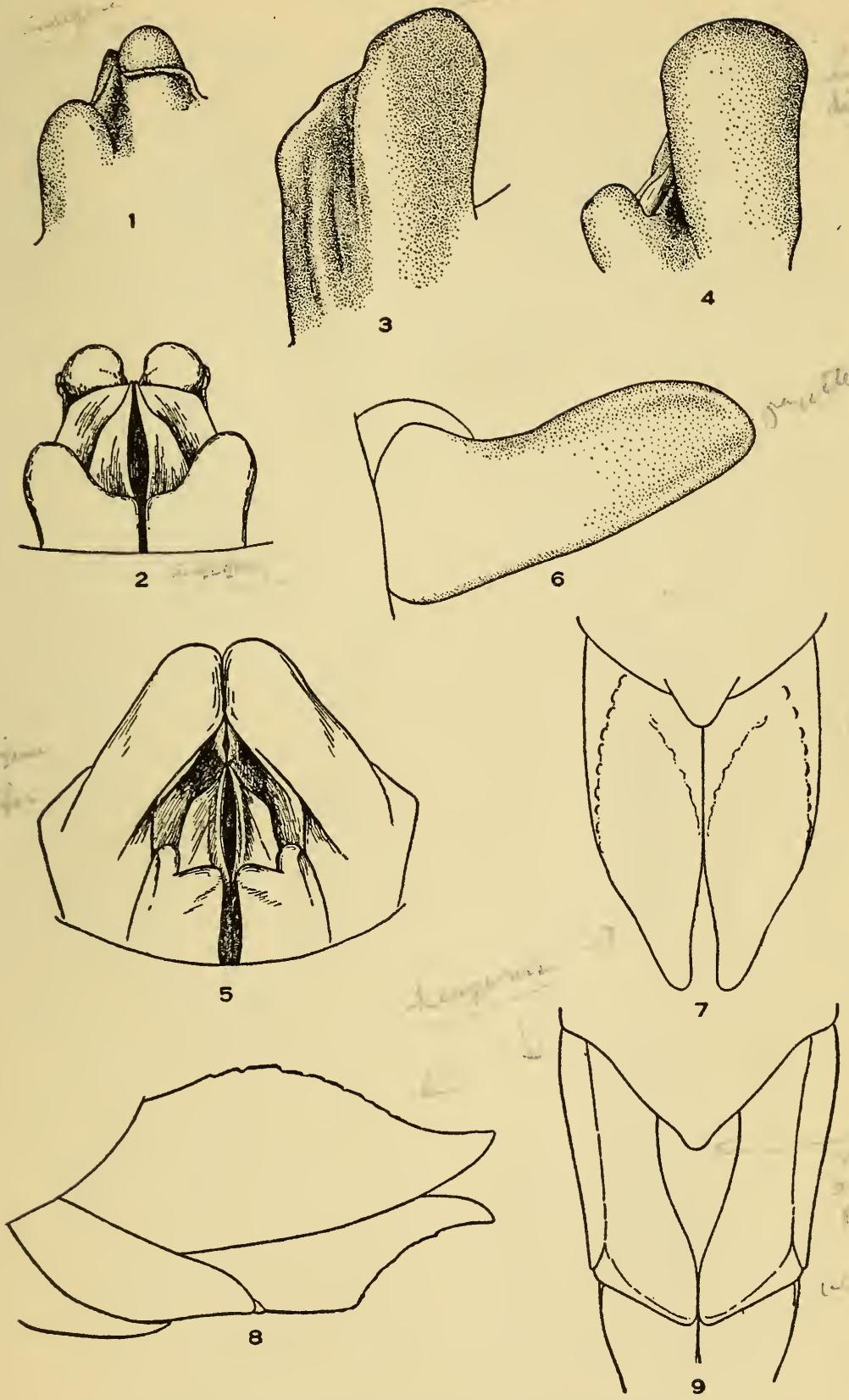

HEBARD-NORTH AMERICAN MELANOPLI 

Trans. Am. Ent. Soc., Vol. LXII.

P1. XIV.
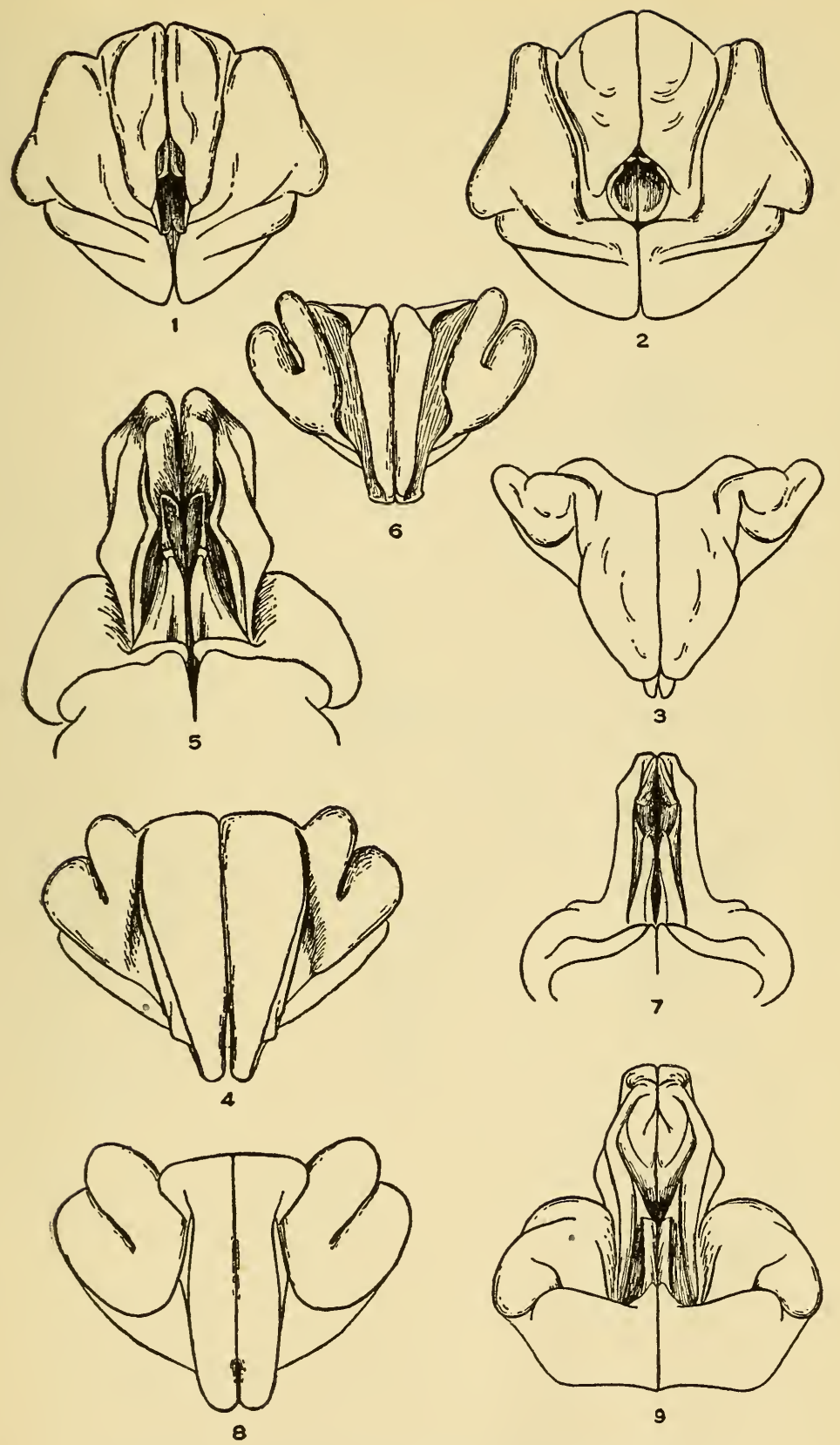

HEBARD--NORTH AMERICAN MELANOPLI 


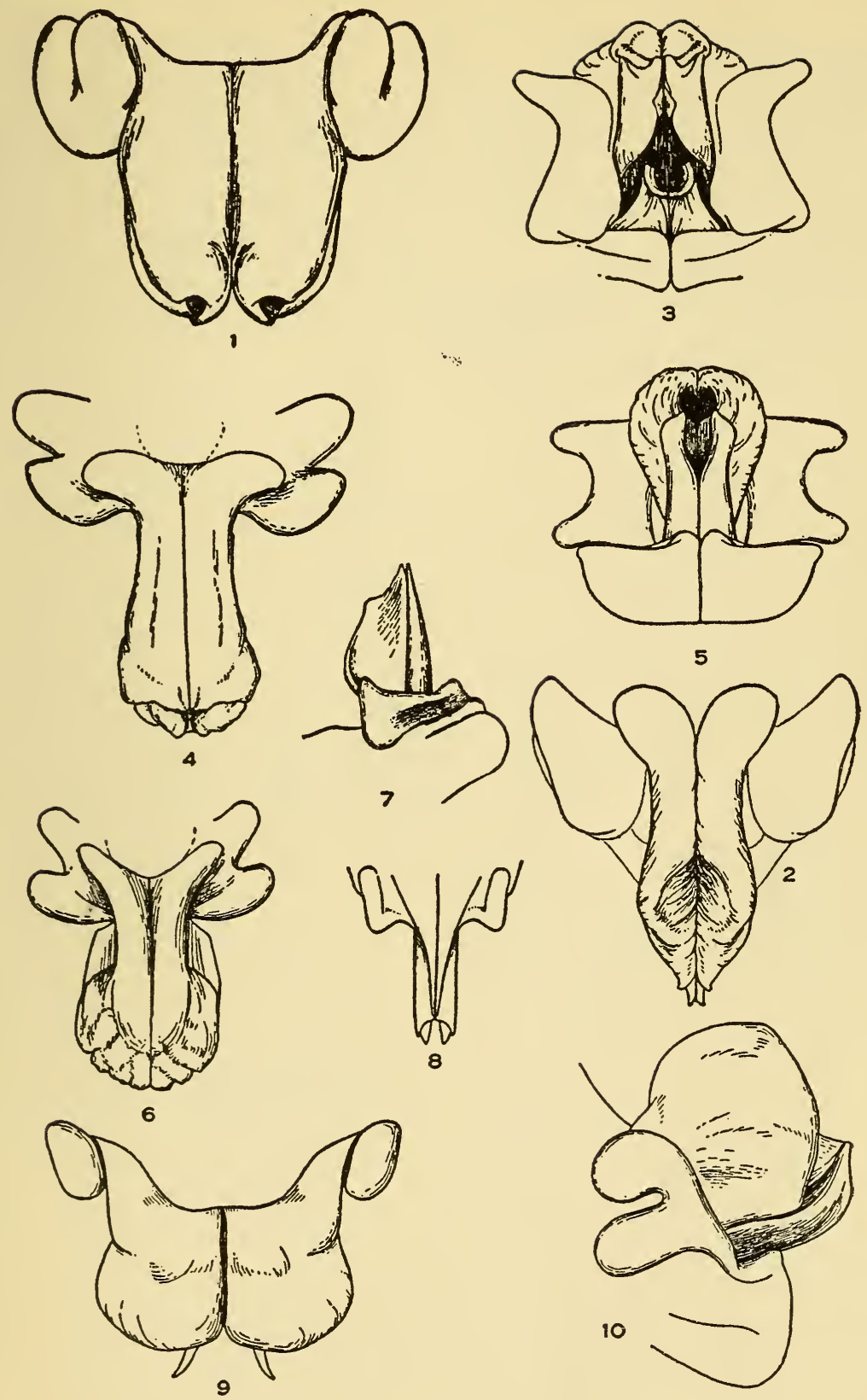

HEBARD-NORTH AMERICAN MELANOPLI 

Trans. Am. Ent. Soc., Vol. LXII.

Pl. XVI.
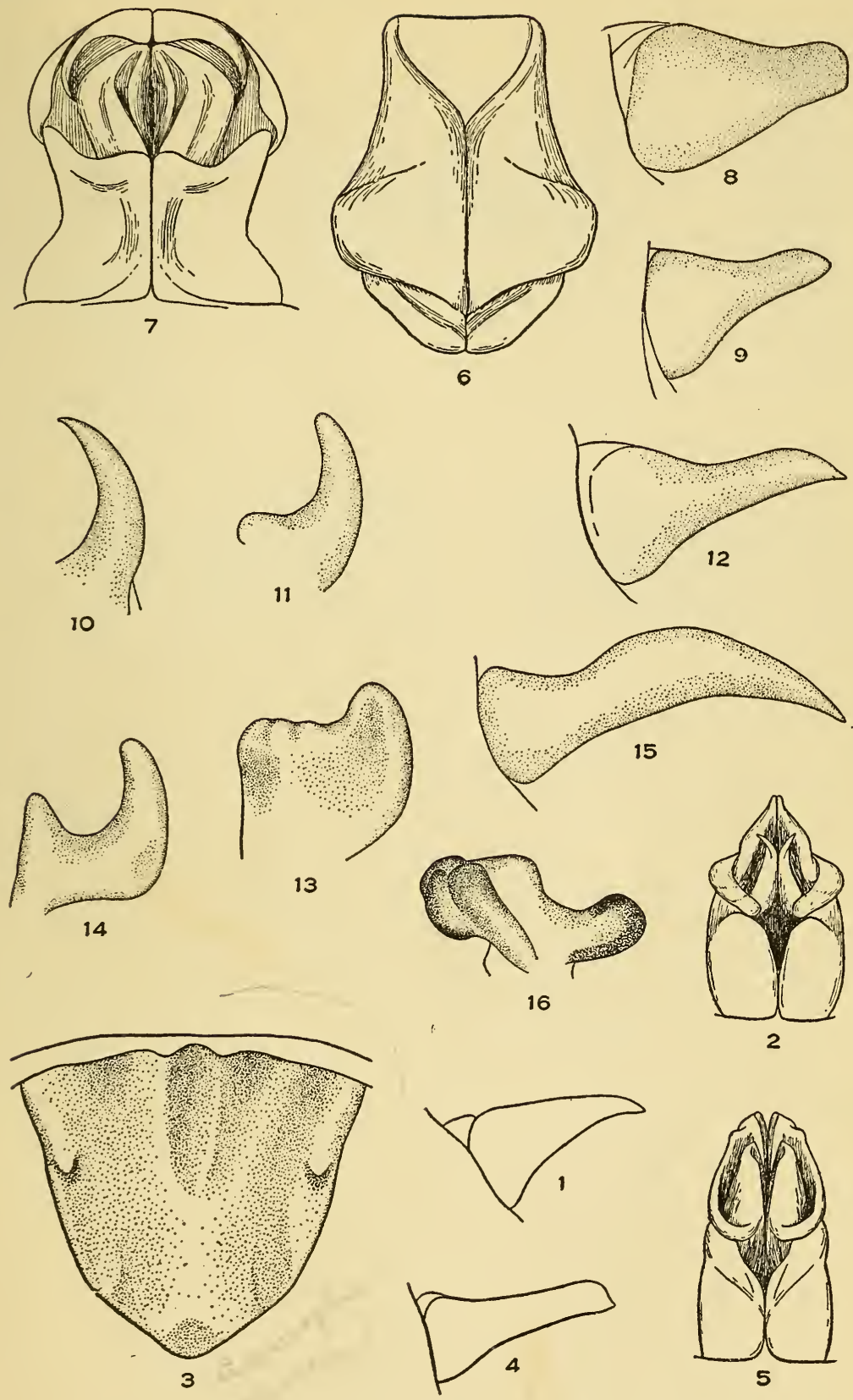

HEBARD-NORTH AMERICAN MELANOPLI 



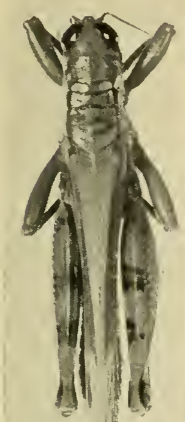

1
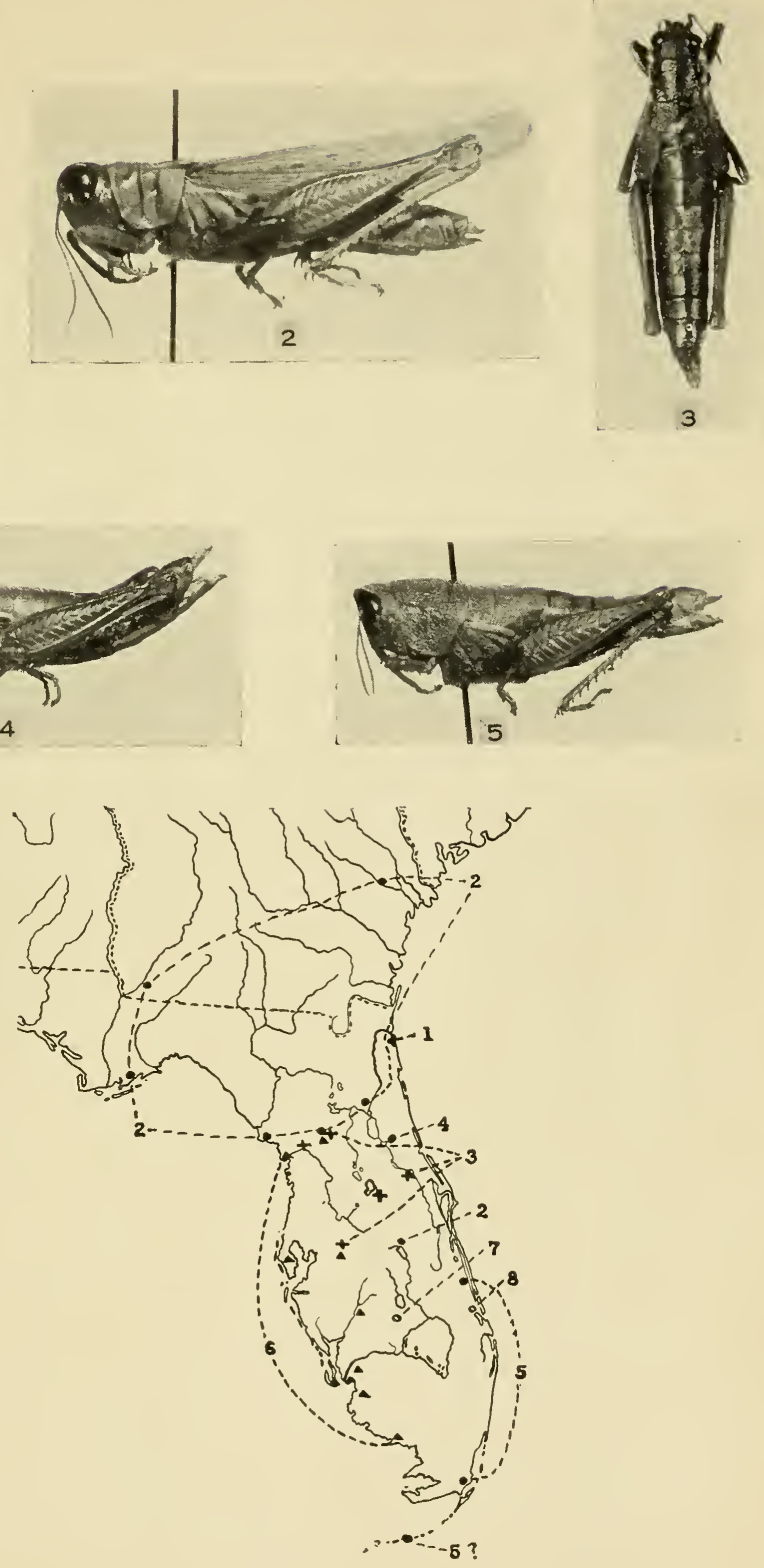

HEBARD-NORTH AMERICAN MELANOPLI 




\section{PUBLICATIONS}

\section{OF \\ THE AMERICAN ENTOMOLOGICAL SOCIETY}

\section{Proceedings of The Entomological Society of Philadelphia}

This series contains most of the important papers on American structural and systematic entomology.

Volumes I to VI, 1861-1867 (Out of print and cannot be supplied).

\section{Transactions of The American Entomological Societr}

A quarterly containing important papers on structural and systematic entomology.

Volumes I to IV, 1867-1873 (Out of print and cannot be supplied).

Volume $\mathrm{V}$ to present (in sets only, but most volumes are available separately) not including supplement to volume XIV. Price on application.

Subscription price per annual volumes, $\$ 5.00$.

\section{Memoirs of The American Entomological Society}

An irregular serial, containing monographic papers by students of authority in their respective subjects.

No. 1. The Cresson Types of Hymenoptera. By Ezra T. Cresson. 1916. 141 pp. Price $\$ 2.00$.

No. 2. The Blattidae of North America, North of the Mexican Boundary. By Morgan Hebard. 1917. 284 pp., 10 pls. Price $\$ 4.50$.

No. 3. A Venational Study of the Suborder Zygoptera (Odonata), with Keys for the Identification of Genera. By Philip A. Munz. 1919. 78 pp., 20 pls. Price $\$ 1.50$.

No. 4. The Blattidae of Panama. By Morgan Hebard. 1920. 148 pp., 60 pls. Price $\$ 2.50$.

No. 5. The Types of Hymenoptera in the Academy of Natural Sciences of Philadelphia other than those of Ezra T. Cresson. By Ezra T. Cresson. 1928. 90 pp. Price $\$ 2.00$.

No. 6. Revision of the Rhipiphoridae of North and Central America (Coleoptera). By Ezekiel Rivnay. 1929. $68 \mathrm{pp} ., 4$ pls. Price $\$ 2.00$.

No. 7. A Revision of the Dipterous Family Rhagionidae (Leptidae) in the United States and Canada. By Mrtimer D. Leonard. 1930. $182 \mathrm{pp}$., 3 pls. Price $\$ 4.50$.

No. 8. The Eumastacinae of southern Mexico and Central America. By James A. G. Rehn and John W. H. Rehn. 1934. 84 pp., 6 pls. Price $\$ 2.50$.

\section{Practical Entomologist}

A journal established in 1865 for distribution among the farmers and agriculturists. This was the first journal of economic entomology published in America. Volumes I and II, 1865-1867, all published. Price $\$ 4.00$ per set.

\section{Entomological News}

A monthly, introduced in 1890 , containing the scientific proceedings of the meetings of the Society, a list of current American entomological literature, and articles of interest to all entomologists Annual subscription, domestic $\$ 3.00$, foreign $\$ 3.25$.

Separates of papers published in the Proceedings and Transactions, if 'in stock, can be supplied at prices given in our price lists, which may be secured upon application, stating order or orders desired. The Society has also inaugurated a system of subscription to papers published by it on individual orders; which arrangement is of material benefit to the student who desires promptly the literature on any special group, but who does not desire to subscribe to entire volumes of the Transactions. Detailed information supplied upon application.

In sending subscriptions or in making inquiries relative to publications, address:

THE AMERICAN ENTOMOLOGICAL SOCIETY, Academy of Natural Sciences, Philadelphia, $\mathrm{Pa}$.

On the date of issue the present publication was mailed to the following institutions with the request that it be placed in their libraries for reference:

Société Entomologique de France

Deutsche Entomologische Gesellschaft

Società Entomologica Italiana

Entomological Society of London

Entomological Society of Ontario
American Museum of Natural History

Boston Society of Natural History

California Academy of Sciences

Field Museum of Natural History

Smithsonian Institution 


\title{
NEW GENERA AND SPECIES
}

\author{
OF \\ MELANOPLI
}

\section{FOUND WITHIN THE UNITED STATES AND CANADA (ORTHOPTERA; ACRIDIDAE)}

\author{
PARTS $\mathrm{X}$ to XIV
}

THE SALTATOR GROUP, THE FEMUR-NIGRUM GROUP (SUPPLEMENT), THE INDIGENS GROUP (SUPPLEMENT), THE MANCUS AND THE TEXANUS GROUPS OF THE GENUS MELANOPLUS.

BY

Morgan Hebard

From the Transactions of the American Entomological Society, LXIII, 147-173 Issued

No. 1030

This is a separatum from the TRANSACTIONS and is not a reprint. It bears the original pagination and plate numbers, and was placed on sale at the price quoted - and library copies mailed at Philadelphia on the above date of issue. 



\title{
NEW GENERA AND SPECIES OF THE MELANOPLI FOUND WITHIN THE UNITED STATES AND CANADA
}

\author{
(ORTHOPTERA: ACRIDIDAE)
}

PARTS X TO XIV

\author{
BY MORGAN HEBARD
}

(Plates $\mathrm{X}$ and $\mathrm{XI}$ )

In completing the arrangement of the brachypterous species of the genus Melanoplus three new species and a new geographic race have been located. In order to consider these properly, I have treated here the Mancus and Texanus Groups and have included supplements to my studies of the Femur-nigrum and Indigens Groups already completed in the present series of papers, ${ }^{1}$ while a brief review of the Saltator Group is given in order to clear up the existing confusion.

My work on the North American Melanopli began in 1917 and the first contribution to the present series appeared the following year. Including the present paper, two new genera, fifty-six species and fifteen subspecies of this category will have been described. Two species only, Melanoplus foxi and Melanoplus beameri have been treated outside this series and one of the species has been synonymized.

In the first sections only new species or races were considered, but later all the species of the Groups involved have in many cases been included in order to gain greater clarity. I would here reiterate my statements, made in 1919, that Scudder's grouping of many of the forms has been found incorrect and that, particularly in the genus Melanoplus, his "Series" are in so many cases composed of widely separated species that a complete rearrangement was found necessary. I had therefore rearranged the species of Melanoplus into "Groups", these "Groups" not in any way corresponding to Scudder's

\footnotetext{
1 The first of these the second section of part VI, Trans. Amer. Ent. Soc., LX, p. 368, (1935) and the second of these part VII, Trans. Amer. Ent. Soc., LXII, p. 168, (1936).
}

TRANS. AMER. ENT. SOC., LXIII. 
"Series" and a different specific name being proposed for each "Group" wherever confusion might otherwise occur.

Unless otherwise noted, the material here recorded is in the author's collection.

\section{PART X. THE SALTATOR GROUP OF THE GENUS MELANOPLUS}

So variable are the forms of this group that much confusion in recognizing the valid species and races has occurred. Although still undescribed species and races may exist, I do not feel that any can safely be described at the present time. The present study is therefore not intended to be as complete as those on other groups of the genus and is undertaken only because it is imperative to correct the numerous errors which have occurred and to give all information available which can help to avoid further mistakes. As a result I am here listing only localities and number of specimens, leaving the date, elevation, collector, environmental data and key to be given later in a more finished study at a time when sufficient additional material has been secured to solve several situations which at present are very baffling.

Additional material is particularly needed from southwestern Washington, the Cascades in that State and in Oregon and from the valleys toward and in the western foothills of those mountains. The few specimens before me from those regions are variously atypic from the recognizable species and races and their true significance can probably be determined only after adequate series from a considerable number of localities throughout that extensive territory have been studied.

It is, however, possible at the present time to define the limits of the valid species and races already described much more satisfactorily than has hitherto been possible and to publish all of the existing synonymy.

The features shown by the male supra-anal plate, cerci and subgenital plate must be handled with particular care, differences which in most groups would warrant racial recognition being here plainly attributable to local variation, occurring more frequently than in almost any other group of the Melanopli. 
The penis may sometimes appear to be of a strikingly distinctive type when such is actually not at all the case. Normally (except in ascensus calapooyae) the cochleate dorsal lobes of this organ stand erect, with their convex surfaces attingent and their concave surfaces directed laterad, embracing the acute apices of the ectoparameres. For some reason rotation has apparently taken place in a very few specimens (two of three males of saltator from Crabtree, Oregon, and three males of atypic ascensus ascensus from Satus Pass and Cliffdell, Washington) and in these the dorsal lobes have moved in such a way that their (normally) cephalic margins are attingent and mesad, their concave surfaces facing cephalad (similarly embracing the apices of the ectoparameres) and their convex surfaces facing caudad. Strange to say, this is the normal position for these lobes in ascensus calapooyae.

At present I feel that two species should be recognized, one of which divides into three geographic races.

\section{Melanoplus saltator Scudder}

(P1. X, fig. 1.)

1897. Melanoplus saltator Scudder (in part), Proc. U. S. Nat. Mus., xx, p. 261, pl. 17, fig. 8. [ $\hat{o}, q$ : Portland (type locality) and Oregon City, Oregon. $\left.{ }^{2}\right]$

The synonymy of $M$. algidus Scudder, described from Mary's Peak, Oregon, was established by Fulton in 1930. Material of this species was incorrectly recorded in the series described as ascensus and as validus by Scudder in 1899 .

The following material is before me.

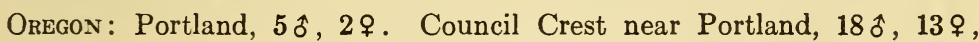
3 juv. ㅇ. Mount Tabor, $3 \hat{\delta}, 3 q$. Clackamas, $1 \hat{\delta}, 2$ ㅇ. Forest Grove, $26 \hat{\jmath}, 18 q$. Salem, $19 \hat{\delta}, 5$. . Turner, $3 \hat{\delta}$. Crabtree, $3 \hat{\delta}$. West Albany,

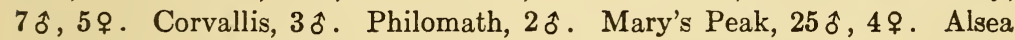
Mountain, 1 . Eugene, $4 \hat{o}, 2$ ㅇ․

In these specimens the caudal tibiae are dull bluish glaucous to buffy in the males, the same or pink in the females. The more sudden and more decided marginal convexity distad on each

2 The male from Soda Springs, Washington, is here discussed under the atypic material of ascensus ascensus. The female from Loon Lake, Washington, was placed under indigens digitifer with a query though definitely as representing that species by Hebard in 1936.

TRANS. AMER. ENT. SOC., LXIII. 
side of the male supra-anal plate and the slenderness of the erect projecting portions of the penis particularly distinguish saltator.

This insect occurs in central western Oregon from Mount Tabor and Forest Grove south to Eugene and Alsea Mountain. It may also extend into adjacent Washington but southward in Oregon is supplanted by the races of ascensus.

Melanoplus ascensus ascensus Scudder

1899. Melanoplus ascensus Scudder (in part), Proc. Davenport Acad. Nat.

Sci., vII, p. 196, pl. 9, fig. 3. [ $\hat{\jmath}$, $q$; Mount Shasta, California. $\left.{ }^{3}\right]$

1930. Melanoplus validus pinicola Fulton, Ann. Ent. Soc. Amer., xxmI, p.

622, fig. 1m. [ $\hat{\sigma}, \mathcal{q}$; [west side of] Klamath Lake (type locality),

Upper Klamath Marsh and Anna, Oregon.]

From study of paratypes of ascensus and validus pinicola in my collection it is evident that the latter is a synonym. Had Fulton Californian material, the name would probably not have been proposed. The differences shown are certainly insufficient to warrant nominal recognition in a species subject to such an unusual amount of both individual and local variation. The color of the caudal tibiae may have been given some weight, but this is clearly shown by series now available to have no racial value.

All of both sexes from the Sierras (except a male from Crater Lake) and the Warner Mountains have the caudal tibiae deep glaucous, but those from the lowlands to the east of the former, a single male from Crater Lake and those from northwestern California have the caudal tibiae coral red. From examination of all the material of this species it is clear that the color of the caudal tibiae has no value in distinguishing any of its races. The same is true of the caudal femora, which in some series are usually very strikingly marked with three pale areas on the external face, but in other series are almost immaculate, particularly in the females.

From saltator all of the races of ascensus may be separated by the weaker and less sudden convexity distad on each side of the male supra-anal plate. In ascensus ascensus the enlarged

3 The male from Portland, Oregon, represents saltator. It is identical with the type of saltator, described and figured from that locality by Scudder in 1897. 
distal portion of the male cerci appears less triangular than in the other races, the dorso-proximal portion and apex being less sharply rounded. The dorsal lobes of the penis in the delicate apical produced portion normally lie between the sharp erect apices of the ectoparameres and curve about them forming a cephalic and caudal lobation of equal size. Each series shows some variation in one or both of these features and, were the species not evidently so plastic, racial separation might in several cases have appeared advisable.

\section{Melanoplus ascensus validus Scudder}

1899. Melanoplus validus Scudder, (in part), Proc. Davenport Acad. Nat. Sci., viI, p. 197. [ô, $\uparrow$; Grants Pass (type locality) and Glendale (atypic), Oregon. $\left.{ }^{4}\right]$

1899. Melanoplus debilis Scudder, Proc. Davenport Acad. Nat. Sci., vir, p. 201. [ $\hat{\delta}, \&$; Ashland (type locality) and Siskiyou (atypic), Oregon.]

Study of the paratypes of ascensus, validus and debilis in the author's collection and the series now at hand shows beyond question not only that validus can not be given higher than racial status but that debilis is a synonym. Scudder separated the latter mainly on size, color and the absence of minute furcula. The first two features have no diagnostic significance and very minute furcula are present in the paratypic male of debilis before me.

In ascensus validus the caudal tibiae are often glaucous (rich or weak) or pink (to coral red) in the same sex in the same series. The caudal femora vary in intensity of color pattern to the same degree as in ascensus ascensus.

The following material is before me.

Oregon: Glendale, 15 $\delta, 9 \uparrow, 1$ juv. $\$$ (slightly atypical toward ascensus ascensus). Grants Pass, $1 \hat{o}$. Medford, $1 \hat{\delta}$. Ashland, $2 \hat{o}, 1 \uparrow$. Siskiyou, $32 \hat{\delta}, 24$ ㅇ, (slightly atypical toward ascensus ascensus).

The Glendale series shows divergence toward ascensus ascensus only in the form of the male cerci while such is true for the Siskiyou series only in the form of the penis.

${ }^{4}$ Scudder also originally included material of saltator from Portland, Corvallis and Philomath and of the subsequently described ascensus calapooyae from Divide, Drain and Roseburg.

TRANS. AMER. ENT. SOC., IXIII. 
It is evident that the individual variability in this insect is great and as it is as yet known typical from only five localities in a small area in central southwestern Oregon its racial validity may yet not be considered unequivocally established.

Melanoplus ascensus calapooyae Hebard

(P1. X, fig. 4.)

1920. Melanoplus calapooyae Hebard, Trans Amer. Ent. Soc., xLvi, p. 385, pl. 17, fig. 8 and pl. 18, fig. 8. [ $\hat{o},+$; Divide (type locality) and Drain, Oregon.1

Fulton reduced calapooyae to racial status in 1930, but placed it as a race of validus. In 1899 Scudder incorrectly recorded material of this race from Divide, Drain and Roseburg in the series described as validus, while in 1930 Fulton also recorded males from Roseburg and Canyonville as validus.

The present race is distinguished by the very much larger distal triangular expansion of the male cerci. The penis also has the cochleation of the dorsal lobes more ample and these are rotated caudad so that their concave surfaces surround the vertical acute apices of the ectoparameres from behind instead of from between them, thus giving a very different appearance. Close agreement in this feature alone is shown by two of the three males from Crabtree, Oregon, here discussed under saltator.

Oregon: Cresswell, $1 \hat{\delta}$. Cottage Grove, $2 \hat{\delta}$. Divide, $99 \hat{\delta}, 76 q, 1$ juv.

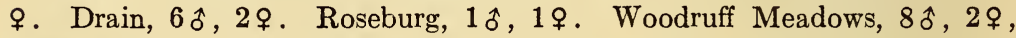
(slightly atypical, the male cerci less triangular distad and thus showing definite divergence toward ascensus ascensus).

The caudal tibiae of the males are buffy, sometimes with a weak glaucous or pink tinge, of the females rich pink, but in the atypic Woodruff Meadow series they are coral red in both sexes. Though marked as in the other races, the caudal femora externally usually show only moderate color contrasts with the paler areas extensive and confluent.

This race evidently occupies the area between the southern limits of saltator and the northern limits of ascensus validus, the series from Woodruff Meadows to the east atypic toward ascensus ascensus.

The following material is before me.

Oregon: Scott, $16 \hat{\delta}, 47 \%$. Dry Butte, $3 \hat{\delta}, 3 q$. Fort Klamath, 5 . Upper Klamath Marsh, $1 \hat{\delta}, 1$. West side of Klamath Lake, $1 \hat{o}$ (slightly 
atypic toward ascensus validus). Walker Mountain, $3 \hat{\delta}, 7$. . Cedar Peak in Warner Mountains, $2 \hat{\jmath}, 1$ ㅇ.

California: Mount Shasta, $2 \hat{o}, 1 \uparrow$. Harkness Peak, $6 \hat{\jmath}, 10 \uparrow$. Juniper Lake, $1 \hat{o}$. Westwood, $2 \hat{o}$.

Beside these specimens other material, undoubtedly representing ascensus, but if referable to the present race atypic in having the dorsal lobes of the penis more slender (much as in saltator), is before me.

Washington: Soda Springs in Yakima County, $1 \hat{\alpha}$ (caudal tibiae pink). OrEgON: Lower northern slopes of Mount Hood, $3 \hat{o}, 1 q$, (caudal tibiae pink).

California: Mount Shasta, $3 \hat{\delta}, 5 \mathfrak{q}$, (caudal tibiae glaucous, rarely pinkish buff in males from this locality).

The following specimens are also atypic, the dorsal lobes of the penis rotated as normal in ascensus calapooyae. They have the caudal tibiae pink.

Wasmington: Satus Pass, $2 \hat{o}$. Cliffdell, $1 \hat{o}$.

Oregon: Crater Lake, $1 \hat{o}$.

In extreme southwestern Oregon and northwestern California intergradation with ascensus validus is shown by the following series.

Oregon: Kerby, $7 \hat{\delta}, 1+$ (caudal tibiae glaucous in $6 \hat{\delta}$, pink in $1 \hat{\delta}$, $1 \uparrow$ ). Holland, $1 \hat{o}$ (caudal tibiae glaucous).

California: Medione Camp ten miles east of Gassquet in Del Norte County, $19 \hat{o}, 7 q$ (caudal tibiae pink), 1 juv. $\$$.

Typically this race is known from Mount Shasta south through the Sierra Nevada of California to Harkness Peak and Westwood, and in Oregon from Cedar Peak in the Warner Mountains and along the eastern base of the Cascade Mountains in the lowlands as far north as Scott. Intergradation with ascensus validus occurs in northwestern California and extreme southwestern Oregon and with ascensus calapooyae in the eastern portion of the Calapooya Mountains near where they join the Cascades. Atypical material of ascensus ascensus is recorded above from the Cascade Mountains from Crater Lake, Oregon, north to Soda Springs, Washington. 


\section{PART XI. THE FEMUR-NIGRUM GROUP OF THE GENUS MELANOPLUS (Supplement)}

I revised this group in 1935, establishing the synonymy and giving the known distribution of the species. A distinct new species, pinaleno, is here described which shows close relationship to magdalenae Hebard.

The following key is given merely as a guide to distinguish the males of the species, (there numbered according to their proper sequence), for the variation occurring in many of the characters which distinguish them prevents the proper presentation of such characters in anything but a detailed discussion.

1. Cercus variously widened distad. Caudal margin of pronotum weakly to distinctly rounded obtuse-angulate produced. ................

Cercus narrowing to apex. Caudal margin of pronotum nearly to definitely truncate. ........................................

2. Cercus with distal portion expanded into a rounded, regular, spatulation which is vertical and not bent inward. .......................

Cercus with distal portion less regularly expanded and bent inward distad. (Subgenital plate normal, very bluntly and broadly binodose at apex, these nodes sometimes fusing. Caudal tibiae glaucous in males, glaucous or pink in females.) .....................

3. Cercus broad and short, its large distal spatulate portion subquadrate with distal margin truncate. Penis distinctive. Subgenital plate weakly produced in a blunt tubercle at apex. Caudal tibiae pink in both sexes. White and Sacramento Mountains, New Mexico.

1. calidus Scudder

Cercus slender and elongate, its much smaller distal spatulate portion well rounded. Penis distinctive but more of the type of that of the following members of the group in having the apical projections elongate and intricately developed. Subgenital plate quite strongly produced in a blunt tubercle at apex. Caudal tibiae glaucous in both sexes. Chiricahua Mountains, Arizona. ......2. chiricahuae Hebard

4. Supra-anal plate more simple, narrower with lateral margins not showing concavity meso-distad. Cercus with irregular distal portion quite sharply inbent, that lamellation narrowing slightly to its moderately oblique distal margin. Arizona plateau and mountains from south rim of Grand Canyon south to Dewey and the vicinity of Prescott.

3. femur-nigrum Scudder

Supra-anal plate more specialized, broader with lateral margins concave meso-distad. Cercus with more irregular distal portion less strongly inbent, the lamellate distal portion elongate and appearing faintly trilobate. Magdalena Mountains, New Mexico; White Mountains and adjacent plateau, Arizona. ................ snowii Scudder 
5. Less robust. Furcula shorter. Cercus tapering more conspicuously in distal portion. Subgenital plate terminated in a prominent apical tubercle..........................................6

More robust. Furcula longer, (represented by small tapering spikes.) Cercus very definitely less than twice as long as broad, not tapering distad and so with apex much broader and much more broadly rounded. Penis highly specialized. Subgenital plate at apex feebly and bluntly tuberculate or bituberculate. (Caudal femora (as in magdalenae normal for group) with external pagina usually dark (particularly in males) with a very conspicuous pale ventral marginal band.) Caudal tibiae normally rich pink; buffy in one male and frequently suffused with brown on the sides proximad and distad in that sex, buffy with a very faint glaucous tinge in rare females. White Mountains, San Francisco Mountains and Bill Williams Mountain, Arizona.

7. truncatus Scudder 5

6. Intermediate in degree of robustness between truncatus and pinaleno. Furcula represented by small tapering spikes, shorter than those of truncatus, longer than those of pinaleno. Cercus narrower than in truncatus, somewhat broader than in pinaleno, slightly to distinctly less than twice as long as the greatest (proximal) width. Penis broader and not as highly specialized as in truncatus, of same character as in pinaleno but broader. Caudal femora normal for group, with external pagina usually dark (particularly in males) with a very conspicuous pale ventral marginal band. Caudal tibiae deep pink. Magdalena Mountains, ${ }^{6}$ New Mexico.........5. magdalenae Hebard

Only moderately robust for group. Furcula very small, short, no longer than broad. Cercus narrowest, fully twice as long as greatest (proximal) width. Penis of same general type but not as broad. Caudal femora distinctive, in males rich deep red ventrad and ventro-externally, entirely lacking a pale ventral marginal band on external pagina. Caudal tibiae glaucous. Mount Graham in Pinaleno Mountains, Arizona. ...................... pinaleno new species

Melanoplus pinaleno new species

(P1. X, figs. 5 to 7.)

As may be found from the accompanying key, the present species is nearest magdalenae Hebard. ${ }^{7}$ It is likely that these insects occur only at high elevations and are isolated and fixed in features which in a great many forms of Orthoptera are sub-

5 This species in the more boreal areas (normally at higher elevations) takes the place of femur-nigrum in the San Francisco Mountains and probably of snowii in similar manner in the White Mountains of Arizona.

6 This species takes the place of snowii in the more boreal areas (normally at higher elevations) in these mountains.

${ }^{7}$ Described Trans. Amer. Ent. Soc., Lx, p. 371, pl. 25, figs. 2 to 5, (1935).

TRANS. AMER. ENT. SOC., IXIII. 
ject to much plasticity. Similar in many features, other characters show them to be definitely distinct.

Type.- ô ; Ridge northwest of Helicopter Peak, Mount Graham, Pinaleno Mountains, Arizona. Elevation 9700 feet. August 21, 1934. (E. D. Ball). [Hebard Collection, Type no. 1309].

Size slightly below medium, form normal for the group. Vertex and frontal costa as in magdalenae. Pronotum with medio-longitudinal carina almost obsolete on prozona, fine and percurrent on metazona, caudal margin of dorsum showing very faint convexity. Prosternal spine comparatively short, shorter even than in magdalenae, its apex moderately transverse and bluntly rounded. Elongate ovate tegminal pads considerably shorter than pronotum, separated by a very considerable interval. Apex of abdomen moderately enlarged. Furcula represented by very small blunt triangular projections, no longer than basal width. Supra-anal plate triangular, basal width equal to length, lateral margins very feebly convex, convergent, medio-longitudinal sulcus deep in proximal two-fifths and moderately deep distad, lateral portions with surface moderately concave. Cercus of same general type as in magdalenae but more slender, fully twice as long as proximal width, external surface moderately swollen except the flattened tip, lateral margins very faintly convergent in proximal three-fifths, thence more strongly convergent in apical portion which is directed dorso-caudad with apex broadly rounded. Penis a moderately broad erect shaft, with margins meeting ventro-caudad to form a narrow V-emargination; proximal processes large, delicately cochleate, distad curving inward so that their acute apices are attingent; succeeding processes very slender, erect, almost concealed along inner margins of proximal processes and not as much produced. Subgenital plate convex with a very prominent blunt apical tubercle.

\section{Allotype.- $\%$; same data as type. [Hebard Collection].}

Larger and more robust than male. Pronotum with medio-longitudinal carina very faintly indicated on prozona, fine but distinct on metazona. Prosternal spine much as in male but with apex less transverse. Tegminal pads similar to those of male but even more widely separated. Ovipositor valves moderately elongate, much as in this sex of chiricahuae.

Measurements. - The measurements of a paratypic male, bearing the same data (a moderately large immature male is also before me), follow those of the type. Length of body $\delta$ (prior to extrusion of penis) 17. and 17., $q$ 18.2; length of pronotum $\hat{o} 4$. and 3.9 , $\& 4.4$; caudal width of pronotal disk $\hat{o} \mathbf{2 . 7}$ and 2.8 , $\uparrow \quad 3.7$; length of tegmen $\hat{o} 3.5$ (estimated, damaged) and 2.9 (2.6 on other side), $\& 3.7$; greatest width of tegmen of 1.6 and 1.8, $q$ 2.; length of caudal femur $\hat{o} 9.7$ and 9.5 , $\& 10.9 \mathrm{~mm}$.

Coloration. - General coloration of male brown, postocular bar broad, broadening very extensively on the pronotal lateral lobes and leaving only a narrow ventral portion paler, but terminating just caudad of the prin- 
cipal sulcus (thus quite different than the normal for the brachypterous members of the genus except those of the Immunis Group). Face, genae, cephalic and median limbs brownish buff. Caudal femora dorsad brownish buff with three slightly darker suffusions, external surface dark brown changing to a garnet brown ventrad, ventral surface brilliant deep nopal red, internal surface dull reddish, genicular areas dark brown. Caudal tibiae glaucous, paler at bases.

Female much paler and more uniformly colored, dull yellowish brown, caudal femora faintly tinged with reddish ventrad. Caudal tibiae light glaucous, paler at bases. Postocular bar and dark areas of caudal femora subobsolete.

The immature male, unlike the adults, has the caudal tibiae buff, the caudal femora with a line dorso-proximad and the dorsal half of the external pagina black. The other portions are buffy brown, the abdomen dull purplish brown dorsad.

\section{PART XII. THE INDIGENS GROUP OF THE GENUS MELANOPLUS (Supplement)}

When studying this Group in 1936 I found that I had determined and returned, without examination of the male penis, a pair from Taft, Montana. As I had a large series of indigens digitifer which I was then describing, ${ }^{8}$ from as close as Haugan, Montana, I felt justified in so recording that pair but wrote for them to verify my decision. The entire series from Taft is now before me, sent through the kindness of the collector E. R. Buckell, and proves to my surprise to represent an undescribed race of the related species payettei Hebard. This species is distinguished from the others of the Group by the very distinctive penis and the less produced apex of the male subgenital plate.

Melanoplus payettei picropidzae new subspecies

(P1. X, figs. 8 to 10 ; pl. XI, figs. 11, 12.)

This geographic race may be separated from payettei payettei, known from the mountains of central western Idaho and adjacent Washington, by the proportionately larger and less divergent furcula, proportionately larger cerci which distad are broader with apex truncate and narrower penis. Females of the species of the Indigens Group possess no striking differences.

The race may be limited in eastward distribution by the area of the Bitter Root Mountains on the western boundary of Mon-

8 Trans. Amer. Ent. Soc., LXII, p. 178, pl. 12, fig. 9, pl. 13, figs. 4 and 5.

TRANS. AMER. ENT. SOC., LXIII. 
tana. It may be the condition present in the mountains of central northern and central Idaho, regions from which very little is yet known as to the distribution of the brachypterous Melanopli.

Type. - ô; Taft, eastern slopes below Saint Regis Pass between the Coeur d'Alene and Bitter Root Mountains, Montana. July 15, 1929. (E. R. Buckell). [Hebard Collection, Type no. 1318].

Indistinguishable from the other nearest species and races of the Indigens Group except as noted above, the coloration of the caudal femora may possibly also prove an aid though probably subject to decided local variation. Size and form medium. Vertex and frontal costa as in indigens missoulae Hebard, 9 the former moderately broad with distinct lateral carinae, its surface impressed weakly (to quite strongly in paratype) at median ocellus. Pronotum with a fine medio-longitudinal carina on metazona, which is absent on prozona. Prosternal spine moderately elongate, rather slender, with apex well rounded. Tegmen ovate, separated by a brief interval, length considerably less than that of pronotum. Apex of abdomen moderately enlarged. Furcula represented by a pair of fairly thick, tapering and moderately divergent projections which are proportionately larger than in typical payettei, each over twice as long as width just beyond the thickened areas from which they spring. Supra-anal plate shield-shaped, lateral margins decidedly thickened and elevated in proximal third, dorsal surface longitudinally broadly concave laterad with median sulcus strongly defined only proximad. Cercus with length slightly over twice proximal width, curvature dorso-caudad almost obsolete; lateral margins faintly convergent in proximal third, very faintly divergent in median third and in distal third parallel, then rounding broadly into the transverse, truncate distal margin; external surface feebly and irregularly impressed submarginally distad. Penis as in payettei payettei with dorsal lobes developed into two large erect transverse adjacent fleshy plates which curve moderately cephalad distad, which plates are however narrower than in that race, the acute apices of the ectoparameres visible meso-proximad at their caudal bases. Apex of subgenital plate as in payettei payettei, slightly but appreciably blunter than in the related species.

\section{Allotype.- + ; same data as type. [Hebard Collection].}

Very similar to male but larger and more robust. Vertex broader with impression weaker. Tegmina as widely separated (varying to slightly more widely separated in paratypes and in them slightly shorter to distinctly more elongate). Prosternal spine shorter, broader (and in some paratypes decidedly heavier). Ovipositor valves of medium length and moderately

${ }^{9}$ Described, Trans. Amer. Ent. Soc., LXII, p. 175, pl. 12, fig. 6, pl. 13, figs. 1 and 2, (1936). 
curved distad; dorsal surface of dorsal valves weakly nodose proximad, the lateral margins acute, the external subcrenulate but very feebly and bluntly toothed proximad.

Measurements.-The extremes are: length of body $\hat{o}$ (before extrusion of penis) 17.5 and 18., $\rho 21.7$ to 26.2 ; length of pronotum $\delta 4.3$ and 4.7 , $\uparrow 4.8$ to 5.2 ; caudal width of pronotal disk $\delta$ 2.6 and 2.7 , $q 3.7$ to 3.9 ; length of tegmen $\hat{\delta} 3$. and 3.8 , $\$ 4.2$ to 4.8 ; length of caudal femur $\hat{o}$ 9.7 and 10.2 , $q 11.5$ to 12 . $\mathrm{mm}$.

Coloration.-Generally dark brown, the paler brown recessive specimens with color pattern weaker. A broad dark postocular bar extends to the principal sulcus of the pronotal lateral lobes and is continued, though weaker, to the caudal margin in all but the palest specimens. Face, ventral portion of pronotal lateral lobes, cephalic and median limbs brownish buff; ventral surface buff, but male subgenital plate dark brown except meso-proximad. Dorsum different shades of brown, with that portion of abdomen buffy in males. Caudal femora with brown markings very weak and suffused, the ventro-external and ventro-internal portions bright salmon orange varying to tinged with scarlet, the intervening ventral and the inner surfaces yellowish. Caudal tibiae glaucous (but buffy in one female) suffused with brown laterad.

From knowledge of the allied species and races I believe it probable that additional series of this race will also show variation in the furcula, supra-anal plate and possibly the cerci of the males. It is this individual and environmental variation coupled with the close general similarity of the species and the abundance of races which makes the Indigens Group one of the most difficult. This is aggravated by the fact that material is yet to be secured in many large areas where the Group is unquestionably present.

A male and four female paratypes bear the same data as the type. This series was found on the slope of a dry ravine among rank grasses and low plants. In the vicinity were a few clumps of Douglas Fir and choke-cherry.

\section{PART XIII. THE MANCUS GROUP OF THE GENUS MELANOPLUS}

The species of this group are of unusual interest. All closely resemble each other in general appearance and structure. The male cerci afford much the most valuable features of external difference, but the characters of the penis are found to be much more important in determining the species and their proper rela-

TRANS. AMER. ENT. SOC., IXII. 
tionships. This latter situation is quite different from that which is shown by the species and races of the evidently more plastic Saltator Group here discussed in Part X.

All of the five species invariably have pink caudal tibiae in both sexes. All are sylvan or are present in the open where usually characteristically sylvan ground cover occurs, such as huckleberry bushes, Sweet Fern, Sheep Laurel and forest grasses. All are found in the Appalachian Mountains, mancus being further widely locally distributed in New England and southeastern Canada, islandicus in the central portion of the northern United States and southern Canada and celatus in the adjacent plateaus and mountains of Tennessee (and probably Kentucky).

Females are indistinguishable or separable only on subtile characters or average slight differences which could be treated only at considerable length and might even then be misleading. The following key is therefore furnished to distinguish only males.

1. Cercus with ventral margin (rounded rect- to obtuse) angulate produced mesad. Penis distinctive (with shaft short and thick, the intricately specialized projections large)................ divergens Morse

Cercus with ventral margin not produced mesad................

2. Cercus with apex faintly to definitely spatulate. Penis with shaft short

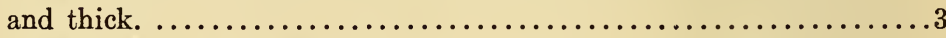

Cercus not enlarged distad. Penis with shaft more elongate and more slender.........................................

3. Penis with shaft short and thick, simple; the intricately specialized projections small. Cercus moderately elongate and moderately broad with apex faintly to definitely spatulate)........... mancus (Smith)

Penis with shaft short and very thick with distal portions cephalad produced in two adjacent cochleate lobes the margins of which are very finely and evenly serrulate. Cercus rather short and stout with apex definitely spatulate. ................ serrulatus new species

4. Penis with shaft very elongate and very slender, the sheath extending equally far distad on all sides, the intricately specialized distal projections smaller. Cercus normally moderately elongate and narrow at apex, varying to (rarely) rather short and (rarely in West, much more frequently in parts of East) with apex conspicuously broader.

2. islandicus Blatchley

Penis with shaft not as elongate and heavier, the sheath leaving much more of the ectoparameres exposed in caudal aspect, the intricately specialized distal projections larger. Cercus normally elongate and very narrow at apex, varying to shorter and with apex conspicuously broader. ................................... celatus Morse 
Sufficient individual variation occurs in the cerci to lead to possible incorrect determinations or the supposition that a distinct race or even species might be represented by certain individuals. This is true for all the species of which $I$ have large series but particularly so for islandicus and celatus, in both of which species incipient racial differentiation is strongly suggested. The species of the Mancus Group are, therefore, much more conclusively distinguished by the characters shown by the penis, which are much more constant.

Melanoplus mancus (Smith)

(P1. XI, figs. 1 and 2.)

1868. Pezotettix mancus Smith, Proc. Portland Soc. Nat. Hist., I, p. 149.

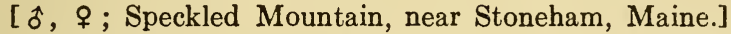

1920. Melanoplus mancus Morse, Orth. of New England, p. 518, pl. 22, figs. 28 to 31 , pl. 23, figs. 9 and 10.

This boreal species is probably widespread in southeastern Canada, but is as yet known there only from the series here recorded. It is widespread in favorable environment in the northern portion of the eastern United States and reaches south in the Appalachian Mountains as far as central Virginia.

The species shows little variation. Only the apices of the male cerci vary individually from feebly elongate spatulate to scarcely at all spatulate, the margins there frequently slightly irregular in curvature and the external surface sometimes weakly dimpled. The large series now available prove to my satisfaction that not even incipient racial differentiation is indicated anywhere in the range of mancus.

The related islandicus Blatchley was placed as a western race of mancus by me in 1932, such being strongly suggested by all external characters but now known to have been a false conclusion, as the form of the penis in islandicus is constant and widely distinct. The new species, serrulatus, from the mountains of western North Carolina, might just as easily have been confused with mancus had the even more distinctive development of the penis not been observed.

The following material is before me:

Quebec: Lac Sainte Marie, IX, 5, 1935, (F. A. Urquhart), $6 \hat{o}, 2$, [Can. Nat. and Hebard Clns.].

TRANS. AMER. ENT. SOC., IXIII. 
MaIne: Mount Sargent, $1 \hat{\delta}, 1$; ; Upper and Lower Hadlock Ponds, all on Mount Desert Island, VIII, 29, 1912, (M. Hebard; in undergrowth of mixed forest), $2 \hat{\jmath}, 1$ ㅇ. Mount Megunticook, VII, 29, 1928, (M. Hebard; at summit in grassy glade of low spruce forest), $7 \hat{\delta}, 2 \%$. Cape Elizabeth, VIII, 1933, (M. Hebard; in huckleberry bushes in low mixed forest near coast), 1 \% .

MASSACHUSETTS: Marion, IX, 1, 1905, (M. Hebard; in undergrowth of sandy pine woods), 1 \%. Heath, VIII, 6, 1932, (M. Hebard; in moss and forest grasses on hilltop at edge of deciduous forest), $3 \hat{\delta}, 2 \uparrow, 1$ juv.

Connecticut: North Madison, $2 \hat{\delta}$. Woodbridge, $1 \hat{\delta}, 1 \uparrow$, [A.N.S.P.].

New York: Danby Hill, $4 \hat{\delta}, 11 \%$. Ithaca, $1 \hat{\delta}, 2 i$.

New Jersey: Newfoundland, 19 .

Pennsylvania: North Mountain, IX, 22, 1935, (H. R. Roberts), 2 ô, 7. Leonardsville, 1800 feet, VII, 7, 1935, (Rehn and Rehn; in huckleberry, Sweet Fern and Sheep Laurel), 1 juv. $\hat{\delta}, 1$ juv. $ᄋ$, [A.N.S.P.]. Skytop, 2075 feet, VII, 19, 1936, (Rehn and Rehn; few in Sweet Fern in oak scrub), $1 \hat{\delta}, 3$ \%, [A.N.S.P.]. Moosic Lake, VIII, 19, 1924, $3 \hat{\delta}$. Williamsport, VIII, 10 and 11, 1924, 1 o, 1․ Poplar Gap in Monroe County, 1850 feet, VII, 19, 1936, (Rehn and Rehn; in huckleberry and Sweet Fern), $2 \hat{\delta}$, 3 \%, [A.N.S.P.]. Trout Creek in Monroe County, 1740 feet, VII, 7, 1935, (Rehn and Rehn; juvs. very abundant, adults few in second growth deciduous forest), $2 \hat{\delta}, 5$ juv. $\hat{\sigma}, 6$ juv. + , [A.N.S.P.]. Scotron in Monroe County, VIII, 17, 1906, (B. Long), 1 ㅇ, [A.N.S.P.]. Buffalo Flat in Union County, 2600 feet, VII, 31, 1935, (Rehn and Rehn; common in huckleberry ground cover in open and second growth mixed forest), 68 $\delta, 78 \uparrow, 3$ juv. \&, [A.N.S.P.]. Buena Vista Springs, VIII, 27, 1916, (M. Hebard), $3 \hat{\jmath}$. Still Run in Warren County, VIII, 19, 1936, (E. S. Thomas), $1 \hat{\delta}, 1 \propto$.

Virginia: Flag Rock Pass near Warm Springs, VII, 10 and 21, 1916, (M. Hebard, $2 \hat{\jmath}$. Hot Springs, VII, 3 to 20, 1916, (M. Hebard), $14 \hat{\jmath}, 12$, 4 juv. $\$$. Dunns Gap in Bath Co., VIII, 20, 1916, (M. Hebard), 1 . Little Mountain near Hot Springs, VIII, 6, 1916, (M. Hebard), $5 \hat{\text { ô, } 2}$.. Deer Lick Mountain near Hot Springs, VII, 10, 1916, (M. Hebard), $6 \hat{\jmath}$, 3 ․ Collision Ridge in Bath County, 3200 feet, VII, 5 to VIII, 23, 1916, (M. Hebard), 35 ô, 36 . Bald Knob in Bath County, 3900 feet, VII, 28 to VIII, 14, 1916, (M. Hebard; generally abundant on summit bald in thick ground cover of greatly stunted trees and mountain plants), $50 \hat{\delta}, 10$ 53 \%, 2 juv. $\uparrow$. Ridge north of Covington, 1500 feet, VIII, 16, 1916, (M. Hebard), $2 \hat{\delta}, 2 \%$. (Generally distributed but in localized colonies in both deciduous and mixed forest undergrowth throughout this mountainous region.)

10 One of these males, though adult, has the genitalia as in the instar preceding maturity. We have previously seen this condition only in a very few males of the Melanopli from the Rocky Mountains. It may be an abnormality produced by the speeding up of period of growth in rigorous areas where the active life of the individual is comparatively short. 
This species is known as far west as Ithaca, New York; Williamsport, Buffalo Gap and Buena Vista Springs, Pennsylvania, and Collison Ridge, Virginia, ${ }^{11}$ while the southernmost locality is a ridge near Covington in the latter State. South of New England it probably occurs only at some elevation in the mountains.

Melanoplus islandicus Blatchley

(P1. XI, figs. 3 and 4.)

1898. Melanoplus islandicus Blatchley, Psyche, vir, p. 196. [ $\hat{\jmath},+$; La

Salle Island in Les Cheneaux Islands, Michigan.]

1920. Melanoplus islandicus Blatchley, Orth. of Northeastern Amer., p. 388, figs. $135 \mathrm{~d}$ and e (outline of cercus greatly foreshortened and misleading).

E. M. Walker described $M$. abortivus from DeGrassi Point, Ontario, in 1898, which name he placed as a synonym of islandicus in 1899.

In 1920 Blatchley incorrectly considered sylvestris Morse a race of islandicus, while in 1932 Hebard incorrectly considered islandicus a race of mancus (Smith). Both of these errors occurred because the vital differences of the penis were unknown.

This species is sylvan, terrestrial and very local in distribution. Its nearest relative, from study of the characters of the penis, can now definitely be said to be celatus Morse, but in spite of the fact that both show variation, even in the large series now before me no suggestion of intergradation is anywhere indicated.

In islandicus the shaft of the penis is much longer and more slender than in any other species of the group. The male cercus is never enlarged distad and is there normally moderately narrow and quite sharply rounded. Slightly wider cercal apices than usual may appear in any series, but in the hilly country of the central and southern portions of eastern Ohio the cercal apices average still wider while the males from Monterey, Virginia though variable in this respect show it even more decidedly. Unusually short and broad are the cerci in the single male from Sounding Knob, Virginia. These differences I believe indicate

${ }^{11}$ McNeill's 1891 record from Illinois has been published as incorrect, properly referable to Melanoplus rusticus obovatipennis.

TRANS. AMER. ENT. SOC., LXIII. 
no more than incipient racial differentiation in the southeastern portion of the distribution of islandicus, for in all series appreciable individual variation is shown and the broadest cercal apices in the series from Pequaming, Michigan, are as wide as the narrowest cercal apices in the series from Monterey, Virginia. Moreover, in the related celatus, even greater cercal variation, with no indication whatever of convergence between these species, is found.

The following material is before me:

Pennsylvania: Mechanicsville in Clarion County, VIII, 29, 1935, (Rehn and Rehn; in openings of mixed forest), $5 \hat{o}, 3$, [A.N.S.P.]. Chestnut Ridge in Westmoreland County, (O. Brugger), $1 \hat{\delta}, 1$ ㅇ, [A.N.S.P.].

Maryland: Jennings in Garrett County, VIII, 1911, (W. Stone), 2 \%, [A.N.S.P.].

Virainia: Sounding Knob, 4200 to 4300 feet, VIII, 21, 1916, (M. Hebard; scarce in undergrowth at edge of forest), $1 \hat{\delta}$ (cerci very short and very broad at apices), 2 \% . Monterey, VIII to IX, 1914, (H. Fox), $9 \hat{o}$ (cerci moderately broad to broad at apices), $11 \%, 12$ [Hebard Cln. and U.S.N.M.].

Ontario: DeGrassi Point, $2 \hat{o}, 2 q$, paratypes of abortivus, [A.N.S.P. and Hebard Clns.]. Gilford, $1 \hat{\delta}, 1$.

Онго: ${ }^{13}$ Perry, VIII, 12, 1931, $11 \hat{\delta}, 5$ 우. Thompson, $1 \hat{\delta}, 1$ ㅇ․ Stebbins

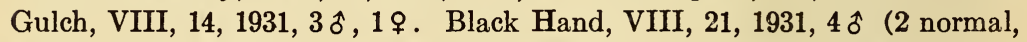
2 with cerci broader than usual at apices), 2 ㅇ. Licking Township, VIII, $19,1931,5$ ô (cerci slightly to markedly broader than usual at apices), 2 . Philo, VIII, 27, 1933, 1 . Deerfield Township in Morgan County, 1 . Berne Township in Fairfield County, X, 29, 1933, $2 \hat{o}$ (1 almost normal, 1 with cerci broader than usual at apices). Clear Creek in Good Hope Township in Hocking County, VII, 24 to VIII, 4, 1932 and 1933, $9 \hat{\delta}$ (cerci individually varying from normal to markedly broader than usual at apices), 7 ㅇ.

Indiana: Clear Lake in Steuben County, $1 \hat{\delta}, 1 q$.

MichigAN: La Salle Island, $3 \hat{\delta}, 3$ $\uparrow$, paratypes, [Hebard Cln. and A.N. S.P.]. Falls of the Slate River in Baraga County, VII, 23, 1921, (M. Hebard), $2 \hat{o}$. Pequaming, $43 \hat{o}, 45 q, 2$ juv. $\hat{o}, 2$ juv. $\uparrow$. HughittRawson Reserve in Gogebic County, $1 \hat{o}$, [A.N.S.P.].

Wisconsin: Upper Brule River in Douglas County, 1ㅇ, [A.N.S.P.]. Pembina, VIII, 1, 1910, (J. G. Sanders), $1 \hat{\delta}$.

Manitoвa: Whitemouth River on Dawson Road, VII, 13, 1925, (N. Criddle), 1 ô.

12 This series was recorded as Melanoplus celatus by Hebard in Fox in 1917.

${ }^{13}$ All of this material was secured by E. S. Thomas and C. F. Walker for the Ohio State Museum. A series of the duplicates is now in the author's collection. 
Minnesota: Kawishiwi River, $2 \hat{o}$. Poplar Lake in Cook County, $1 \hat{\delta}$. Two Harbors, $1 \hat{\delta}$. Cook County, VII, 30, 1936, (C. E. Mickel), $1 \hat{\delta}, 2$ 오 , [Univ. of Minn.]. Ely, IX, 7, 1935, (R. H. Daggy), 1 ㅇ, [Univ. of Minn.]. Friesland, $1 q$. Sunrise, $1 \hat{\jmath}$. St. Croix Springs, $1 \hat{\delta}, 1 q$. Pine River in Cass County, VIII, 13, 1935, (A. B. Gurney), 1 ㅇ, [Univ. of Minn.].

Eastern known limits for islandicus are North River and Island Lake in Algonquin Park and Tornoto, Ontario; Mechanicsville in Clarion County and Chestnut Ridge in Westmoreland County, Pennsylvania; Jennings, Maryland, and Sounding Knob, Virginia. Northern limits are Mechanicsville, Pennsylvania; North River and Island Lake in Algonquin Park, Lake Kabinakagami in Algoma and Fort William, Ontario, and the Whitemouth River on Dawson Road, Manitoba. Western limits are the latter, Big Falls in Koochiching County and Pine River in Cass County, Minnesota. Southern limits the latter and Sunrise, Minnesota; ${ }^{14}$ Pembine, Wisconsin; Clear Lake in Steuben County, Indiana; Clear Creek in Hocking County and Deerfield Township in Morgan County, Ohio, and Sounding Knob, Virginia.

\section{Melanoplus celatus Morse}

(P1. XI, fig. 5.)

1904. Melanoplus celatus Morse, Psyche, XI, p. 10. [ $\hat{o} ;$ Wytheville, Virginia, at 3000 to 4000 feet.]

1904. Melanoplus sylvestris Morse, Psyche, XI, p. 10. [ $\hat{\delta}, \stackrel{\imath}{\text {; Blowing }}$ Rock (type locality), Linville, Lovering's and Pineola, North Carolina; all at 3500 to 4000 feet.]

Comparison of paratypes in the author's collection prove beyond doubt the synonymy indicated above. The male cerci are unusually variable in this species and the differences noted by Morse for those of sylvestris do not have even racial significance.

The penis in this species is nearest that of islandicus but has the shaft shorter and thicker, the sheath (formed by the dorsal

\footnotetext{
14 Although I recorded this species as mancus islandicus in 1932 from Lansing, Hamburg and Bedford, Iowa and that name was consequently included in the Iowa list published by Knutson and Jaques in 1935, I believe that the insect has not yet been taken in Iowa. Somes so labelled material now in my collection though he did not record the species from Minnesota. I believe that he used by mistake numbers for Iowa which actually had been given for Minnesota localities. Several other equally serious mistakes are known to have been made by that author who at that time was far from well.
} 
lobes) leaving much more of the ectoparameres exposed in caudal aspect, while their complex exposed distal portions are larger. No intergradation between these conditions is shown by any of the material studied.

The following material is before me.

Virginia: Wytheville, $1 \hat{\delta}$, paratype.

North Carolina: Blowing Rock, $1 \hat{\delta}, 1 q$, paratypes of sylvestris. Lovering's in Burke County, $1 \hat{\delta}, 1$, paratypes of sylvestris.

South Carolina: Caesar's Head in Greenville County, VI, 29, 1926 and VIII, 23, 1933, (F. Sherman), $2 \hat{\delta}$ (apices of cerci slightly broader than typical), 1\%, [Sherman and Hebard Clns.]. Pinnacle Mountain in Pickens County, VI, 19, 1934, (F. Sherman), $1 \hat{\text { ô }}$ (apices of cerci unusually broad, as broad as broadest developed in islandicus, from Sounding Knob, Virginia). Rocky Bottom in Pickens County, VI, 16 to X, 3, 1927 to 1932, (F. Sherman), $5 \hat{\delta}$ (apices of cerci varying from slightly to decidedly broader than typical), $9 \%$, [Sherman and Hebard Clns.]. Cashiers Valley Road in Oconee County, X, 16, 1934, (O. L. Cartwright), $1 \hat{\delta}$ (apices of cerci considerably broader than typical).

Georaia: ${ }^{15}$ Pinnacle Peak in Rabun County, 1q. Rabun County, $1 \%$, [A.N.S.P.]. Clayton, 2000 feet, $1 \hat{\delta}$ (apices of cerci considerably broader than typical).

Tennessee: Clinch Mountains in Grainger County, IX, 2, 1933, (R. Dury), $1 \hat{o}, 1$ ( (typical, size very large for the species), [Ohio State Mus.]. Allardt in Fentress County, 1200 feet, VIII, 16, 1922, (T. H. Hubbell), $1 \delta$ (apices of cerci slightly broader than typical). Grassy Cove in Cumberland County, 1800 and 2000 feet, VII, 11 and 13, 1922, (T. H. Hubbell), $2 \hat{\delta}, 2$ ㅇ.

The known distribution of this insect is defined by the above localities. More material from all parts of its range is badly needed. The single series before me, from Rocky Bottom, South Carolina, shows so much individual variation in the form of the male cerci that I do not believe a geographic race of the more southern area can be recognized, though an average greater, and sometimes strikingly greater, width of the cercal apices is there present.

Melanoplus serrulatus new species

(P1. X, figs. 6 to 8. )

Generally similar to the other species of this group, the present species is nearest mancus in the form of the male cerci which,

15 This material and a female from Black Mountain, North Carolina, was recorded as sylvestris by Rehn and Hebard in 1916, at which time that the possibility that it represented a race of islandicus was suggested. 
similarly spatulate, are definitely shorter and broader. The penis is, however, not only differently developed than in any other species but shows decidedly the highest specialization.

Type.- o ; Nantahala Mountains, extreme western North Carolina. Elevation 2500 feet. October 5, 1933. (C. F. Walker). [Hebard Collection, Type no. 1319].

Size medium small, form compact and fairly robust for the brachypterous Melanopli. A weak longitudinal concavity present between the eyes and frontal costa weakly concave below the median ocellus, above that point broader and deplanate, rounded into the deplanate fastigium of the vertex. Antennae medium, decidedly shorter than caudal femur. Eye prominent, vertical length intermediate between that of sub-ocular sulcus and that of cheek. Pronotum with medio-longitudinal carina present only in metazona, three transverse sulci well defined (complete in type, with first or first and second briefly obsolete mesad in paratypes); caudal margin broadly convex, its lateral portions nearly straight. Tegmina represented by small rounded moderately separated pads, their apices showing a trace of angulation, their surface evenly weakly convex and covered by a rather regular network of decided veinlets. Prosternal spine short, stout, tapering abruptly to the sharply rounded apex, approximately as long as basal width. Furcula represented by a pair of short stout parallel fingers, their swollen bases attingent. Supra-anal plate rather small and narrow triangularly shield-shaped, approximately one-third longer than broad; median sulcus very deep in proximal two-thirds, lateral portions deeply concave. Cerci short and stout, tapering moderately in proximal half, then expanding into the moderately spatulate apical portion, there with outer surface convex but dimpled at the distal margin. Subgenital plate small, blunt conical, at the transverse rounded apex very slightly produced (with surface there sometimes dimpled). Penis with base very large, its shaft short and thick, the margins flaring in cephalic meso-internal portion into bilobed projections which have their margins microscopically serrulate; from within these project a pair of small vertical transverse and before them a pair of small vertical longitudinal lamellae, just caudad of which the simple aciculate apices of the ectoparameres project not as far.

\section{Allotype.— \& ; same data as type. [Hebard Collection].}

Larger and more robust than male. Concavity of interocular area and frontal costa even weaker and the former more limited in extent. Tegmina faintly more separated (in allotype, but attingent in paratype). Prosternal spine similar to that of male. Ovipositor valves moderately elongate, curvature at apices extensive, not strong.

Coloration. - The small series before me is dark brown with caudal femora showing externally the usual (in the group) three paler areas ex-

TRANS. AMER. ENT. SOC., LXIII. 
tensive but obscured. All are darker and less red-brown than is usual in this group, in this respect showing nearest superficial similarity to the series of divergens Morse which I secured on Jones Peak. Different responses in these features to immediate environment is, however, to be expected. Other paler and dark markings just as in the other species of the group.

Measurements.-Two male and one female paratypes bearing the same data show, with the type and allotype, the following extremes in measurements: length of body $\hat{\sigma} 16.2$ and 17.2 , ㅇ 22.3 and 23.3 ; length of pronotum $\hat{\sigma} 4.2$ and 4.4, \% 5.2 and 5.3 ; caudal width of pronotal disk $\hat{o} 2.8$ and 3., +3.8 and 3.8; length of tegmen $\hat{o} 2.8$ and 2.9 , $+\quad 3.8$ and 4.; length of caudal femur $\hat{o} 9.7$ and 10.3 , $q 11.5$ and $12.2 \mathrm{~mm}$.

This may prove to be a species confined to the valleys and lower slopes in the mountains.

Melanoplus divergens Morse

(P1. XI, figs. 9 and 10.)

1904. Melanoplus divergens Morse, Psyche, XI, p. 8. [ $\hat{o}$, + ; [Jones Knob in] Balsam [Mountains], North Carolina.]

1904. Melanoplus divergens Morse, Carnegie Inst. of Washington, Publ. 18 , p. 54 , fig. 5 .

I collected a series of this interesting species, distinctive in the angulate production of the ventral margin of the male cerci at 4000 feet on Jones Knob in the Balsam Mountains in a glade in the deciduous forest (just below the thickly conifer-clad summit), which was reported by Rehn and Hebard in 1910.

Specimens now before me.

North Carolina: Crestmont in Haywood County, from 1800 to 3000 feet, VII, 28 and 29, 1922, (T. H. Hubbell), $2 \hat{\sigma}, 2$. . Indian Pass in the Great Smoky Mountains, IX, 4, 1933, (R. Dury), $4 \hat{o}, 2 q$, [Ohio State Mus. and Hebard Cln.]. Hendersonville, VI, 21, 1924, (H. Fox), 1 ㅇ. Jones Knob in Balsam Mountains, $2 \hat{o}, 2 \hat{q}$, paratypes; $3 \hat{\jmath}, 3 \hat{q}$, [Hebard Cln. and A.N.S.P.].

Georgia: Rabun Bald, 4600 to 4717 feet (summit), IX, 5, 1917, (Rehn and Hebard; very scarce in huckleberry bushes and grasses under low oaks and chestnut trees), $3 \hat{o}, 4$, [Hebard Cln. and A.N.S.P.]. Chestnut Ridge on Rabun Bald, IX, 5, 1917, 4000 feet, (Rehn and Hebard; few in similar environment but richer undergrowth under higher trees), $3 \hat{\delta}, 5$ q , [Hebard Cln. and A.N.S.P.].

This species is, I believe, confined to the most boreal spots in the southern Appalachian Mountains. Its distribution is, therefore, highly discontinuous. 


\section{PART XIV. THE TEXANUS GROUP OF THE GENUS MELANOPLUS}

Discovery of a new species of this Group and realization that the previously known four species have in all cases been treated separately in the literature, makes it advisable to comment on the characters which they share and publish a key when describing the fifth species, oklahomae, there giving a number before each to indicate the proper sequence.

All of the species are large for the brachypterous forms of Melanoplus and are very similar in general appearance. They are light and somewhat reddish brown with a heavy sharply defined blackish brown postocular band stopping abruptly at the principal sulcus on the lateral lobes of the pronotum, the pleura black with a striking oblique brownish buff band. The caudal femora have two weak (rarely decided) oblique dark markings on the external surface in its dorsal portion individually ranging to immaculate. The caudal margin of the pronotal disk is obtuseangulate produced with apex rounded. The tegmina are lanceolate and slightly overlapping. The caudal tibiae are pink.

All are found only from southern Kansas to south-central eastern Texas in that area which intervenes between the definitely humid East and the typical plains. This includes western Arkansas and southeastern Missouri, in which latter area none have as yet been found but almost certainly occur. All are probably inhabitants of the open grasslands.

Females appear to be indistinguishable. Males may be separated by the following key.

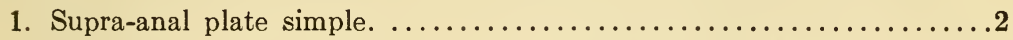

Supra-anal plate with two large longitudinal subadjacent rectangular areas meso-proximad. (Cercus large, expansion curved inward and twisted horizontally distad in a large irregularly trilobate lamellate plate with its dorsal surface moderately concave. Exposed portion of parameres very elongate, tubular, curved cephalad but not specialized at apices.) From Ben Wheeler to Walker County, central eastern

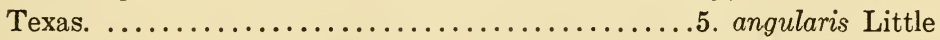

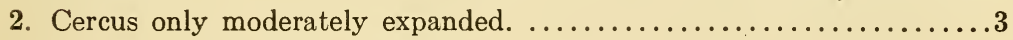

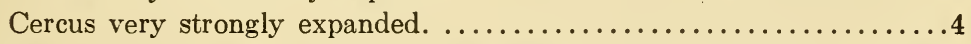

3. Penis with apices of ectoparameres scarcely produced beyond the surrounding thickened dorsal margins of the dorsal lobes. Cercus mod-

TRANS. AMER. ENT. SOC., LXIII. 
erately elongate, gradually and evenly tapering to distal third, there with dorsal margins feebly divergent then rounding into the transverse distal margin, this enlarged distal portion inbent with dorsal surface (which slants dorso-laterally) feebly concave. Occupies that portion of the prairie strip between the humid East and semi-arid plains from Labette and Cowley Counties in southeastern Kansas south to Waxahatchie and Comanche County in northeastern Texas. ${ }^{16}$

1. texanus (Scudder)

Penis with exposed portion of parameres elongate, tubular, curved cephalad but not specialized at apices. Cercus comparatively small, straight, tapering in proximal third, thence expanding moderately and then narrowing, thus forming a moderately elongate spatulate distal portion which is not incurved and is rounded to its acute apex, fully twice as long as broad with external surface feebly concave. Known from Montgomery County in southeastern Kansas to Magazine Mountain, Arkansas and Bonita, Texas. .......... inconspicuus Caudell 17

4. Cercus not bent inward, produced as symmetrical lamellate plates (which curve gently into a dorso-lateral slant, with dorsal margin broadly and ventral margin more weakly convex to the rounded apex and external surface slightly convex but becoming impressed toward the margins. Penis with dorsal lobes produced to form a tubular sheath for the ectoparameres, its truncate apex simple and not surpassed by the latter which may be seen within the deep meso-caudal cleft of the tube so formed. Brazos County in south-central eastern Texas 18 (in open Post Oak woods).............. warneri Little

Cercus bent dorsad and inward in all but basal quarter, the enlarged lamellate plates then formed (which slant dorso-laterally) roughly quadrate with dorso-proximal and ventro-distal angles broadly rounded and external surface irregularly flattened. Penis with dorsal lobes produced to form a longer and more slender tubular sheath for the ectoparameres, its apex expanded and produced in points to their apices as shown in plate X, figure 13. McCurtin County and Nashoba in extreme southeastern Oklahoma....4. oklahomae new species

It will be seen that the higest specialization of the supra-anal plate and cerci occurs in angularis, highest specialization of the penis in oklahomae. There are four distinctive types of penis;

16 Though not yet known from Oklahoma the species undoubtedly occurs in the eastern portions of that State.

17 Morse's latens was placed as a synonym by Hebard in 1931, Proc. Acad. Nat. Sci., Phila., LxxxiIr, p. 178. 1926.

18 First incorrectly recorded as texanus from this locality by Little in 
the first in texanus, the second in warneri, the third in inconspicuus and angularis, the fourth in oklahomae.

Melanoplus oklahomae new species

(P1. X, figs. 11 to 13 ; pl. XI, fig. 12.)

This insect occupies a position nearest texanus (Scudder) and warneri Little, agreeing generally closely as well as in form of male furcula, supra-anal and subgenital plates. The male cercus, however, has the lamellate distal portion not at all symmetrical with dorsal section much the more produced. The penis is very different from that of either of those species, but specialization of that organ, though often of very great diagnostic value, frequently has no phylogenetic significance.

The characters which distinguish the generally very similar species of the Texanus Group are given in the preceding key.

Type. - ô ; McCurtin County, Oklahoma. June 10, 1931. [Hebard Collection, Type no. 1310].

Size large, form medium for the brachypterous species of Melanoplus. Fastigium normal, its surface definitely concave medio-longitudinally. Frontal costa weakly impressed at median ocellus, without lateral carinae, its surface dorsad with minute impressed punctae. Eye large, moderately prominent, nearly twice as long as the infra-ocular sulcus. Pronotum with moderate precurrent medio-longitudinal carina cut only by the principal sulcus, caudal margin of disk obtuse-angulate produced with apex rounded. Prosternal spine moderately elongate, tapering distad to the sharply rounded apex. Tegmina lanceolate, slightly longer than pronotum, slightly overlapping, tapering to the narrowly rounded apices, definition between dorsal and lateral fields feebly suggested. Genitalia as described in key, the cercus and penis of very decided diagnostic importance. Furcula very minute, well separated points. Supra-anal plate triangular, slightly broader than long, its medio-longitudinal sulcus decided in proximal half, the lateral portions broadly concave and lateral margins simple. Subgenital plate small, the apex moderately produced and bluntly rounded.

Allotype.—o; Nashoba, Oklahoma. June 16, 1934. (J.Stankovitch). [Hebard Collection].

Very similar to male but decidedly larger and more robust. Eye distinctly less than twice as long as infra-ocular sulcus. Prosternal spine shorter, its apex bluntly rounded. Ovipositor of medium length, distal portion of dorsal valves short and rather strongly recurved with dorsal surfaces concave, delimited proximad by a transverse ridge.

TRANS. AMER. ENT. SOC., LXIII. 
Measurements.-Length of body $\hat{\sigma} 24.3$, 우 28.7; length of pronotum $\hat{\delta}$ 5.8, $q$ 6.7; caudal width of pronotal disk $\hat{\delta} 3.2$, $q$ 4.2; length of tegmen $\hat{o} 7.2$, $q$ 8.8; length of caudal femur $\hat{o} 12.7$, $ᄋ 16.2 \mathrm{~mm}$.

Coloration.-Generally light, dull reddish brown; occiput, dorsum of pronotum, tegmina dorso-proximad and in lateral portions brown (but the lighter and darker portions gradually merging and not in distinct contrast). A broad shining post-ocular blackish band terminates abruptly at the principal sulcus on the pronotal lateral lobes. Abdomen of female delicately marbled with dark brown dorso-laterad. Caudal femora with dorsal surface showing two transverse suffusions and genicular portions brown; internal surface buffy weakly tinged with orange; ventro-external surface the same in male, dull morocco-red in female. Caudal tibiae bittersweet orange (evidently recessive) in male, rich pink in female; internal spines black in distal half, external spines wholly black.

\section{Explanation of Plates}

\section{Plate X}

Fig. 1.-Melanoplus saltator Scudder. Topotype. Portland, Oregon. Lateral view of distal portion of penis. (Greatly enlarged.)

Fig. 2.-Melanoplus ascensus ascensus Scudder. Paratype. Mount Shasta, California. Lateral view of distal portion of penis. (Same scale as Fig. 1.)

Fig. 3.-Melanoplus ascensus validus Scudder. Paratype. Grants Pass, Oregon. Lateral view of distal portion of penis. (Same scale as Fig. 1.)

Fig. 4.-Melanoplus ascensus calapooyae Hebard. Paratype. Divide, Oregon. Lateral view of distal portion of penis. ${ }^{19}$ (Same scale as Fig. 1.)

Fig. 5.-Melanoplus pinaleno new species. Type. Mount Graham, Arizona. Dorsal view of male supra-anal plate and furcula. (Much enlarged.)

Fig. 6.-Melanoplus pinaleno new species. Paratype. Mount Graham, Arizona. Lateral view of male cercus. (Much enlarged.)

Fig. 7.-Melanoplus pinaleno new species. Type. Mount Graham, Arizona. Caudal view of penis. (Greatly enlarged.)

Fig. 8.-Melanoplus payetti picropidzae new subspecies. Type. Taft, Montana. Dorsal view of male supra-anal plate and furcula. (Much enlarged.)

Fig. 9.-Melanoplus payettei picropidzae new subspecies. Paratype. Taft, Montana. Lateral view of male cercus. (Much enlarged.)

Fig. 10.-Melanoplus payettei picropidzae new subspecies. Paratype. Taft, Montana. Dorso-caudal view of penis. (Greatly enlarged.)

19 Due to the fact that the cochleation of the dorsal lobes of the penis is rotated caudad in ascensus calapooyae, the lateral external surface of one of these lobes is seen in a lateral view of the distal portion of the penis, whereas in figures 1,2 and 3 the whole internal surface of one of these lobes is seen in the same aspect. 
Fig. 11.-Melanoplus ollahomae new species. Type. McCurtin County, Oklahoma. Dorsal view of male supra-anal plate and furcula. (Much enlarged.)

Fig. 12.-Melanoplus oklahomae new species. Type. McCurtin County, Oklahoma. Lateral view of male cercus. (Much enlarged.)

Fig. 13.-Melanoplus oklahomae new species. Type. McCurtin County, Oklahoma. Caudal view of distal portions of penis. (Greatly enlarged.)

\section{Plate XI}

Fig. 1.-Melanoplus mancus (Smith). Topotype. Speckled Mountain, Maine. Lateral view of male cercus. (Much enlarged.)

Fig. 2.-Melanoplus mancus (Smith). Topotype. Speckled Mountain, Maine. Caudal view of penis. (Greatly enlarged.)

Fig. 3.-Melanoplus islandicus Blatchley. Mechanicsville, Pennsylvania. Lateral view of male cercus. (Greatly enlarged.) (Same scale as Fig. 1.)

Fig. 4.-Melanoplus islandicus Blatchley. Mechanicsville, Pennsylvania. Caudal view of produced portions (not including base) of penis. (Same scale as Fig. 2.)

Fig. 5.-Melanoplus celatus Morse. Paratype. Wytheville, Virginia. Caudal view of penis.20. (Same scale as fig. 2.)

Fig. 6.-Melanoplus serrulatus new species. Paratype. Nantahala Mountains, North Carolina. Lateral view of male cercus. (Same scale as (Fig. 1.)

Fig. 7.-Melanoplus serrulatus new species. Paratype. Nantahala Mountains, North Carolina. Caudal view of penis. (Same scale as Fig. 2.)

Fig. 8.-Melanoplus serrulatus new species. Paratype. Nantahala Mountains, North Carolina. Lateral view of penis. (Same scale as Fig. 2.)

Fig. 9.-Melanoplus divergens Morse. Paratype. Jones Knob, Balsam Mountains, North Carolina. Lateral view of male cercus. (Same scale as Fig. 1.)

Fig. 10.-Melanoplus divergens Morse. Paratype. Jones Knob, Balsam Mountains, North Carolina. Lateral view of penis. (Same scale as Fig. 2.)

Fig. 11.-Melanoplus payettei picropidzae new subspecies. Paratype. Taft, Montana. Lateral view of male. ( $\times 13 / 4$.

Fig. 12.-Melanoplus payettei picropidzae new subspecies. Allotype. Taft, Montana. Dorsal view of female. $\left(\times 13 \frac{3}{4}\right.$.)

Fig. 13.-Melanoplus oklahomae new species. Allotype. Nashoba, Oklahoma. Lateral vew of female. (X13/4.)

20 The apex of the penis which curves strongly cephalad is consequently greatly foreshortened in this figure. 

Trans. Am. Ent. Soc., Vol. LXIII.

Pl. X.

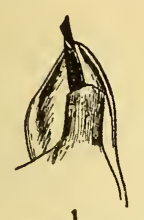

1
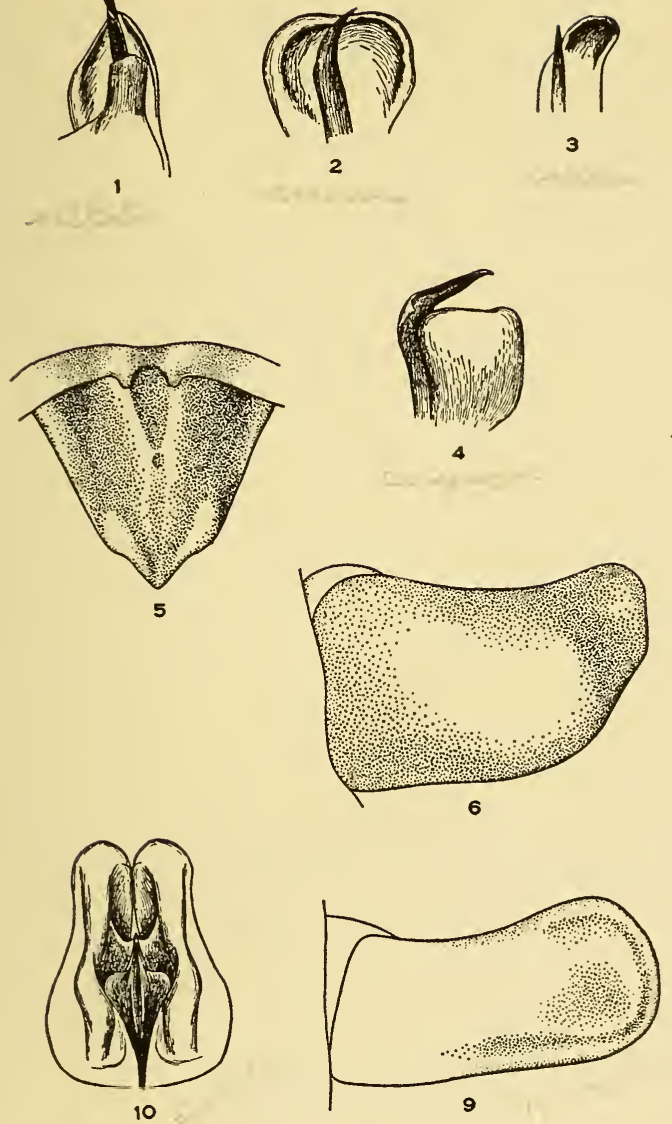

3



4
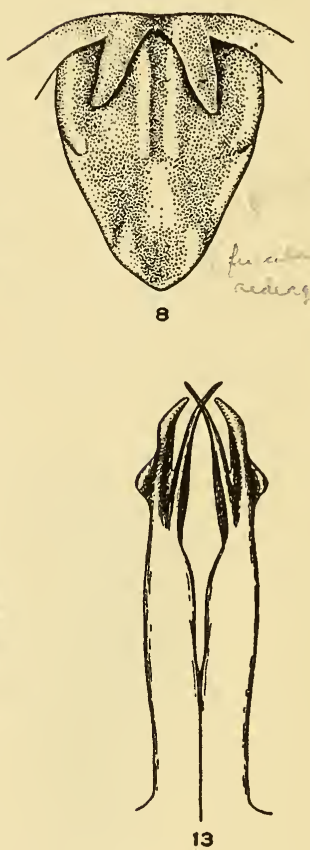
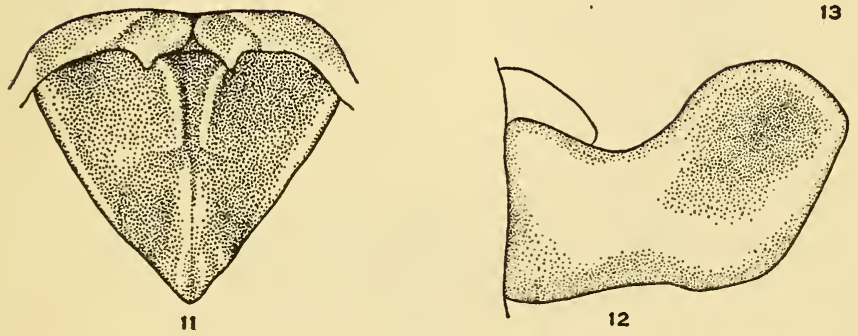

HEBARD-NORTH AMERICAN MELANOPLI 


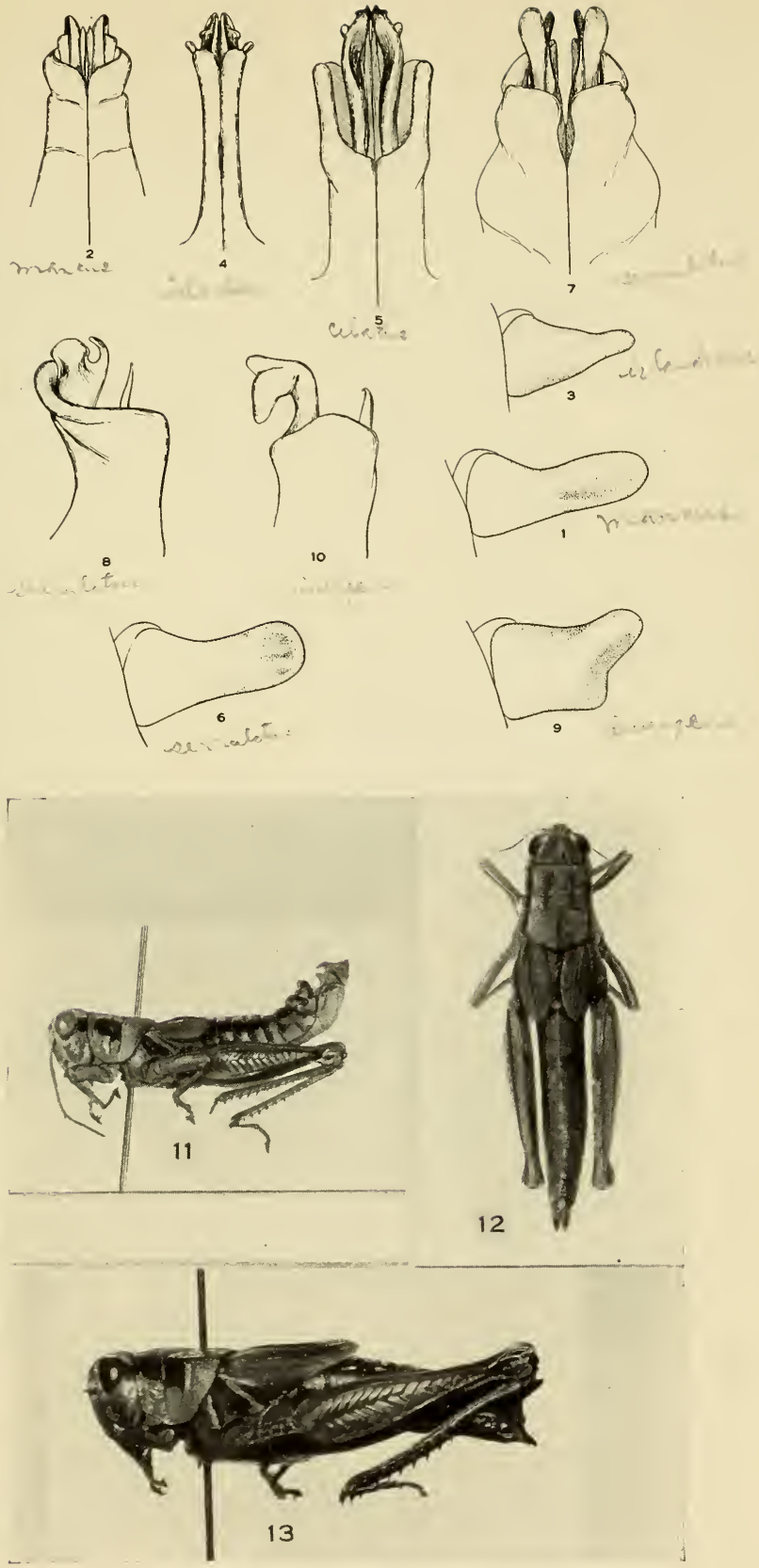

HEBARD-NORTH AMERICAN MELANOPLI 






\section{THE AMERICAN ENTOMOLOGICAL SOCIETY}

\section{Proceedings of The Entomological Society of Philadelphia}

This series contains most of the important papers on American structural and systematic entomology.

Volumes I to VI, 1861-1867 (Out of print and cannot be supplied).

Transactions of The American Entomological Societr

A quarterly containing important papers on structural and systematic entomology.

Volumes I to IV, 1867-1873 (Out of print and cannot be supplied).

Volume $\mathrm{V}$ to present (in sets only, but most volumes are available separately) not including supplement to volume XIV. Price on application.

Subscription price per annual volumes, $\$ 5.00$.

\section{Memoirs of The American Entomological Society}

An irregular serial, containing monographic papers by students of authority in their respective subjects.

No. 1. The Cresson Types of Hymenoptera. By Ezra T. Cresson. 1916. 141 pp. Price $\$ 3.00$.

No. 2. The Blattidae of North America, North of the Mexican Boundary. By Morgan Hebard. 1917. 284 pp., 10 pls. Price $\$ 5.50$.

No. 3. A Venational Study of the Suborder Zygoptera (Odonata), with Keys for the Identification of Genera. By Philip A. Munz. 1919. 78 pp., 20 pls. Price $\$ 2.00$.

No. 4. The Blattidae of Panama. By Morgan Hebard. 1920.148 pp., 60 pls. Price $\$ 3.00$.

No. 5. The Types of Hymenoptera in the Academy of Natural Sciences of Philadelphia other than those of Ezra T. Cresson. By Ezra T. Cresson. 1928. 90 pp. Price $\$ 2.00$.

No. 6. Revision of the Rhipiphoridae of North and Central America (Coleoptera). By Ezekiel Rivnay. 1929. 68 pp., 4 pls. Price $\$ 2.00$.

No. 7. A Revision of the Dipterous Family Rhagionidae (Leptidae) in the United States and Canada. By Mortimer D. Leonard. 1930. 182 pp., 3 pls. Price $\$ 4.50$.

No. 8. The Eumastacinae of southern Mexico and Central America. By James A. G. Rehn and John W. H. Rehn. 1934. 84 pp., 6 pls. Price $\$ 2.50$.

\section{Practical Entomologist}

A journal established in 1865 for distribution among the farmers and agriculturists. This was the first journal of economic entomology published in America. Volumes I and II, 1865-1867, all published. Price $\$ 4.00$ per set.

\section{Entomological News}

A monthly, introduced in 1890 , containing the scientific proceedings of the meetings of the Society, a list of current American entomological literature, and articles of interest to all entomologists Annual subscription, domestic $\$ 3.00$, foreign $\$ 3.25$.

Separates of papers published in the Proceedings and Transactions, if in stock, can be supplied at prices given in our price lists, which may be secured upon application, stating order or orders desired. The Society has also inaugurated a system of subscription to papers published by it on individual orders; which arrangement is of material benefit to the student who desires promptly the literature on any special group, but who does not desire to subscribe to entire volumes of the Transactions. Detailed information supplied upon application.

In sending subscriptions or in making inquiries relative to publications, address:

THE AMERICAN ENTOMOLOGICAL SOCIETY, Academy of Natural Sciences, Philadelphia, $\mathrm{Pa}$.

On the date of issue the present publication was mailed to the following institutions with the request that it be placed in their libraries for reference:

Société Entomologique de France

Deutsche Entomologische Gesellschaft

Società Entomologica Italiana

Entomological Society of London

Entomological Society of Ontario
American Museum of Natural History

Boston Society of Natural History

California Academy of Sciences

Field Museum of Natural History

Smithsonian Institution 




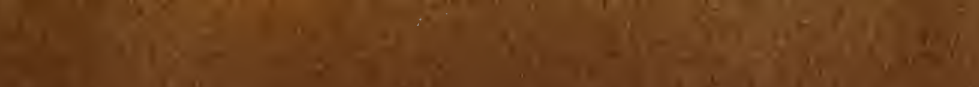

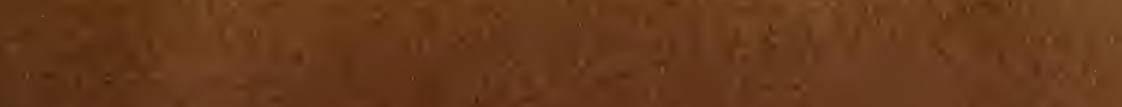

$-13$

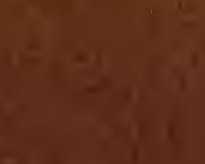

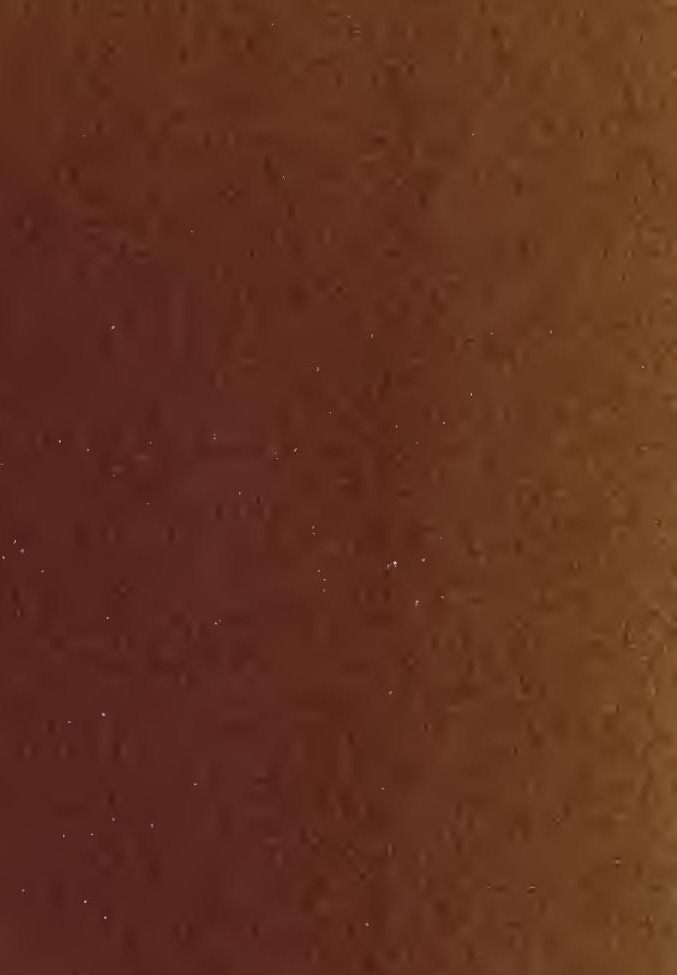

.

$$
\text { a }
$$




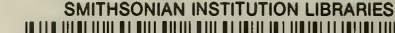

